
\title{
RE-ENVISIONING HYBRID STREET RE-ENVISIONING HYBRID STREET 鼻;
}

Exploring new terms of street typology 'Hybrid Street' which has both functions of street and transportation hub's roles with a proposed commuter rail network and other existing public transport infrastructures in Western Bay of Plenty.

By Dorothy Yeseul Kang A 120 point thesis submitted to the fictoria University of Wellington in fulfillment of the requirements for the degree of Masters of Architecture (Professional)

Victoria University of Wellington School of Architecture 2020 


\section{Table of Contents 4}

Table of Contents

Abstract

Motivation/Issues

01. Introduction \& Context

1.1 Introduction

1.2 Background

National Context

Western Bay of Plenty

Population Changes

Access to Public Transports

Dispersed Land-Use Pattern

Aligned Growth and Transport Infrastructure

Development in Bay of Plenty Region

2. Project Investigation

2.1 Problem Statement

2.2 Research Opportunities

2.3 Purpose

2.4 Research Objectives

2.5 Research Question

2.6 Investigation Approach/ Research Methodology $\quad 35$

03. Regional Context; Anchor Projects

Background/Context: Western Bay of Plenty

3.1 Regional Rapid Rail

3.2 Bay of Plenty metro passenger service

opportunities

3.3 SmartGrowth Future Development Strategy $\quad 44$

3.4 The Urban Form and Transport Initiative (UFTI) $\quad 45$

04. Defining Street Design

Introduction

4.1 Streets as Public Spaces: Theory Based Literatures 48 Urban Renaissance

New Urbanism

4.2 Streets as Public Spaces: Design Focused

4.2 Streets as
Literatures

\begin{tabular}{ll}
\hline BORROWED CITY & 52 \\
\hline Path, Tracks, and Trails & 54 \\
\hline Movement and access ("path") & 57 \\
\hline 4.3 Dimensions of Street Design By NACTO & 63
\end{tabular}

\section{Design Criteria}

Introduction

Design Criteria

06. Design Toolkits for 'Hybrid Street’ Introduction

6.1 Hybrid Street Type 1: Street Focused on

105

Sustainable Transport Modes

6.2 Hybrid Street Type 2: Active Street 106

6.3 Hybrid Street Type 3:Linear Park Street 107

6.4 Hybrid Street Type 4:Commercial Street

6.5 Hybrid Street Type 5:Transport Interchange 108

Street

5 Hybrid Street Typologies

07. Case Studies

Hybrid Typology Type1-5

08. Design Opportunities

8.1 Sites For Design

8.2 Existing Condition

09. Design Development

9.1 Conceptual Approach

9.2 TAURANGA City Streets

10. Conclusion

Conclusion

215

10.1 A Key Transformation and Design Outcomes $\quad 216$

10.2 Design Limitations and Further Study

10.3 Conclusion

References/List of figures 


\section{Abstract}

The relationship between well-being and vibrant cities is the most important factor to create a liveable city. Most of New Zealand and worldwide other cities have been facing many issues in transportation planning which directly affect to people's wellbeing and vibrant life. Policies in New Zealand intended to create "Auto-Based Cities", because of extensive construction of highways and parking garages that facilitate and encourage faster and longer trips by car (Ooi\&Yuen 108).

Urban transport planning and infrastructures often less focus on public transport system and its us ers, and it led to the following activities and results (Newman and Kenworthy) such as first, resulting automobile dependency leads to increased driving and increased traffic congestion, second, pedestrians are neglected and it causes a limiting cities liveability, and finally, transport poverty and socia deprivation in the suburb areas. This physical and psychological separating issue has been emphasised with increased attention to the importance of relationships between street accessibility and so-

$$
\text { cial inclusion. }
$$

A street designed by special conditions with heavy vehicles such as railways and large roads, creates physical and psychological barriers between communities. Individual travel behaviour is also significantly influenced by the street conditions, as a result, the value of effective street design with its social and psychological influences requires a deep understanding of its complexity.
Nowadays, street design guidelines in many other worldwide cities are focusing on the importance of activeness and liveliness in how we experience streets while still maintaining the conventional street functions with transport accessibility and connectivity. However, there are no specific researches that articulate the design strategy to identify 'Hybrid accessible open spaces to encourage public transports which connecting the rich native sub-regional and regional cultures between neighbourhood, city, and region.

Tauranga is a high growth urban area and, given its rapid growth, developing a new public transpor system has been emphasised to improve the traffic issues in Tauranga's long-term planning through the SmartGrowth Strategy. Unfortunately, despite of a high growth rate, the number of trips on public transport per person per year in Tauranga is continuing to trend downwards. (Statistics New Zealand 2019).

The viability of a passenger rail service linking Tau ranga, Auckland and Hamilton in a network dubbed the "golden triangle" is being investigated by the Bay of Plenty Regional Council and the current situation of Western Bay of Plenty rail network has capacity for further services and given the connection is in place. It also could be technically feasible to run a passenger service on these lines (Joyce 2019) The research, 'Hybrid Street Design' supports gov ernment's long-term plan 'an integrated transport planning with new commuter rail network in Western Bay of Plenty.
Research paper explores a 'Hybrid Street' which has both functions of street and transportation hub's roles with the connections of existing railway network and other public transport infrastructures in Western Bay of Plenty.

Design framework advocates a pedestrian and transit-friendly streetscape connecting the rail lines to encourage street activities on the urban and suburban fabric, and also supports other types of sustainable transport modes. A hybrid term of street typology articulates a vision and strategic approach with design criteria to advance key objectives.

The research objective has been investigated from a research question of 'How to avoid the mono-functional logics of street with its public transport connections and how to translate it to a hybrid space that supports a variety of different types of sustainable transport modes to improve the accessibility between the neighbourhoods, cities, sub-regions and region.

The design objective will be achieved through a systematic research methodology with an idea of mono-functioned street networks connecting with vast overland rail routes in West Bay of Plenty is a positive opportunity to test the research ideas.

The investigated hybrid street typology will be applied and tested on nine different streets in Tauranga city business district areas (CBD) where have significantly different spatial characteristics to see how it advances key objectives and achieves the research visions through the design developing stage. 


\section{Motivation/ Issues}

As a local resident in Western Bay of Plenty, I always felt that a lack of connectivity in the regional public transport systems between Tauranga Central area and other suburbs.

In general, Western Bay of Plenty's street accessibility to public transport is not enough to serve the entire community in the old settled neighbourhoods and recent developed areas.

Tauranga Central area is not suitable to build a new transport infrastructure but has many opportunities in and-uses with public transport systems because of a higher street connection.

Developing a new public transport system has been emphasised to improve the traffic issues in Tauranga's longterm planning through the SmartGrowth Strategy. The current Western Bay of Plenty rail network has capacity for further services and given the connection is in place it could be technically feasible to run a passenger service on these lines (Joyce 2019).

Then, I established my thesis statement from the research question of 'How can we shift away from traditional street designs in a way that allows for new forms ('Hybrid Streets') of streets which offer a variety of different transport modes and public activities on the top of the basic street functions with a proposed commuter rail infrastructure in Western Bay of Plenty?

believe that 'Hybrid Functioned Street Design Study' suggests a solution to improve current issues and will indicate a good strategy for supporting a government's long-term plan 'integrated transport planning with new commuter rail network in Western Bay of Plenty'. Moreover, the provision of 'Hybrid Street' is an important healthy social promotion to encourage physical activity and to improve social participations on the street in vibrant cities. 


\section{Introduction \& Context}

Finding a new way of street typology and developing a design toolkit for 'Hybrid Street' will enhance our community connection between neighbourhood, city, and region by

the vibrant streets and it will promote people's life more liveable.

\section{1}




\subsection{Introduction 4}

Nowadays, street design guidelines in many other worldwide cities are focusing on the importance of activeness and liveliness in how we experience streets while still maintaining the conventional street functions with transport accessibility and connectivity. However, there are no specific researches that articulate the design typology to identify 'Hybrid Street' which has both functions of street roles and public transport park connecting the rich native culture between neighbourhood, city, and region by different types of public transport modes. 
1.2 Background

Western Bay of Plenty

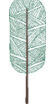




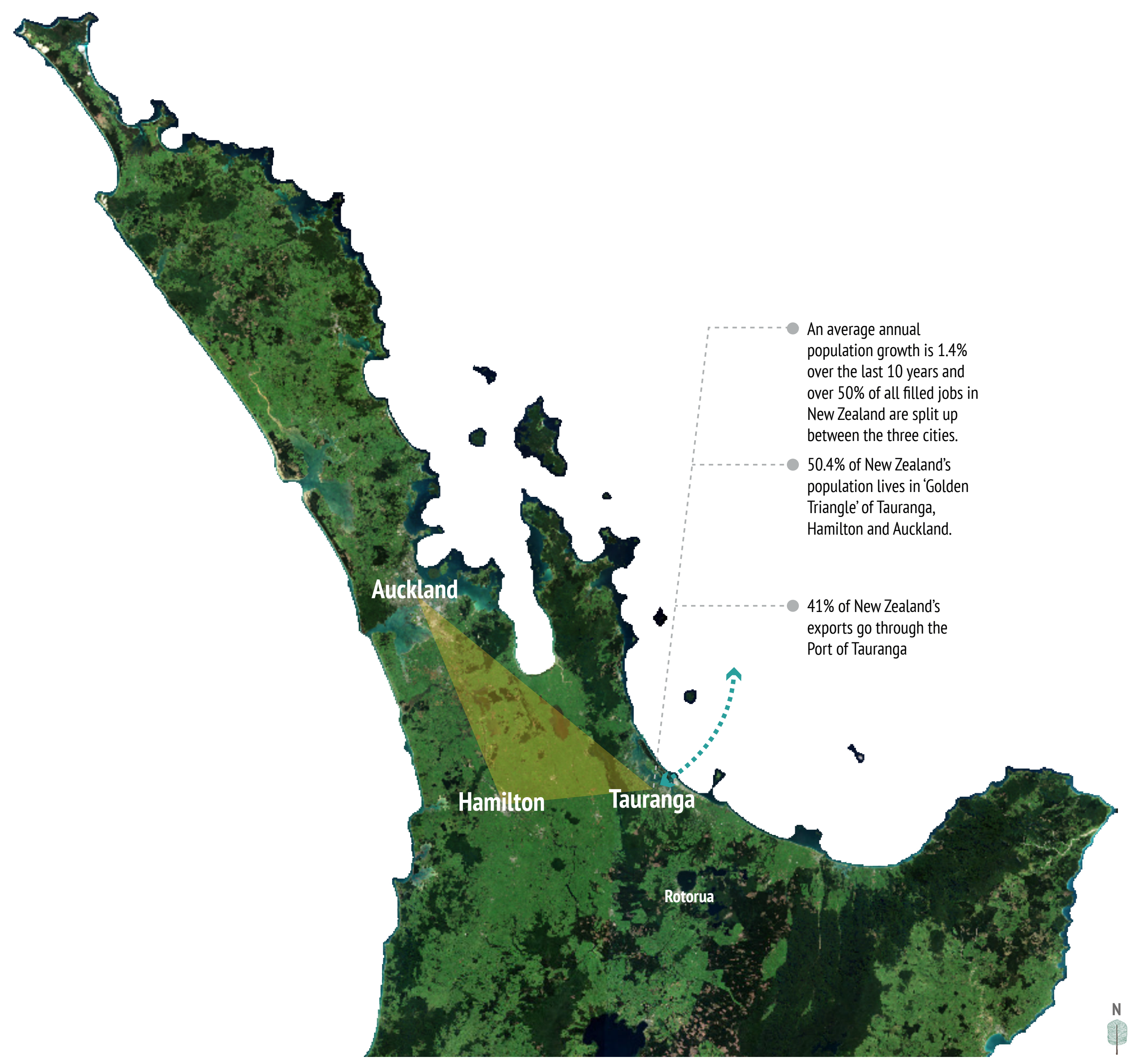

Figure 1. National Context

$50.4 \%$ of New Zealand's population lives in 'Golden Triangle' of Auckland, Hamilton and Tauranga.

An average annual population growth is $1.4 \%$ over the last 10 years and over 50\% of all filled jobs in New Zealand are occupied in "Golden Triangle'. However, the economic and commuting linkages between three cities have significantly low level of travelling rate. 

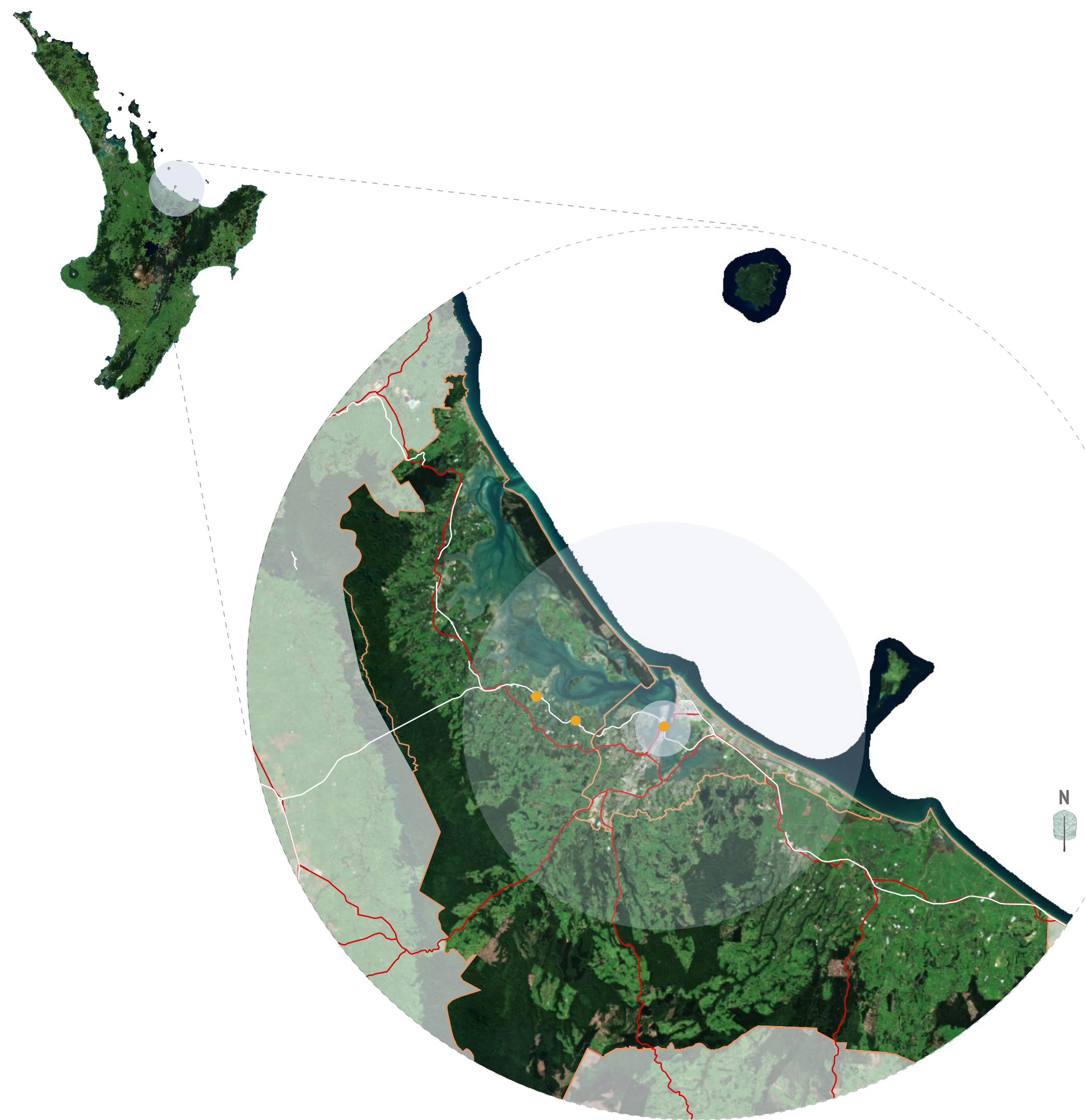

Figure 2. Western Bay of Plenty Wider National Land Transport Network q

Western Bay of Plenty

The western Bay of Plenty plays a key role in the upper North Island to connect the wider national land transport network. Important inter regional connections move significant volumes of people and goods from Tauranga to Auckland, Waikato and Taupo with state highways and freight train. The Western Bay is home to the country's largest export port, and the sub-region's productive rural and horticultural land resource is a major contributor to the economy.

Western Bay of Plenty is a high growth urban area and a polycentric land-use pattern with the geography of the sub-regional areas, negatively impacts on the transport and efficient connection between people, locations of employment, recreational spaces and education.

Given its rapid growth incorporated with the physical constraints by dispersed land use pattern, developing a new public transport system has been emphasised in Western Bay of Plenty's long-term planning through the SmartGrowth Strategy to improve the current traffic issues and to achieve the people's demands to create a vibrant connection between rural communities and urban central business district. 
Population Changes

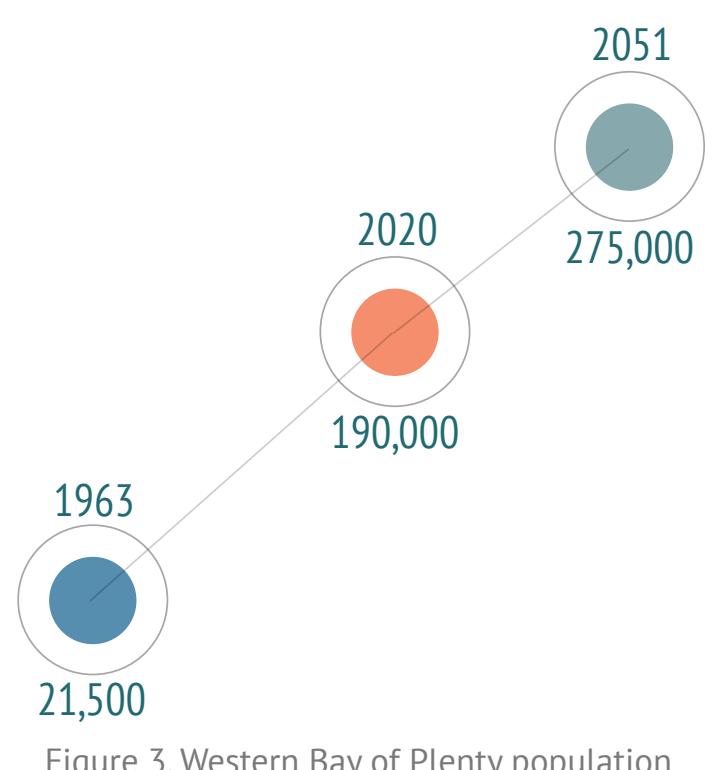

両

The western Bay of Plenty sub-region has grown significantly over the last 80 years.

In 1963, Tauranga had a population of just 21,500 people but today the western Bay of Plenty's population is around 190,000 and the SmartGrowth Strategy projecting a doubling of population 275,000 by 2051 .

Growth over a relatively short time-frame has put increased pressure on the sub-region's inrastructure and services to support people's desired outcomes and public transport user demands. 
$2018 / 2019$

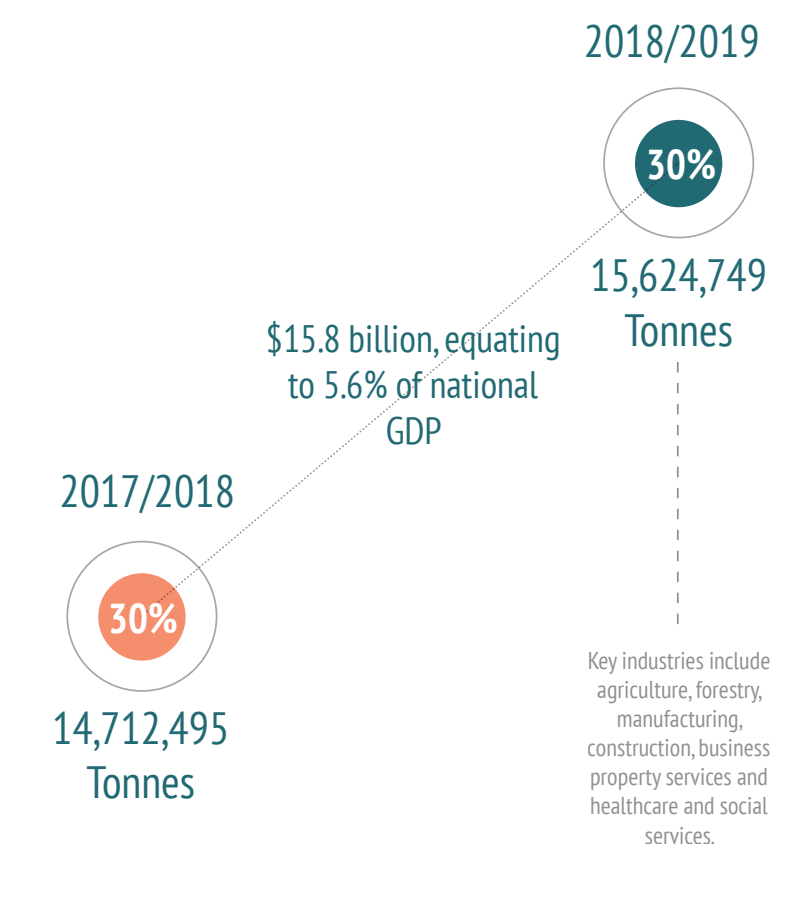

Figure 4. Bay of Plenty's economic contribution

\section{艘}

The Bay of Plenty region is home to the Port of Tauranga, New Zealand's largest export port, which handles $30 \%$ of the country's imports and exports. The Port is a key connection between the upper North Island, central New Zealand and international markets with significant volumes of product by ship, freight rail and road. The Bay of Plenty section of the East Coast Main Trunk line (ECMT) carries over a third of New Zealand's rail traffic and is the most densely utilised section of the national rail network. The Bay of Plenty region contributed $\$ 15.8$ billion to the economy in 2018 , equating to $5.6 \%$ of national GDP. Export volumes loaded at the Port of Tauranga increased $6.2 \%$ in the last year from $14,712,495$ tonnes in $2017 / 2018$ to $15,624,749$ in $2018 / 2019$. 
Projected demographic change in Western Bay of Plenty sub-region 2018-2048

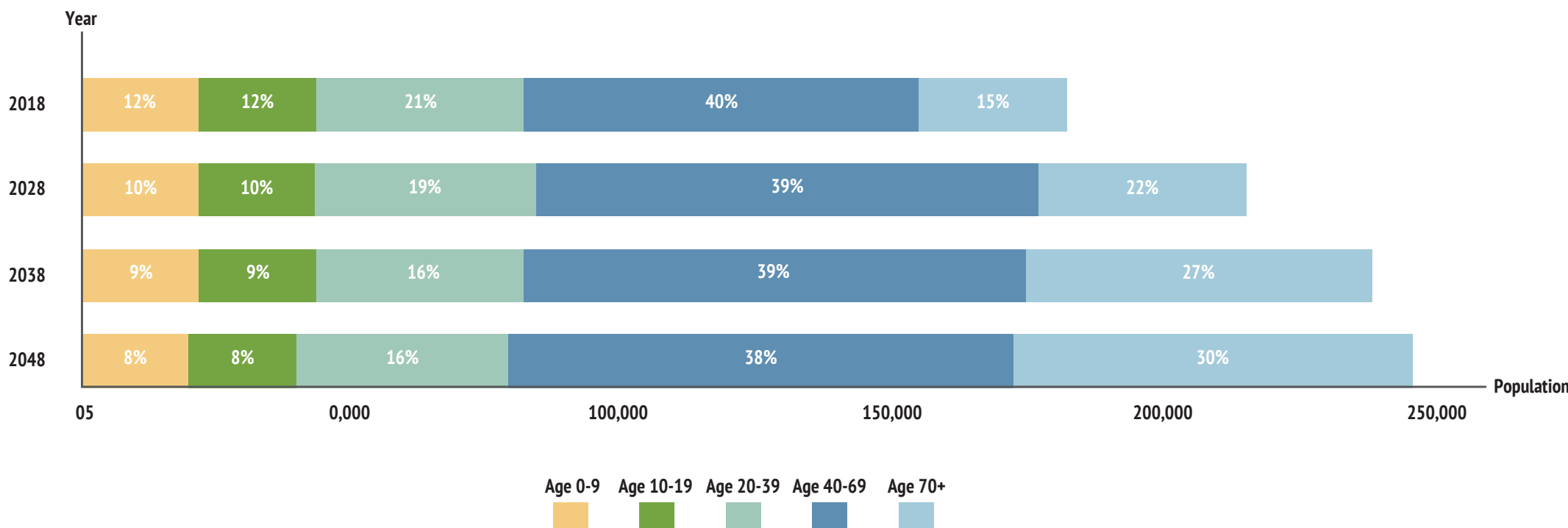

Figure 5. Projected demographic Change $\$$

As a significant population growth, Western Bay of Plenty's demographics are also changed rapidly. Statistics New Zealand estimates that a higher proportion of Western Bay of Plenty region's population over the age of $40+$ will attain $68 \%$ increase in 2048 from $55 \%$ in 2018.

Demographic change increases the demands for affordable housing with effective and diverse connections by public transport, walking and cycling infrastructure from Bay of Plenty sub-regional areas to City Centre. 
Household Travel Survey

Household Travel Survey Data 2009-12

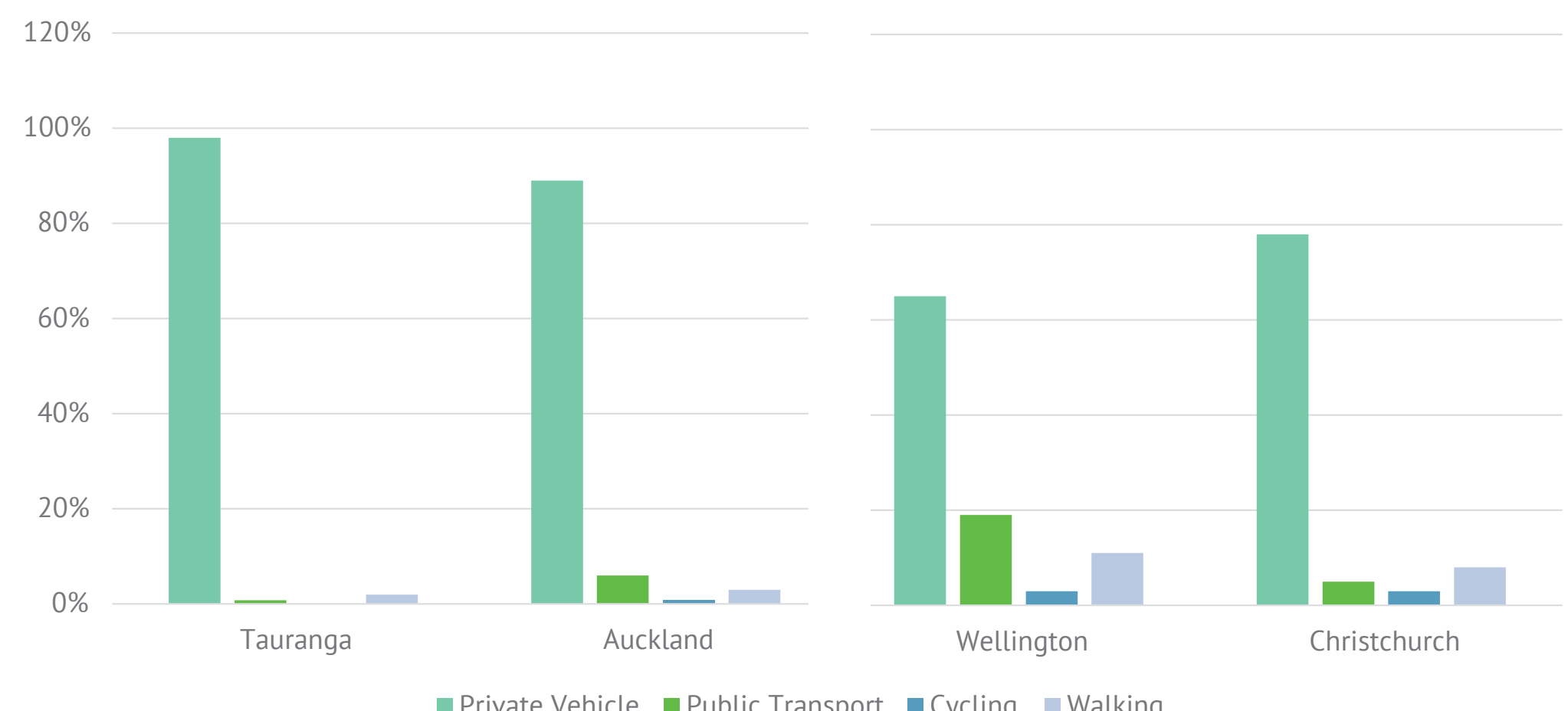

Figure 6. Household Travel Survey Data $\$$

Tauranga has the highest single rates of private vehicle use in the county for journey to work in four New Zealand major cities.

Due to the high motor vehicle usage and poor connectivity in public transport system, Tauranga's carbon emissions per capita transport are higher than Wellington (Arataki).

Therefore an enhancing public transport system in Western Bay of Plenty region is one of the considerable way to achieve environmental benefits to reduce the higher emission rate in Tauranga. 
Variety of Transport Uses in Four Main Cities

AUCKLAND

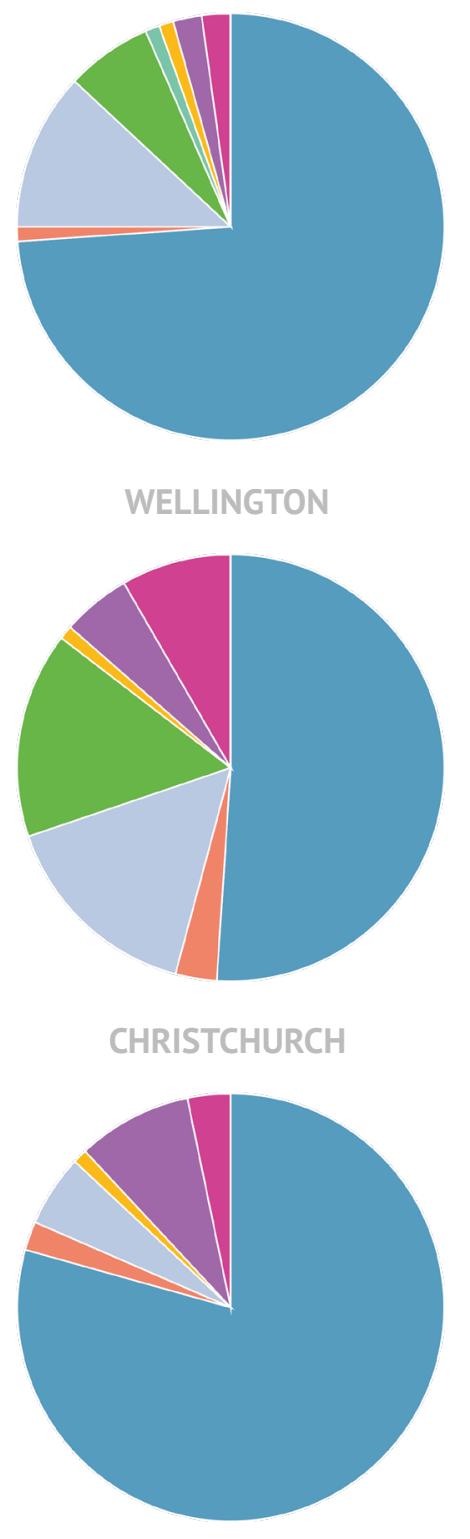

TAURANGA

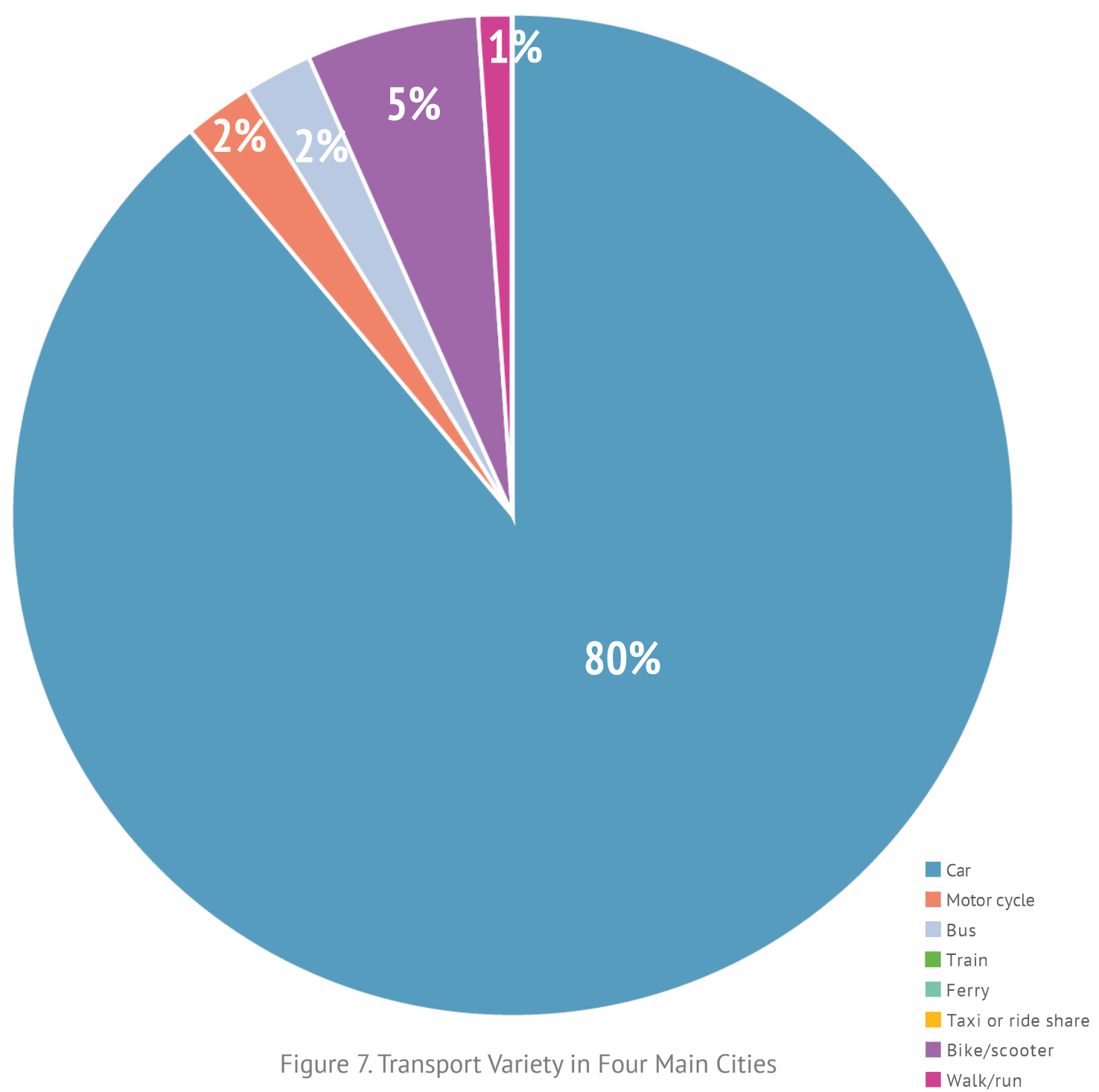

舟

Comparing with the result in the use of private vehicles of the four main cities, public transport use in Tauranga is the lowest and walking and cycling is lower than both Wellington and Christchurch in NZ.

Public transport system within the Bay of Plenty region is underutilised and the lack of transport choice with a high dependency on private vehicles is leading to poor social and environmental outcomes in subregional areas. 
Bay of Plenty Annual Bus Trips

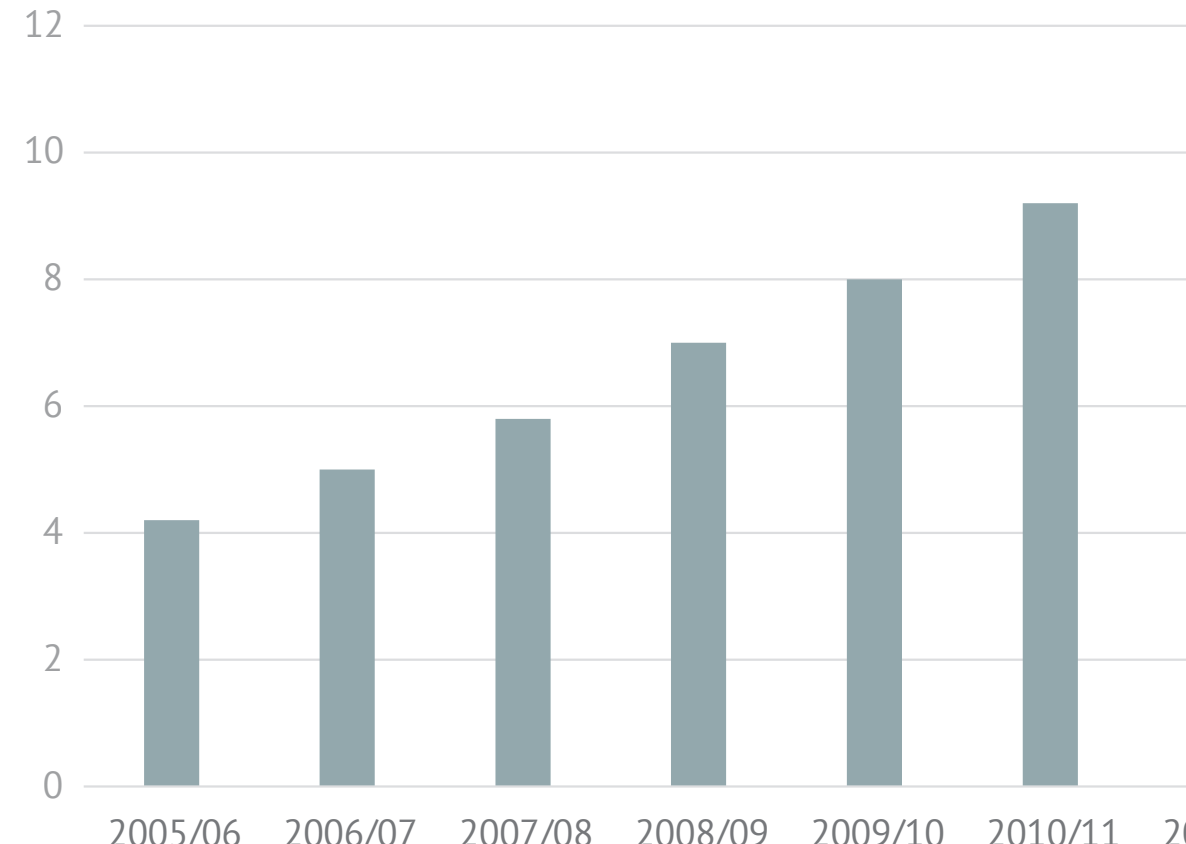

$\begin{array}{llllll}2005 / 06 & 2006 / 07 & 2007 / 08 & 2008 / 09 & 2009 / 10 & 2010 / 11\end{array}$
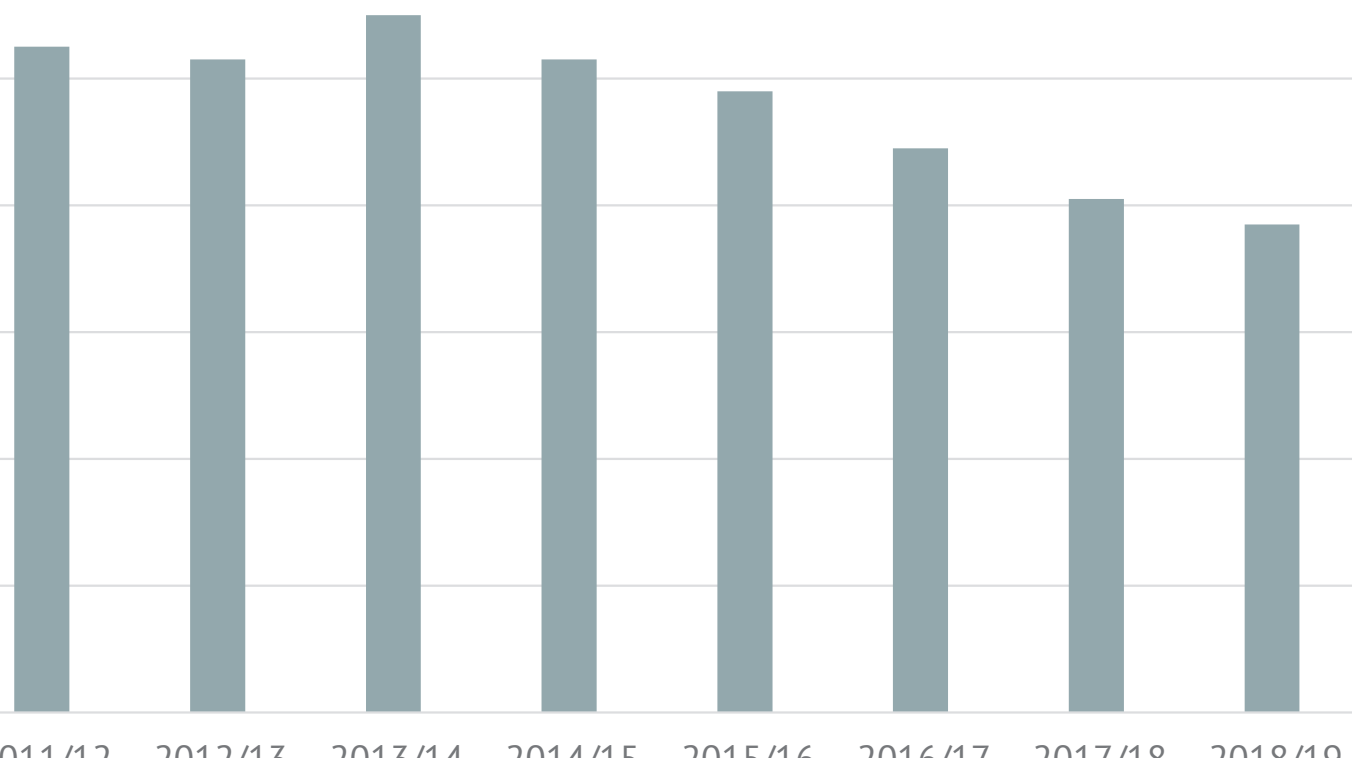

- Bay of Plenty
Figure 8. Annual Bus trips in Bay of Plenty $\$$

Unfortunately, despite of a high growth rate, the number of trips on public transport per person per year in Tauranga is continuing to trend downwards.

As shown in figure 7 , the use of public transport in Western Bay of Plenty, smoothly increased between 2005-2013 from below 4.2 to 11 trips per person annually. However, growth in patronage started to decline from 2014 to now. Western Bay Public Transport Blueprint said that an average bus trip takes approximately two and a half times longer to travel between the Central Business District and key sub-urban locations than car.

New transport provision in the Bay of Plenty region over the last decades has mainly focused on auto vehicle's infrastructure. 
The Proportion of all Trips with Sustainable Modes

Figure 9. The Proportion of Sustainable Modes

The proportion of all trips with sustainable modes

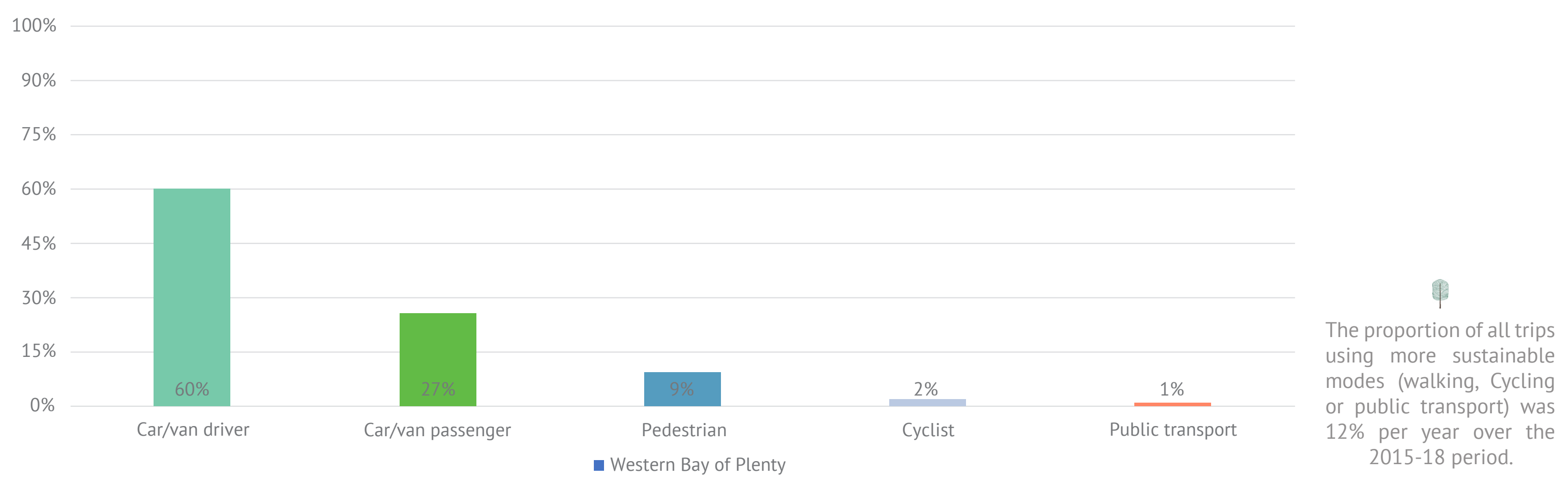




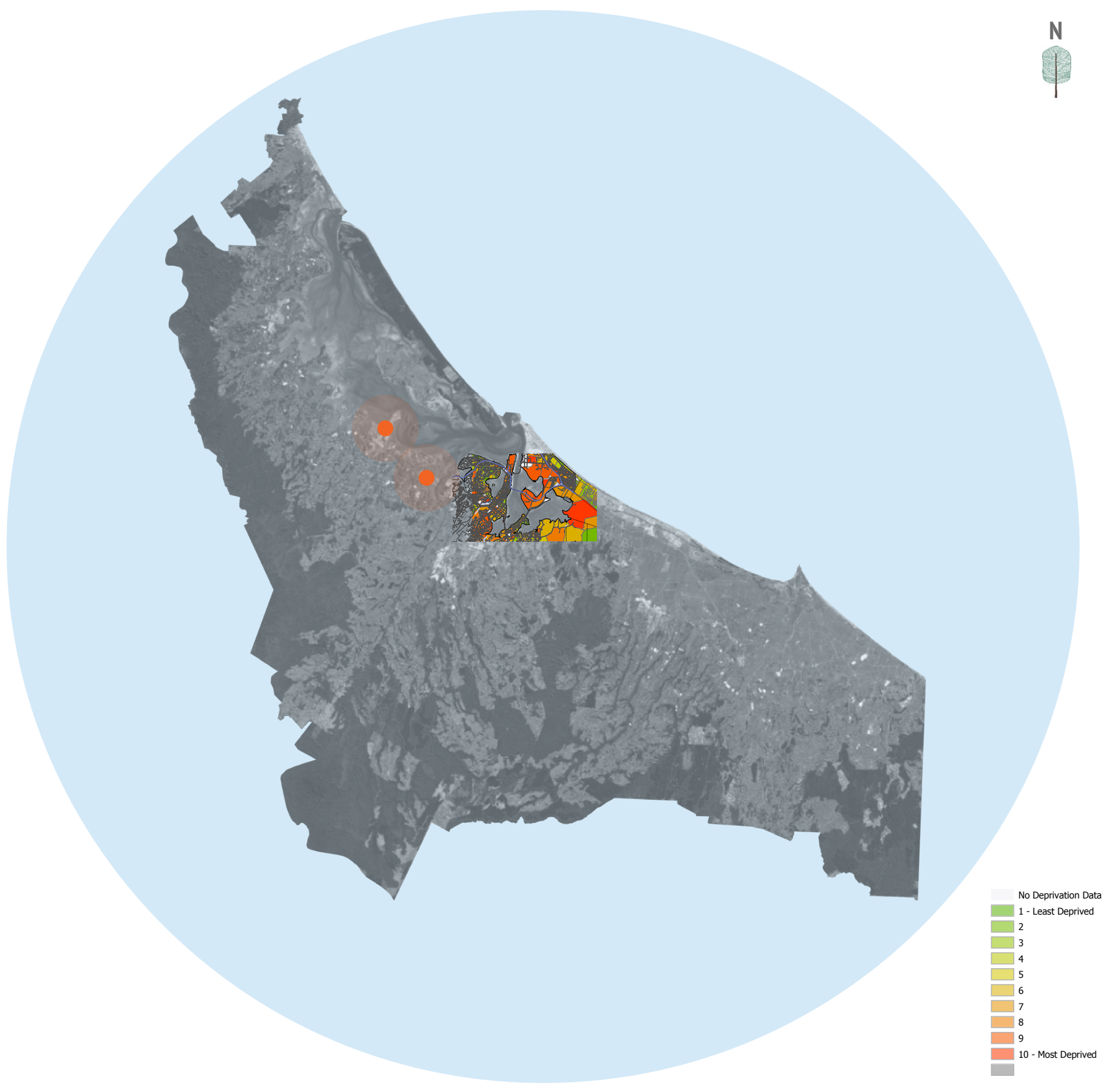

q

Access to community facilities and jobs is critical for the sub-regional development. NZ Index Deprivation report indicates that $42 \%$ of Tauranga's population live in the two most deprived quintiles.

Currently, most of the low density housings on the edge of the city typically places significant pressure on the transport network. The sub-regional areas do not have enough transport options, as a result, serious inequalities are occurred.

Existing communities and future residents need access to high quality physical and social infrastructure to meet and play. Various transport options is the most considerable factor to achieve existing transport issues and prepare future development.

Figure 10. Public Transport System and deprivation in Western Bay of Plenty Region 
Morphological Distribution

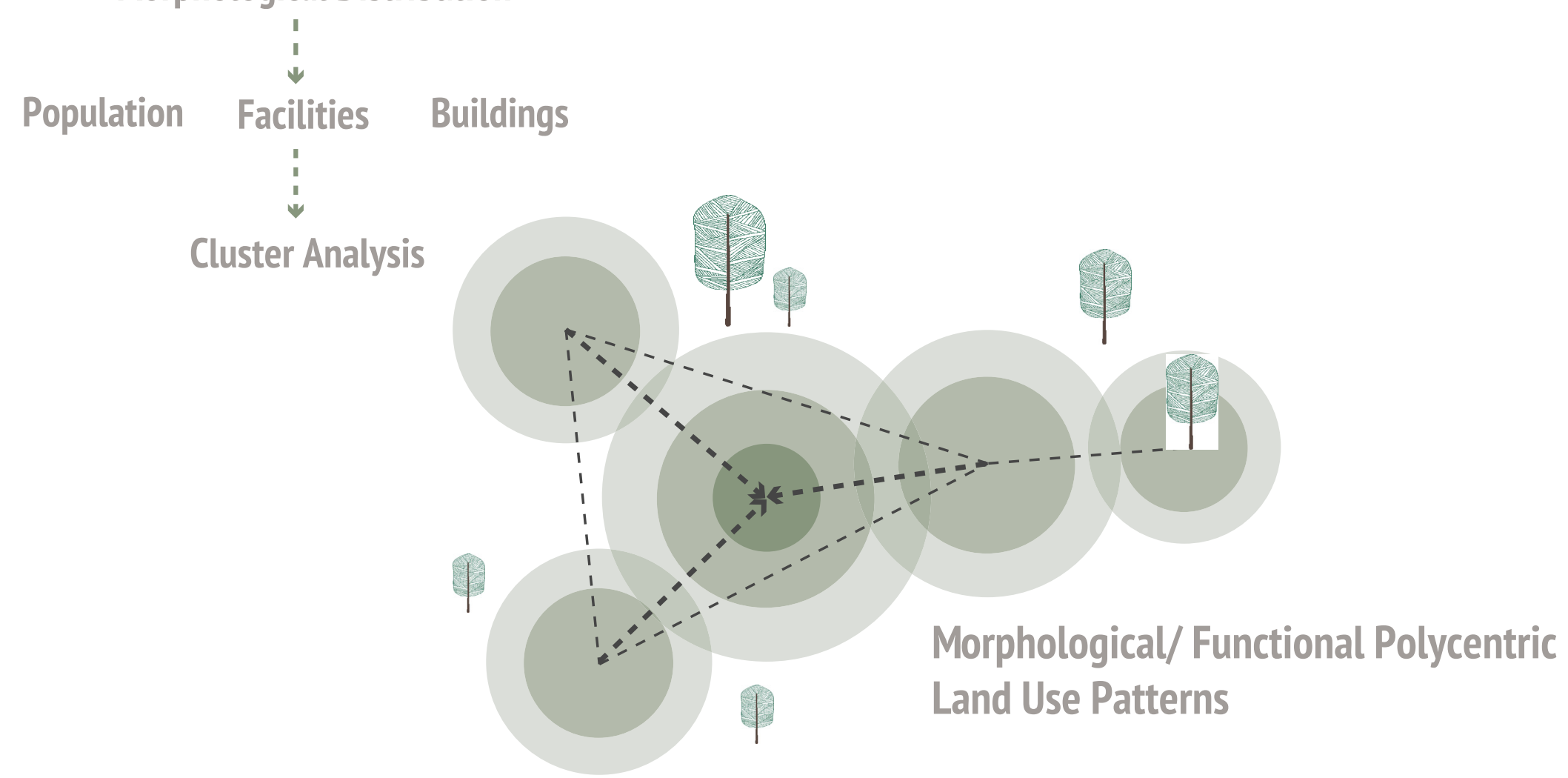

Figure 11. Land Use Patterns 


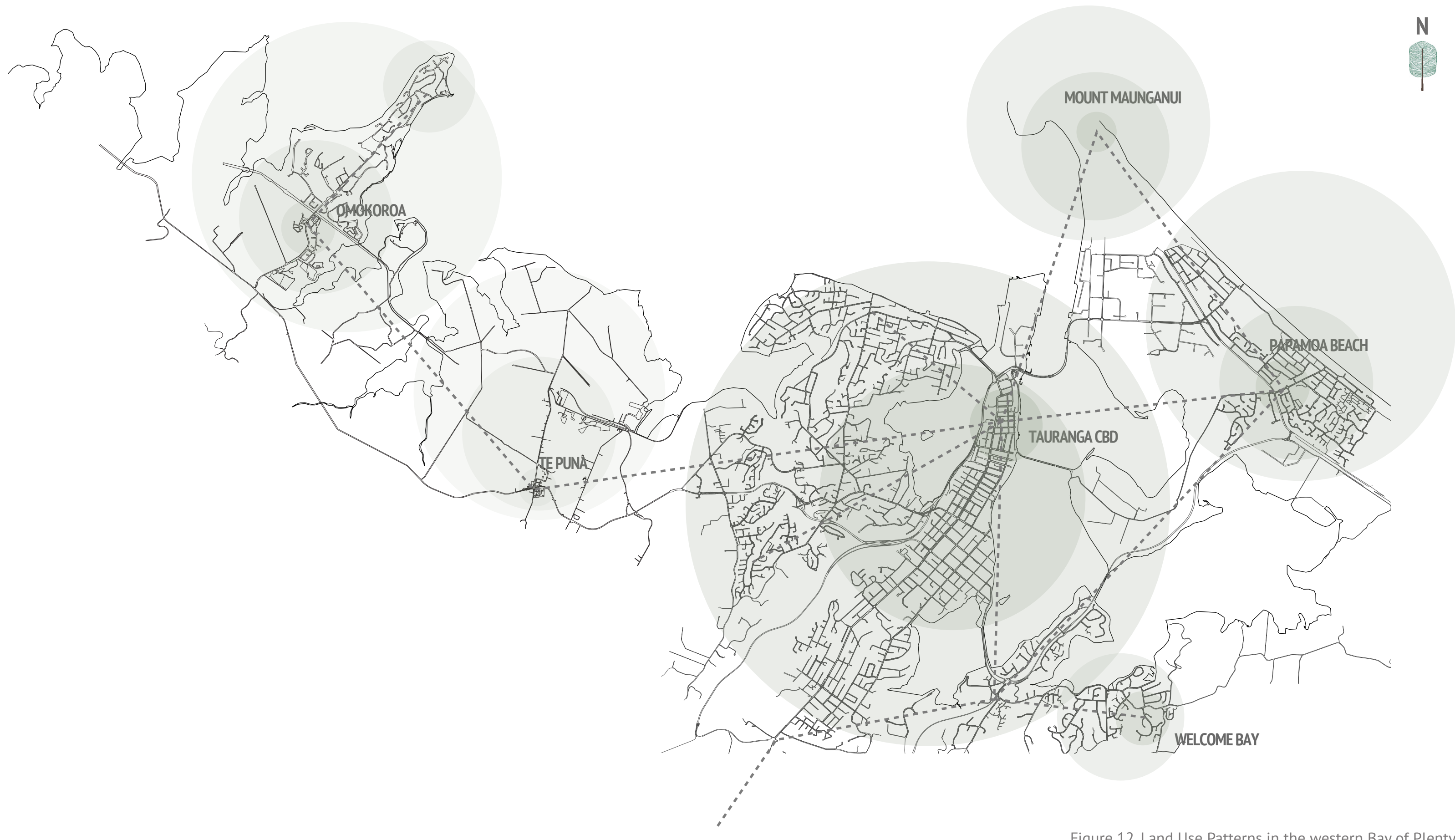

Figure 12. Land Use Patterns in the western Bay of Plenty 
Functional Linkage

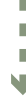

Information Flow People Flow Goods Flow

$$
\text { i }
$$

\section{Network Analysis}

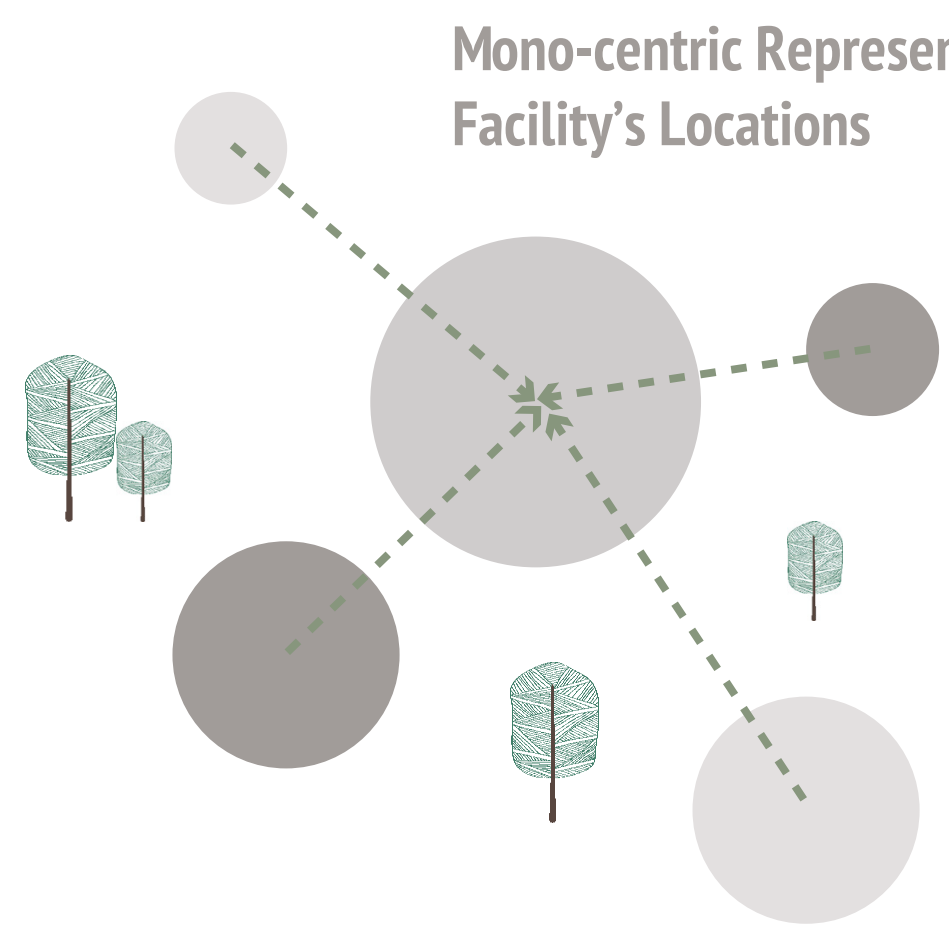

Figure 13. Mono-centric Representation

\section{$\phi$ \\ Network Analysis with Traffic \\ Conflicts}

Figure illustrates people's movement travelling to Tauranga Central District from sub-regional urban developments. Particular Tauranga's geography with peninsula based narrow land development pattern, the functional linkage is quite inefficient by the transport system which has not got enough capacity to support the growing population in the western Bay of

$$
\text { Plenty region. }
$$

One of the morphological distribution, 'the location of facilities' is also the important aspect that determines the transport movements. Most of key facilities are located in

Tauranga CBD or within Sub-regional areas. However, there are a lack of public transport choices to access the locations other than a private vehicle. 
Figure 14. Network Analysis with Traffic Conflicts

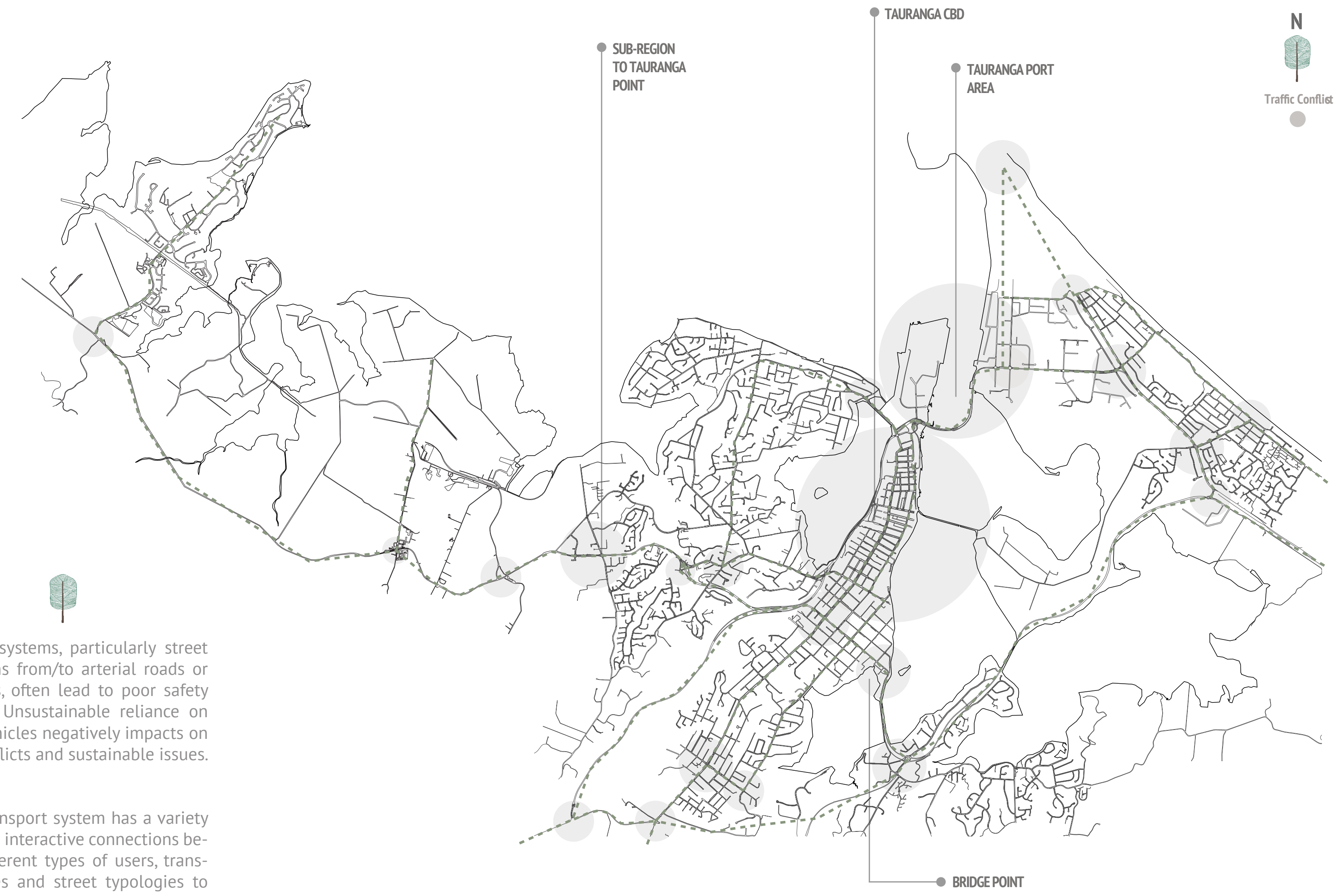

Transport systems, particularly street connections from/to arterialy roads or motorways, often lead to poor safety outcomes. Unsustainable reliance on private vehicles negatively impacts on traffic conflicts and sustainable issues.

A good transport system has a variety to increase interactive connections beport modes and street typologies to the multiple housing, educational, employment, and community hubs across the sub-region to/from the city. 


\section{Aligned Growth and Transport Infrastructure}

Development in Bay of Plenty Region

Figure 15. Aligned growth and transport infrastructure development in Bay of Plenty Region

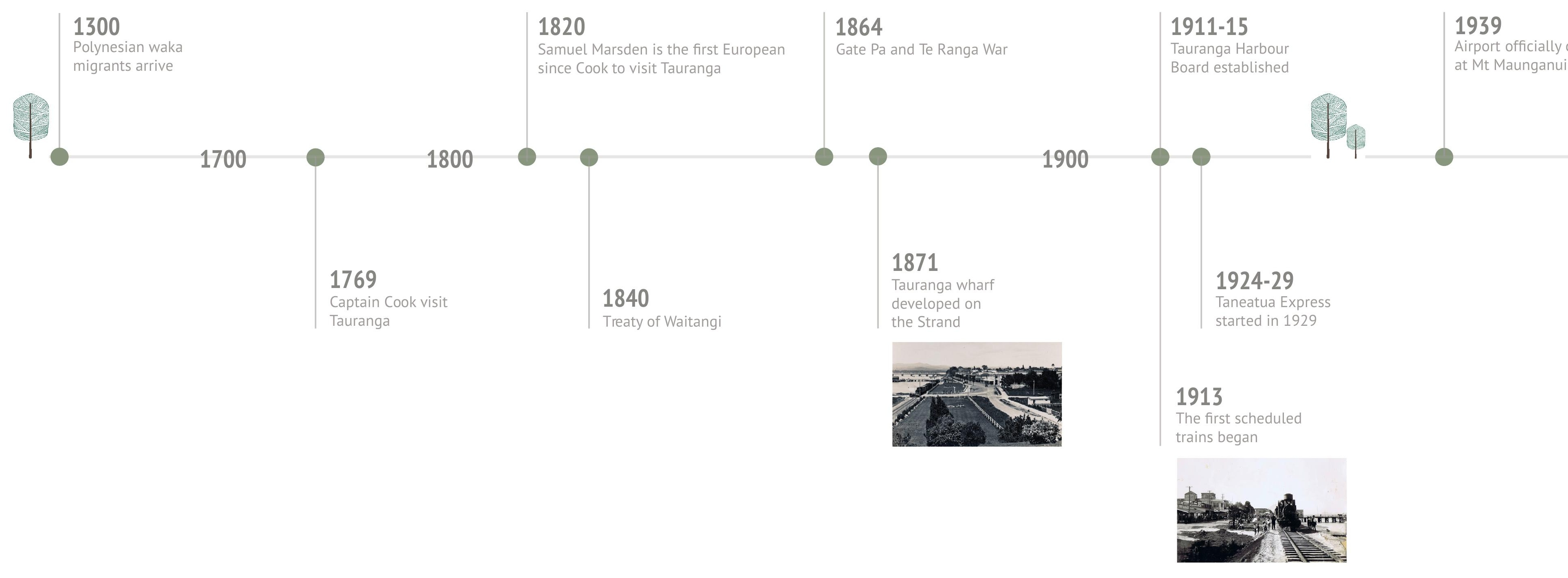




\subsection{Problem Statement}

The context of the western Bay of Plenty with the population and economic growth, simply establishing more transport infrastructures for the private vehicles is not a feasible and effective solution. Street condition varies from travel characteristics, supported transport modes and users' behaviours.<smiles>C1CC1C1CC1</smiles> 


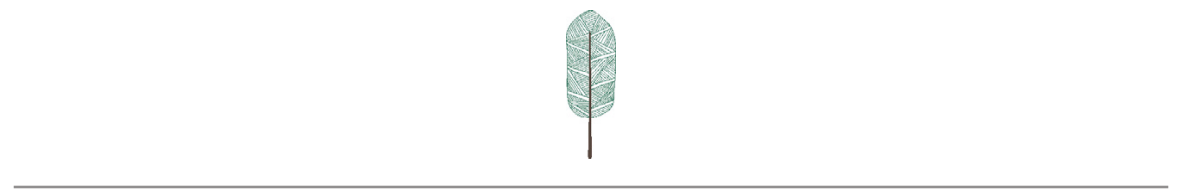

National Problem Statement

The national issues with investigated strategy include:

Significant population change highlights the demand for accessible and effective linkages between different type of transport modes such as public transport, walking and cycling infrastructure.

Because of lack of strategic direction and design guidance on network development, traditional and existing streets were sometimes only designed to increase the connectivity between place to place; car-oriented design. This provides resulting in conflicts between active users and street's liveability. 
Problem Statement in Western Bay of Plenty Region

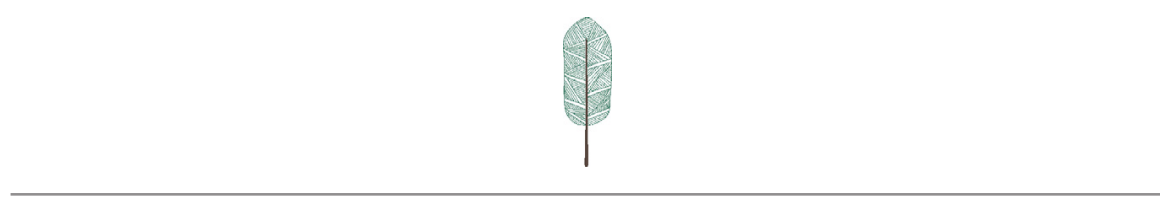

Problem Statement in Western Bay of Plenty Region

The issue focuses on transport networks and street utility to acof Bay of Plenty region.

Tauranga's geography with peninsula based narrow land devel opment pattern, the functional linkage is quite inefficient by the transport system which has not got enough capacity to support the growing population in the western Bay of Plenty region.

Mono-centric representation of key facility's locations with ineffectively connected networks are not aligned with community demands to access community facilities in sub-regional areas.

Transport systems, particularly street connections from/to arterial roads or motorways, often lead to poor safety outcomes.

Unsustainable reliance on private vehicles negatively impacts on traffic conflicts and sustainable issues.

A low level of street utility and limited street uses caused by disconnected or not supported public transport modes.

Socioeconomic inequalities related with quality of street accessibility by public transport.

Journey times are long and the location of stops are not enough to connect between different types of transport modes in Western Bay of Plenty PT service.

Most of streets were not designed to support multi-modal transport choices and better access for people of all ages and levels of physical mobility. 


\subsection{Research Opportunities}

The street is primarily public places where the city's economic, cultural and social activity are occurred. Street capacity and design layouts determine street's function and its important access corridors which encourage people to use public transport and other sustainable transport modes. 
Research Opportunities

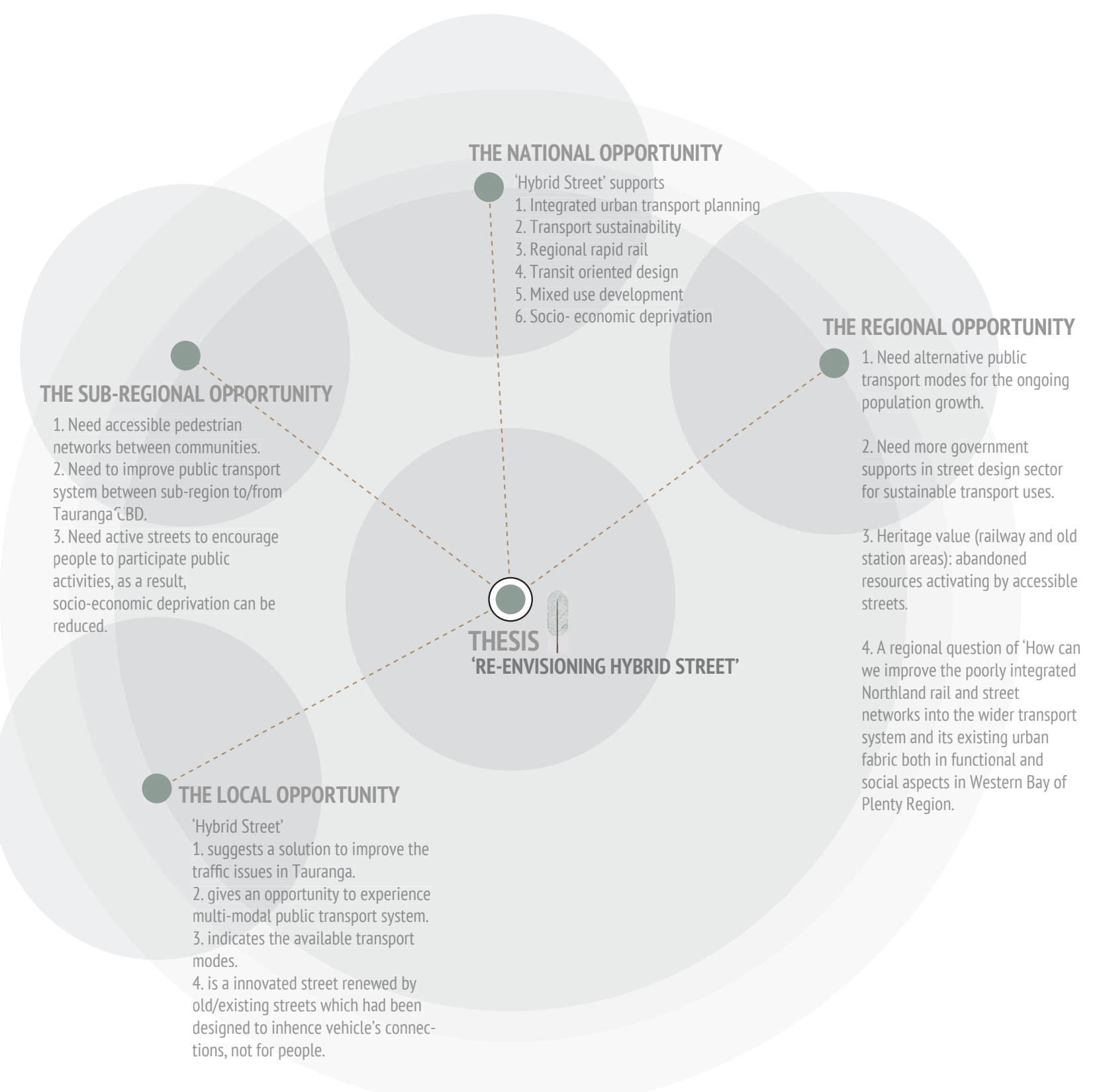

Figure 16. Research Opportunities

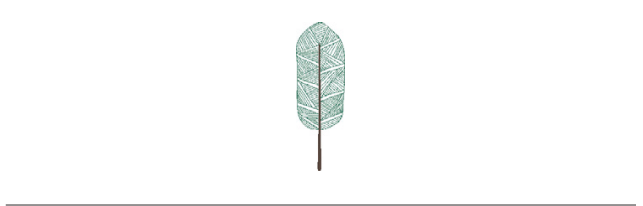

Research Opportunities

Existing street design guidelines in many other worldwide cities are focusing on the importance of activeness and liveliness in how we experience streets while still maintaining the conventional street functions with transport accessibility and connectivity. However, there are no specific researches that articulate the design strategy to identify a hybrid street typology which has both functions of transport park's and street roles connecting the rich native culture between neighbourhood, city, and region. 


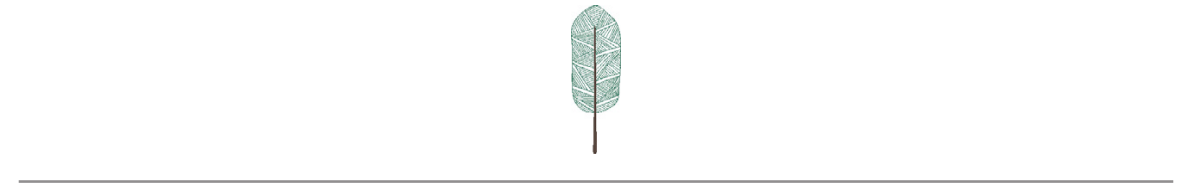

\section{Design Opportunities}

A LINEAR STREET TRANSPORT PARK

A high accessible transport interchange street operates transport variety to encourage the sustainable uses such as cycling, walking, skate boarding and e-scooter to all types of different aged users.

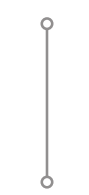

DESIGN FOR ACCESSIBILITY AND SUSTAINABILITY

from all types of users such as cycling, walking, skate boarding and e-scooter. As a result, a high accessible transport interchange space will operate transport va-

riety to encourage the sustainable uses.

DESIGN FOR CONNECTIVITY

with active public transport and surrounded facilities

to support an integrated transport planning from sub-regional trip to central area.

DESIGN FOR ACTIVE AND SAFE STREET

that people can participate and enjoy the street activities to spend their time and communicate each others, as a result, the street is more liveable.

\section{DESIGN FOR EQUITY}

'Equity street' supports multi-modal transport modes to everyone. The street allows to access many economic and social opportunities as Western Bay of Plenty's population grows. 


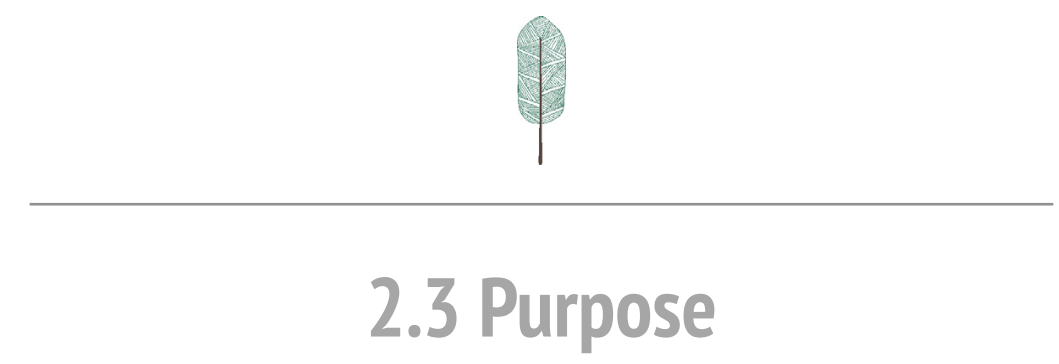

Research paper is intended to develop a new street typology which has a hybrid of street functions and transportation park's activities with the existing railway network in Western Bay of Plenty.

Existing street design guidelines in many other worldwide cities are focusing on the importance of activeness and liveliness in how we experience streets while still maintaining the conventional street functions with transport accessibility and connectivity. However, there are no specific researches that articulate the design strategy to identify a hybrid street typology which has both functions of transport park's and street roles connecting the rich native culture between neighbourhood, city, and region.

Developing a new way or toolkit to enhance our community connection between neighbourhood, city, and region by the vibrant streets will promote people's life more liveable. 


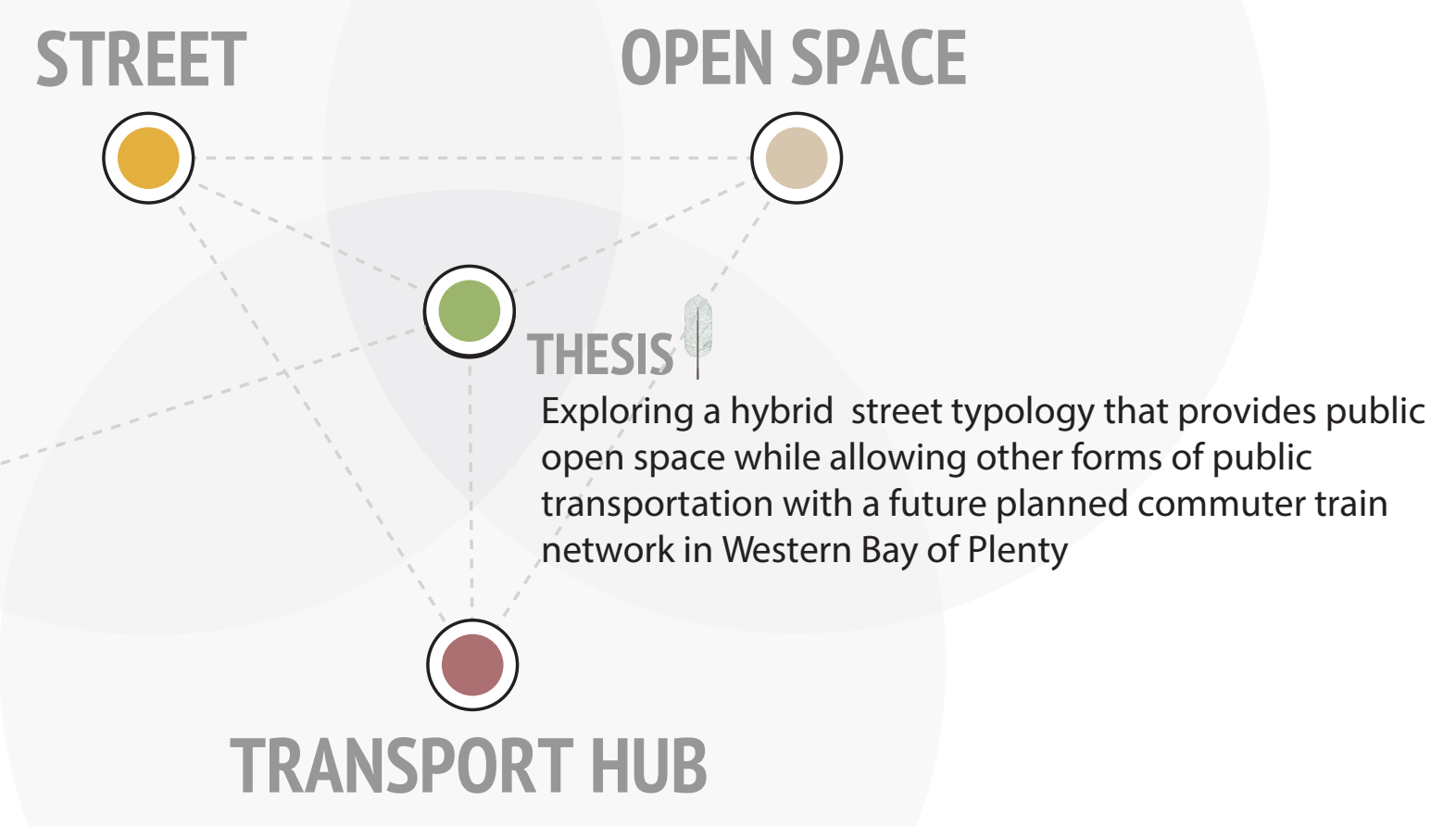

Figure 17. Research Purpose 


\subsection{Research Objectives}

The research paper 'Hybrid Street' has five main objectives. First equity streets, second sustainable streets, third safe, accessible and active streets, fourth effective streets, fifth culturally protected streets.<smiles>C#CC#CC1CC1</smiles> 


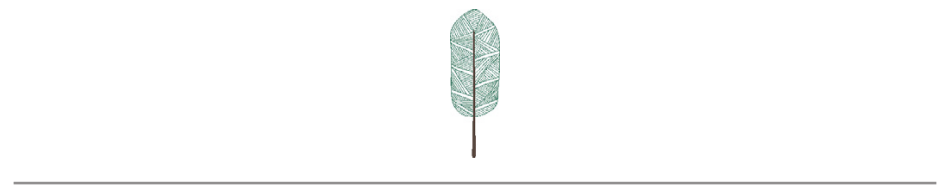

The research for the 'Hybrid Street' has five main objectives:

'Hybrid Street'

1. 'Equity Hybrid Street' operates multi-modal trans port modes to everyone. The street allows to access many economic and social opportunities to all types of people by effectively connected streets.

2. Supports various users such as cycling, walking, skate boarding and e-scooter. As a result, a high accessible 'transport interchange street' will operate cessible 'transport interchange street' will operate
transport variety to encourage the sustainable uses.

3. Shapes a safe and vibrant street to encourage public transport. People can participate and enjoy the street activities to spend their time and communicate each others, as a result, the street is more liveable.

4. Creates measurable outcomes in transport congestion, auto-vehicle dependency, CO2 emissions, travel inequity and street safety issues.

5. Strengthen neighbourhood and community interaction to the street, therefore each street has their own function and community identity. 


\subsection{Research Question}

Paper's topic has been settled with a starting point of two part of research questions, first question focuses on transport and urban planning and second one for landscape architectural design terms. Those interconnected research questions are a valuable starting point to define new term of 'Hybrid Street'.<smiles></smiles> 


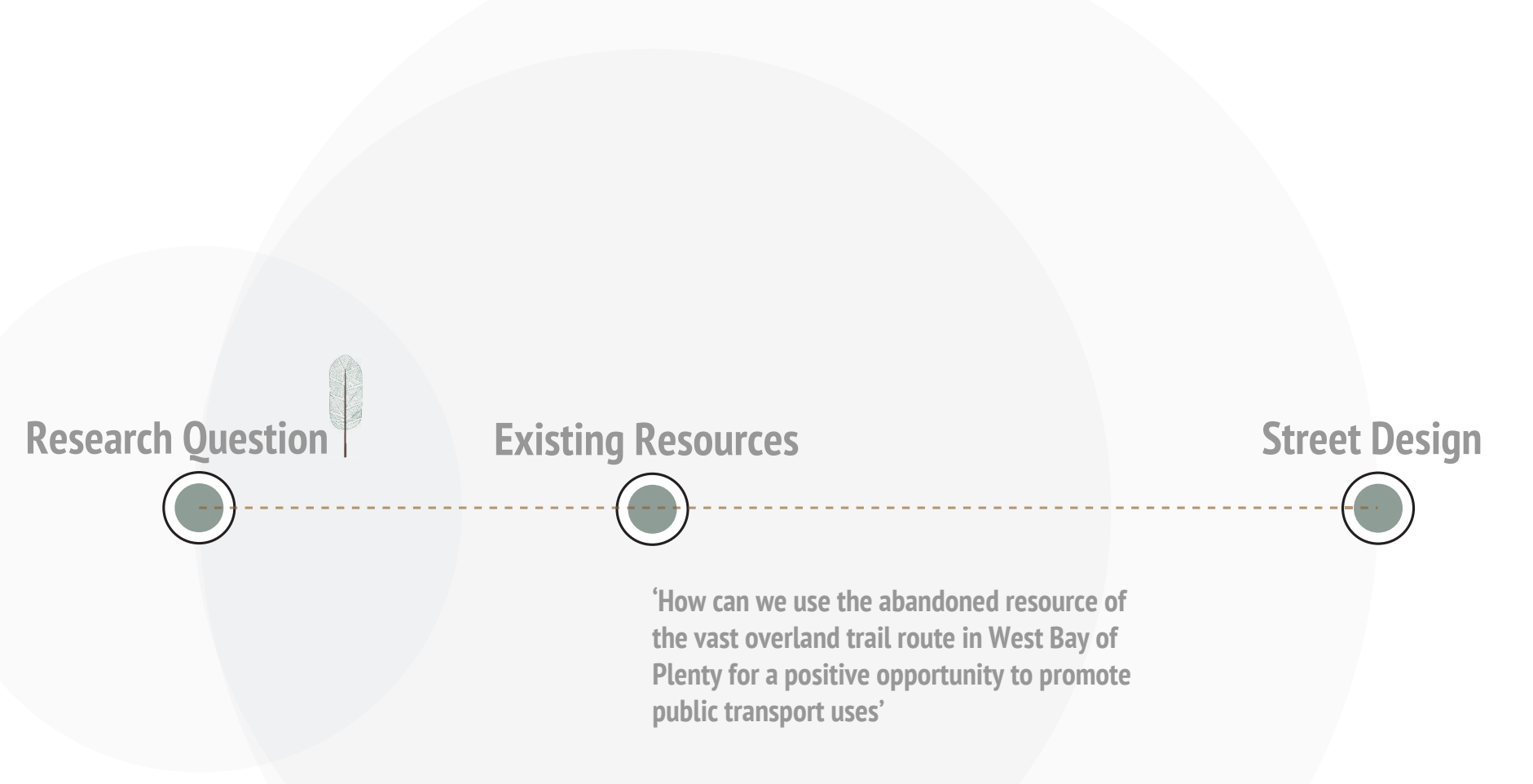

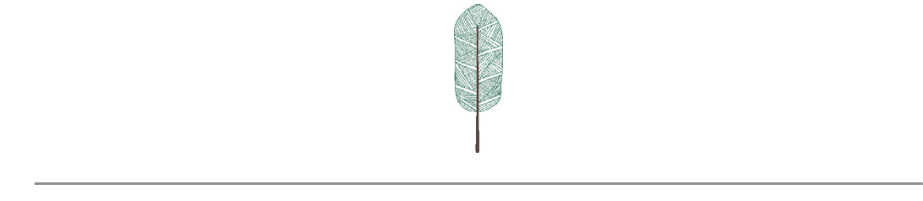

\section{Research Question}

'How to avoid the mono-functional logics of transit corridor/ street and translate the street to a complex public space that fulfils many functions beyond auto-mobile transportation'

Design Outline

How can we shift away from traditional street designs in a way that allows for new forms of 'Hybrid Streets'

i

Design Results

Did the hybrid street design encourage the use of public transport and at the same time, protect a sense of place and spatial identity? 


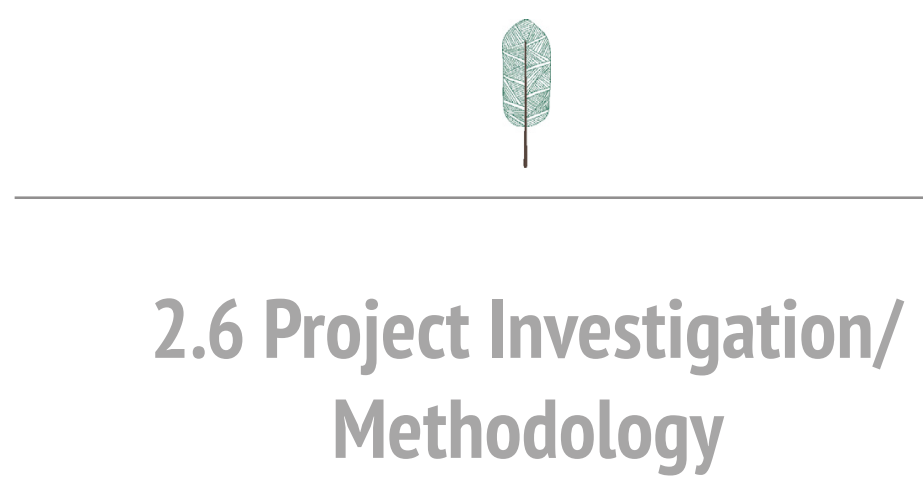

To achieve the research question, existing studies and reviews of street typology need to be dealt with to understand the basic roles of transit street's characteristics in 'Literature Review. Through a 'Design Criteria' stage, an articulate 'Hybrid Street Typology' will be defined to be ready to use in 'Design Stage'. At the design stage, a comprehensive hybrid street typology will be used as an associated reference or a design toolkit to test the research ideas on nine different areas and two station's sites in Tauranga and finally see, how it supports the design question of 'How the hybrid street design will change people's travel

behaviours by supporting the increased uses of the variety modes of transports and at the same time, how it protects a sense of place and community identity? 
Investigation Approach: Structure of Research Framework

Figure 19. Research Investigation and Methodology

\section{Current Situation/Issues}

\section{Topic: Hybrid Street Design}

\section{Sub-topics:}

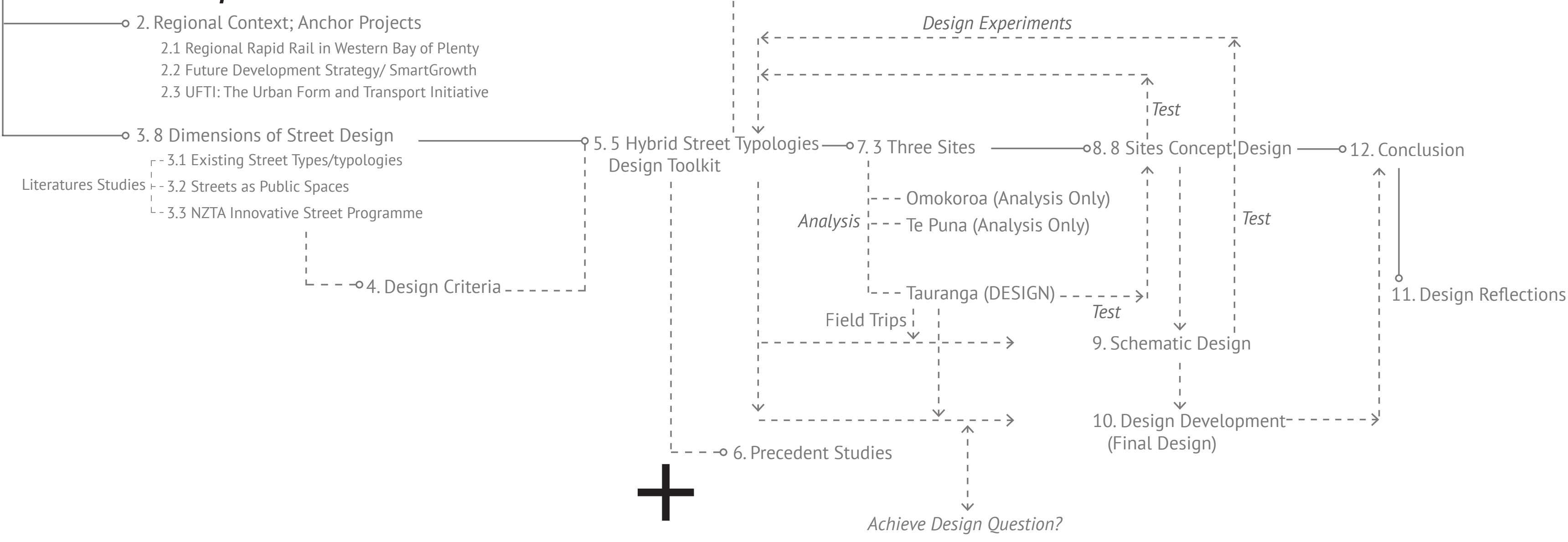




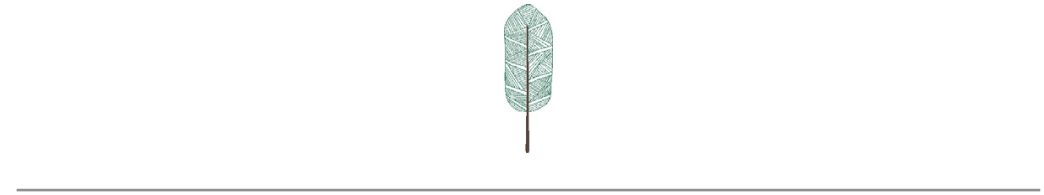

\section{Anchor Projects}

The research 'Re-envisioning Hybrid Street' will develop multi-functioned street's design outcomes with a government's longer term of transport planning. Connection between the research and current government's planning, significant strategies, and policy works will be undertaken in the research to looking at future transport scenarios and options including the future commuter train. The ex-

isting documents can be used to guide discussions concerning transport infrastructure especially rail in the Bay of Plenty region. 
The current projects include:

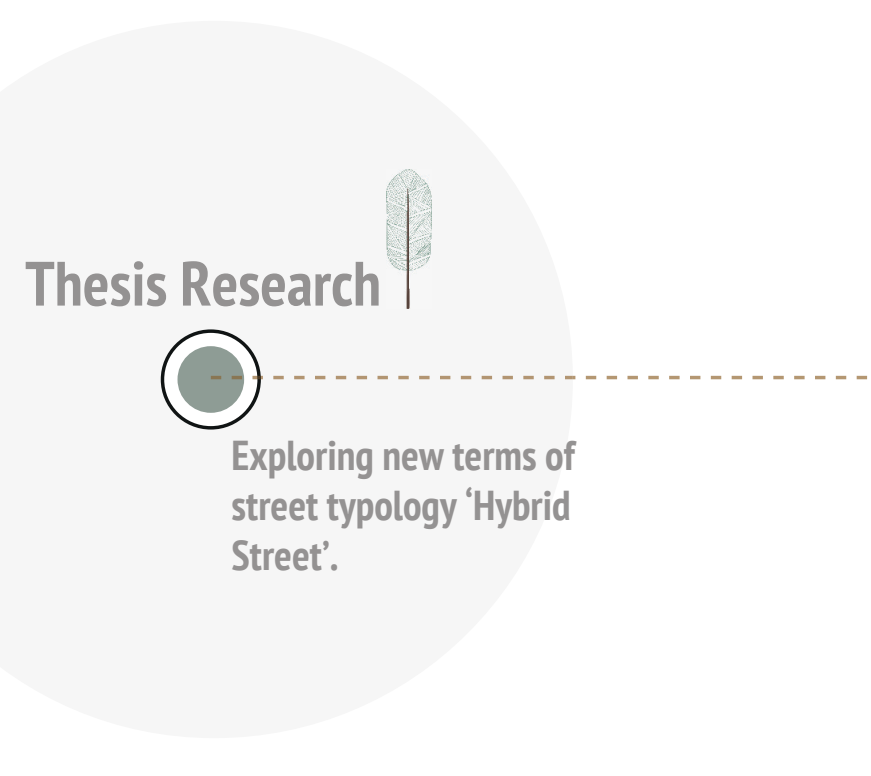

Inter-Regional Rail Connection
1
1

Regional Rapid Rail By Greater Auckland

Bay of Plenty metro passenger service opportunities By KiwiRail

Future Development Strategy By SmartGrowth

The Urban Form and Transport Initiative (UFTI) By

SmartGrowth and NZ

Transport Agency 


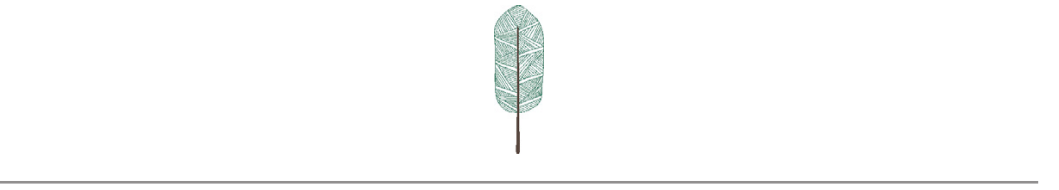

\section{RESEARCHES: REGIONAL RAPID RAIL}

\section{Greater Auckland}

Inter-Regional Rail Connection

Regional Rapid Rail is a proposal to activate an upper north island's passenger rail network connecting the "Golden Triangle" of Auckland, Waikato and Bay of Plenty. Three cities are expected to account for over $70 \%$ of New Zealand's growth in the future, however, the necessary transport infrastructure is not enough to support this rapid growth happening in three regions.

Regional Rapid Rail proposal has a three-stage processes to achieve feasibility. First is an interim-stage to be set up quickly and inexpensively using existing trains running on the current network. Second one represents an investment in new higher speed rapid trains. Third step is an expansion to increase the stations, journey frequency and reducing travel time.

The proposal of the revitalised network will provide fast and reliable travel options to regular commuters, business travellers, shoppers, students, local visitors and international tourists alike to extend the benefits of New Zealand growth and economy. 


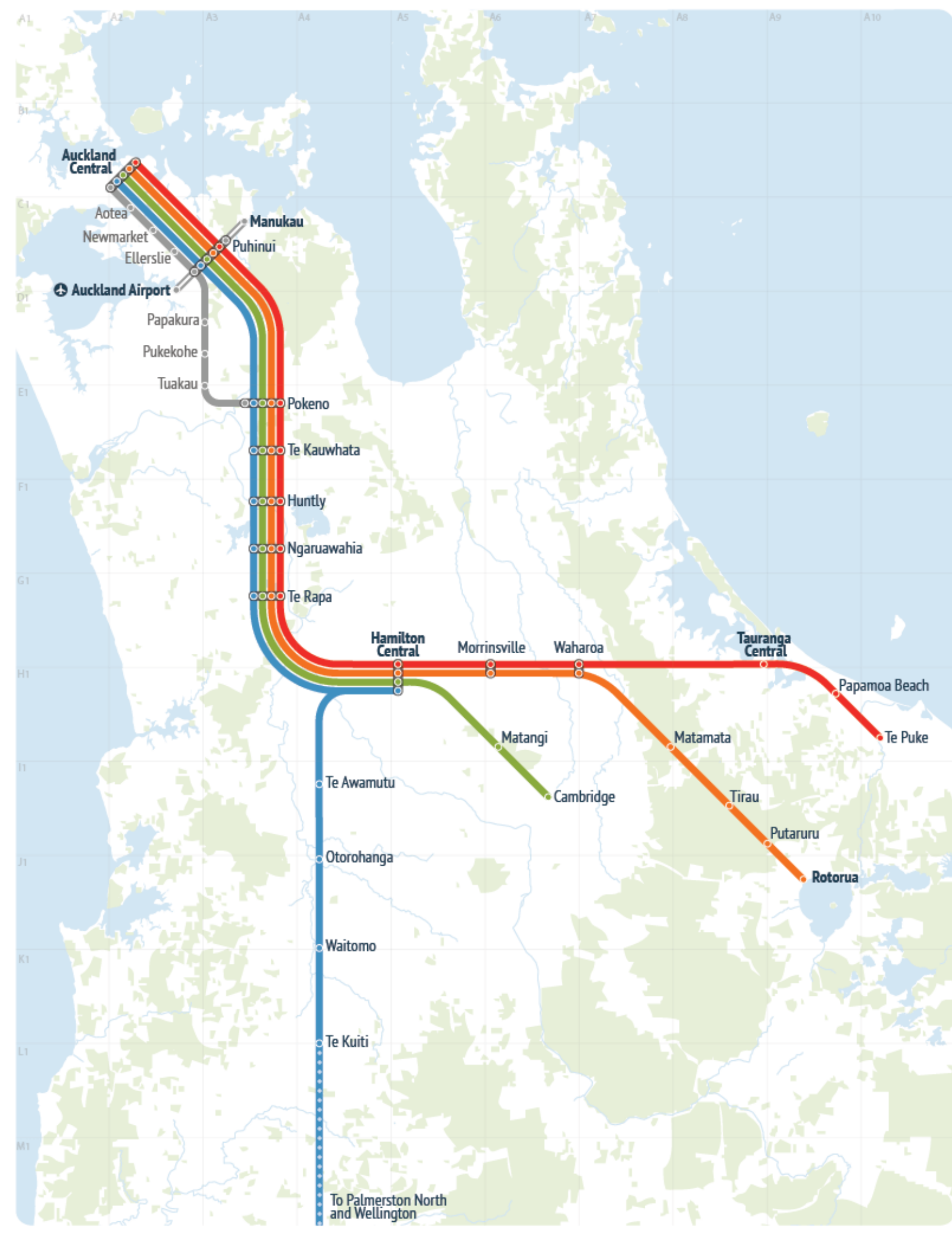

GREATER $\triangle$ :

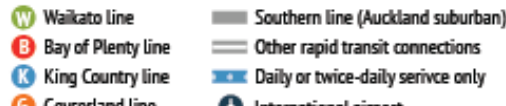

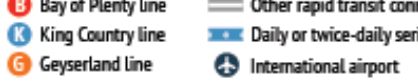

Regional Rapid Rail
Figure 20. Regional Rapid Rail Proposal By Grater Auckland

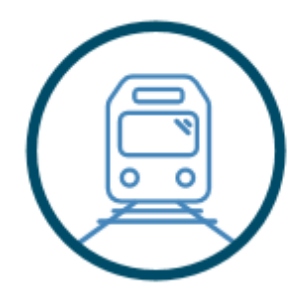

ftage is an interim, to be set up quickly and inexpensively using existing trains running on the current network. It is intended to build patronage and show the viability of regional intercity rail in the short term while subsequent stages are being procured.

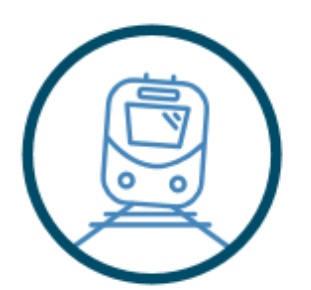

The second stage represents an investment in new higher speed tilting trains and network upgrades to create a truly regional network of rapid trains.

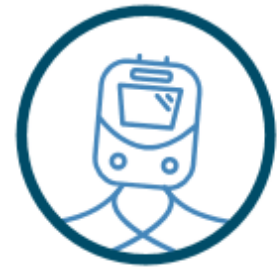

The third stage expands this network, extending the lines across the Waikato and Bay of Plenty, and further improving train speeds and journey times. 
3.2 Bay of Plenty Metro Passenger Service Opportunities

\section{1 \\ RESEARCHES: Bay of Plenty metro passenger service opportunities}

\section{KiwiRail}

Bay of Plenty metro passenger service opportunities Report had been developed in order to advance a vision for activated commuter rail in the Bay of Plenty region. This strategy is intended to focus on rail infrastructure to understand how to move forward in the new rail environment.

There are a number of opportunities for commute rail in the western Bay of Plenty in long term planhing. The vision of commuter rail is to explore th use of rail for passenger transport to connect new developed settlements to urban district areas. Inter-regional rail corridors between Auckland, Hamilton and Tauranga are another important opportunity to achieve national values of vibrant economic outcomes in New Zealand.

The report will be used only for the extract contains of the Bay of Plenty commuter rail network and its feasibility.

The identified potential rail journeys are: Omokoroa - Otumotai - Tauranga CBD 2. Mt Maunganui to Tauranga CBD

3. Paengaroa - TePuke - Baypark - Tauranga CBD

\subsubsection{Passenger Rail}

Passenger rail services were previously operated between Tauranga, Hamilton and Auckland, however ceased operation in 2001 due to low patronage numbers and increasing costs.

- KiwiRail have confirmed that there is sufficient capacity within the Bay of Plenty rail network. This capacity could accommodate future passenger rail services. However, it is important to note, that the establishment of any passenger rail services will require significant advanced planning and investment.

- Passenger rail requires high populations and high population densities to be viable in economic or financial terms.

Tauranga as the region's largest city is

currently well below the thesh, is

References from the report 
Inter-Regional Rail Connections Between Other Key Settlements (e.g. Hamilton, Auckland and Wellington)

by rail between the two

stations is approximatel

15 minutes at $60 \mathrm{~km} / \mathrm{h}$

2. Mt Maunganui to Tauranga CBD

3. Paengaroa - TéPuke - Baypark - Tauranga CBD

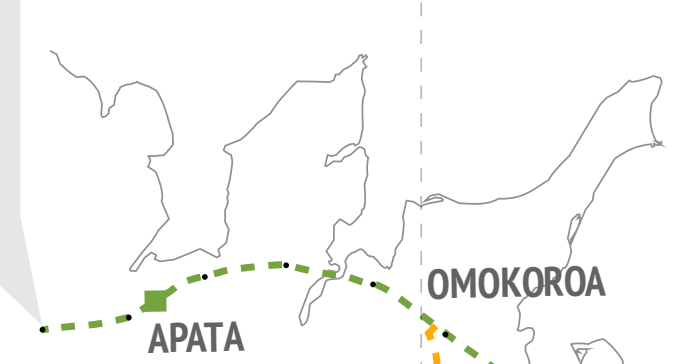

$\because \because, \frac{3}{4}$

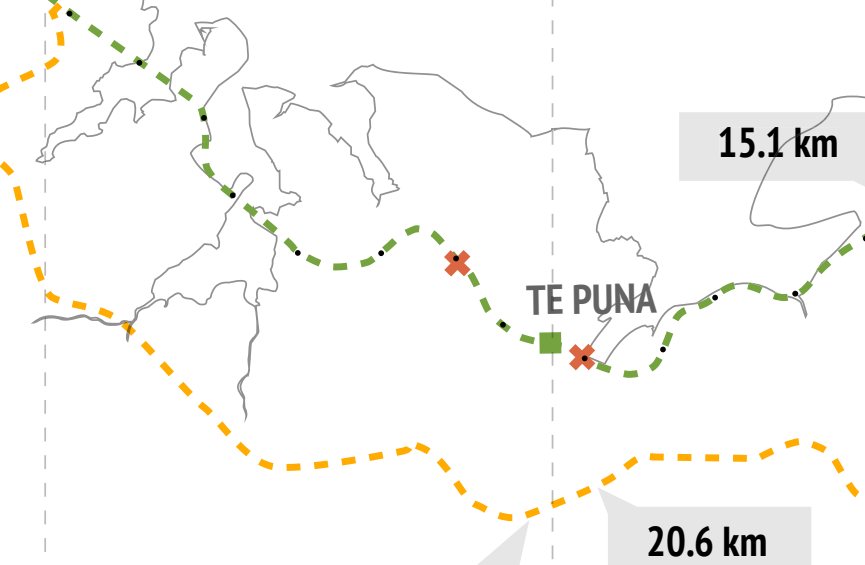

The average transit time

by road between the two

stations is 29 minutes

\section{$20.6 \mathrm{~km}$}




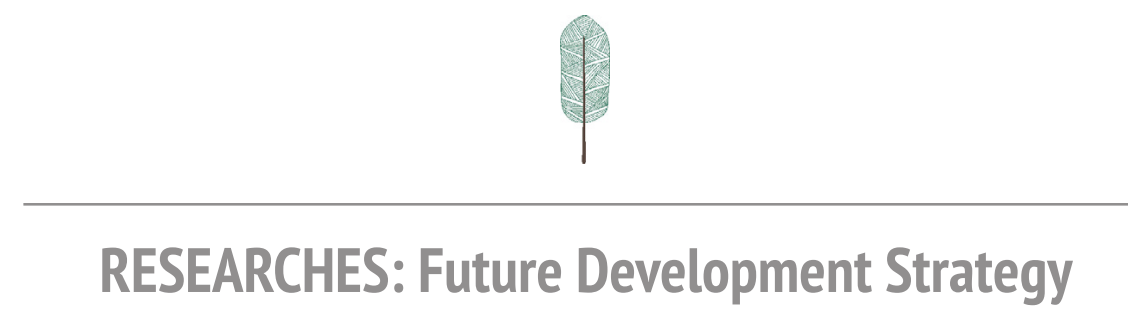

\section{SmartGrowth}

As population is significantly growing, there is a tension between the current settlement pattern, new greenfield growth areas and a compact city in the western Bay of Plenty. Transport infrastructure is particularly challenging as it is expensive to implement and there is also a highly dynamic two-way relationship between the way the sub-region grows and the transport

$$
\text { system that supports it. }
$$

This proposed strategy outlines how we will work to ensure we provide sufficient development capacity for new homes and businesses to meet the needs of our communities and how can we develop a desired long-term outcome of a compact city that provides more sustainable environmental outcomes and affordable transport.

The development strategy will be used in design stage for project references to understand the Omokoroa (appendix 1) and Tauranga City's new settlement patterns (appendix 2) and future planed transport infrastructure (appendix 3). 


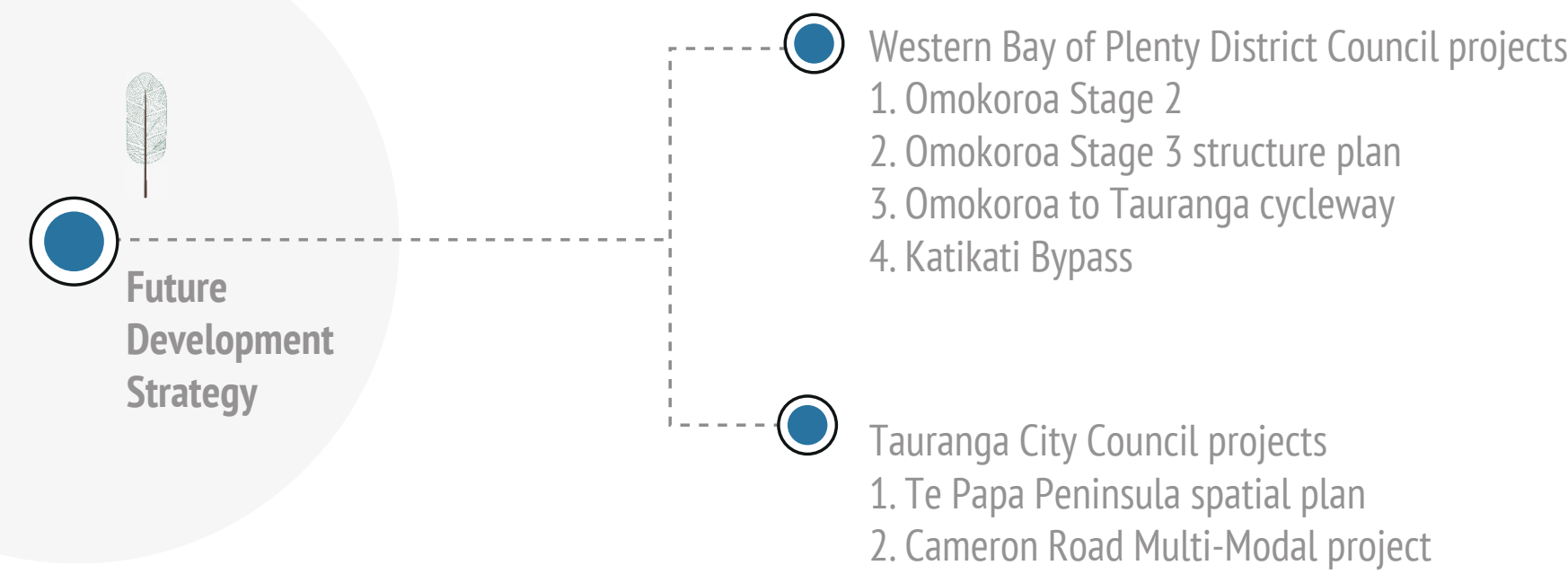

Figure 22. Future Development Strategy By SmartGrowth 


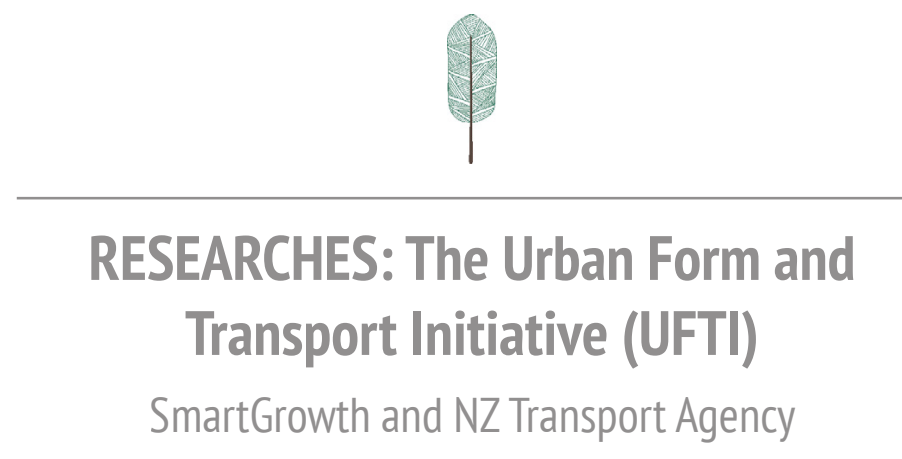

The urban form and transport initiative (UFTI) Report suggests a strategic and integrated plan for the western Bay of Plenty's future urban form and multi-modal transport system. The Report defines many transport infrastructure programmes to test the idea that 'How we can create the most effective way to provide vibrant and connected urban form between the sub-regional areas and urban centres',

Four Programmes were shortlisted: 1. 1. Dispersed growth 2. Two Urban centres 3. Connected Urban Villages 4. Rail-Enabled Growth.

Each programmes has been deigned to consider different land use patterns, densities expected, and transport system response.

Option 4, 'Rail-Enabled Growth' programme will be used in overall site analysis stage as an expert proofed reference to manipulate a new public transport infrastructure's possibility and the commuter rail feasibility. 
Table 1
Summary of macro transport modelling - high level and indicative key outputs

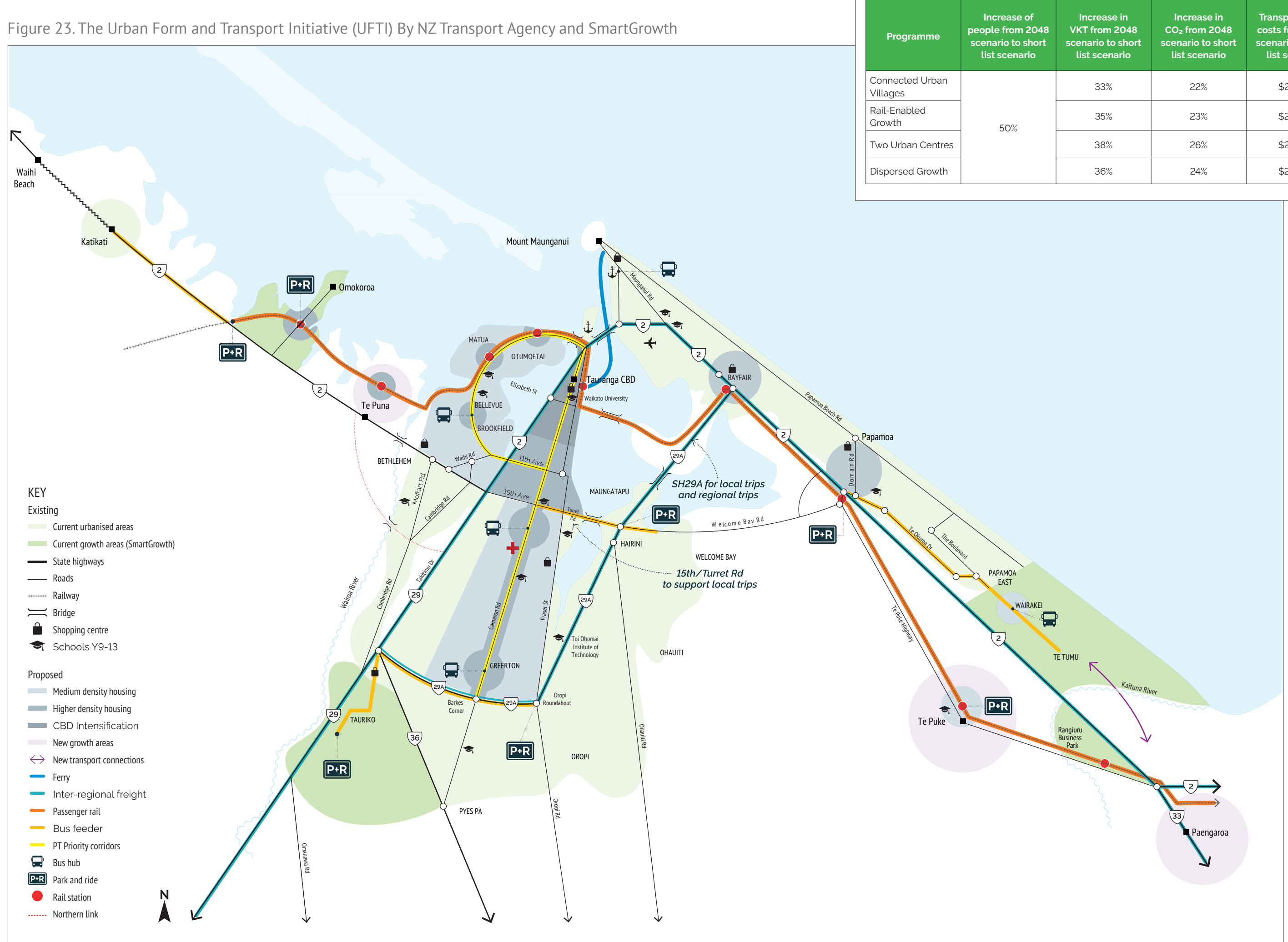

References from the report

\section{Option 4. The Rail-enabled Growt}

- The programme includes using the rail network to move people from the Northern and Eastern Corridors into the

- A frequent bus-based public transport system would support the rail movements along with a ferry service between Mount Maunganui and the CBD.

- Additional growth is enabled in the north and east along with intensification predominantly in Te Papa and Otumoetai areas and at other key areas such as Bayfair/Baypark and Papamoa.

- Increased dwelling densities around core transport-based hubs would be implemented to further encourage public transport movements. 
04. Literature Review

P 
Figure 24. Literature Review

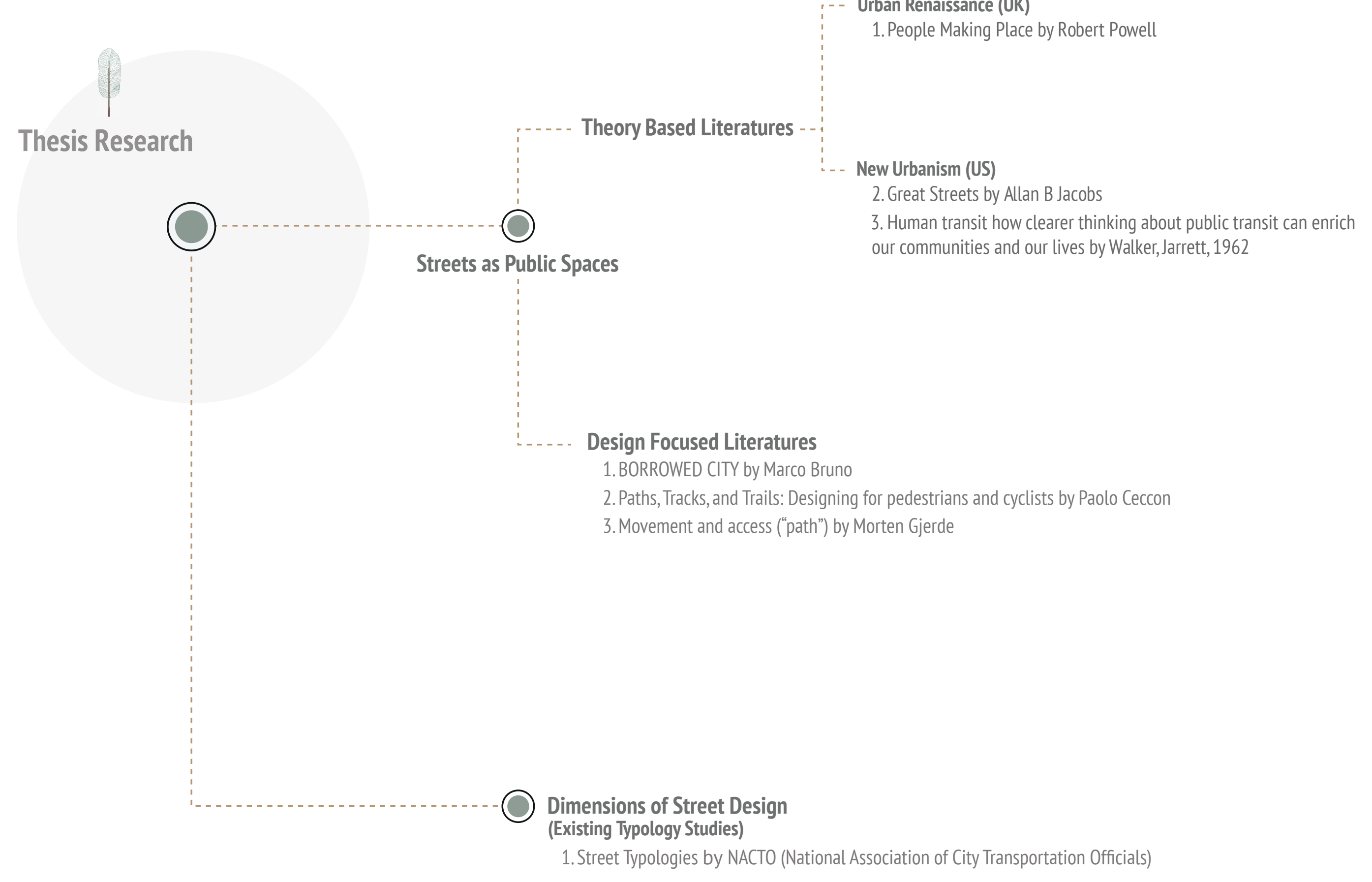




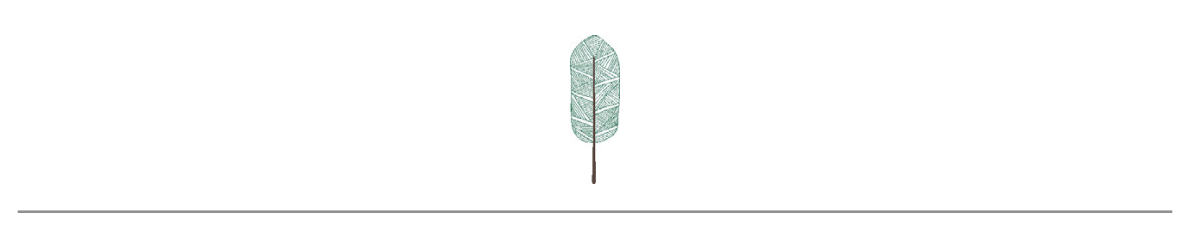

\section{Urban Renaissance}

People Making Place

By Robert Powell

The urban renaissance is the mid-20th century of city regeneration movements to build spatial contributions that support and help communities to become an equally central part of the process. The most important aspects in the design concept of the urban renaissance are how the urban design can encourage and enable the cities, towns and districts within the region to work together.

Streets and public places are a central part of the urban renaissance's invention to achieve a higher quality of the 'public domain' in urban environments. They believe, the social network between different types of people and communities is determined by the quality of the streets and public spaces. In order to create well-designed valuable streets, the designer has to understand and interact with various street users which involved in or affected by the design of the public realm both in the physical; streets, parks, buildings, squares and the invisible; emotion, memory, aspiration, pride, power (00). These urban design movements in the street design have provided visions for the future of both town centre and neighbourhoods, embracing all types of people both young and old, encouraging the regeneration of the places into exciting and vibrant places. 


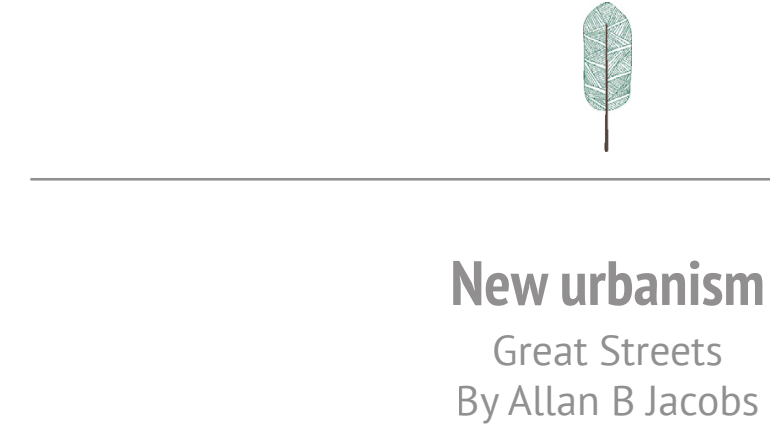

New Urbanism is an American urban design strategy that came out in the early 1980s. The strategies has influenced in many American urban-planning projects focusing on two different aspects, establishing a sustainable community and developing ecological practices. The urban movement, New Urbanism provides and promotes the environment-friendly walkable networks to access a wide range of liveable built environments. The urban movement also covers issues such as historic preservation, safe street, green building and the redevelopment of brownfield land. They believe that development and planning policies focusing on single-use zoning and heavy automobile usage create poor living

$$
\text { environments for people. }
$$

Jane Jacobs is a representative activist which transformed the field of urban planning in many American cities. She argued that with a few exceptions, 'urban renewal' did not respect the needs of citydwellers. Then Jacobs suggested a new method of urban design to replace modernism. She said that a continuous street system with small blocks and sidewalks to support a variety of different tand uses by well-connected sustainable transports or foot. She also outlines 'comparative analysis' which is a multi-dimensional spatial investigation in not just only site itself but also experiential consequences. For example,"The impact of street trees on human's physical comfort and experience by physical phenomena of light patterns, colour, shadow, leaf movement, spatial rhythm, shade and light penetration, generates visual stimulation and spatia complexity of the street."

\footnotetext{
The basic principles of New Urbanism are Unvironment should include:

1. Liveable streets arranged in compact walkable connections.

2. A variety of housing choices to support people of diverse ages and income levels.

3. Important facilities such as schools, stores and other nearby destinations have to be reachable by walking, bicycling and public by walking, bicycling and
transport service.

4. Human focused spatial design

5. The street design proposal, 'New Urbanism' provides a considerable data about the physical components of streets and valuable understanding of how the street components work together to create coherent public spaces.

6. "The physical and designable characteristics of streets"

: Investigation of street frontage and the use of sectional diagrams to classify street's characteristics.

The Urban Section: An Ana Streets By Robert Mantho. 2014
} 


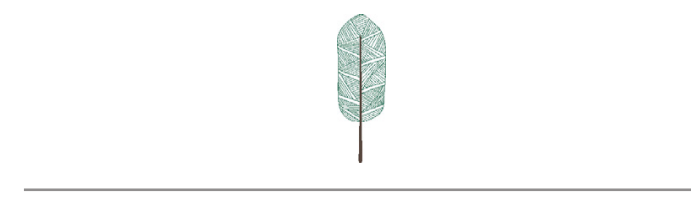

\section{New urbanism}

Human transit how clearer thinking about public transit can enrich our communities and our lives

By Jarrett Walker

The physical urban design of cities is the most important aspect to determine satisfactory transit outcomes by the users. The quality of transit is identified by three physical design aspects that are the locations of transit stops (connectivity) and its facilit patterns of urban development and existing street typologies or types. But, most of existing street has mono-function of street characteristic that means the street does not support the integrated transport system.
Facilities of the public transit are often treated as a separate infrastructure that cannot be integrated into the mixed-use urban street. However most of successful worldwide city's streets support the integrated transport system to serve the various kinds of public transit into the development. Public transit can enrich our communities and our lives. For that reason, the street needs to be more carefully investigated.

To sum up, many great urban design ideas can follow from accepting the needs of connecting transit services into the structure of an urban street. A multi-functioned transit friendly street is the way to offer the abundance of transit, and the crucial role of transit connections, into a positive feature of the centre's life. 
4.2 Streets as Public Spaces: Design Focused Literatures

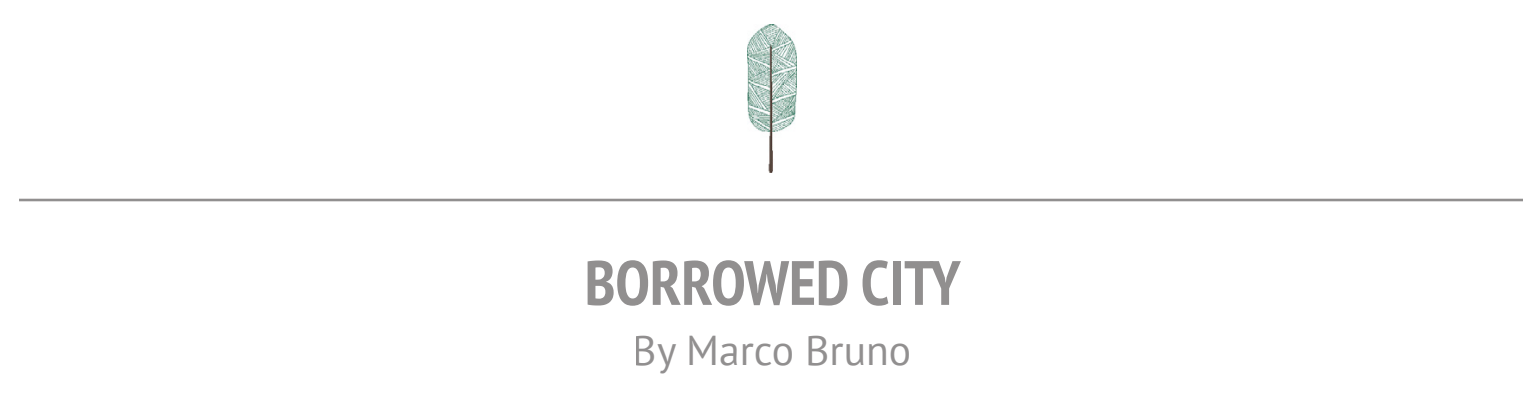

Borrowed City shows that how private Borrowed City has two intention points citizens use public space for their own which are 1 . To encourage people to use personal benefit. People spend a consid- public space in a respectful and creative erable amount of their lives in spaces way, 2. To consider borrowing a valuable that belong to entire community such as resource for a more sustainable way of streets, parks, squares, rivers and oceans. life. The use of public spaces in a creative Public spaces have many functions and way is a natural system that identifies people use them to perform differently. their local characteristics. 'Owing is an illusion, borrowing is a necessity, and our

The author of the book emphasises that depending on how much time we spend

on the area and how intensively we use it, The book investigates a research metha complex interaction between the space odology that explains how a specific area and user will be initiated. Through the in- being used differently by various types of teracting process, people negotiate with people and try to find design opportunithe rest of the community to maximise ties in their creative occupation process. their personal benefit in the use of public space. Roles of the public spaces and streets are established by different actors such as local government, residents, building owners and passersby within the aw. However, in some cases, the negotia-

tion has been suggested by the local community and the role occasionally has been redefined its own level of tolerance. 
3. Shops

4. Home

5. Workshops

6. Street Leisure
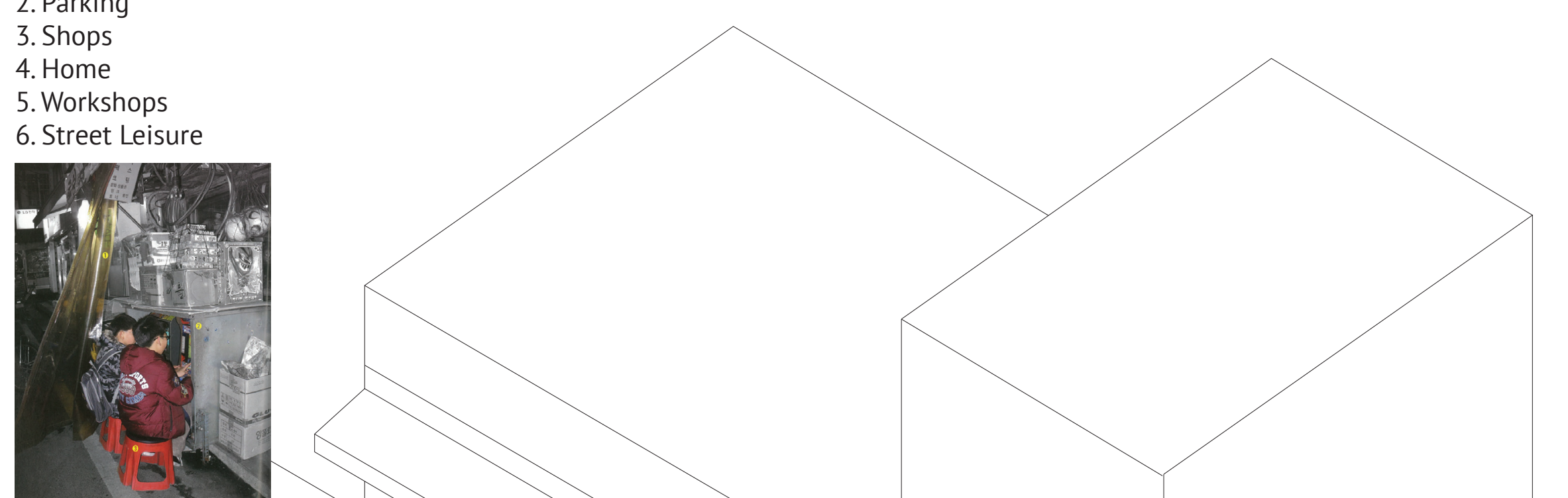

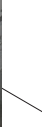
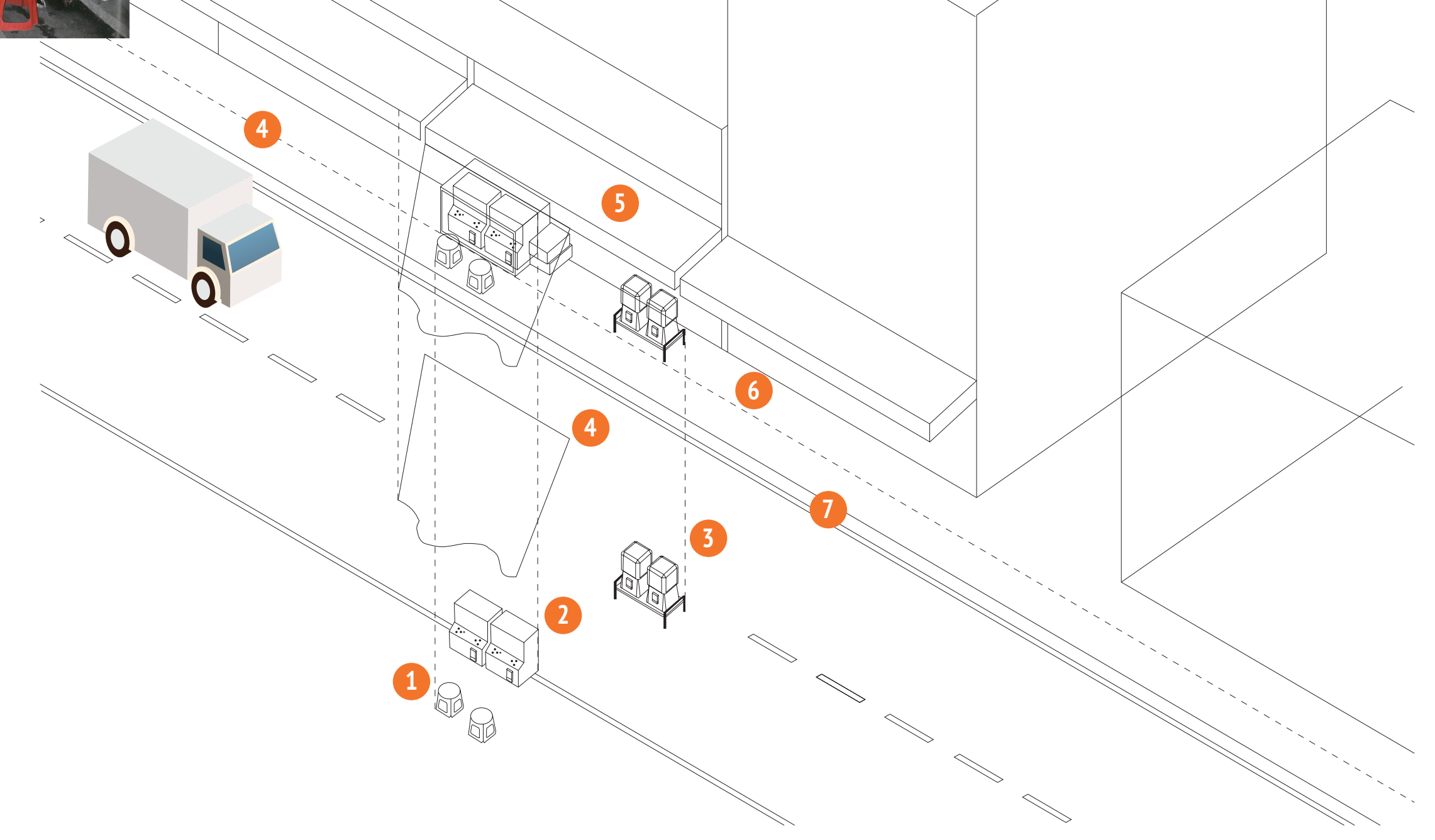

Figure 25. STREET USES FOR PLAYING VIDEO GAMES

\section{Methodology}

Figure00 is illustrated by the use of an isometric drawing that show how this "borrowing" process takes place in Seoul. Each space borrower (street user) is able to perform the specific activity with "spatial ingredients". The spatial ingredient is a research term of design elements composing the street or space for example, in here, 1. Signboards 2. Parking 3. Shops 4. Home 5. Workshops 6. Street Leisure. Those ingredients give us some hints to help us better understanding of their own occupation strategy adding new character and personality to public space.

The investigated phenomenon of private exploitation of the public realm can be detected or used within different fields to understand site's characteristics. 
Paths,Tracks,and Trails:Designing for pedestrians and cyclists

By Paolo Ceccon

The condition of "network" associated with sustainable mobility should be taken as "incremental palimpsest" by connecting human and environmental values and developing a complex system built on the large and small urban and regional infrastructure.

Walking and cycling paths, public transportation systems, energy and waste management, and hydraulic plants are all common elements of the reinvention of the landscape of our cities.

There is interaction and restriction between movement and space. The public space allows all possible movements and at the same time, influences the forms of the movements.

The book called 'Paths, Tracks, and Trails' illustrates that the main design criteria for walking paths and also identifies the details of a typical footpath. 
Design Criteria for Walking Paths:

Public and private spaces and roads have to be equipped with sidewalks where is pedestrian need.

\section{Literatures}

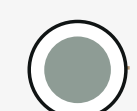

Paths, Tracks, and

Trails: Designing for

pedestrians and cyclists

The dimensions and geometries of sidewalks should ensure accessibility for all.

Construction materials should take into consideration safety, beauty, and affordability.

Spatial design should be considered to integrate signage, street furniture, and lighting

The driveway should be identified prior to the design of urban space to achieve a more integrated plan.

Solutions to potential conflicts between different modalities in shared spaces should be provided through the design of the open space.

The project should be strictly linked with the public transportation stops.

1. Walking Path Zones

O 2. Width of Zones

3. Passing Places

4. Overhead Clearances

5. Cross Fall

6. Surfaces

7. Grates and Covers

9. Ramps and Steps

10. Crossing 


\section{Table 1 Width of zones on a typical footpath}

\begin{tabular}{|c|c|c|c|c|c|c|}
\hline \multirow[b]{2}{*}{ Location } & \multirow{2}{*}{$\begin{array}{l}\text { Maximum } \\
\text { pedestrian } \\
\text { flow }\end{array}$} & \multicolumn{4}{|c|}{ Zone } & \multirow[b]{2}{*}{ Total } \\
\hline & & Kerb & $\begin{array}{l}\text { Street } \\
\text { furniture }\end{array}$ & $\begin{array}{l}\text { Through } \\
\text { route }\end{array}$ & Frontage & \\
\hline $\begin{array}{l}\text { Arterial roads in } \\
\text { pedestrian districts }\end{array}$ & \multirow{3}{*}{$80 \mathrm{P} / \mathrm{min}$} & \multirow{3}{*}{$0.01-0.15 \mathrm{~m}$} & \multirow{3}{*}{$1.2 \mathrm{~m}$} & \multirow{3}{*}{$2.4 \mathrm{~m}$} & \multirow{3}{*}{$0.75 \mathrm{~m}$} & \multirow{3}{*}{$4.36-4.5 \mathrm{~m}$} \\
\hline CBD & & & & & & \\
\hline $\begin{array}{l}\text { Alongside parks, } \\
\text { schools and other major } \\
\text { pedestrian generators }\end{array}$ & & & & & & \\
\hline $\begin{array}{l}\text { Local roads in } \\
\text { pedestrian districts }\end{array}$ & \multirow{2}{*}{$60 \mathrm{P} / \mathrm{min}$} & \multirow{2}{*}{$0.01-0.15 \mathrm{~m}$} & \multirow{2}{*}{$1.2 \mathrm{~m}$} & \multirow{2}{*}{$1.8 \mathrm{~m}$} & \multirow{2}{*}{$0.45 \mathrm{~m}$} & \multirow{2}{*}{$3.46-3.6 \mathrm{~m}$} \\
\hline $\begin{array}{l}\text { Commercial/ industrial } \\
\text { areas outside the CBD }\end{array}$ & & & & & & \\
\hline Collector roads & $60 \mathrm{P} / \mathrm{min}$ & $0.01-0.15 \mathrm{~m}$ & $0.9 \mathrm{~m}$ & $1.8 \mathrm{~m}$ & $0.15 \mathrm{~m}$ & $2.86-3 \mathrm{~m}$ \\
\hline $\begin{array}{l}\text { Local roads in } \\
\text { residential areas }\end{array}$ & $50 \mathrm{P} / \mathrm{min}$ & $0.01-0.15 \mathrm{~m}$ & $0.9 \mathrm{~m}$ & $1.5 \mathrm{~m}$ & $0.15 \mathrm{~m}$ & $2.56-2.7 \mathrm{~m}$ \\
\hline
\end{tabular}

1. Walking Path Zones

Most of the pathways are formed between the edge of the driveway and the front of the buildings or the limits of the adjacent private areas. There are four distinct areas, and it is important to distinguish between their overall width and the width of the area for pedestrians (the direct path).

2. Width of Zones

The width of walking paths depends on the urban zones where they appear, the flow of people, and the importance of connected elements.

In general, the areas that require more extensive pedestrian areas are those

A proximity to high-speed vehicles, and/ or high volumes of vehicles

High pedestrian number of pedestrians who are stationed on the sidewalk.

$$
\text { 3. Landscaping }
$$

Landscaping, which is highly varied across different climatic tones, is to create a visually attractive space and a buffer between the sidewalk and the road. The presence of plants can give drivers the sensation of being in a "restricted space, inviting them to reduce speed while providing shade and shelter for pedestrians from wind and sun. 


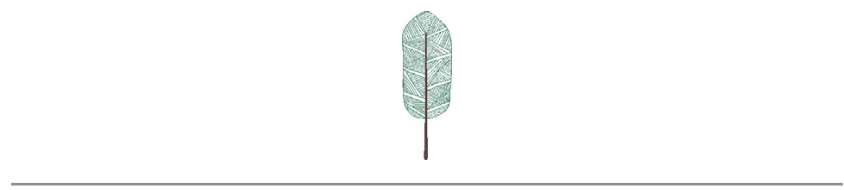

\section{Movement and access ("path")}

By Morten Gjerd

The book, 'Movement and access ("path")' written by Morten Gjerd illustrates that the quality of movement and access can be controlled or anticipated by the designer's ability.

A definition "Positive Guidance" is the design measures that show how the way people move forward, keep on in the same direction or turn aside, slow down their pace or speed up. In the book. Morten said depends on moving motive and our reaction to surroundings (created by characteristic links between features), the direction of people's movement and speed can be determined. This specific morphological factors affects user's progress, especially two elements are crucial, 'anticipatory orientation' and that for proceeding as 'inattentively' as possible. 


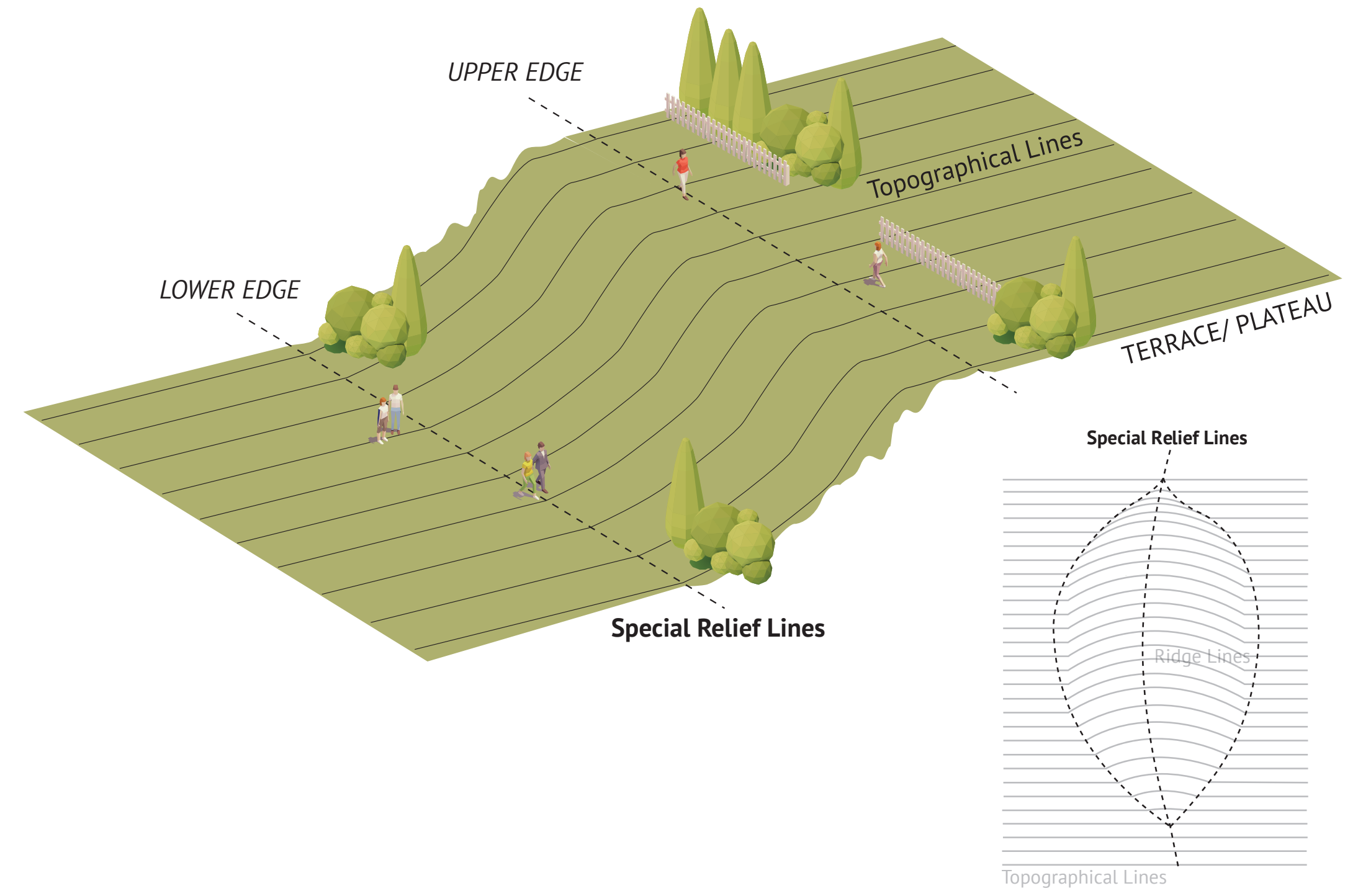

\section{Anticipatory orientation}

A path indicates connections that allow people to take certainty about direction, familiarity and predictability.

Anticipatory orientation is a landscape architectural design term that if there is no actual path available, the path will be created by frequent lines of movement which indicates a line that can be followed "with certainty". In this situation, we instinctively know that the point related to "path-markers" and it helps us to "form" and predict our own movement lines.

Path makers are recognisable forms which provide reference points to help us to move forward confidently over long stretches. The path is created not only by particular points such as striking individual trees, rock formations and buildings, but also Special Lines in the terrain relief such as linear markers like small ridges, shorelines and little valley.

Landscape design terms of path makers are used consciously or instinctively as important aids to progress. For instance, terraces and hills are followed for preference along the bottom of a slope or the top of a terrace, or over the top of a low hill. These special lines function as linear path-markers which rarely occur within the topography. 
Directly goal-oriented

Starting Point

Destination

C

$\rightarrow$
Figure 27. Path and goal

\section{Path and goal}

An connective system is all the more successful the more interesting destinations are built in as a matter of course, and the more clearly users are supported in their instinctive urge to address a particular goal. The less intrusive a necessary deviation form the line of the path is, the more "palatable" attractive reference points are made to the user, the less shifts in the line of the path will be seen as constrains on forward movement "Positive Control".

"Negative Control" makes people feel that they are being prevented form arriving their destination, and that they are having to avoid obstacles. This usually means that they leave the prescribed path to reach their chosen goal more directly. If this is not possible, they feel uncomfortable to use the path.
Negative control

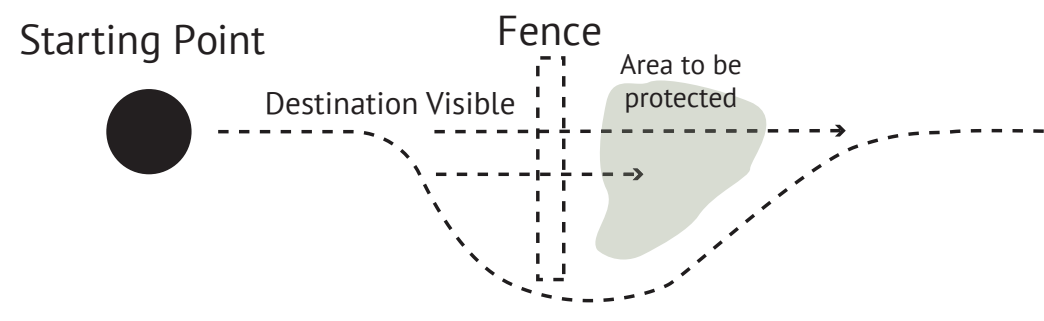

Positive control: destination not visib motivation to divert

comes from

intermediate goal
Destination

C
Negative control:

goal-oriented, blocked:

instinctive urge to take

the direct route. 
Figure 28 Path routing visual links

\section{Path routing and visual links}
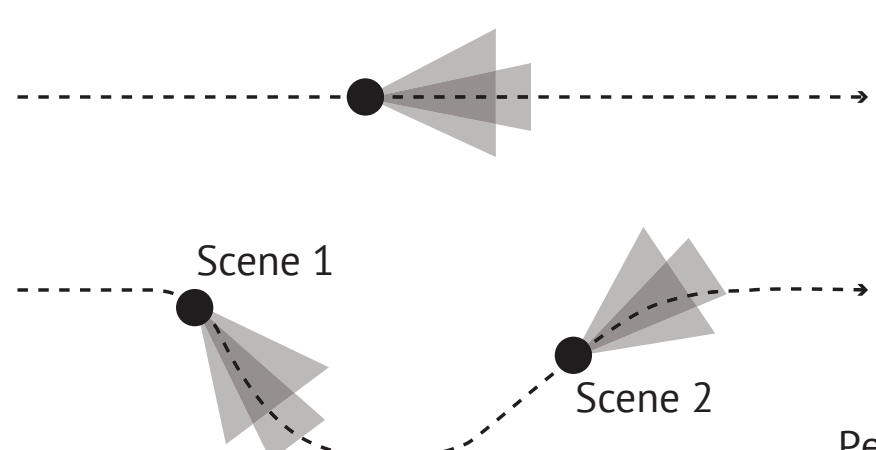

Perception field for shifted routing: access to a wide range of scenes but they have to be there to be seen.
Figure 29. Path routing: use of the area

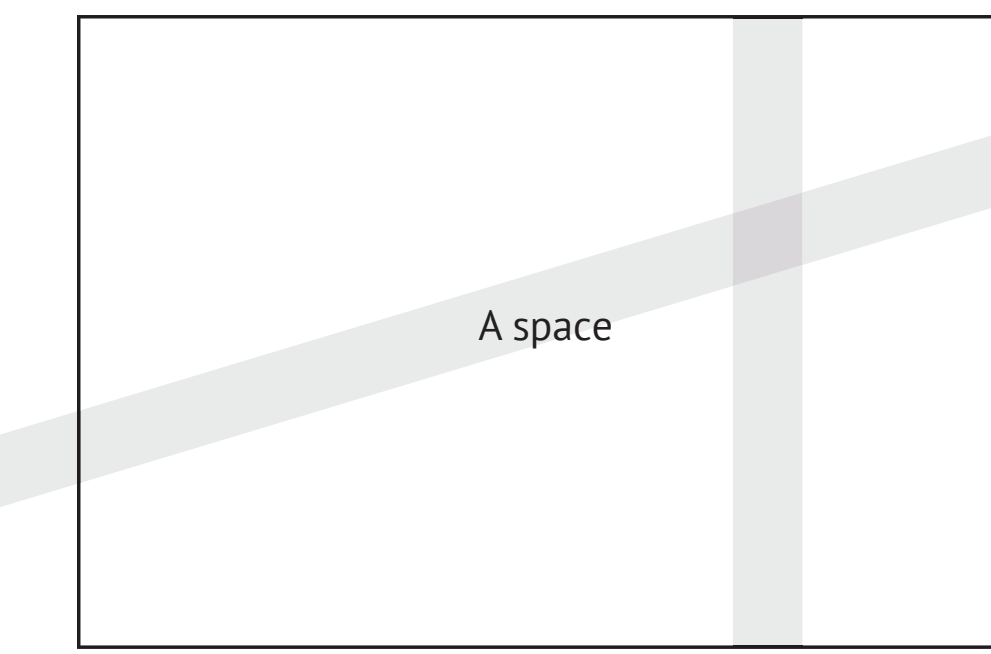

Area 2

Area 1

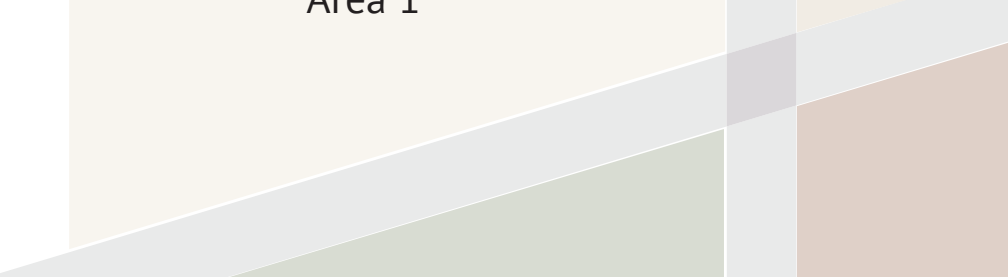

Area 3

\section{Path Routing}

High quality path is judged by its potential for creating or retaining useful spaces for people to experience. This is why paths often aid along boundaries: the mutual disturbance caused by linear movement (path) and use of area can be minimised by this, and larger areas remain coherent units. The boundary is also additionally strengthened by the path running by it.

Path routes that follow a strongly dominant direction within areas or parts of areas "automatically" offer guidance (positive control): the directional nature of the path and of the space are mutually reinforcing.

Creating an area with paths 
Figure 30. Path Junctions

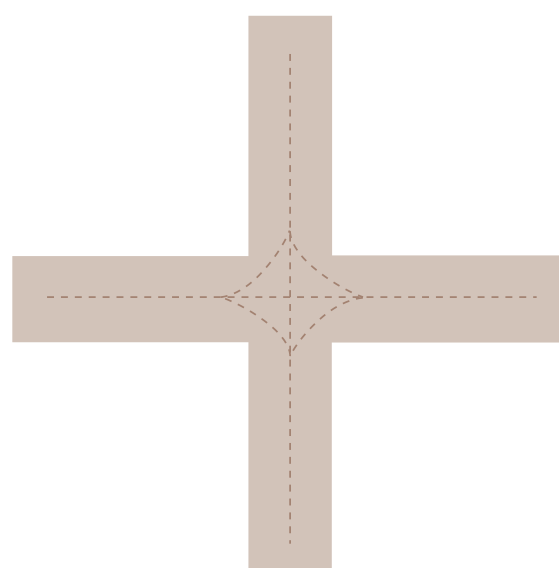

The classic road junction has no points of repose

Protected back

Open, attractive view

Rest area

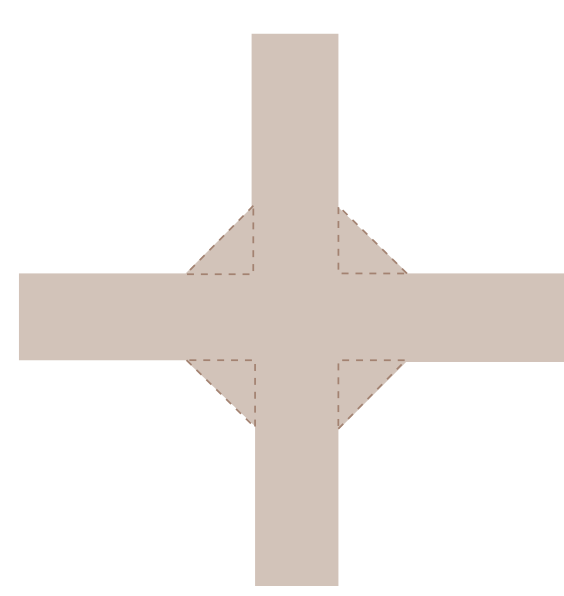

This enlargement does

not make a good joint for

the paths: capped corners

are not areas of repose,

but the area with the

most traffic in them

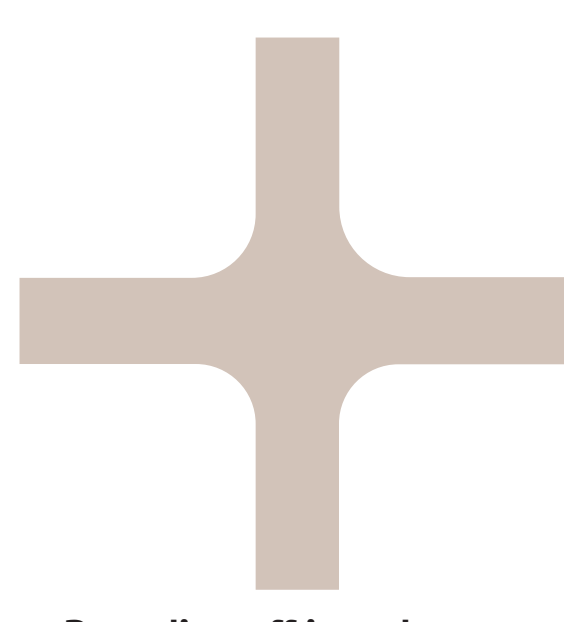

Rounding off is no better

it just creates an absence

of corners

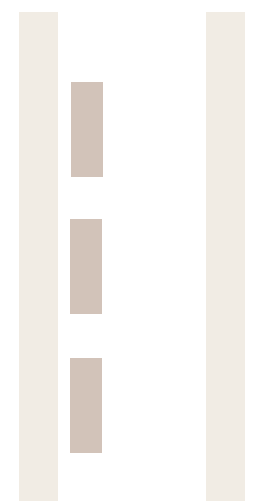

Bench on the path - possible
for very wide paths

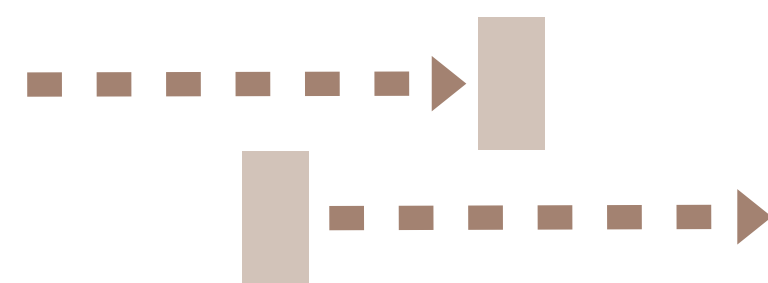

Offsetting

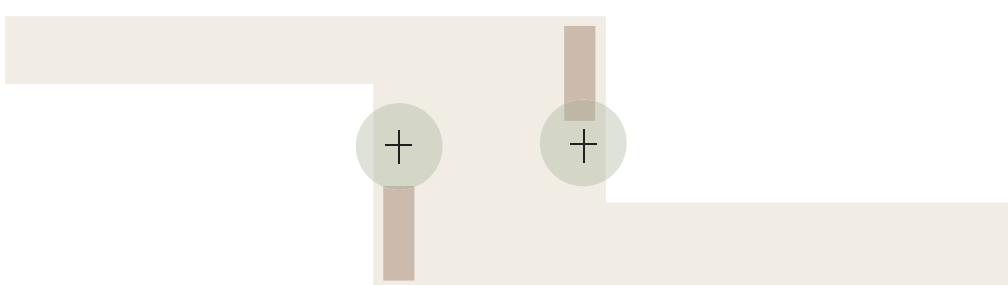

Offset point as a stopping-place (with the basic building bricks of repose, "bench and tree")

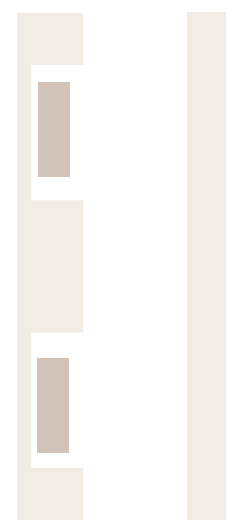

Bench havens

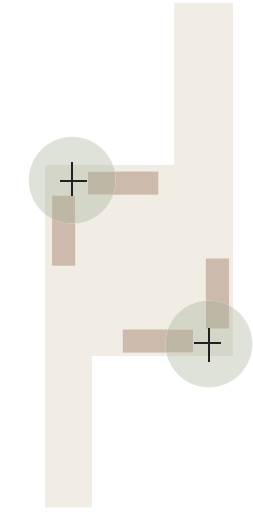

Usually better:

with benches

(additionally

marked with trees)
Figure 31. Path Junctions and a Stopping Behaviour

\section{The seat or bench - a stopping behaviour}

Landscape features such as benches and seats are essential "building bricks" for open/public space, complementing movement and offering a clear invitation to stop and rest.

There are three crucial design criteria for bench position.

1. Quiet surroundings 2. Clear view of a busy urban square, facing a striking landscape and the approaching path 3 . Safe protections by a wall, hedge, tall grass, tree-trunk and terrace. 


\section{PATH POINTS}

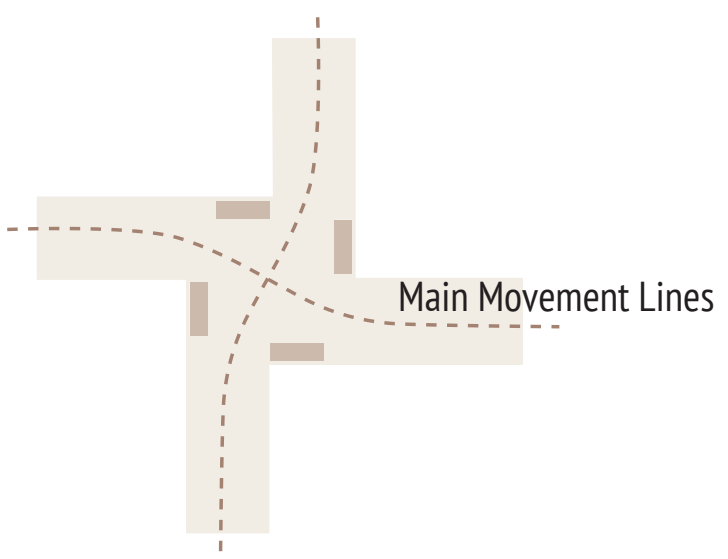

Radially offset

intersecting paths,

benches in quiet zones

Equal status junction - al

directions have the same

value

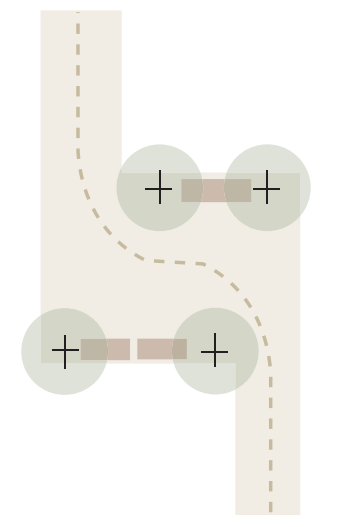

1. Stopping-place as a joint in the path - interrupting a

long run of pathway

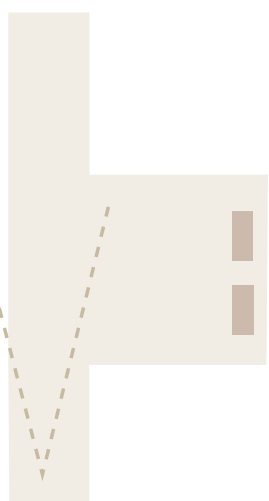

2. Niche "by" the path

neither part of the path nor the field of vision $\left(30-35^{\circ}\right)$, long view retained. Not to be recommended

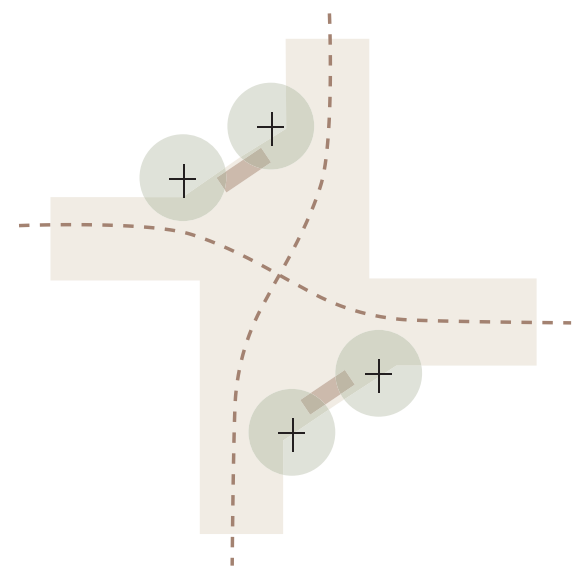

Extending the joint,

benches with trees on

each side

Hierarchical junction -

"opening" the corner

makes the north-south

link "more important"

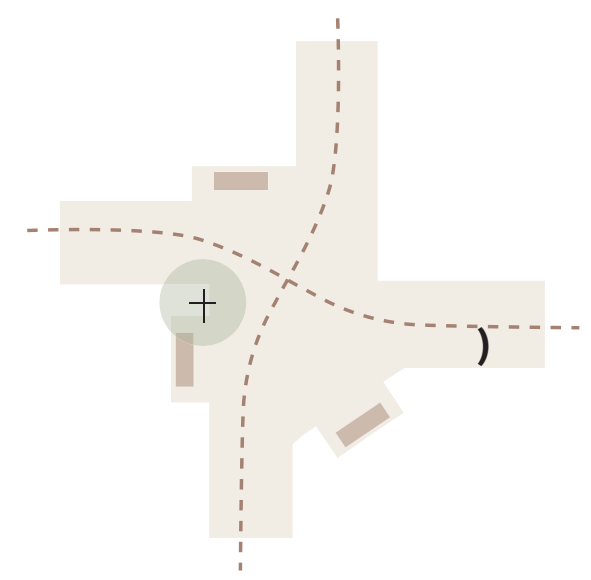

Expanding the joint

calming with bench

"havens"

Additional marking of the

end (beginning) of the

side paths (bench, tree)

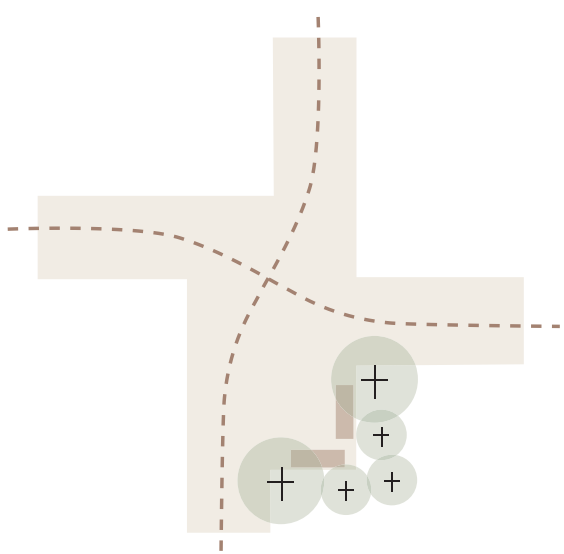

Expanding the joint,

unmistakable place for

sitting

\section{STOPPING PLACES}
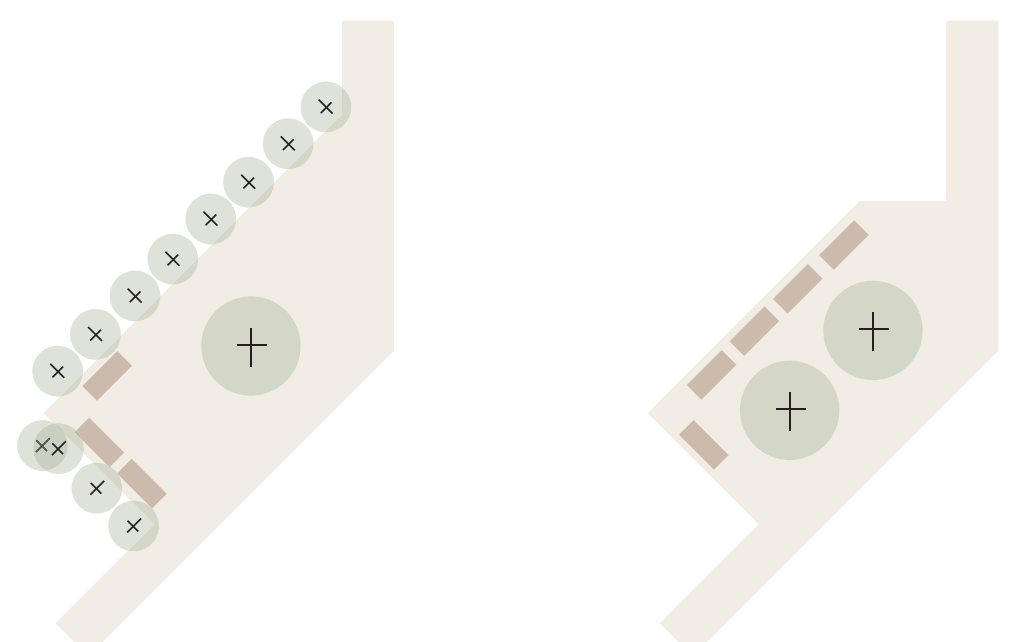

4. Stopping-place where the path swings - maintaining a link with the direction of the paths by being at right angles to the main movement line, stopping-place is part of the path. Better than example 2

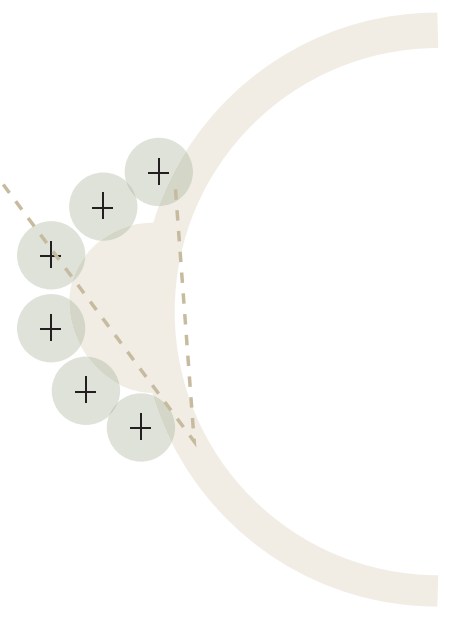

5. Stopping-place at the apex of a curve in the path clearly "in the field of vision". Functionally similar to 


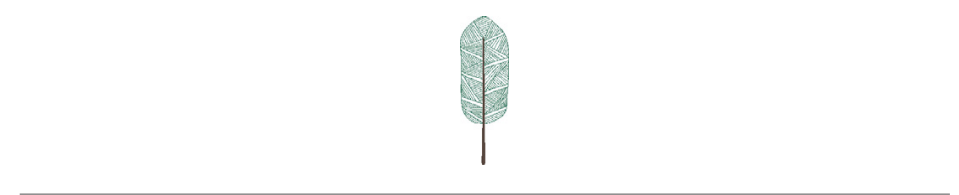

4.3 Dimensions of Street Design

To achieve the research objectives, existing studies and reviews of street typology need to be dealt with

to understand the basic roles of street characteristics in 'Literature Review' and 'Dimensions of Street Design': 


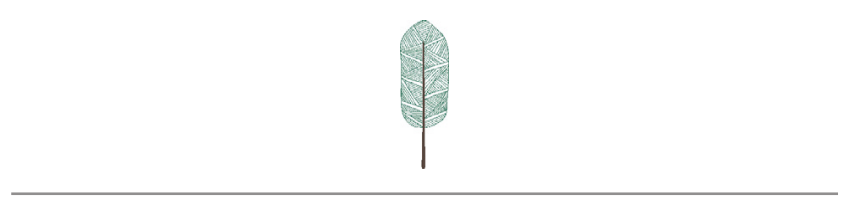

\section{Street Typology Studies}

By NACTO (National Association of City Transportation

$$
\text { Officials) }
$$

Street Typology Studies by NACTO identify the range of street typologies and its basic roles of street characteristics. To investigate and developing a new design concept of street typology, existing streets must be documented and analysed as part of the site investigation.

Use the guidance in this chapter to identify opportunities to develop a new design concept of street typology, 'Hybrid Street'. The samples included here are placed in sections to illustrate how different street types support a variety of street users, transport modes and characteris-

$$
\text { tic conditions. }
$$

A variety of street users, transport modes and characteristic of the street conditions have diverse design requirements and landscape ar-

chitecture involves this consideration. 


\section{A Variety of Street Users}

1. Pedestrians

(2) Cyclists

3) Taking Transit Users

(4) Doing Business

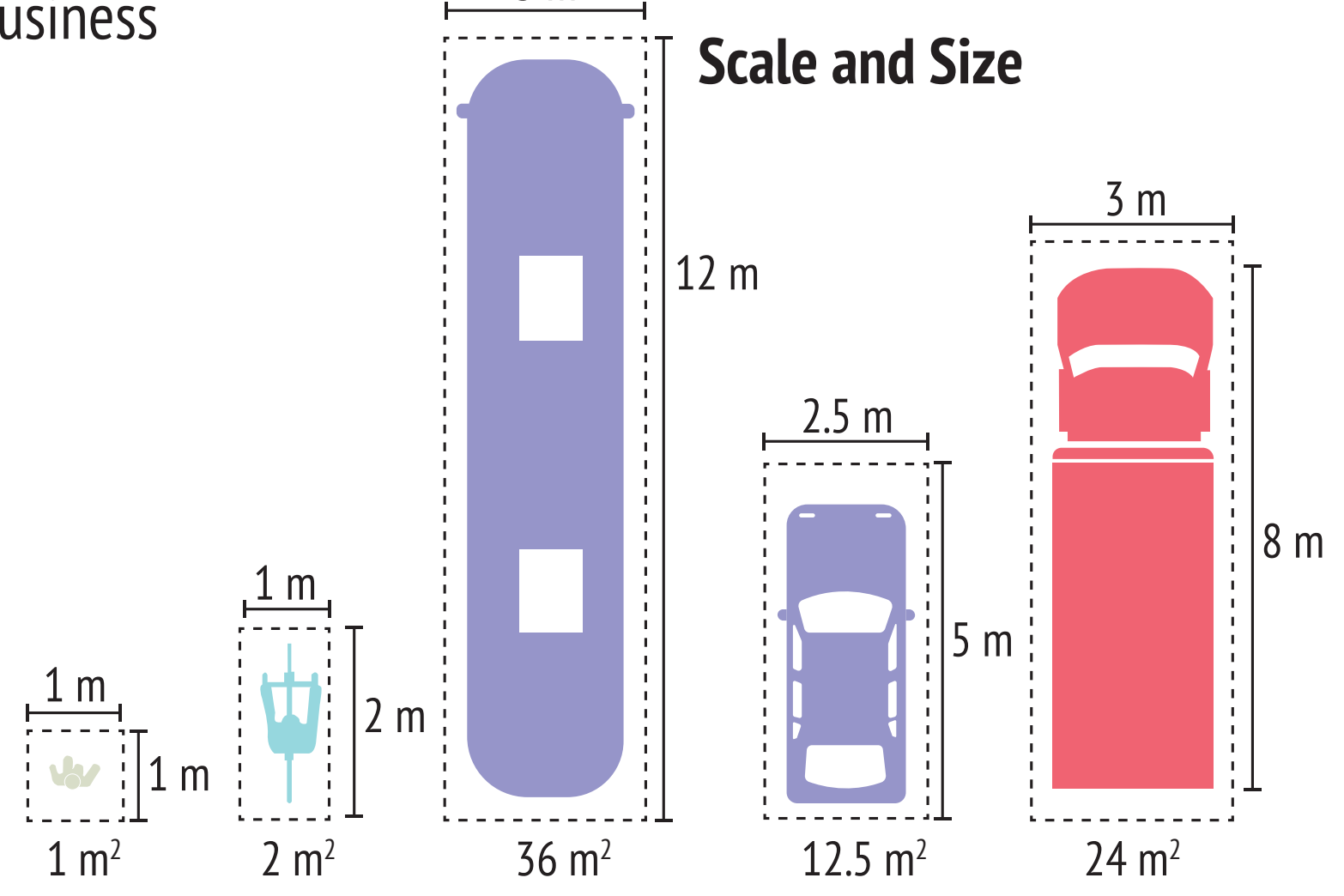

A Variety of Street Users

Streets constitute the largest percentage of public property, and this space must equitably accommodates people between the needs of the many different users. To support 'Equitable Streets', design elements and criteria have to be identified to encourage the variety of people using.

In the chapter of 'A Variety of Street Users' illustrates street users for walking, cycling, taking transit, participating street activities, using city services, finding public spaces and working own business, and how the people use the streets differently recreated by different users. 


\section{Street Design for Pedestrians}

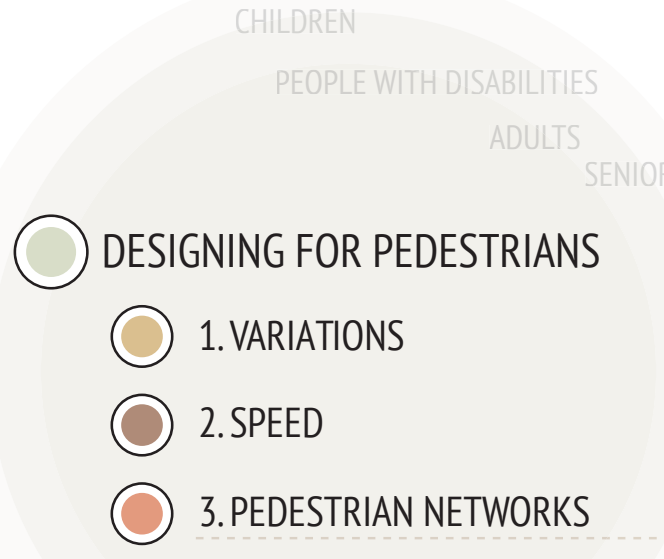

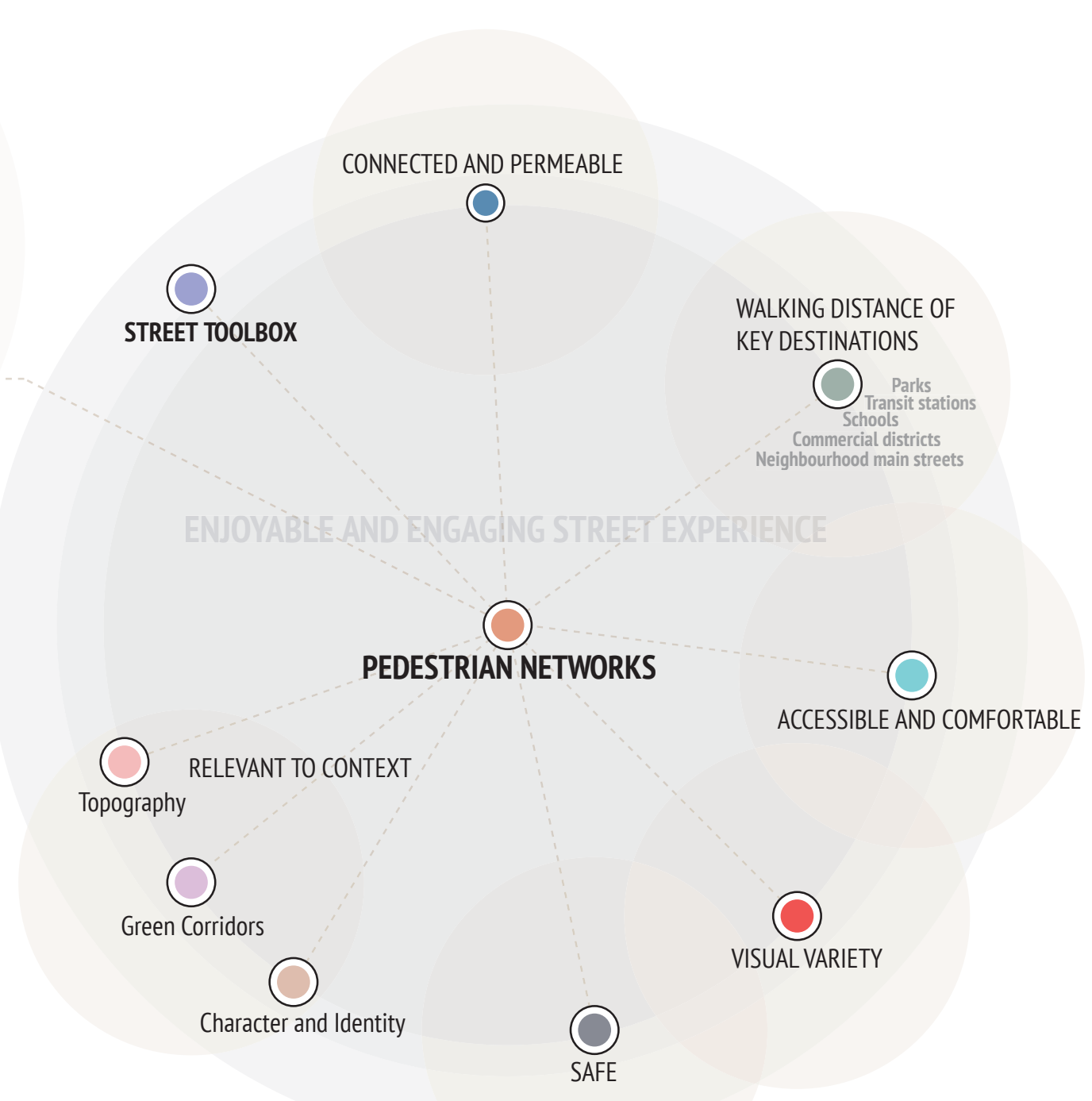

Street Design for Pedestrians Pedestrian-Priority Street means making streets accessible to the most vulnerable users and people of all ages, sitting walking, pausing and resting within urban streets. 


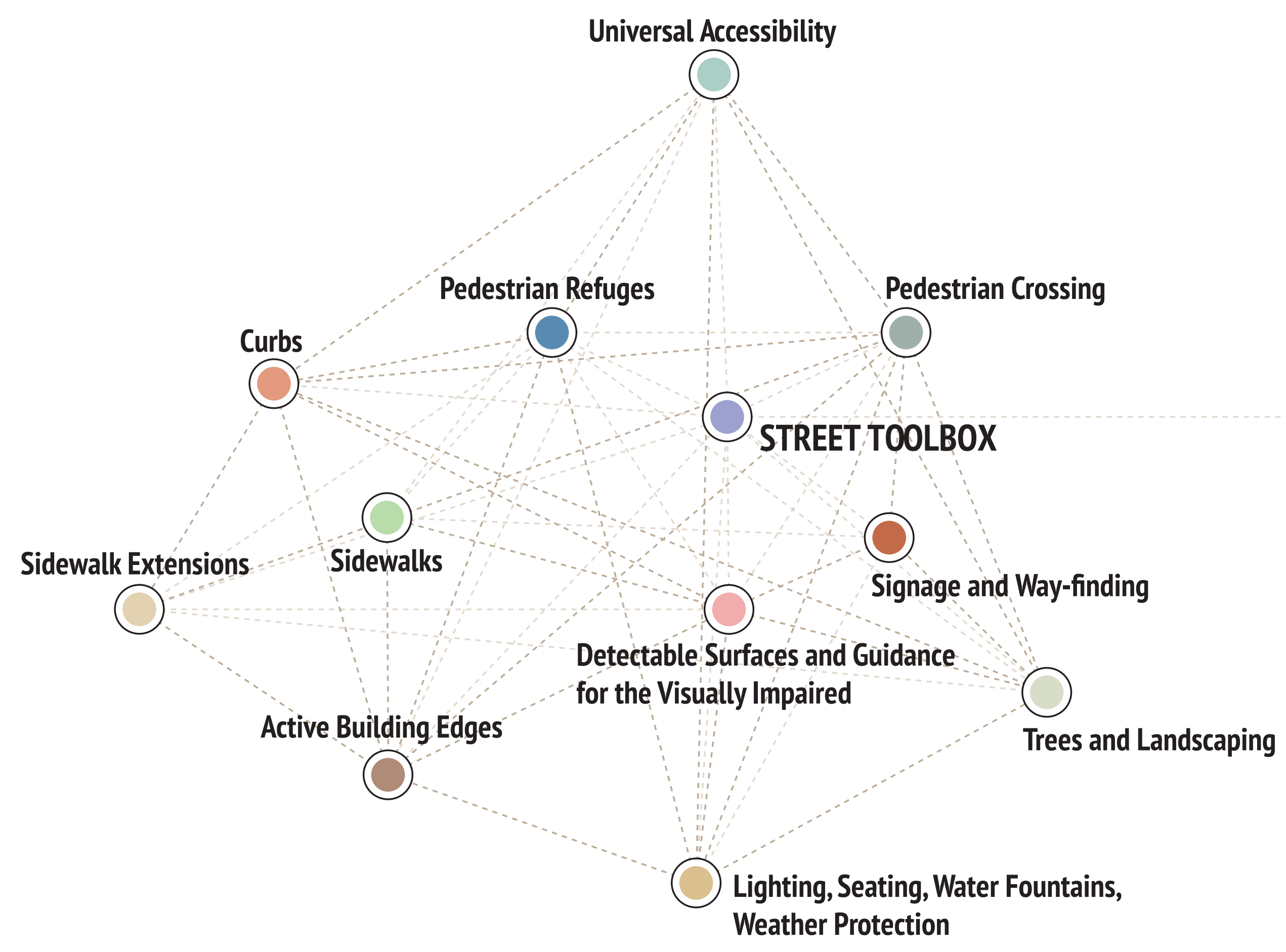

Designing Street for People

O

Pedestrian Street Design Toolbox

Following collections are essential street elements to design a 'Hybrid Functioned Street'. The toolbox can be used as a reference to check the design elements for all types of street design. 


\section{Pedestrian Crossing Types}

Pedestrian crossing is one of the most important factors to create an active and vibrant street. Efficient street crossings

encourage people to use street more frequently and safely. Pedestrian crossings sometimes shape pedestrian behaviour, for example, there is a more direct route, even if, it is unsafe and unprotected, people prefer to cross the road to use it. Therefore, placing a site to locate the pedestrian crossing requires a deep understanding about its physical layout of the street, types of users and their behaviours.

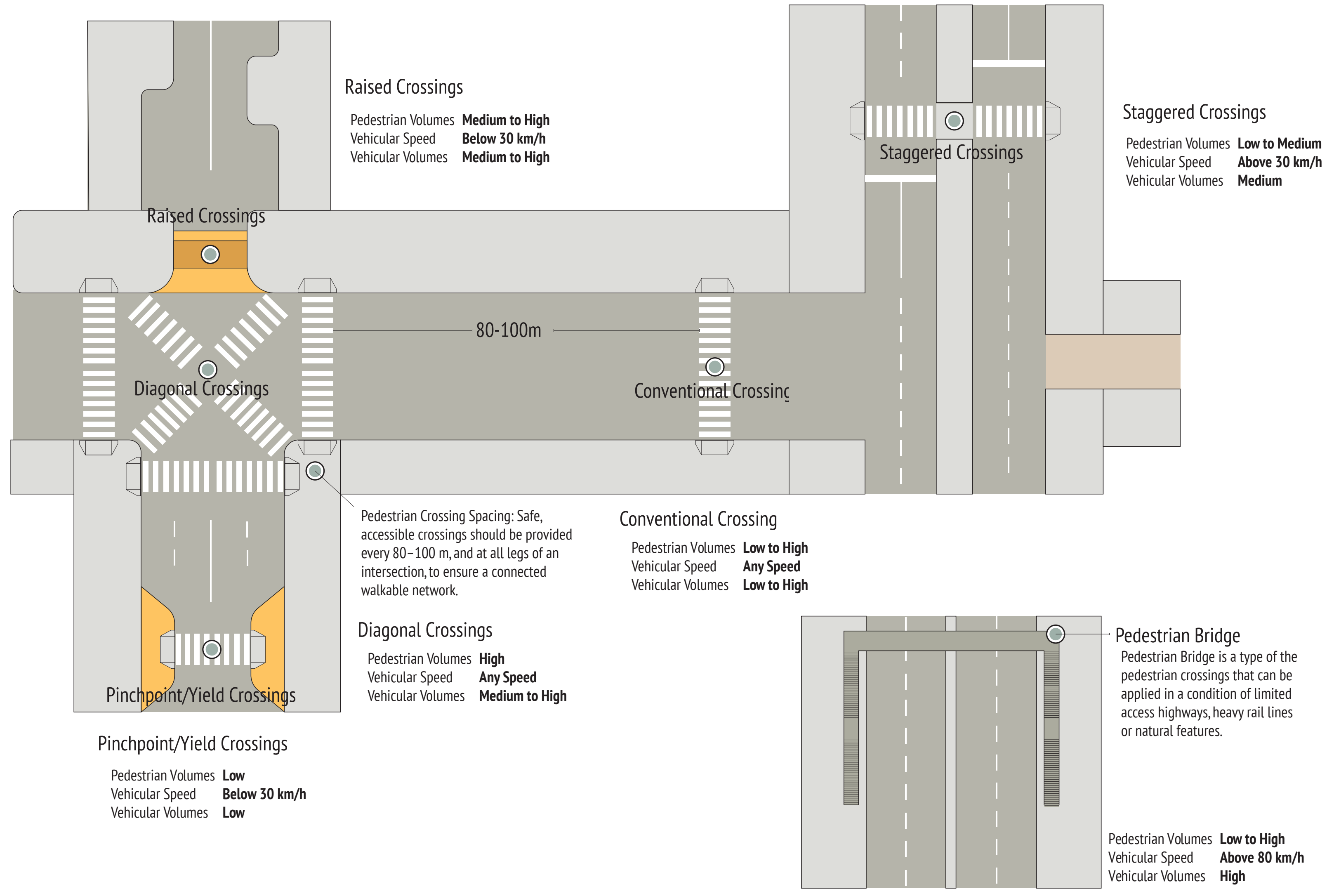


Pedestrian Refuges/Medians

Pedestrian refuges and Medians are a pedestrian crossing that provides easier and safer pedestrian accesses to cross multiple

lanes of traffic or narrower streets where speeds and vehicular volumes make unsafe crossing conditions.

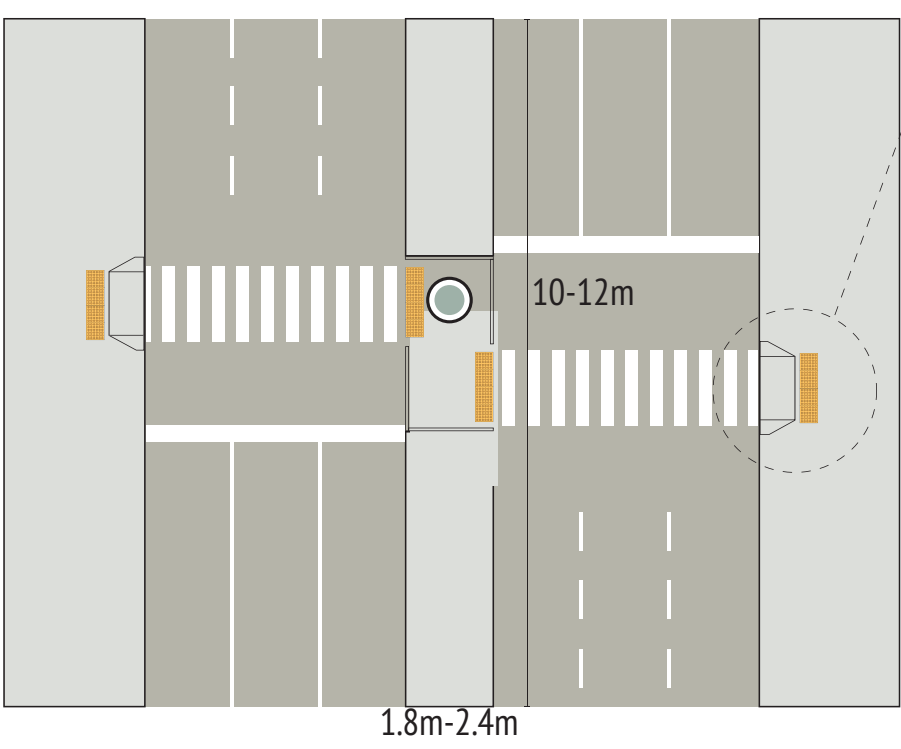

Islands should be at least 1.8-2.4 $\mathrm{m}$ deep and $10-12 \mathrm{~m}$ long With providing

ong protion at

each end of the

waiting space.

\section{Signage and Way-finding}

Signage and Way-finding is a street system that offers multi-modal information to all different types of street users. The system encourages a sustainable transport uses and walking and cycling by informing th available transit types and how those are connected each other to preferred destinations. Wayfinding recommended to install every 5-10 minute walking distances and its location has to be placed on the streets with high pedestrian volumes near transit stops, parks, public facilities and markets.
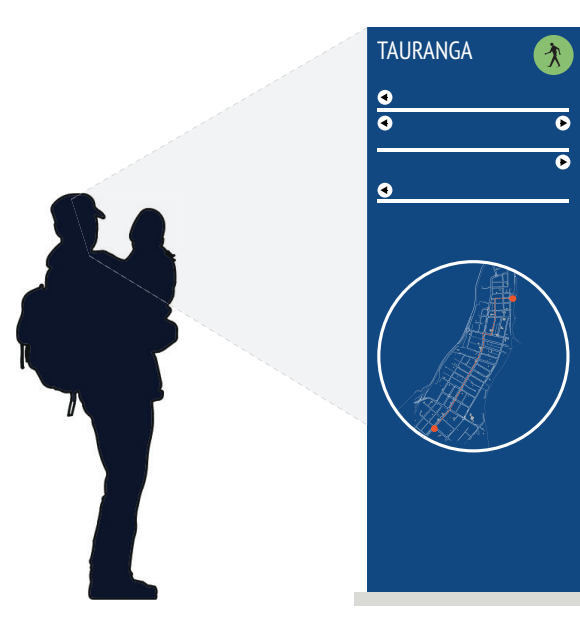
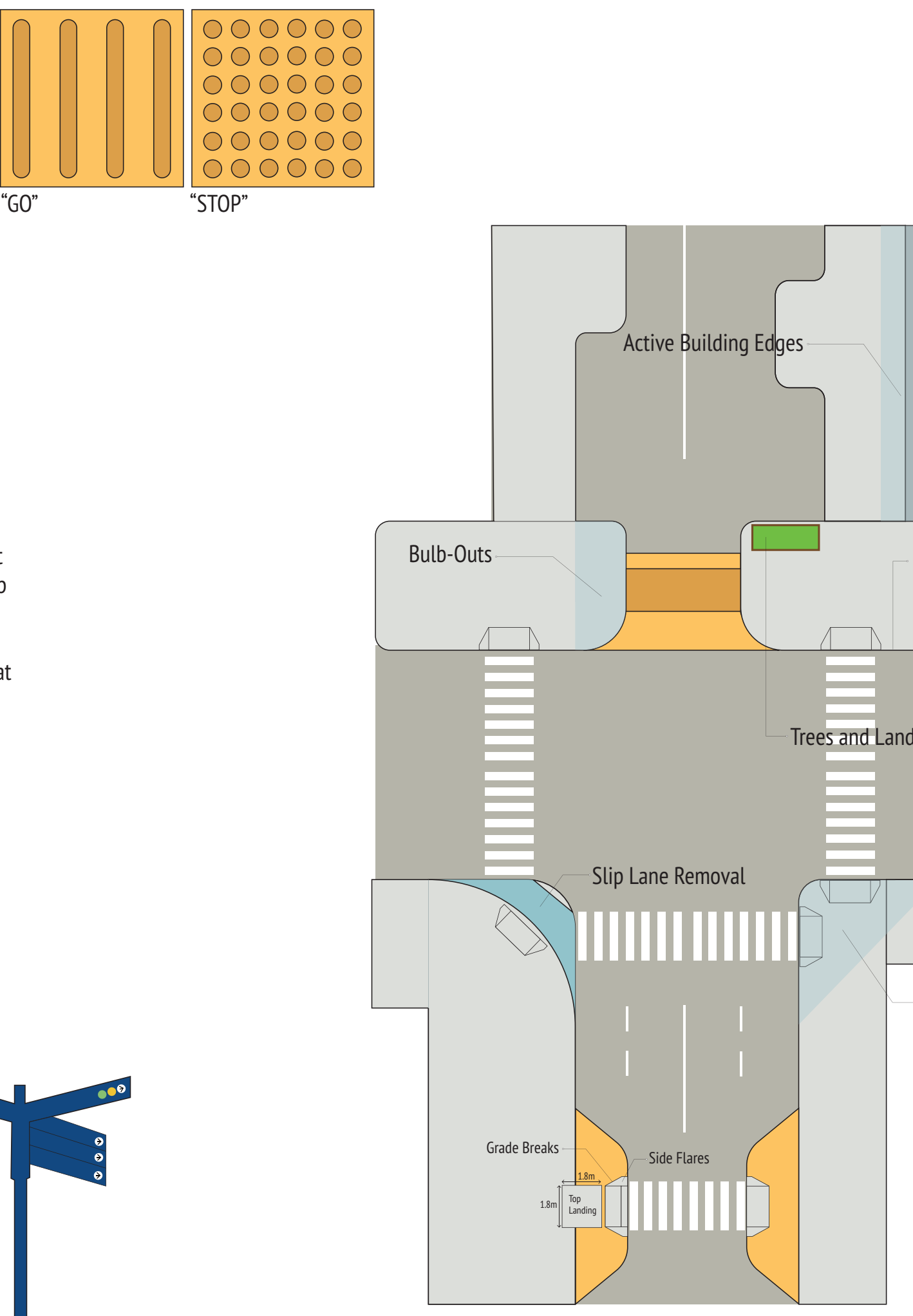

Sidewalk Extensions

Sidewalk extensions physically and visually narrow the roadway while increasing the available waiting space to cross the roads and provide areas for street furniture and

benches, transit stops, trees, and landscaping.

The extensions sometimes gives an

opportunity to show street identities which

created by local, community and

neighbourhood users, and engineering

systems such as stormwater management

and other public space enhancements.

Sidewalk Extensions Types:

Bulb-Outs

Slip Lane Removal

Corner Alignments

Kerbs: Kerbs should not be more than $15 \mathrm{~cm}$ high. They should incorporate ramps at pedestrian crossing to facilitate safe access.

Trees and Landscaping

Pleasant walking environments Neighbourhood characters

Active transportation choices

Microclimatic conditions

Clean the air and filters water

Biodiversity of a city

Physical and mental health benefits
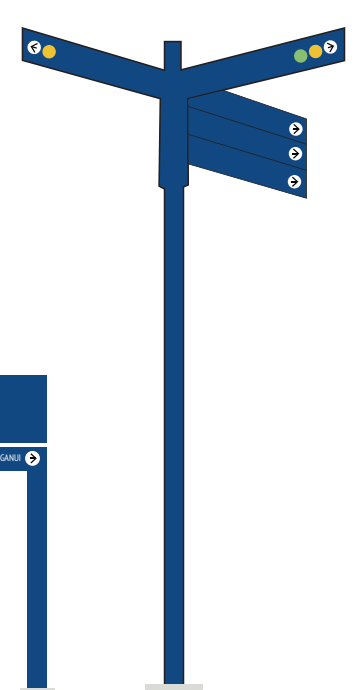

Corner Alignments

\section{Universal Accessibility}

Pedestrian Ramp is a facilitating area that provides the access of sidewalks for people using personal mobility devices.

Pedestrian ramp is composed of three

elements which are the slope, the top lading and the side flares and it has to be built of non-slip materials. The slope of the ramp should have a $10 \%-12 \%$ gradient with universal standard measured detectable surfaces. 


\section{Variations}

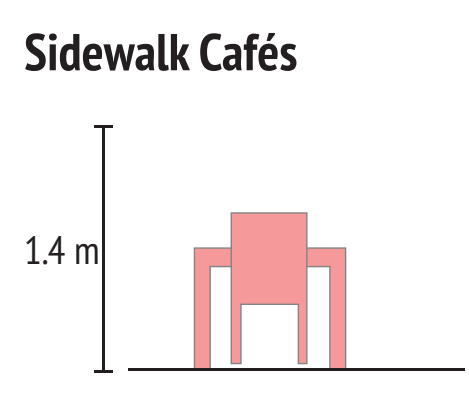

$0.5 \mathrm{~m}$
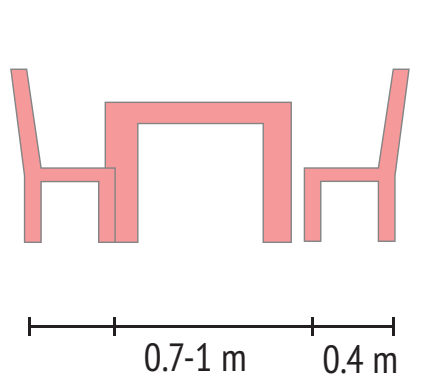

Storefront Spillovers and Stalls

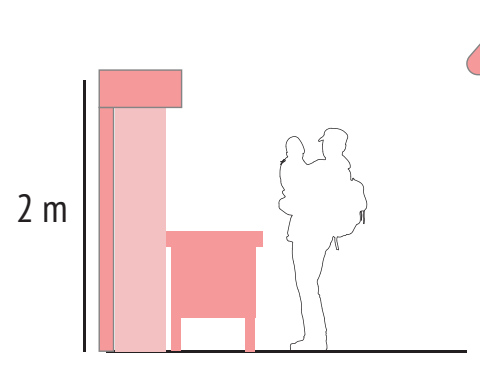

$\overline{0.5 \mathrm{~m}} \overline{0.3 \mathrm{~m}}$

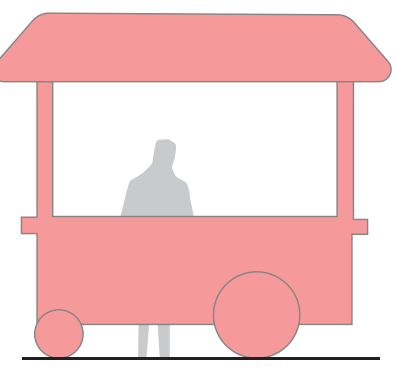

$2 \mathrm{~m}$

Street Vendors and Kiosks
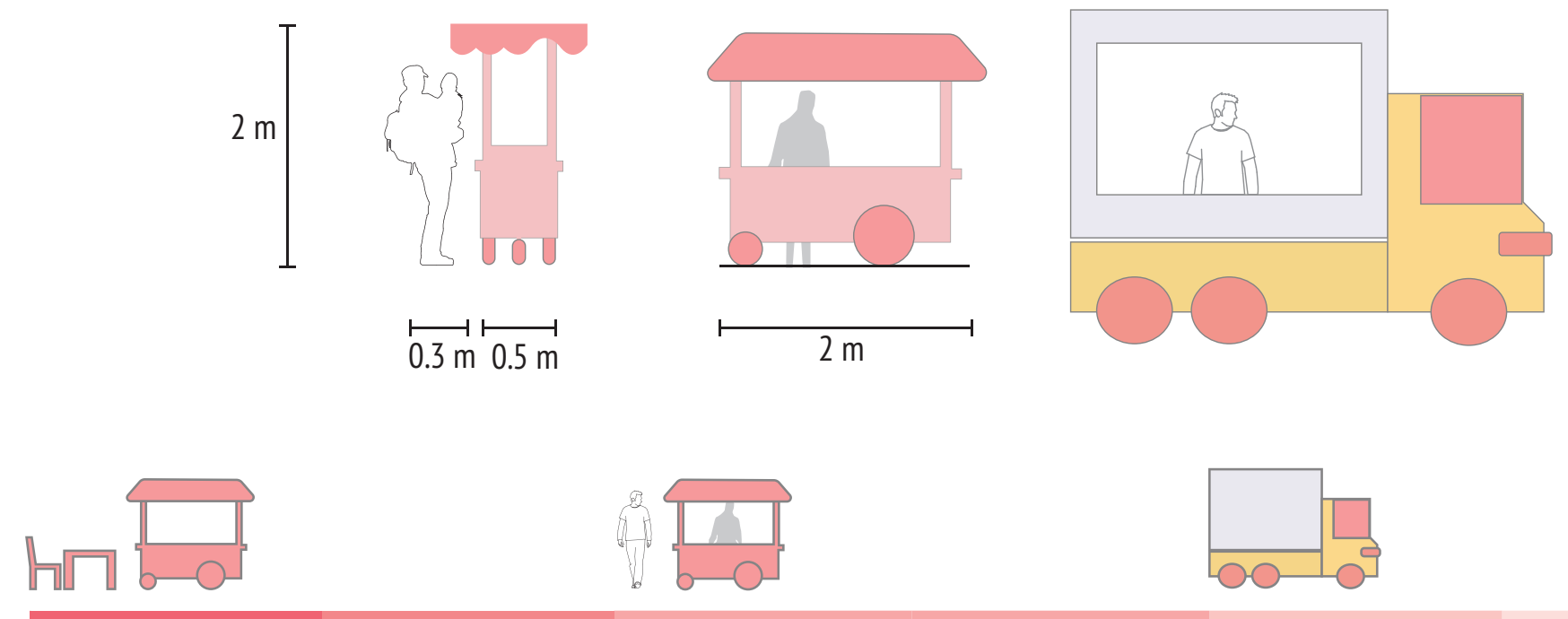

$0 \mathrm{~km} / \mathrm{h}$

$5 \mathrm{~km} / \mathrm{h}$

$10 \mathrm{~km} / \mathrm{h}$

$15 \mathrm{~km} / \mathrm{h}$

Street Design for Commercial Uses

Business is part of every city and streets should be designed to provide formal and informal on-street commercial activity. Supporting commercial activity should balance the various different users in a given environment of safe and vibrant street. 


\section{Geometry}
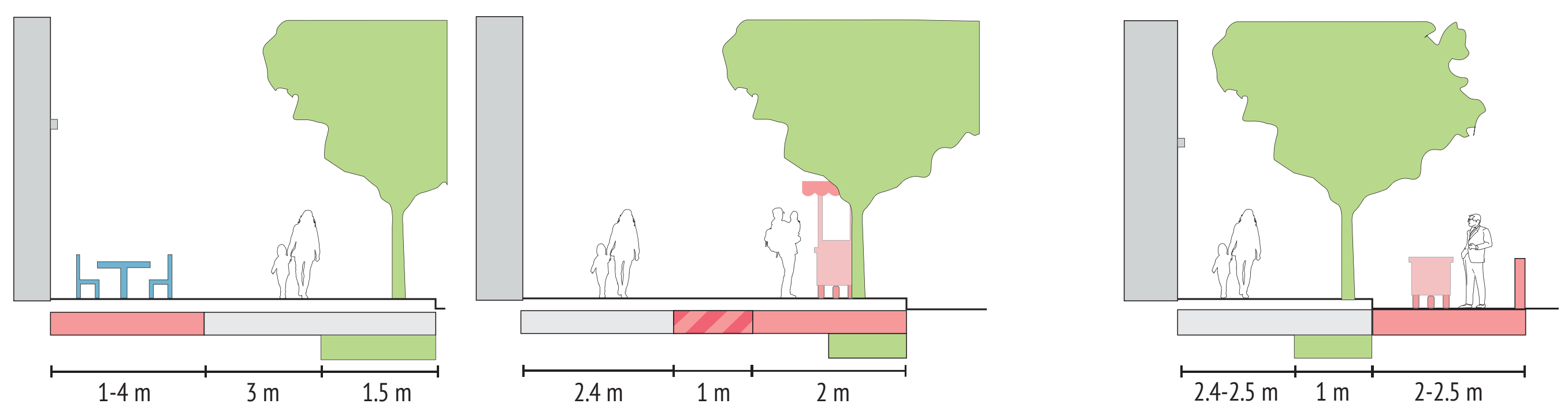

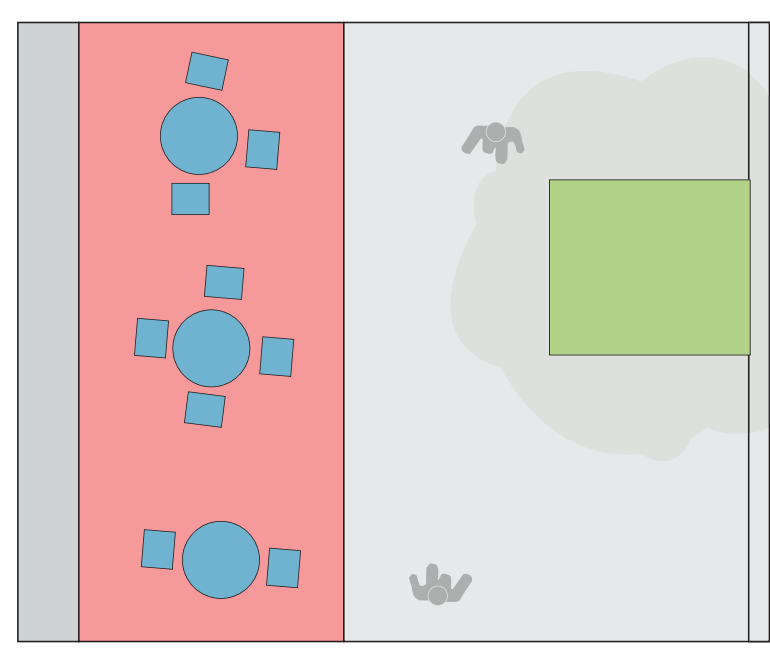

Commercial Use Extension

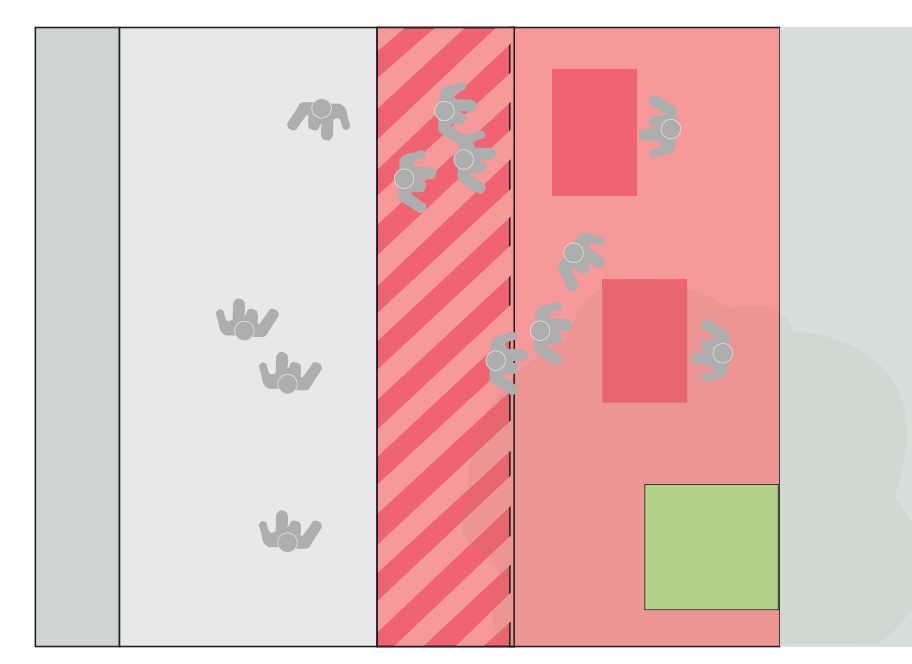

Vendors on Sidewalks

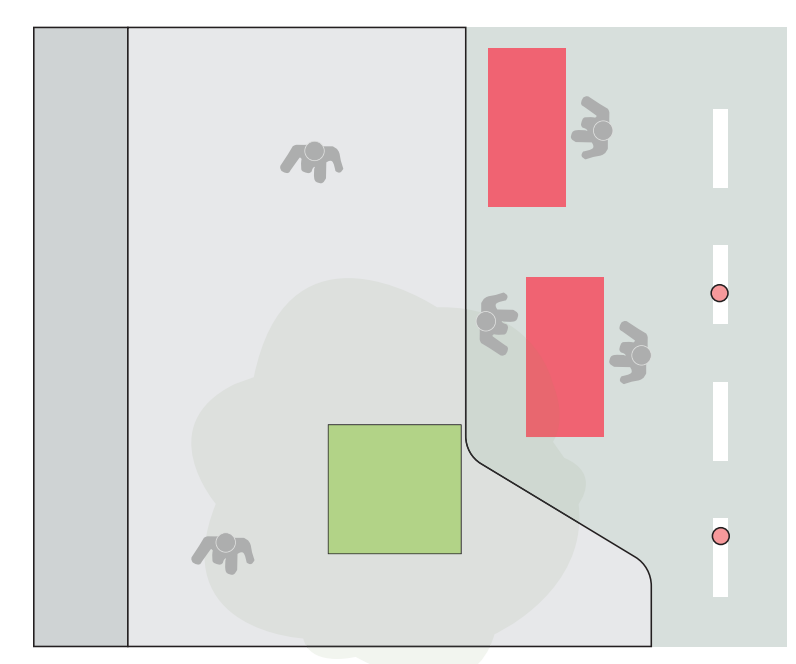

Vendors in Enhancement 


\section{Siting Guidance}

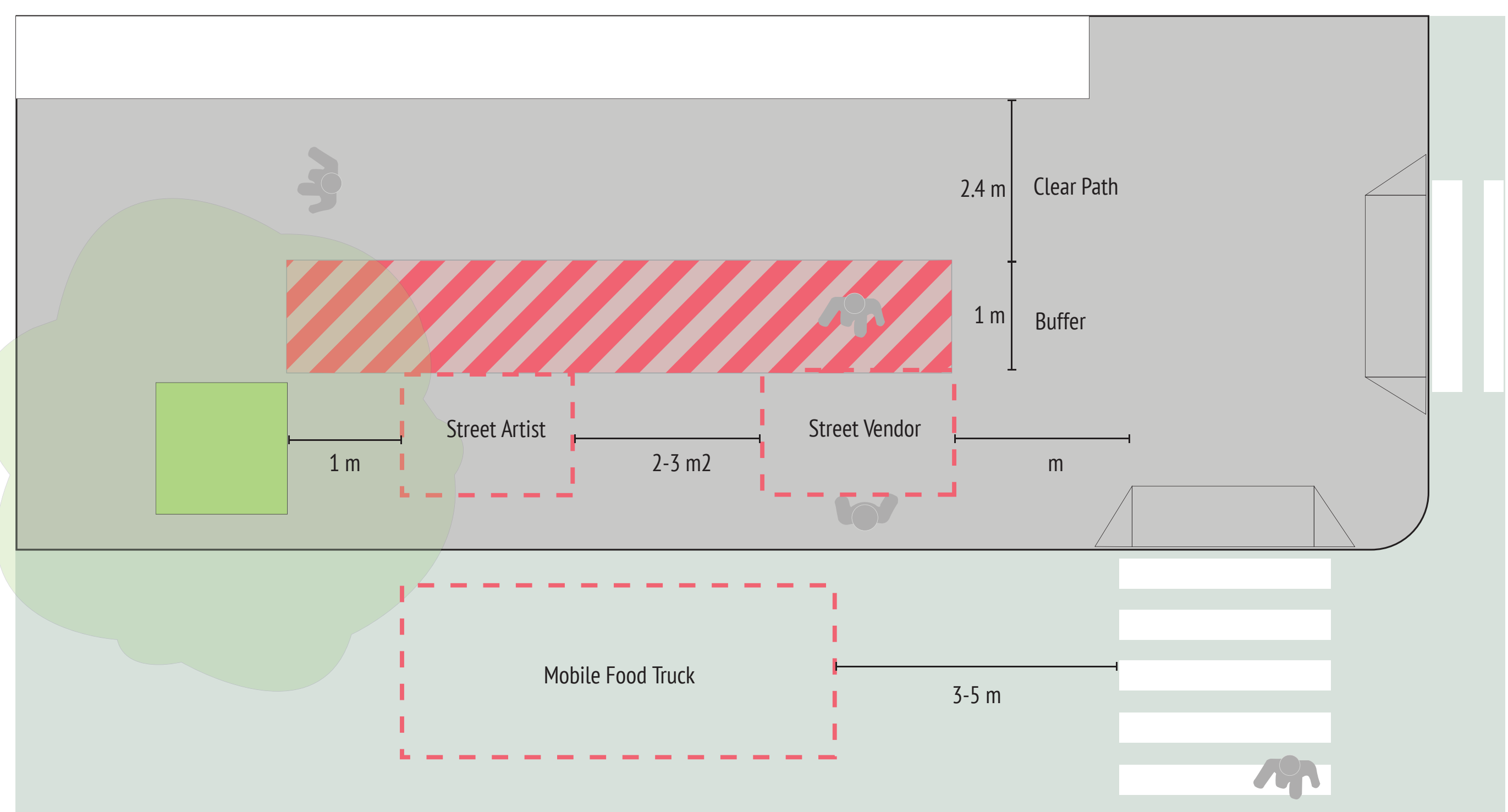


3) Taking Transit Users

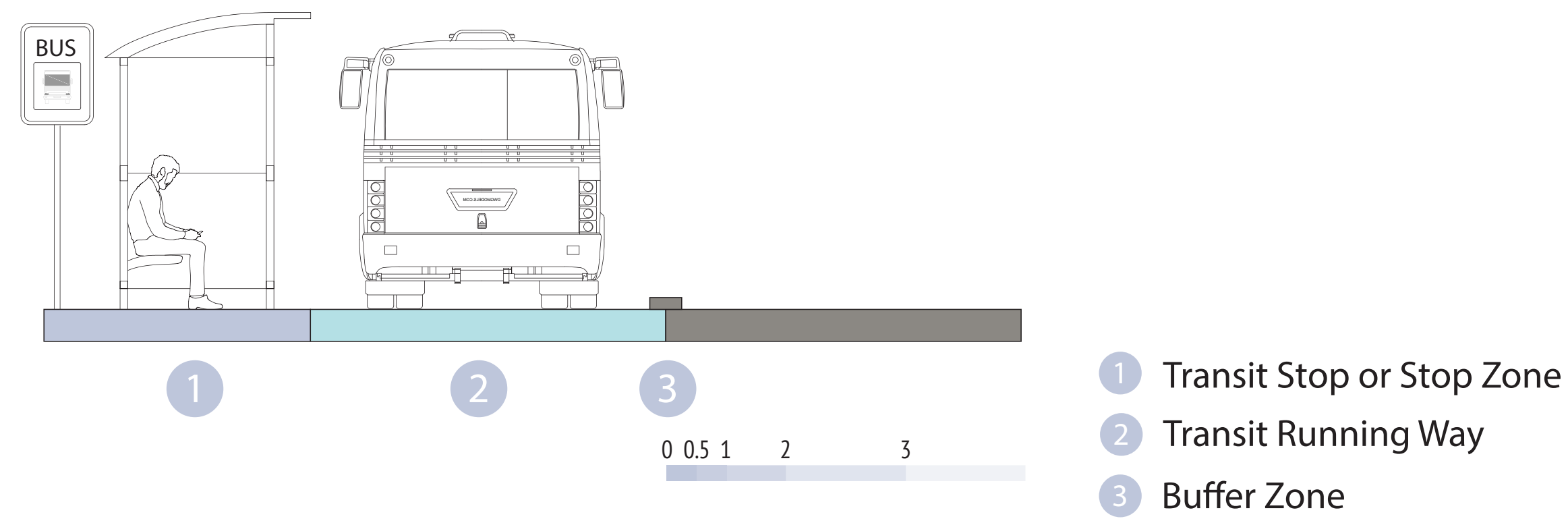

\section{Transit Facilities}

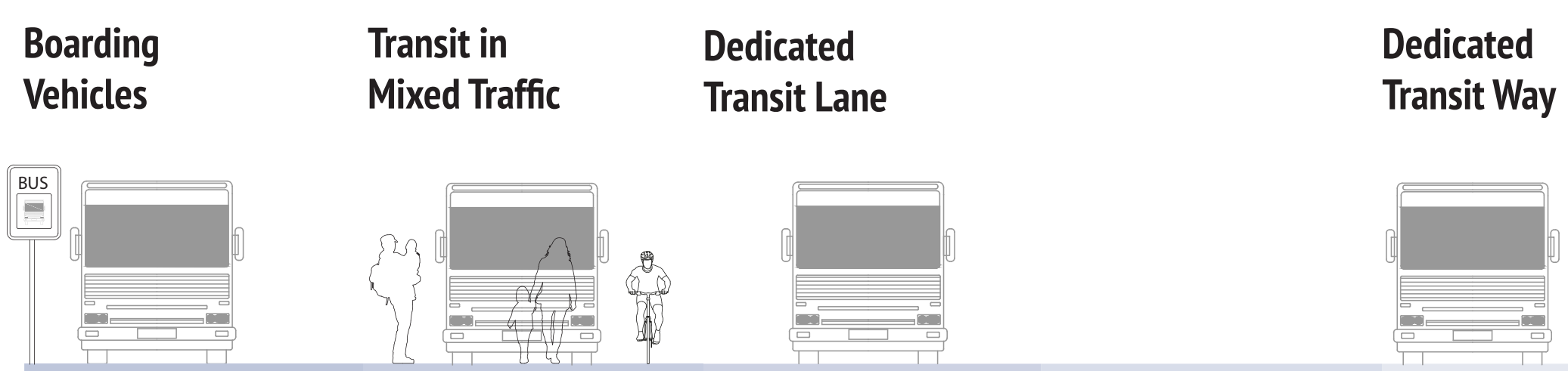

Street Design for Transit

Public transport offers a sustainable and efficient way to move people in an urban setting. The street has to be designed to support various transit networks to maintain transit movement in a pedestrian-friendly and safe environment for all users.

Creating dedicated space within the street helps transit networks to provide reliable, convenient and frequent service to passengers without delays from mixed traffic, while increasing the mobility ca$0 \mathrm{~km} / \mathrm{h}$ $10 \mathrm{~km} / \mathrm{h}$ $20 \mathrm{~km} / \mathrm{h}$

$40 \mathrm{~km} / \mathrm{h}$

$50 \mathrm{~km} / \mathrm{h}$ of the city.' 
Stop Types

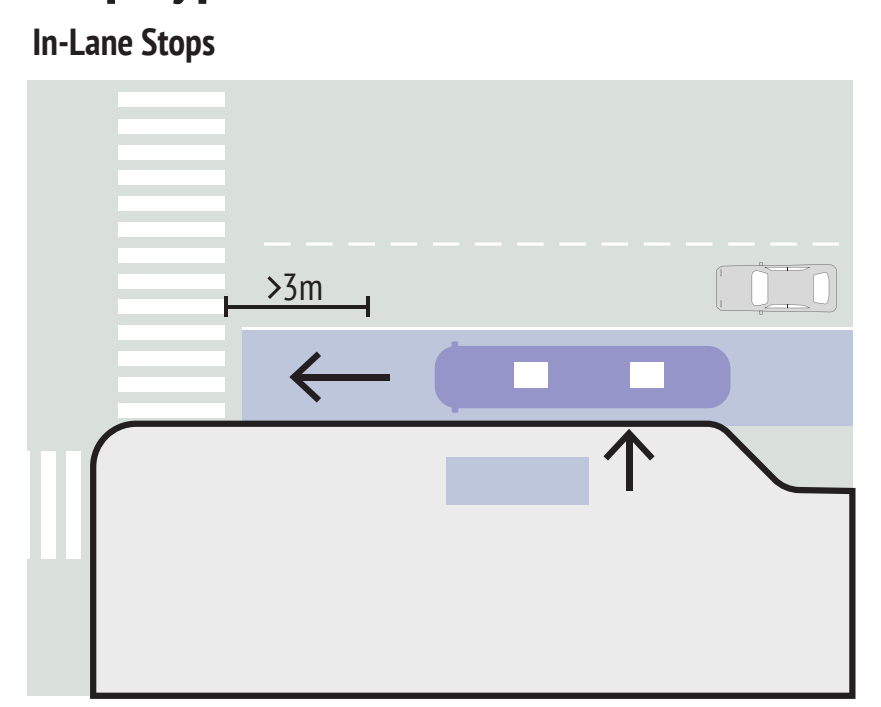

Island Stops

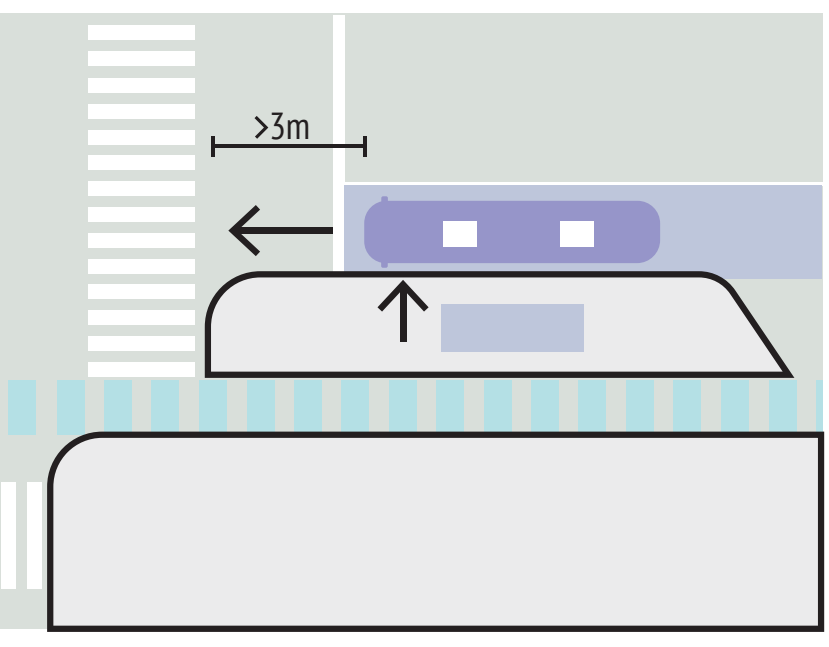

Boarding Lanes and Transit Stands

Pull-Out Stops

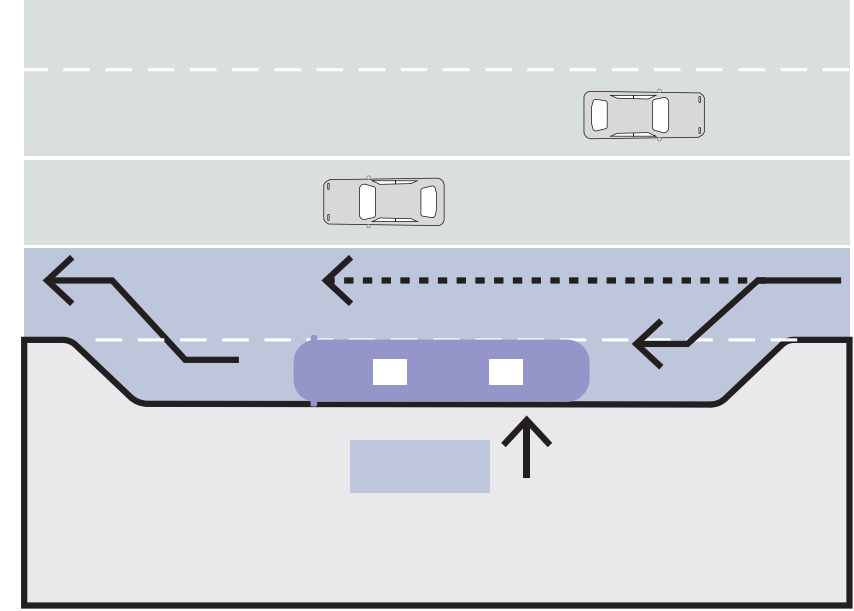

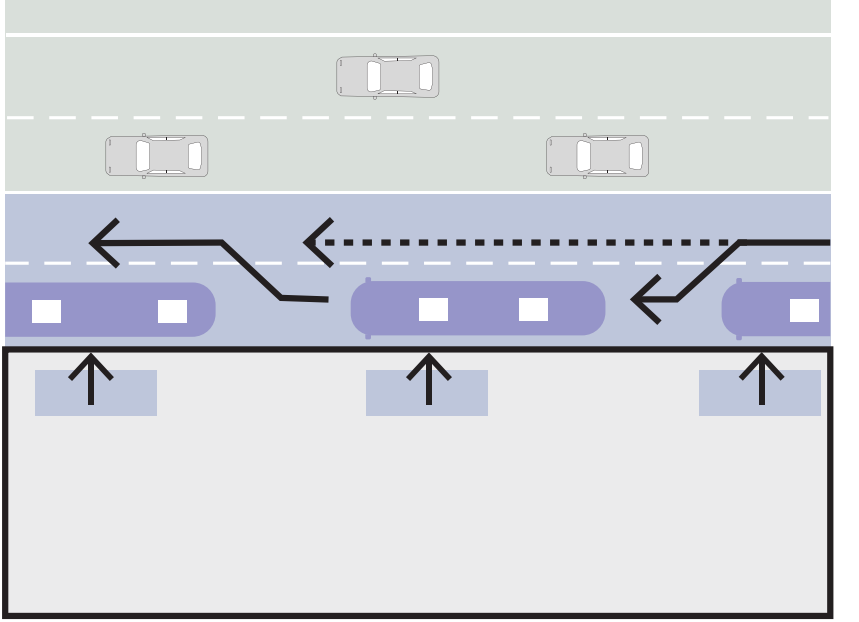

Median Stops

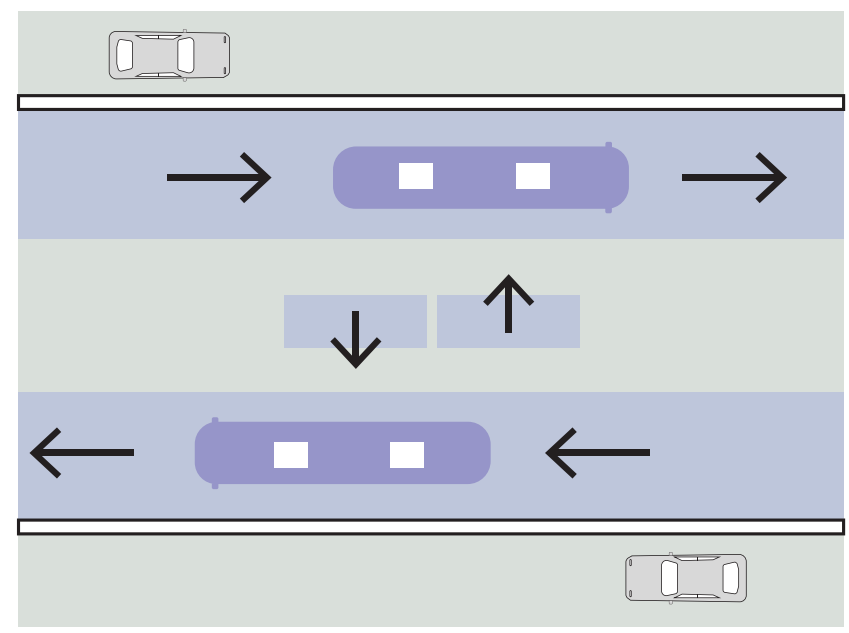

Shared Stops or Easy Access Stops

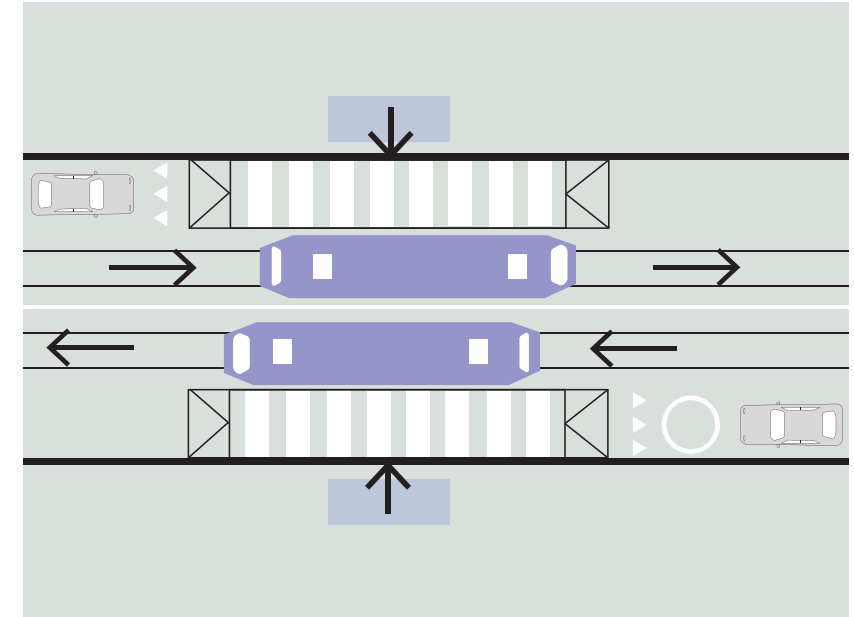




\section{Station Dimensions}

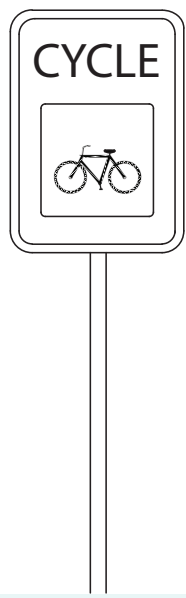

$0 \mathrm{~km} / \mathrm{h}$

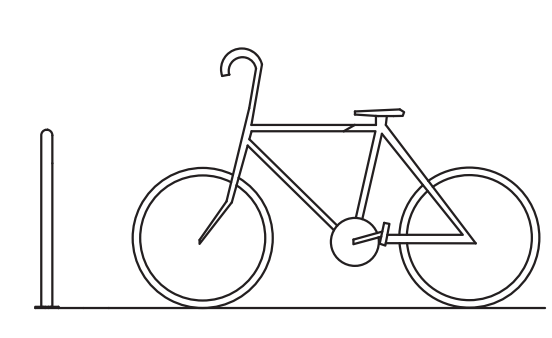

$2-2.5 m$

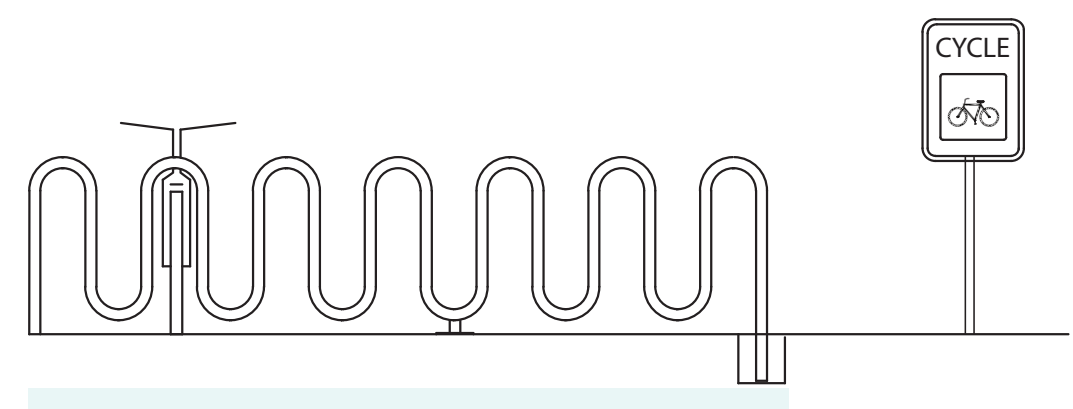

$12-15 \mathrm{~m}$

(Minimum)
Parked Cycles

Children and Families
CommuterR

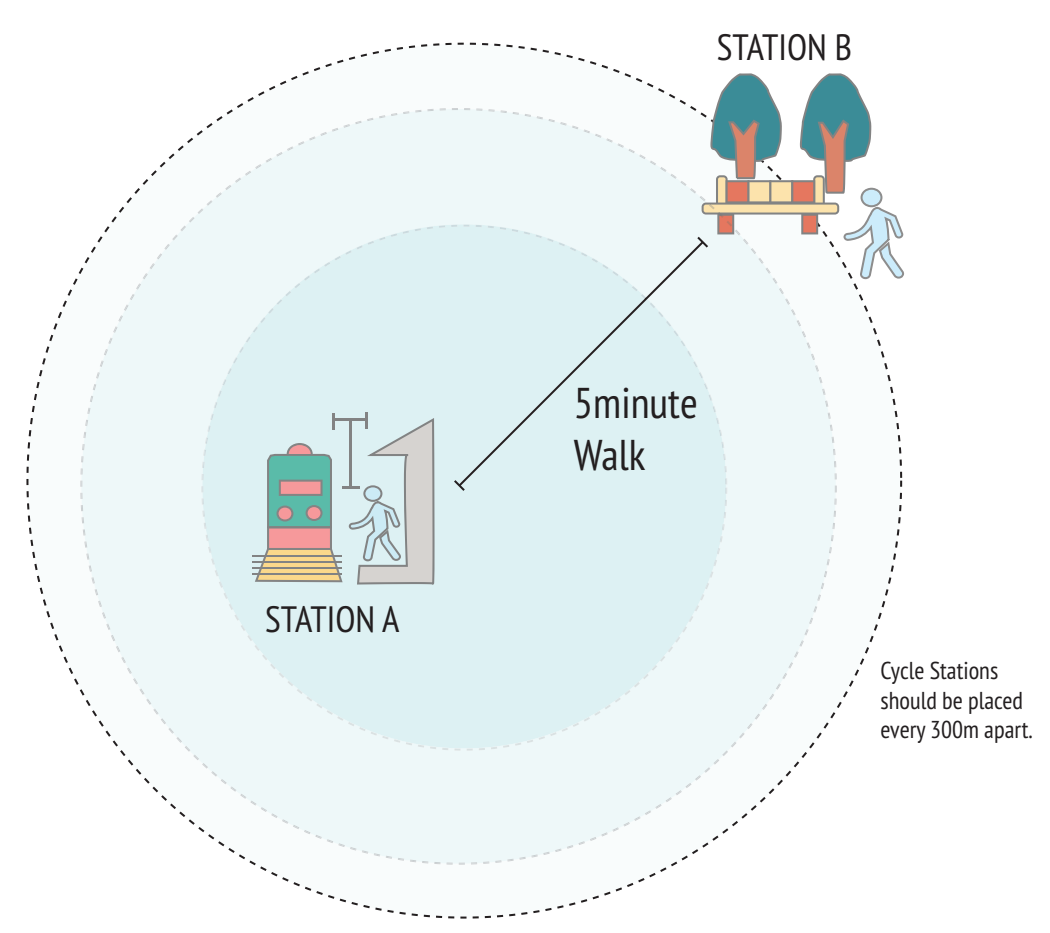

ecreational Cyclist

Street Design for Cyclists

Street design for cyclists should allow for social and conversational riding for everyday use as well as long commutes.

Cycle tracks should be designed for all type of riders and all levels of comfort. 


\section{Cycle Share Station Configurations}

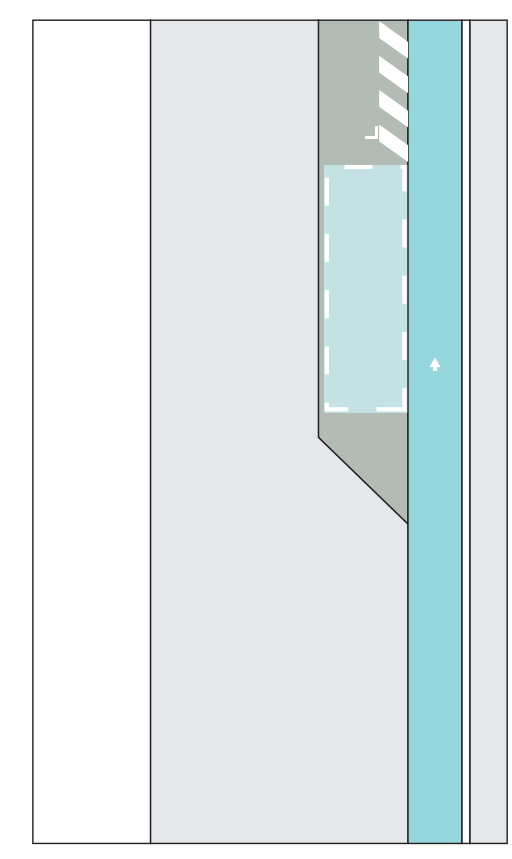

Configuration 1

Parking spaces adjacent to sidewalks

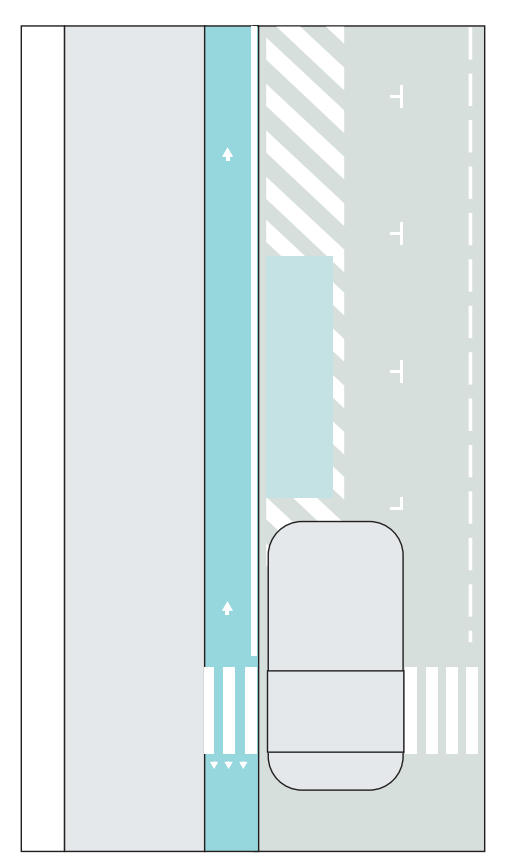

Configuration 2

Parking spaces adjacent to cycle lanes

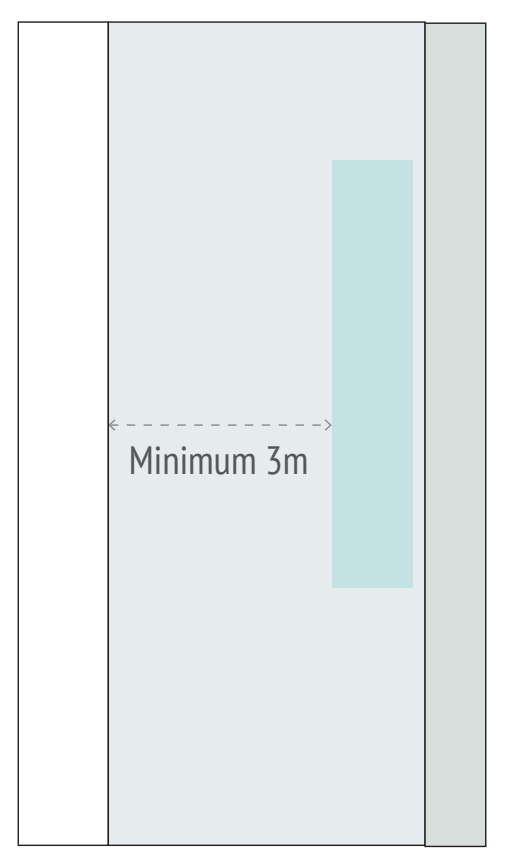

Configuration 3

On wide sidewalks

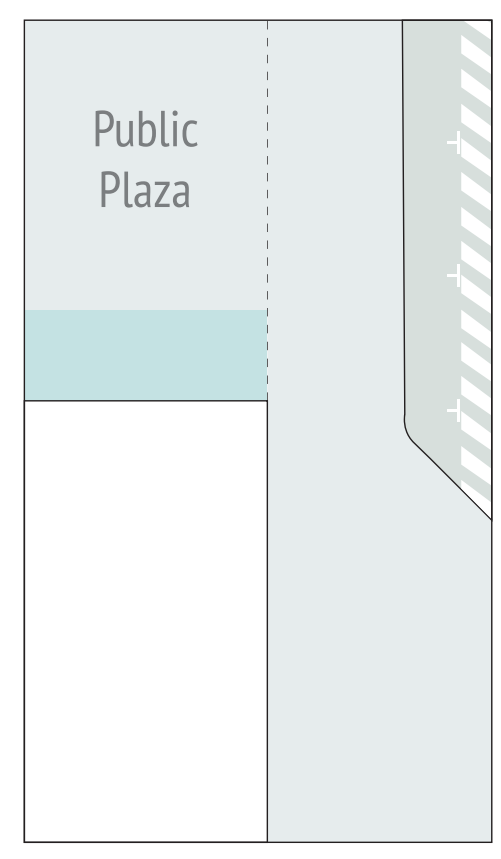

Configuration 4

In adjacent public spaces, parks, or destination sites outside the publi right-of-way

\section{Cycle Facilities at Transit Stop}

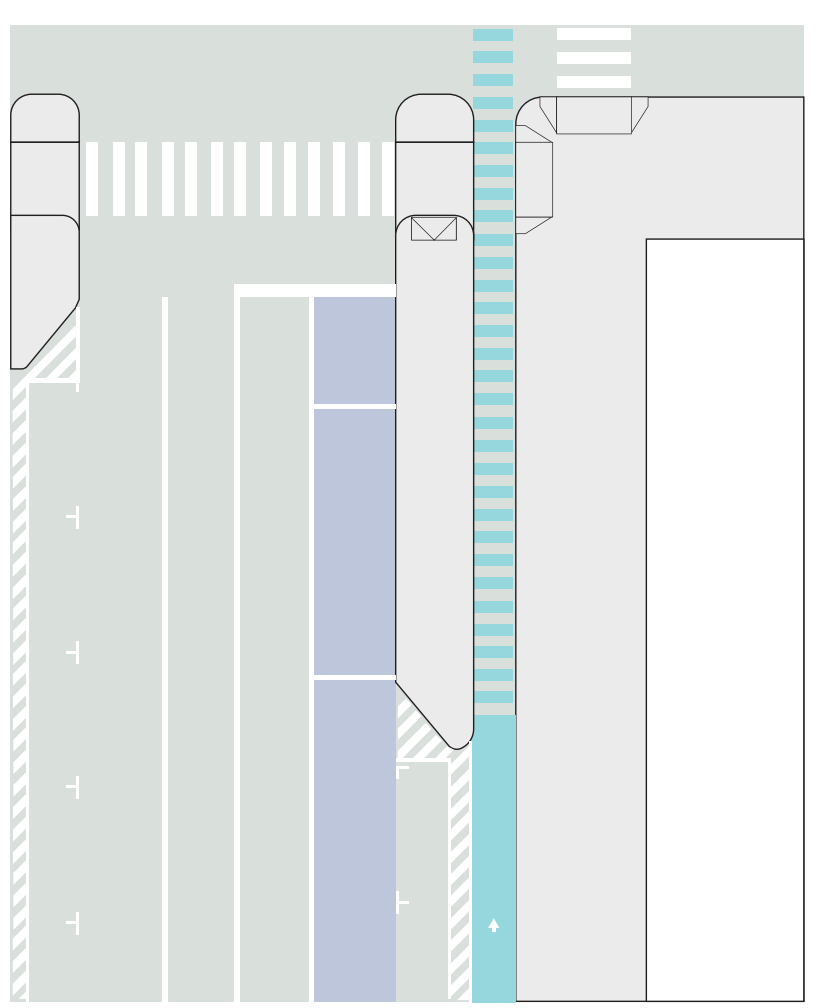

Cycle Track Behind Boarding Island

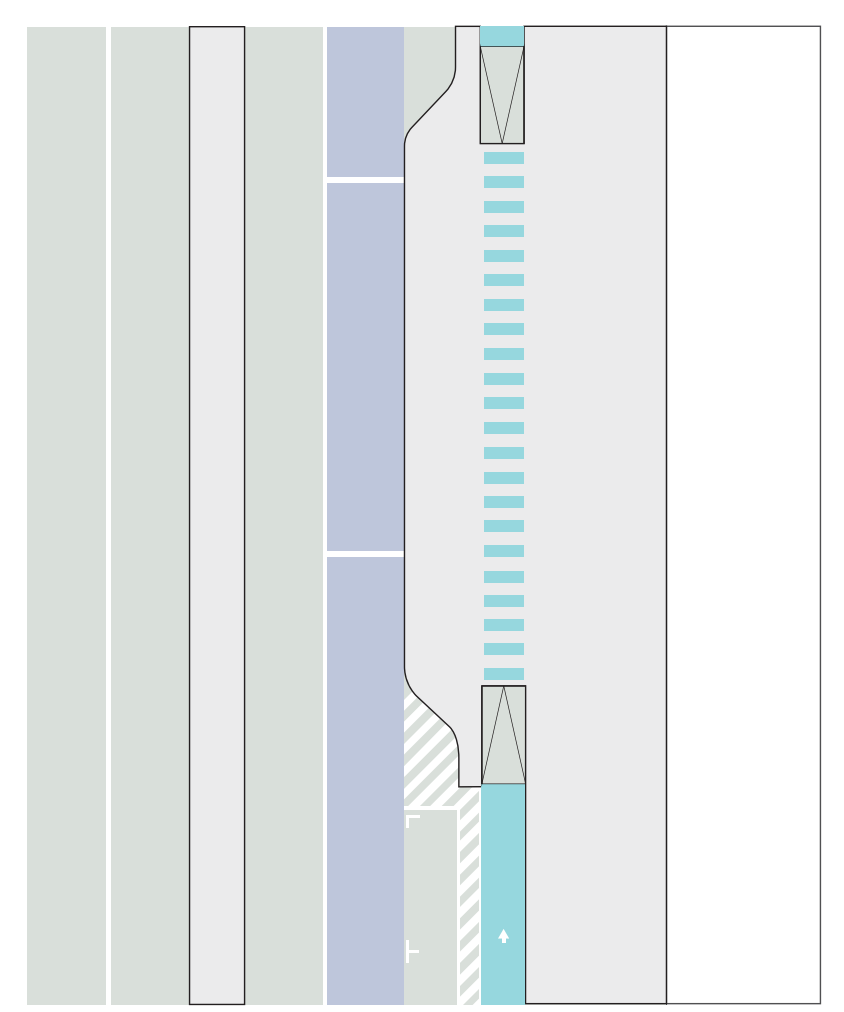

Cycle Track on Bus Bulb

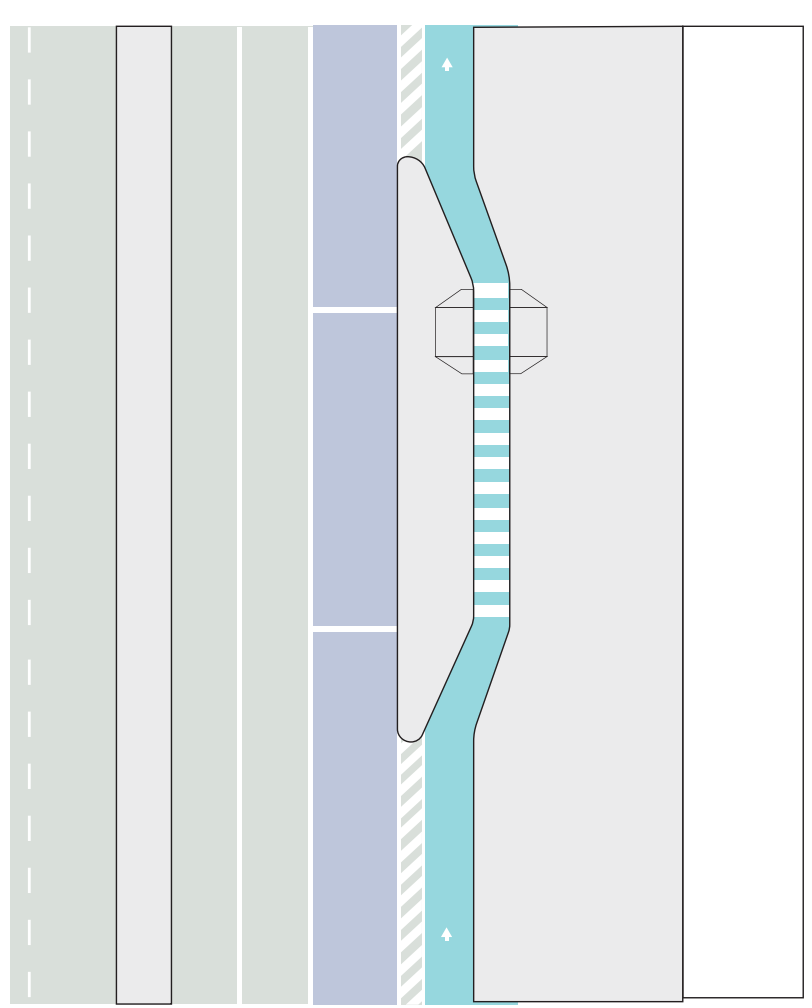

Cycle Lane Behind Boarding Island 


\section{Protected Cycle Facilities at Intersections}

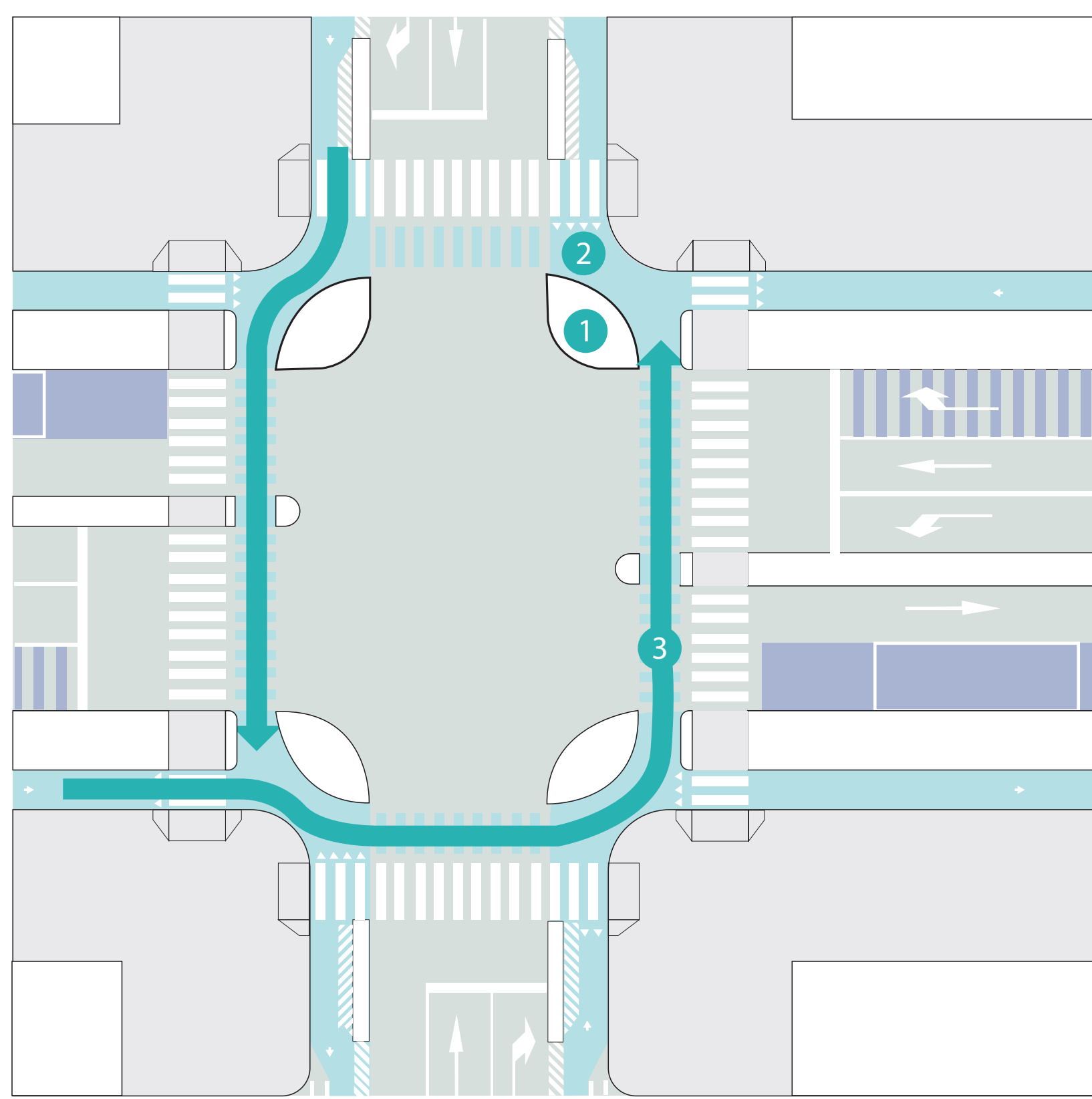

(1) Corner refuge island

(2) Forward stop line

3 Setback crossing by extending the curb 


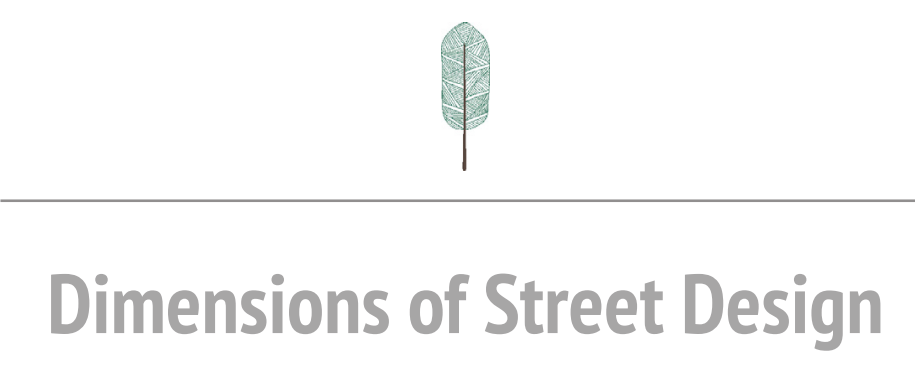

Evaluate different types of street typology depending on a variety of street users, supported transport modes and characteristics of street condition. 
A Variety of Street Users: Pedestrians, Cyclists, Taking Transit Users, Doing Business, Children/ Parents and People with Disabilities

Supported Transport Modes: Local Bus, Inter-Regional Bus, Rapid, Transit Bus, Sustainable Transports, Taxi

Characteristic Conditions: Safe and Secure,

\section{Pedestrian-Priority Spaces}

(1) Frontage Zone

(2) Clear Path

(3) Street Furniture Zone

(4) Cycleway

(5) Buffer Zone

6) Public Transit Corridor Universal, Connectivity and Legibility, Walking and Cycling Friendly, Accessibility; Places for Every Person, Comfort and Convenient, Building Edges Vibrancy

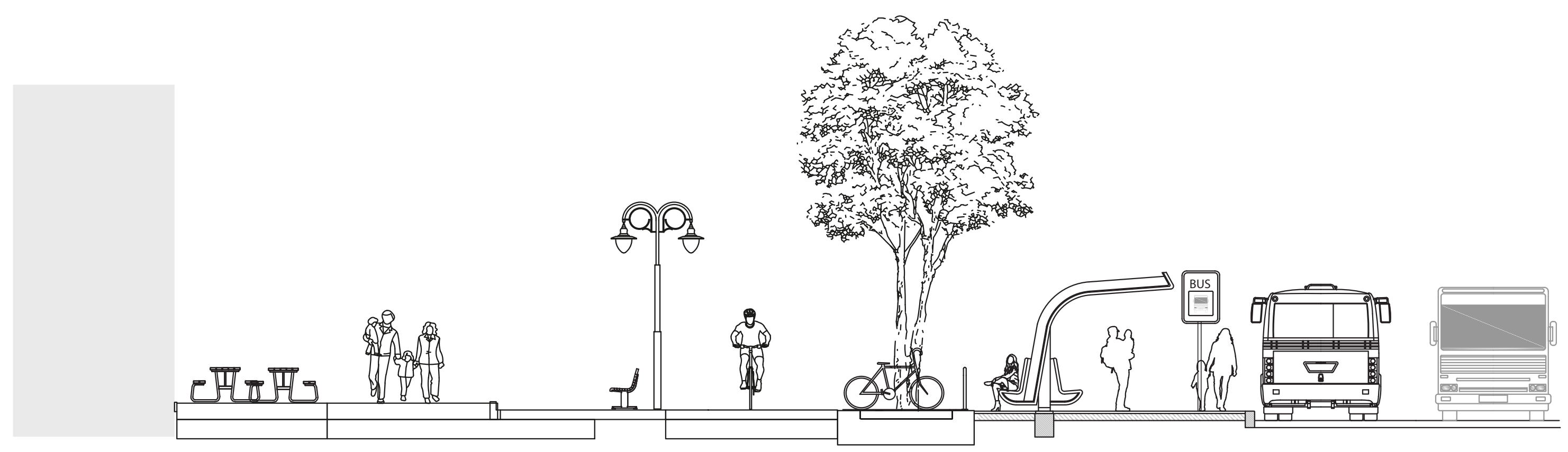

(1)

(4)

5

6 
A Variety of Street Users: Pedestrians, Cyclists, Taking Transit Users, Doing Business, Children/ Parents and People with Disabilities

Supported Transport Modes: Sustainable Transports

Characteristic Conditions: Safe and Secure, Walking and Cycling Friendly, Accessibility; Places for Every Person, Comfort and Convenient, Green, Building Edges Vibrancy, Pleasant; Creative and Inviting, Flexible and Resilient, Cultural Preservation
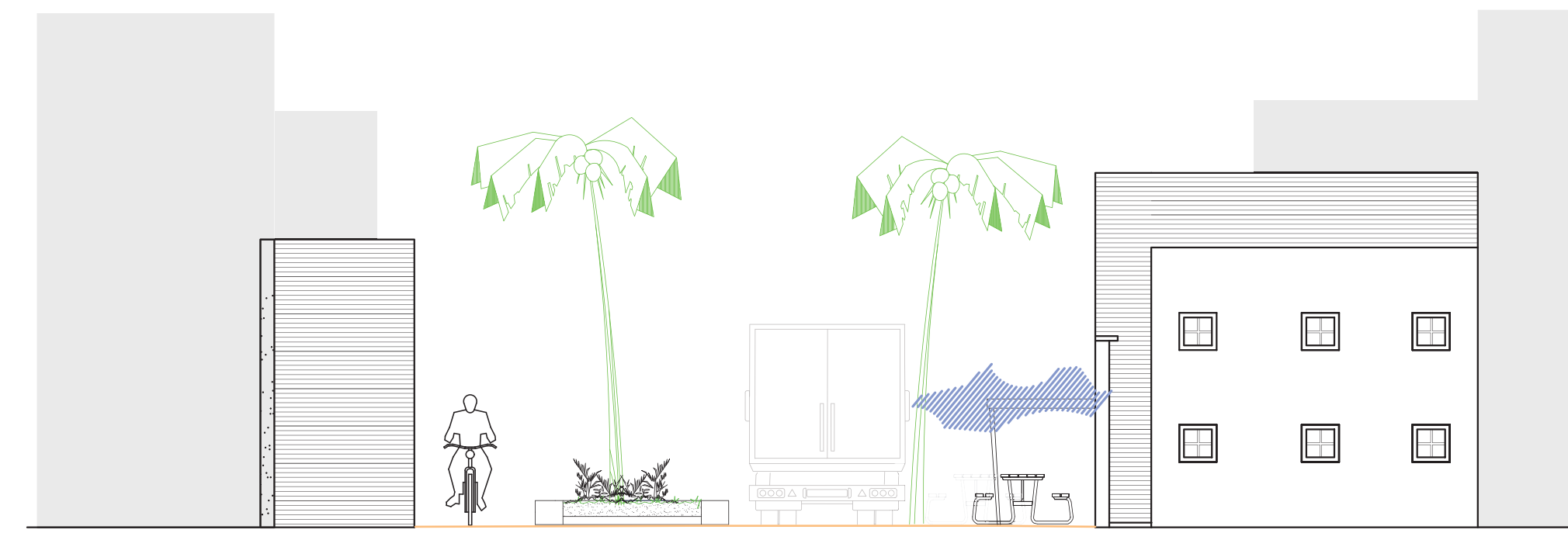

1

\section{Shared Streets}

(1) Residential Zone

2 Residential Share

3 Seating Boundaries

4 Loading Vehicle Zone/ Mixed Uses

5 Commercial Share

6 Commercial Zone 
A Variety of Street Users: Taking Transit Users and Private Vehicle Users

Supported Transport Modes: Auto Vehicles, Inter-city Bus, Local Bus, Inter-Regional Bus, Rapid Transit/ Tram and Taxi

Characteristic Conditions: Universal, Connectivity and Legibility, Creating

\section{Avenues and Boulevards}

(1) Pedestrian and Cycle Share

(2) Road

(3) Large Street with Transit

(4) Street Station

5 Open Space for Transit Exchanges

6 Protected Cycle Path

7) Street Buffer

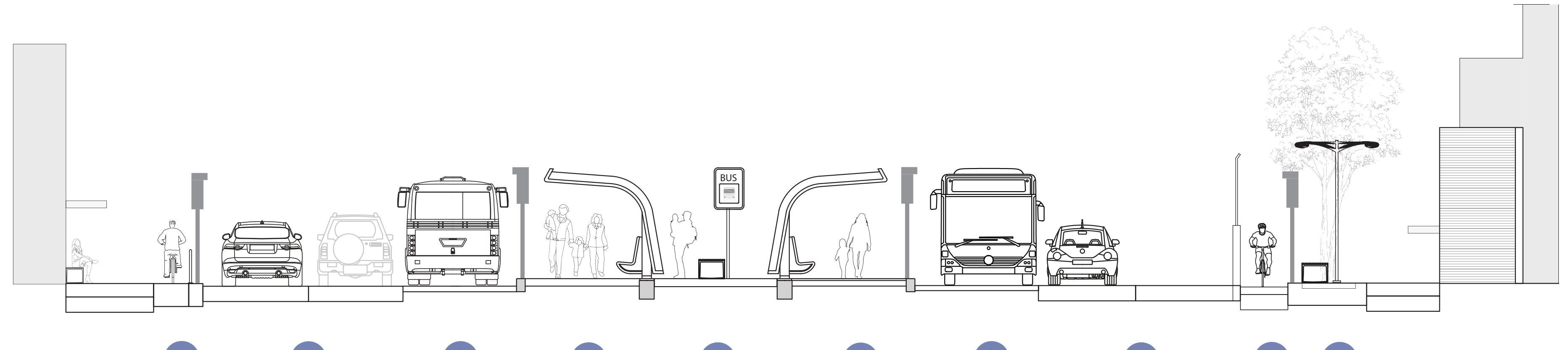

12

(3)

4

5

(4)

3

2

(6) 7 


\section{Neighbourhood Streets}

1) Residential Zone

(2) Semi-Private Frontage

(3) Buffer Zone/Cycle Parking

(4) Street Car Parks/Bus Lane

5 Cycleway

6 Neighbourhood Main Street

(7) Transit Stop

8 Residential Path
A Variety of Street Users: Pedestrians, Cyclists, Taking Transit Users, Doing Business, Children/ Parents and Students

Supported Transport Modes: Auto Vehicles, Inter-city Bus, Local Bus, Inter-Regional Bus, Rapid Transit Bus, Sustainable Transports and Taxi

Characteristic Conditions: Safe and Secure, Universal, Connectivity and Legibility, Walking and Cycling Friendly, Accessibility; Places for Every Person, Comfort and Convenient, Building Edges Vibrancy, Creating and connecting a Vibrant Sub-region

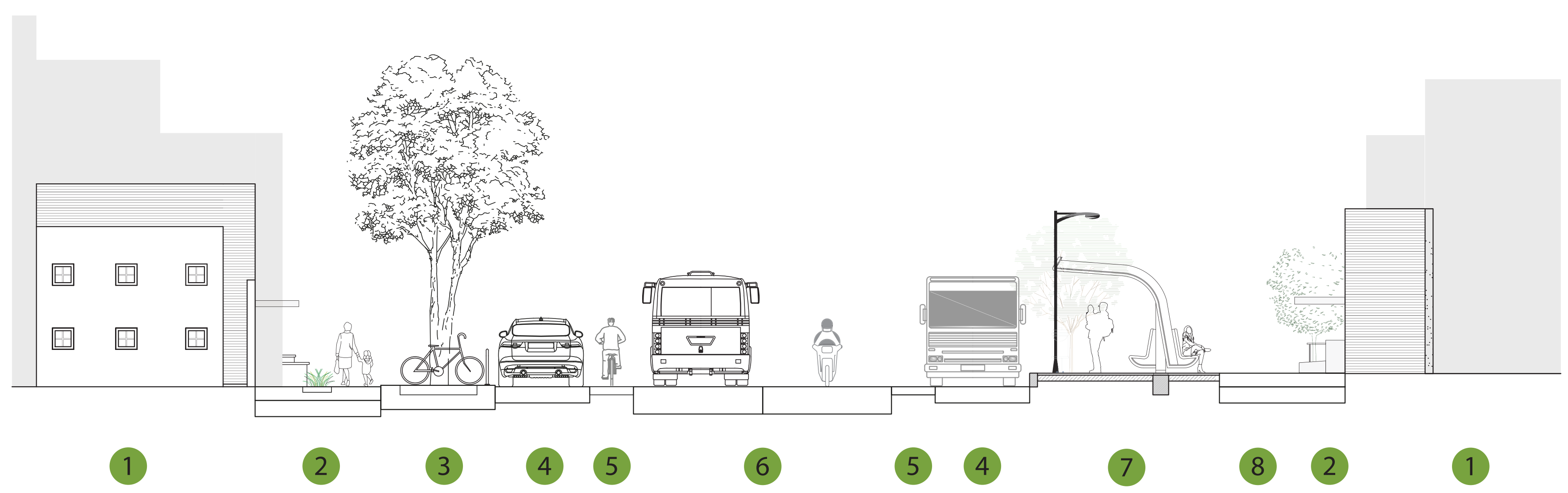


RAILWAY STATION STREET 1

\section{Special Conditions}

1 Drop Off Area

2 Pedestrian Connection

3 Planting Protection

4 Railway Stop

5 Double-Track Railway

6 Transport Hub

7 Bus Interchange

8 Crossing Bridge
A Variety of Street Users: Taking Transit Users and Private Vehicle Users

Supported Transport Modes: Rail/ Train and Auto Vehicles

Characteristic Conditions: Universal, Creating and connecting a Vibrant Sub-region, Connectivity and Legibility

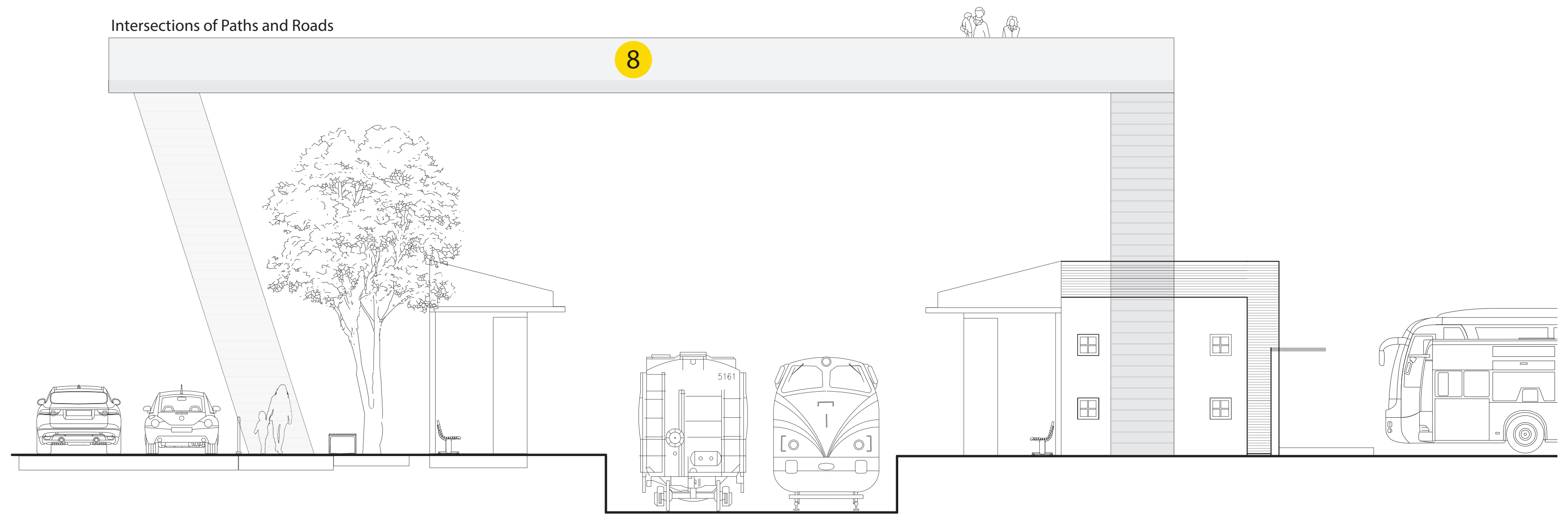


A Variety of Street Users: Taking Transit Users and Private Vehicle Users

Supported Transport Modes: Rail/ Train and Auto Vehicles

Characteristic Conditions: Universal, Creating and connecting a Vibrant

RAILWAY STATION STREET 2

\section{Special Conditions}

(1) Drop Off Area

2. Bus Only Lane

3 Underpass

4 One-Side Rail Track

5 Both-Side Station

6 Footpath

7 Park and Ride

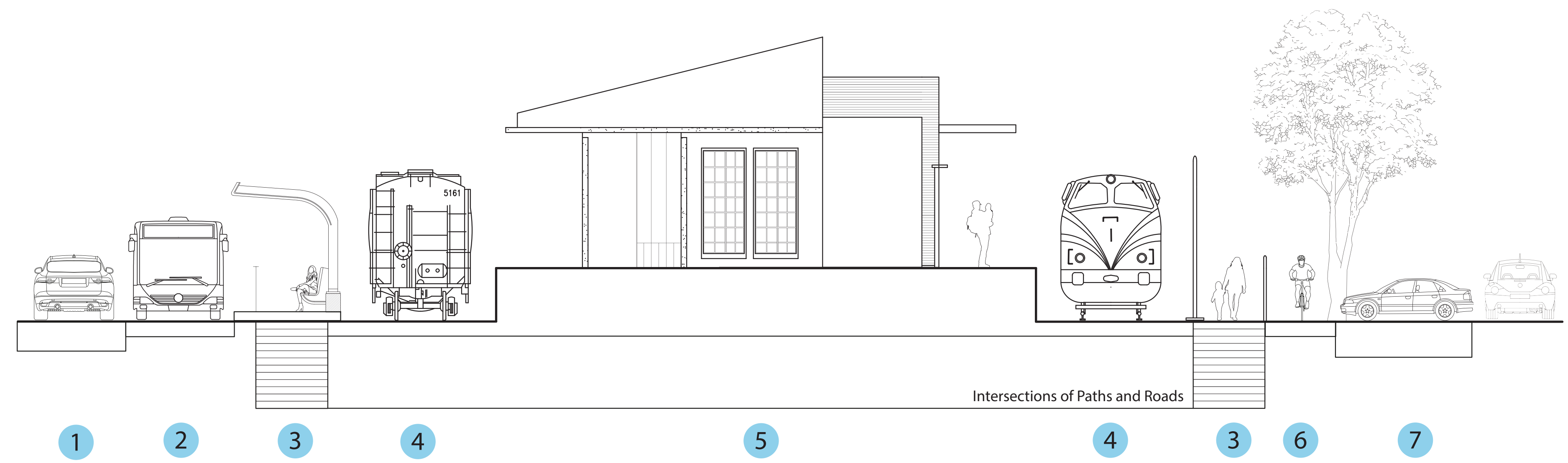


A Variety of Street Users: Pedestrians, Cyclists, Children/ Parents and People with Disabilities

Supported Transport Modes: Rail/

Train (not accessible), Sustainable Transports and Ferry

Characteristic Conditions: Safe and Secure, Walking and Cycling Friendly, Accessibility; Places for Every Person, Comfort and Convenient, Green, Pleasant; Creative and Inviting,

Flexible and Resilient.

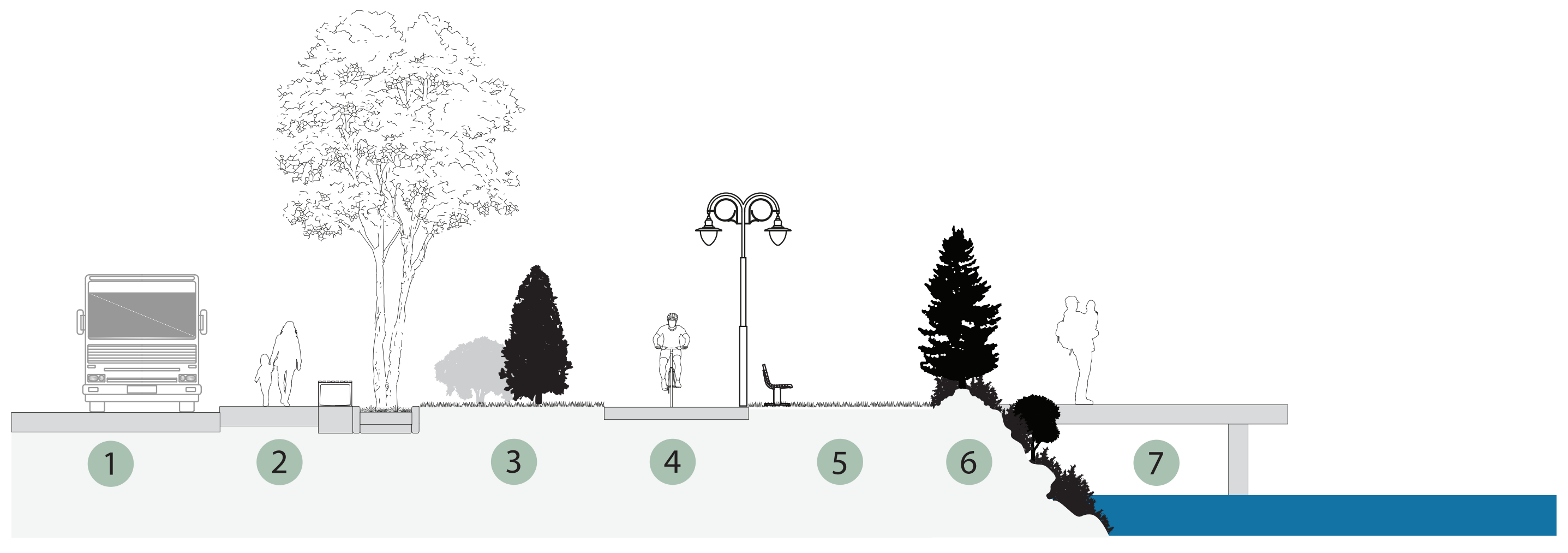

WATERFRONT CORRIDOR Special Conditions
(1) Road
(2) Footpath
(3) Vegetation Buffer
(4) Harbour Walkway
5 Embankment
6 Natural Barrier
(7) Boardwalk 
A Variety of Street Users: Pedestrians, Doing Business, Children/ Parents

Supported Transport Modes: Local Bus and Sustainable Transports

Characteristic Conditions: Safe and Secure, Walking and Cycling Friendly, Accessibility; Places for Every Person, Comfort and Convenient, Green, Building Edges Vibrancy, Pleasant; Creative and Inviting, Flexible and Playing Streets

(1) Commercial Zone Resilient, Cultural Preservation

(2) Commercial Share

(3) Open Street

(4) Pedestrian Only Zone Boundary

(5) Transport Connection

6 Public Transit Corridor

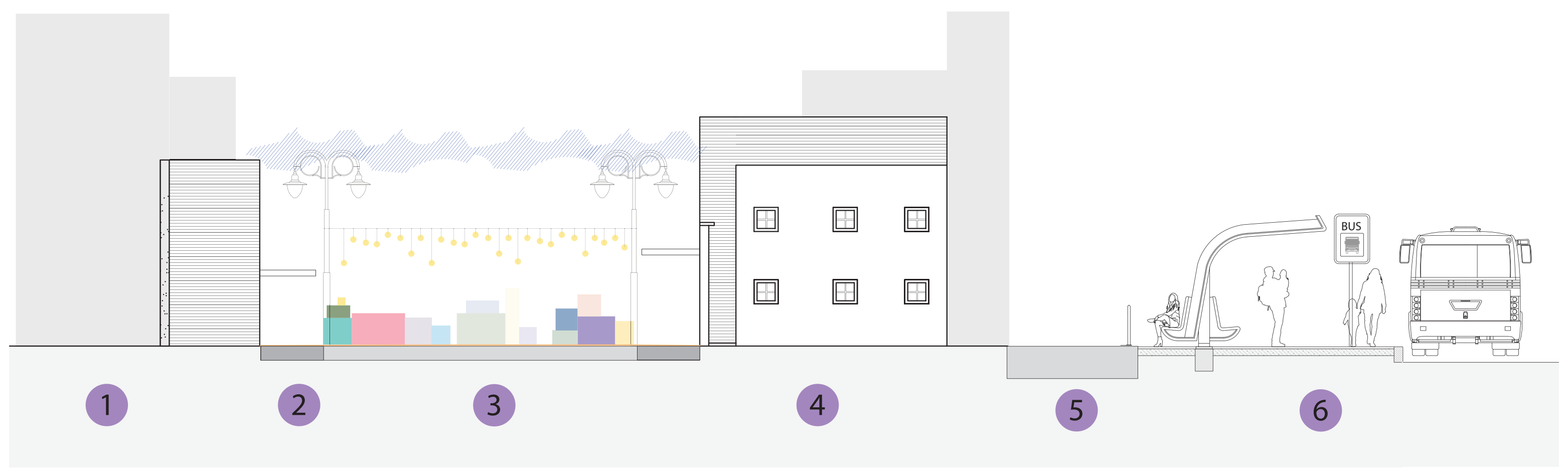




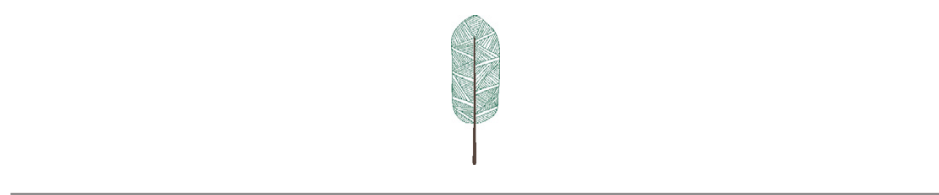

\section{Design Criteria}

Under design principle, 'Hybrid Streets' provides specific design criteria, which are outlined in chapter 5 . The main design criteria for Hybrid Streets are Safe and Secure, Universal, Connectivity and Legibility, Walking and Cycling Friendly, Accessibility; Places for Every Person, Comfort and Convenient, Green, Building Edge Vibrancy, Pleasant; Creative and Inviting, Creating and Connecting A Vibrant Sub-Region, Flexble and Resilient, Cultural Preservation. 

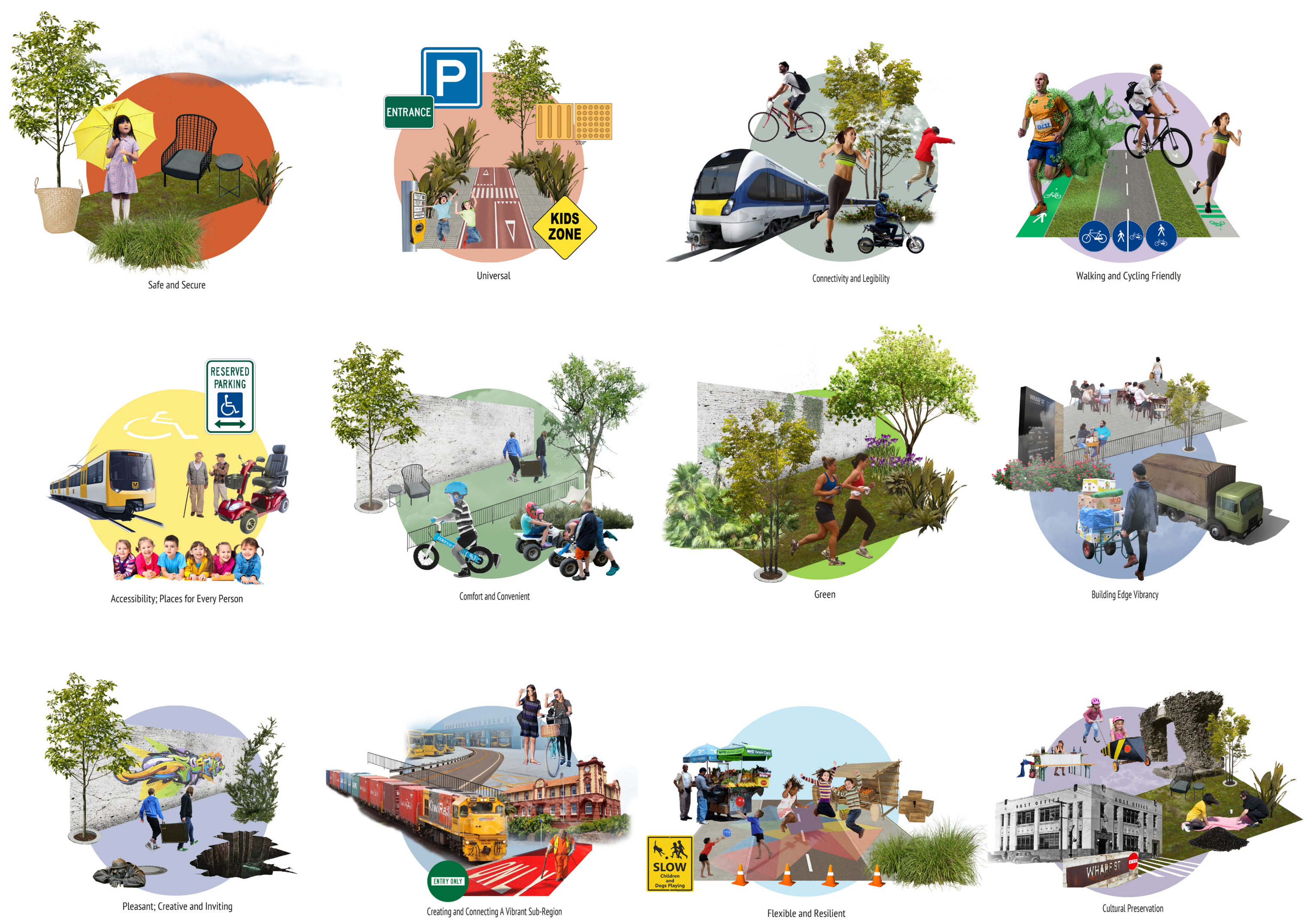


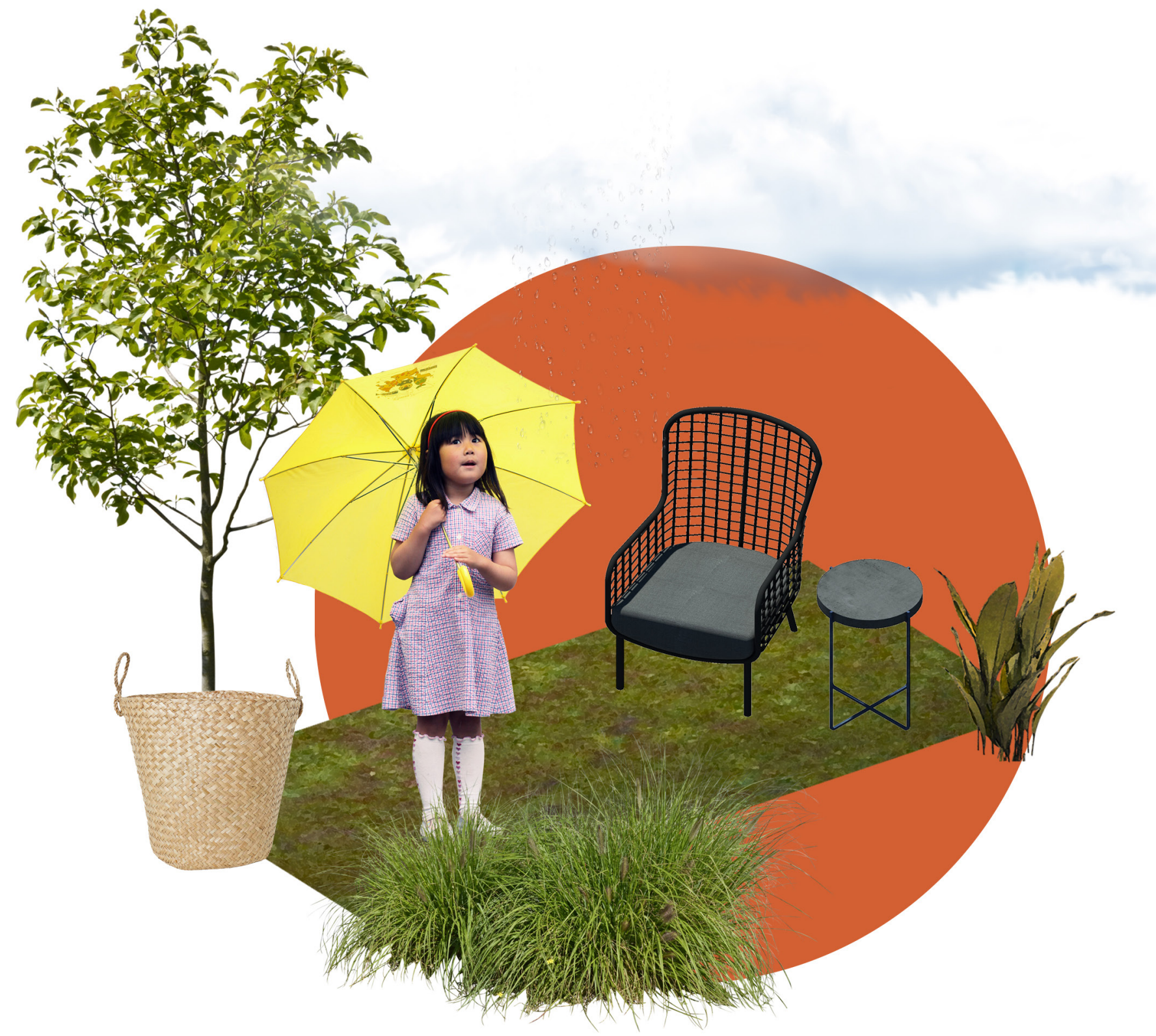

Safe and Secure

\section{Safe and Secure}

Construction materials in public spaces and streets should be safe and secure to support various street users especially the most

vulnerable users such as children, the elderly, and disabled and

modes of pedestrians and cyclists. Key contributors to safety are appropriate geometric design, facility design and transport operations with protection from high-speed traffic and appropriate lighting.

Appropriate speed limit for the safe and secure street is $30 \mathrm{~km} / \mathrm{h}$ at schools, town centres, bus services and neighbourhoods street. 


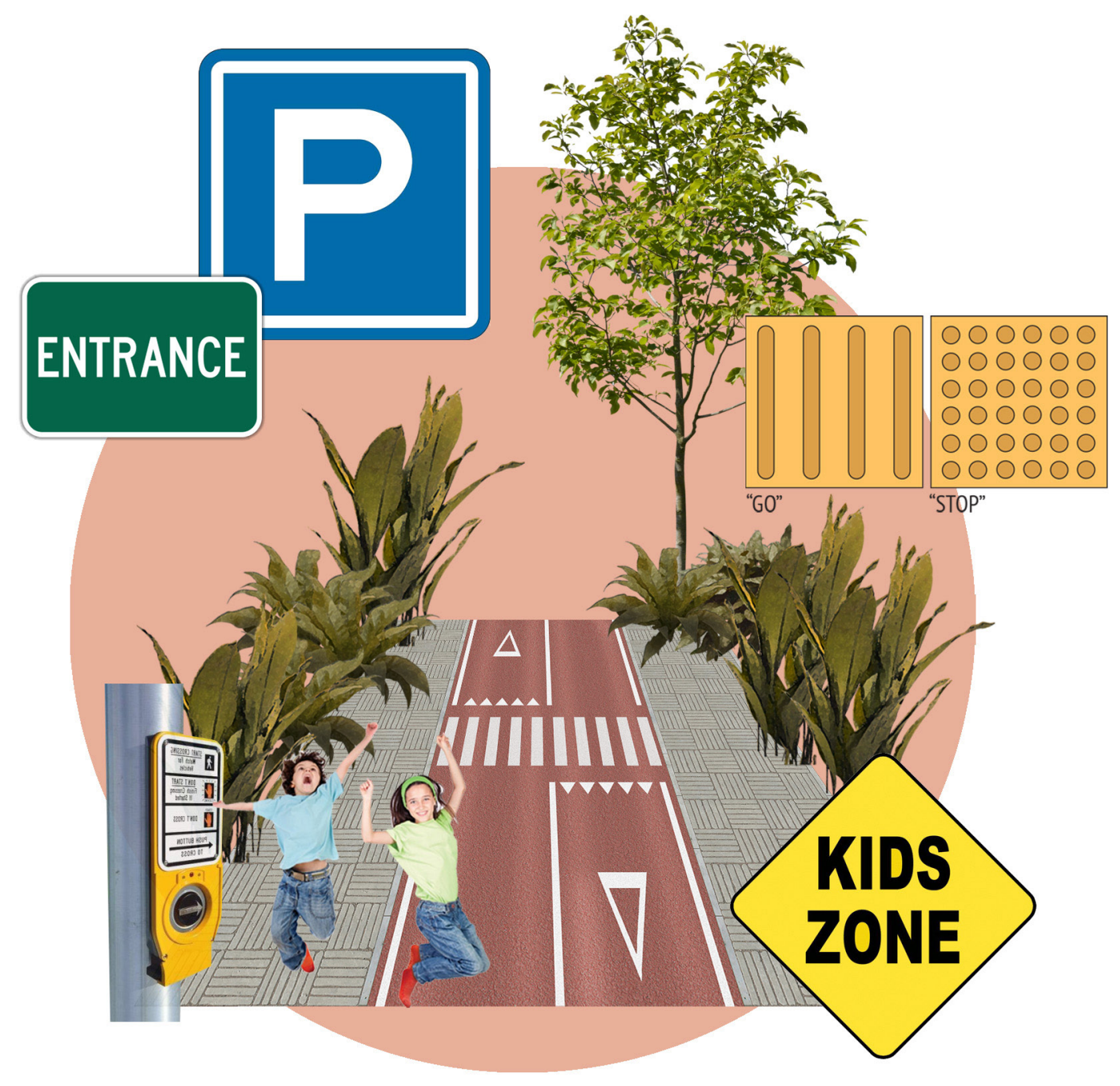

The routes must be equipped with

devices to ensure access for people

with limited mobility through gentle

slopes, visual contrasts, sounds and

specific tactile characteristics.

Universal 


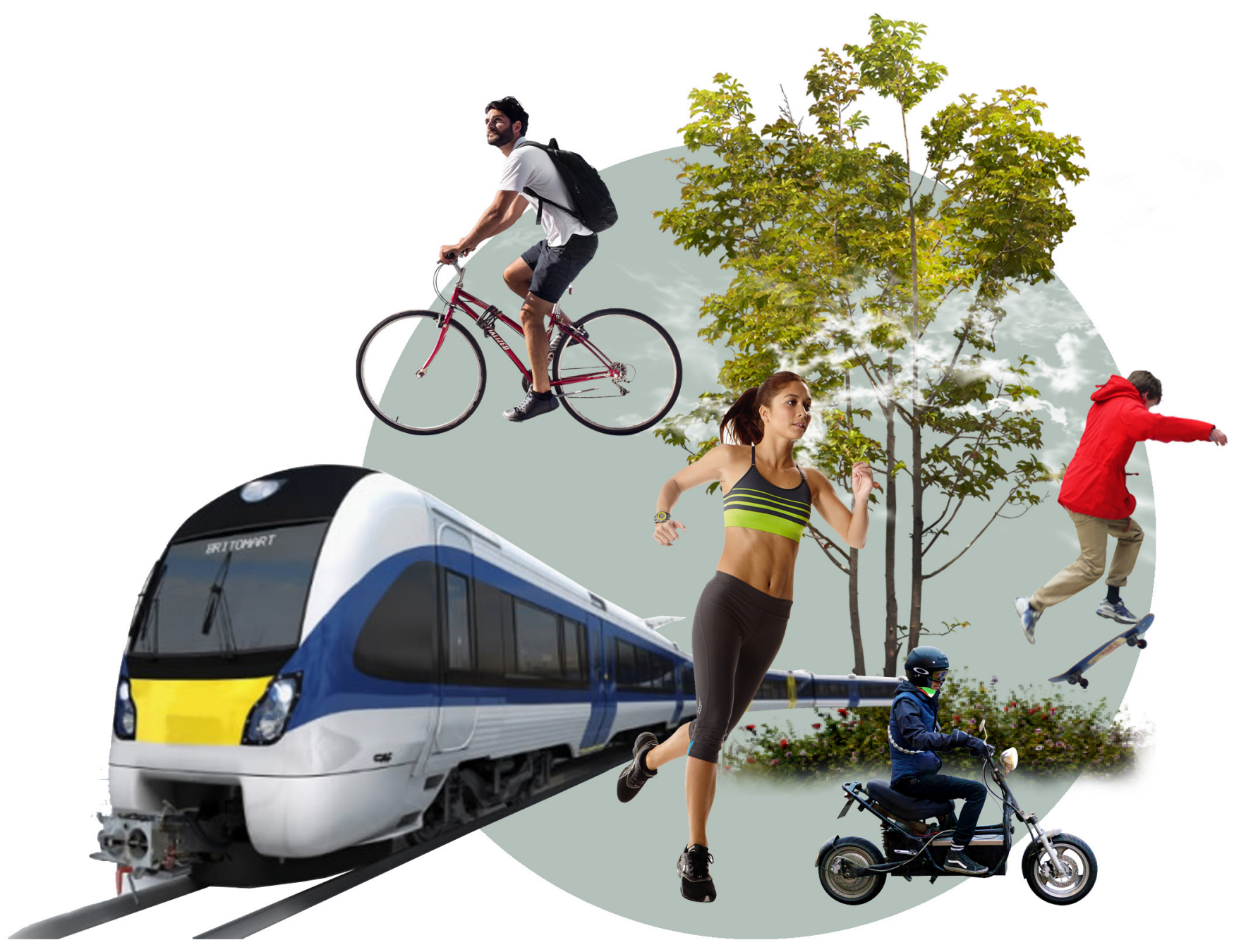

Connectivity and Legibility

\section{Connectivity and Legibility}

To provide a feasible and attractive alternative to other modes of

transport, pedestrian connections

need to offer clear, continuous, direct paths and maximised route choice.

When the various modes of

transport work together in

interconnected networks, access to

many destinations is provided.

Street networks should minimise

block sizes and maximise pedestrian

connections. The attractiveness

of walking versus other modes

of transport increases over short

trips and where quality pedestrian

connections are provided,

particularly where a more direct

path is provided for people on foot

than for other modes. 


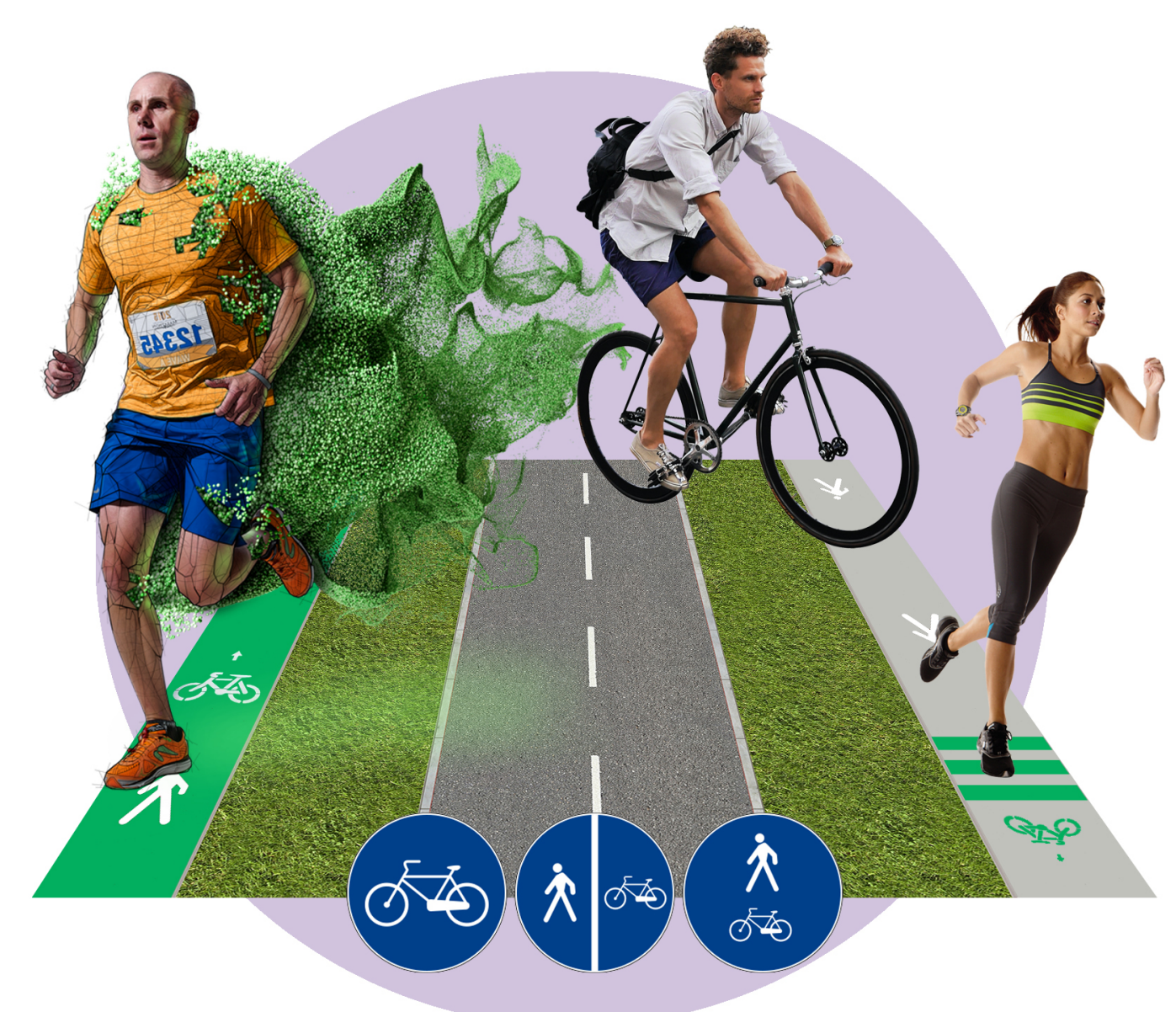

Walking and Cycling Friendly

\section{Walking and Cycling Friendly}

Our most valued urban places are those principally designed for the use and enjoyment of people on foot. This requires a closely spaced network of streets and blocks that offer direct, safe, varied pedestrian routes made interesting through careful design.

Provide cycle-share systems and shared micromobility options,

improve or add new transit services,

revise transit schedules, invite

electric vehicle share systems,

and offer electric vehicle charging

stations. These offer families

more choices for traveling to their destinations. 


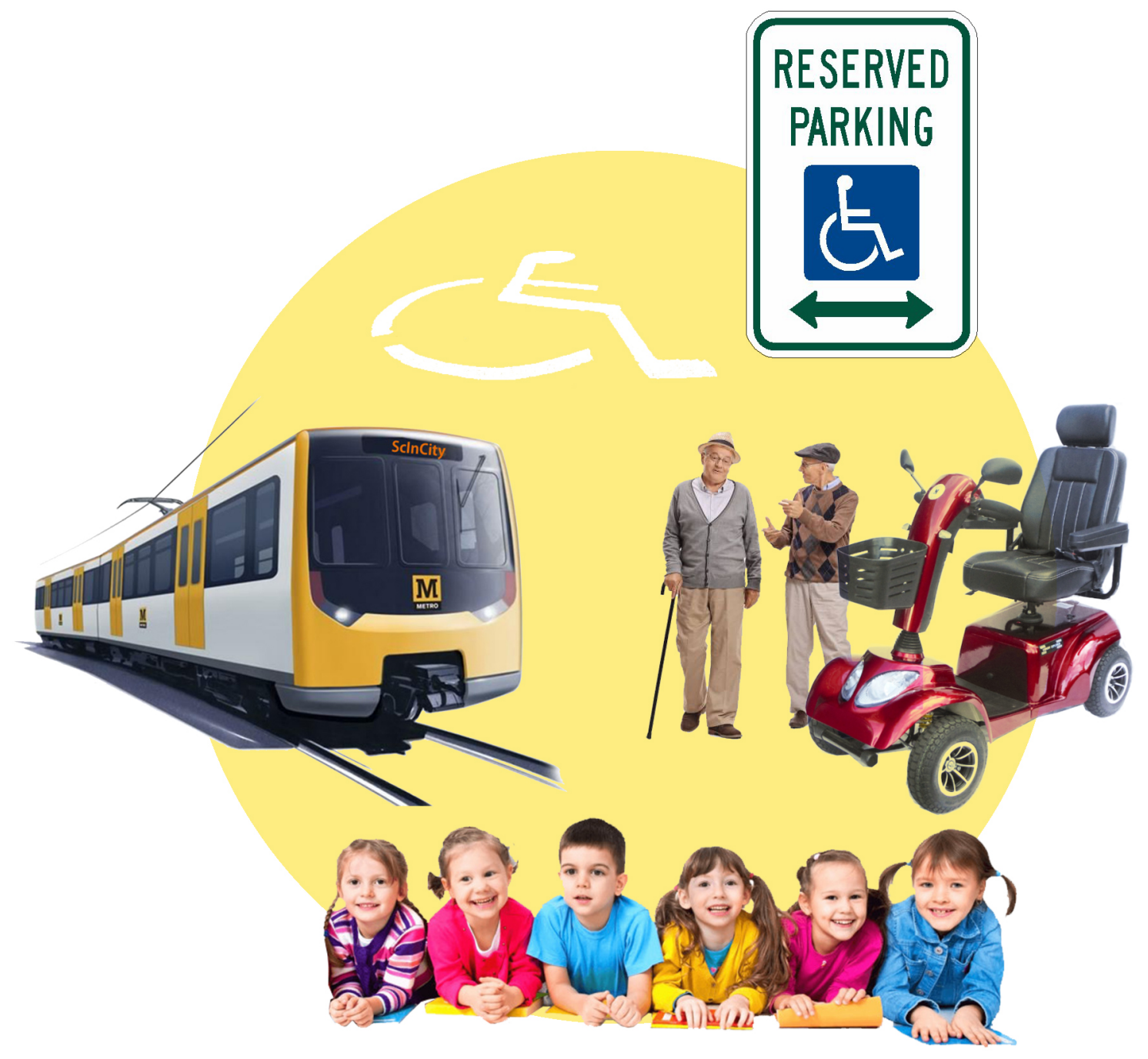

\section{Accessibility; Places for Every}

\section{Person}

Accessible Streets aims to support a shift from private vehicles to more energy efficient, low-cost and healthier modes of transport

like walking, cycling and public

transport. Everyone who uses the

transport network will be affected

by these proposed changes.

Accessibility; Places for Every Person 


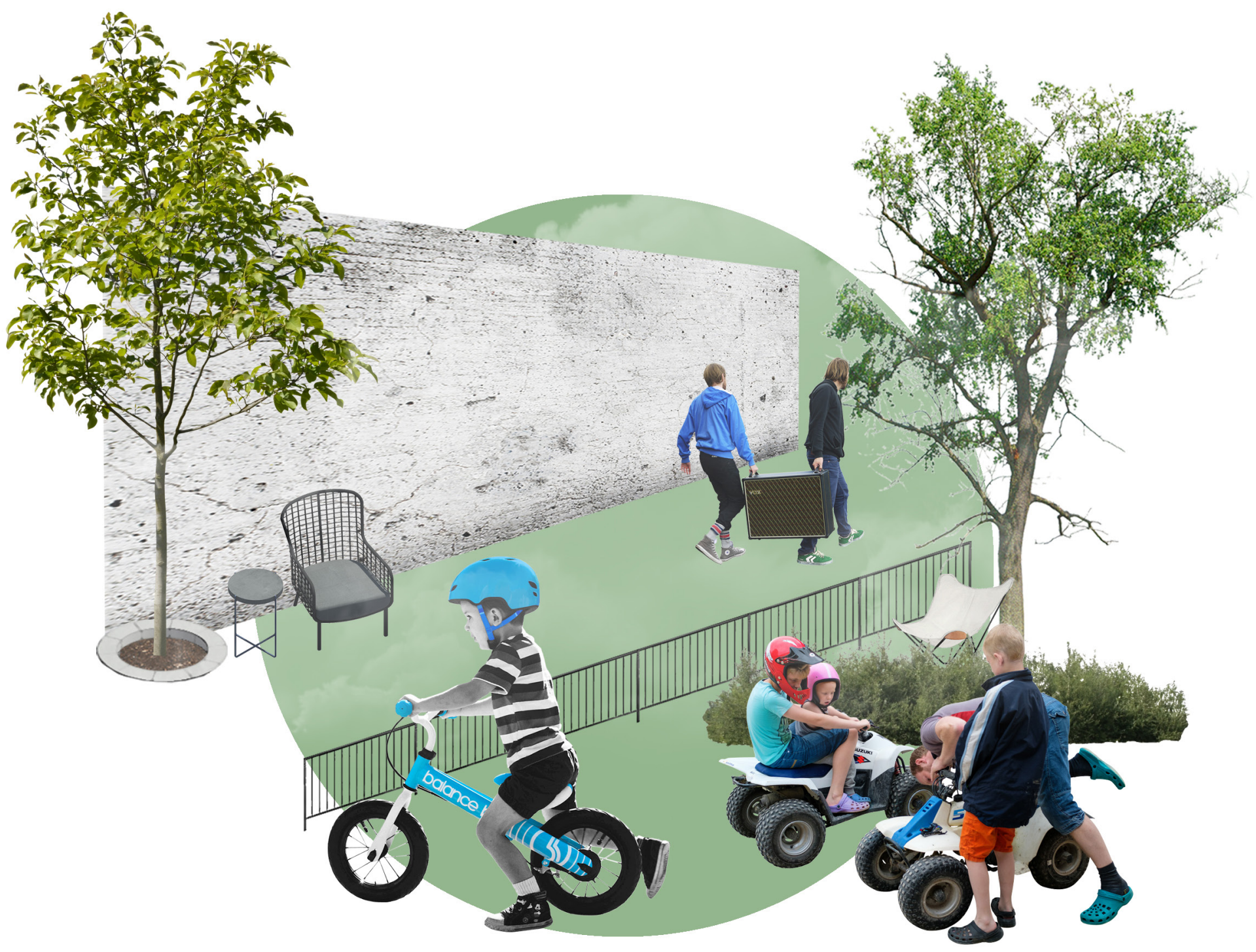

\section{Comfort and Convenient}

Streets should be designed according to the scale of the human body and to function according to

the senses. Scale is determined

by spatial design and detailing,

including building massing, street

furniture design and wayfinding.

Streetscapes should be comfortable

rather than intimidating

Comfort and Convenient 


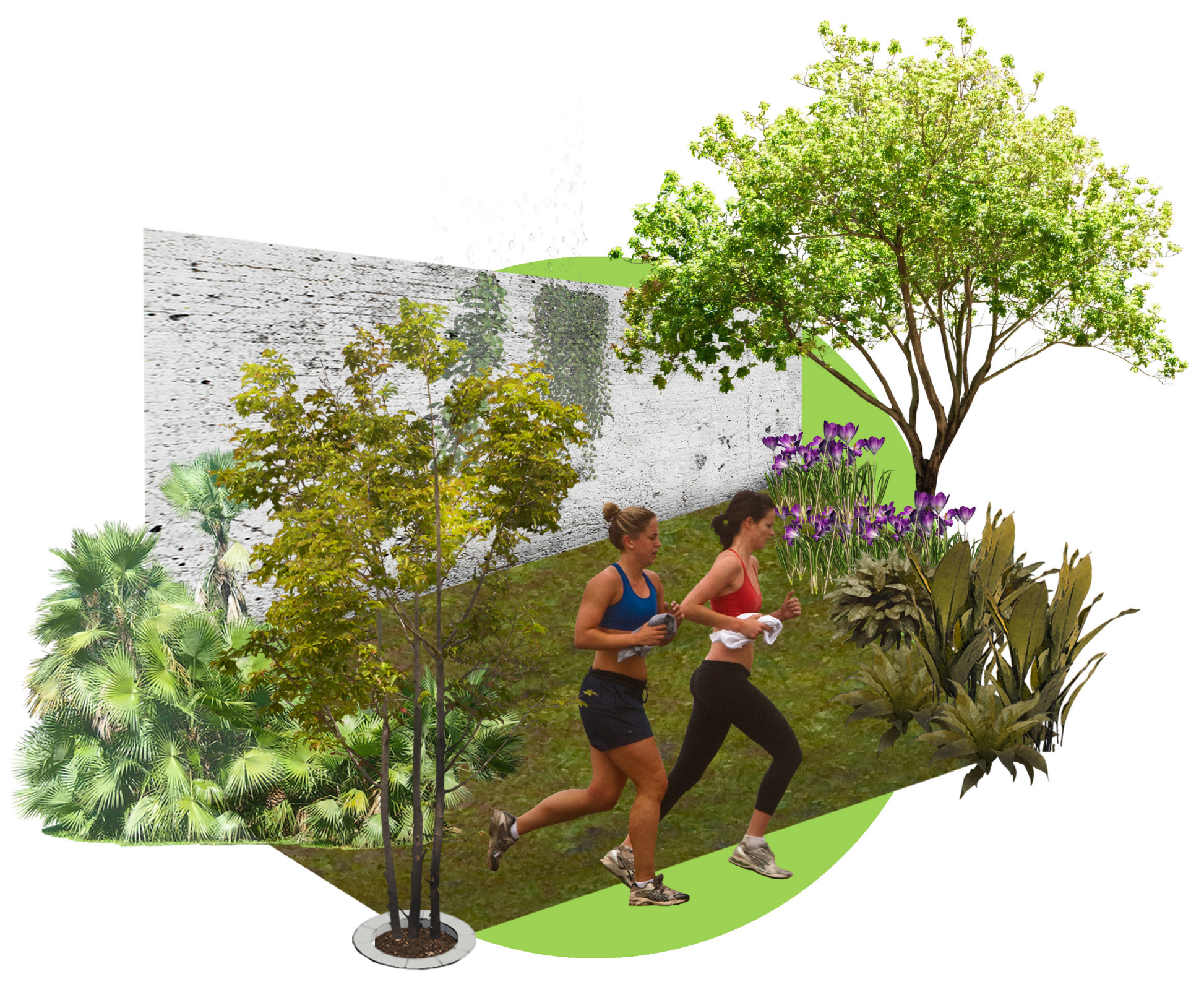

\section{Green}

Street trees and low planting provide amenity to city streets. Street trees visually define the

continuous path, slow traffic down, form a barrier between vulnerable

users and moving vehicles, and

provide shade. All vegetation

provides oxygen, filters air pollution,

reduces rain run- off, cools the air

and visually softens the public

realm. Street vegetation should be

considered as an integral part of the

design of pedestrian connections.

Vegetation can be accommodated in

berms, in kerb build-outs between

carparks or in raised planters.

Green 


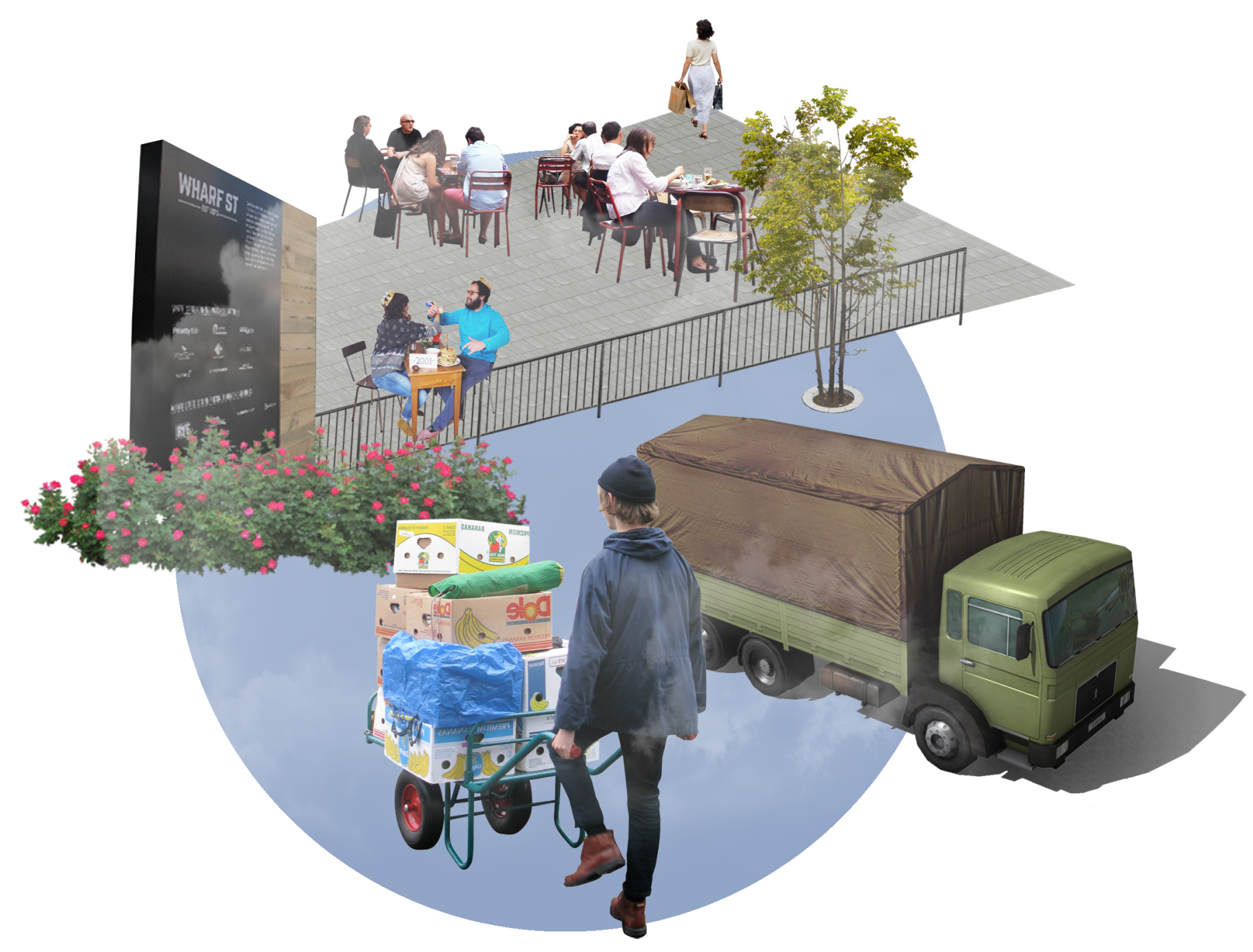

Building Edge Vibrancy

\section{Building Edge Vibrancy}

Street design should encourage and enable recreation, social

interaction and business activity.

Designs should maximise the

road reserve space that will be used for social, economic and

environmental purposes. Streets

should be designed to create an

attractive, comfortable, pedestrian-

scale environment with a range of

amenities, including street trees

and other vegetation. Streets serve

as the key platform for economic

exchange in cities. Improved

accessibility and a more welcoming

street environment attract more

people and more activity, thus

strengthening communities, the

businesses that serve them and the overall city economy. 


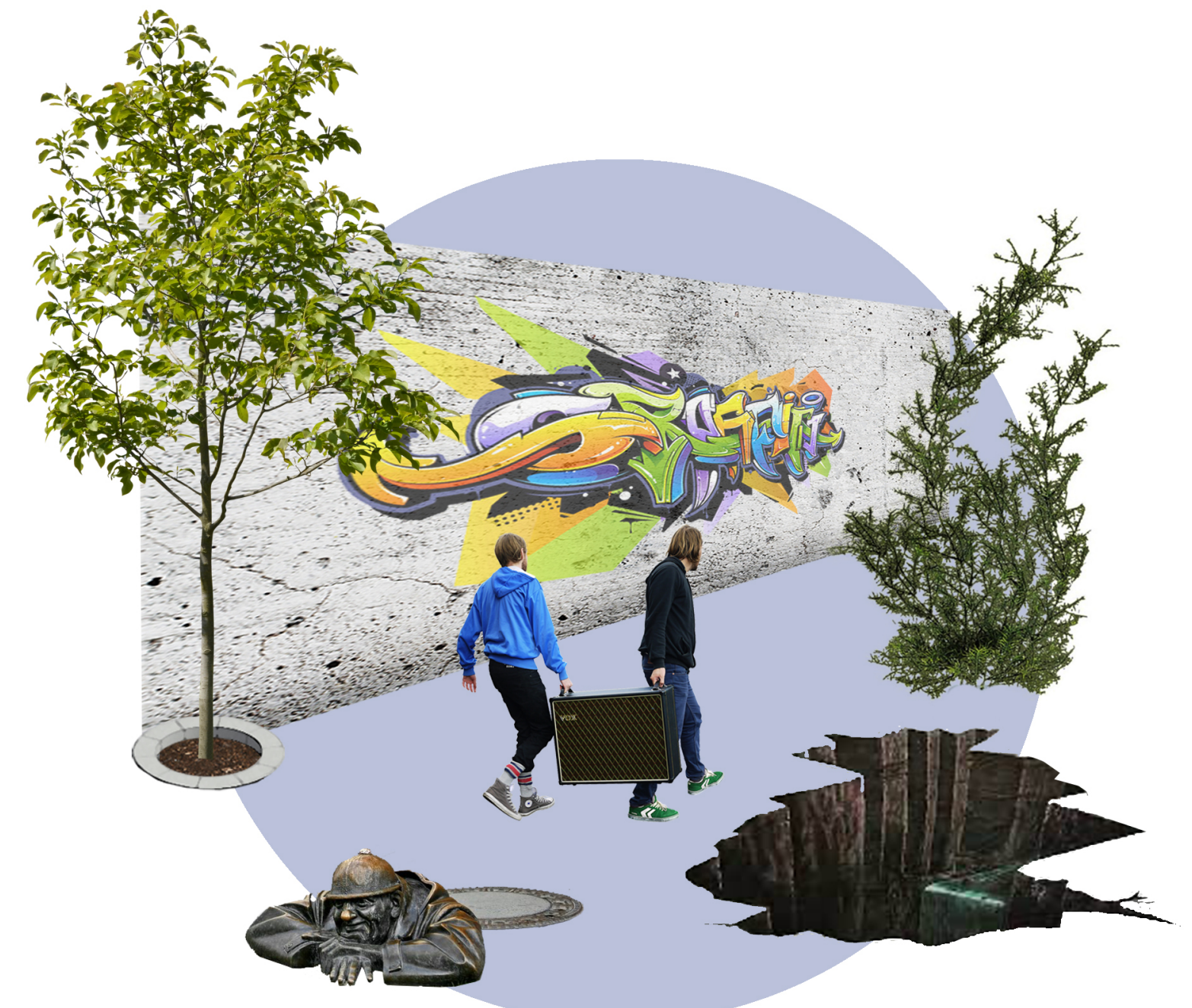

Pleasant; Creative and Inviting

\section{Pleasant; Creative and} Inviting

Consistency of quality is important - the network is only as good as its weakest link and people will avoid routes where footpaths are uneven, obstructed or end abruptly, even if the interruption is for a short stretch. Route choice allows flexibility for different users, for example where some streets are steep, other

continuous, low-gradient routes can provide an alternative. 


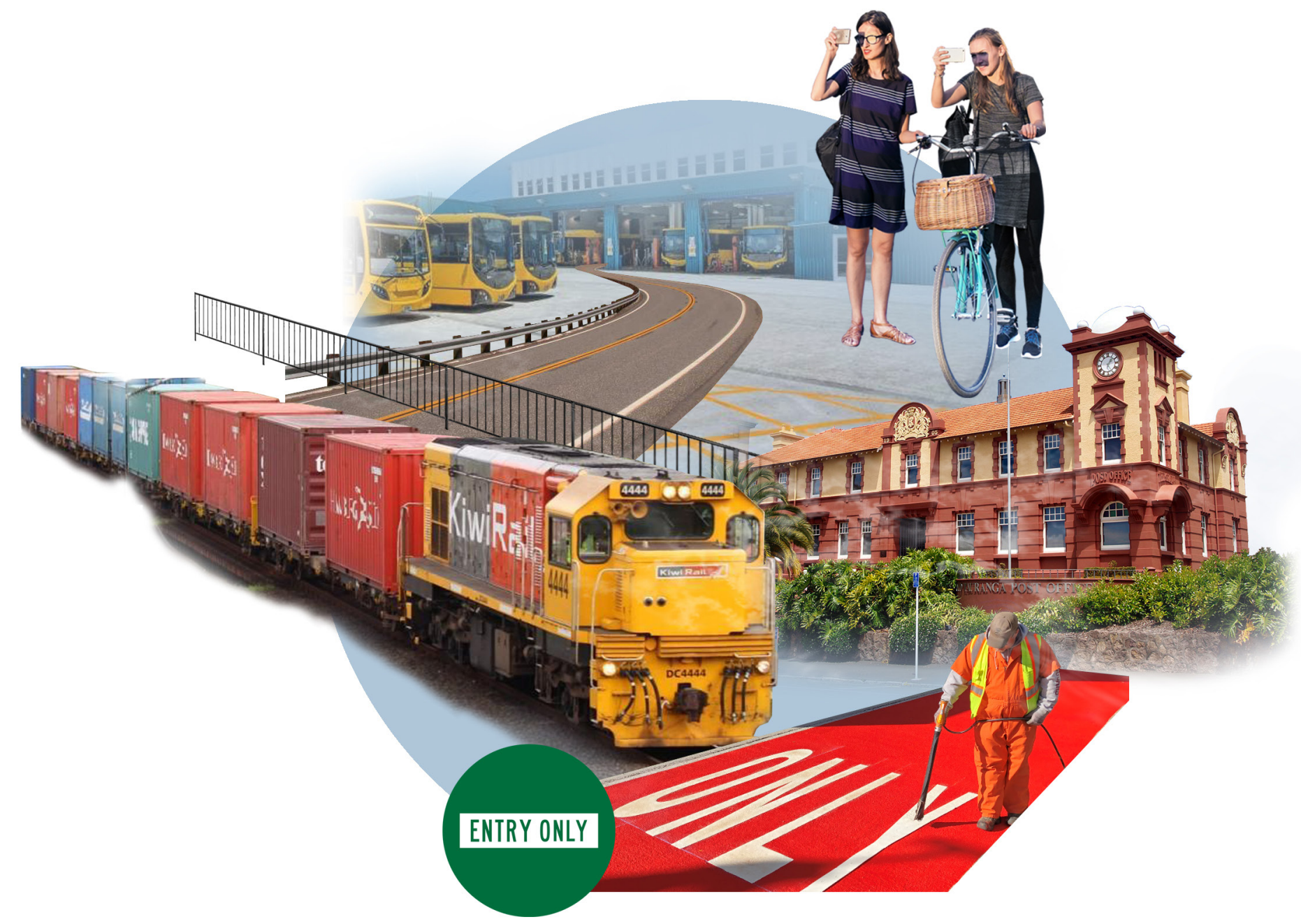

Creating and Connecting A Vibrant Sub-Region

\section{Creating and Connecting $\mathrm{A}$} Vibrant Sub-Region

A collection of streets form

and define the structure of

neighbourhoods and places. They

set and influence the long-term

patterns of development. They

connect people to each other and

to destinations. Street networks

are not just about transport and

infrastructure, but also about the movement of people, goods, ideas, and wealth. They foster economic

activity and provide public space for human interaction. 


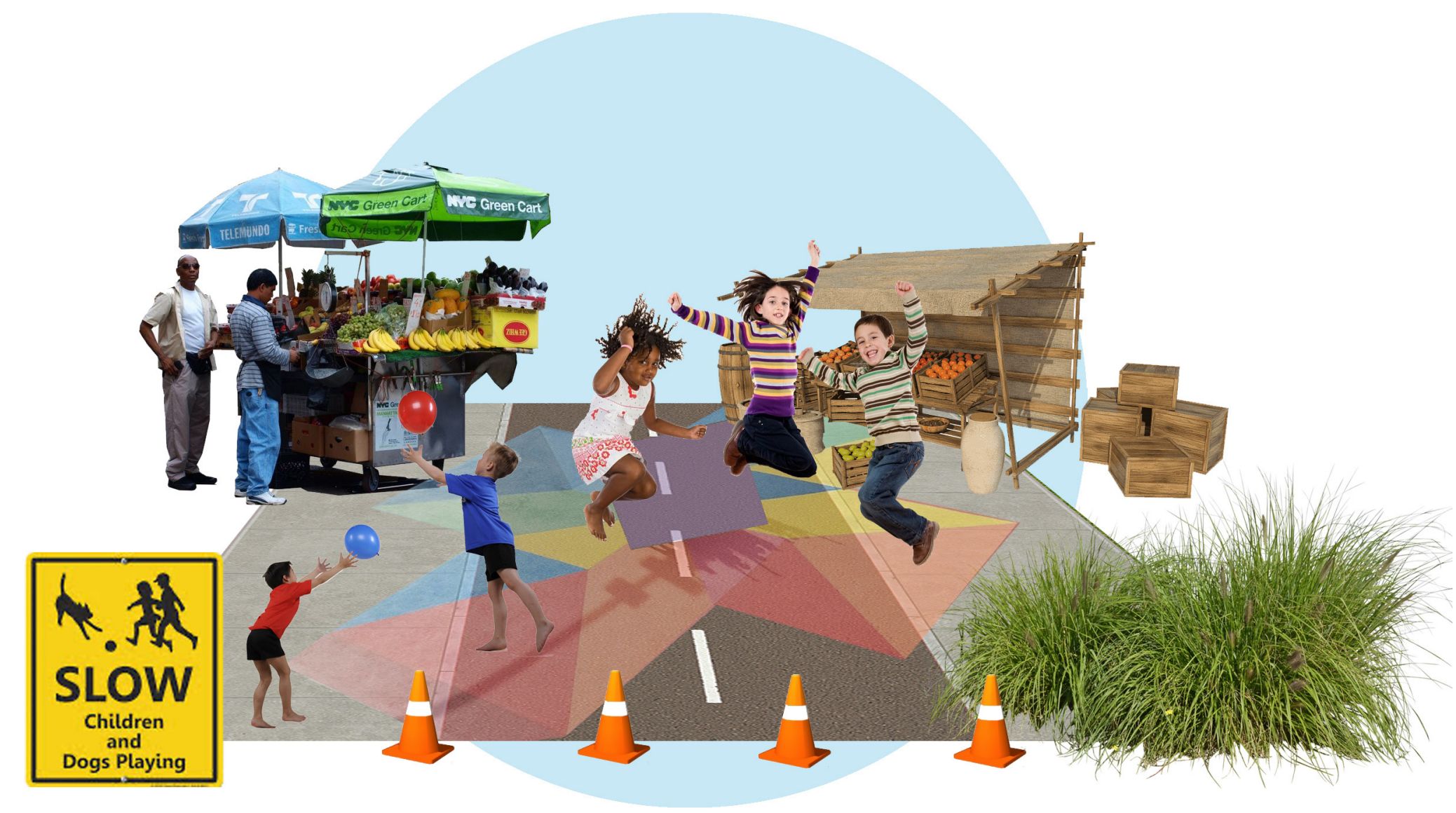

Flexible and Resilient

Many streets today reflect the priorities and practices from the time they were first built. The street designs should reflect these new

conditions and priorities. Streets can change through major interventions and capital improvement projects, and they can also change

systematically through road renewals

and ongoing maintenance. Street

designs can also be strategically

implemented through quick, low-

cost interventions that can serve as

interim stages to more long-term

visions.

Flexible and Resilient 


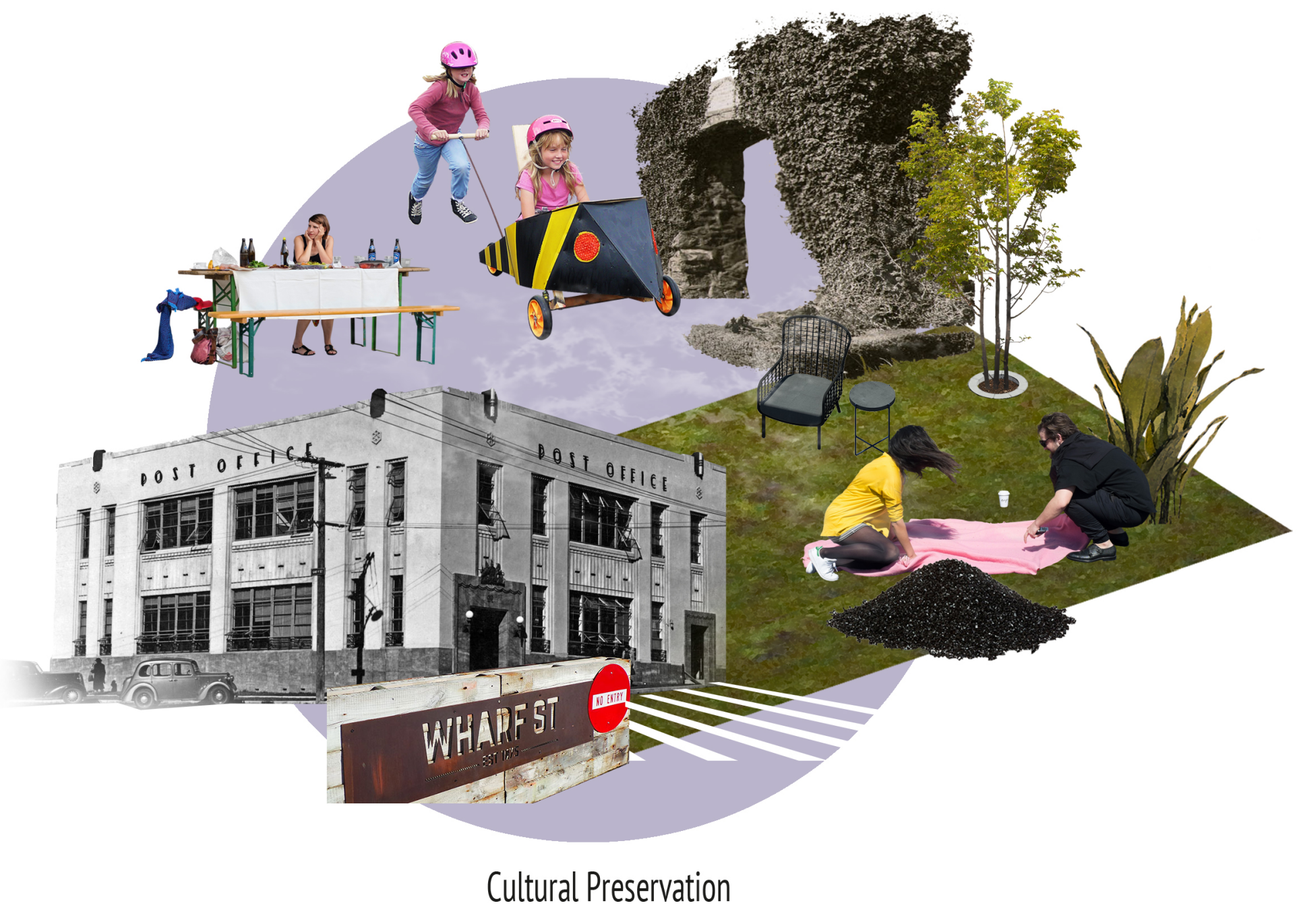

\section{Cultural Preservation}

Te Aranga Māori Design Principles

are founded on intrinsic Māori

cultural values. They have arisen

from a widely held desire by Māori

to enhance their presence, visibility

and participation in the design of

the physical realm.

Cultural Preservation 
Pedestrian-Priority Spaces

\section{Shared Streets}

\section{Neighbourhood Streets}

Avenues and Boulevards

Streets with Special Conditions 1

Streets with Special Conditions 2

Streets with Special Conditions 3

\section{Playing Streets}

A Variety of Street Users

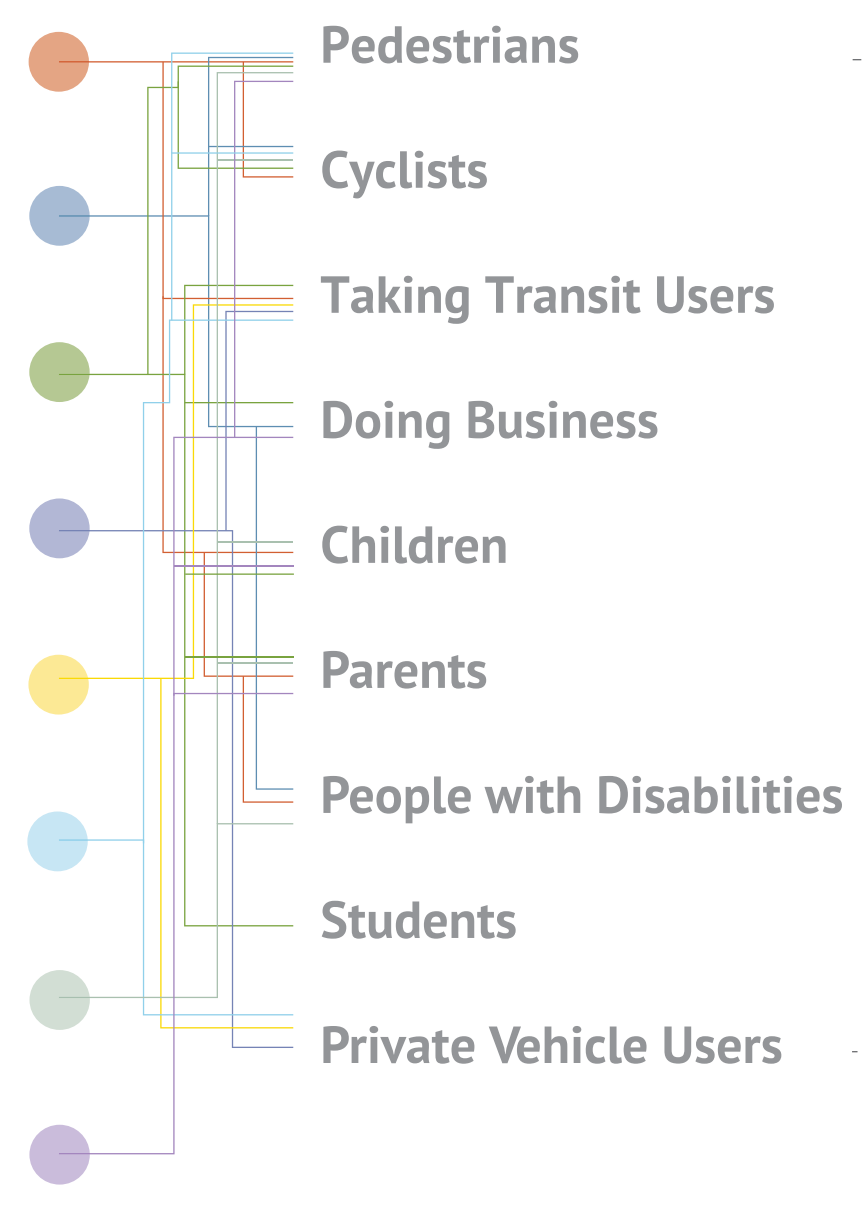

Supported Transport Modes

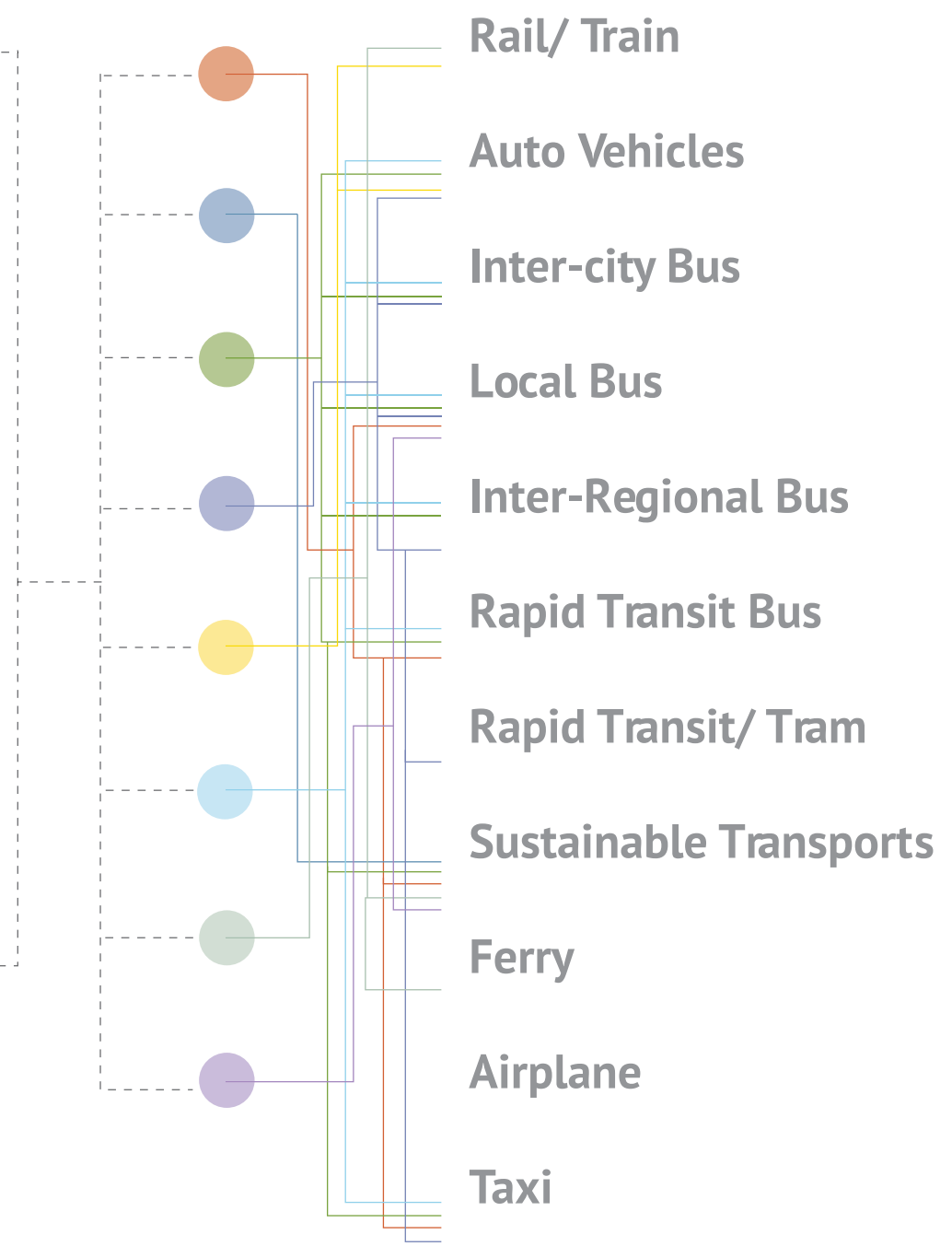


Characteristic Conditions

Pedestrian-Priority Spaces

Shared Streets

Neighbourhood Streets

Avenues and Boulevards

Streets with Special Conditions 1

Streets with Special Conditions 2

Streets with Special Conditions 3

Playing Streets
Safe and Secure

Universal

Connectivity and Legibility

Walking and Cycling Friendly

Accessibility; Places for Every Person

Comfort and Convenient Green

Building Edges Vibrancy

Pleasant; Creative and Inviting

Creating and connecting a Vibrant Sub-region

Flexible and Resilient

Cultural Preservation

\section{Hybrid Street Typology}

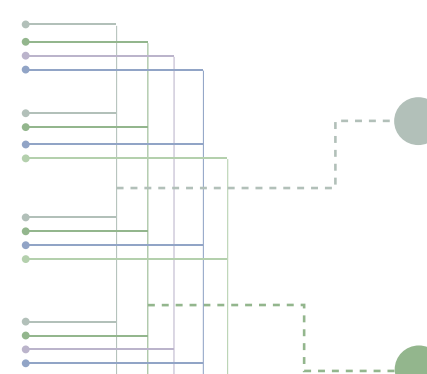

Hybrid Street Type1: Street Focused on Sustainable Transport Modes |

Hybrid Street Type2: Active Street 1

Hybrid Street Type3: Linear Park Street 1

Hybrid Street Type4: Commercial Street $\mid$

Hybrid Street Type5: Interchange Street $\mid$ 


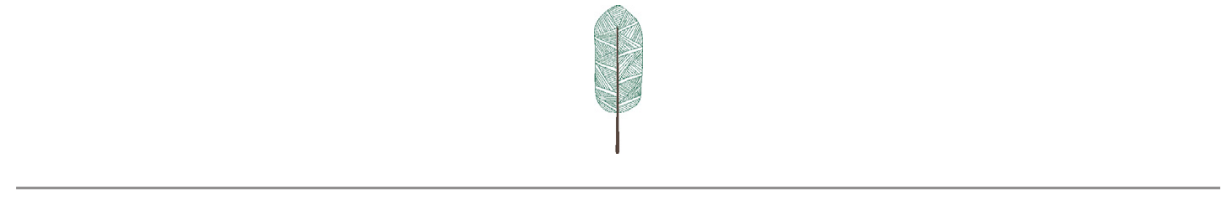

\section{Design Toolkits for 'Hybrid Street'}

This section provides the design toolkits of ' 5 Hybrid Street'.

The five hybrid street typologies take into account the scale, density, diversity of destinations, quality of place as well as the significance of movement by different modes. The investigated hybrid street typology will be applied and tested through the design developing stage. 


\section{Design Toolkits for 'Hybrid Street'}

Hybrid Street Typology 1: Street Focused
on Sustainable Transport Modes
Safe and Secure
Universal
Connectivity and Legibility
Walking and Cycling Friendly
Accessibility; Places for Every Person
Comfort and Convenient
Green
Building Edges Vibrancy
Pleasant; Creative and Inviting
Creating and connecting a Vibrant
Sub-region
Flexible and Resilient
Pedestrian-Priority Spaces
Streets with Special Conditions 2
Streets with Special Conditions 3

\section{Hybrid Street Typology 2: Active Street}

Safe and Secure

Universal

Connectivity and Legibility

Walking and Cycling Friendly

Accessibility; Places for Every Person

Comfort and Convenient

Green

Building Edges Vibrancy

Pleasant; Creative and Inviting

Creating and connecting a Vibrant Sub-region

Flexible and Resilient

Cultural Preservation

Shared Streets

Neighbourhood Streets
Hybrid Street Typology 3: Linear Park

Street

Safe and Secure

Walking and Cycling Friendly

Accessibility; Places for Every Person

Comfort and Convenient

Green

Building Edges Vibrancy

Pleasant; Creative and Inviting

Flexible and Resilient

Cultural Preservation

Streets with Special Conditions 3
Playing Streets

Hybrid Street Typology 4: Commercial

Street

Safe and Secure

Universal

Connectivity and Legibility

Walking and Cycling Friendly

Accessibility; Places for Every Person

Comfort and Convenient

Green

Building Edges Vibrancy

Pleasant; Creative and Inviting

Creating and connecting a Vibrant

Sub-region

Flexible and Resilient

Cultural Preservation

Shared Streets

Avenues and Boulevards
Hybrid Street Typology 5: Transport Interchange Street

Universal

Connectivity and Legibility

Accessibility; Places for Every Person

Creating and connecting a Vibrant Sub-region
Avenues and Boulevards

Streets with Snecial Conditions 1

Streets with Special Conditions 2 


\section{Hybrid Street Typology 1: Street Focused on Sustainable Transport Modes}

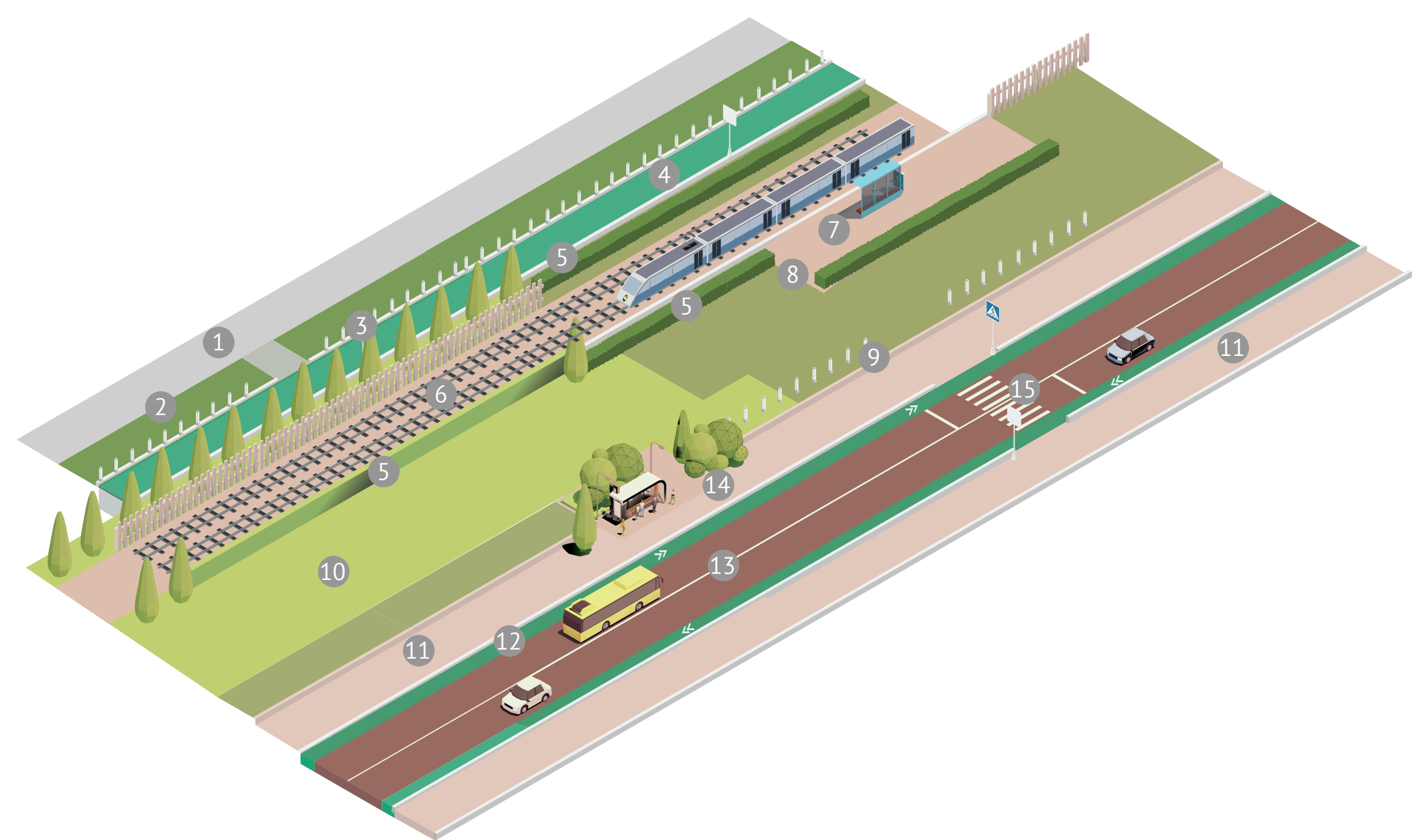

A Variety of Street Users: Pedestrians, Cyclists, Taking Transit Users, Doing Business, Children/ Parents, People with Disabilities and Private Vehicle Users

Supported Transport Modes: Auto

Vehicles, Local Bus, Inter-Regional Bus, Rapid, Tram Sustainable Transports, Taxi

Characteristic Conditions: Safe and Secure, Universal, Connectivity and Legibility, Walking and Cycling Friendly, Accessibility; Places for Every Person, Comfort and Convenient, Green, Building Edges Vibrancy, Pleasant; Creative and Inviting, Creating and connecting a Vibrant Sub-region, Flexible and Resilient

Street Focused on Sustainable Transport Modes

Provide accessible spaces for sustainable transport uses which include walking and cycling, rapid rail and local bus.

\section{(1) Pedestrian Path}

(2) Green Space

(3) Kerbline and Safety Fence

(4) Coloured Bike Lane

5 Barrier Treatments/ Buffers, and Signage

(6) Railway Corridor

7 Railway Platform

8 Entrance Point
(9) Kerbline and Safety Fence

10 Open Space

(11) Pathway

(12) Coloured Bike Lane

13 Road

(14) Bus Stop

(15) Flush Pedestrian Crossing 
A Variety of Street Users: Pedestrians, Cyclists, Taking Transit Users, Doing Business, Children/ Parents, People with Disabilities and Students

Hybrid Street Typology 2: Active Street

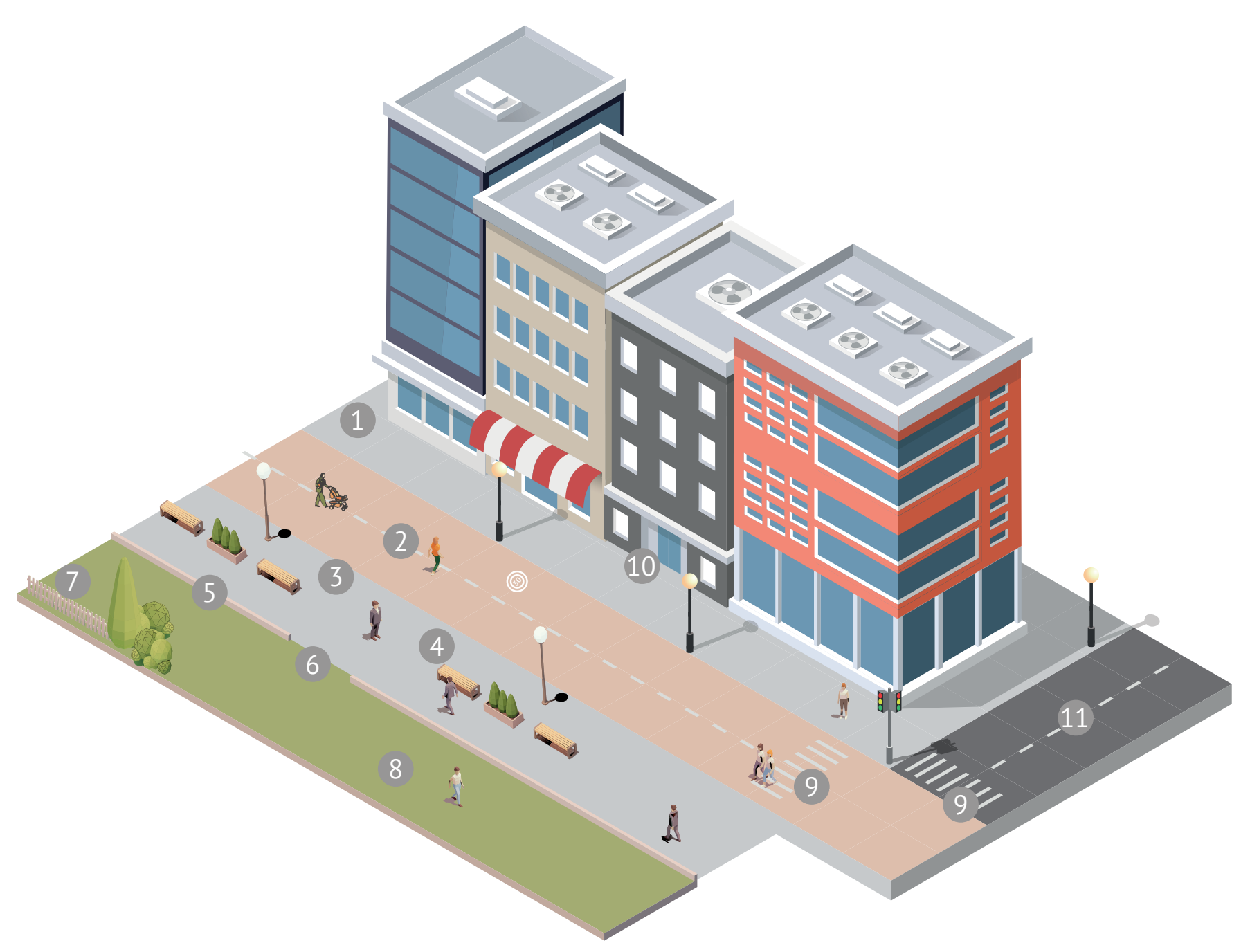

Supported Transport Modes: Auto

Vehicles, Inter-city Bus, Local Bus, Inter-Regional Bus, Rapid Transit

Bus, Sustainable Transports and Taxi

Characteristic Conditions: Safe and Secure, Universal, Connectivity and Legibility, Walking and Cycling Friendly, Accessibility; Places

for Every Person, Comfort and Convenient, Green, Building Edges Vibrancy, Pleasant; Creative and Inviting, Creating and connecting a Vibrant Sub-region, Flexible and Resilient, Cultural Preservation

\section{Active Street}

Low speed shared street which offers active spaces for urban activities such as shopping, outdoor dining and play-alongthe-way.

\author{
(1) Pedestrian Path \\ (2) Low Speed Shared Street \\ (3) Pedestrian Path \\ (4) Street Furnitures \\ (5) Kerbline \\ (6) Entrance Point
}

(7) Fence

8 Green Space

9) Flush Pedestrian Crossing

(10) Building Frontage

(11) Different Type of Road Connection 


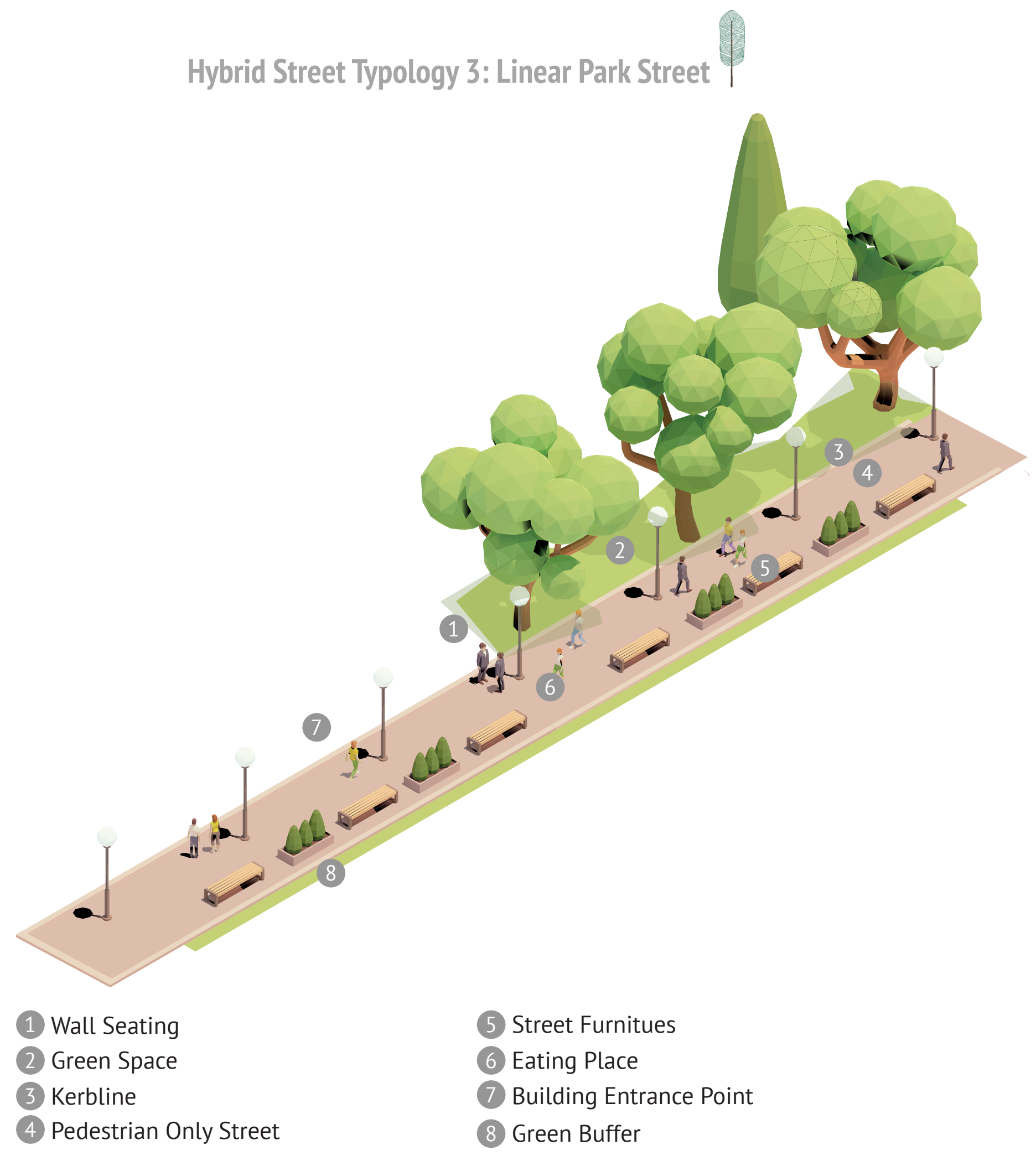

A Variety of Street Users: Pedestrians,

Cyclists, Doing Business, Children/

Parents and People with Disabilities

Supported Transport Modes: Sustainable Transports

Characteristic Conditions: Safe and

Secure, Walking and Cycling

Friendly, Accessibility; Places

for Every Person, Comfort and

Convenient, Green, Building Edges

Vibrancy, Pleasant; Creative and

Inviting, Flexible and Resilient,

\section{Cultural Preservation}

Linear Park Street

Provide a pedestrian-only connection

which creates an safe and accessible

street plaza to offer urban activities such

as walking and cycling, play-along-the-

way, picnic and rest.

$\begin{array}{ll}\text { (1) Wall Seating } & \text { (5) Street Furnitues } \\ \text { 2) Green Space } & 6 \text { Eating Place } \\ \text { (3) Kerbline } & 7 \text { Building Entrance Point } \\ \text { 4) Pedestrian Only Street } & \text { 8 Green Buffer }\end{array}$




\section{Hybrid Street Typology 4: Commercial Street}

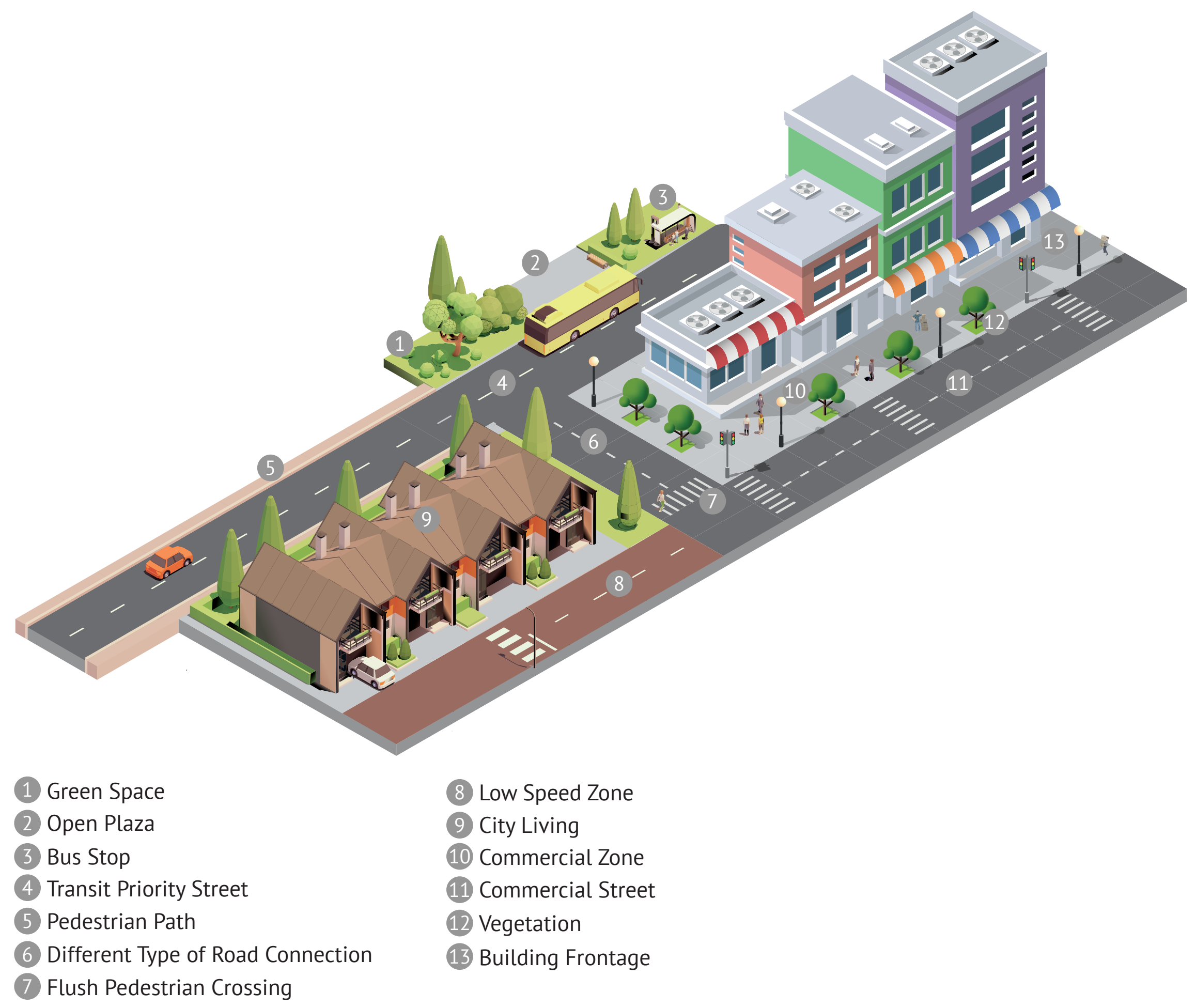

A Variety of Street Users: Pedestrians,

Cyclists, Taking Transit Users,

Doing Business and People with

Disabilities and Private Vehicle

Users

Supported Transport Modes: Auto

Vehicles, Inter-city Bus, Local Bus,

Inter-Regional Bus, Sustainable

Transports and Taxi

Characteristic Conditions: Safe and

Secure, Universal, Connectivity

and Legibility, Walking and Cycling

Friendly, Accessibility; Places

for Every Person, Comfort and

Convenient, Green, Building Edges

Vibrancy, Pleasant; Creative and

Inviting, Creating and connecting

a Vibrant Sub-region, Flexible and

Resilient, Cultural Preservation

\section{Commercial Street}

Provide commercial activities such as

shopping, outdoor dining and play-alongthe-way. The commercial street includes 'Food District Street' and 'City Living Street' 
A Variety of Street Users: Pedestrians,

Cyclists, Taking Transit Users, People

with Disabilities and Private Vehicle

Users

Hybrid Street Typology 5: Transport Interchange Street

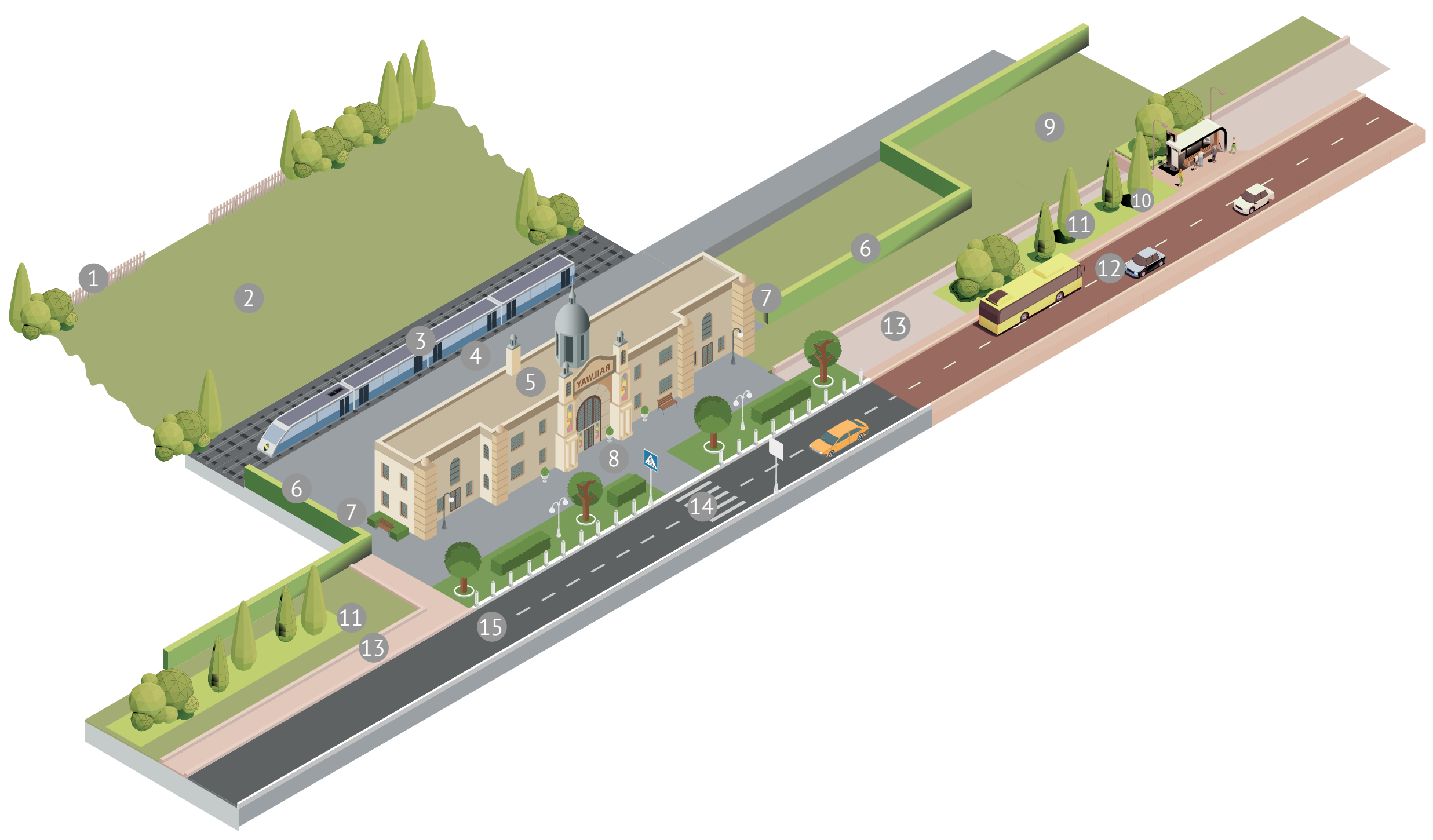

Supported Transport Modes: Rail/ Train, Auto Vehicles, Inter-city Bus, Local

Bus, Inter-Regional Bus and Taxi

Characteristic Conditions: Universal,

Connectivity and Legibility, Creating and connecting a Vibrant Subregion

Railway Station or Transport Interchange Street

Supporting a variety of public transport modes along the transit-friendly designed street. Open spaces are required to offer safety protection boundary between railway platform, station and connected streets.

\begin{tabular}{|c|c|}
\hline atments/ & Space \\
\hline 2 Hills & (10) Bus Stop \\
\hline Railway Corridor & (11) Vegetation \\
\hline Railway Platform & (12) Transit Priority Street \\
\hline ilway Station & (13) Pathway \\
\hline Barrier Treatments/ Buffer & (14) Flush Pedestrian $\mathrm{Cr}$ \\
\hline Entrance Points & (15) Low Speed Zone \\
\hline
\end{tabular}

8 Railway Station Frontage Space 
Hybrid Street Typology 1: Street Focused on Sustainable Transport Modes

\section{STREET USERS}

PEDESTRIANS

CYCLISTS

TAKING TRANSIT USERS
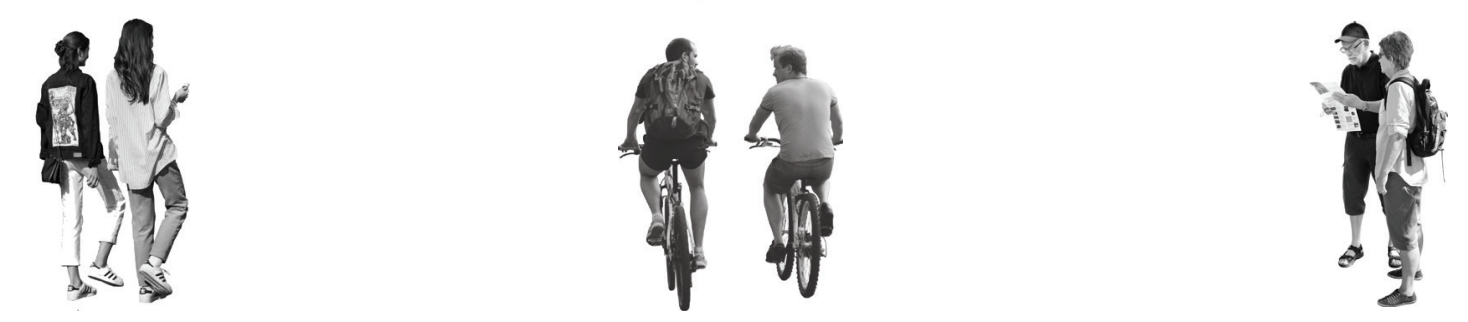

DOING BUSINESS

CHILDREN/ PARENT

PEOPLE WITH DISABILITIES
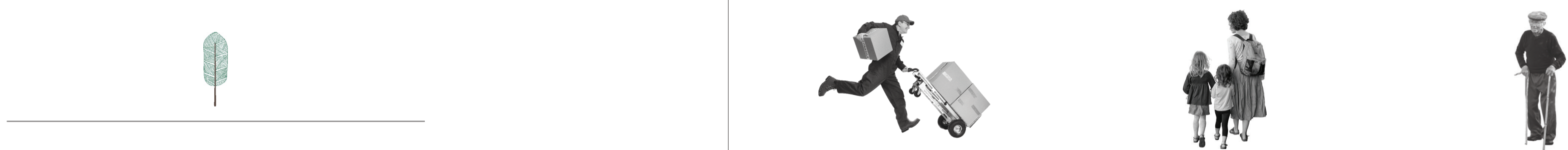

5 Hybrid Street Typologies

PRIVATE VEHICLE USERS

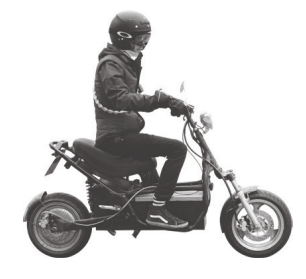

ACTIVITIES

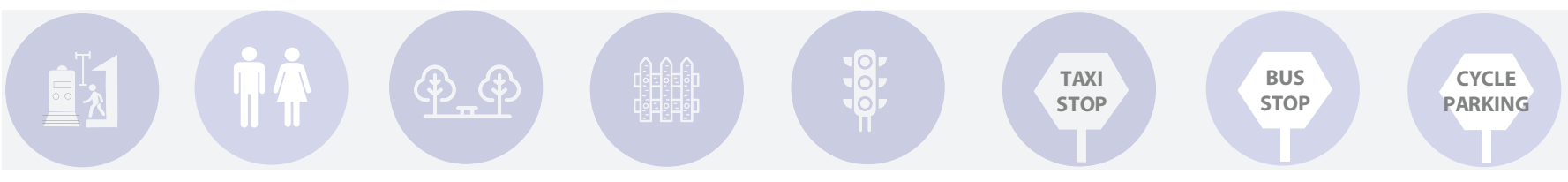

MODE OF TRANSPORT

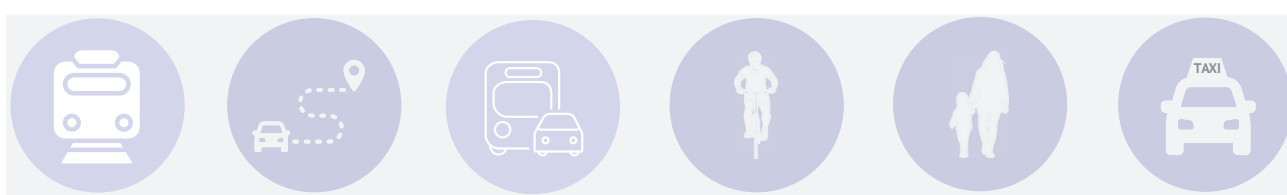


Hybrid Street Typology 2: Active Street

\section{STREET USERS}

PEDESTRIANS

CYCLISTS

TAKING TRANSIT USERS

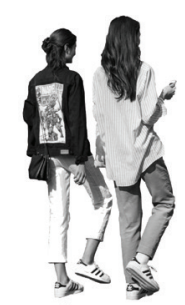

DOING BUSINESS

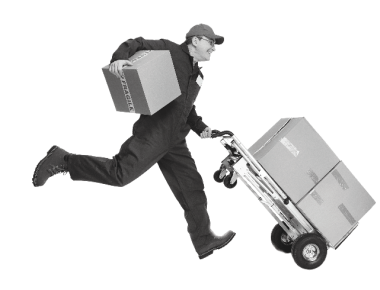

STUDENTS

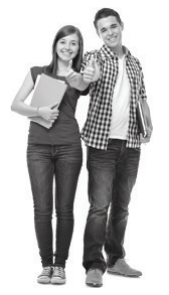

ACTIVITIES

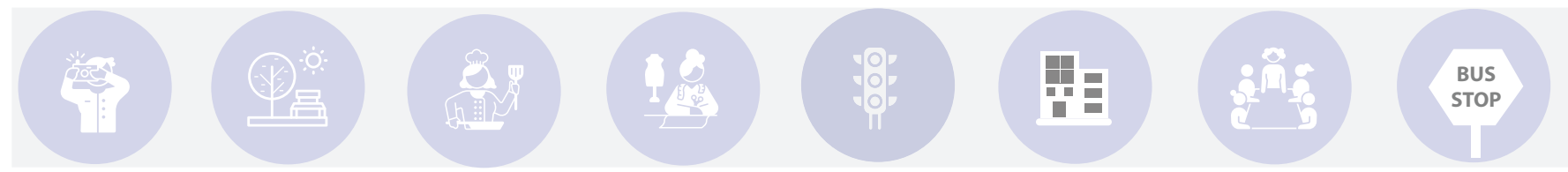

MODE OF TRANSPORT

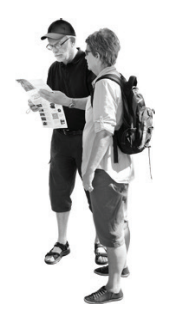

Hybrid Street Typology 3: Linear Park Street

\section{STREET USERS}

PEDESTRIANS

CYCLISTS

DOING BUSINESS

PEOPLE WITH DISABILITIES
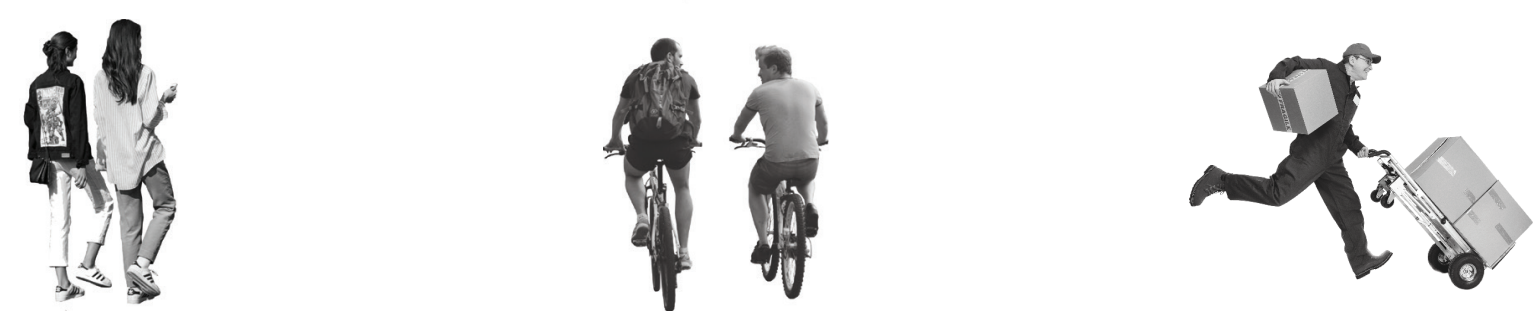

CHILDREN/ PARENT

PEOPLE WITH DISABILITIES
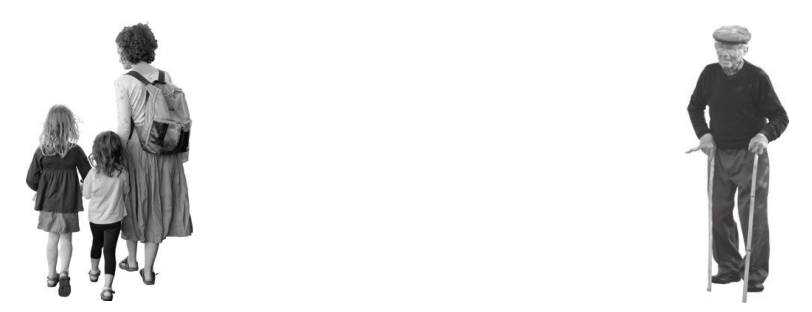

ACTIVITIES

MODE OF TRANSPORT 
Hybrid Street Typology 4: Commercial Street

\section{STREET USERS}

PEDESTRIANS

CYCLISTS

TAKING TRANSIT USERS

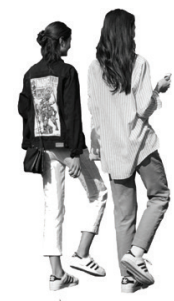

DOING BUSINESS
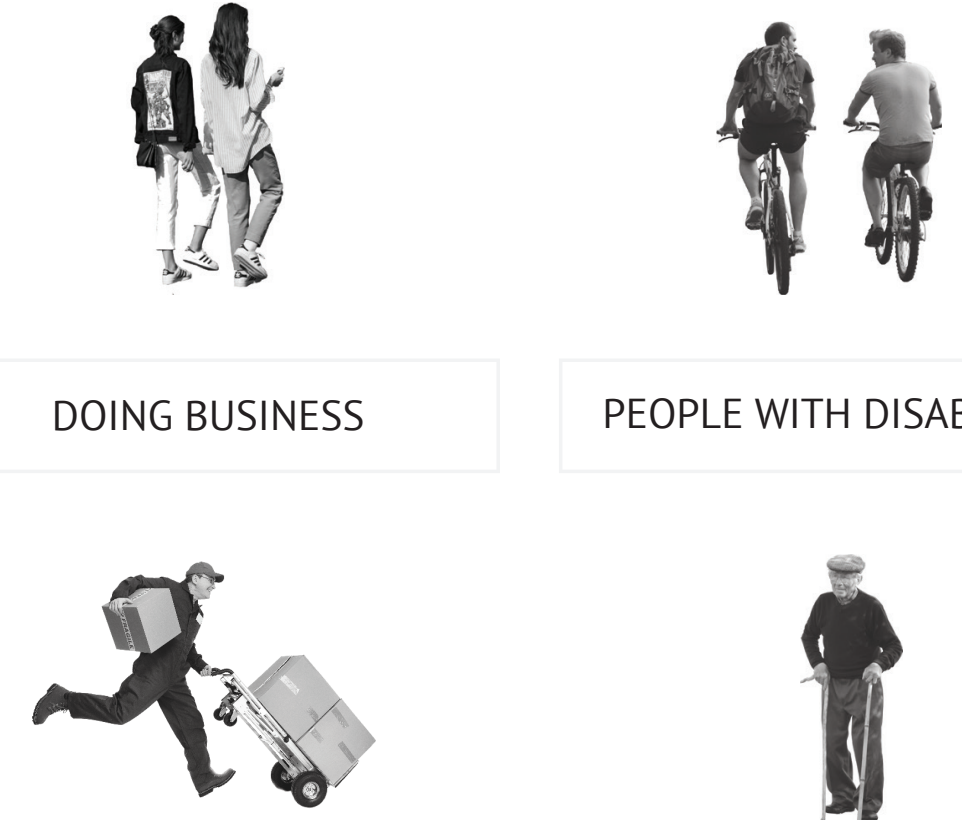

PEOPLE WITH DISABILITIES

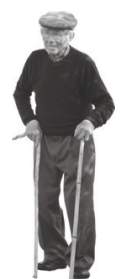

ACTIVITIES

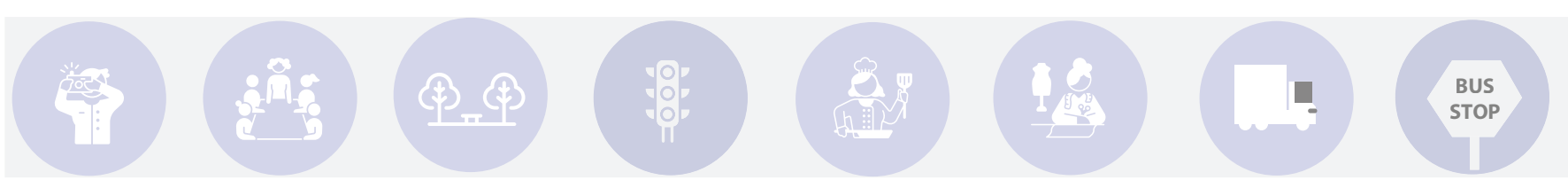

MODE OF TRANSPORT
Hybrid Street Typology 5: Transport Interchange Street

\section{STREET USERS}

\begin{tabular}{|l|l|}
\hline PEDESTRIANS & CYCLISTS \\
\hline
\end{tabular}
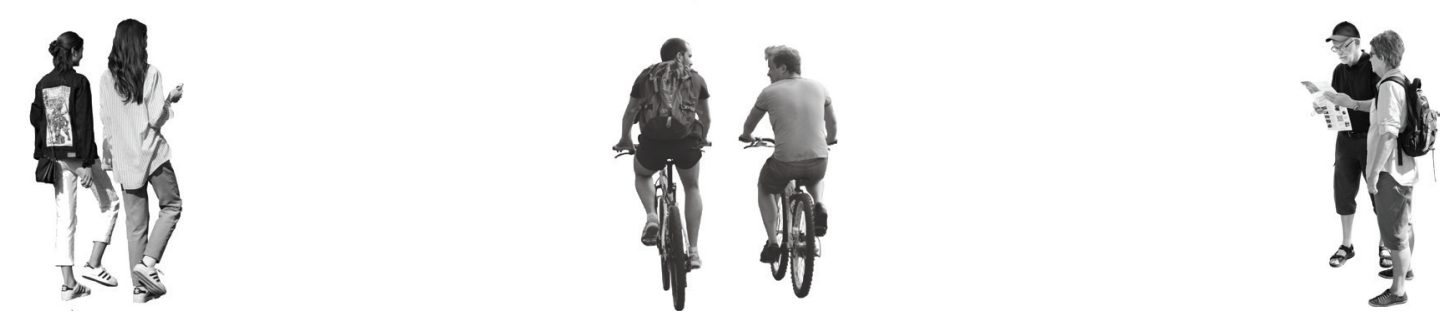

PRIVATE VEHICLE USERS

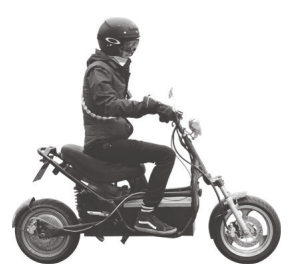

\section{ACTIVITIES}
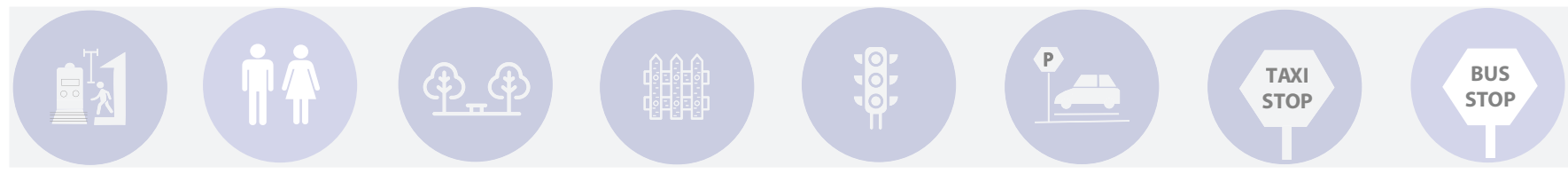

MODE OF TRANSPORT 


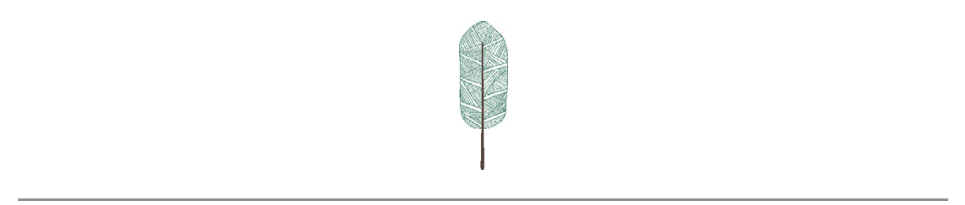

\section{Case Studies}

The case studies explore the concept of landscape architecture with 'Multi-functional Street Design

with variety transport options' as a methodology to articulate the terms of 'Hybrid Street' on the practical worldwide sites. 

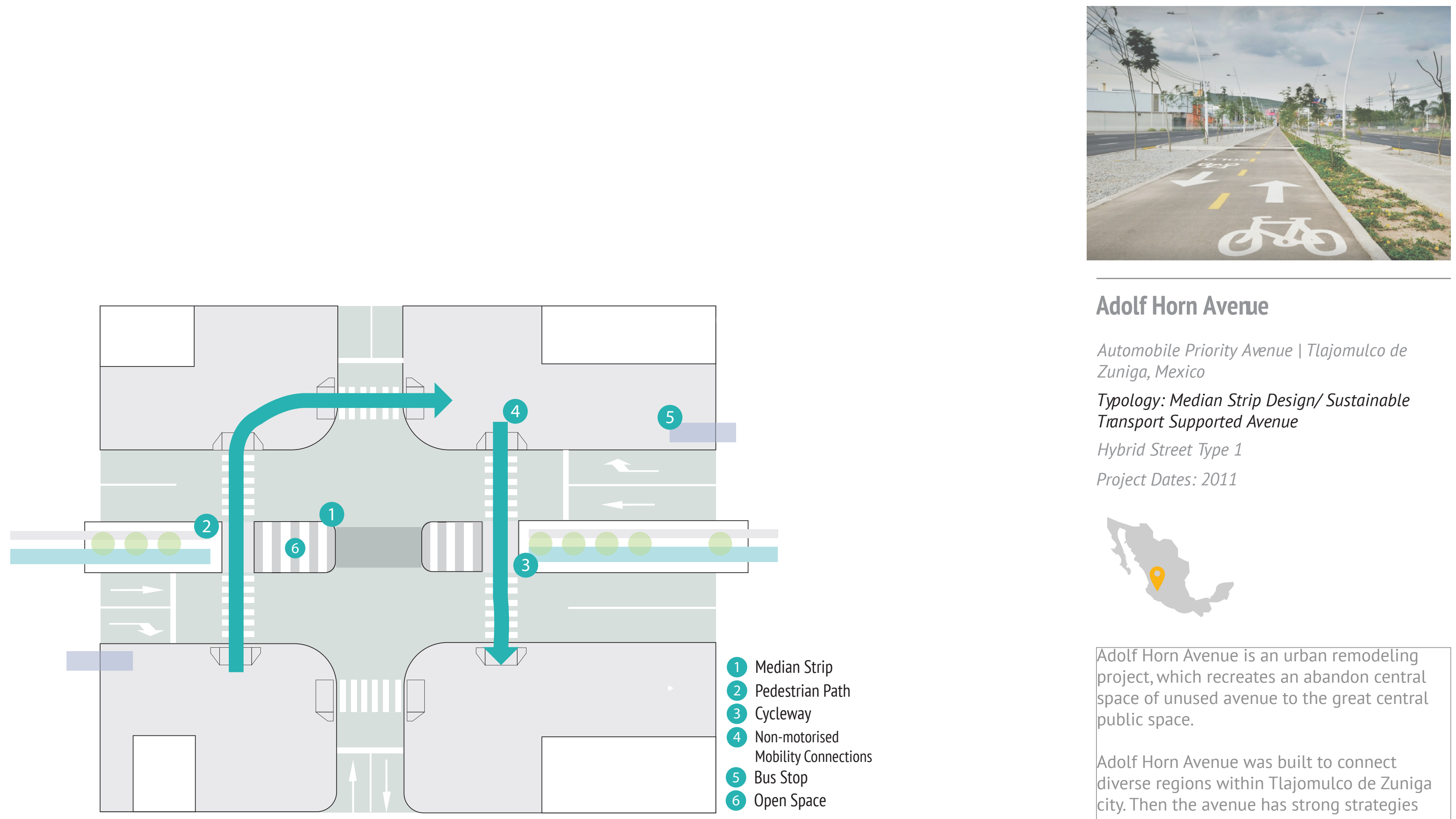

\section{Adolf Horn Avenue}

Automobile Priority Avenue | Tlajomulco de Zuniga, Mexico

Typology: Median Strip Design/ Sustainable

Transport Supported Avenue

Hybrid Street Type 1

Project Dates: 2011

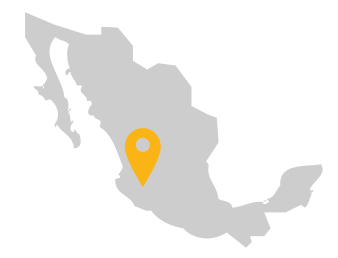

Adolf Horn Avenue is an urban remodeling project, which recreates an abandon central space of unused avenue to the great central public space.

Adolf Horn Avenue was built to connect

diverse regions within Tlajomulco de Zuniga city. Then the avenue has strong strategies to offer a good connection between nonmotorised mobility and public transports.

The median strip provides a 3-kilometre

bicycle lane and pedestrian path giving

priority to public space and green areas, over automobiles.

Adolf Horn Avenue's central trip is the greatest example that shows how the automobile priority avenue can be translated to

'Sustainable Transport Supported Street' 


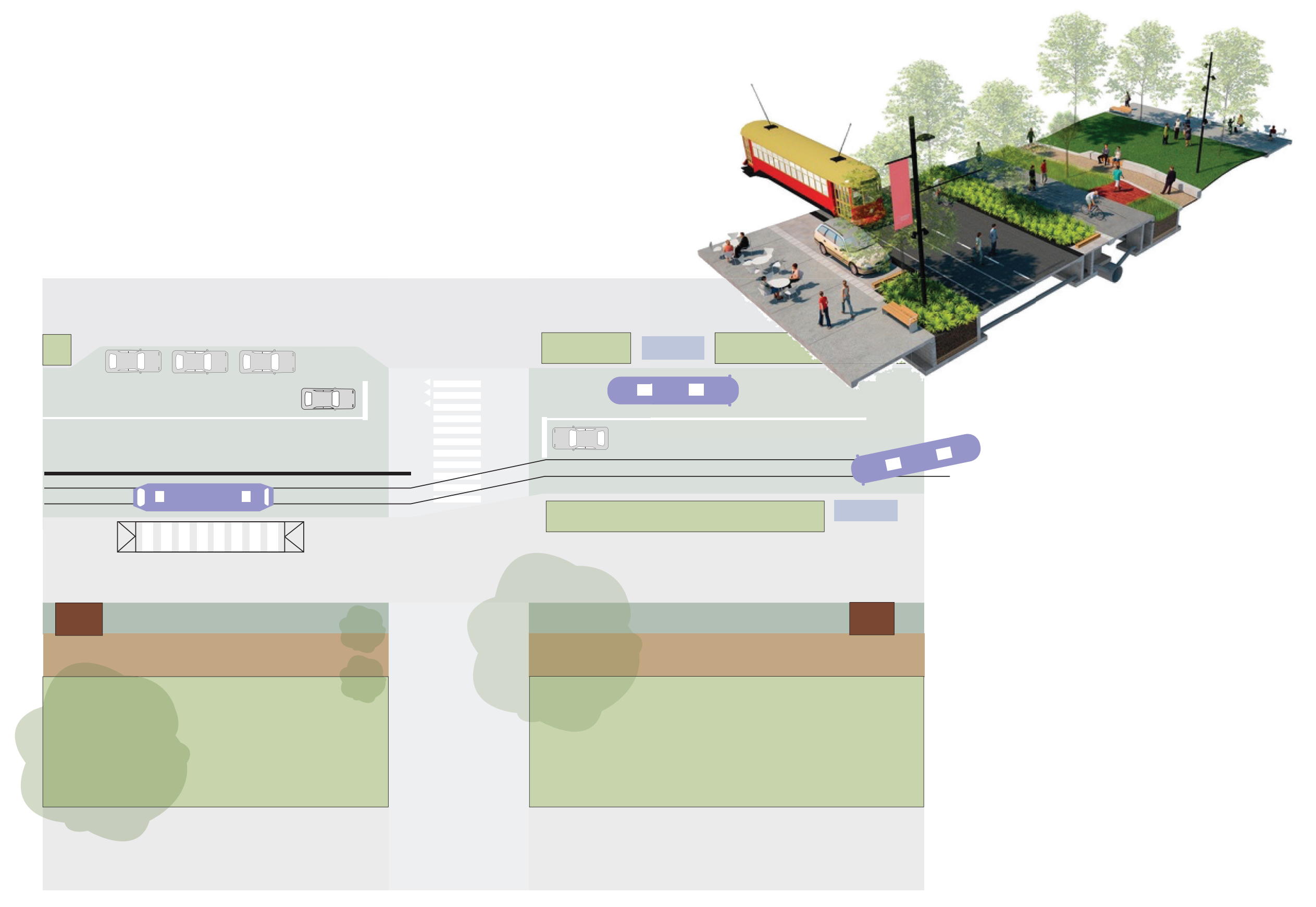

\section{Daldy Street Linear Pak}

Post-Industrial Terrain Vagued Street | Auckland, New Zealand

Typology: Linear Park/ Sustainable Design

Hybrid Street Type 1

Project Dates: 2009-2013

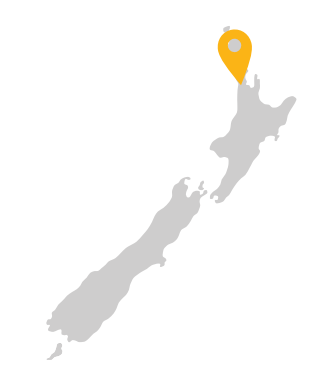

Daldy Street Linear Park is the second of the Wynyard Quarters urban renewal project focused on integrated urban transport system between sustainable infrastructure and movement networks.

Hybrid combination of the street's

functionality and linearity from the edge of Auckland city central area to harbour with rhythmical spatial episodic design elements provides diverse programs to people to revitalise post-industrial area.

This multi-functioned street park supports a variety of sustainable transport users such as cyclists, public transit users and trams; private vehicles are of lowest priority here. The kerbless street offers a four metre wide pedestrian connection with shaped landscape areas and rain gardens connected by small timber bridges between open space areas and streets. 

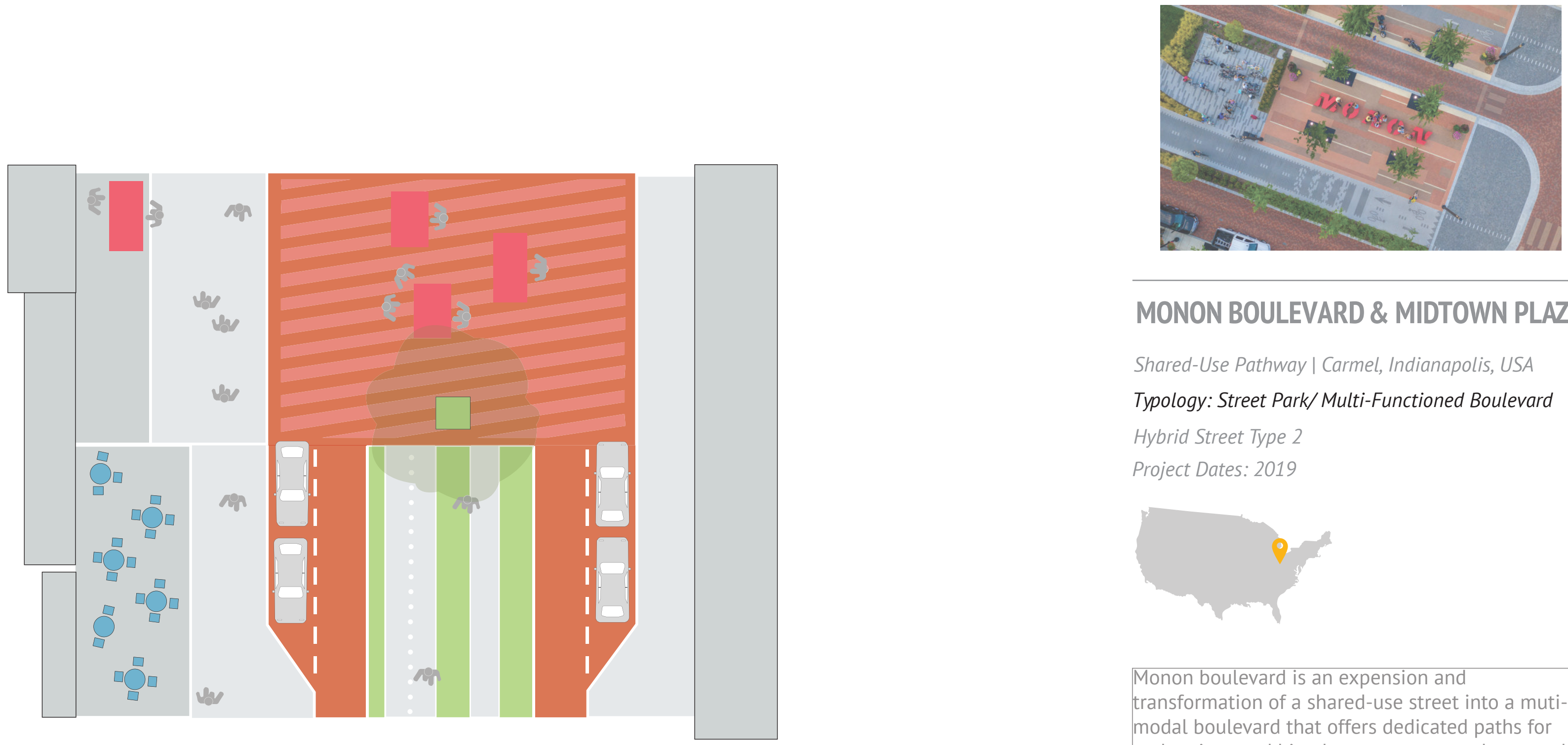

MONON BOULEVARD \& MIDTOWN PLAZA

Shared-Use Pathway | Carmel, Indianapolis, USA

Typology: Street Park/Multi-Functioned Boulevard

Hybrid Street Type 2

Project Dates: 2019

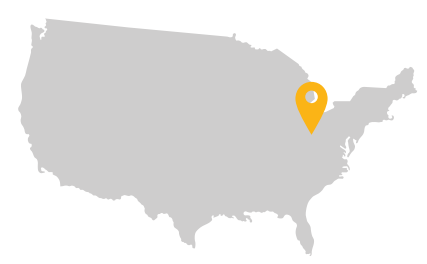

Monon boulevard is an expension and

transformation of a shared-use street into a mutimodal boulevard that offers dedicated paths for pedestrians and bicycles, open spaces, plazas, and activity zones and traffic-calmed roadways.

A range of amenities have been integrated within the expanded corridor to support a rapidly growing of new mixed-use development.

The Monon bolevard is the valuable project which illustrates how a well-designed and highly programmed linear park space can provide an organising spine for innovative placemaking and multimodal connectivity beyond its simple utilitarian function. 


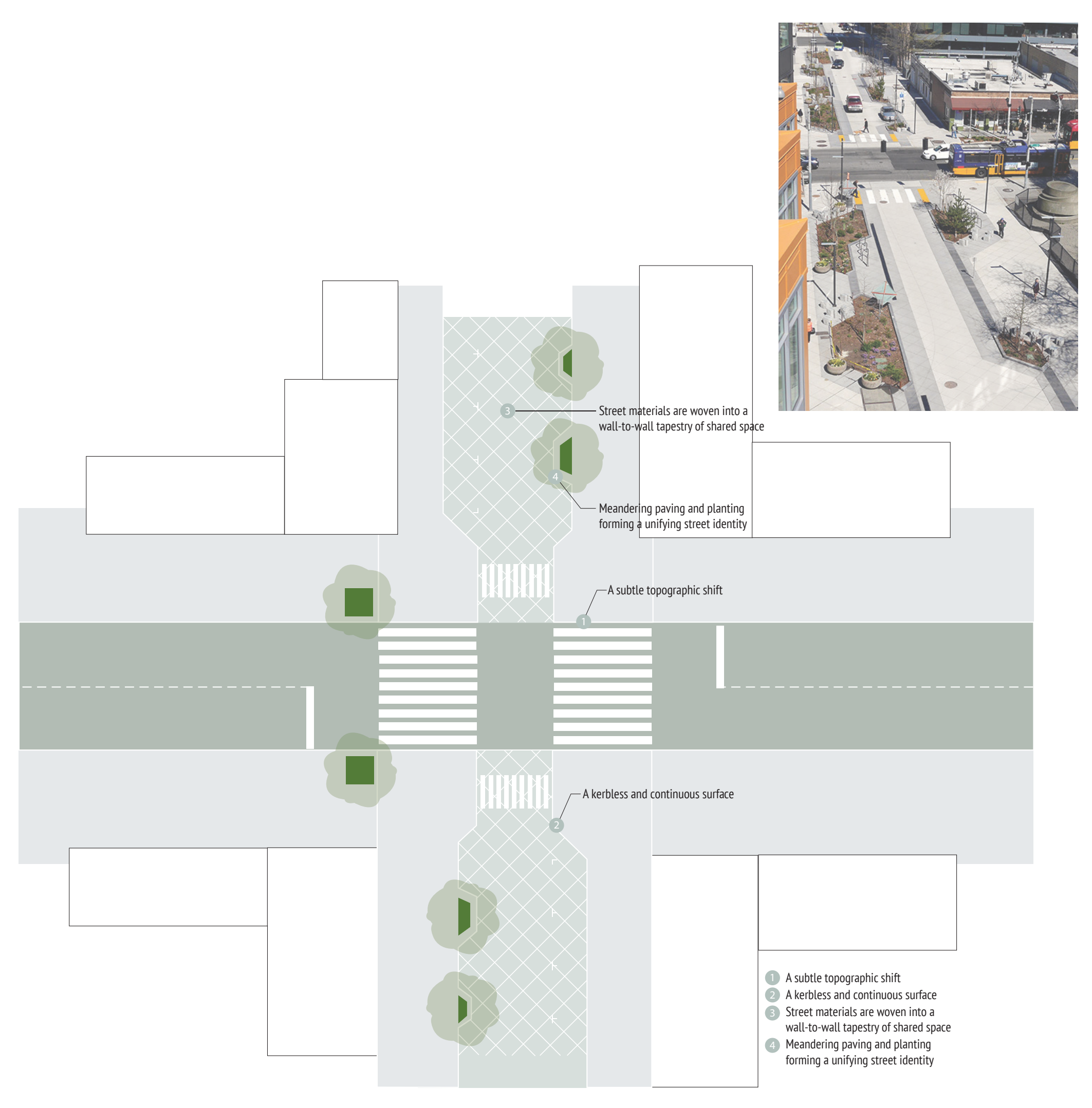

\section{Bell Street Park}

4-Block Sectioned Neighbourhood Street Seattle, WA, USA

Typology: Woonerf; Living Street/Multi-Modal Transport

Hybrid Street Type 3

Project Dates: 2009 - 2014

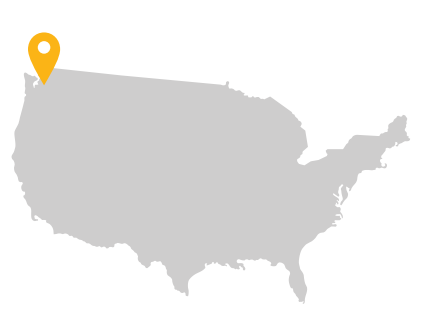

Bell Street Park is a globally proven "Shared Street" where pedestrians, bikes and cars peacefully coexist without any traffic engineering or posted regulations.

The Bell street was a single-purpose rightof-way which had a design characteristic of auto-vehicle priority street. However, supported by a Dutch urban design strategy of 'Woonerf (living street)', the street was finally transformed into a multi-functional open corridor where supports the public right-ofway to every transportation users.

The street provides an outdoor living room to residents of Seattle's high-density neighbourhood while allowing automobiles, public transports and bicycle. 


\section{Geometry}
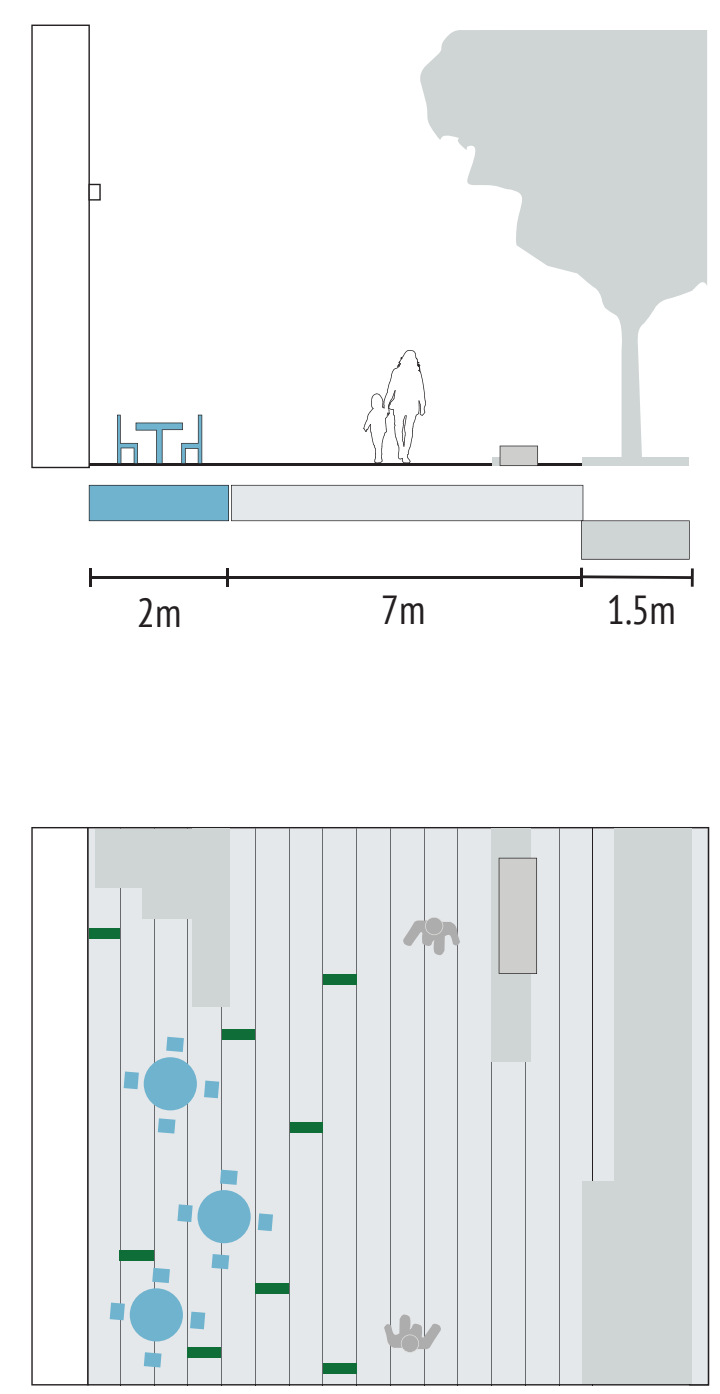

'The Greenway'
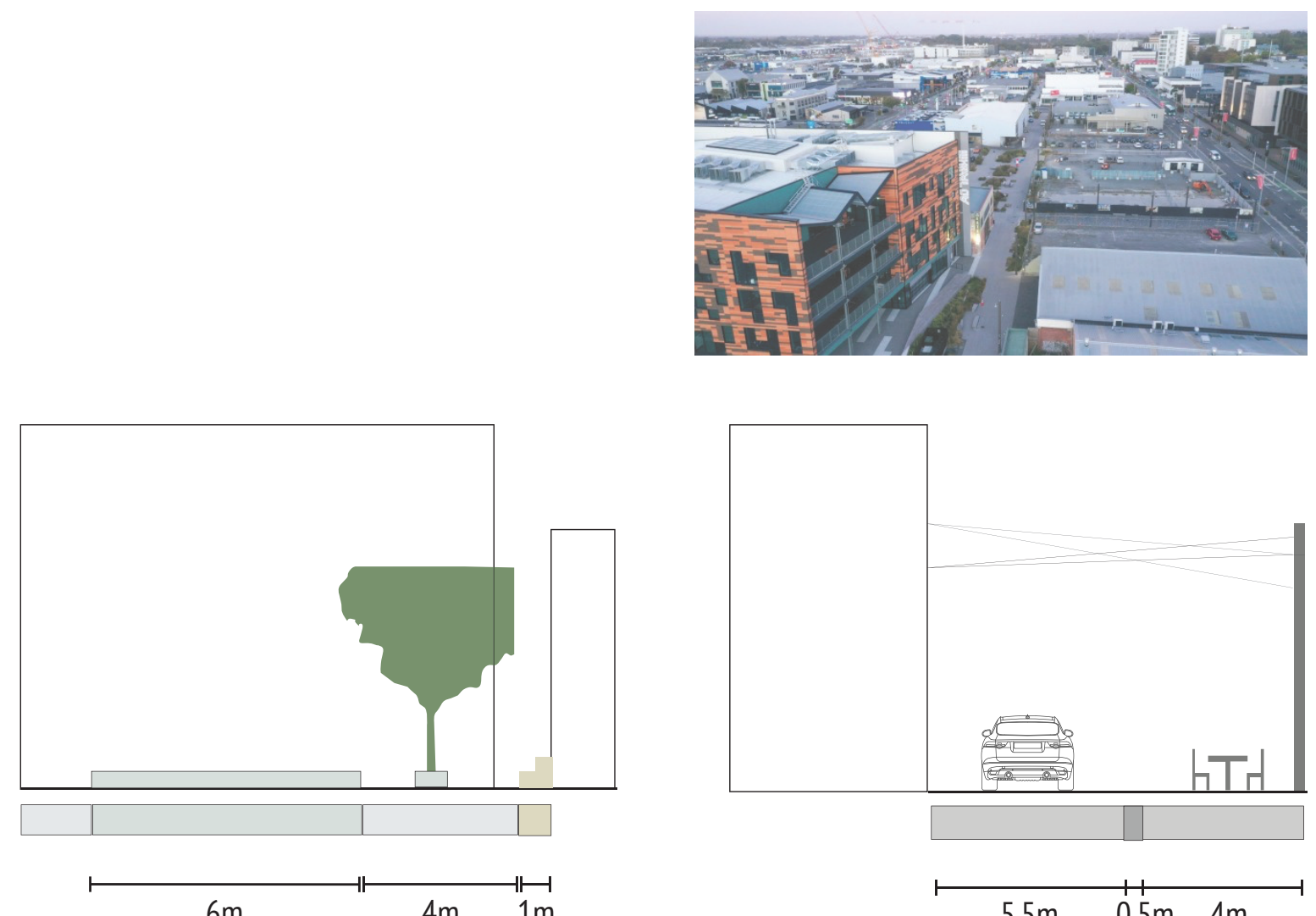

$6 \mathrm{~m}$

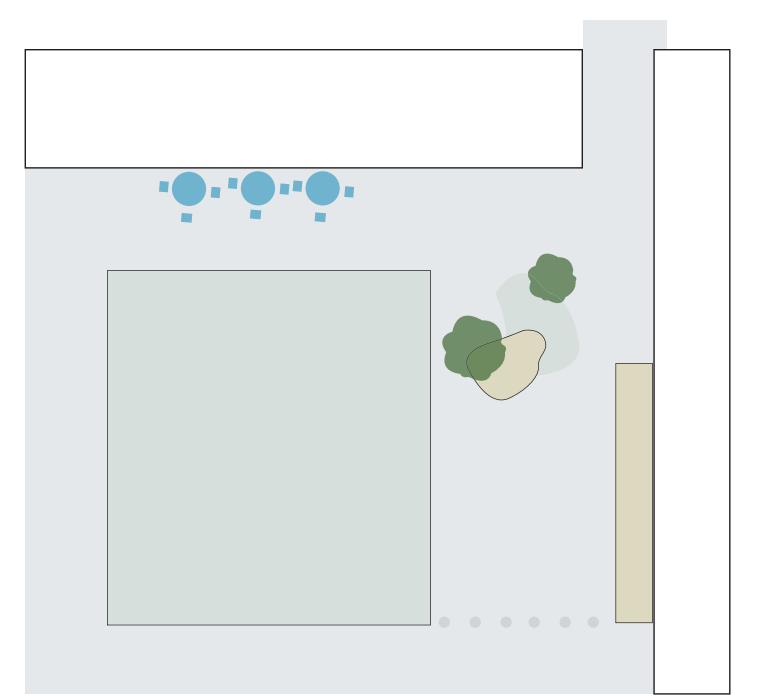

'The Yards' $\begin{array}{lll}5.5 \mathrm{~m} & 0.5 \mathrm{~m} \quad 4 \mathrm{~m}\end{array}$

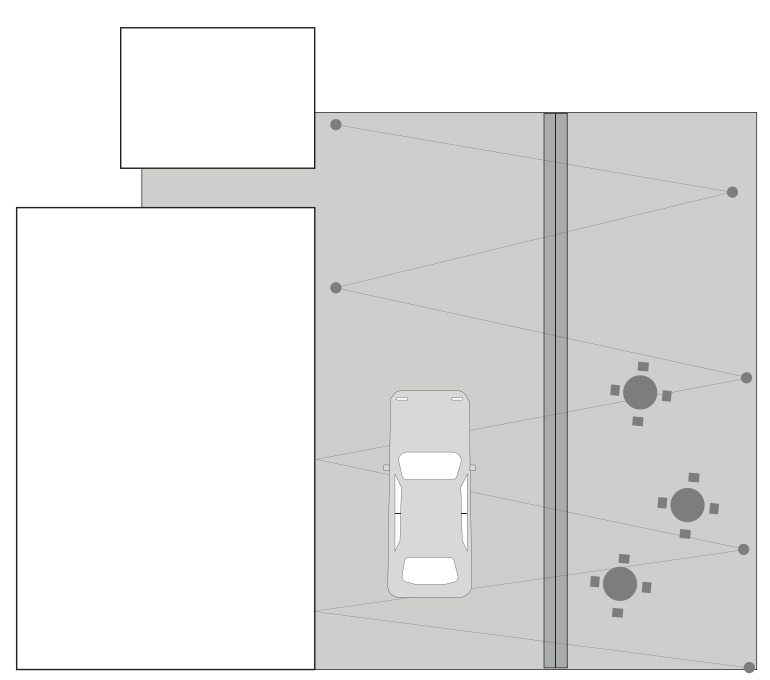

'The Lanes'

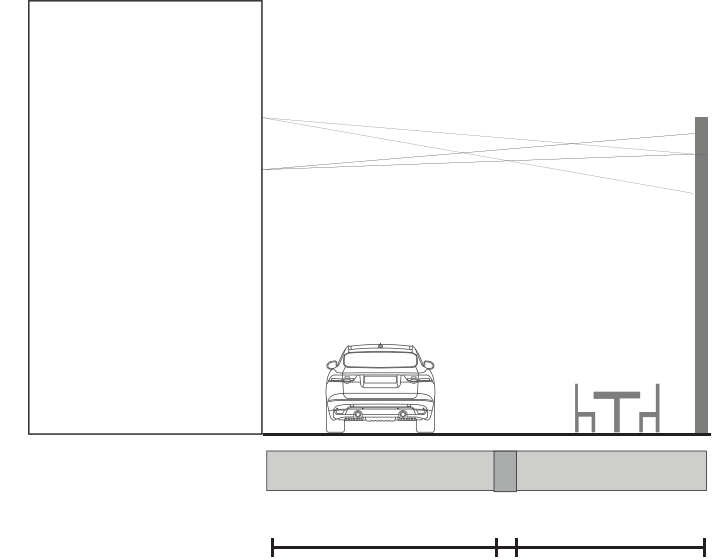

\section{South Frame Public Ream}

7 Former Industrial City Fringe Blocks I

Christchurch, New Zealand

Typology: Pedestrian Priority/Shared Streets

Hybrid Street Type 4

Project Dates: 2015

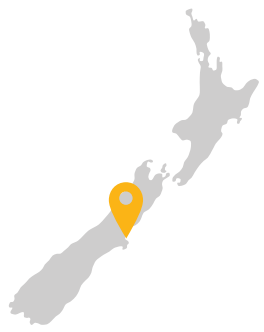

The South Frame Public Realm is a

transformational regeneration project in 7 existing former industrial city fringe blocks in Christchurch.

This 20,000sqm of new public realm offers emerging inovative, educational and entertainment activities to support the cities renewal.

The South Frame network comprises of three key strategic design concepts which are 'The Greenway', 'The Lanes' and 'The Yards'.

The Greenway is an urban garden that identifies Christchurch's ecology, archaeology and social infrastructure into an integrated stroy-telling journey throrugh the corridor.

The Lanes is a new lane-way network which provides north-south pedestrain priority connections to improve the higer accessibility from the east-west South Frame main corridor.

The Yards is a public open space or sqaure of landscape destinations that offers social cultural and economic activities. 


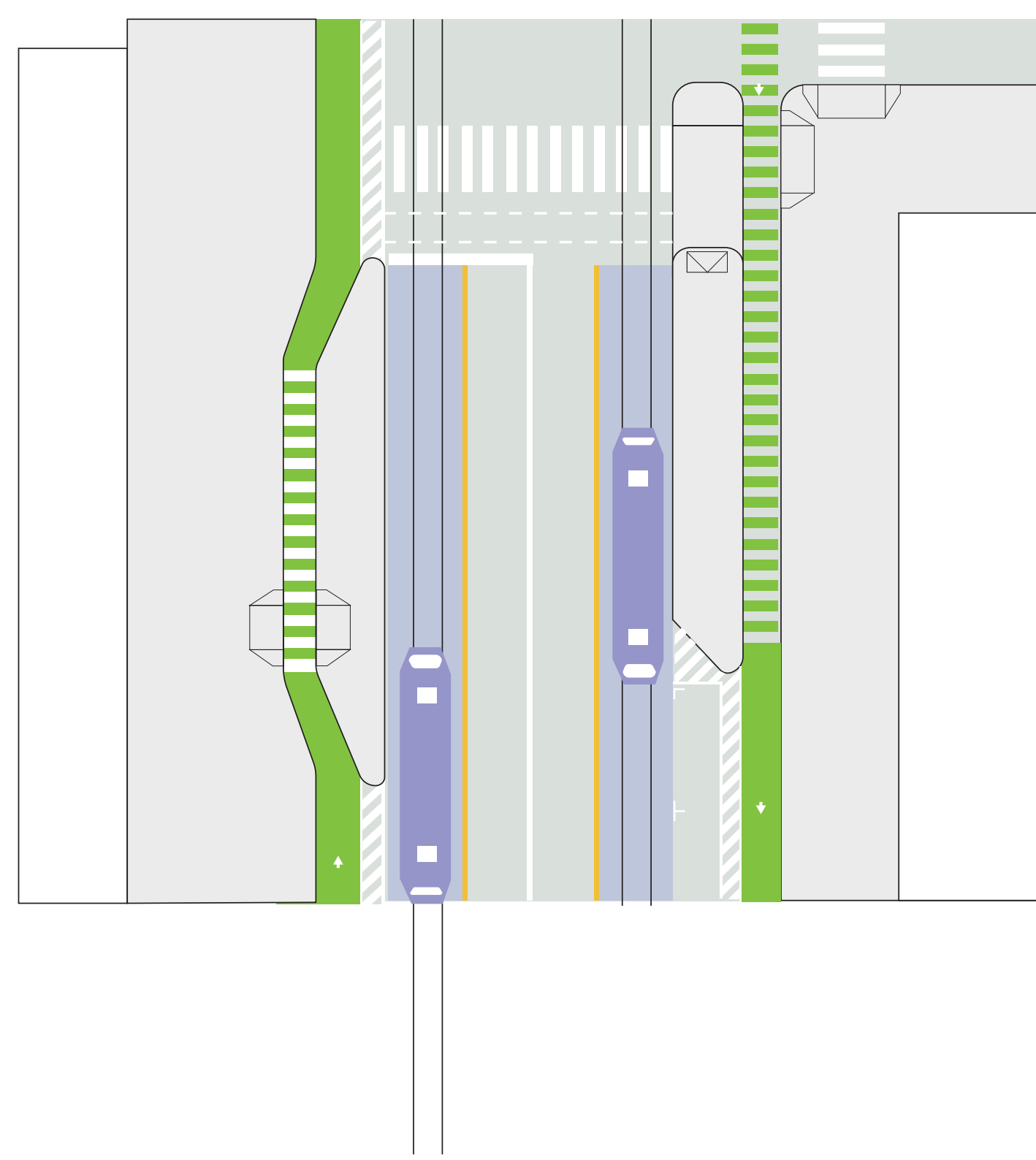

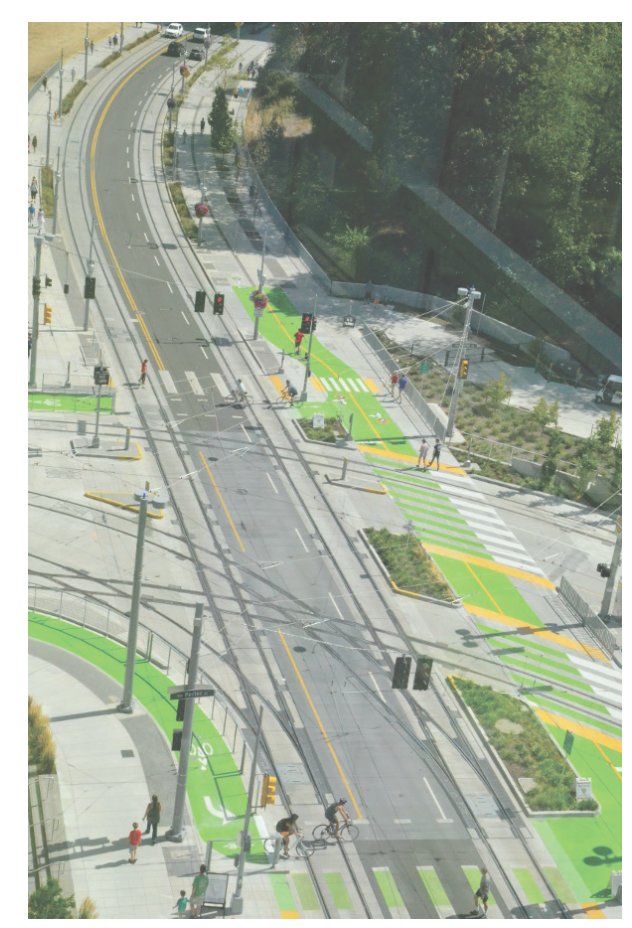

(1) Shared Street

(2) Cycleway Separation

3 Pedestrian Island and Transit Stop
Max Orange Line, Portlandto

Milwaukie Streets

MAX ORANGE LINE Corridor | Oregon, USA

Typology: Sustainable Corridor/Multi-Modal Paths

Hybrid Street Type 5

Project Dates: 2015

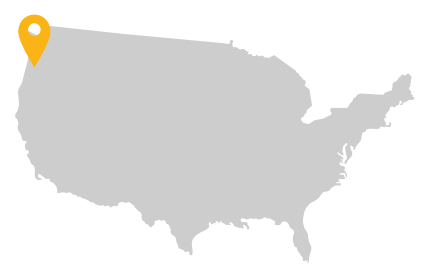

Portland to Milwaukie Streets aligned with the $11.7 \mathrm{~km}$ MAX Orange Line is vital strategy for growth management and

liveable communities.

Inter-related street system with light rail, streetcar, bus, pavements and multi-modal paths provides a safe and efficient access to stations for all types of different transit users.

It is a multi-modal network of vibrant, healthy, community places that help

neighbourhoods maintain liveability while supporting the future growth of the region 


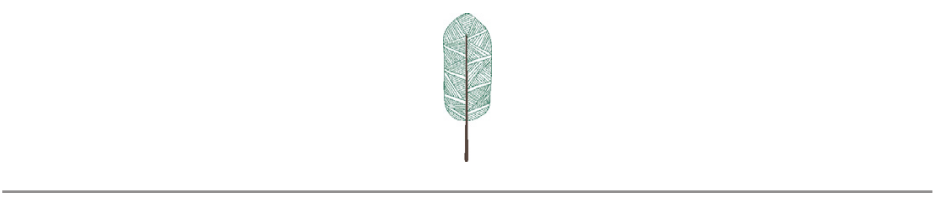

08. Design Opportunities 


\section{City Centre Spatial Framework} Strategies

The City Centre Spatial Framework identifies twelve Key Moves to strengthen the city centre. Each street offers the potential to deliver at least six design strategies.

Design framework advocates a pedestrian and transit-friendly streetscape connecting the rail lines to encourage street

activities on the urban and suburban fabric, and also supports

other types of sustainable transport modes. A hybrid term of

street typology articulates a vision and strategic approach

with design criteria to advance key objectives.

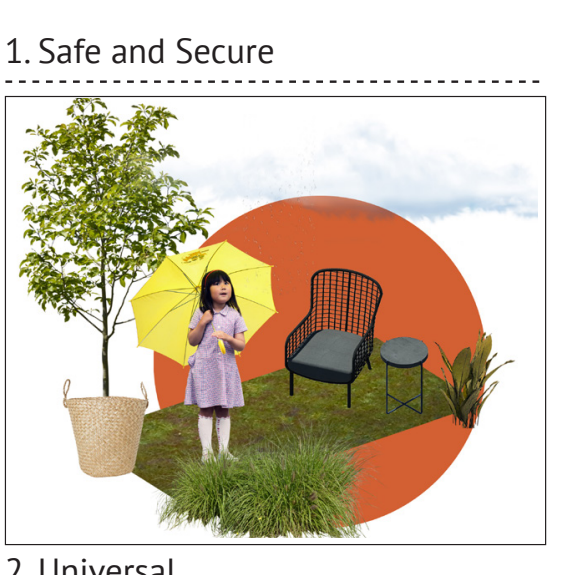

2. Universal
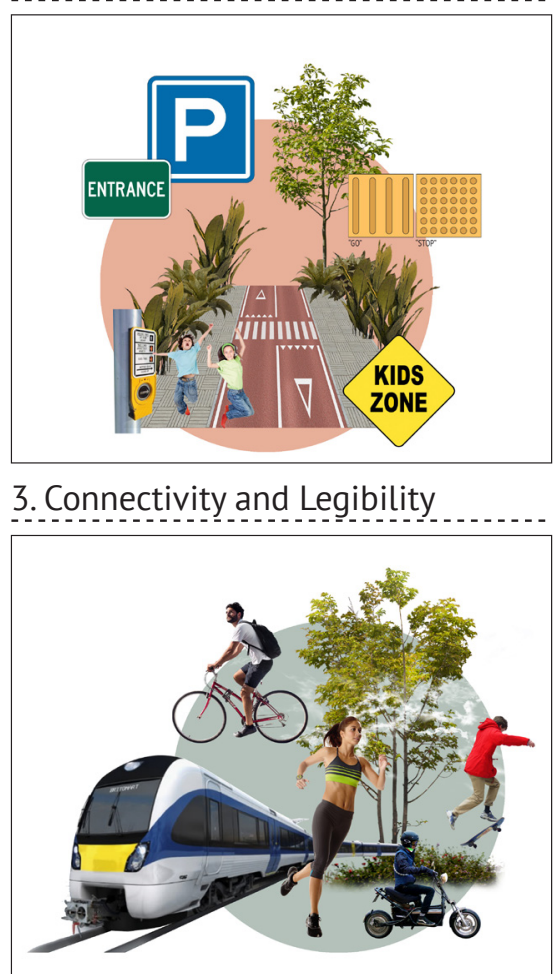

4. Walking and Cycling Friendly

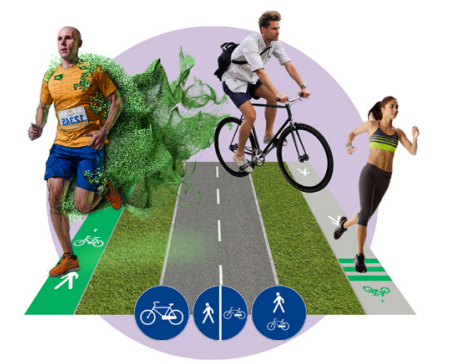

5. Accessibility, Places for Every

Person

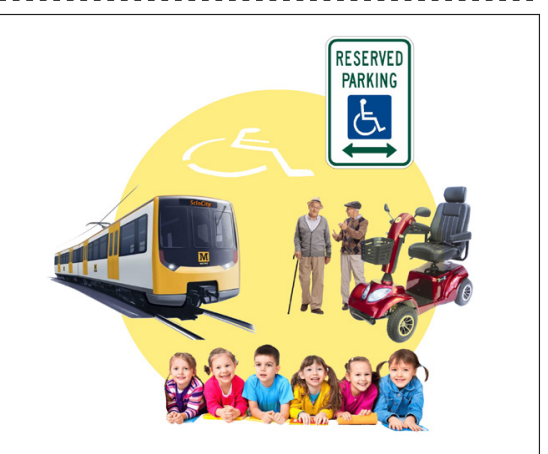

6. Comfort and Convenient

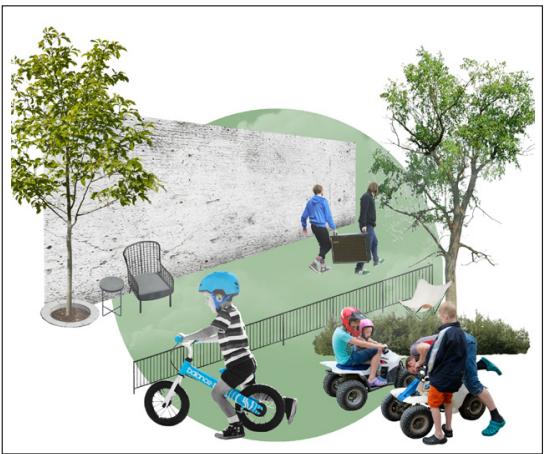

7. Green

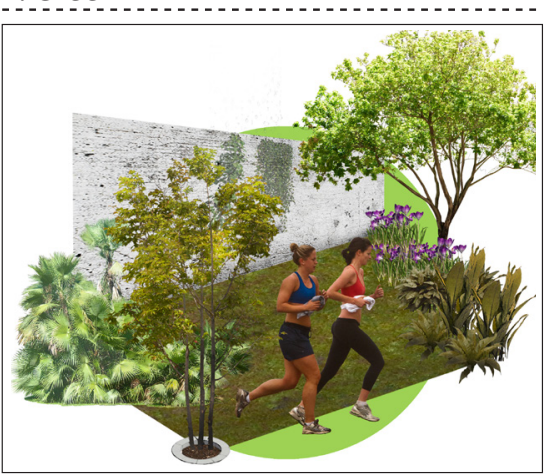

8. Building Edge Vibrancy

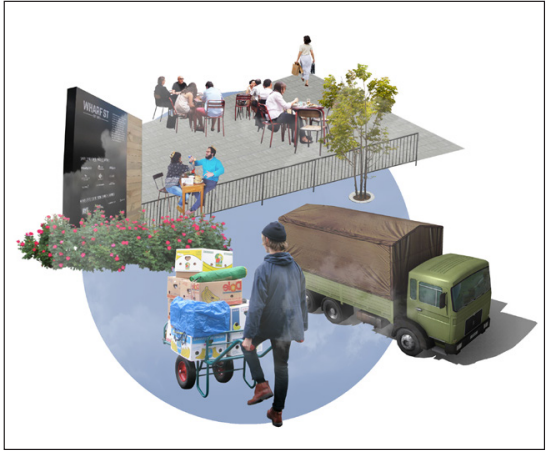

9.Pleasant, Creative and Inviting

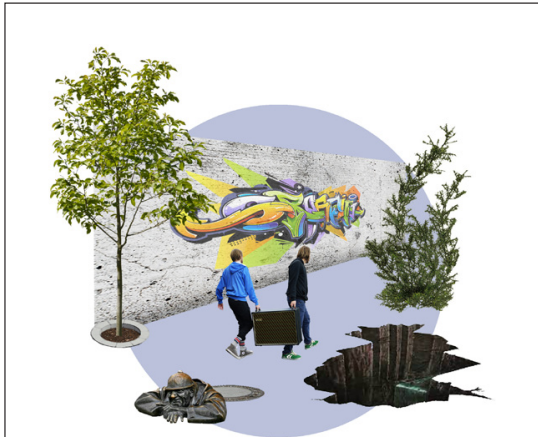

10. Creating and Connecting A Vibrant Sub-Region

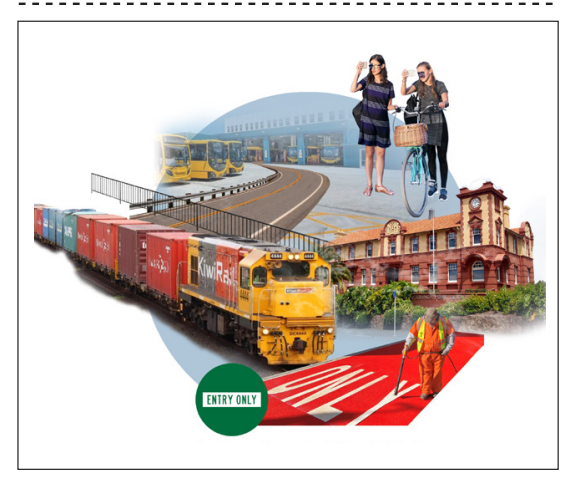

11. Flexible and Resilient

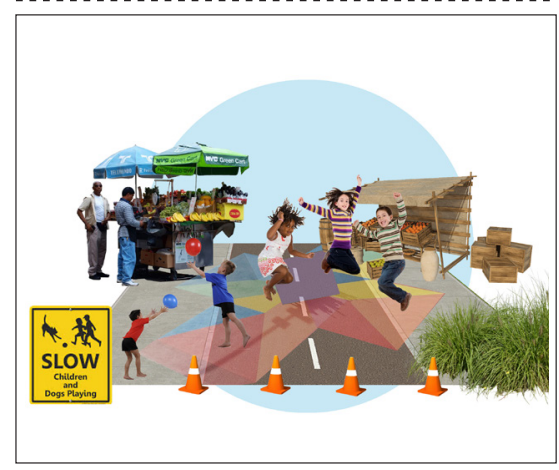

12. Cultural Preservation

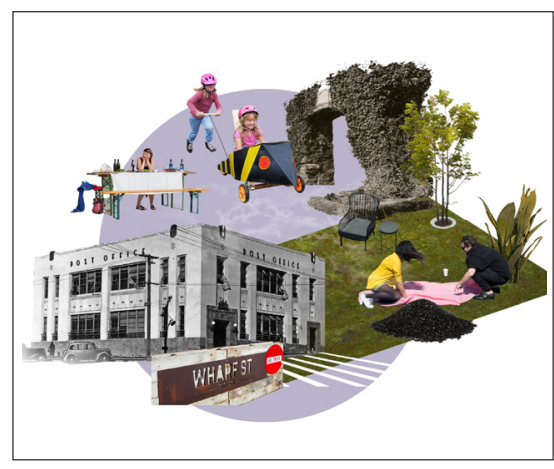




\section{Street Design In Context}

\section{Street Focused on Sustainable} Transport Modes

Provide accessible spaces for

sustainable transport uses which

include walking and cycling, rapid

rail and local bus.

\section{Active Street}

Low speed shared street which

offers active spaces for urban

activities such as shopping,

outdoor dining and

play-along-the-way.

\section{Linear Park Street}

Provide a pedestrian-only

connection which creates an safe

and accessible street plaza to offe

urban activities such as walking

and cycling, play-along-the-way,

picnic and rest.
Through previous stage, five different types of 'Hybrid Street' have been investigated from a research question of 'How the mono-functional street can be translated to a hybrid space

that supports a variety of the sustainable transport modes to improve the accessibility between the neighbourhoods, cities, sub-regions and region.

FIVE DIFFERENT TYPES OF HYBRID STREET IDENTIFIED THROUGH THE PREVIOUS INVESTIGATION ARE.

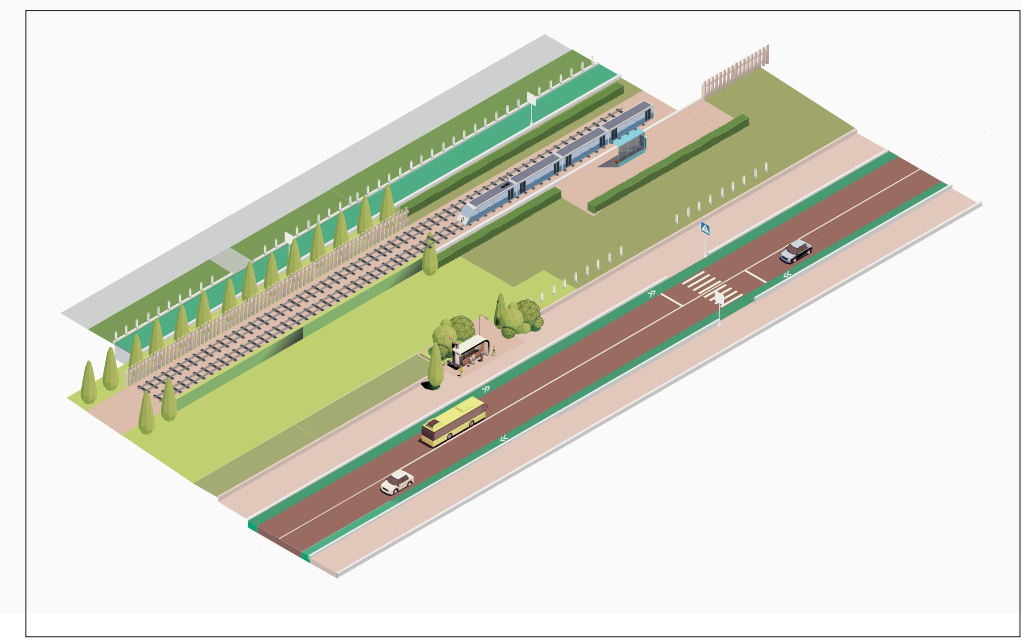

\section{Commercial Street}

Provide commercial activities such

as shopping, outdoor dining and

play-along-the-way. The

commercial street includes 'Food

District Street' and 'City Living

Stree

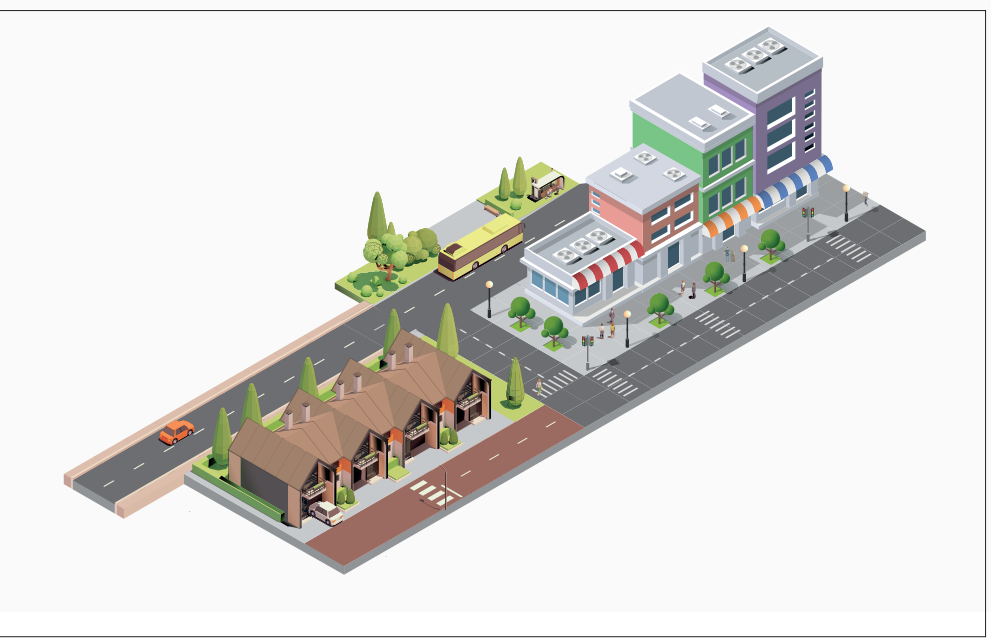

Railway Station or Transport Interchange Street

Supporting a variety of public

transport modes along the

transit-friendly designed street

Open spaces are required to offer

safety protection boundary

between railway platform, station

and connected streets.

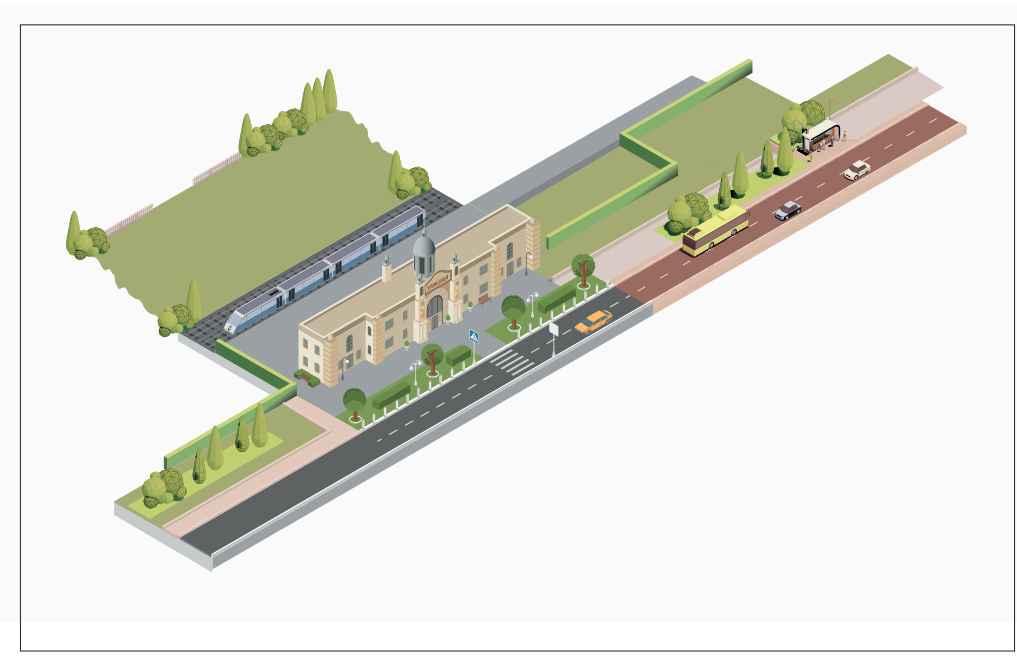

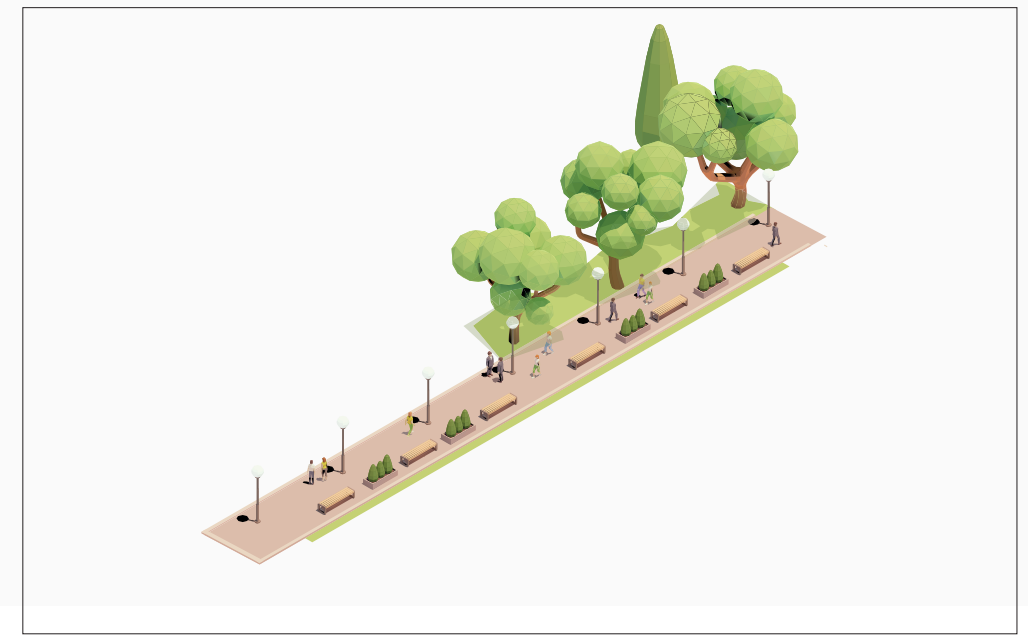




\section{Heavy Rail}

Proposed Passenger Train Service

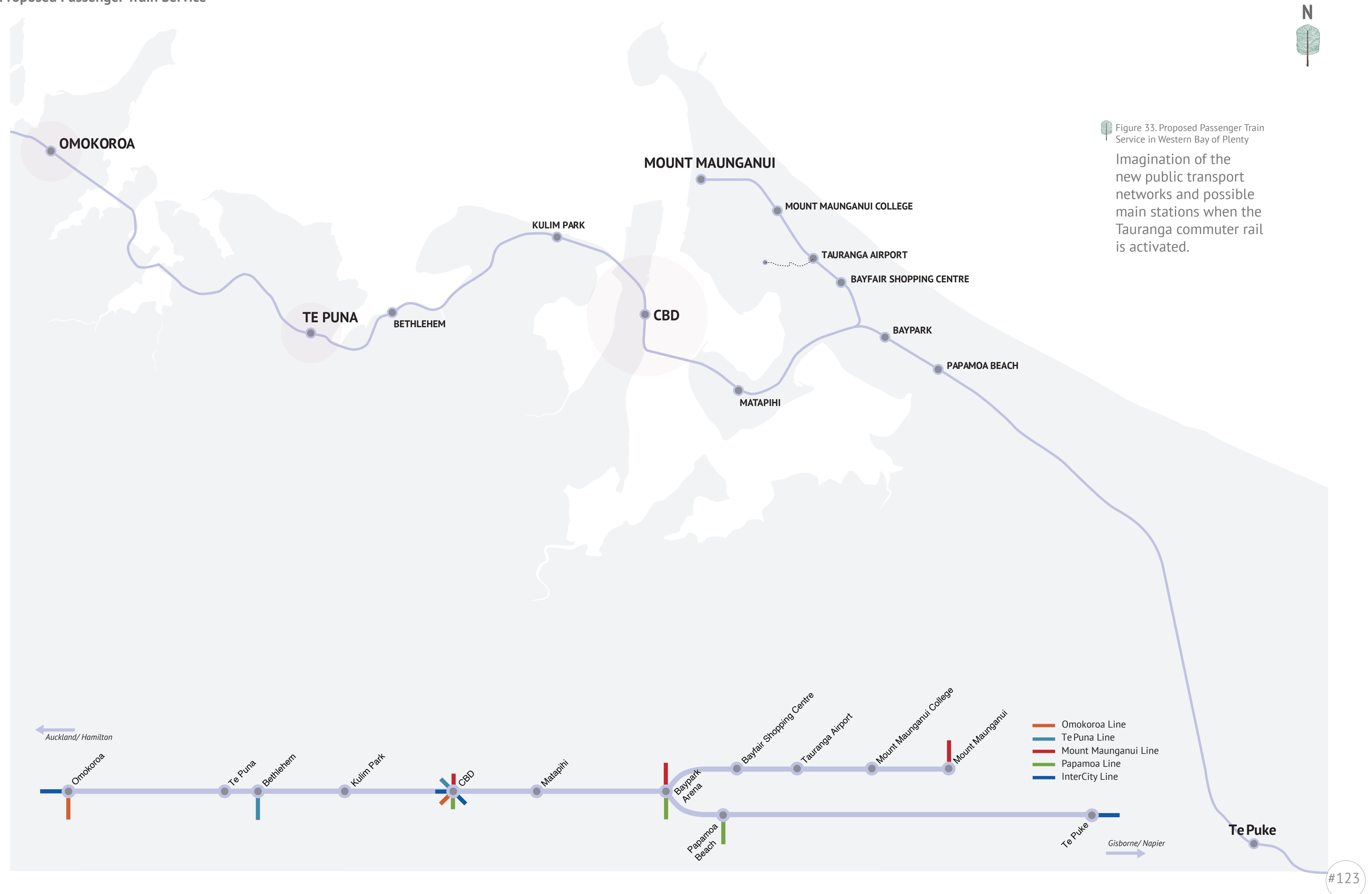




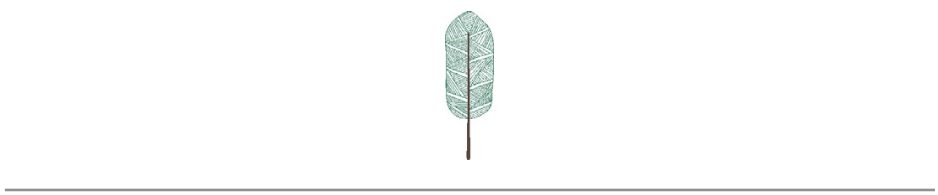

\subsection{Sites For Design}

The investigated hybrid street typology will be applied and tested on 11 different sites in Tauranga city business district areas (CBD) where have significantly different spatial characteristics to see how it advances key objectives and achieves the research visions. 


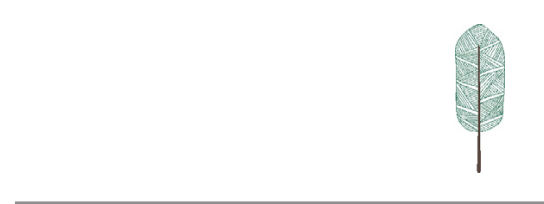

Site Analysis

\#125 


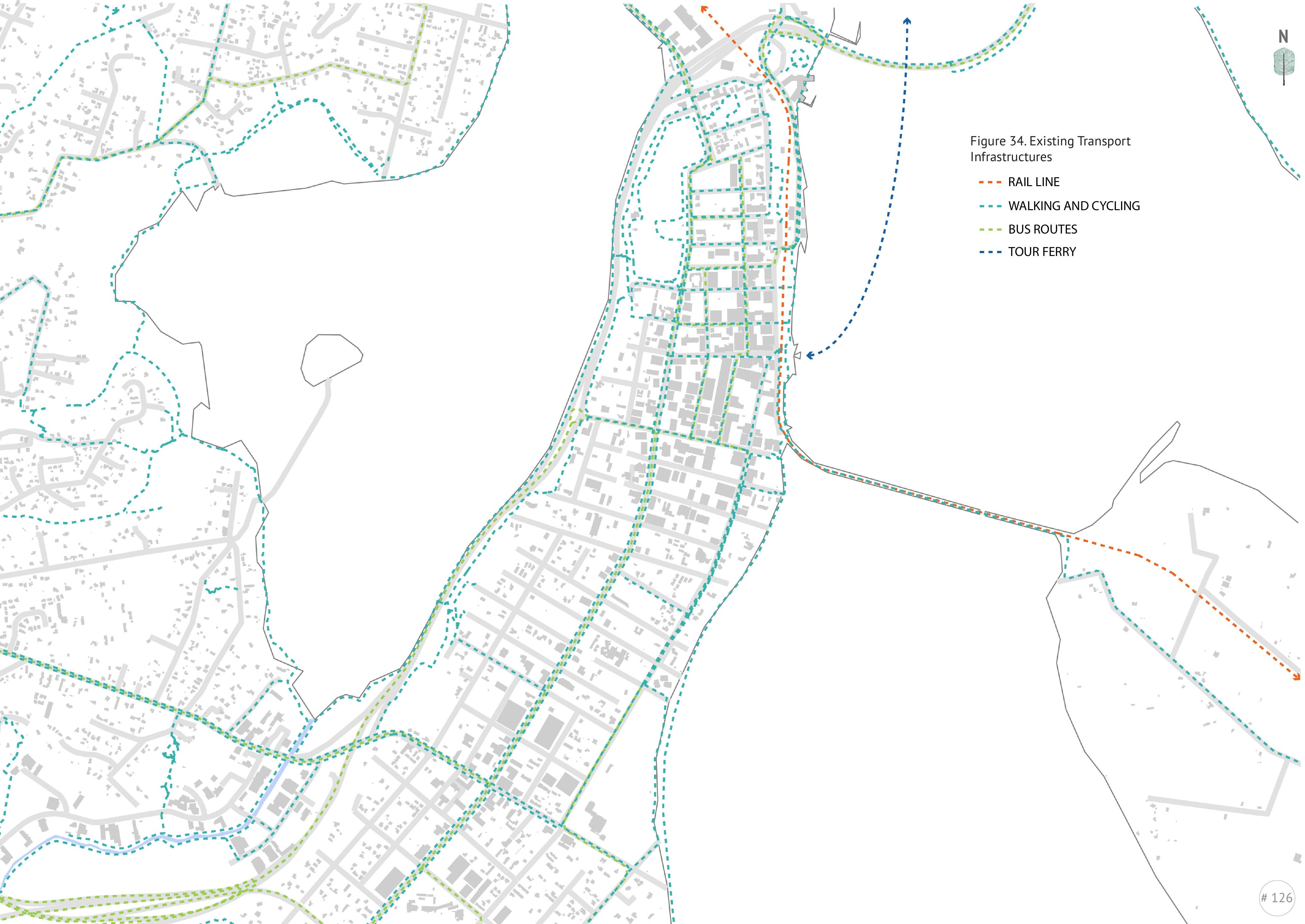




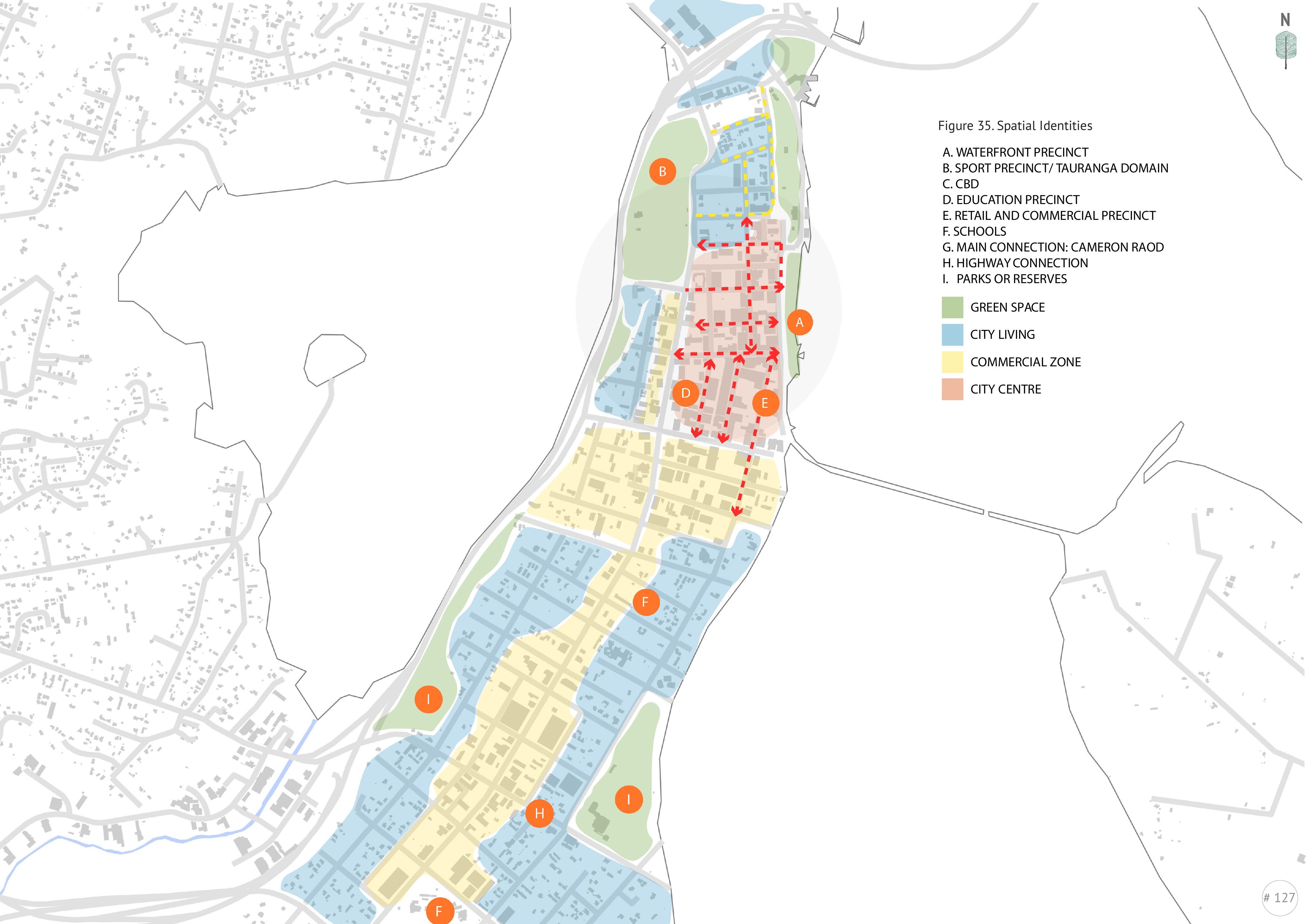




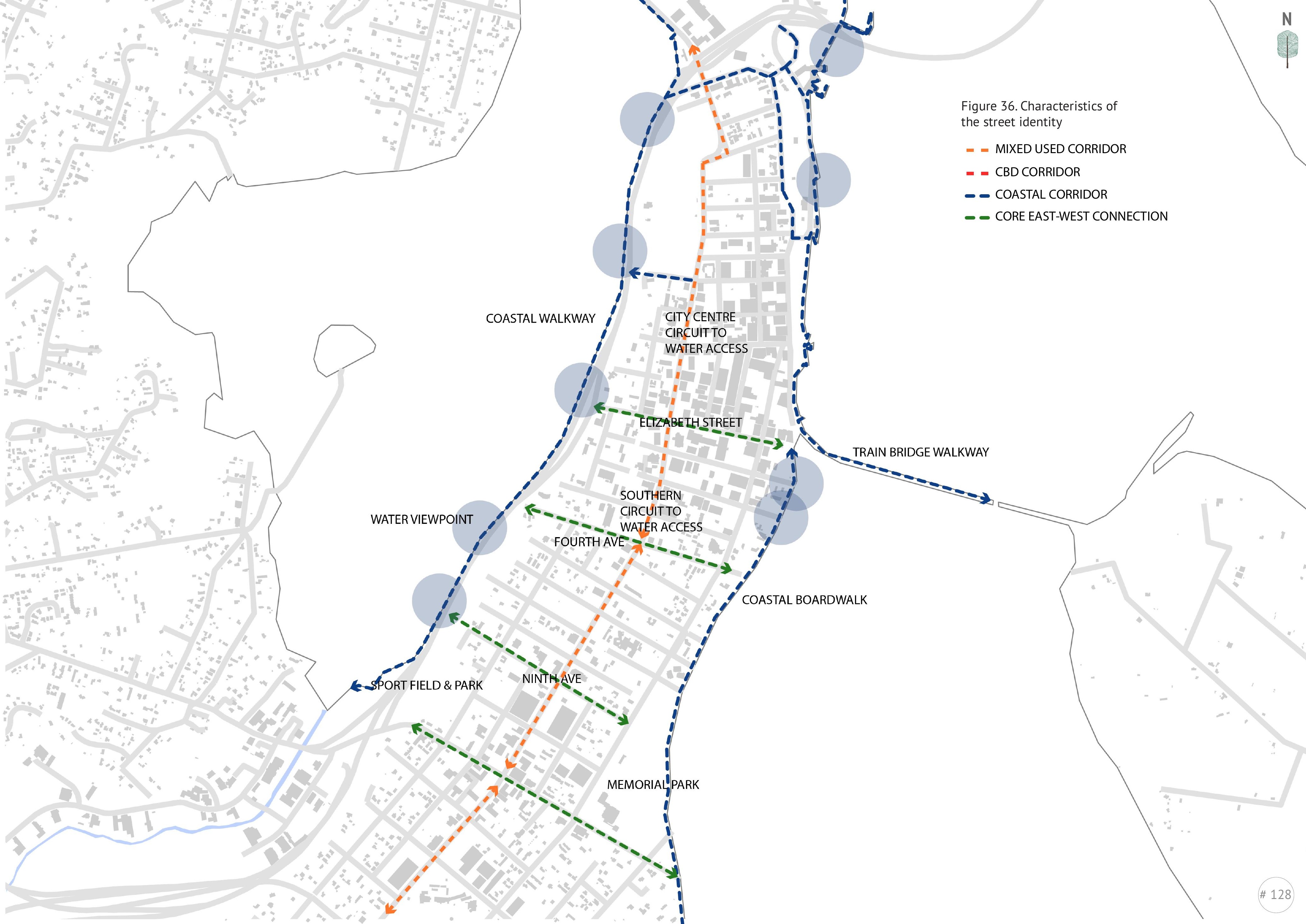




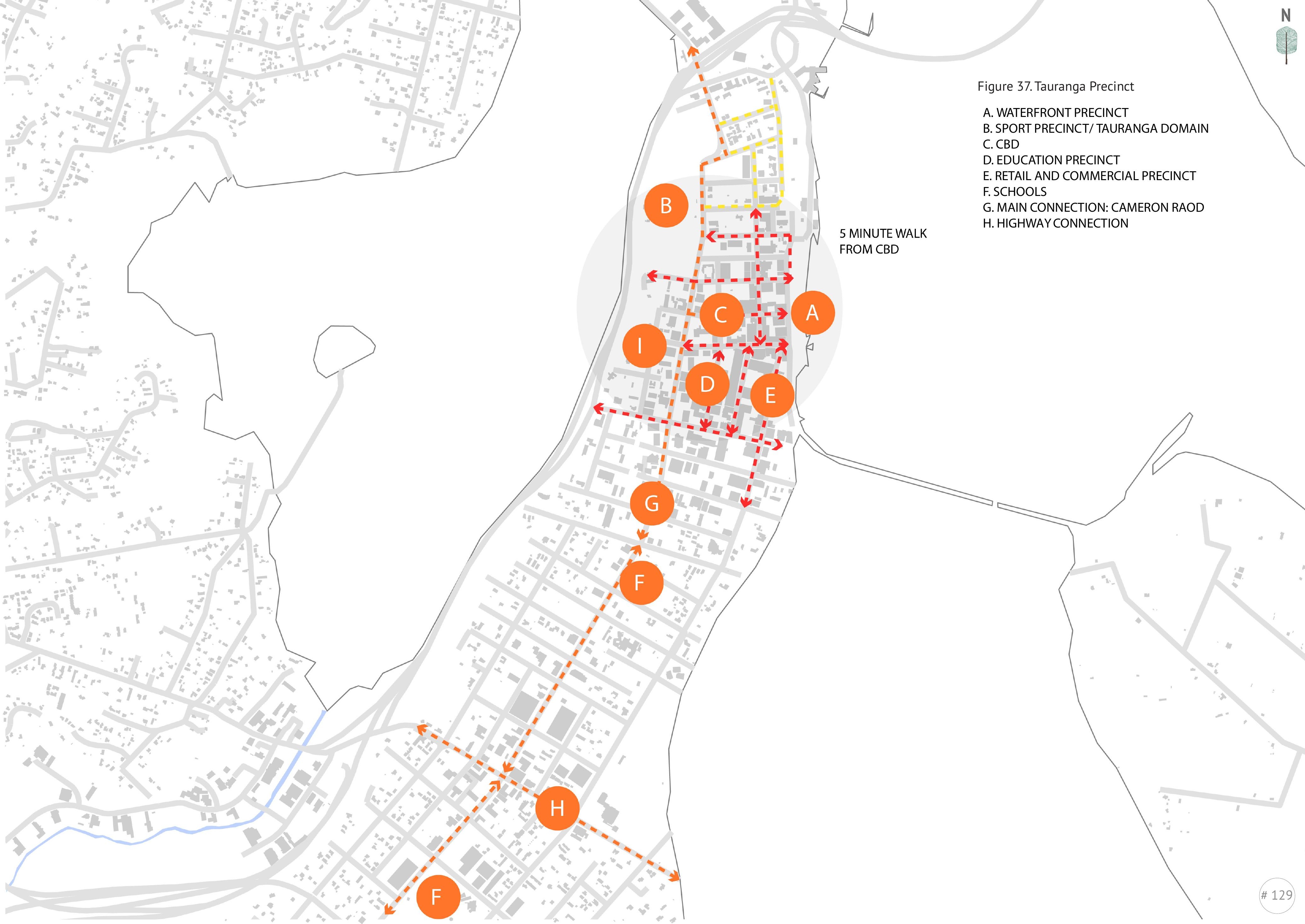


Characteristic of the Tauranga CBD Streets

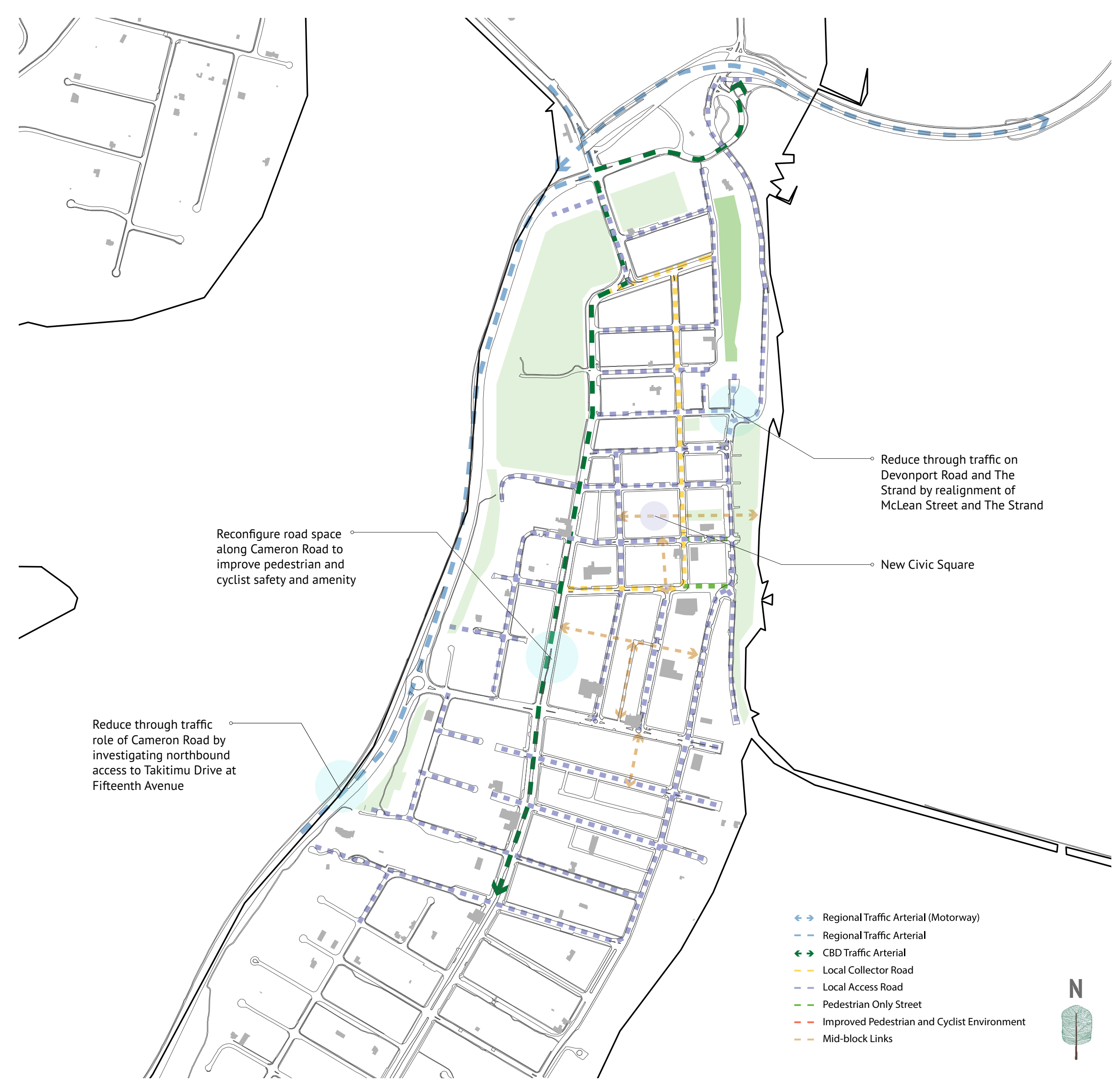




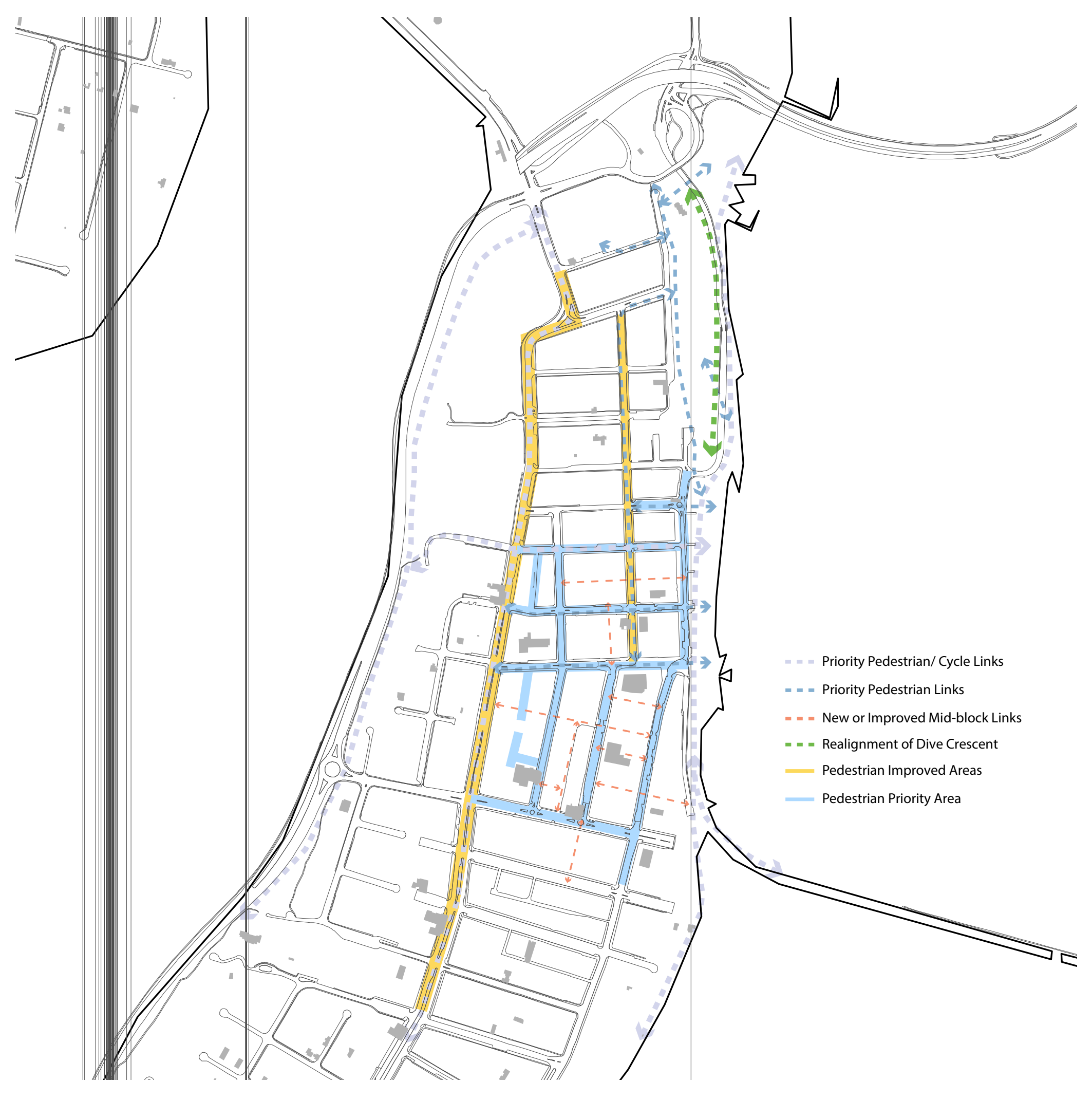




\section{Tauranga City Street Typologies}

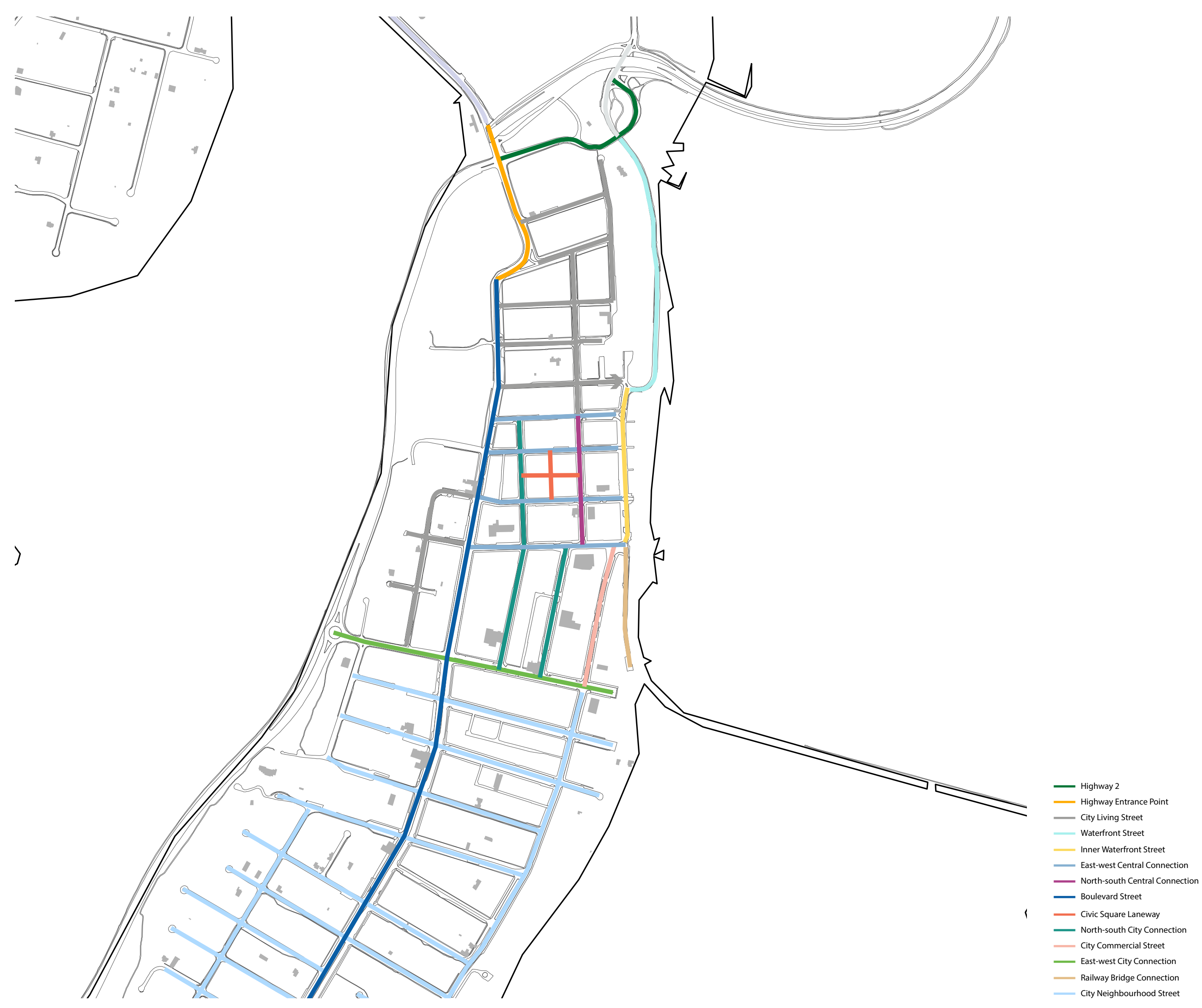




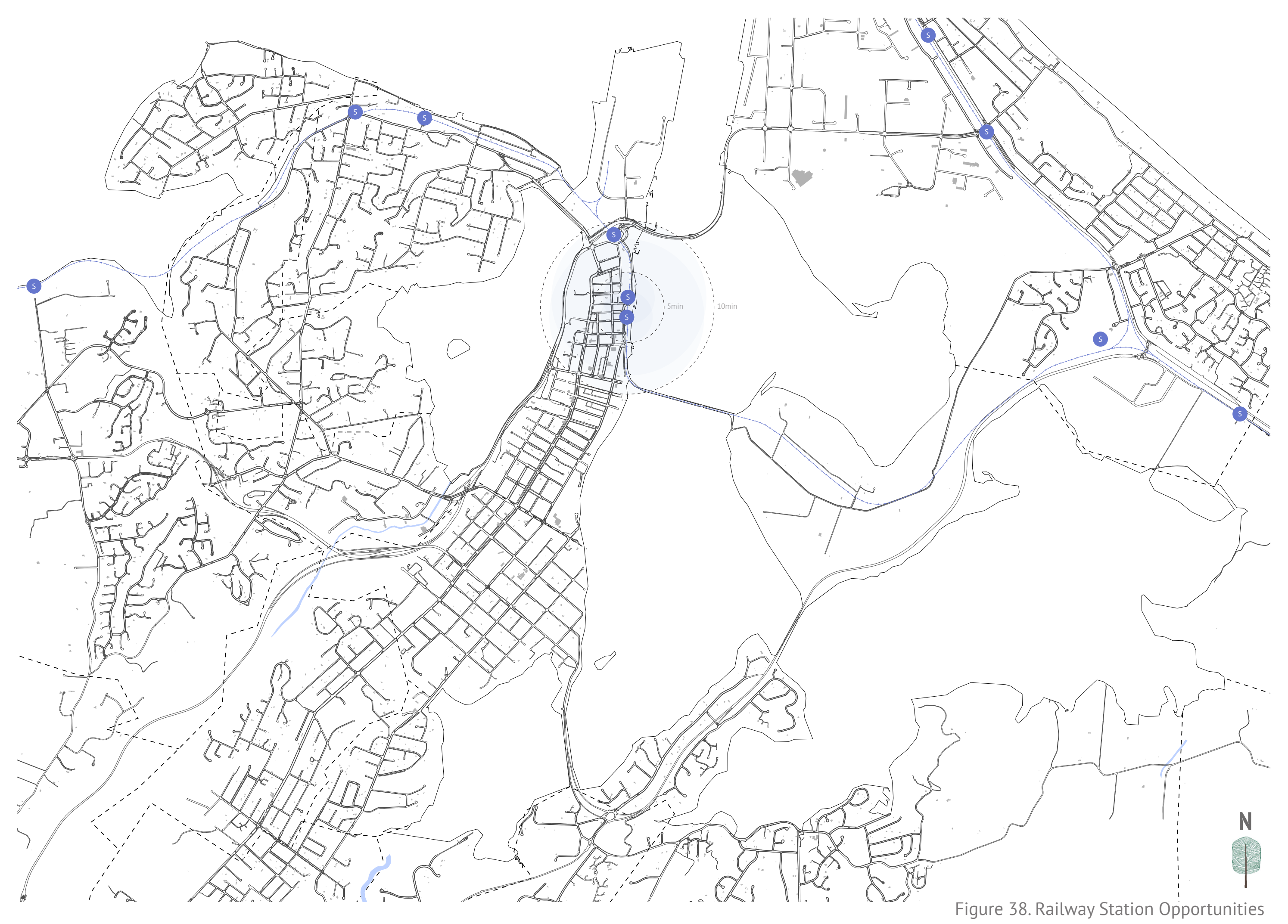




\subsection{Existing Conditions}

The investigated hybrid street typology will be applied and tested on seven different streets and fourr sites in Tauranga city business district areas (CBD)

where have significantly different spatial characteristics to see how it advances key objectives and achieves the research visions. 


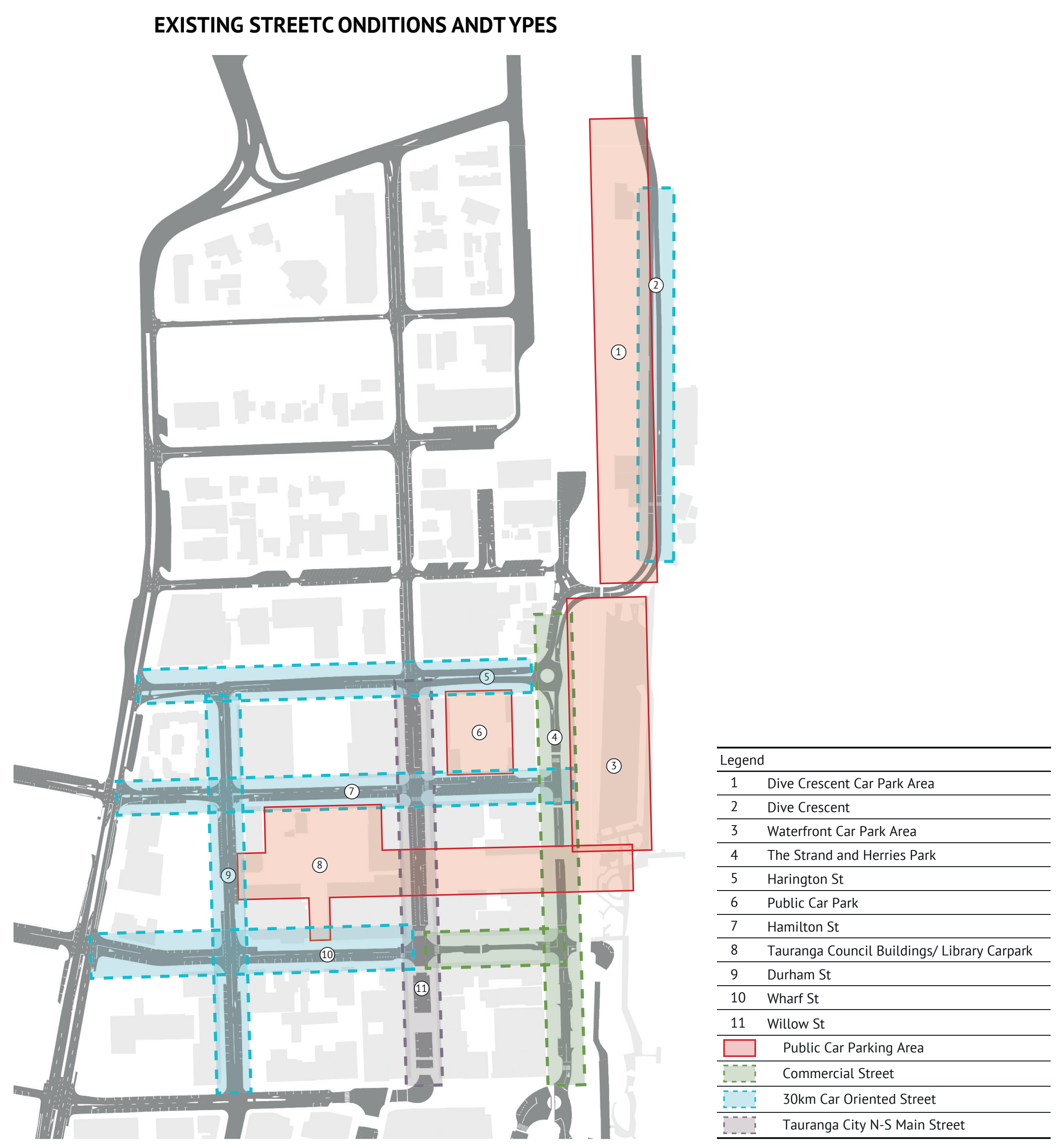




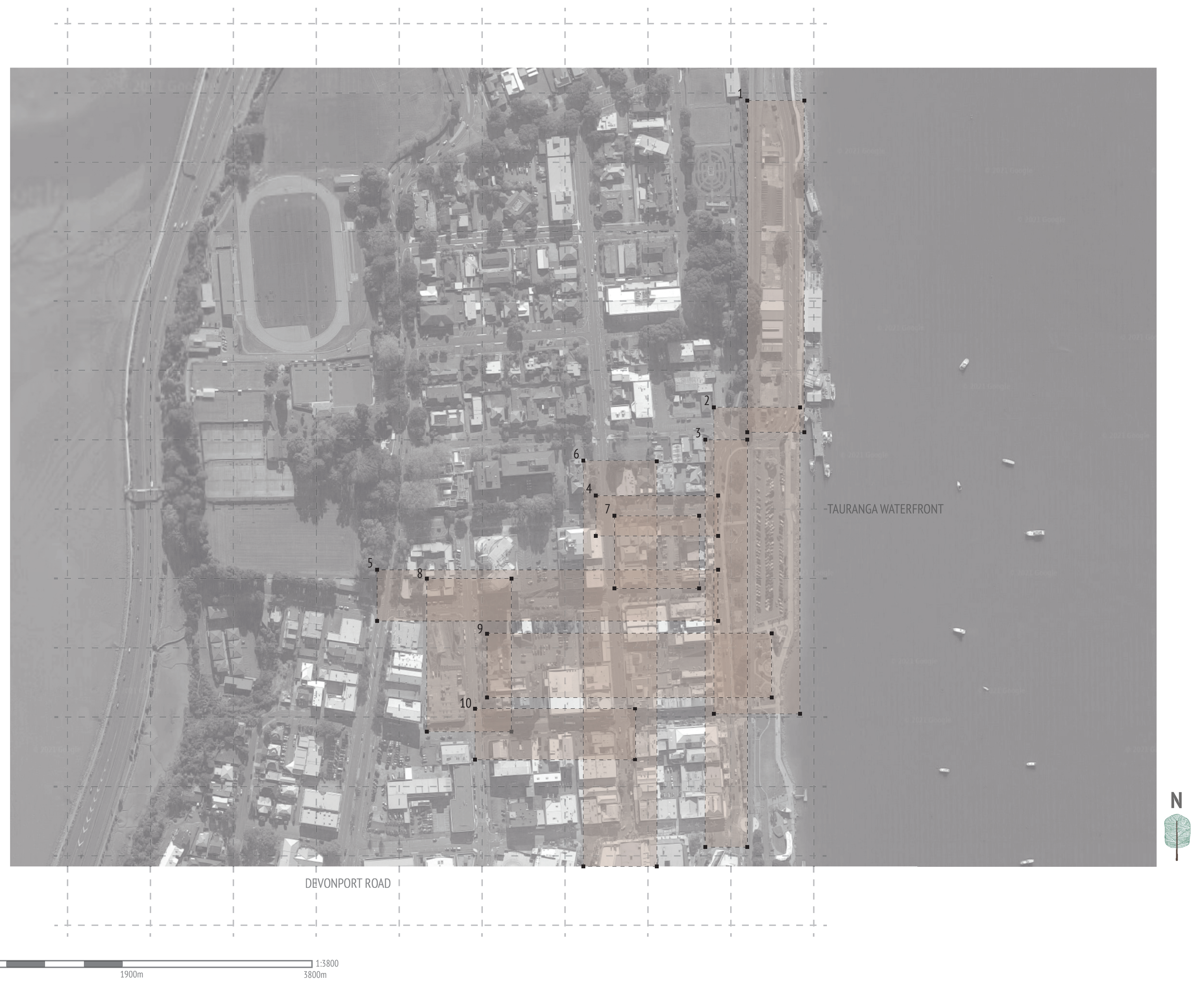




\section{WATERFRONT OLD RAILWAY STATION STREET 1: Dive Crescent/}

\section{Dive Crescent Parking Areas}

Design Objectives:

1. Street Focused on Sustainable Transport Modes (Hybrid Street Type 1)

2. Linear Park Street (Hybrid Street Type 3)

Key features:

- 9 to 11 metres wide street

- Vehicle dominated street

- Low quality three different car

parks

Design Concept:

- New mid-block north-south

public transport priority street

- Linear park with a new railway

station

\section{Existing Condition}

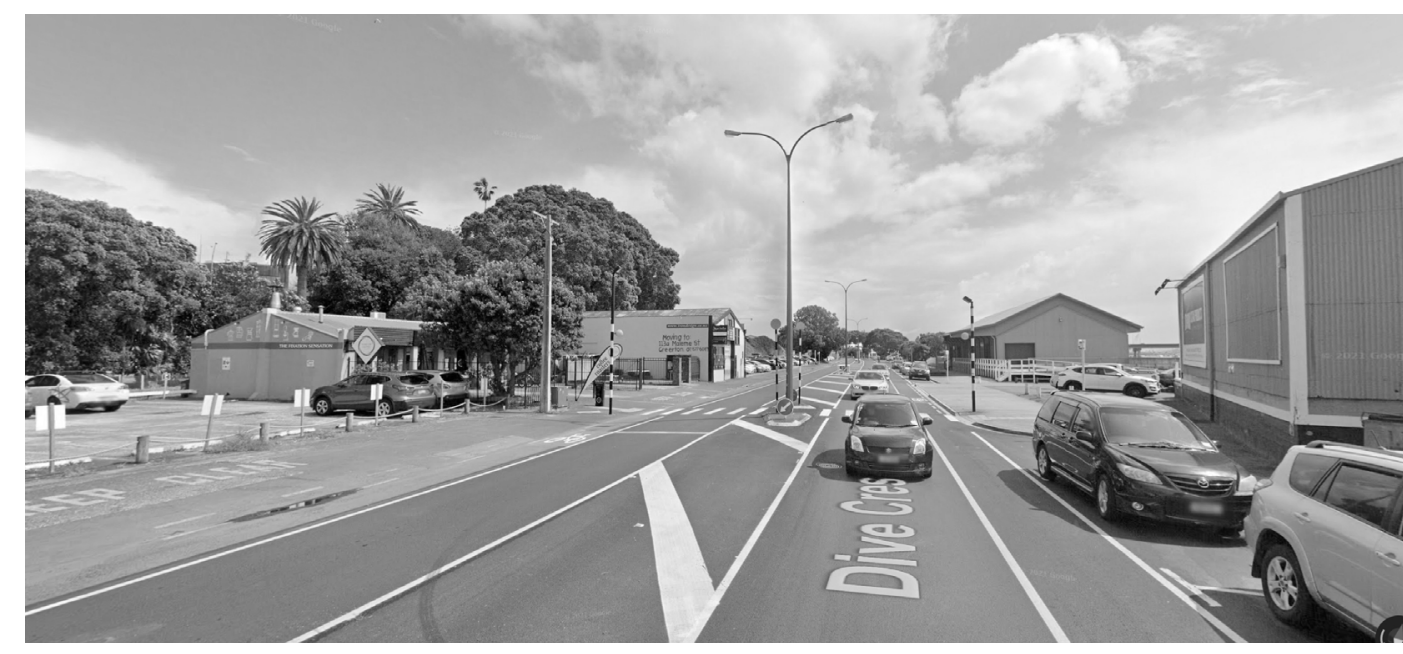

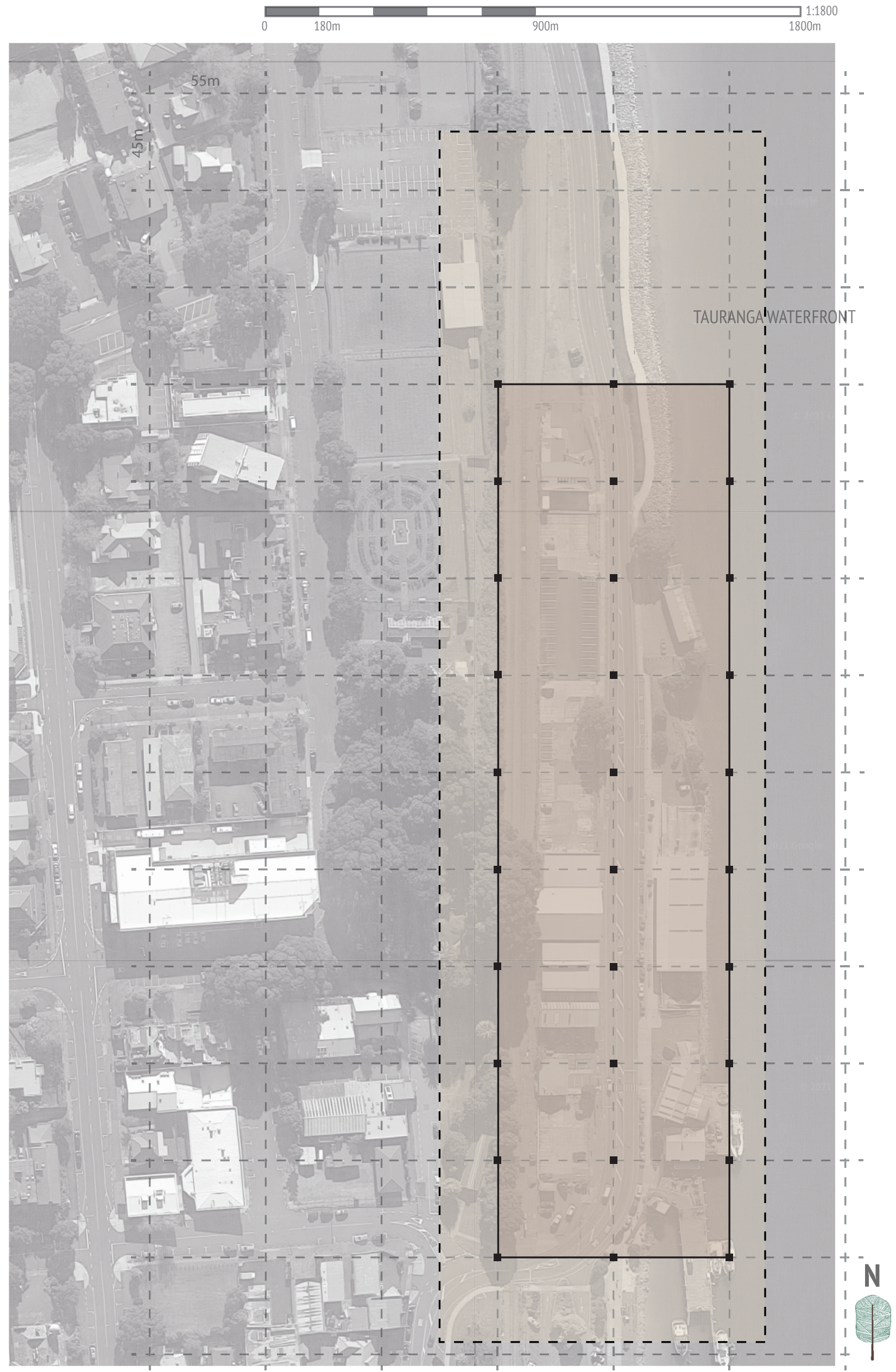

DEVONPORT ROAD 
Dive Cres/ Dive Cres Parking Area

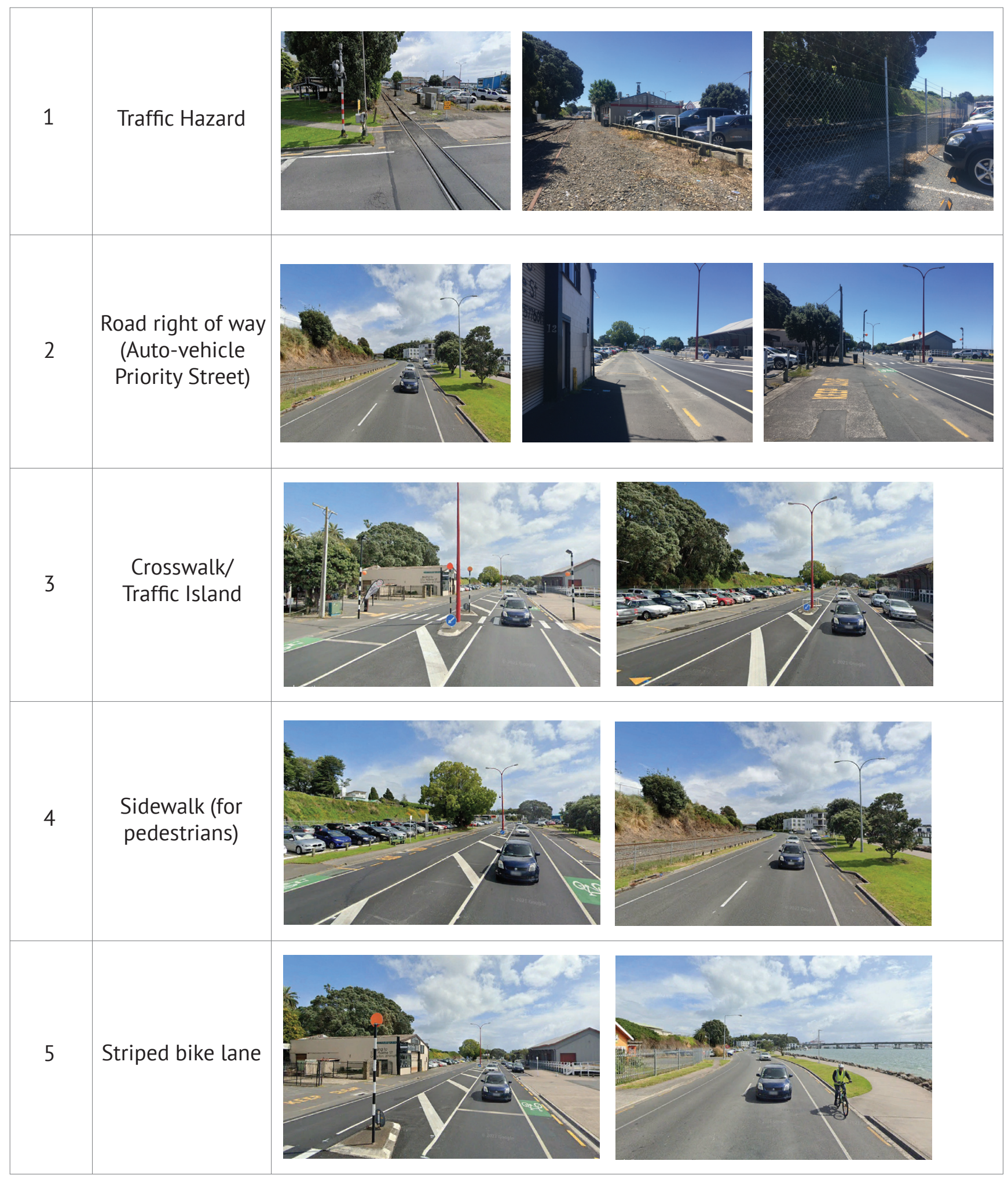

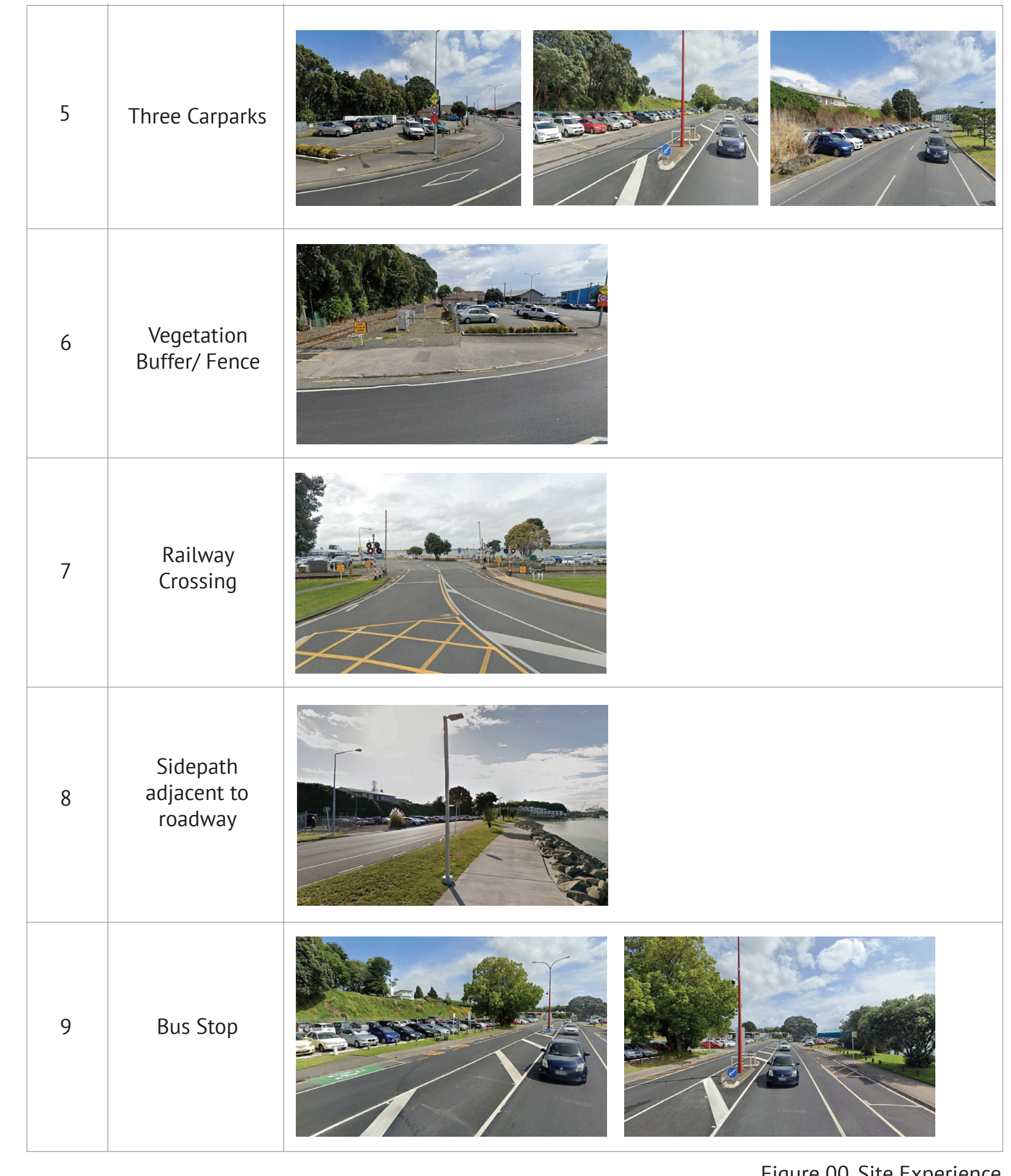

Figure 00. Site Experience 


\section{WATERFRONT OLD RAILWAY STATION STREET 2: Herries Park}

Design Objectives:

1. Linear Park Street (Hybrid Street Type 3)

2. Transport Interchange Street (Hybrid Street Type 5)

Key features:

- Limitation to design

open space with heavy rail

infrastructure

-Discontinuous E-W pedestrian

connection to waterfront

- Waterfront car park

- Railway hazard

- Low quality green space

Design Concept:

- Linear park with a new railway

platform

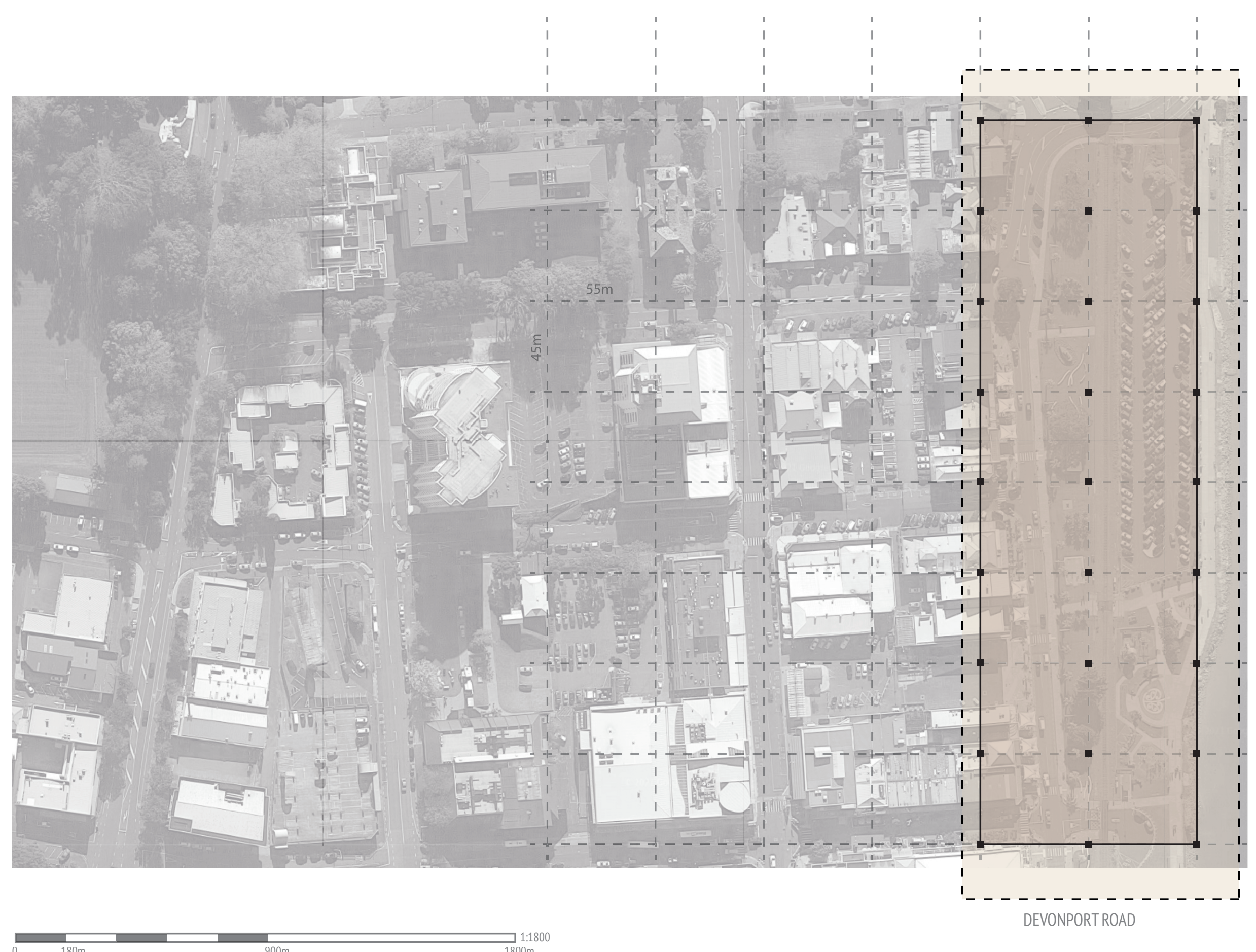




\section{WATERFRONT OLD RAILWAY STATION STREET 2: The Strand}

Design Objectives:

1. Active Street (Hybrid Street Type 2)

2. Linear Park Street (Hybrid Street Type 3)

3. Commercial Street (Hybrid Street Type 4)

Key features:

- Tauranga main commercial

street

- Narrow street, between 7 and

9 metres wide.

- Discontinuous E-W pedestrian

connection to waterfront

- Waterfront car park

- Railway hazard

- Low quality green space

- Salvaged clay pavers

\section{Design Concept:}

- Low speed shared street

Existing Condition

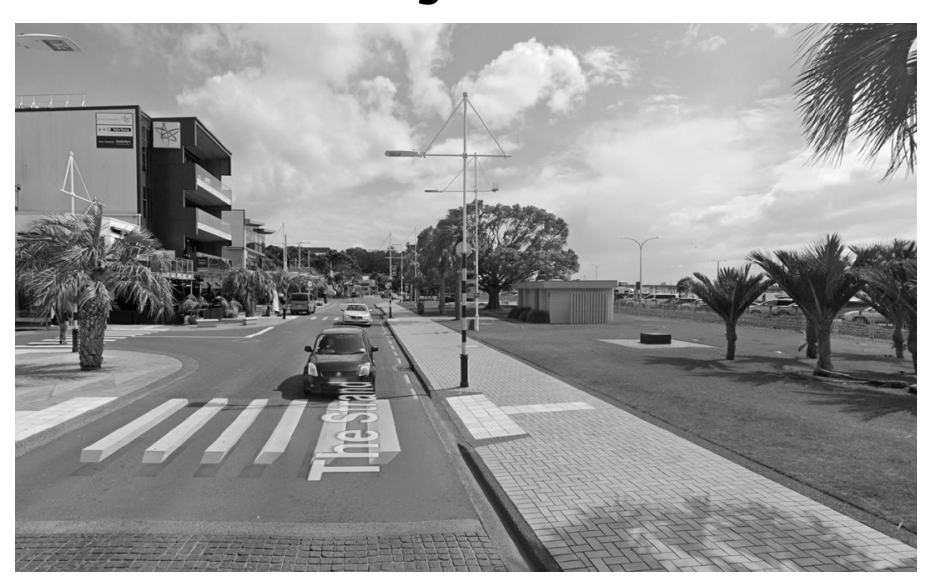

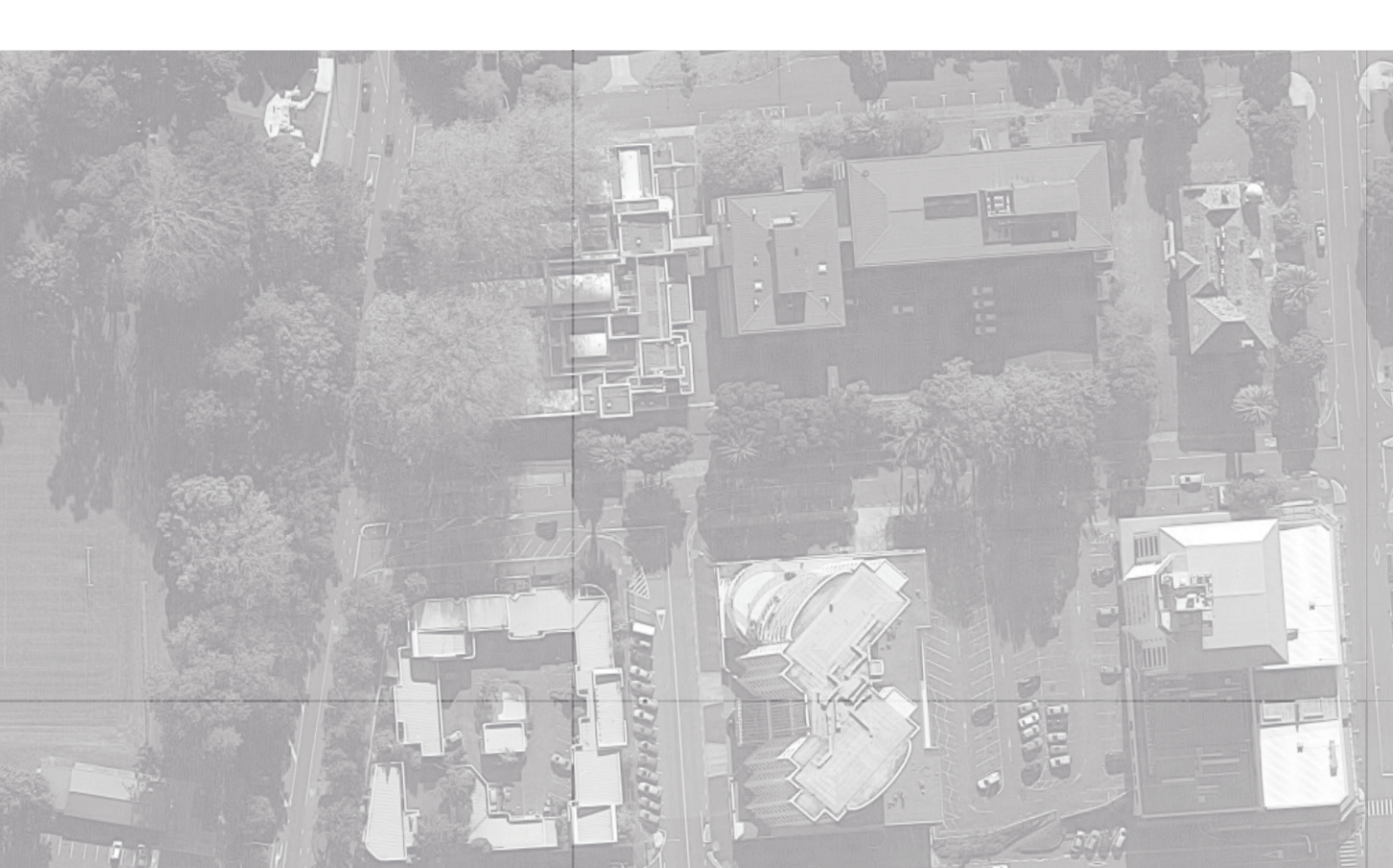

$--\cdots---\cdots---$

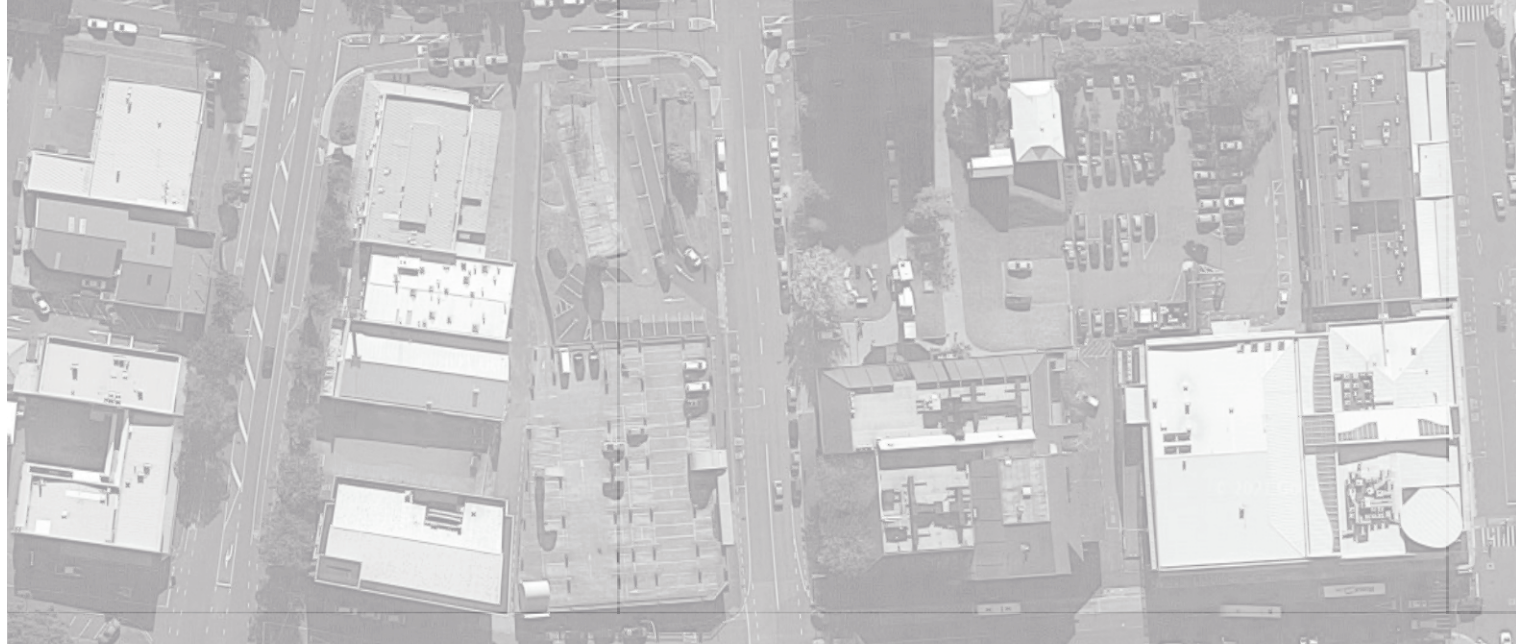

1:1800 
The Strand/ Herries Park

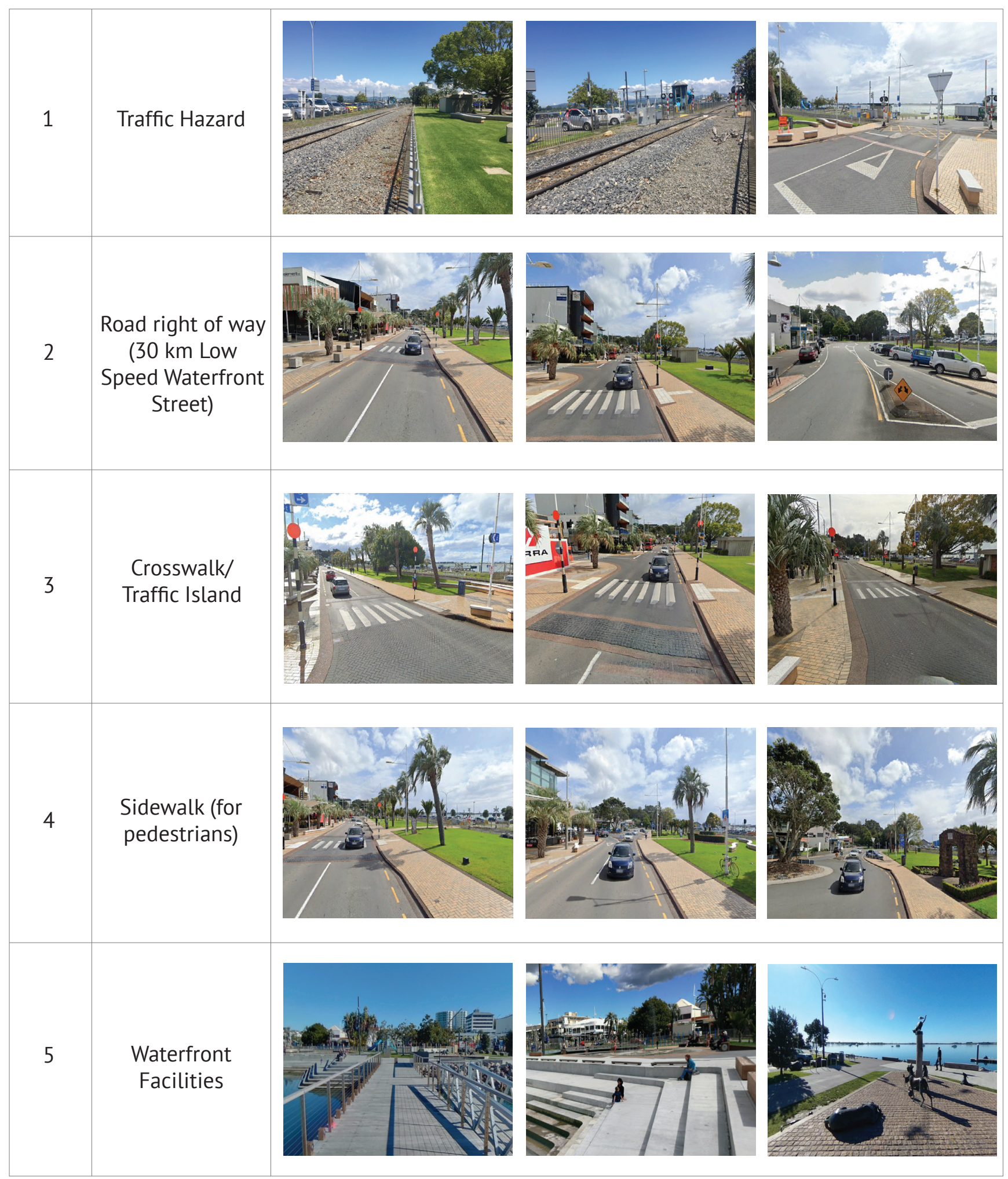

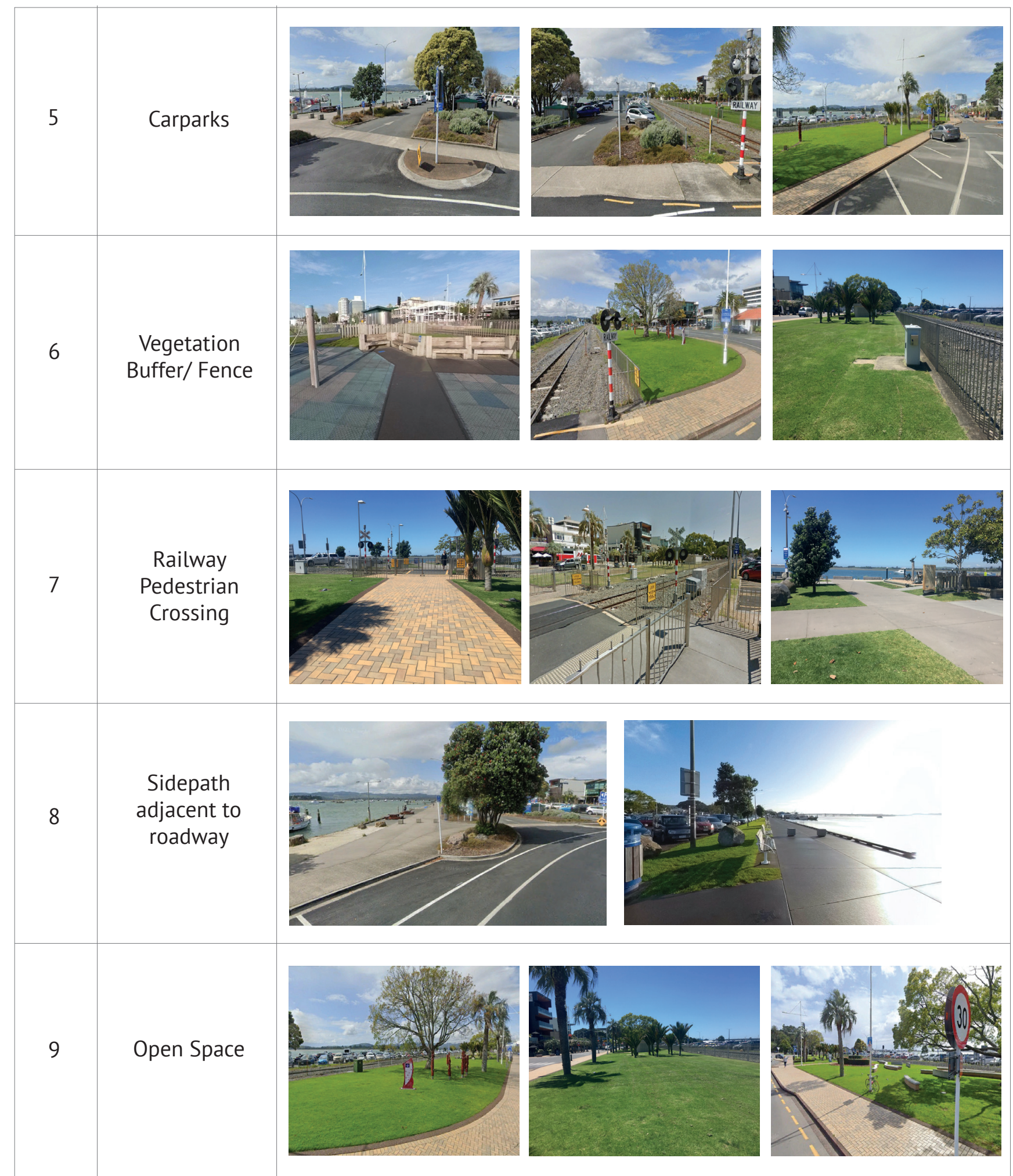

Figure 00. Site Experience 


\section{E-W RAILWAY STATION CONNECTION STREET: Harington St}

Design Objectives:

1. Active Street (Hybrid Street Type 2)

2.Linear Park Street (Hybrid Street Type 3)

\section{Key features:}

- 20-22m wide commercial

street (including street car

parking area)

- Vehicle dominated street

- Lack of amenity for

pedestrians

- Minimal green within the

street

Design Concept:

- Low speed shared street

DEVONPORT ROAD
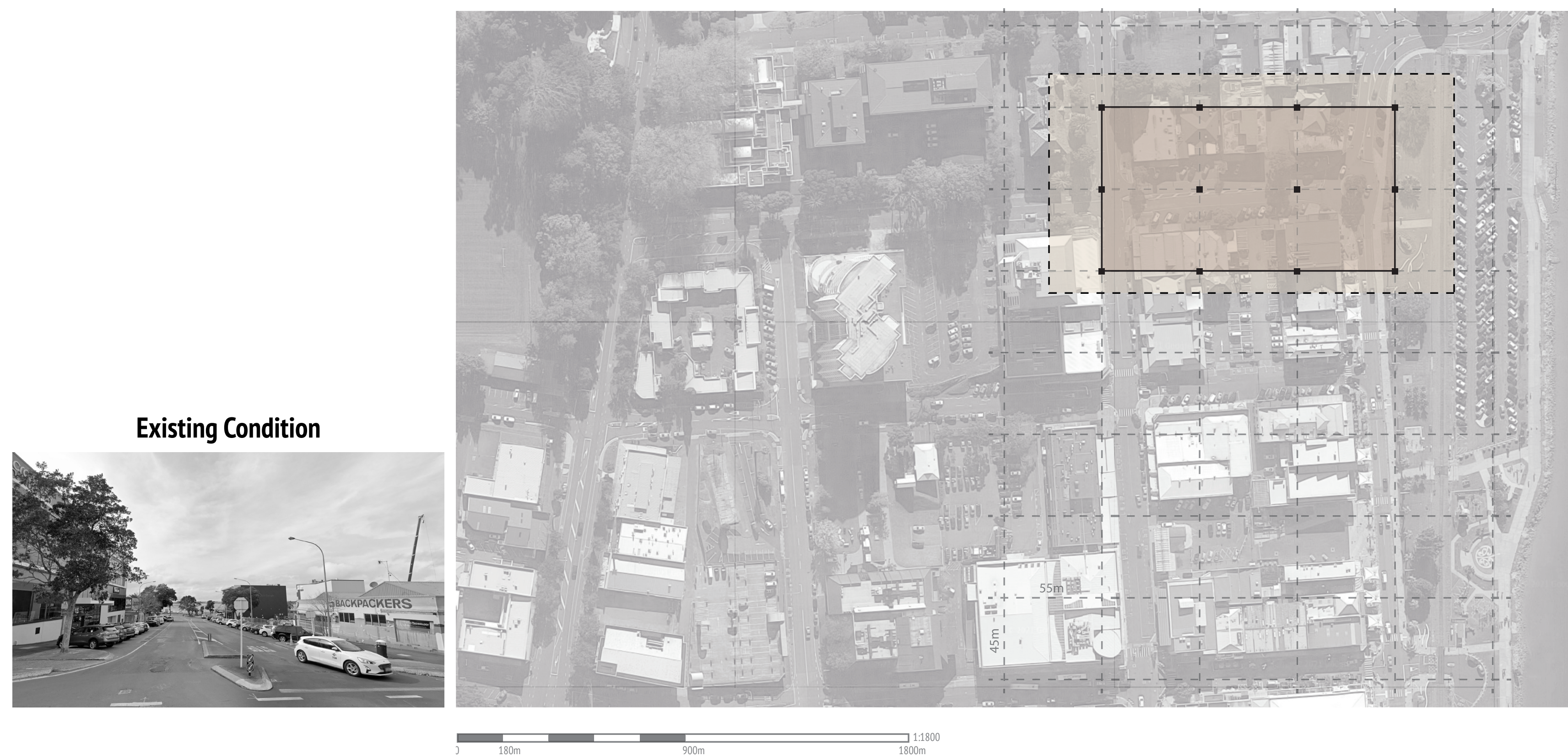
Harington St



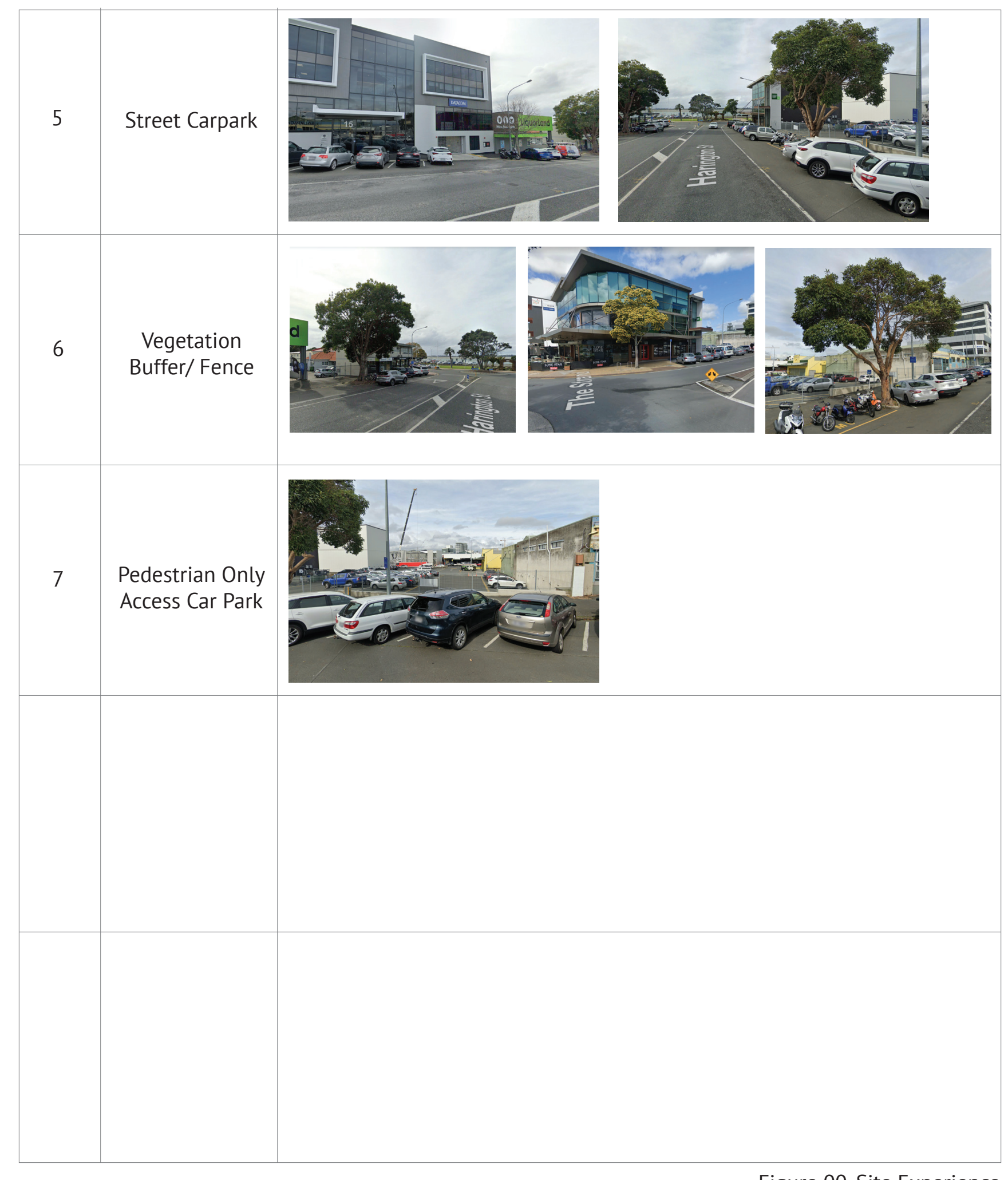




\section{PUBLIC TRANSPORT PRIORITY SHARED STREET: Hamilton St}

Design Objectives:

1. Street Focused on Sustainable Transport Modes (Hybrid Street Type 1)

Key features:

- $30 \mathrm{~km}$ car oriented street

- 11 to 12.5 metres wide

- Lack of amenity for

pedestrians

- Minimal green within the

street

Design Concept:

- Sustainable transport priority

street

\section{Existing Condition}
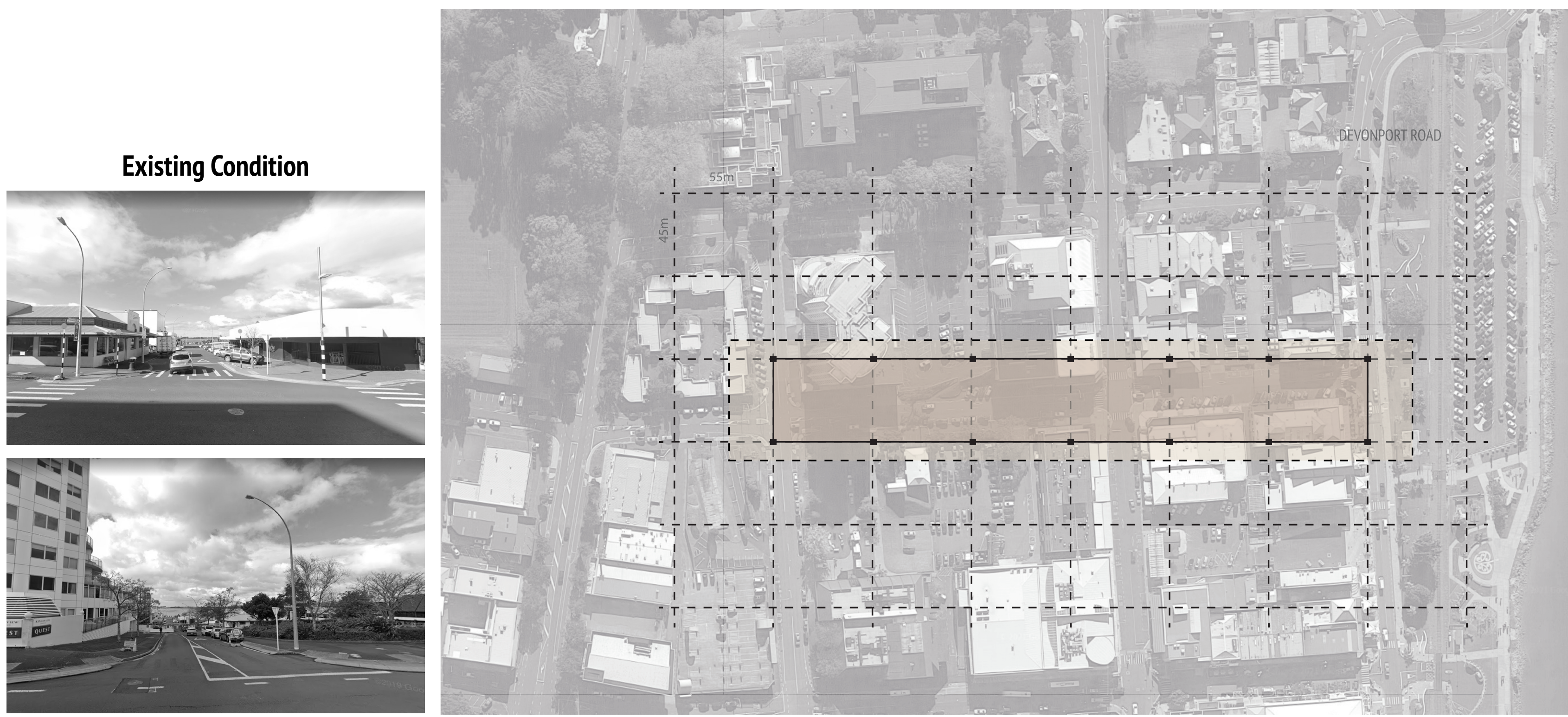


\section{Hamilton St}

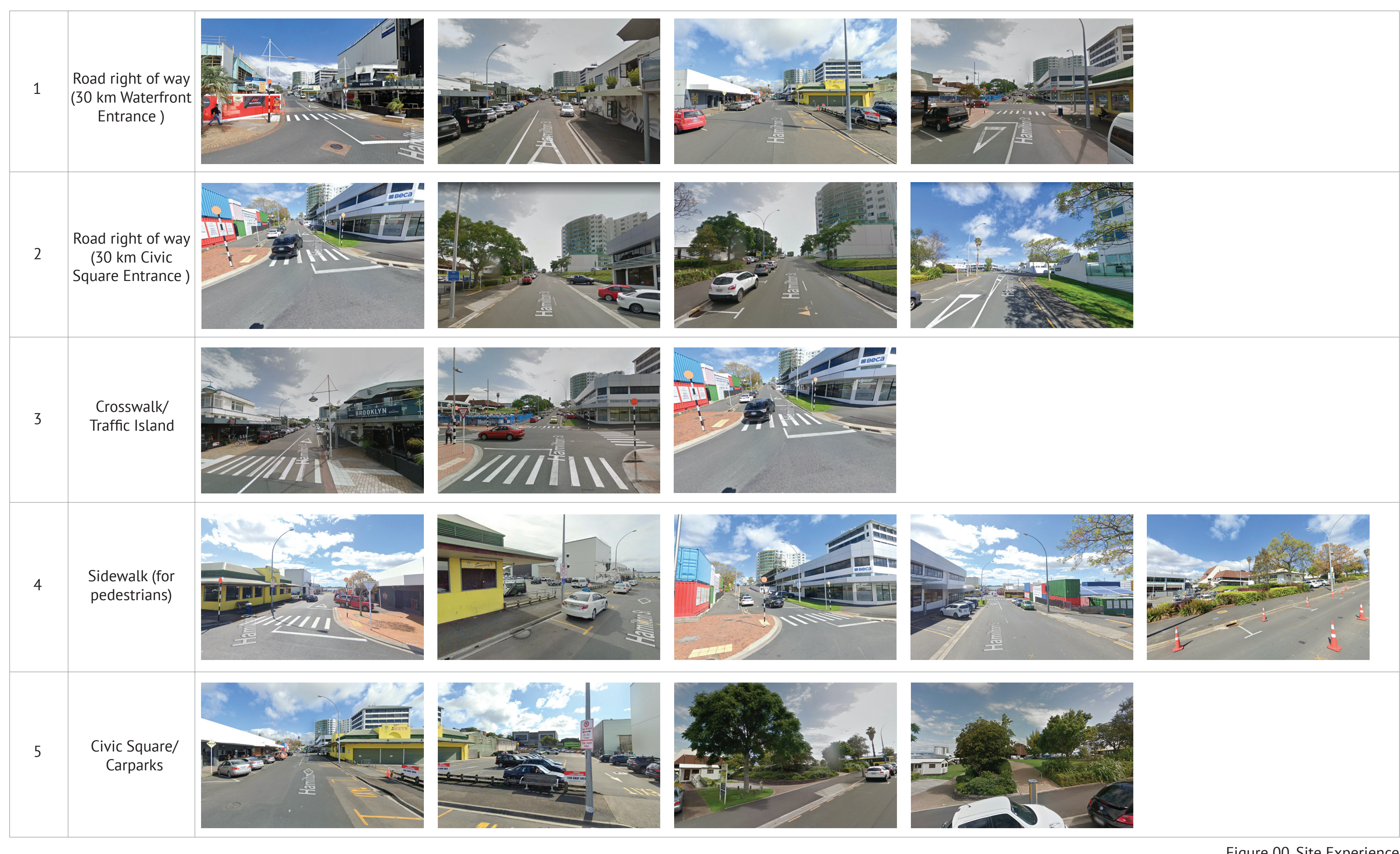




\section{N-S CITY CONNECTION STREET: Willow St}

Design Objectives:

1. Street Focused on Sustainable Transport Modes (Hybrid Street Type 1)

2. Active Street (Hybrid Street Type 2)

\section{Key features:}

- Tauranga city N-S main street

- 11 to 12.5 metres wide

- Local bus stops/ junctions

- Minimal green within the

street

Design Concept:

- Pedestrian priority multi-

modal street
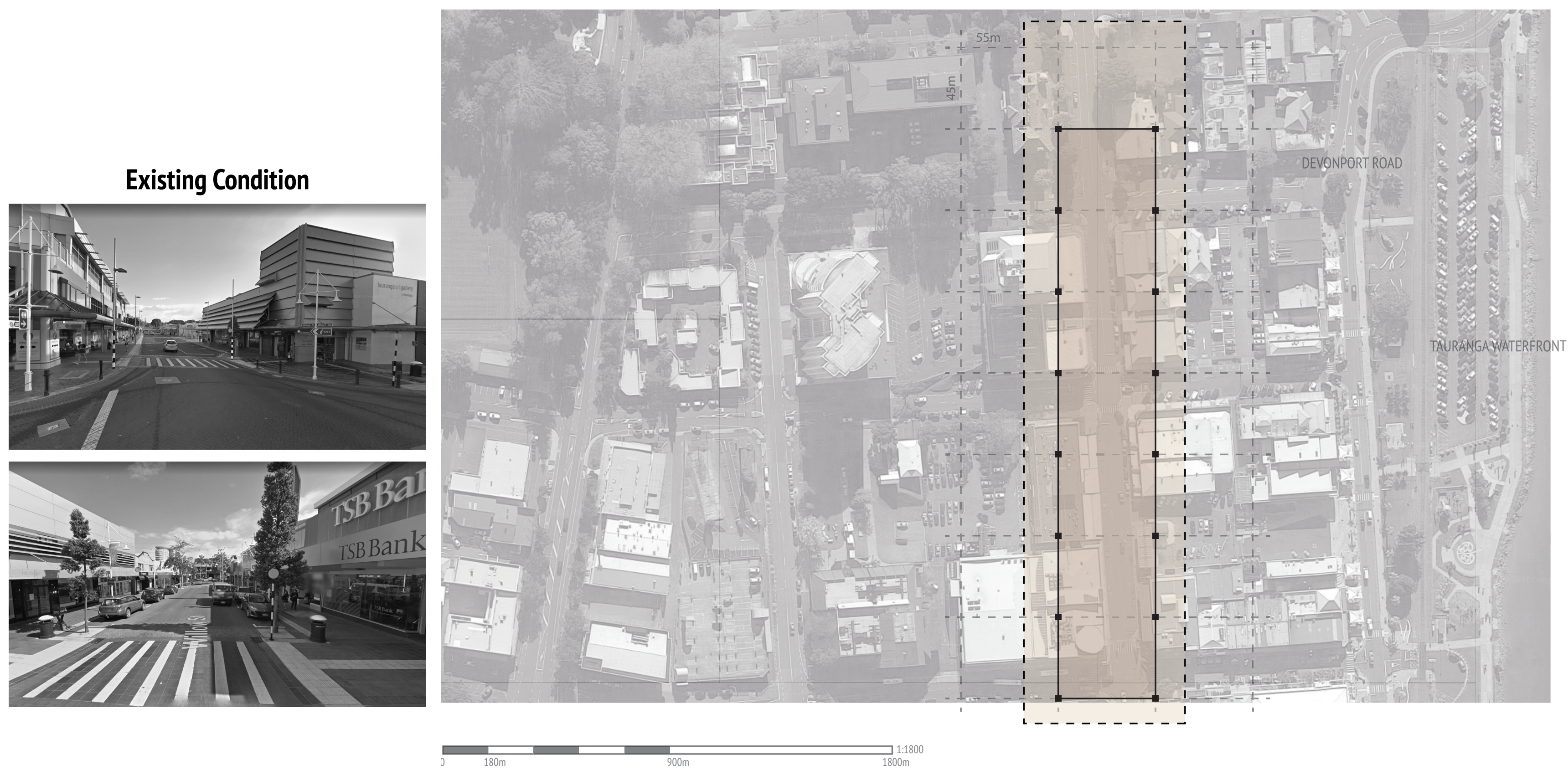
Willow St

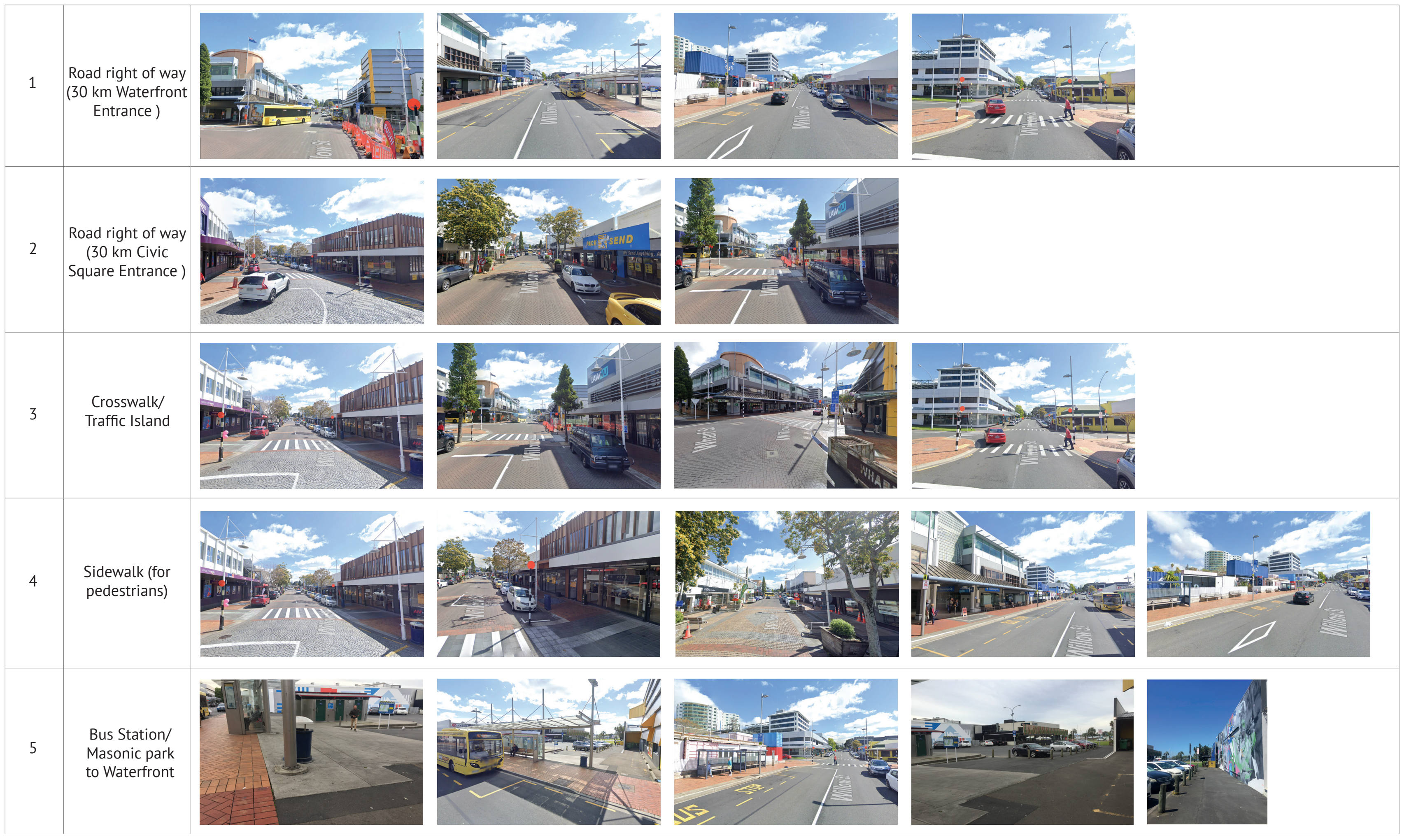

Figure 00. Site Experience 


\section{BUS INTERCHANGE SPACE: In-between Harington St and Hamilton St}

Design Objectives:

1. Transport Interchange Street (Hybrid Street Type 5)

Key features:

- Public car park space

- Empty Buildings

Design Concept:

- Regional bus interchange

space

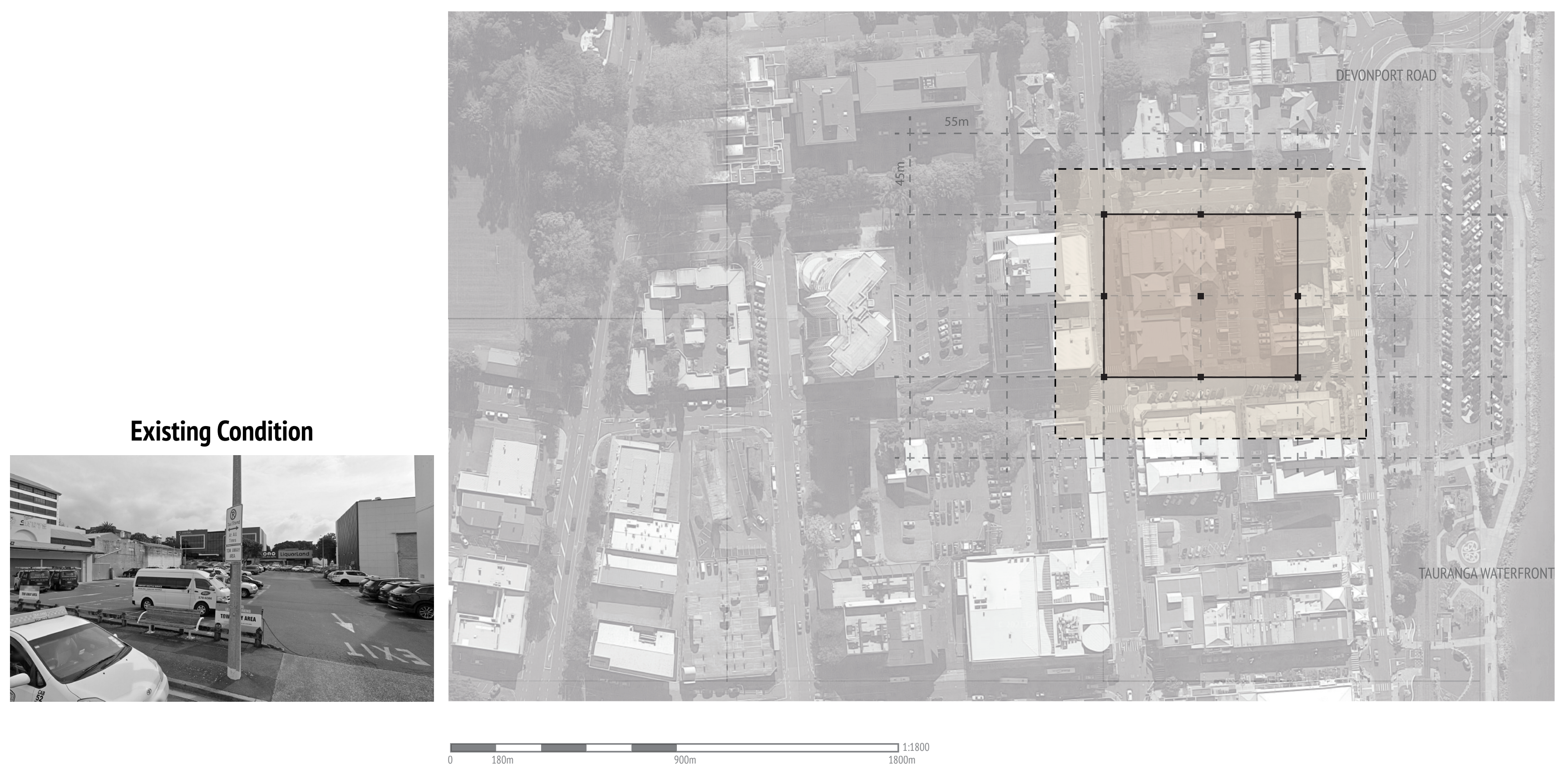




\section{CIVIC HEART STREET: Wharf St}

Design Objectives:

1. Street Focused on Sustainable Transport Modes (Hybrid Street Type 1)

2. Active Street (Hybrid Street Type 2)

Key features:

- $30 \mathrm{~km}$ car oriented street

- 11 to 12 metres wide

- Regional bus stops

- Minimal green within the

street

- East Wharf St had been

developed to Tauranga food

district street (pedestrian only

street)

Design Concept:

- Sustainable transport priority

street

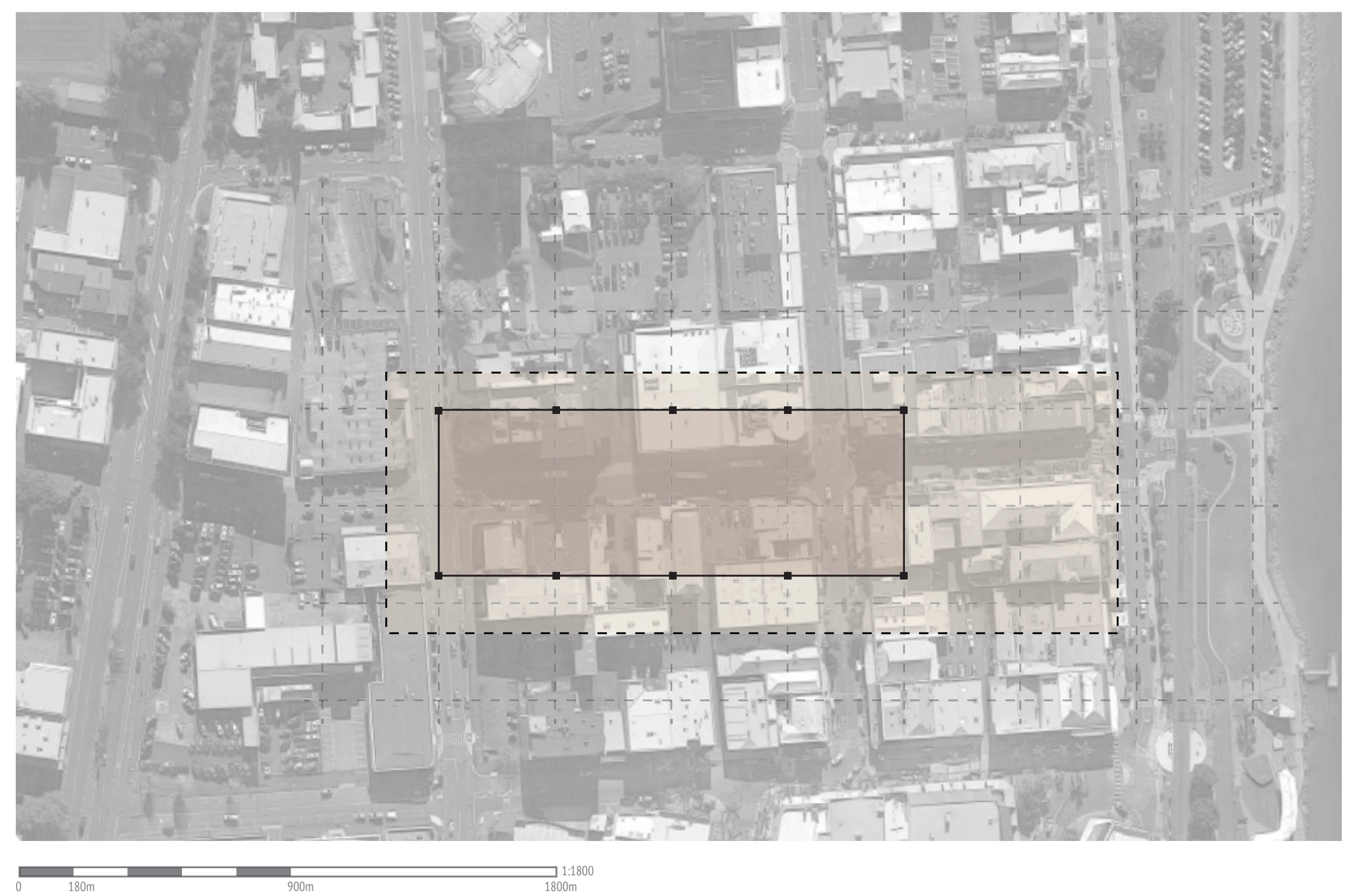




\section{Wharf St}

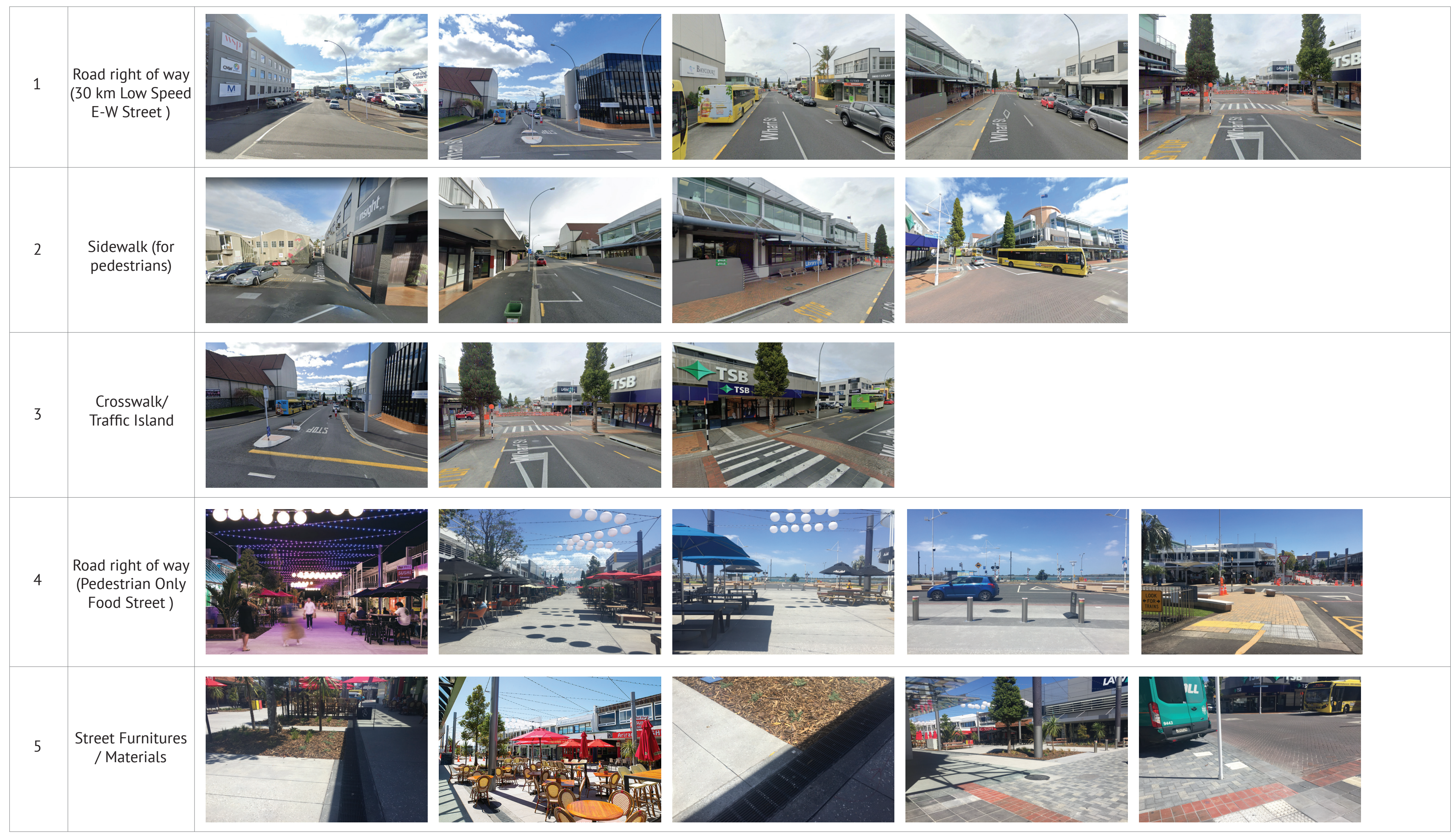




\section{GREEN STREET PARK: Durham Street}

Design Objectives:

1. Active Street (Hybrid Street Type 2)

2.Linear Park Street (Hybrid Street Type 3)

Key features:

- $30 \mathrm{~km}$ vehicle dominated

street

Narrow carriageway width of

8.5 to 9 metres wide

- Lack of amenity for

pedestrians

- Entrance point to Tauranga

Civic Square

Design Concept:

- Pedestrian only linear park

street

Existing Condition

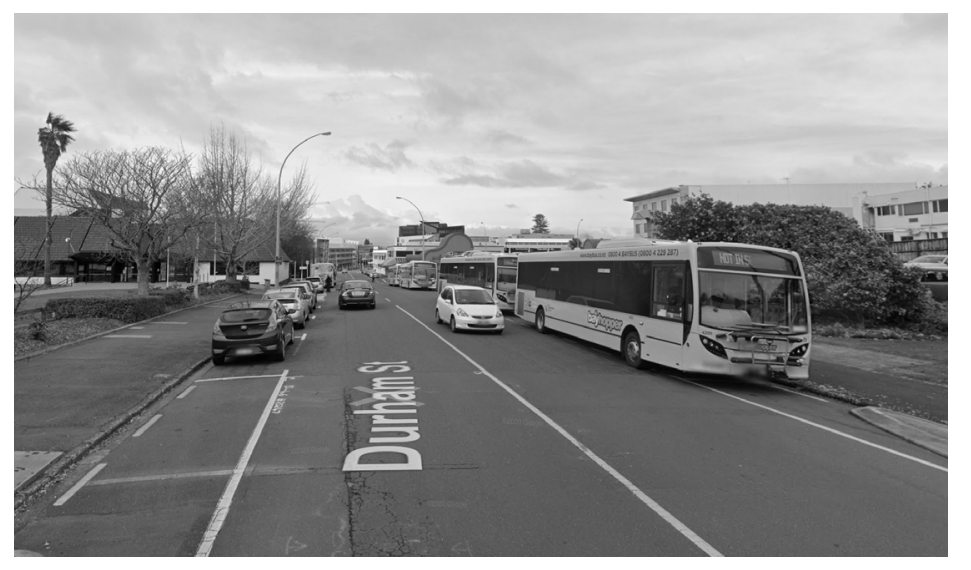

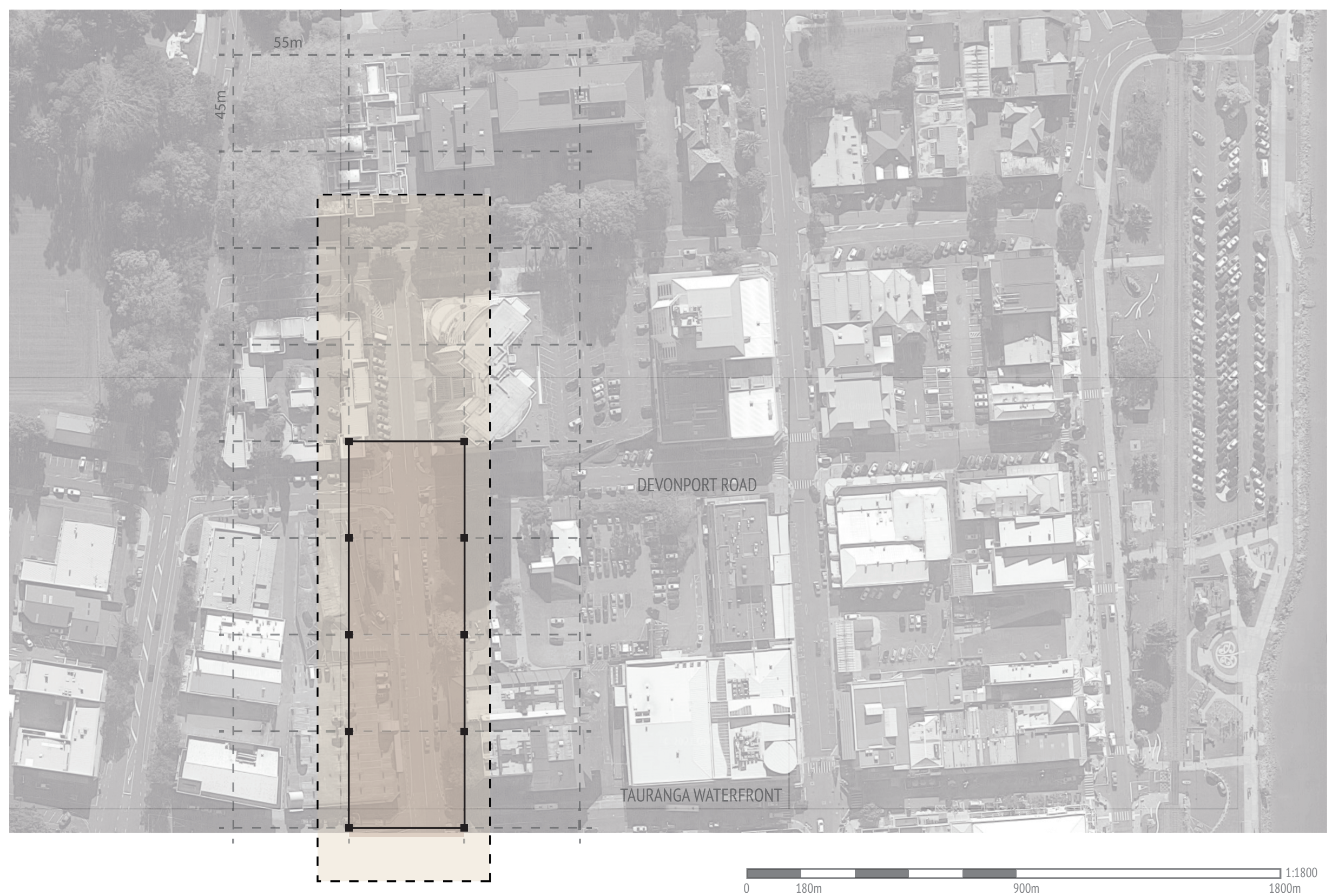




\section{CIVIC SQUARE TO WATERFRONT: Civic Square/ Masonic Park}

Design Objectives:

1. Active Street (Hybrid Street Type 2)

2.Linear Park Street (Hybrid Street Type 3)

Key features:

- Tauranga Civic Square to

Masonic park to Waterfront

connection

- Lack of amenity for

pedestrians

- Two public car parks

Design Concept:

- Civic Square/ Linear park

pedestrian corridor

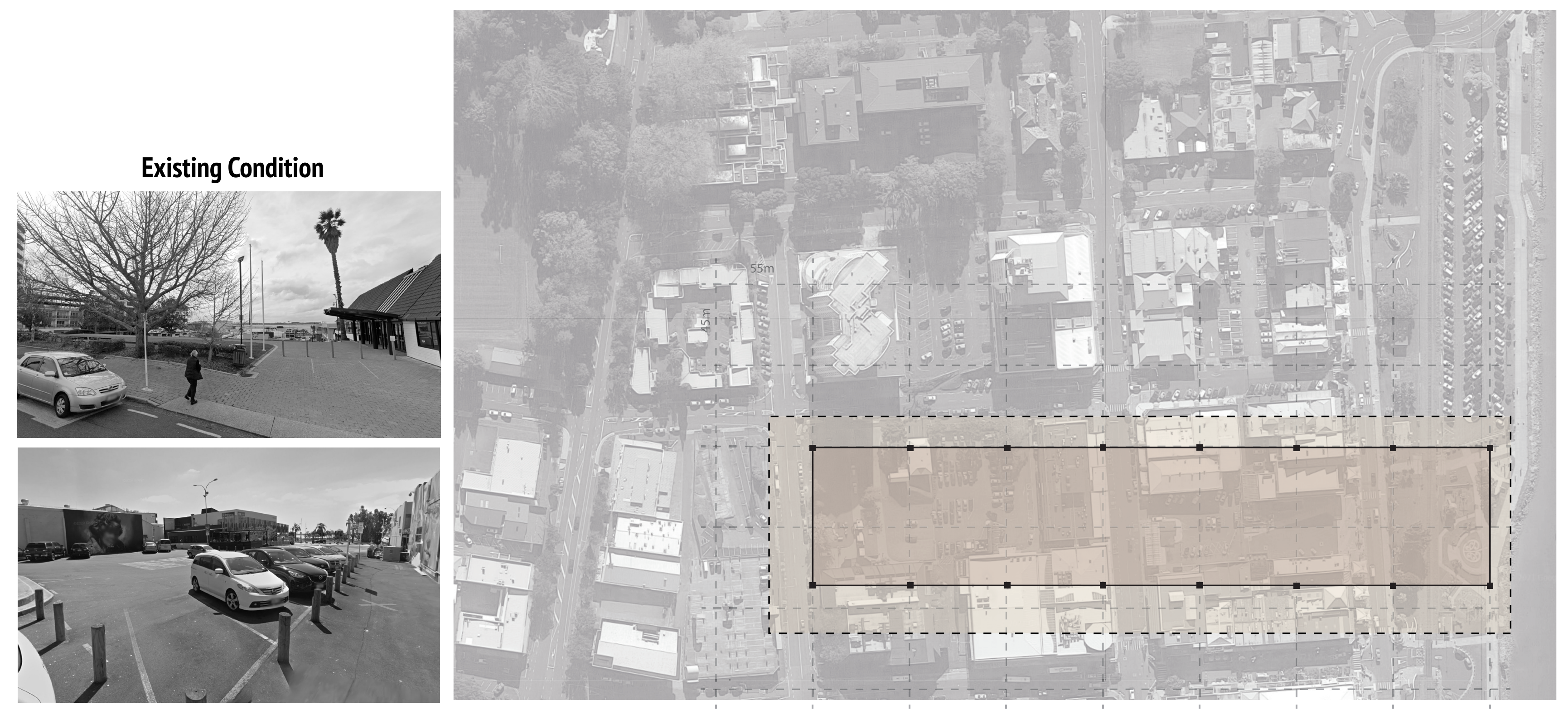




\section{Masonic Park}

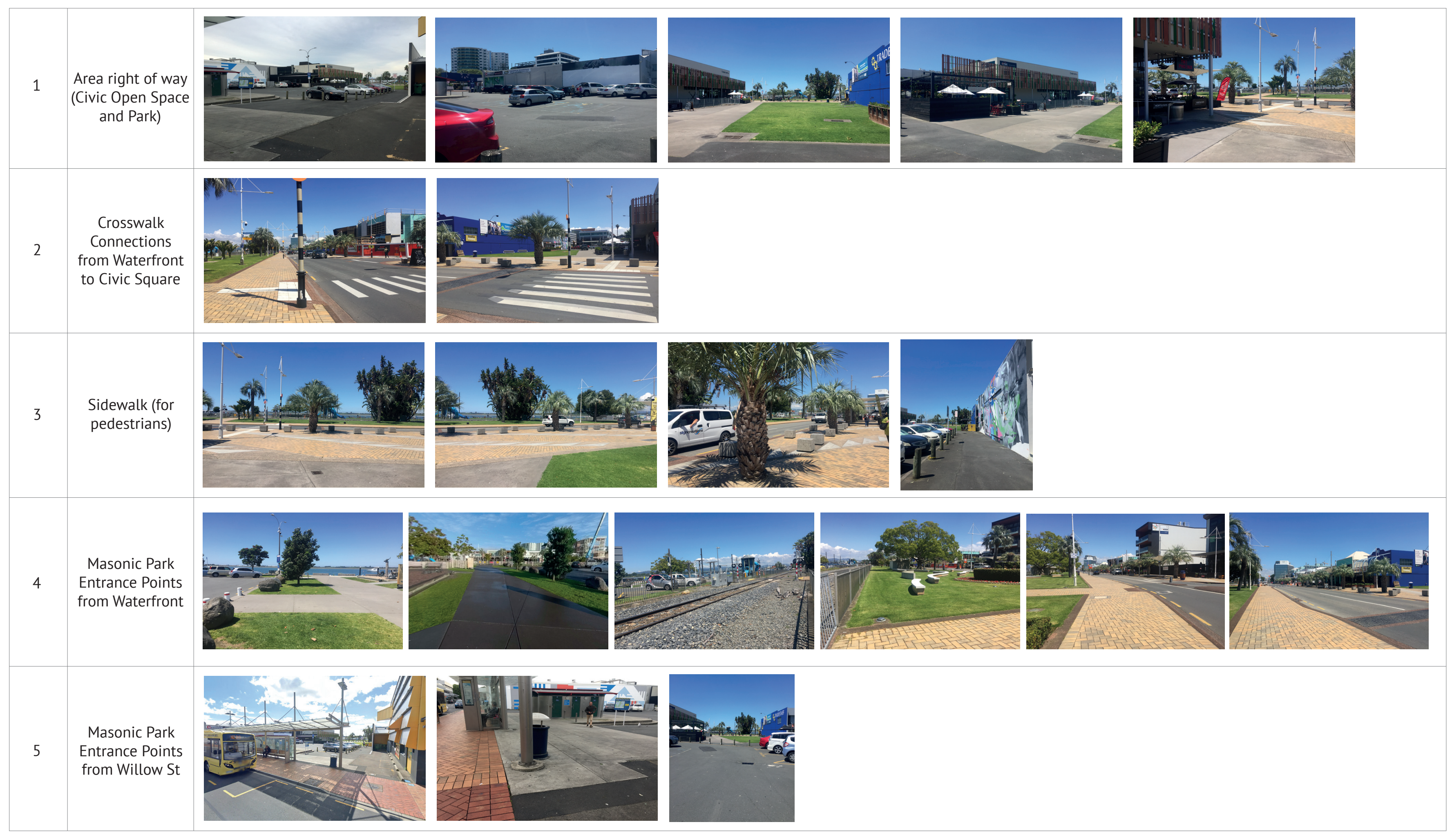


WATERFRONT OLD RAILWAYSTATION STREET 1: Dive Crescent/ Dive Crescent Parking Areas

\section{STREET USERS}

CYCLISTS

DOING BUSINESS

PRIVATE VEHICLE USERS
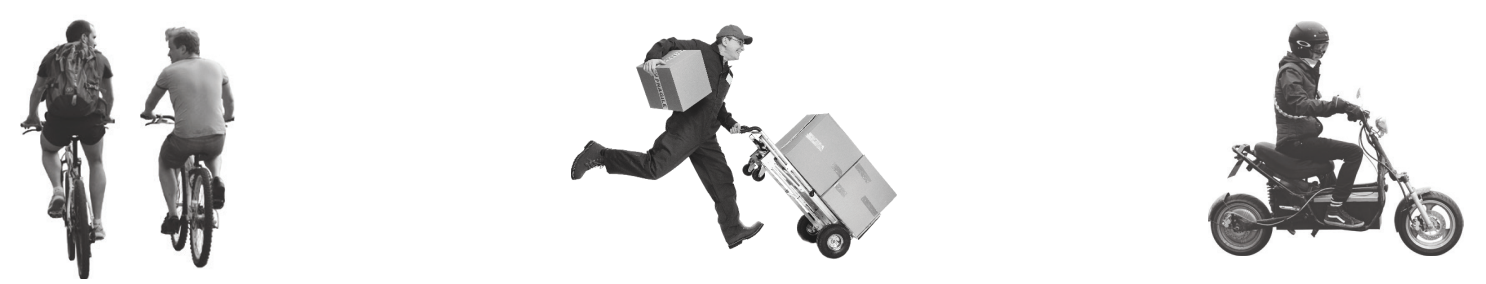

CAR PARKING

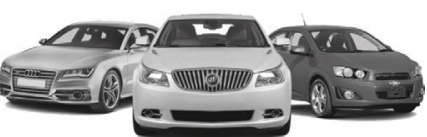

ACTIVITIES

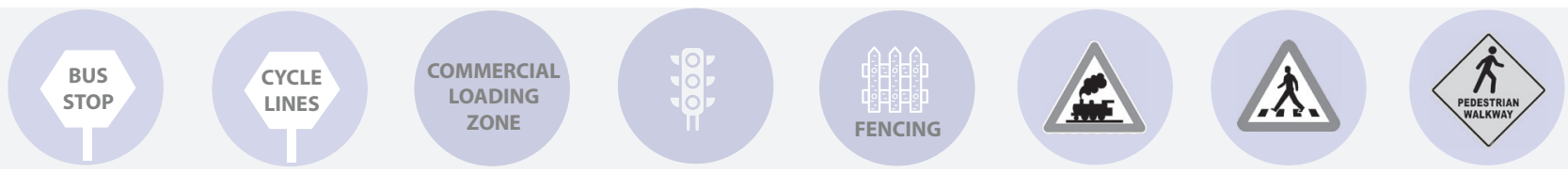

MODE OF TRANSPORT
WATERFRONT OLD RAILWAY STATION STREET 2: The Strand/ Herries Park

\section{STREET USERS}

PEDESTRIANS DOING BUSINESS

CHILDREN/ PARENT
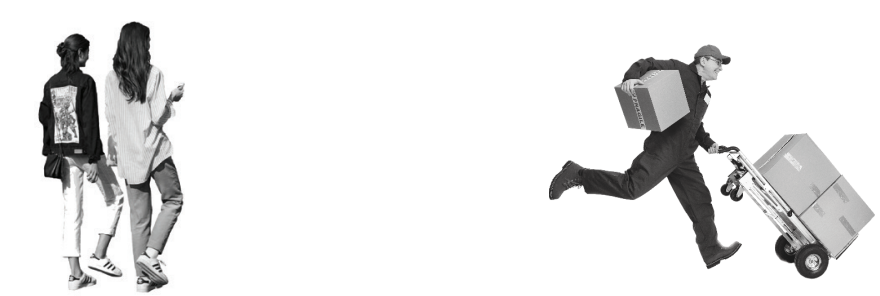

EATING DISTRICT

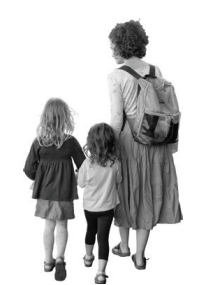

PEOPLE WITH DISABILITIES

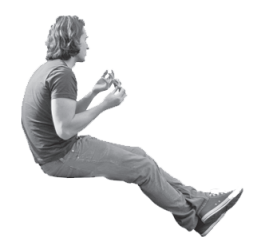

CAR PARKING
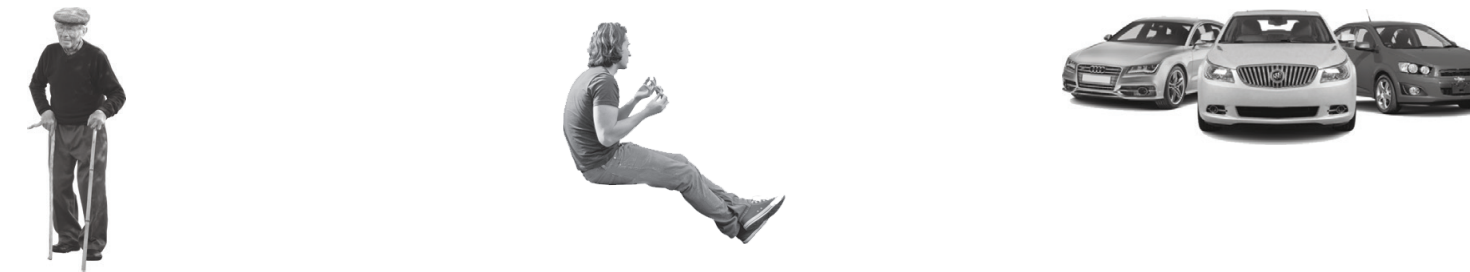

ACTIVITIES

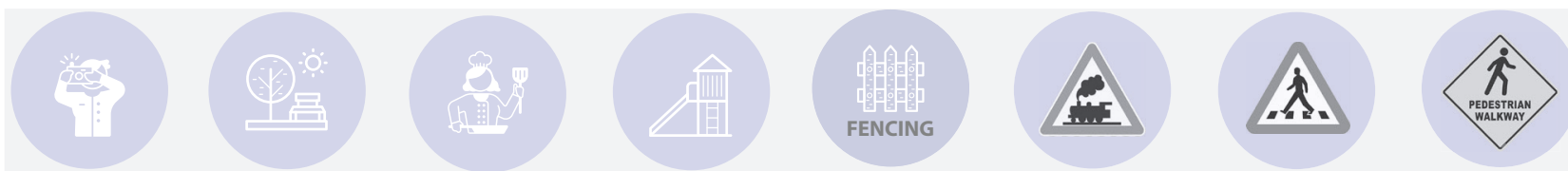

MODE OF TRANSPORT

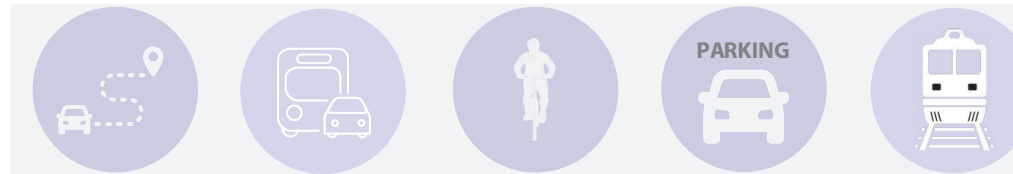




\section{E-W RAILWAY STATION CONNECTION STREET: Harington St}

\section{STREET USERS}

PEDESTRIANS

DOING BUSINESS

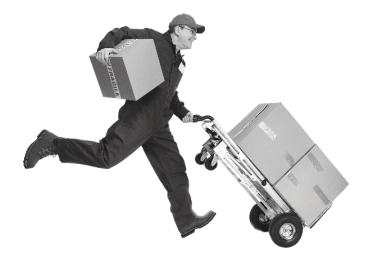

PRIVATE VEHICLE USERS

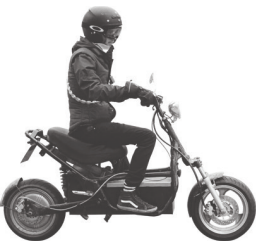

BUSINESS PEOPLE

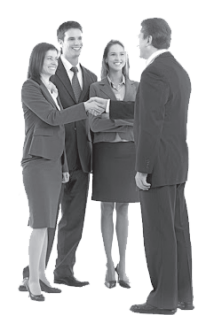

ACTIVITIES

STREET CAR PARKING

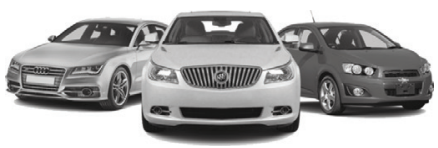

MODE OF TRANSPORT

\section{PUBLIC TRANSPORT PRIORITY SHARED STREET: Hamilton S}

\section{STREET USERS}

PEDESTRIANS

DOING BUSINESS

PRIVATE VEHICLE USERS

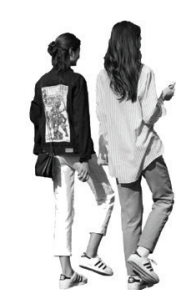

STREET CAR PARKING

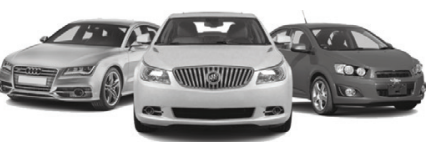

1.
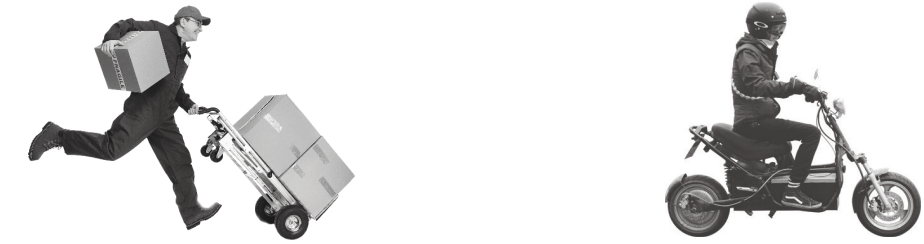

BUSINESS PEOPLE

ACCOMMODATION USERS
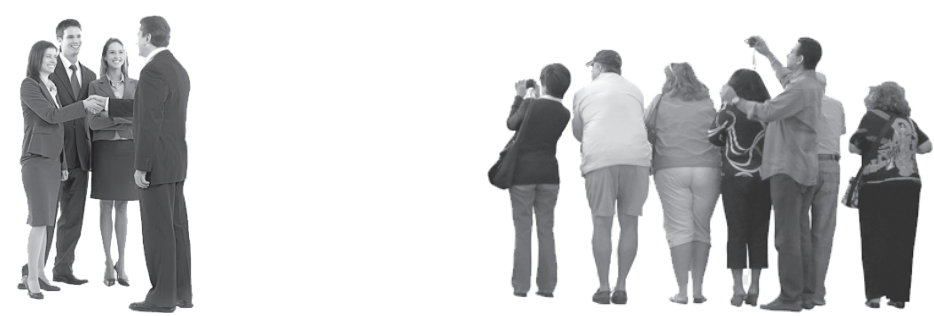

ACTIVITIES

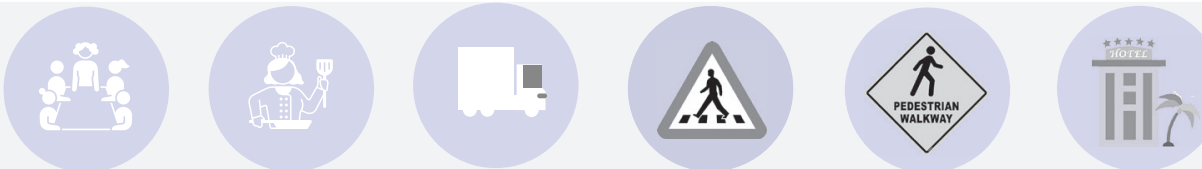

MODE OF TRANSPORT 
N-S CITY CONNECTION STREET: Willow St

\section{STREET USERS}

PEDESTRIANS

PRIVATE VEHICLE USERS

TAKING LOCAL TRANSIT USERS

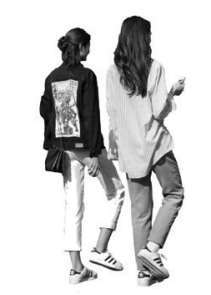

DOING BUSINESS

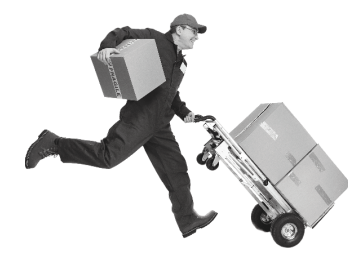

PEOPLE WITH DISABILITIES
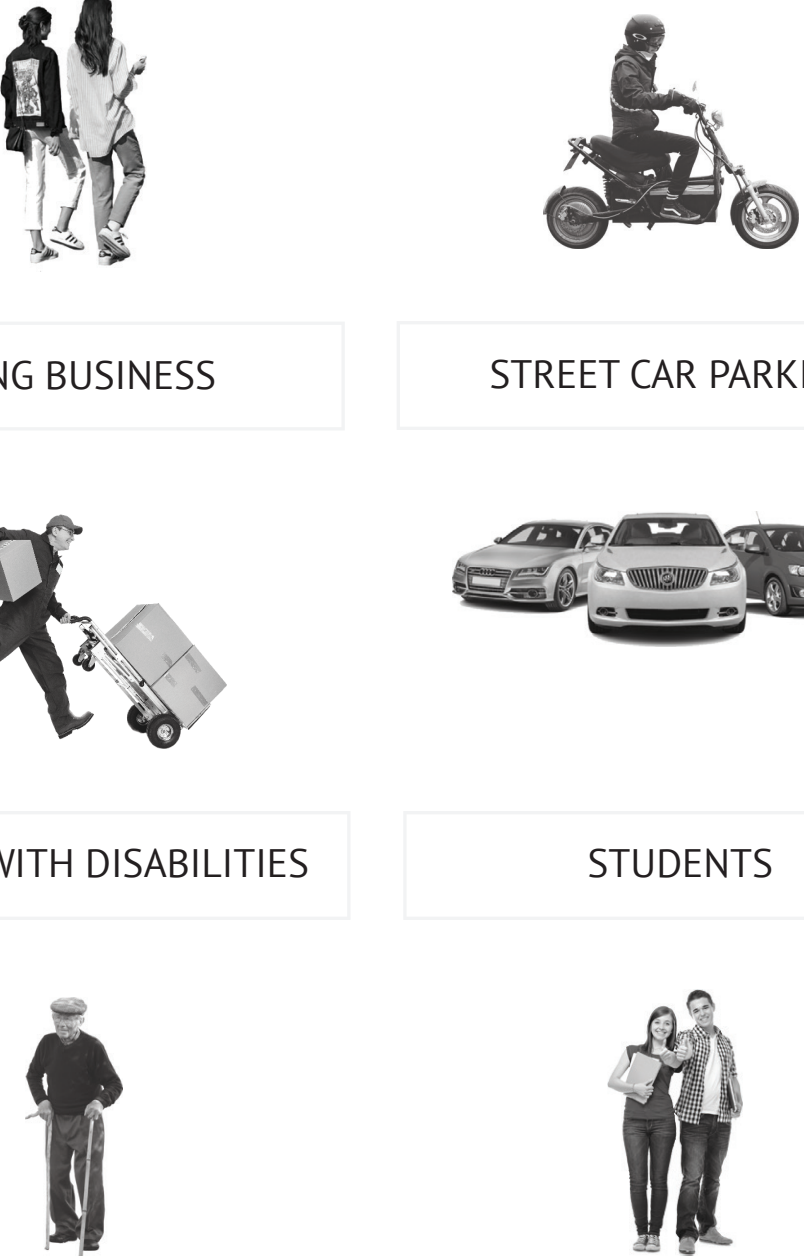

STREET CAR PARKING

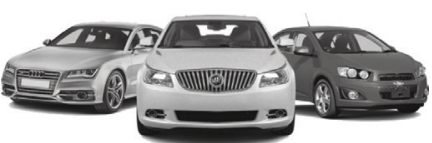

STUDENTS

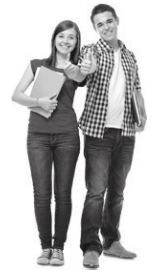

ACTIVITIES

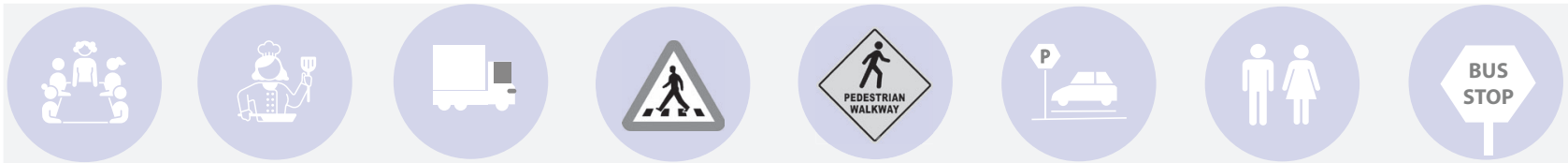

MODE OF TRANSPORT

CIVIC HEART STREET: Wharf St

\section{STREET USERS}

PEDESTRIANS

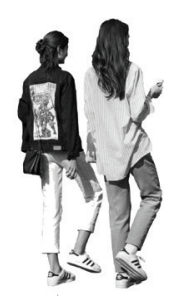

TAKING REGIONAL TRANSIT USERS

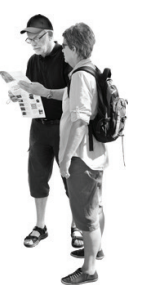

PRIVATE VEHICLE USERS

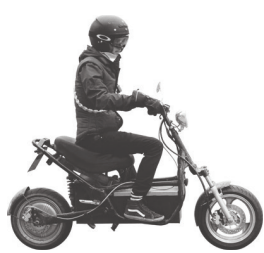

STREET CAR PARKING

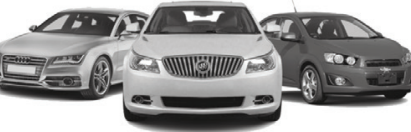

ACTIVITIES

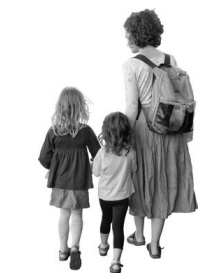

a)

MODE OF TRANSPORT

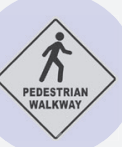

DOING BUSINESS

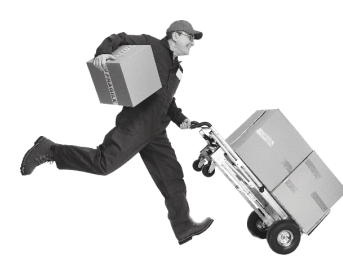

EATING DISTRICT

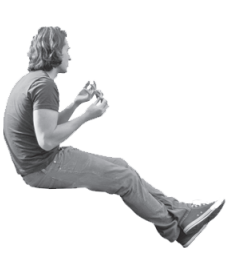




\section{GREEN STREET PARK: Durham Street}

STREET USERS

PEDESTRIANS

PRIVATE VEHICLE USERS

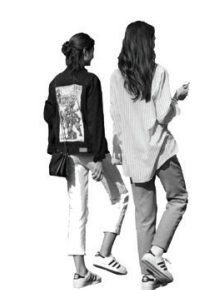

ACTIVITIES

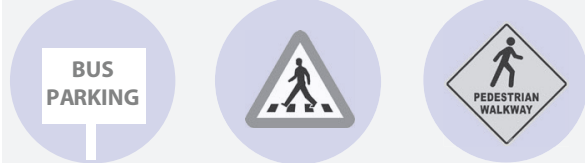

MODE OF TRANSPORT
CIVIC SOUARE TO WATERFRONT: Civic Square/ Masonic Park

\section{STREET USERS}

PEDESTRIANS

CAR PARKING

DOING BUSINESS
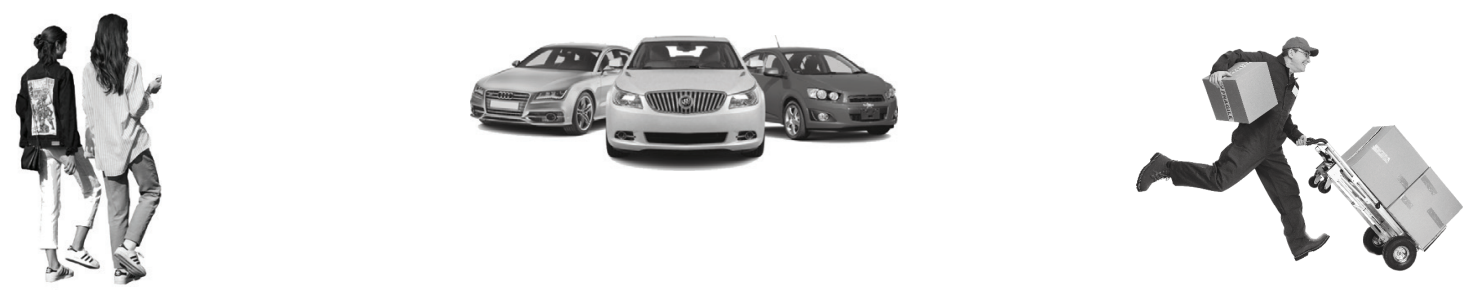

PRIVATE VEHICLE USERS

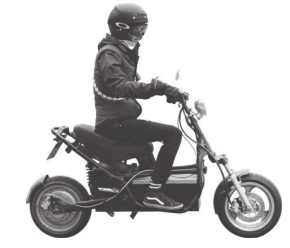

ACTIVITIES

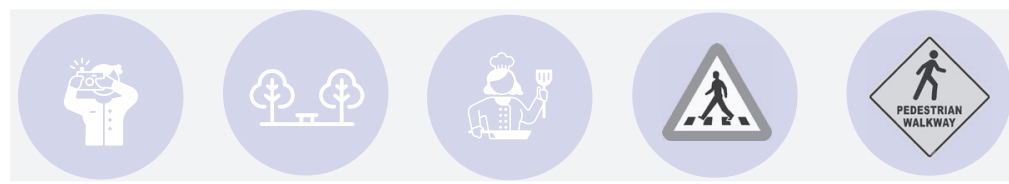

MODE OF TRANSPORT

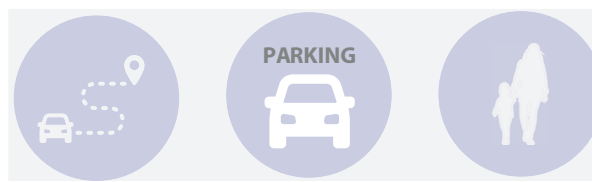




\section{Design Development}

The project has been developed the following five design strategies for the vision of 'Hybrid Street':

Sustainable Transport Priority Street, Active Street,

inear Park Street, Commercial Street and Transport

Interchange Street on 11 existing sites or streets in

Tauranga CBD area. These 'Hybrid Street Typologies'

indicate the direction of how to best activate the

space for both mobility and community life. 

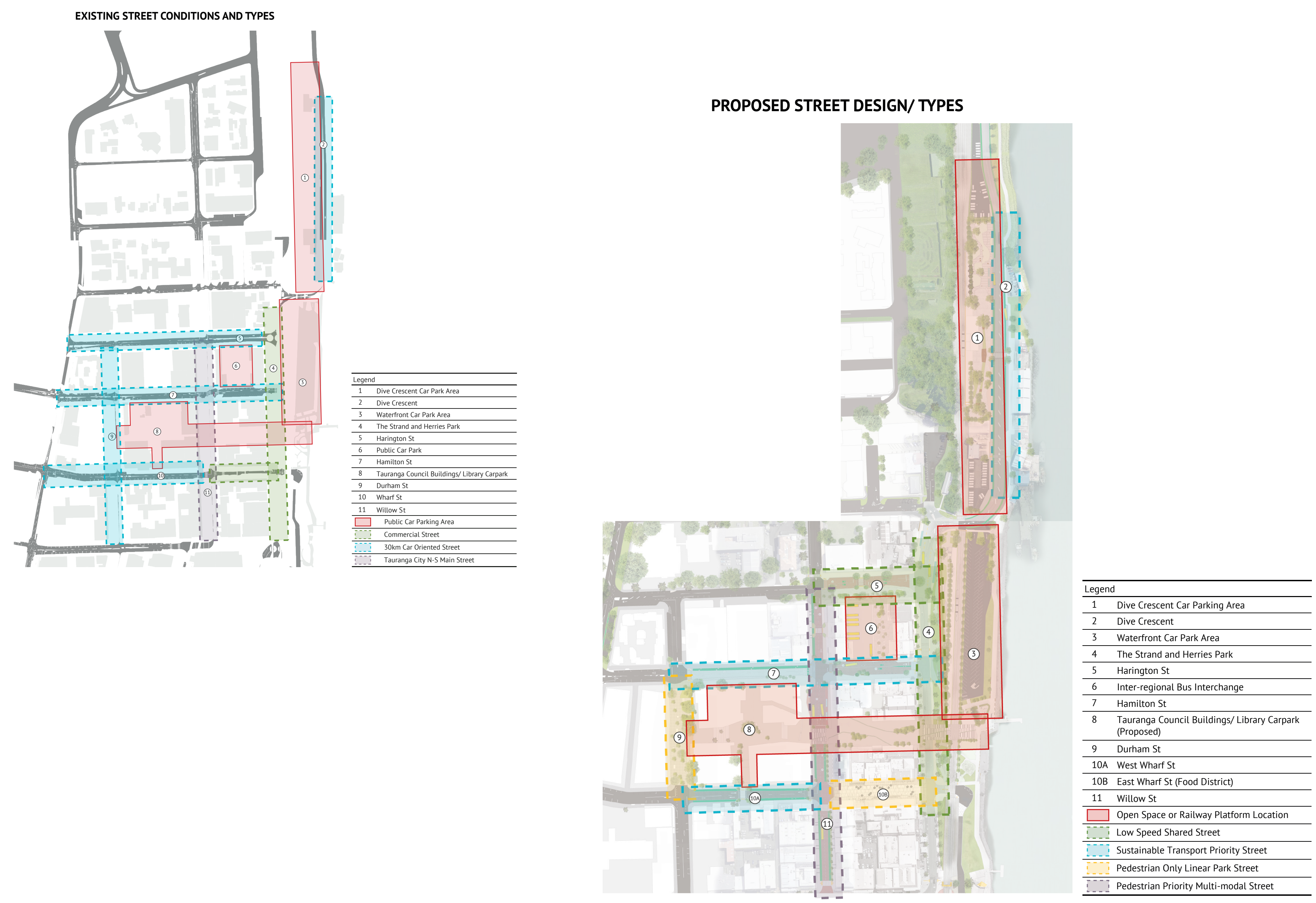


\section{Conceptual Approach}

Design framework advocates a pedestrian and transit-friendly streetscape connecting the rail lines to encourage street activities on the urban and suburban fabric, and also supports other types of sustainable transport modes. A hybrid term of street typology articulates a vision and strategic approach with design criteria to advance key objectives.

The research objective has been investigated from a research question of 'How to avoid the mono-

functional logics of street with its public transport connections and how to translate it to a hybrid space that supports a variety of different types of sustainable transport modes to improve the accessibility between the neighbourhoods, cities, sub-regions and region.

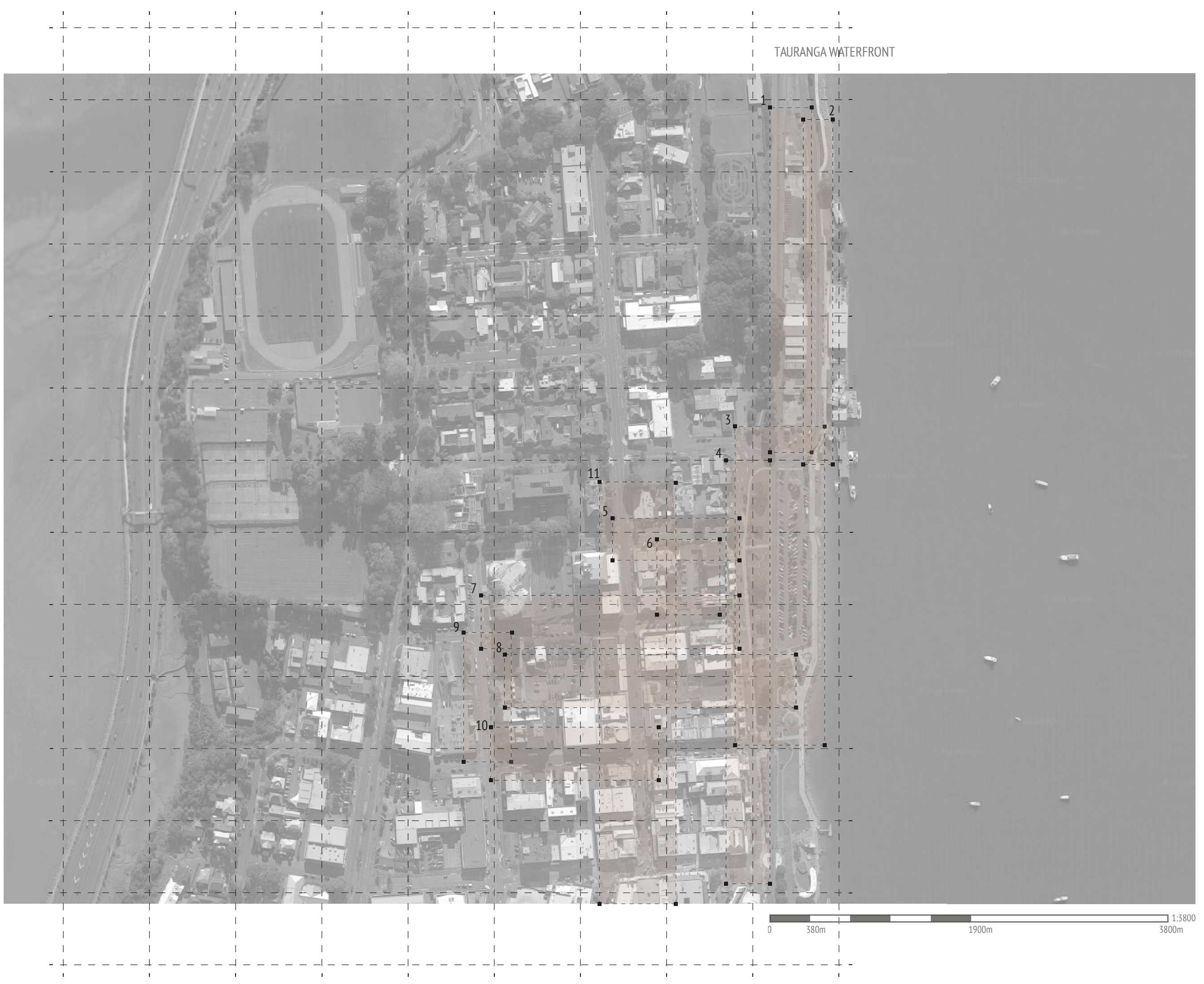




\section{SITES}

1 Railway Platform A Location \& Station Park : A series of raised and recessed landscape structures, paved areas along the street providing a sequence of urban station park and public transit-friendly street.

3 Railway Platform B Location \& Station Park :Vegetation protection, creating two entrance points for regional trips and paved areas along the street providing a sequence of urban station park.

6 Regional Bus Interchange \& Open Space Provide spaces for sustainable transport uses which include walking and cycling, taxi and regional bus.

8 Civic Square Plaza

1. Provide a pedestrian-only connection from Civic square to Tauranga waterfront area.

2. Offering urban activities including walking and cycling, play-along-the-way, picnic and rest.

\section{HYBRID STREETS}

2 Sustainable Transport Priority Street

: Provide spaces for sustainable transport uses which include walking and cycling, rapid rail and local bus.

4 Low Speed Shared Street

: Provide spaces for commercial uses such as shopping and outdoor dining.

5 Low Speed Activate Street

Provide spaces for urban activities such as play-along-the-way, picnic and rest.

7 Sustainable Transport Priority Street

: Accessible street to support sustainable transport modes connecting the Bus-Interchange and Railway Platform B.

Pedestrian Only Linear Park Street

Creating an accessible street park connecting proposed Hotel area, Civic Suqare and Waterfront.

- Sustainable Transport Priority Street (West Wharf St) \& Food District Street (East Wharf St)

: Offering urban activities including walking and cycling, play-along-the-way, picnic and rest. 


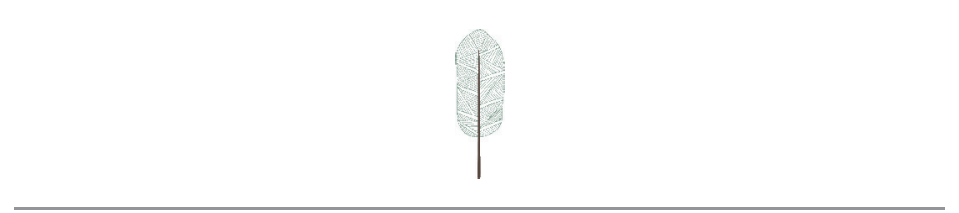

09. Design Development 9.2. TAURANGA City Streets

\# 162 


\section{Site Plan}
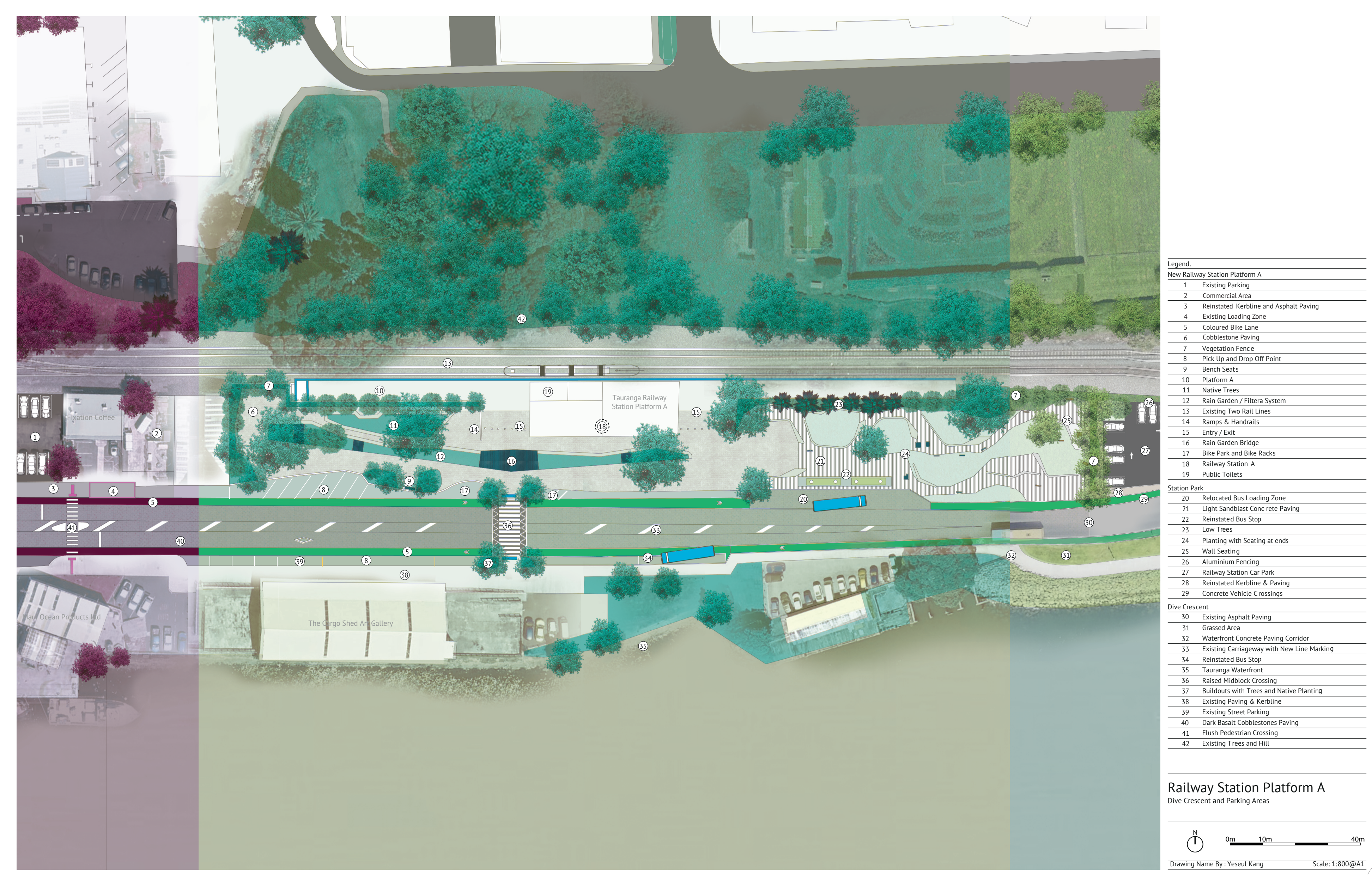

Railway Station Platform A

Dive Crescent and Parking Aress

$\stackrel{\mathrm{N}}{\mathrm{Om} \quad 10 \mathrm{~m}} \underset{\text { Scale: } 1: 800 @ \mathrm{QA1}}{40 \mathrm{~m}}$ 


\section{Site Programming}

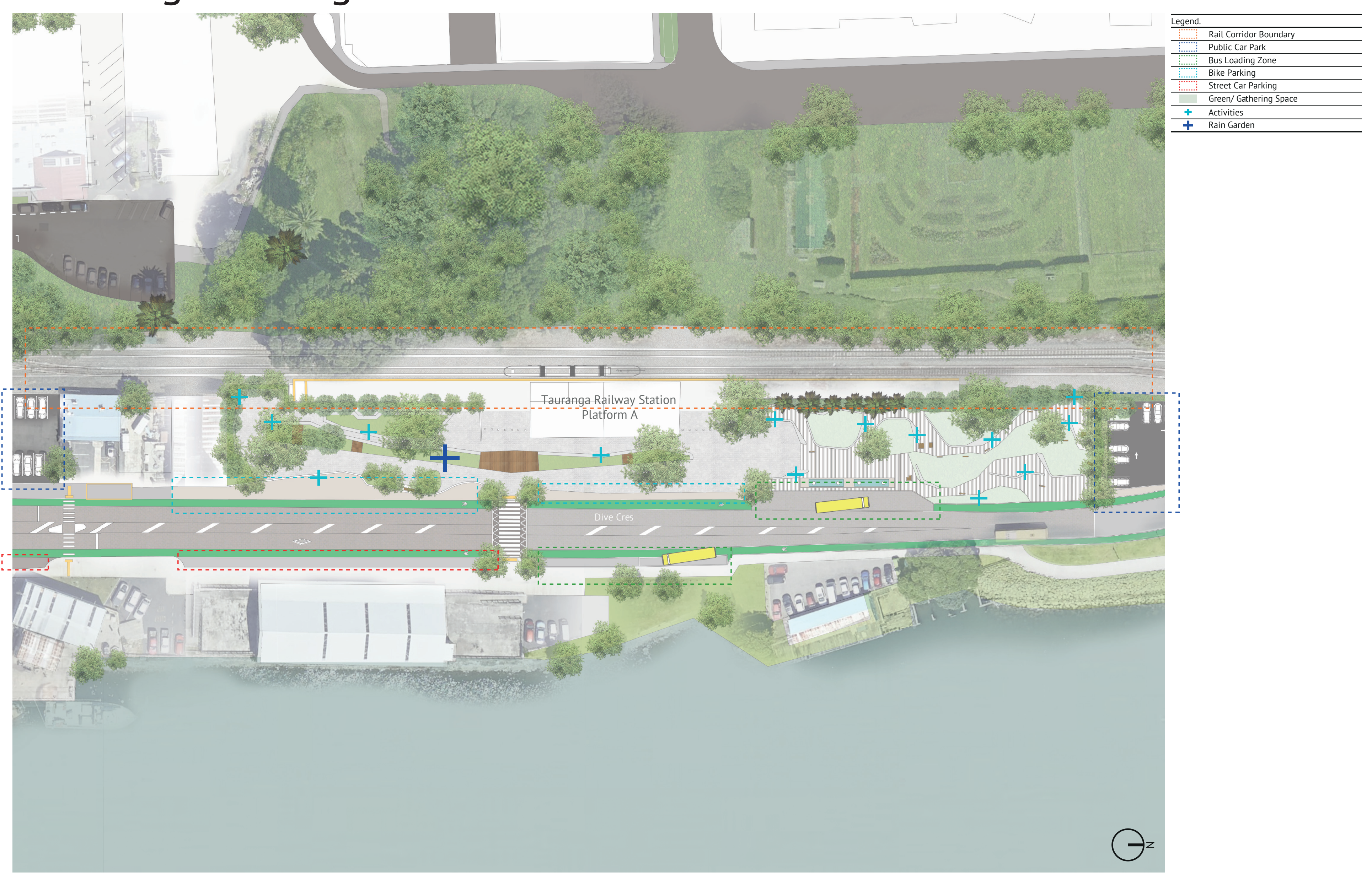




\section{Movement}

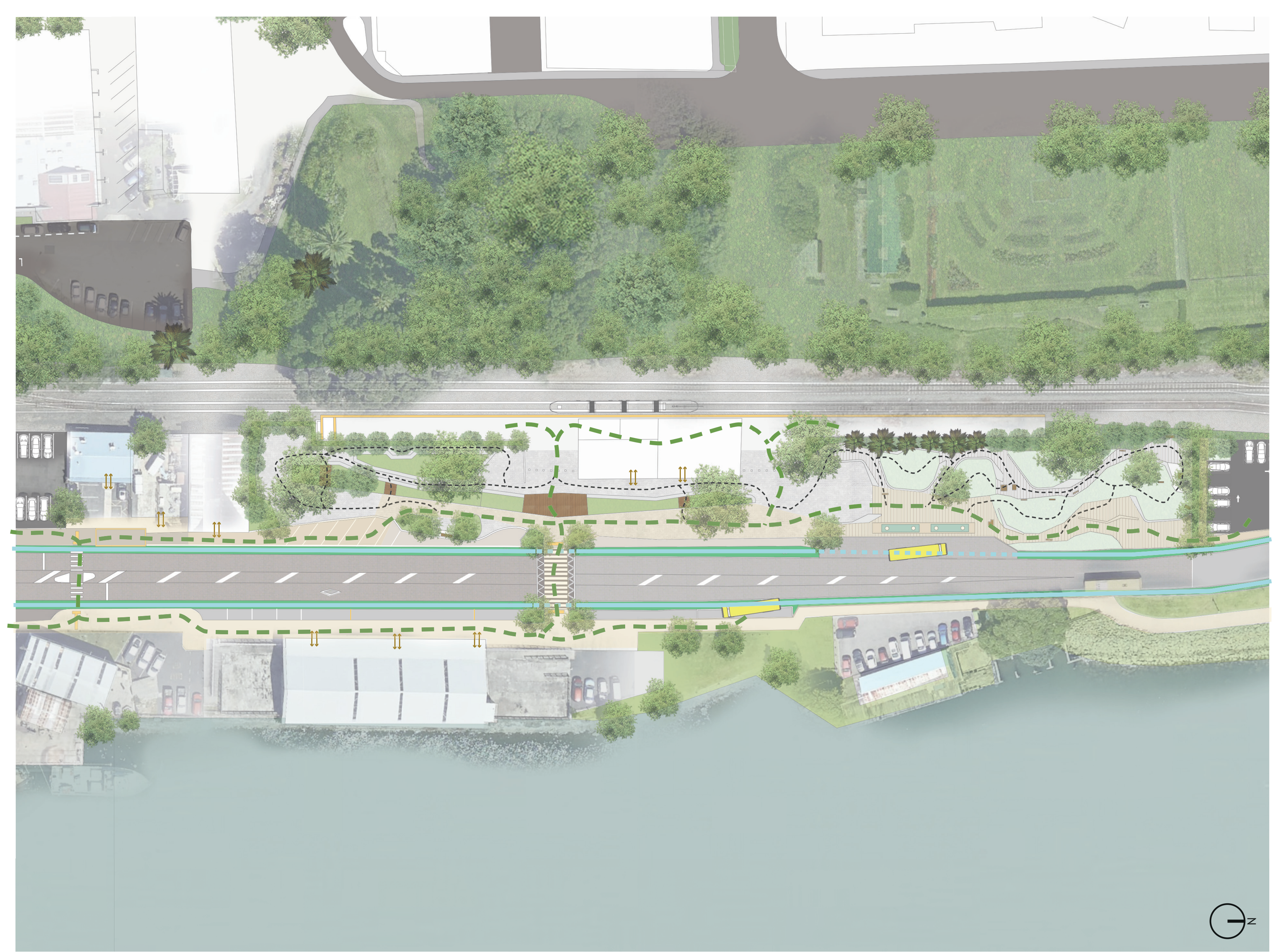




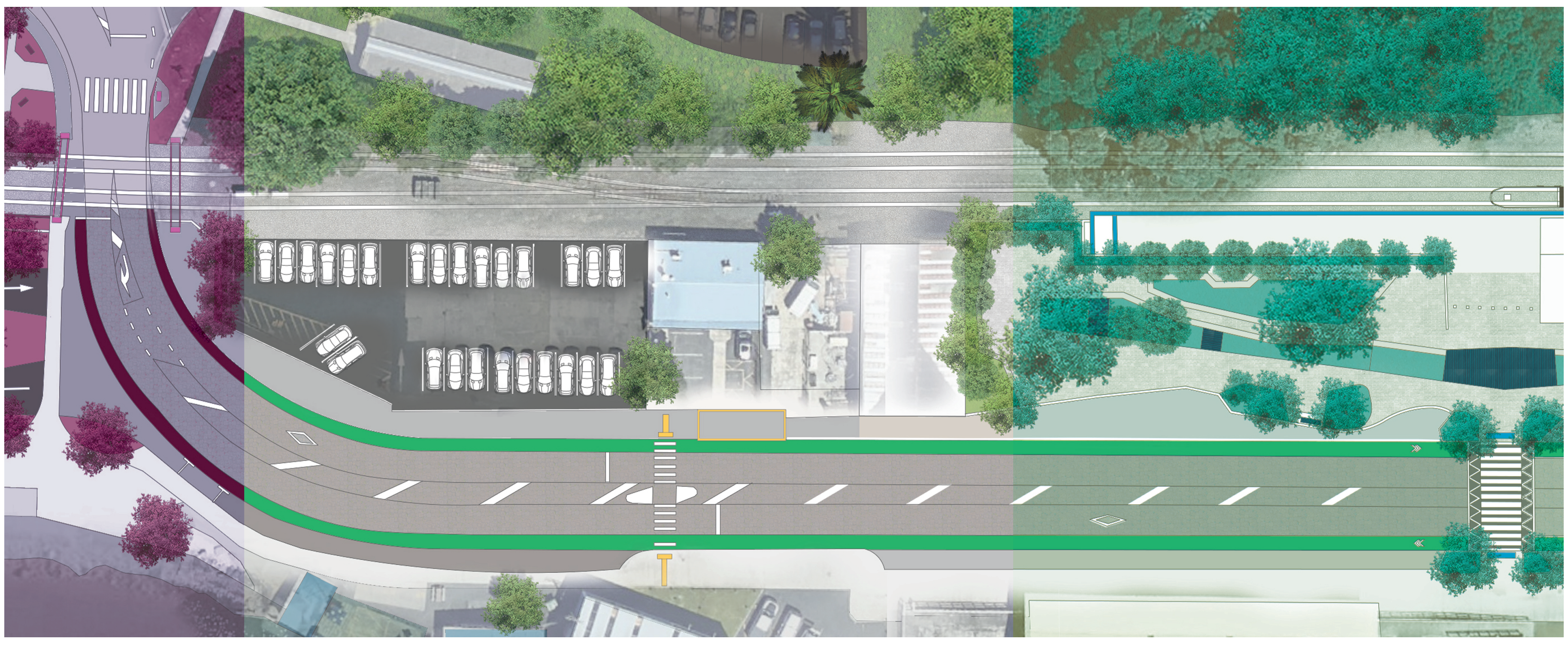

\section{WATERFRONT RAILWAY STATION}

STREET 1: Dive Crescent/ Parking Areas

\section{Public Transport}

\section{Supported Street}

Design Objectives:

1. Street Focused on Sustainable Transport Modes

(Hybrid Street Type 1)

2. Linear Park Street (Hybrid Street Type 3)

Railway Platform A Location \& Station Park

: A series of raised and recessed landscape

structures, paved areas along the street providing

a sequence of urban station park and public

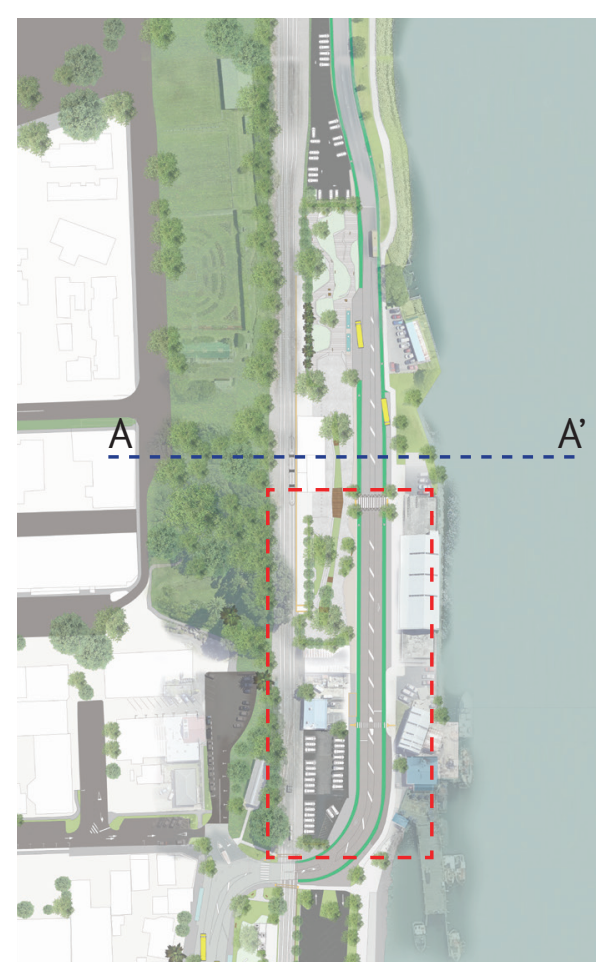

transit-friendly street. 


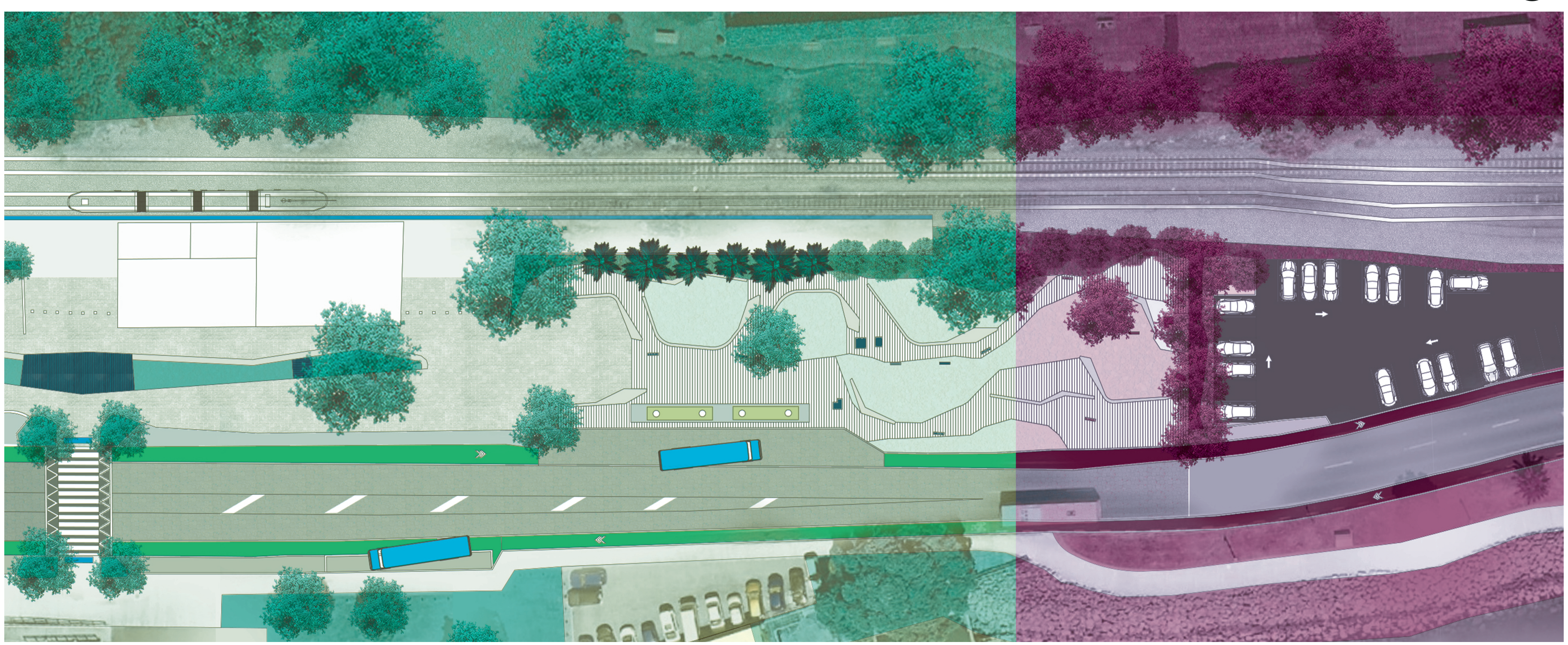

\section{WATERFRONT RAILWAY STATION}

STREET 1: Dive Crescent/ Parking Areas

\section{Public Transport Supported Street}

Design Objectives:

1. Street Focused on Sustainable Transport Modes

(Hybrid Street Type 1)

2. Linear Park Street (Hybrid Street Type 3)

Sustainable Transport Priority Street

- Provide spaces for sustainable transport uses

which include walking and cycling, rapid rail and

local bus.

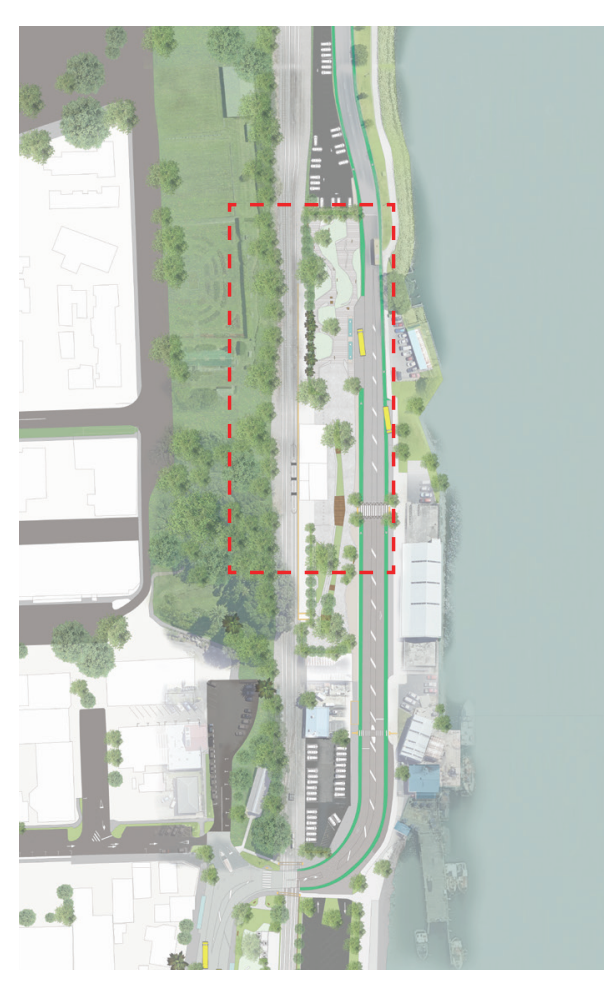




\section{Waterfront Railway Station Street 1}
1 Vegetation Buffer
(2) Maintenance Zone
(3) Railway Track
(4) Station
5 Open Space
6 Rain Garden
7 Footpath
8 Cycleway
(9) Hybrid Street Type 1

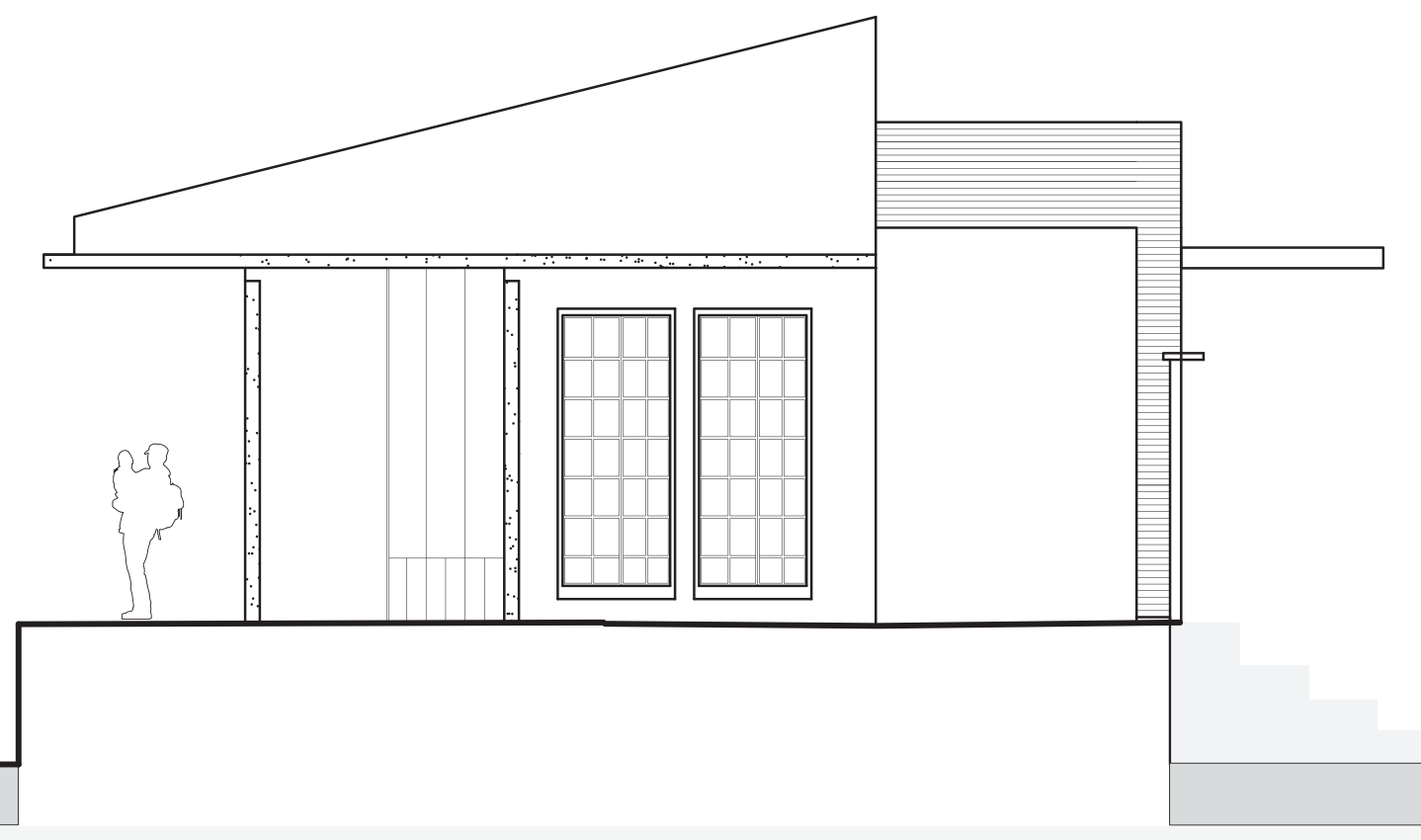

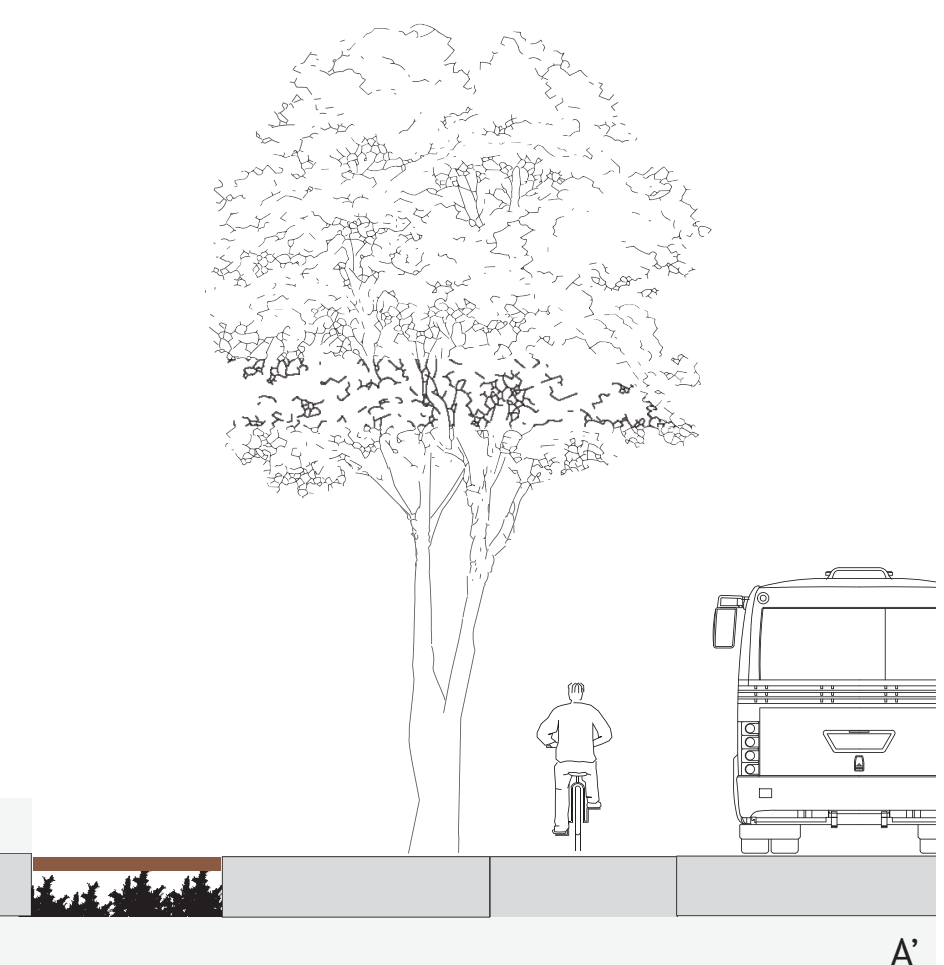

6

(7) 8 


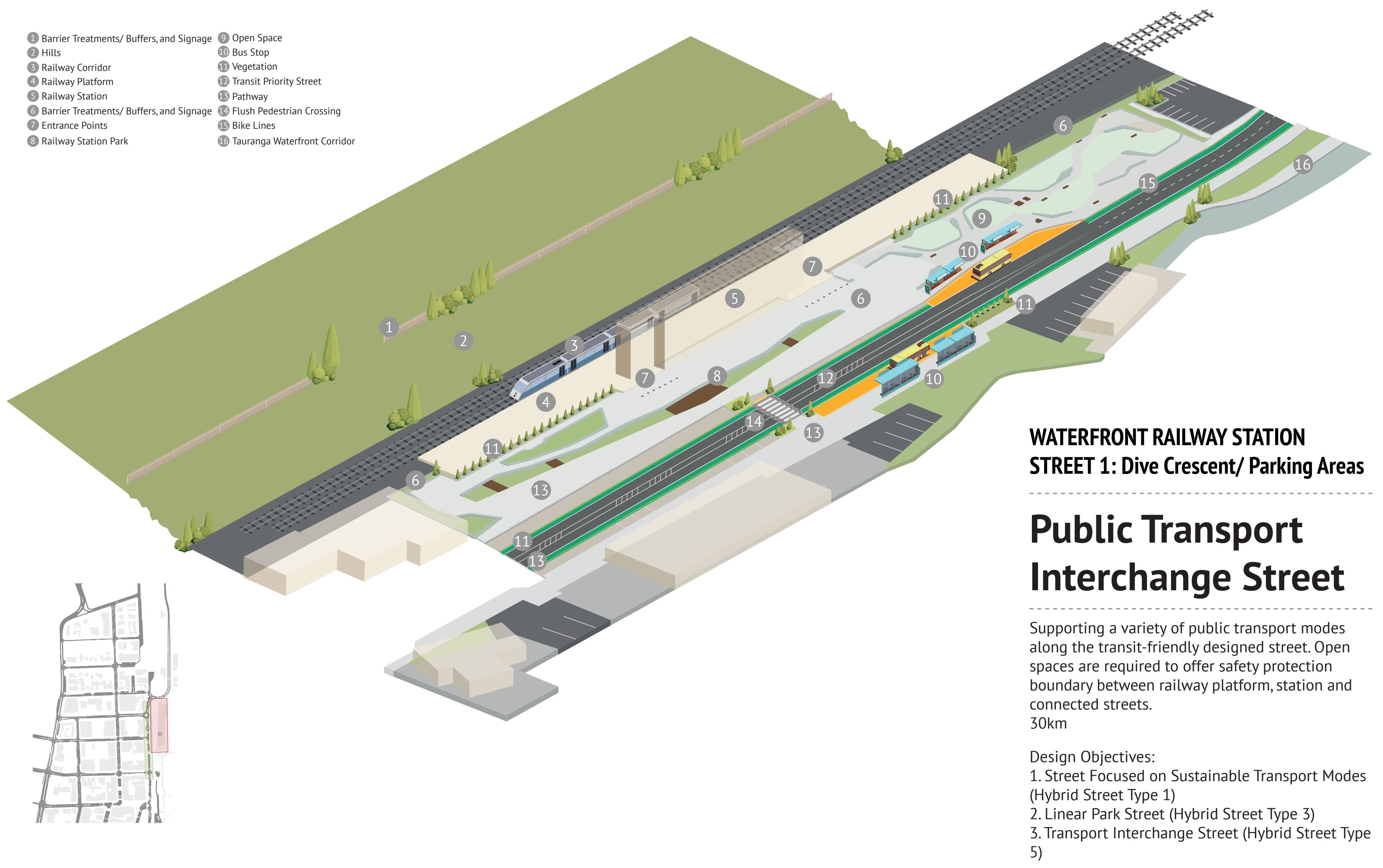


WATERFRONT OLD RAILWAY STATION STREET 1: Dive Crescent/ Dive Crescent Parking Areas

\section{STREET USERS}

CYCLISTS DOING BUSINESS
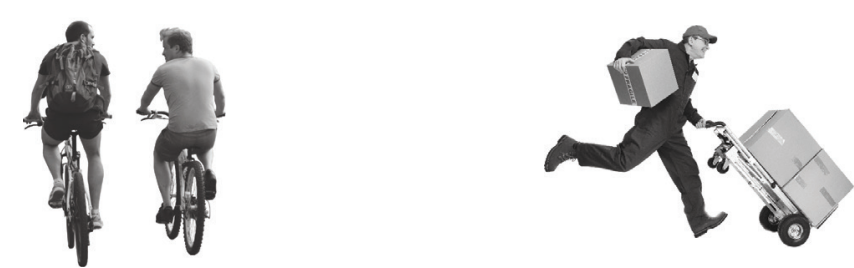

CAR PARKING

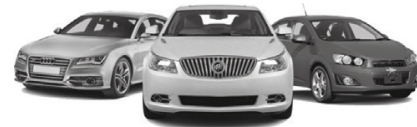

ACTIVITIES

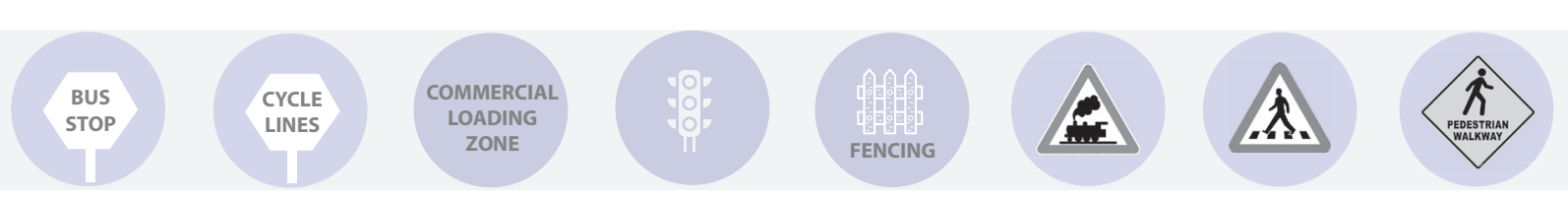

MODE OF TRANSPORT
WATERFRONT OLD RAILWAY STATION STREET 1: Dive Crescent/ Dive Crescent Parking Areas

\section{STREET USERS}

PEDESTRIANS PRIVATE VEHICLE USERS TAKING LOCAL TRANSIT USERS

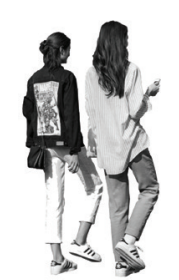

DOING BUSINESS
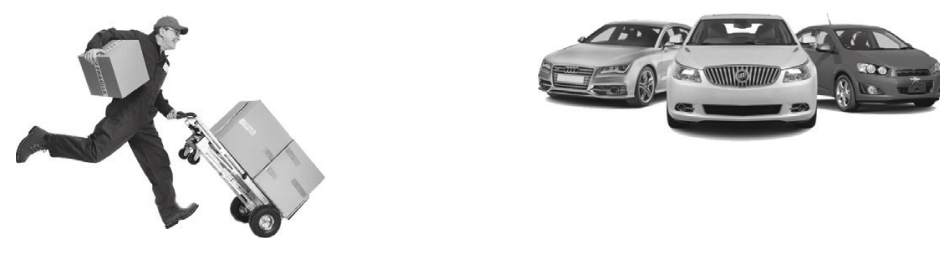

STUDENTS

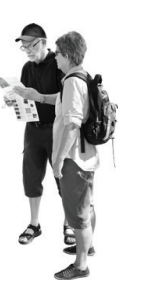

CYCLISTS

PEOPLE WITH DISABILITIES
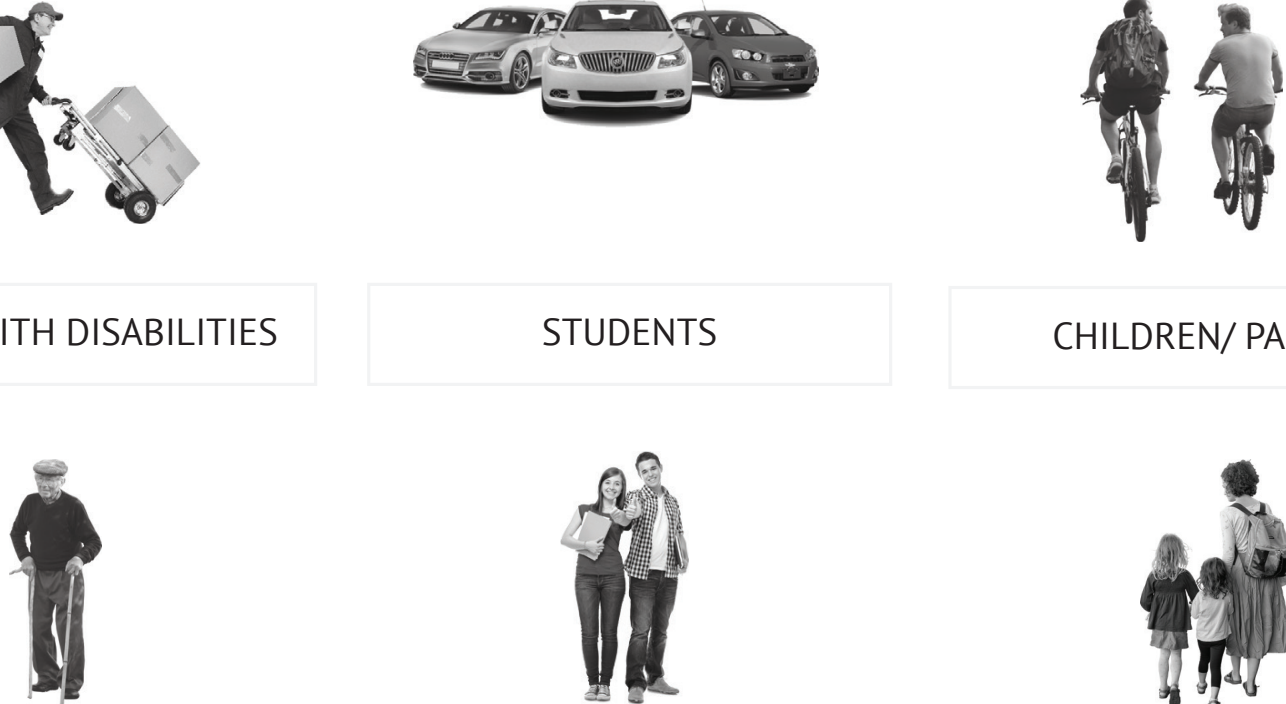

CHILDREN/ PARENT

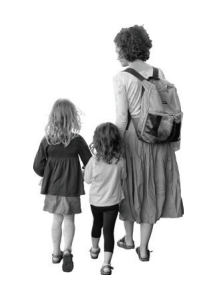

ACTIVITIES

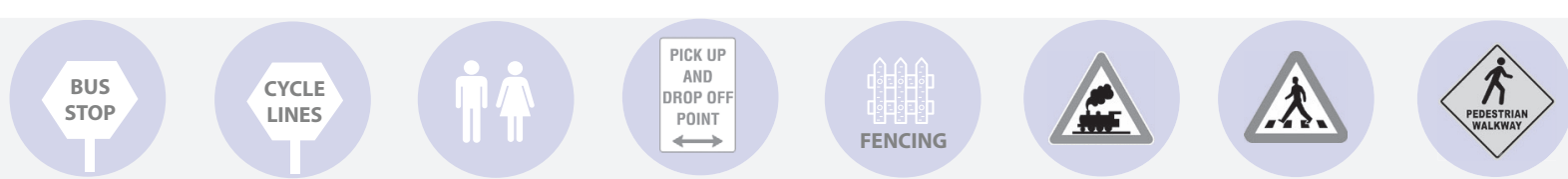

MODE OF TRANSPORT

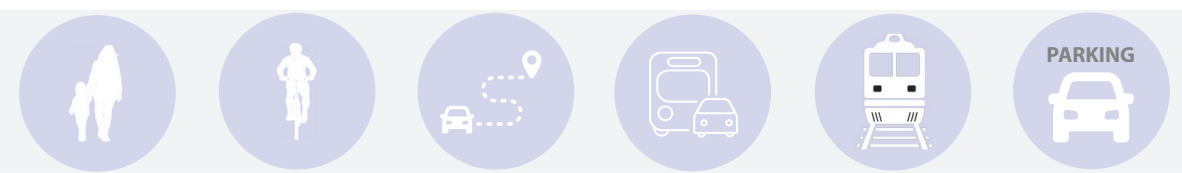




\section{Site Plan}
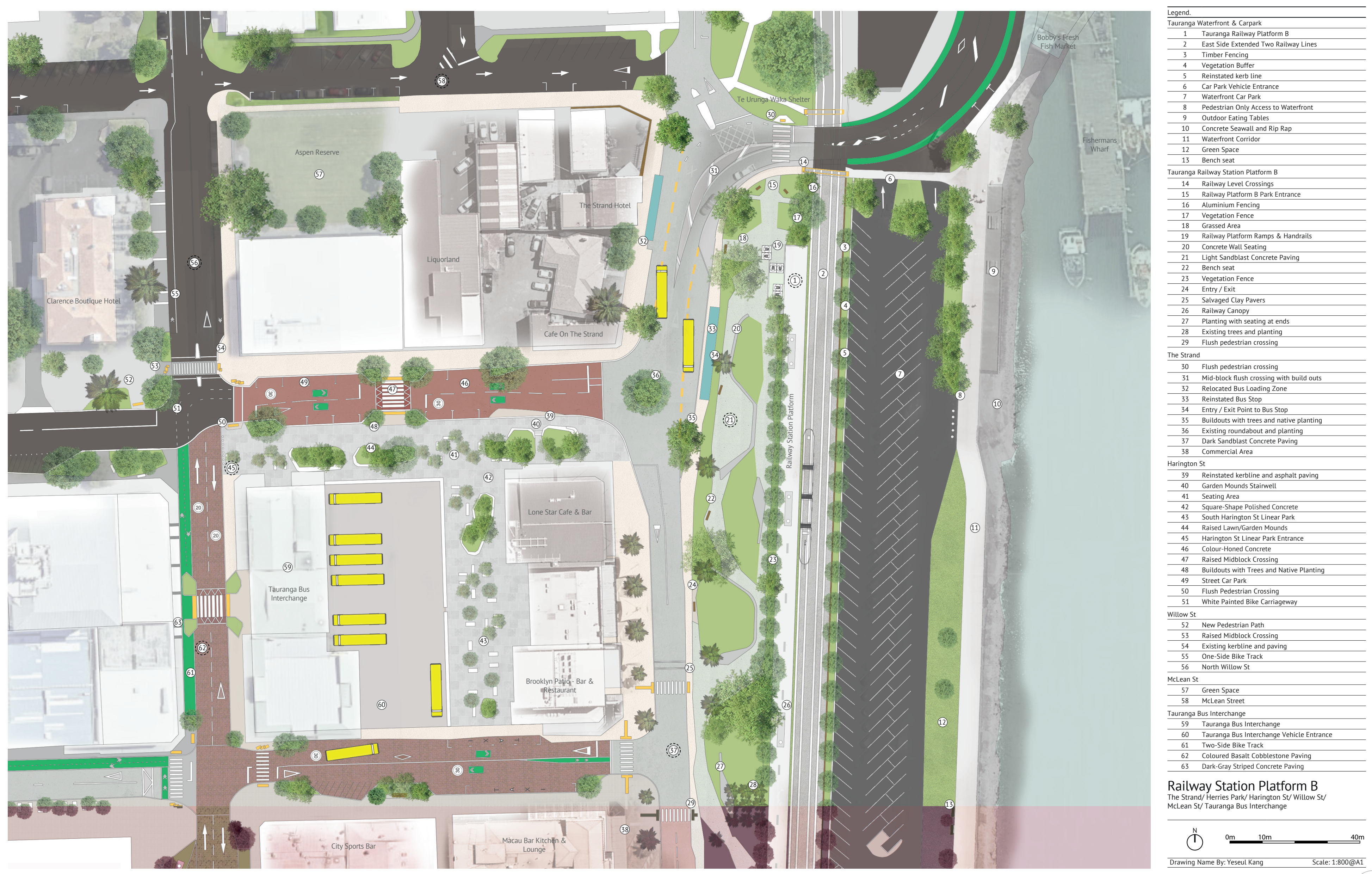


\section{Site Programming}

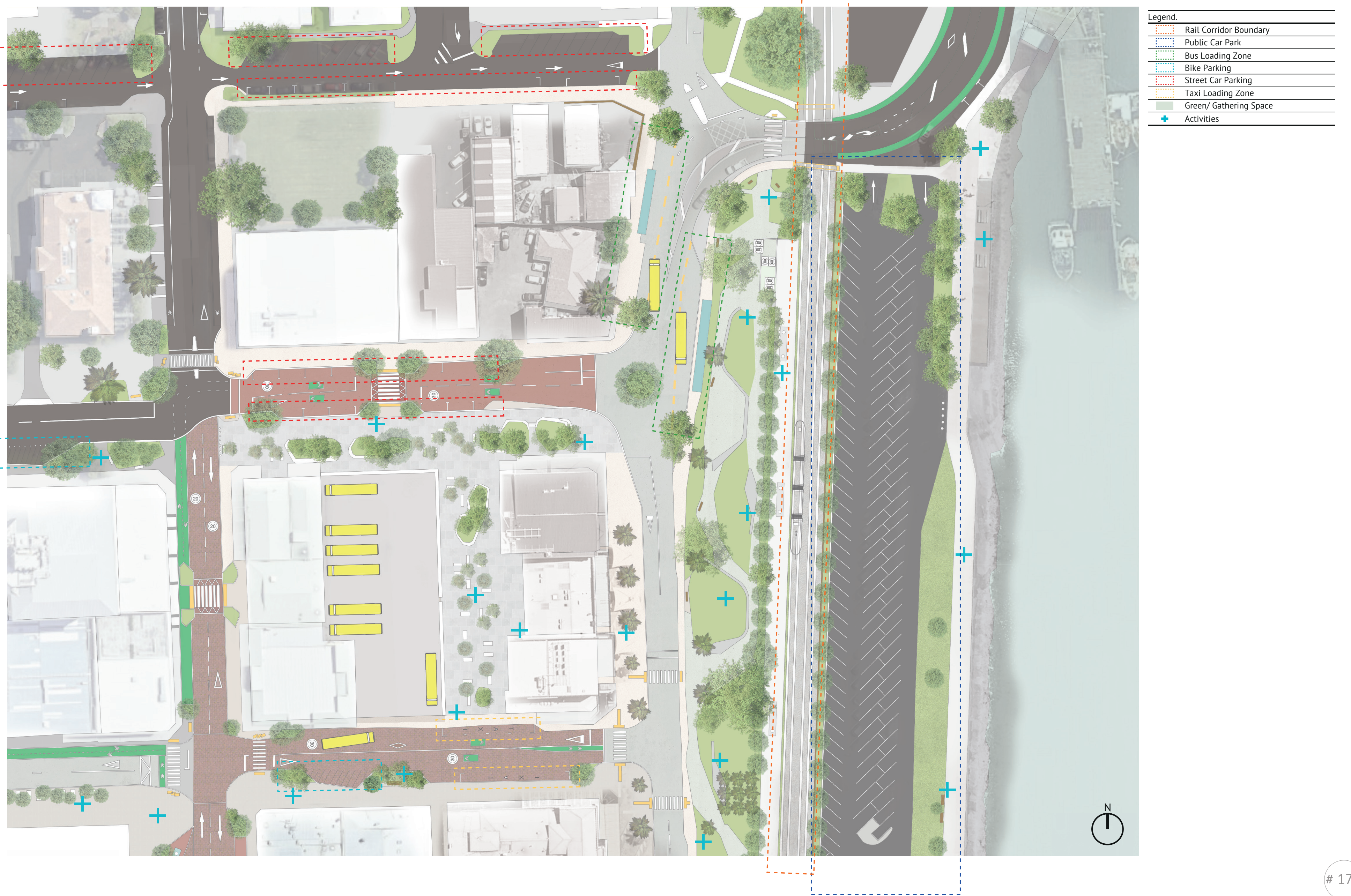




\section{Movement}

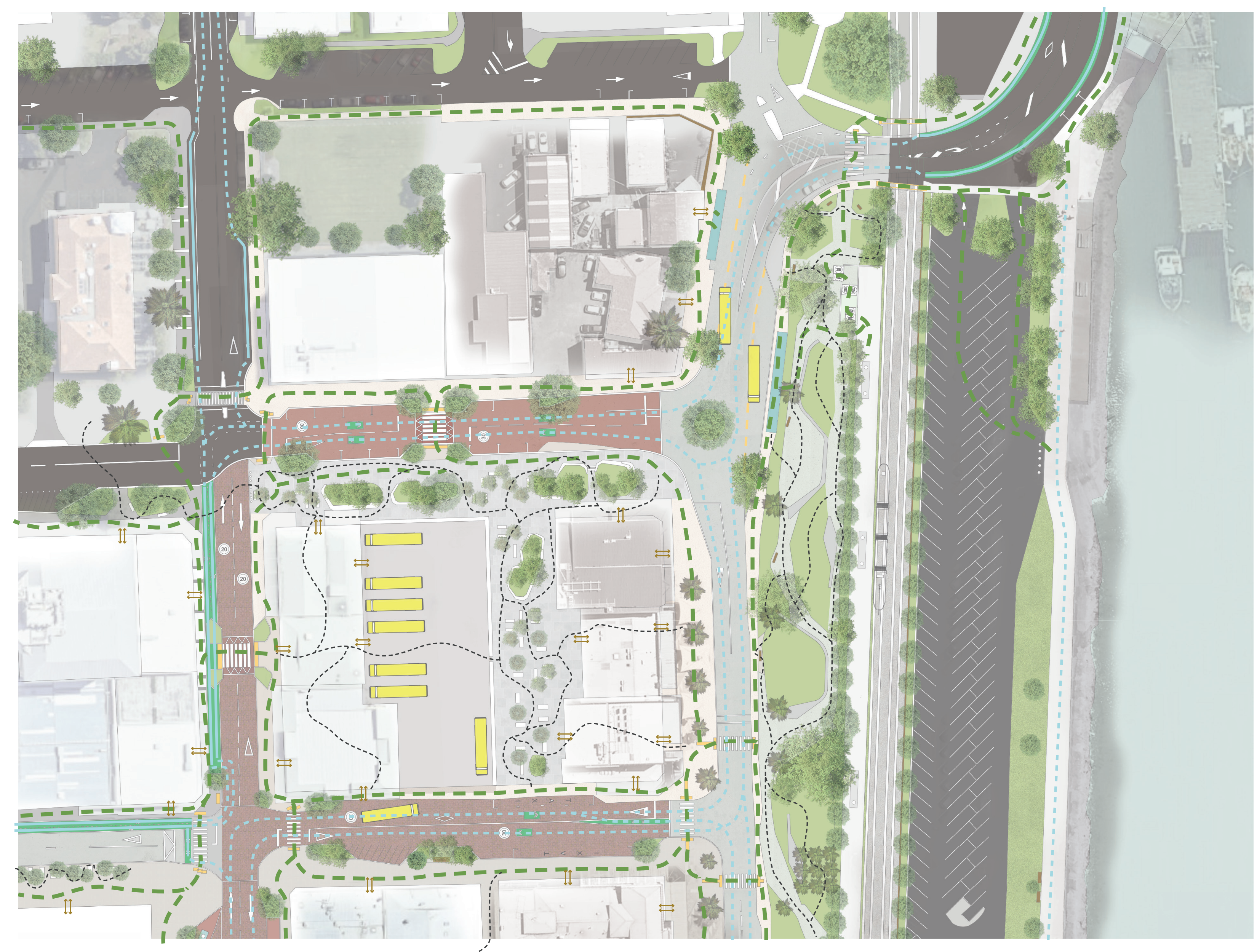




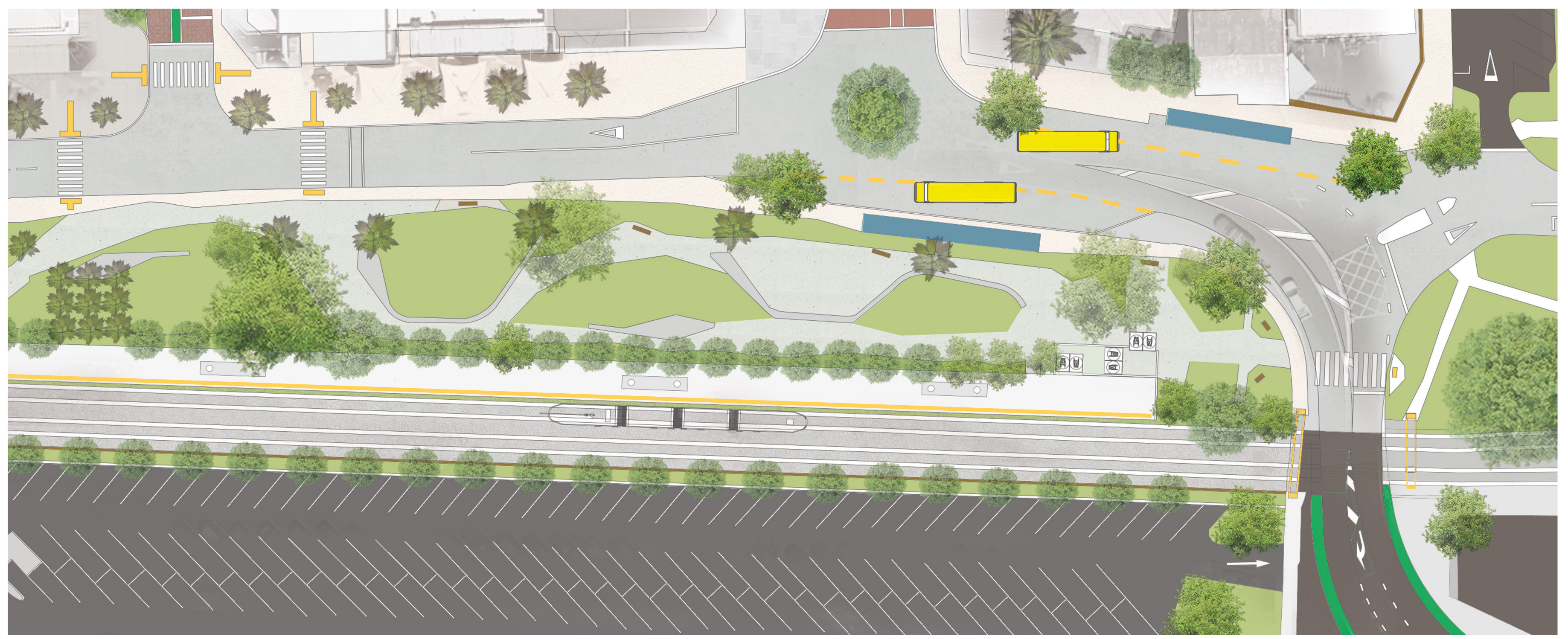

WATERFRONT RAILWAY STATION AREA/ STREET 2: The Strand/ Herries Park

\section{Waterfront Precinct}

\section{Shared Spaces}

\section{Design Objectives:}

\section{Design Objectives:}

1. Linear Park Street (Hybrid Street Type 3)

2. Commercial Street (Hybrid Street Type 4)

3. Transport Interchange Street (Hybrid Street

Type 5)

Railway Platform B Location \& Station Park

Vegetation protection, creating two entrance

points for regional trips and paved areas along

the street providing a sequence of urban station

park.
Detail Drawing (1:500) in A3

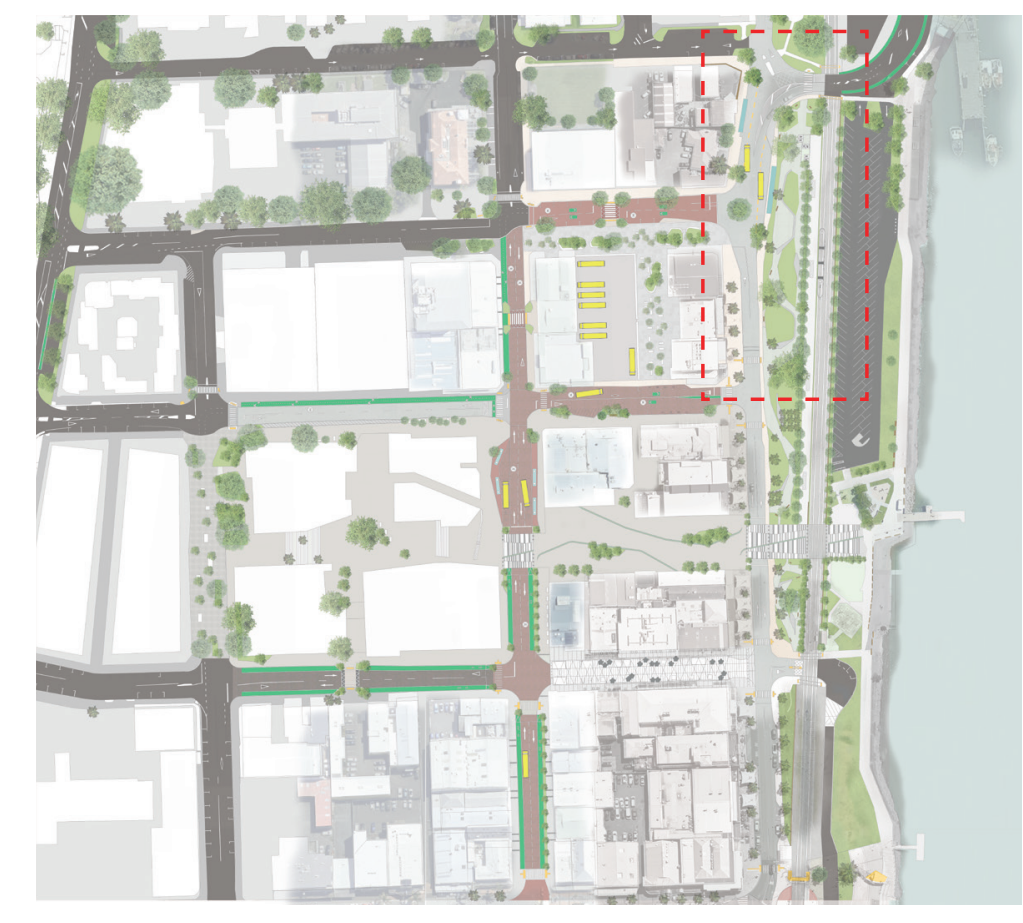




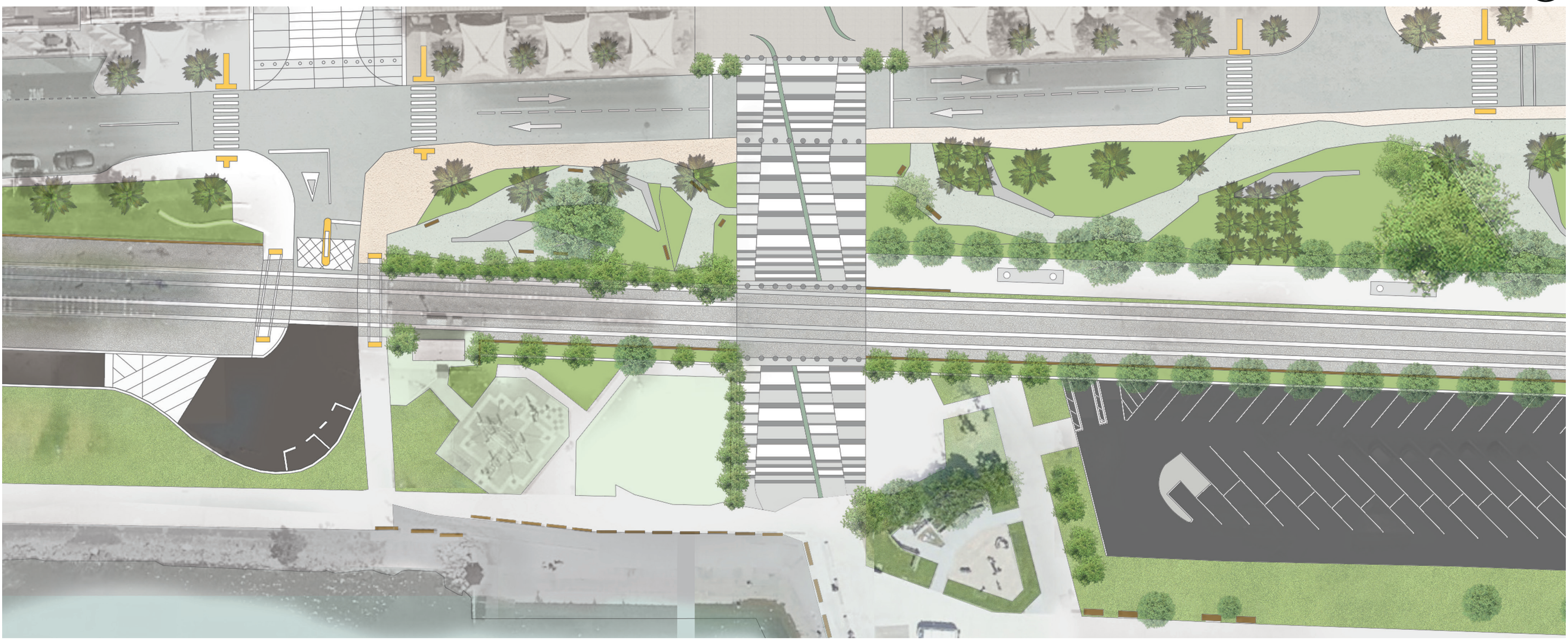

WATERFRONT RAILWAY STATION AREA/

STREET 2: The Strand/ Herries Park

\section{Waterfront Precinct}

\section{Shared Spaces}

\section{Design Objectives:}

Design Objectives:

1. Linear Park Street (Hybrid Street Type 3)

2. Commercial Street (Hybrid Street Type 4)

3. Transport Interchange Street (Hybrid Street

Type 5

Low Speed Shared Street

Provide spaces for commercial uses such as

shopping and outdoor dining.

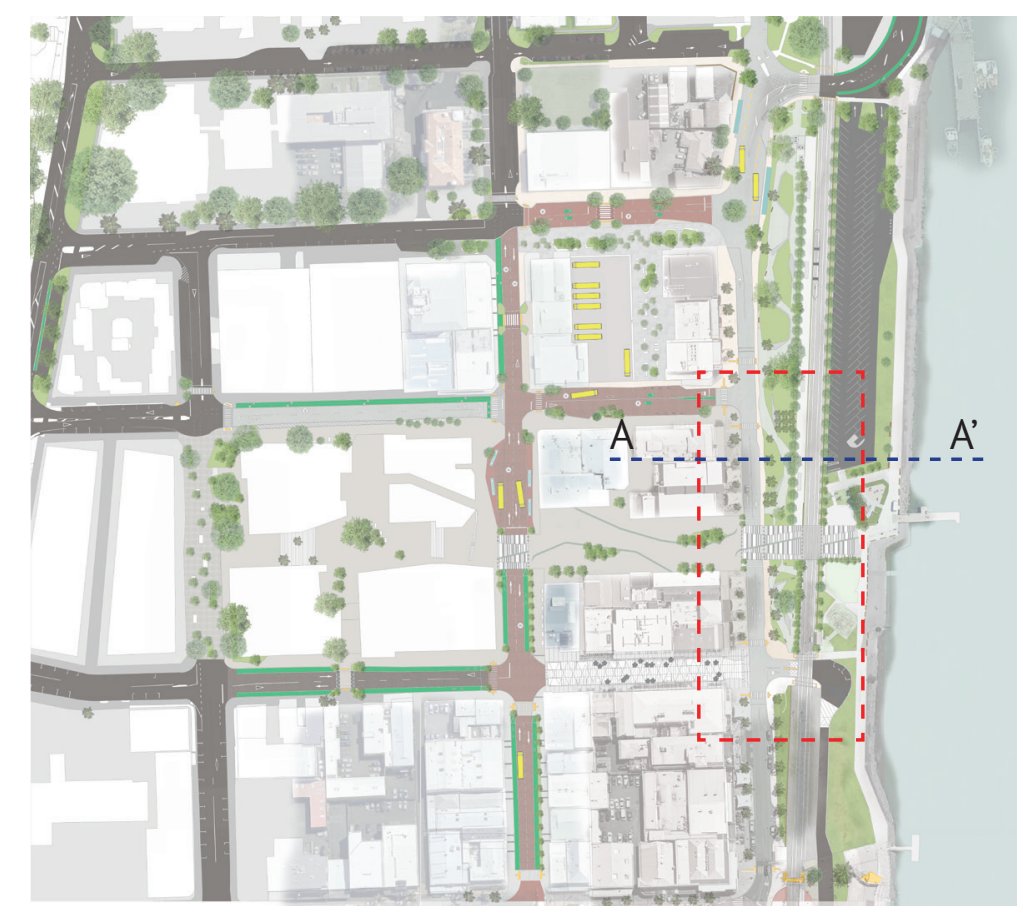


WATERFRONT CORRIDORS

Waterfront Railway Station 2

(1) Footpath

(2) Vegetation Buffer

(3) Verge

(4) Barriers

5 Rail

6 Embankment

(7) Open Space

8 Natural Barrier

9 Harbour Bus/ Ferry Stops

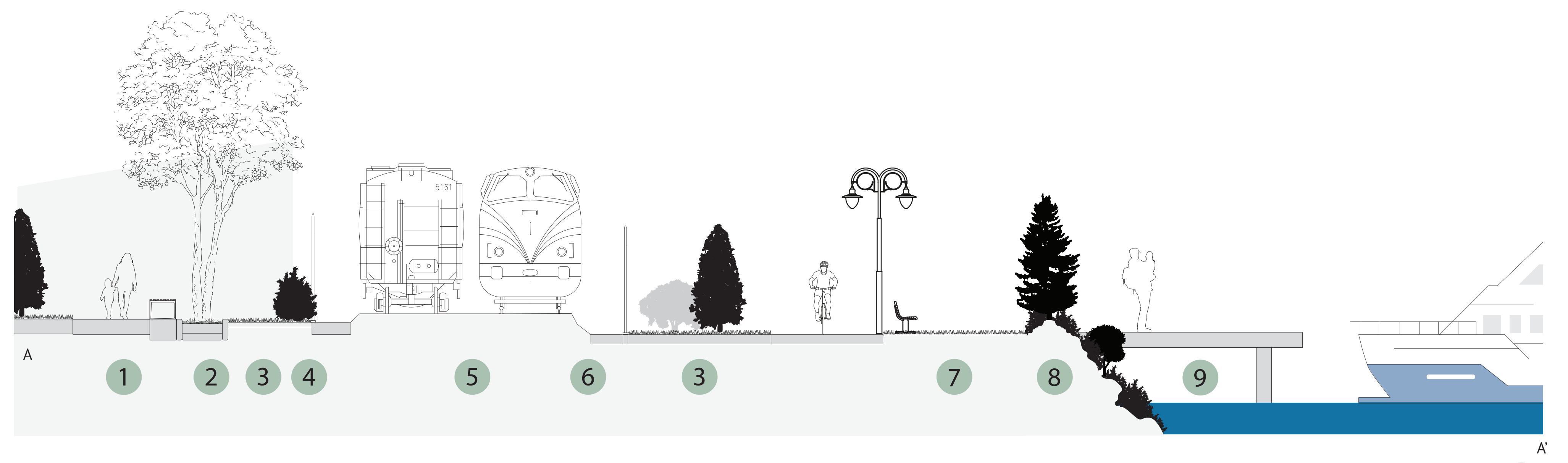




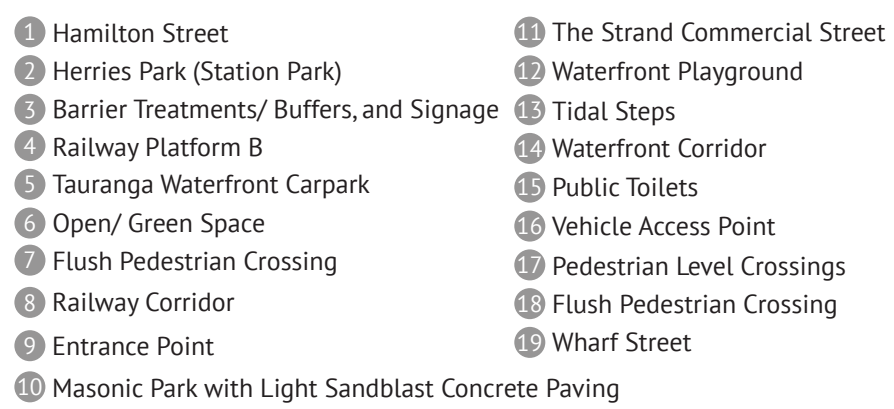

(1)




\section{WATERFRONT OLD RAILWAY STATION STREET 2: The Strand/ Herries Park}

\section{STREET USERS}

PEDESTRIANS

DOING BUSINESS
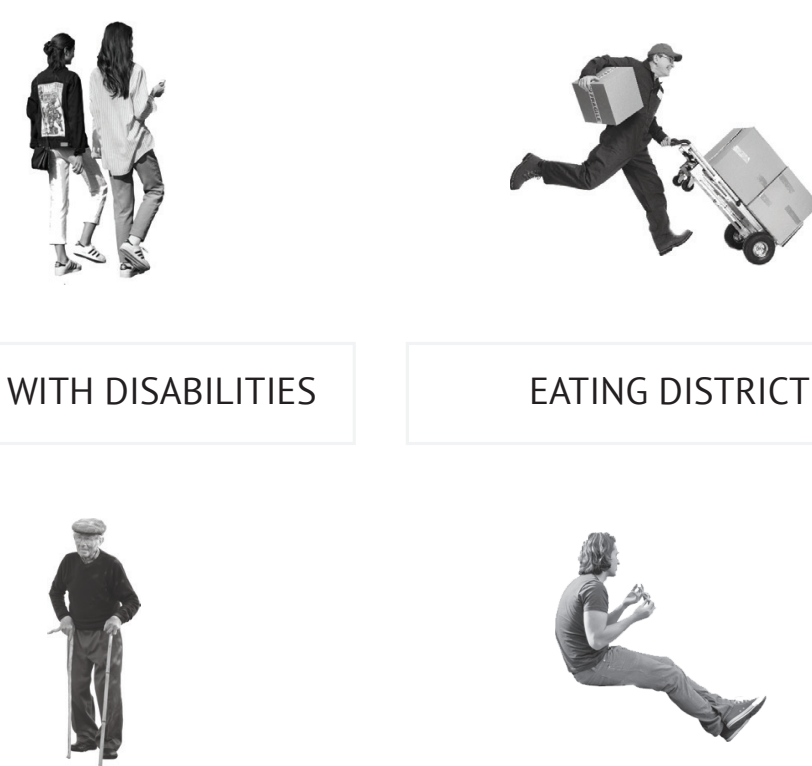

EATING DISTRICT

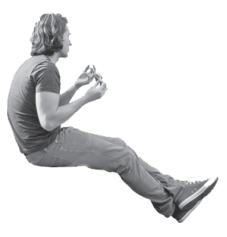

PEOPLE WITH DISABILITIES

ACTIVITIES

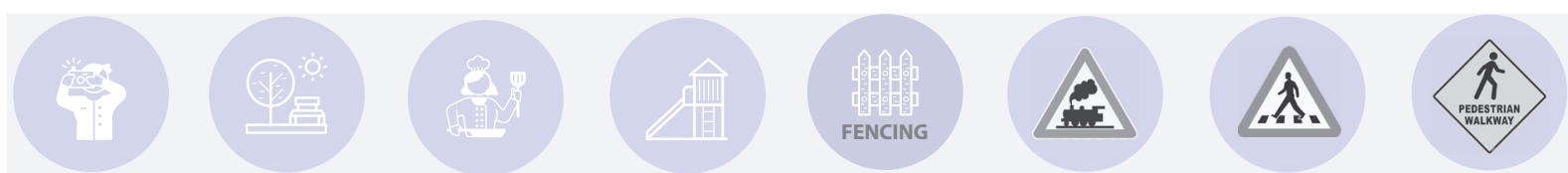

MODE OF TRANSPORT
CHILDREN/ PARENT

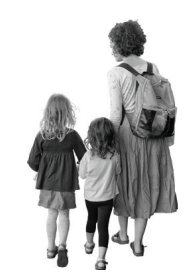

CAR PARKING

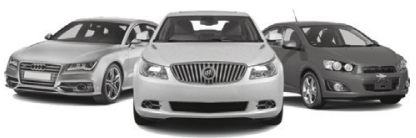

WATERFRONT OLD RAILWAY STATION STREET 2: The Strand/ Herries Park

\section{STREET USERS}

PEDESTRIANS $\quad$ PRIVATE VEHICLE USERS

TAKING LOCAL TRANSIT USERS

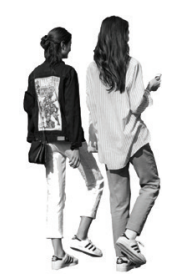

CAR PARKING

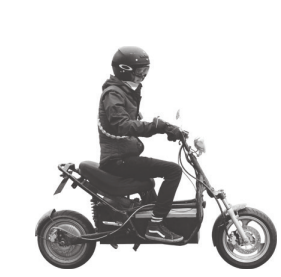

DOING BUSINESS

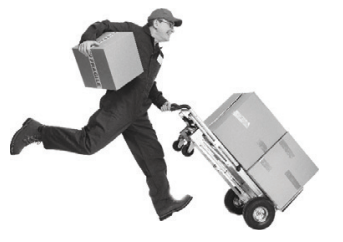

STUDENTS

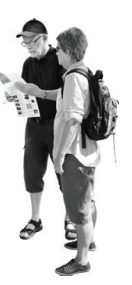

EATING DISTRICT

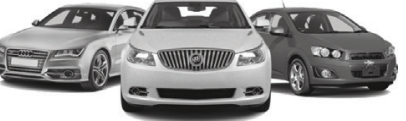

PEOPLE WITH DISABILITIES
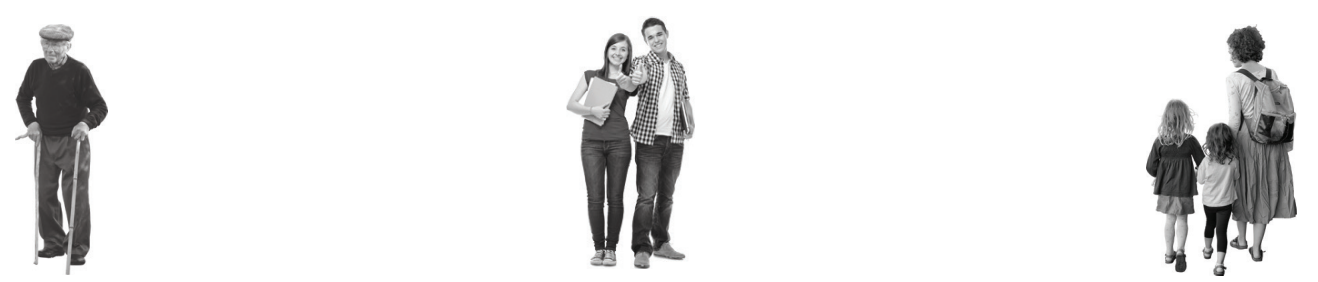

ACTIVITIES

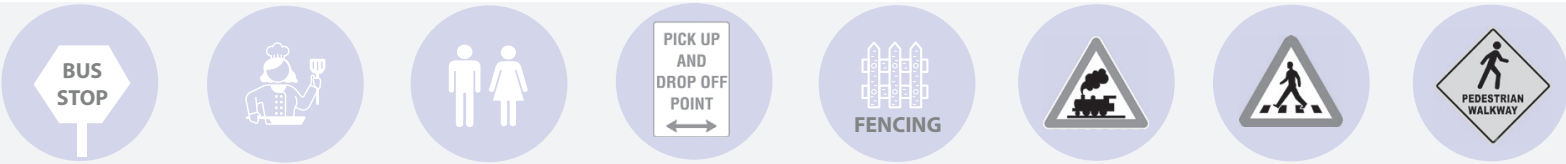

MODE OF TRANSPORT

\section{pooge}


Detail Drawing (1:500) in A3

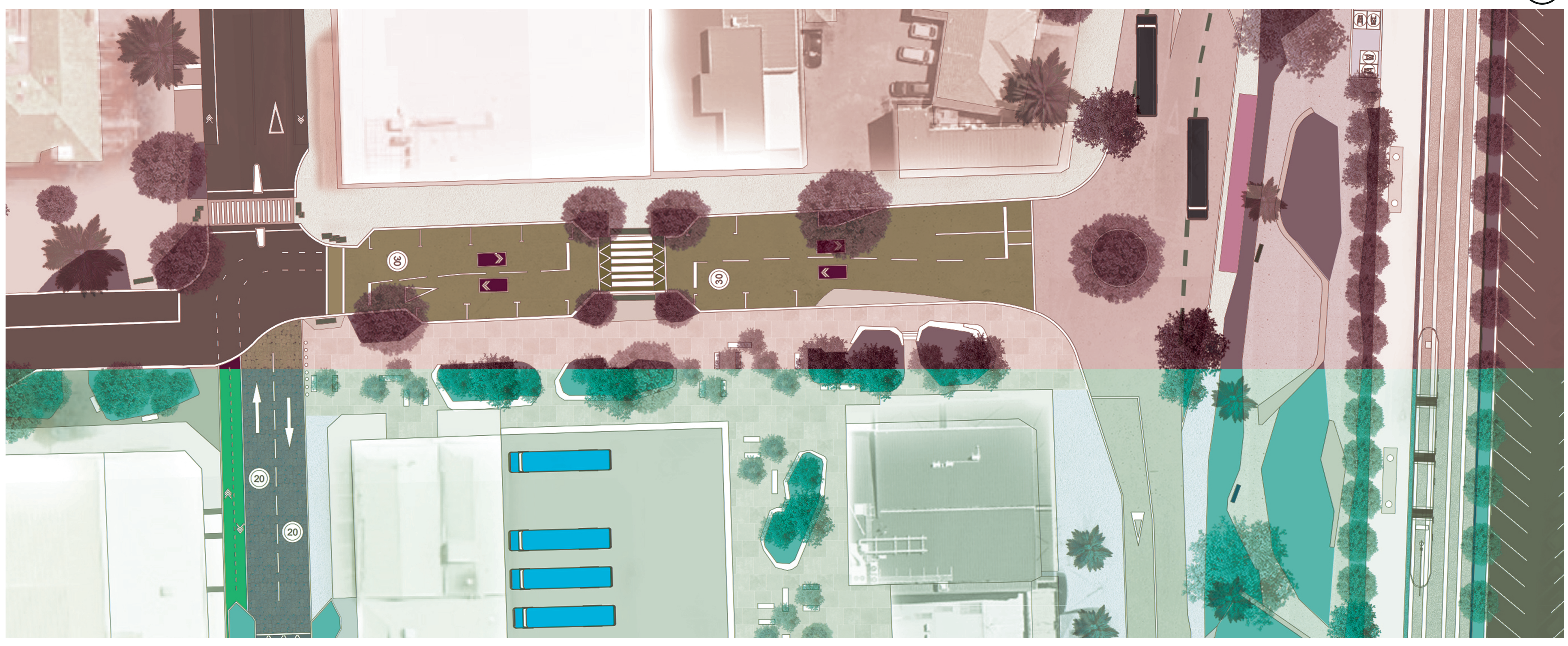

\section{Harington Street}

\section{East-West Railway}

\section{Station Access}

\section{Design Objectives:}

Design Objectives:

1. Active Street (Hybrid Street Type 2)

2.Linear Park Street (Hybrid Street Type 3)

Low Speed Activate Street

: Provide spaces for urban activities such as

play-along-the-way, picnic and rest.

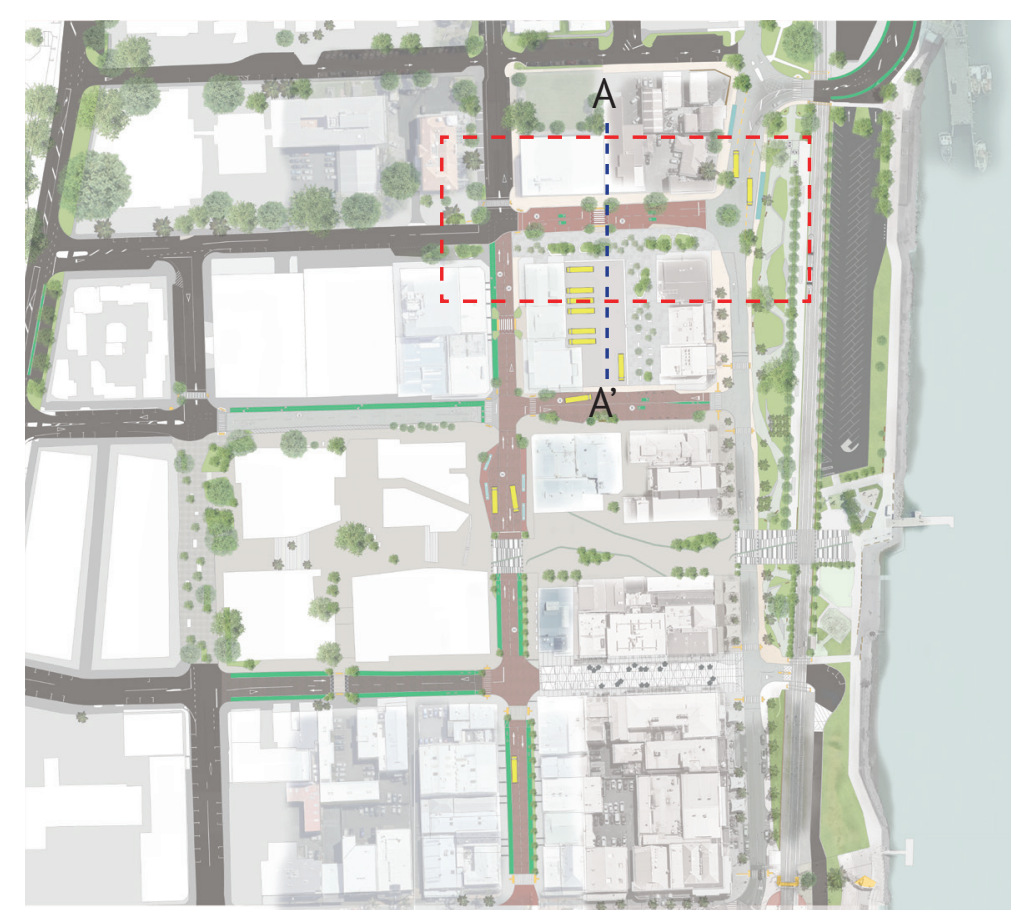


E-W Railway Station Street

(1) Building Frontage

(2) Footpath

3 Low Speed Traffic Zone

(4) Vegetation Buffer

(5) Linear Park Street

6) Commercial Area

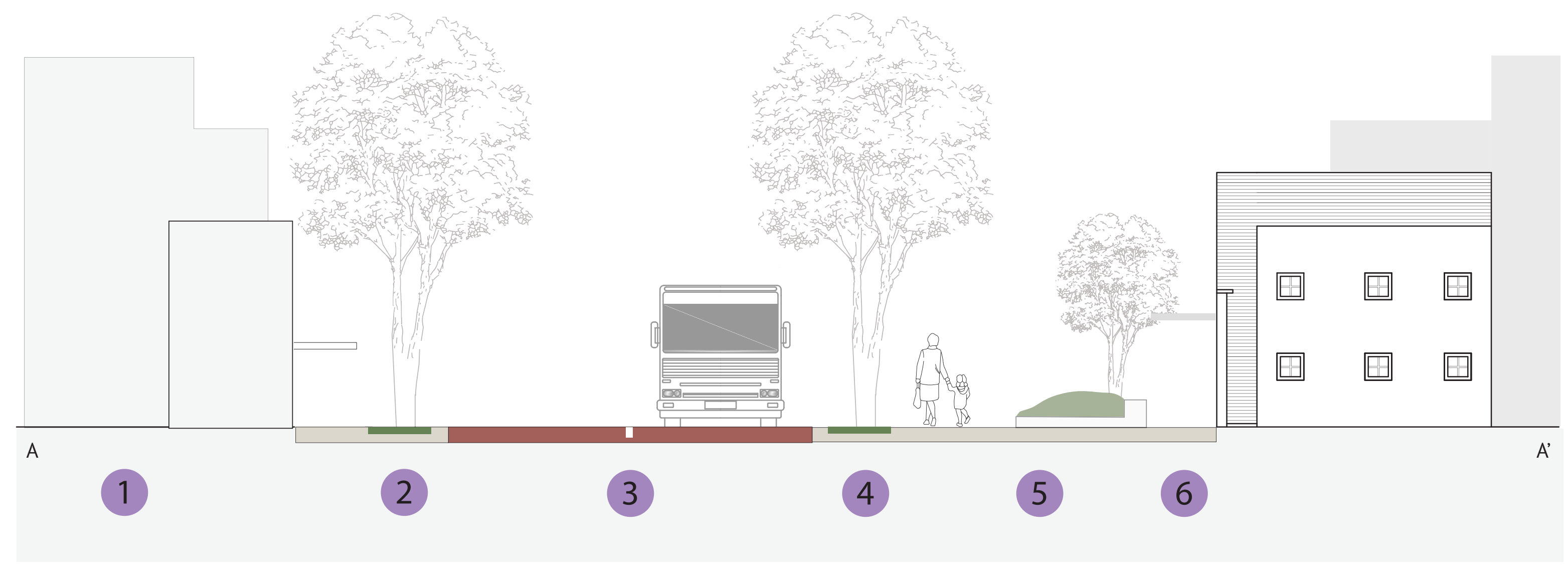




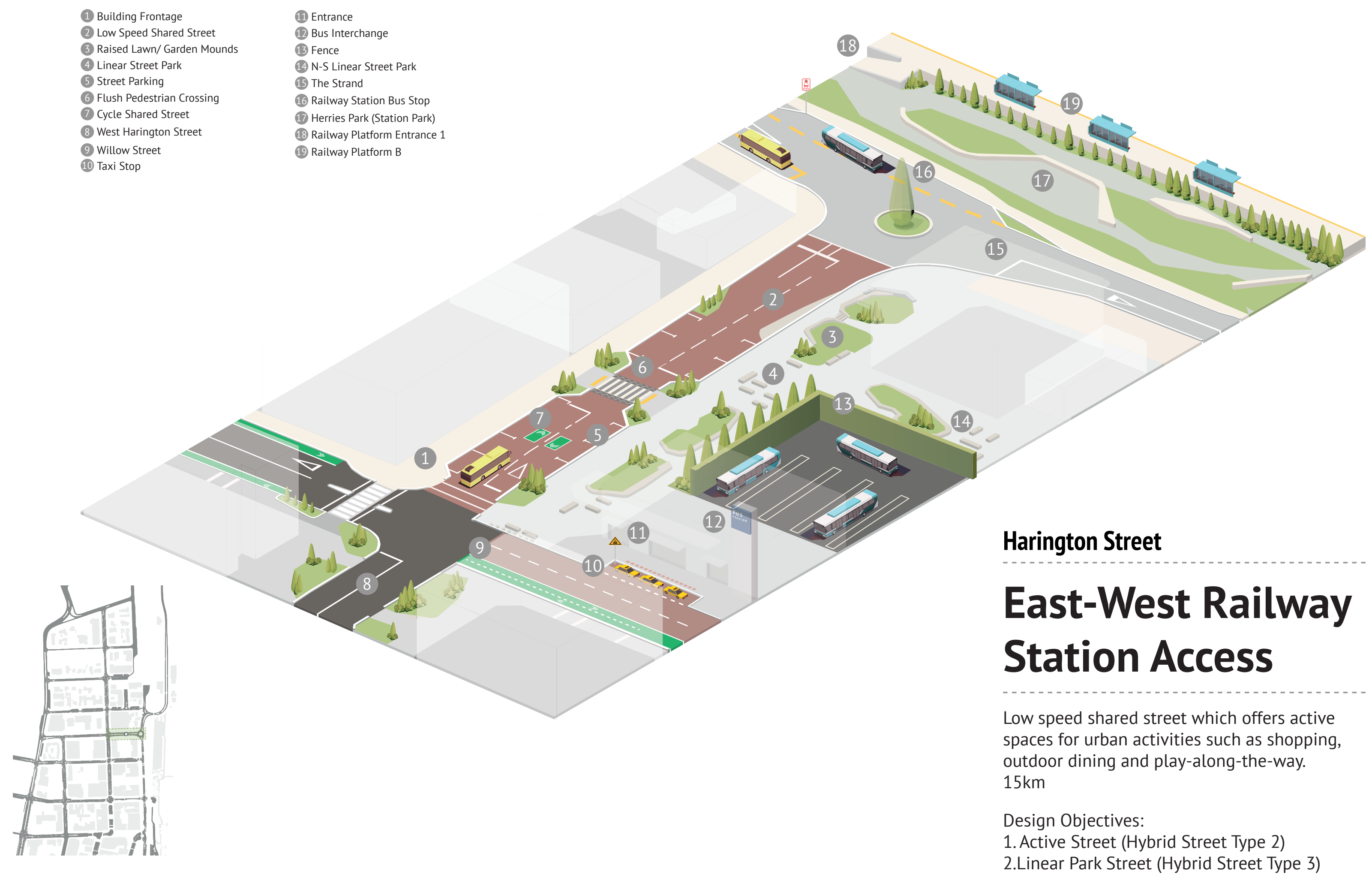




\section{E-W RAILWAY STATION CONNECTION STREET: Harington St}

\section{STREET USERS}

PEDESTRIANS

DOING BUSINESS

PRIVATE VEHICLE USERS

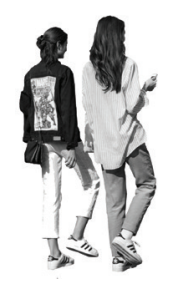

STREET CAR PARKING

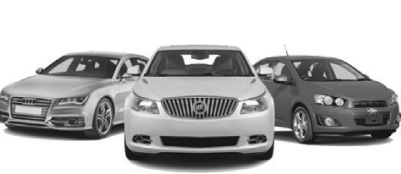

ACTIVITIES

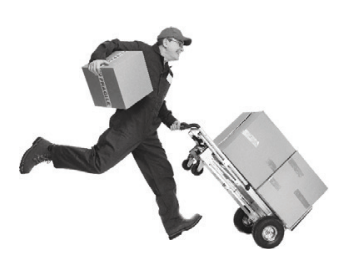

BUSINESS PEOPLE

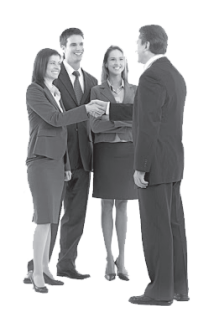

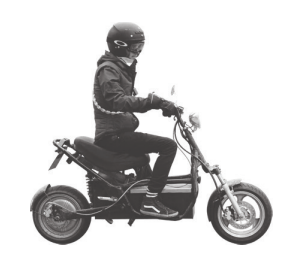

E-W RAILWAY STATION CONNECTION STREET: Harington St

STREET USERS

\begin{tabular}{l|l} 
PEDESTRIANS & PRIVATE VEHICLE USERS
\end{tabular}

CYCLISTS

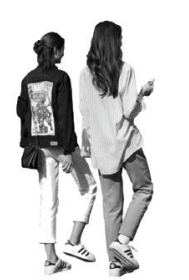

STREET CAR PARKING

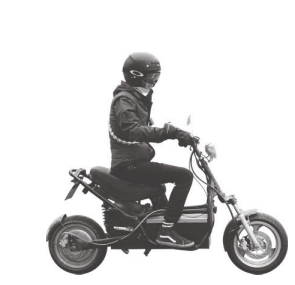

DOING BUSINESS

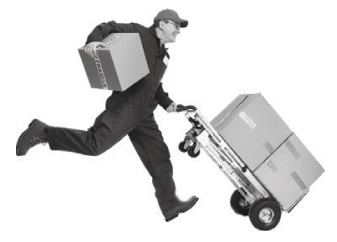

BUSINESS PEOPLE

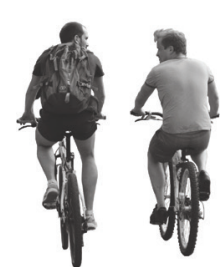

EATING DISTRICT

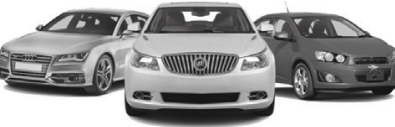

PEOPLE WITH DISABILITIES

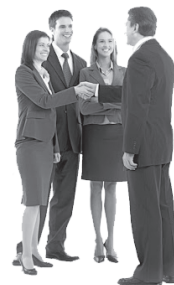

ACTIVITIES

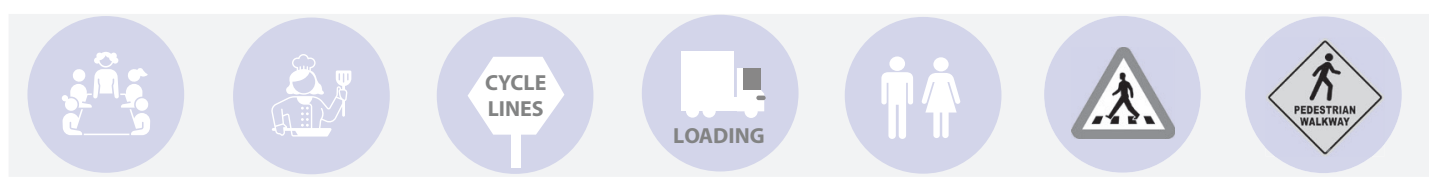

MODE OF TRANSPORT

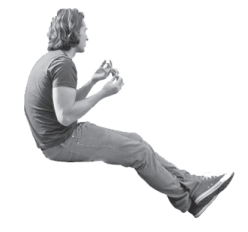

CHILDREN/ PARENT

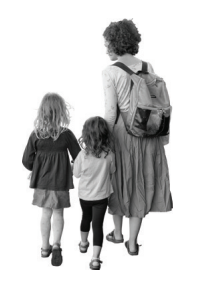

MODE OF TRANSPORT 


\section{Site Plan}

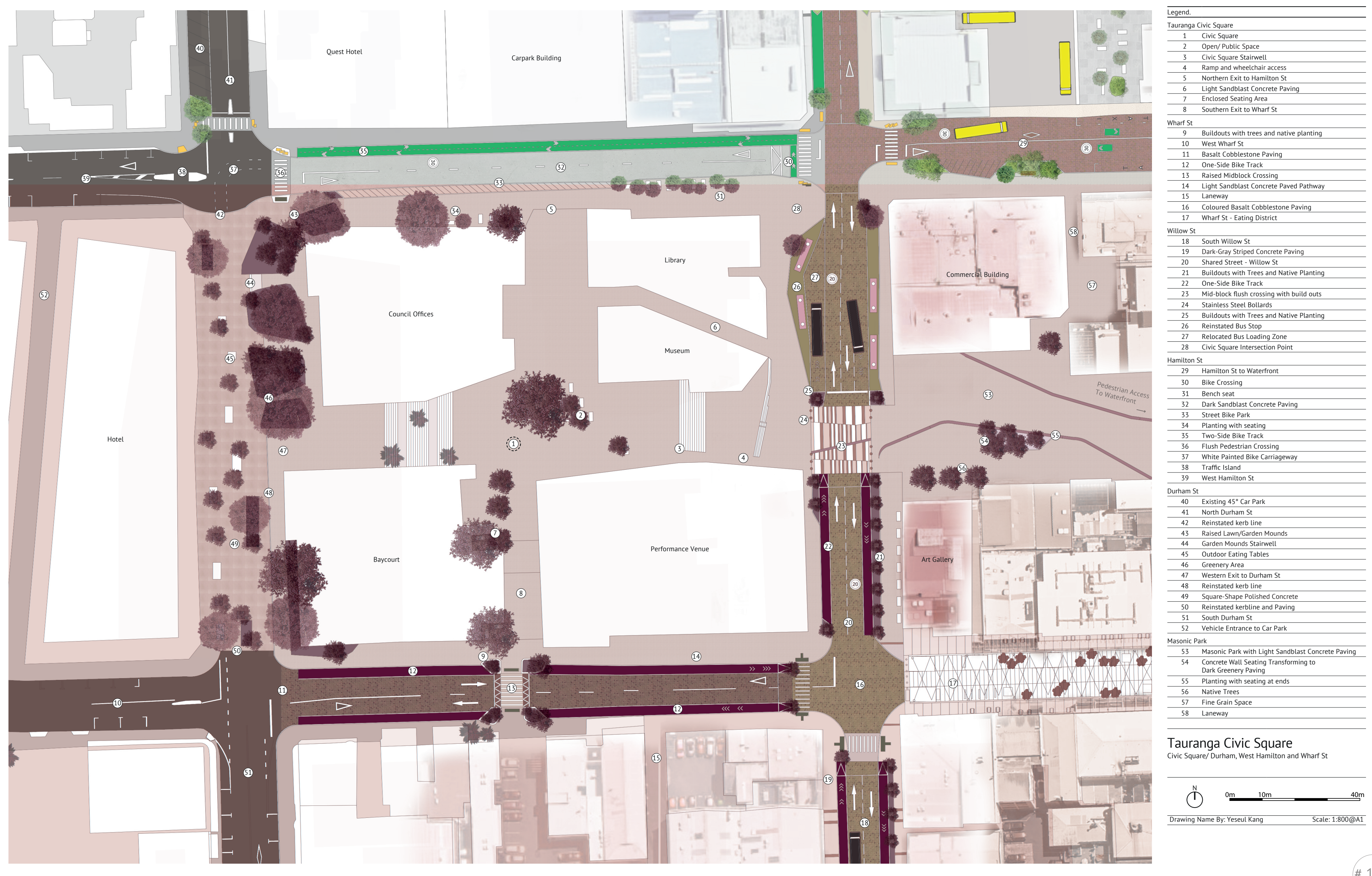




\section{Site Programming}

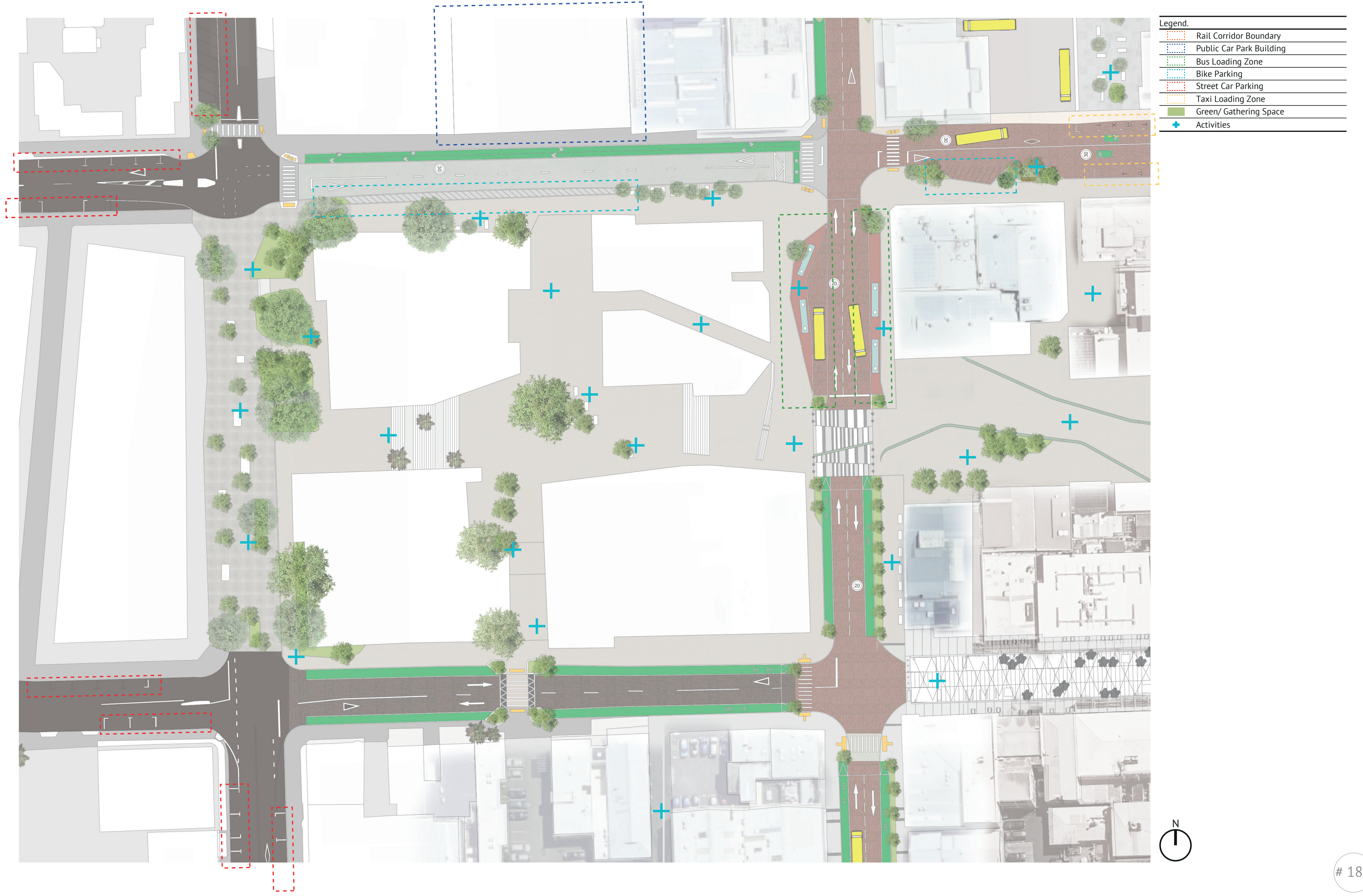




\section{Movement}

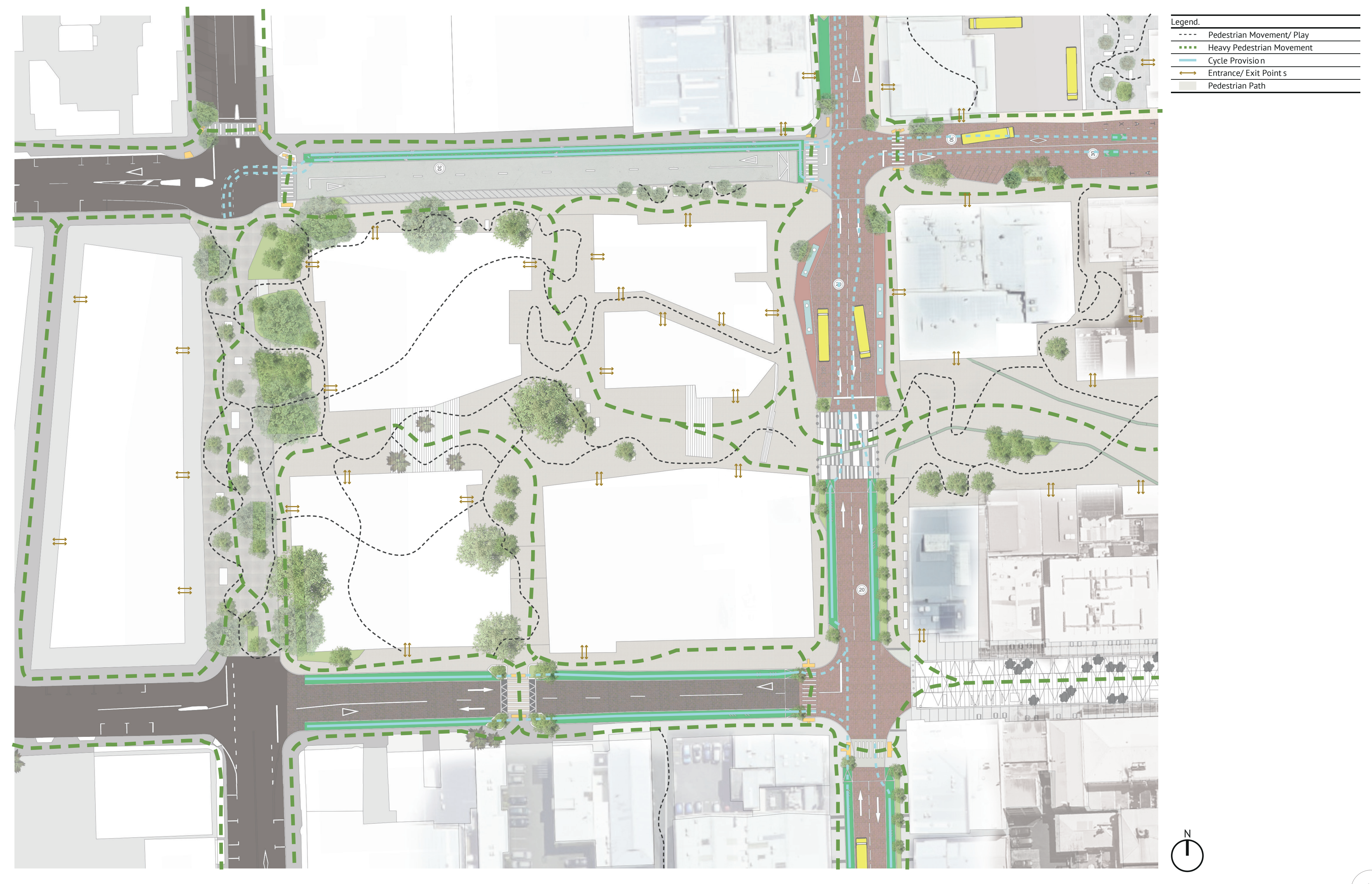




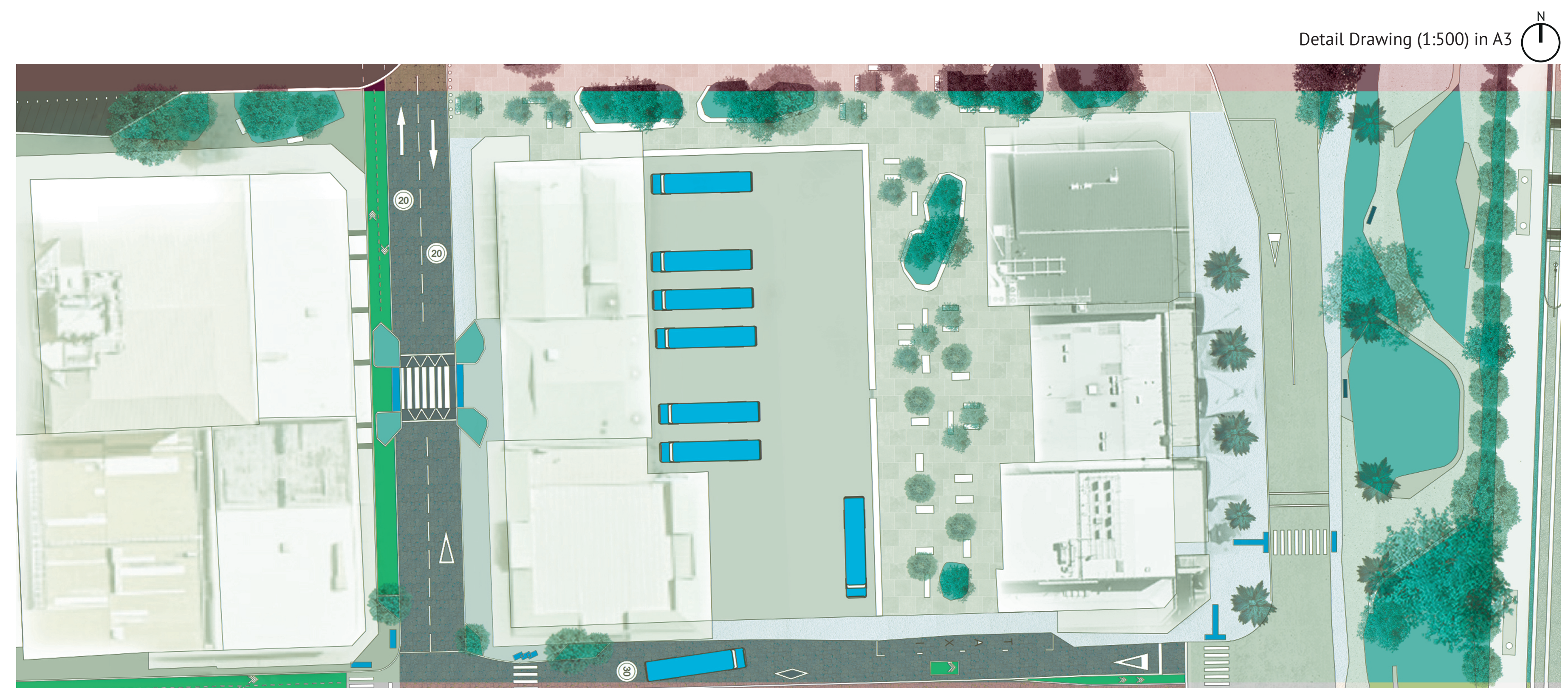

\section{BUS INTERCHANGE SPACE}

\section{Starting point of} Inter-Regional Journey

\section{Design Objectives:}

Design Objectives:

1. Transport Interchange Street (Hybrid Street Type 5)

Regional Bus Interchange \& Open Space

: Provide spaces for sustainable transport uses which

include walking and cycling, taxi and regional bus.

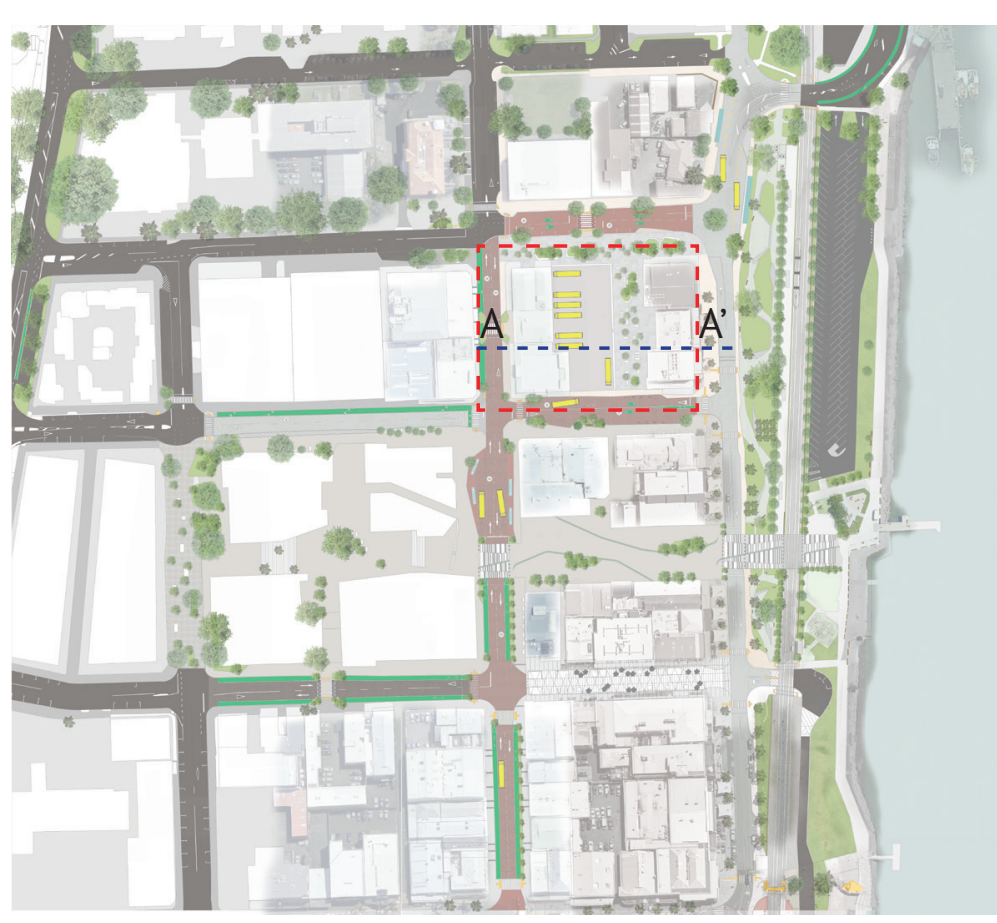




\section{Bus Interchange Space}

(1) Regional Bus Interchange

(2) Street Furnitures

(3) Green Laneway

(4) Commercial Share Zone

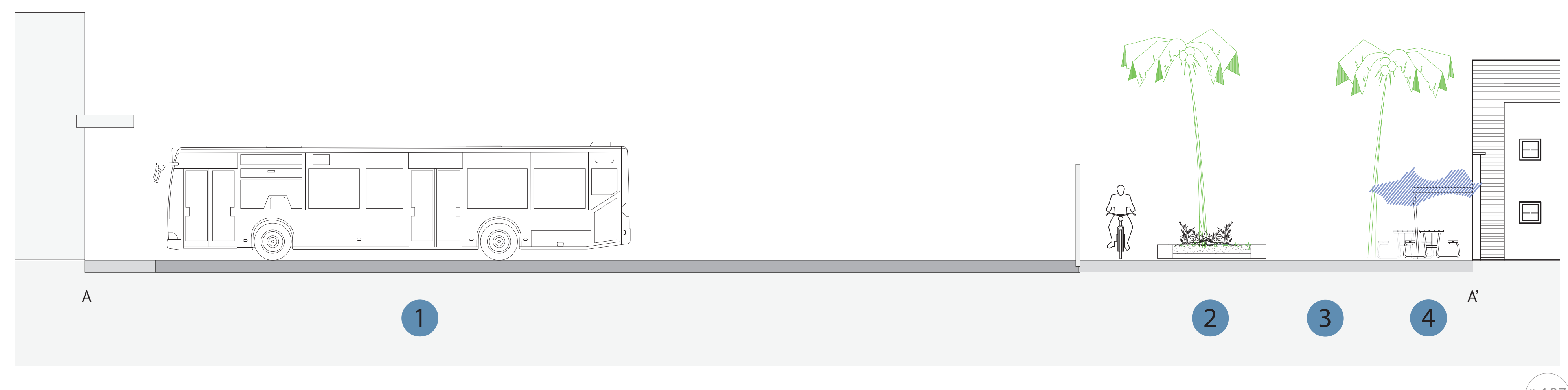




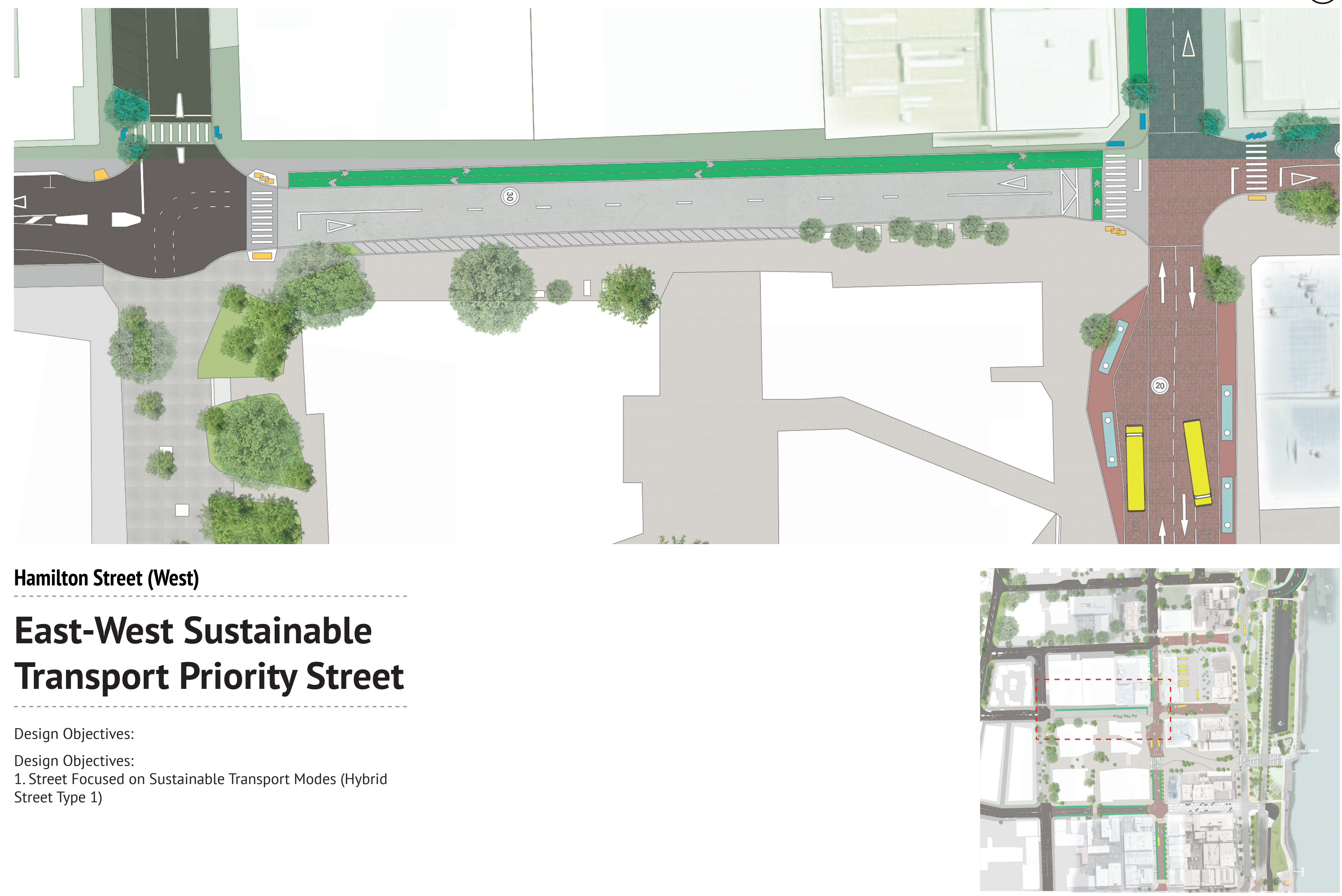


Detail Drawing (1:500) in A3

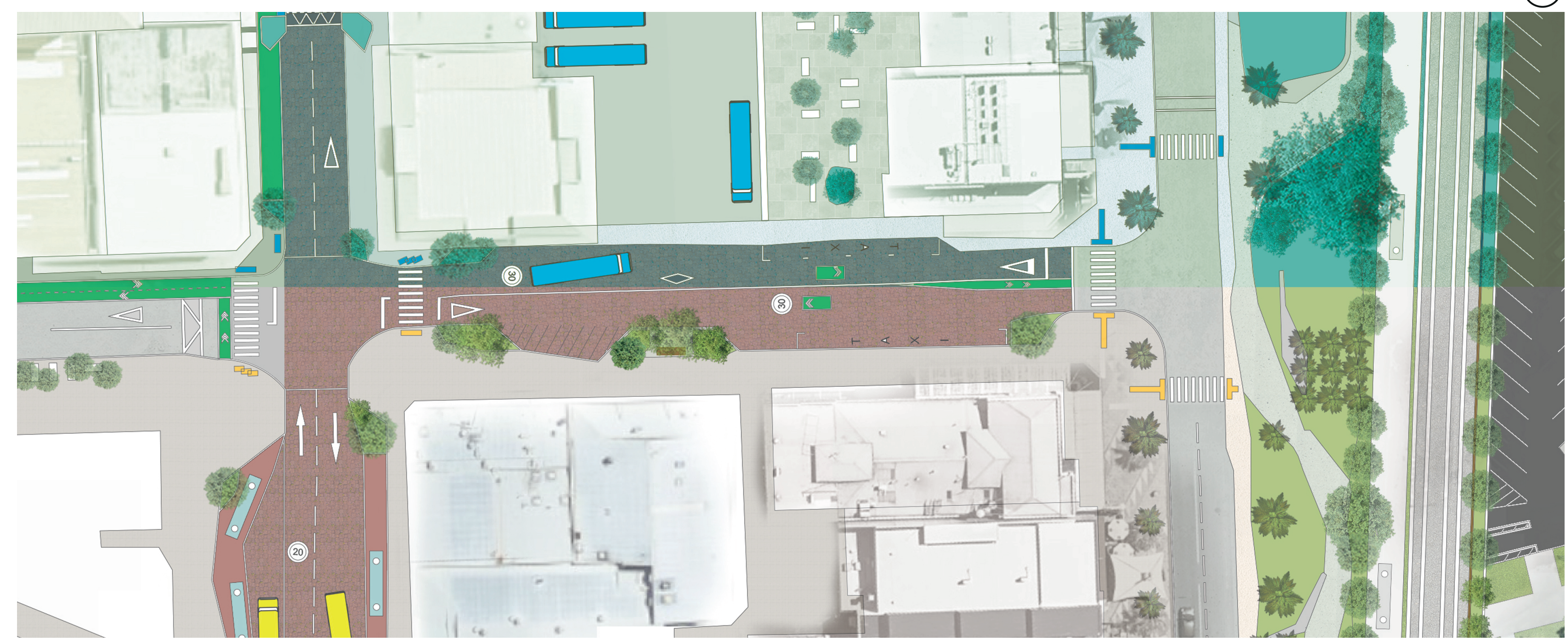

\section{Hamilton Street (East)}

\section{East-West Sustainable} Transport Priority Street

\section{Design Objectives:}

Design Objectives:

1. Street Focused on Sustainable Transport Modes (Hybrid Street Type 1)

Sustainable Transport Priority Street

:Accessible street to support sustainable transport modes connecting the Bus-Interchange and Railway Platform B.

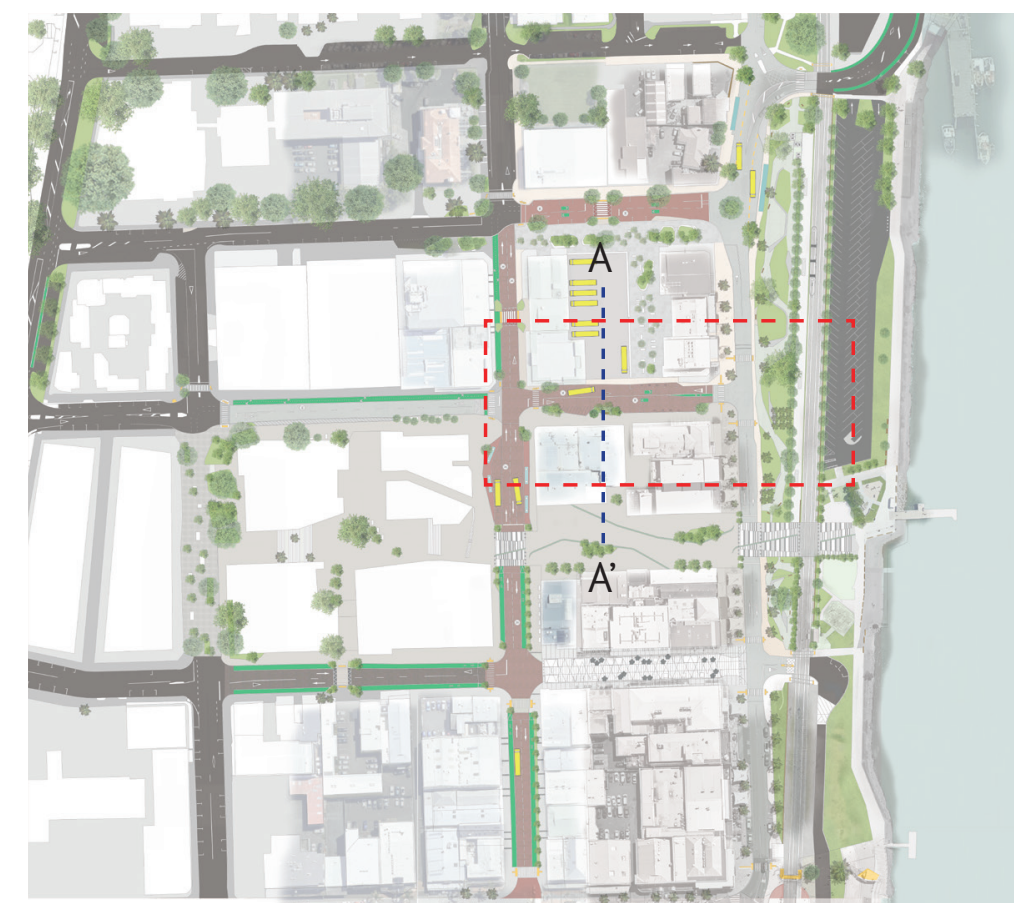




\section{Public Transport Priority Shared Street}

\section{(1) Bus Interchange}

2 Footpath

(3) Buffer Zone

4 Double Side Cycleway

5 PT Priority Shared Street

6 Cycle Parking

(7) Street Furnitures

8 Open Street

9 Civic Square Entrance Point

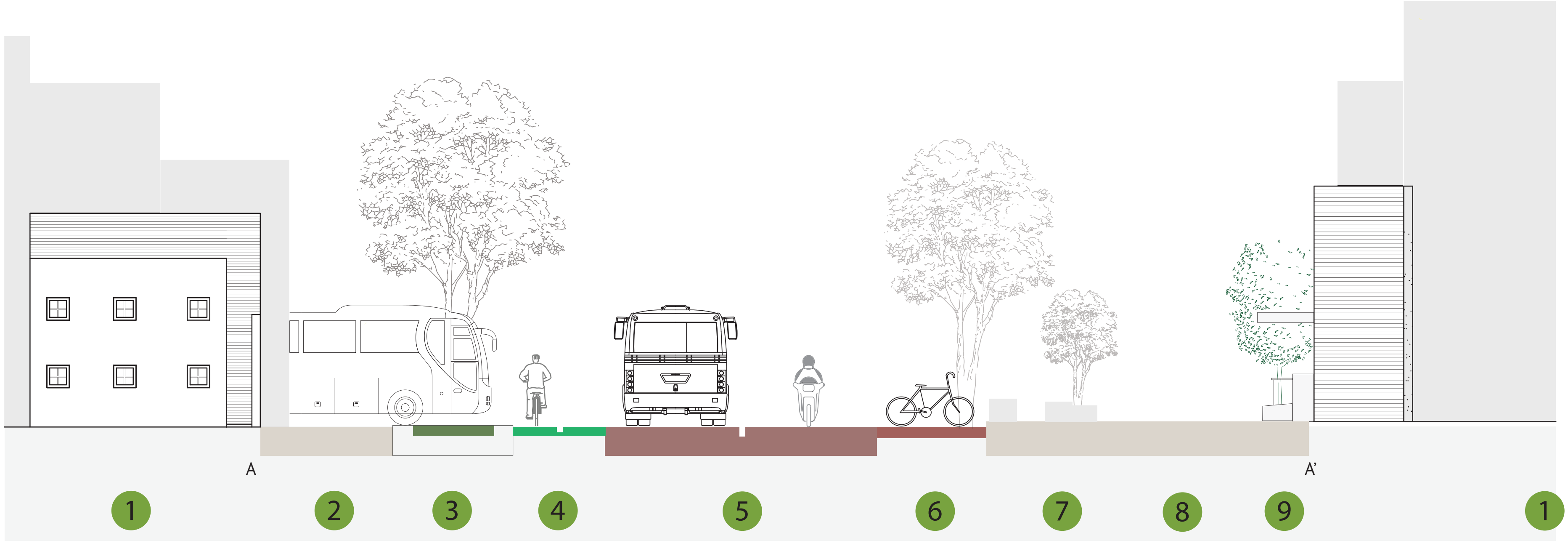




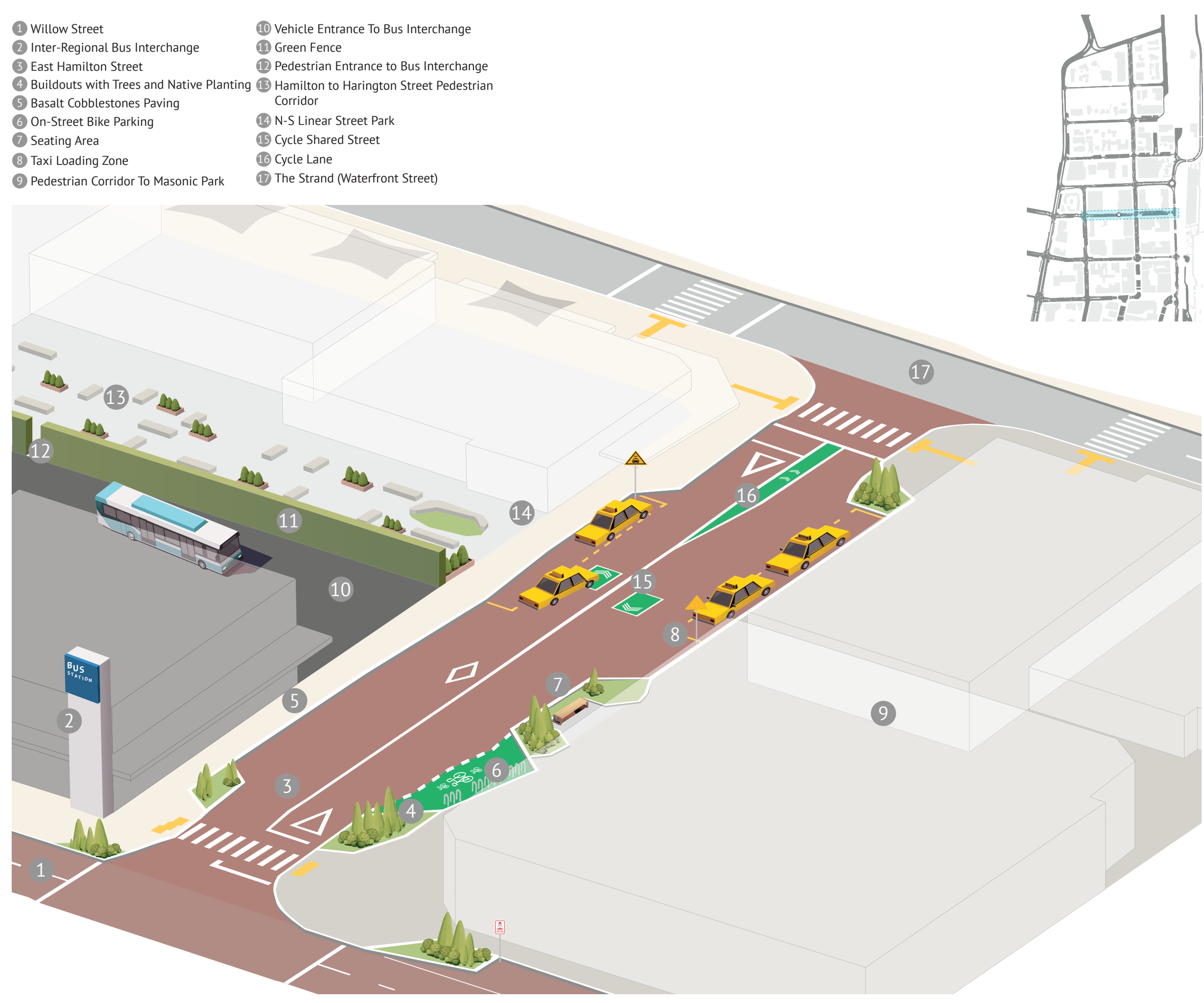

Hamilton Street (East)

East-West Sustainable Transport Priority Street

East-west connected Hamilton street provides accessible spaces for sustainable transport uses which include walking and cycling, rapid rail and local bus. Supporting a variety of public transport modes along the transit-friendly designed street enhances street connectivities not only in public transport (Bus Interchange - Railway Platform B) but also pedestrian amenity (Open views to the harbour).

\section{$30 \mathrm{~km}$}

Design Objectives:

1. Street Focused on Sustainable Transport Modes (Hybrid Street Type 1)

2. Active Street (Hybrid Street Type 2) 


\section{PUBLIC TRANSPORT PRIORITY SHARED STREET: Hamilton St}

\section{STREET USERS}

PEDESTRIANS

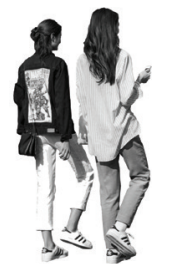

STREET CAR PARKING

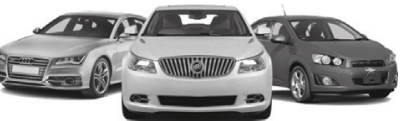

ACTIVITIES

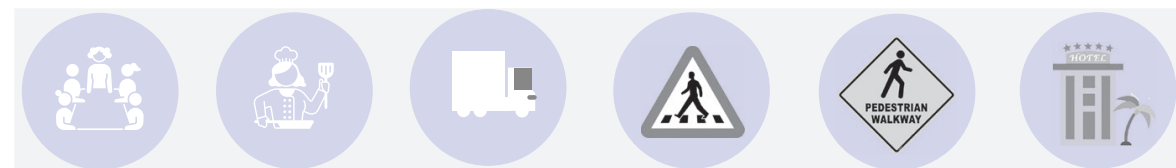

MODE OF TRANSPORT

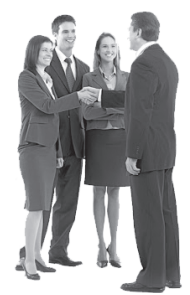

\section{PUBLIC TRANSPORT PRIORITY SHARED STREET: Hamilton St}

STREET USERS

\begin{tabular}{l|l} 
PEDESTRIANS & PRIVATE VEHICLE/TAXI USERS \\
\end{tabular}

PRIVATE VEHICLE USERS

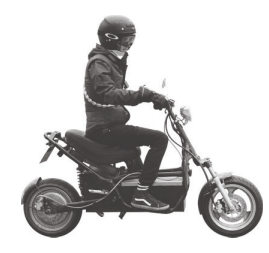

ACCOMMODATION USERS

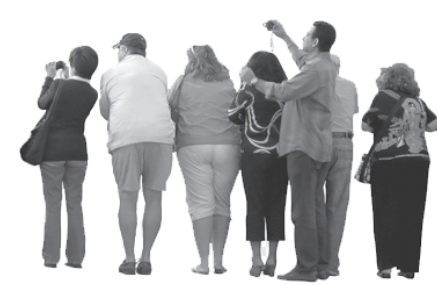

ACCOMMODATION USERS
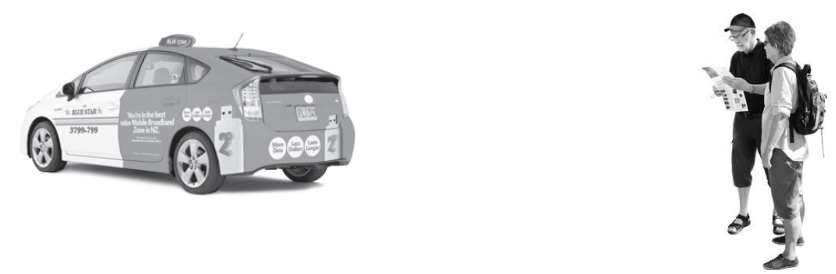

CAR PARK BUILDING

DOING BUSINESS

EATING DISTRICT
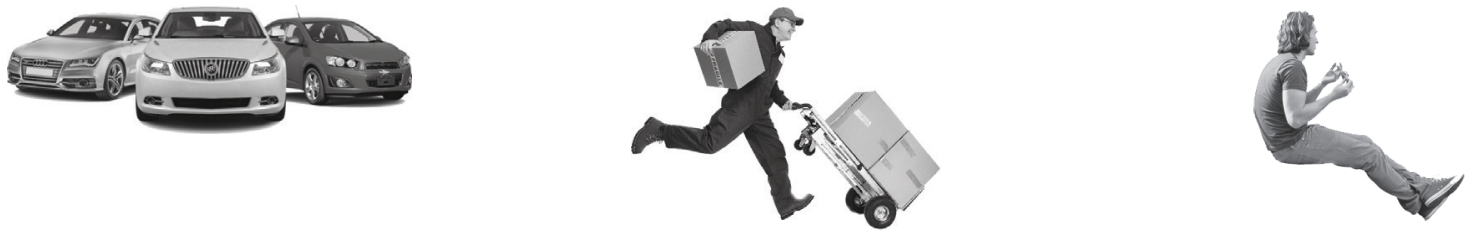

CYCLISTS

BICYCLE PARKING
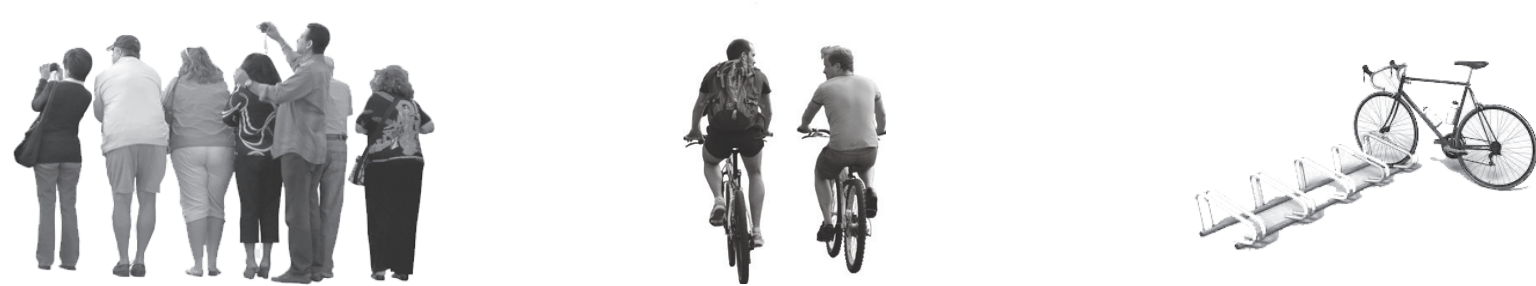

ACTIVITIES

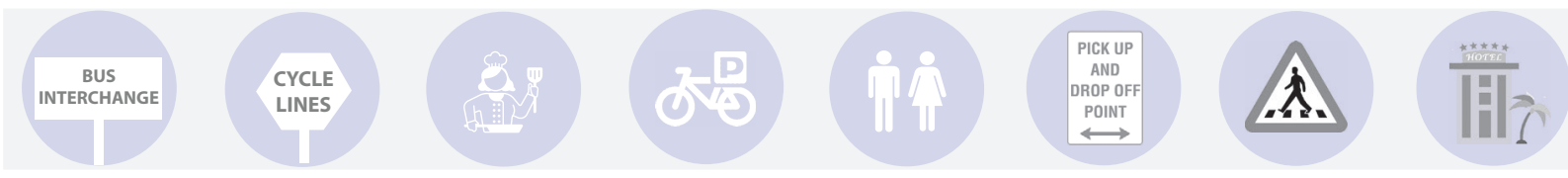

MODE OF TRANSPORT 


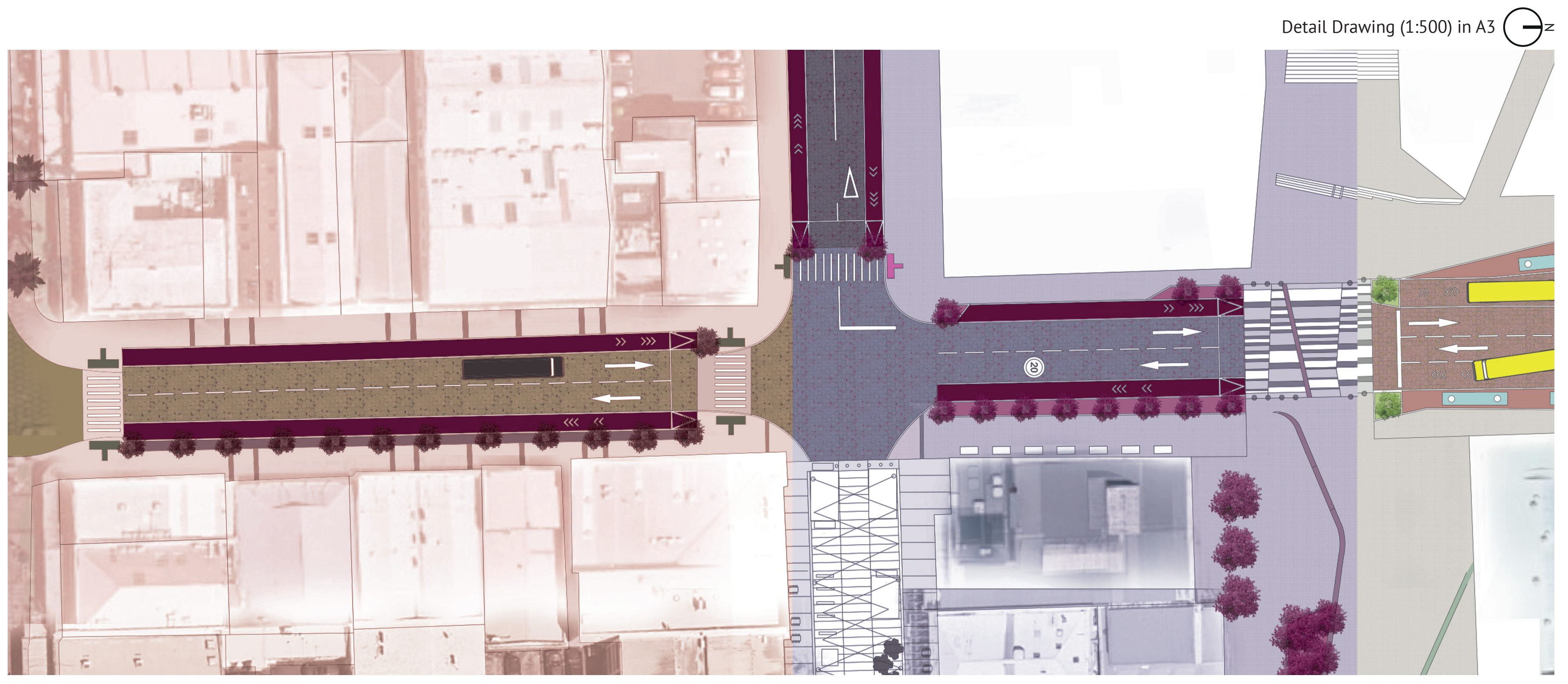

Willow Street

\section{North-South City Connection Street}

\section{Design Objectives:}

Design Objectives:

1. Street Focused on Sustainable Transport

Modes (Hybrid Street Type 1)

2. Active Street (Hybrid Street Type 2)

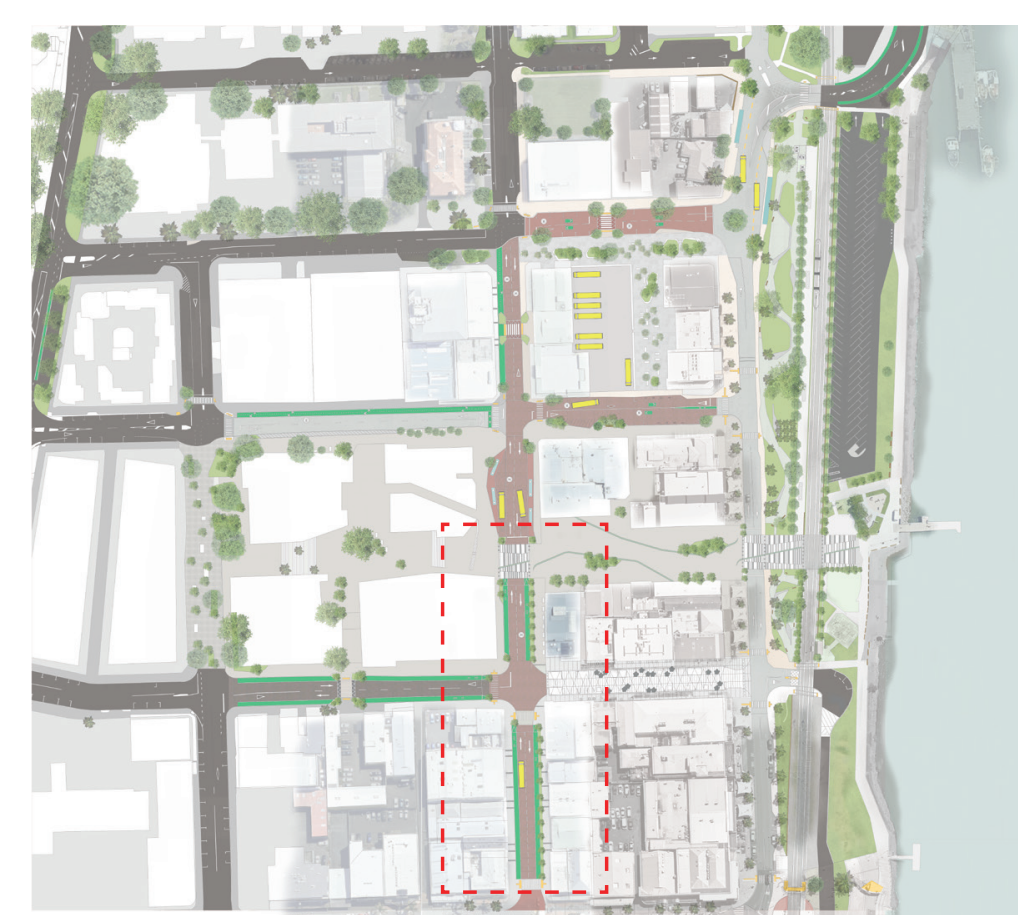




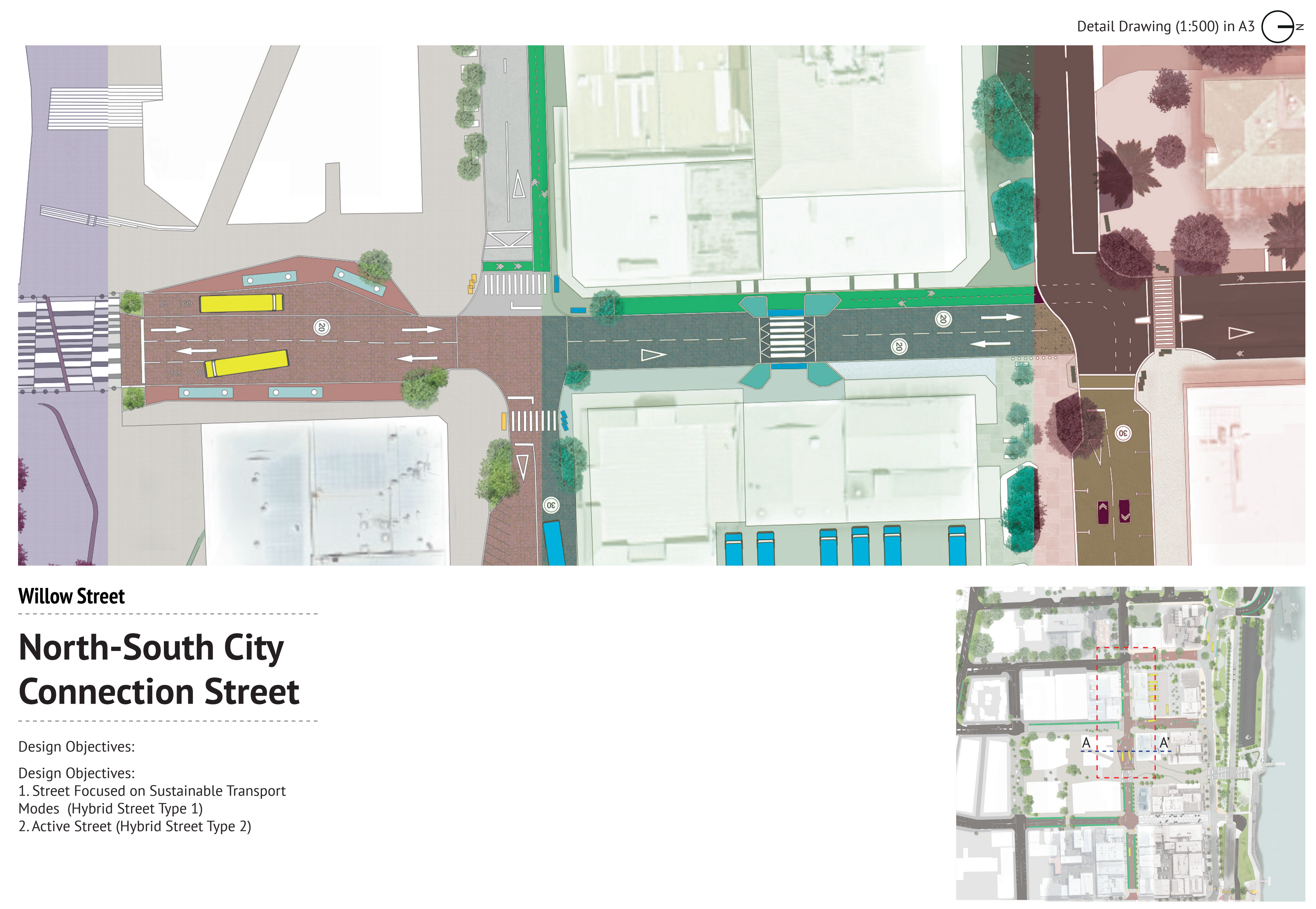


N-S City Connection Street

(1) Civic Square

2. Open Space for Transit Exchanges

(3) Local Bus Station

4 Transit Priority Street

(5) Commercial Street

6 Waterfront Entrance Point
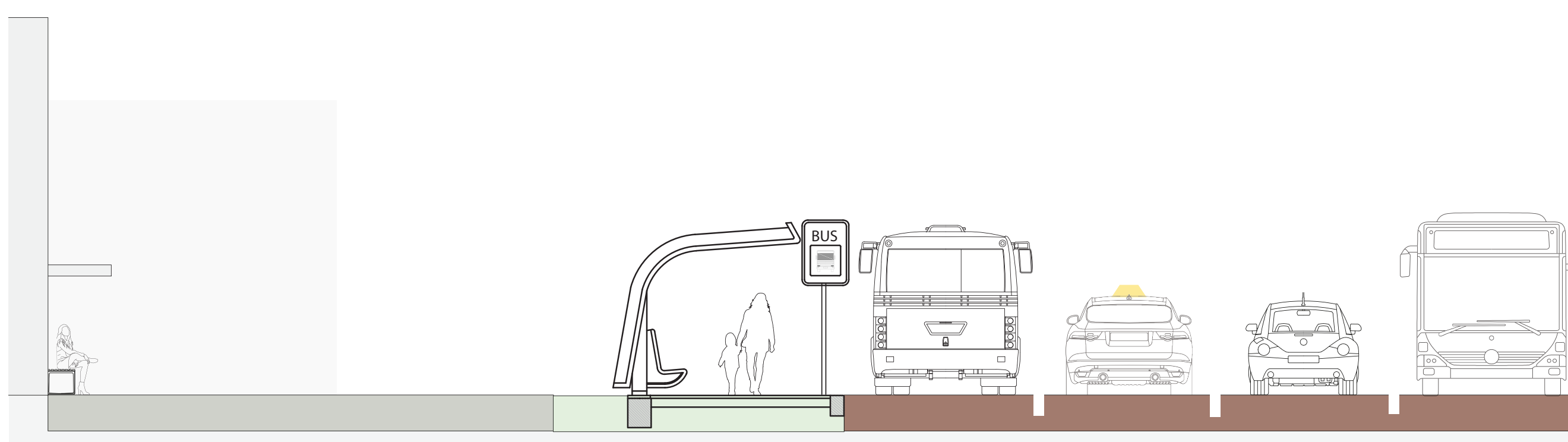


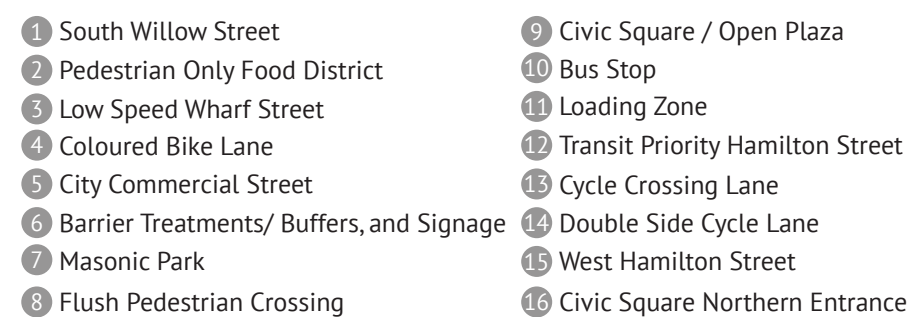

(10) Civic Square Northern Entrance

\section{Willow Street}

\section{North-South City Connection Street}

Provide commercial activities such as shopping,

outdoor dining and play-along-the-way. The

commercial street includes 'Food District Street' and 'City Living Street'.

$15 \mathrm{~km}$

Design Objectives:

1. Street Focused on Sustainable Transport

Modes (Hybrid Street Type 1)

2. Active Street (Hybrid Street Type 2) 


\section{N-S CITY CONNECTION STREET: Willow St}

\section{STREET USERS}

PEDESTRIANS

PRIVATE VEHICLE USERS

TAKING LOCAL TRANSIT USERS

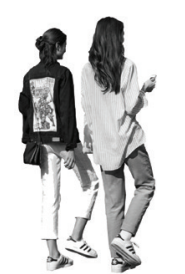

DOING BUSINESS

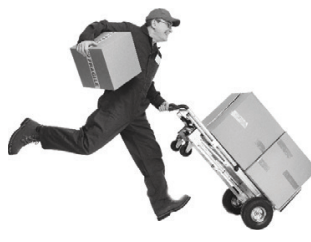

PEOPLE WITH DISABILITIES
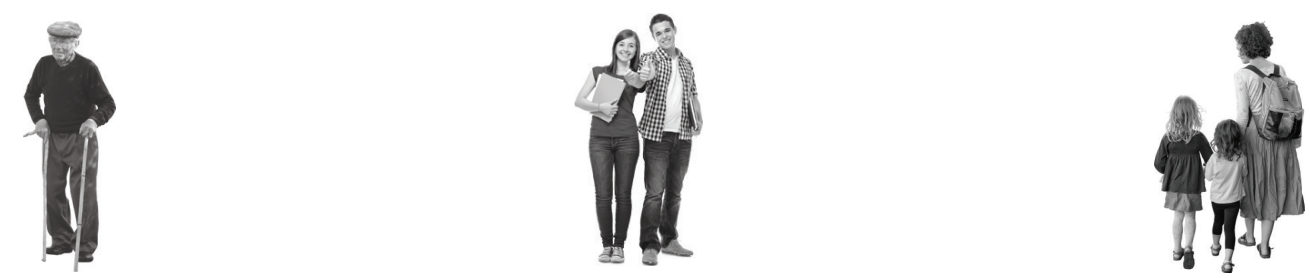

ACTIVITIES

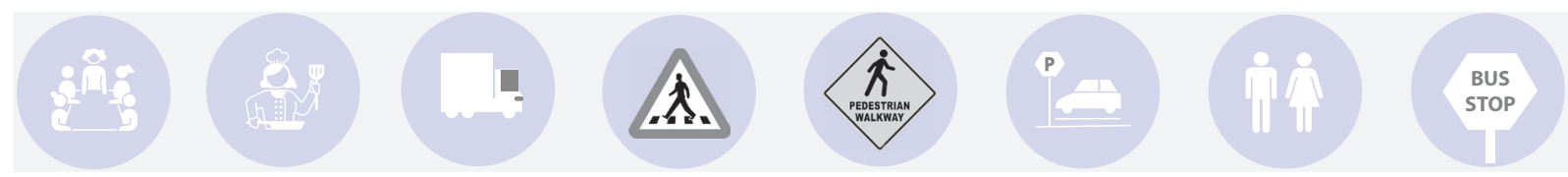

MODE OF TRANSPORT

CHILDREN/ PARENT

\section{N-S CITY CONNECTION STREET: Willow S}

STREET USERS

\begin{tabular}{l|l} 
PEDESTRIANS & PRIVATE VEHICLE USERS
\end{tabular}

TAKING LOCAL

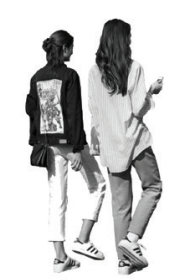

CHILDREN/ PARENT
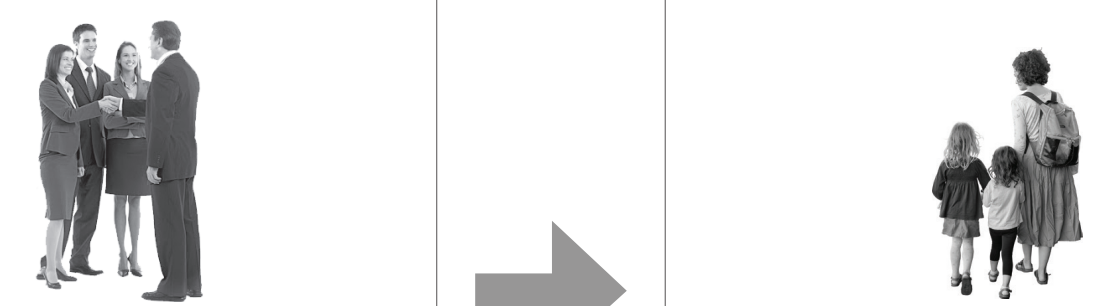

PEOPLE WITH DISABILITIES
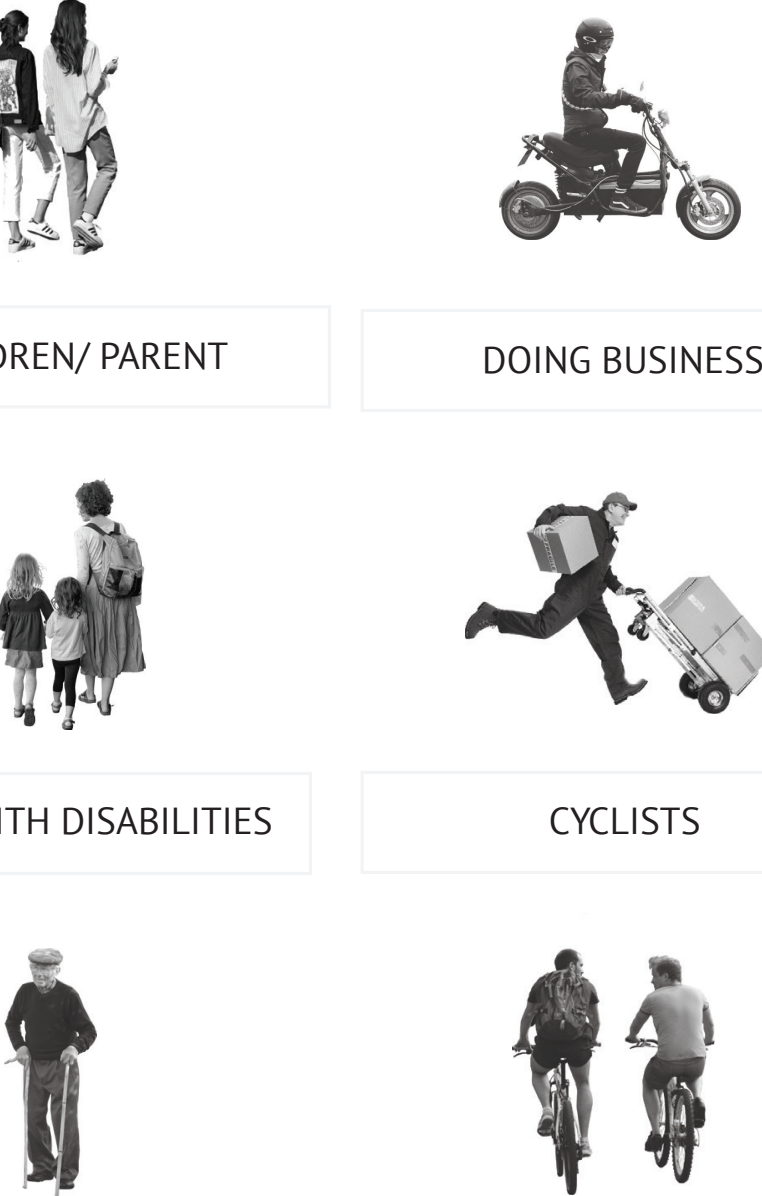

DOING BUSINESS

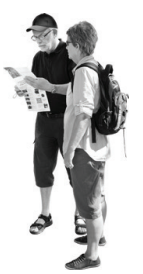

EATING DISTRIC

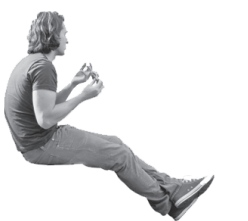

BUSINESS PEOPLE

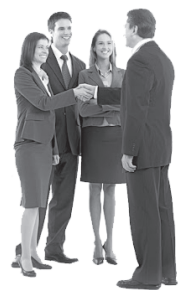

ACTIVITIES

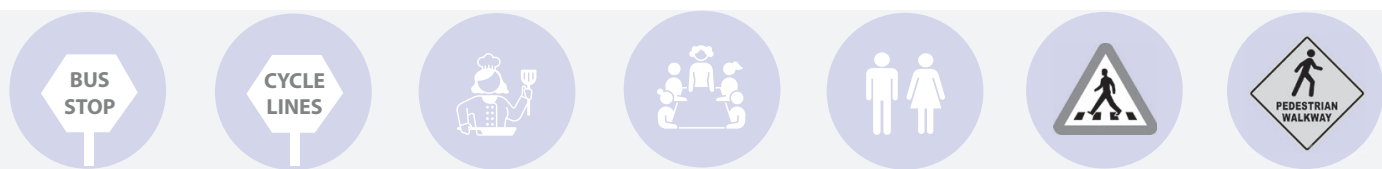

MODE OF TRANSPORT 


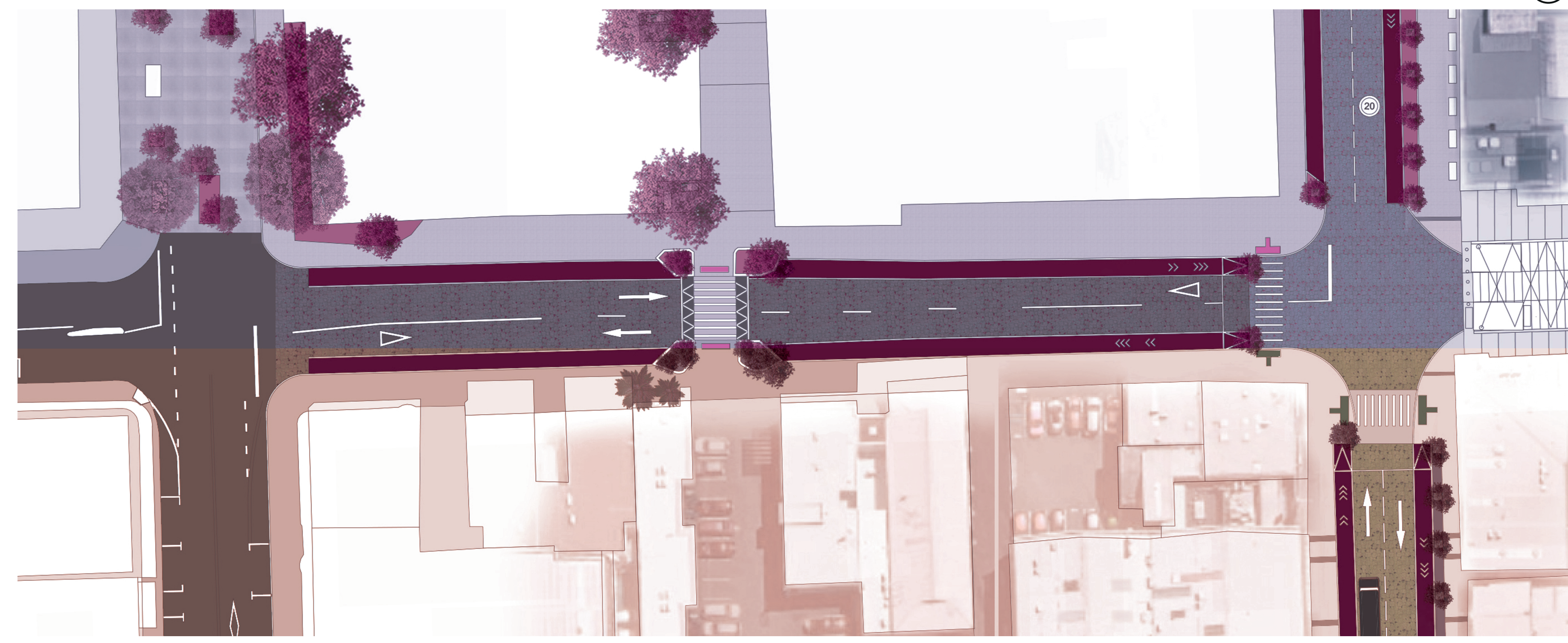

Wharf Street West

\section{East-West Pedestrian Priority Street}

1. Street Focused on Sustainable Transport Modes (Hybrid Street Type 1)

2. Active Street (Hybrid Street Type 2)

3. Commercial Street (Hybrid Street Type 4)

Sustainable Transport Priority Street (West Wharf St)

\& Food District Street (East Wharf St)

: Offering urban activities including walking and

cycling, play-along-the-way, picnic and rest.

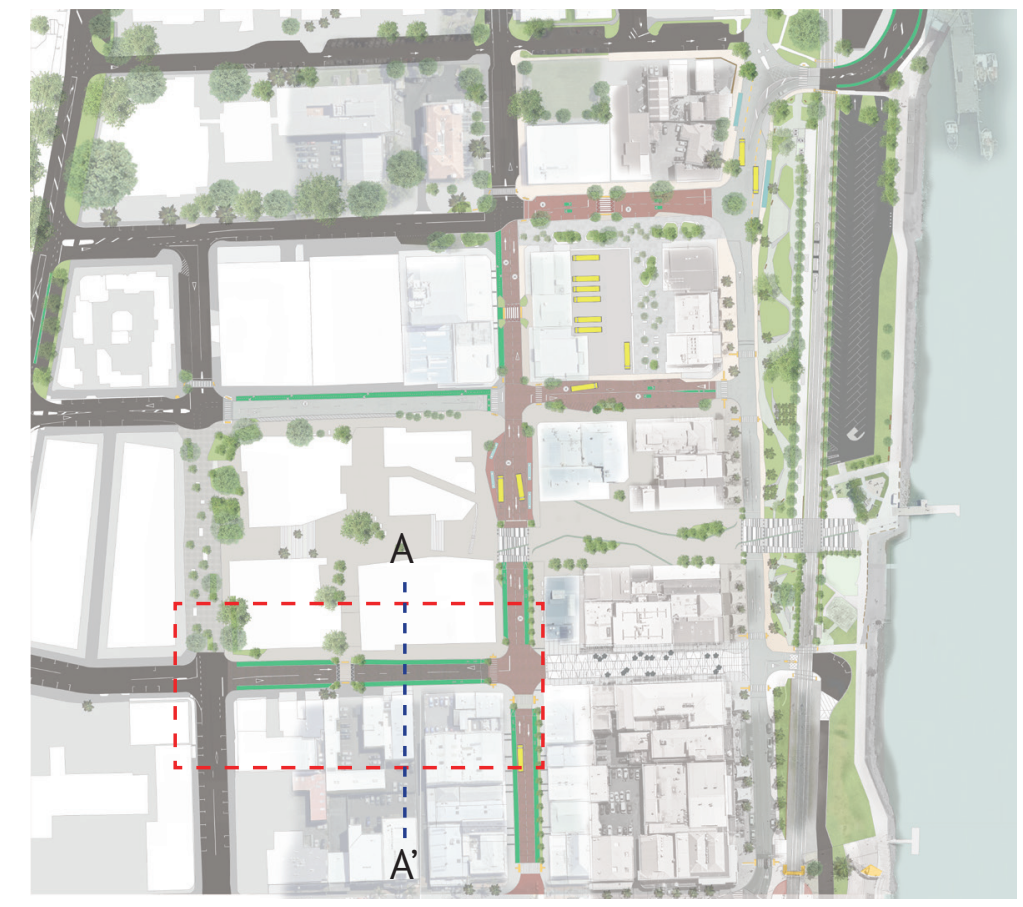


Pedestrian-Priority Spaces

(1) Frontage Zone

(2) Clear Path

(3) Street Furniture Zone

(4) Cycleway

5 Buffer Zone

6 Public Transit Corridor

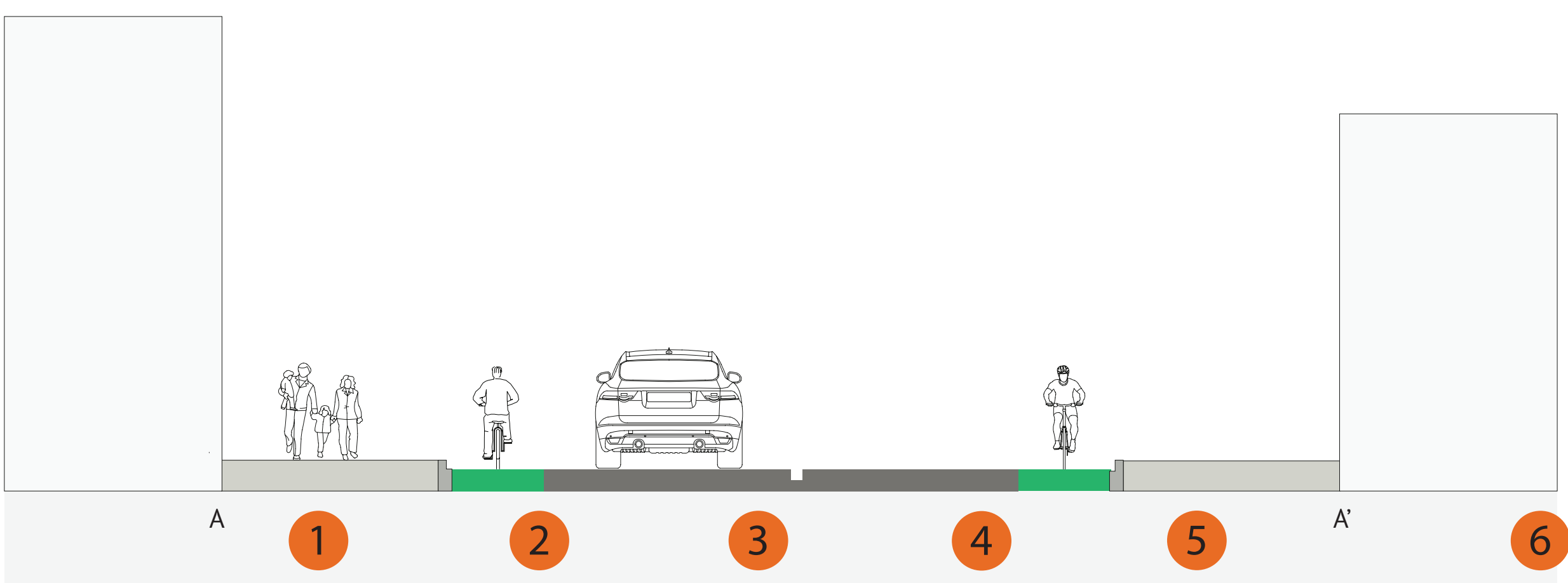




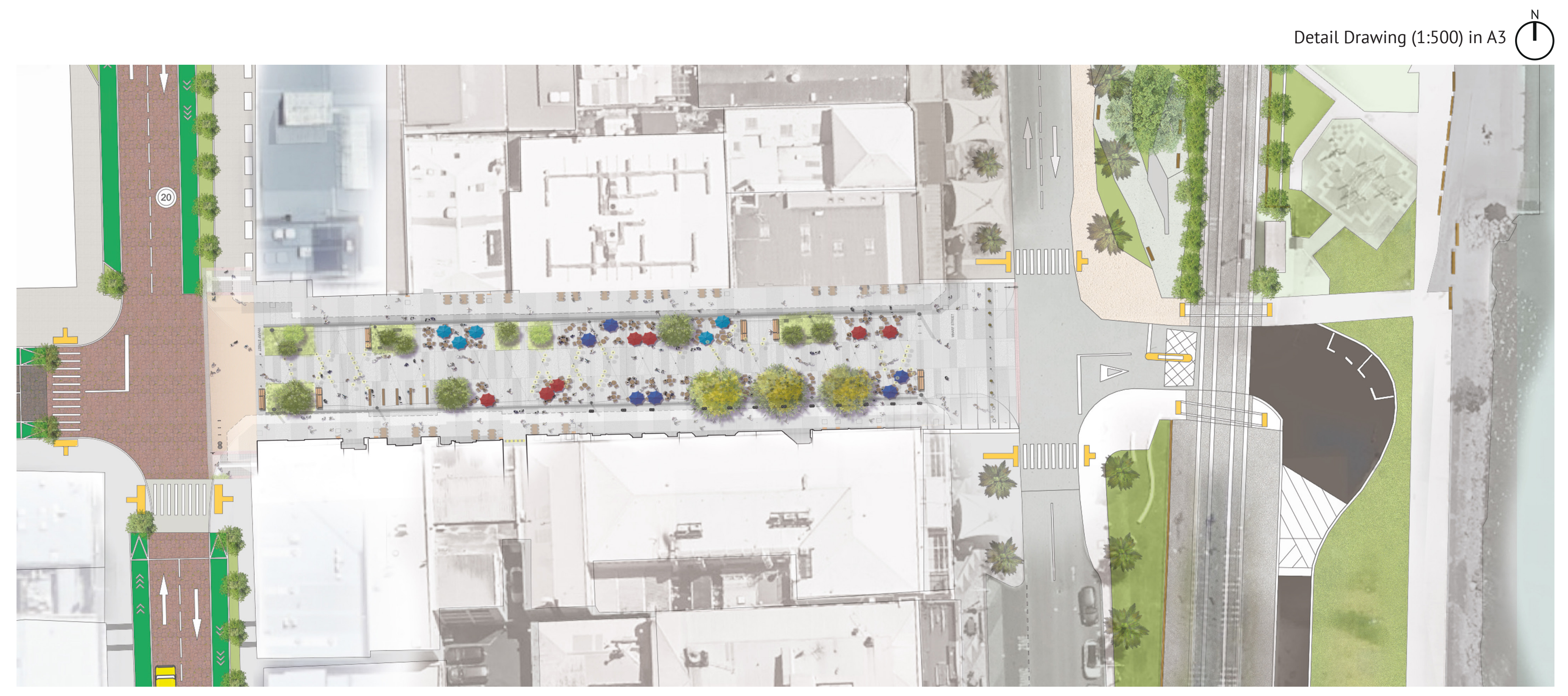

Wharf Street West

\section{East-West Pedestrian}

\section{Priority Street}

1. Street Focused on Sustainable Transport Modes

(Hybrid Street Type 1)

2. Active Street (Hybrid Street Type 2)

3. Commercial Street (Hybrid Street Type 4)

Sustainable Transport Priority Street (West Wharf St)

\& Food District Street (East Wharf St)

: Offering urban activities including walking and

cycling, play-along-the-way, picnic and rest.

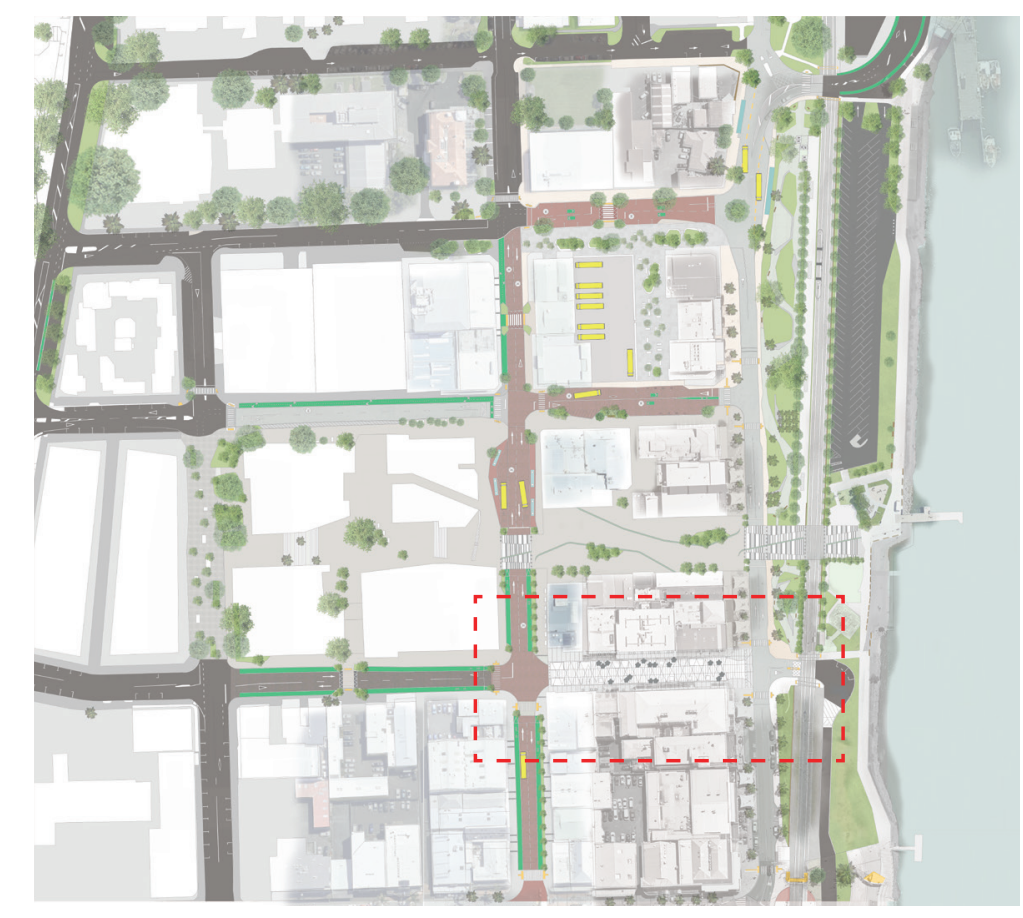




\begin{tabular}{|c|c|}
\hline $\begin{array}{l}\text { 1) South Willow Street } \\
2 \text { Delivery Truck Loading Zone } \\
3 \text { Public Biccle Racks } \\
4 \text { 4 Pedestrian-Only Central Clearway } \\
\text { 5 Dining Precinct } \\
6 \text { Garden Bed } \\
7 \text { Commercial Zone } \\
8 \text { Previous Vehicle Access }\end{array}$ & 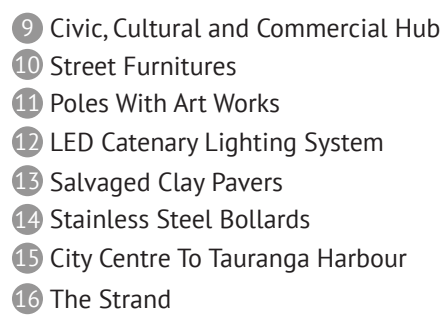 \\
\hline
\end{tabular}

\section{Wharf Street East}

\section{Pedestrian Only Food District}

Sustainable Transport Priority Street (West Wharf St)

\& Food District Street (East Wharf St):

1. Offering a central clearway which is uniquely

combined with art, culture and cuisine.

2. Provide a safe pedestrian connection from city

centre to Tauranga harbour.

3. New lighting system, native planting, seats, and

bike racks create a vibrant place day and night to

support urban activities.

$0 \mathrm{~km}$

Design Objectives:

1. Street Focused on Sustainable Transport Modes

(Hybrid Street Type 1)

2. Active Street (Hybrid Street Type 2)

3. Commercial Street (Hybrid Street Type 4) 


\section{CIVIC HEART STREET: Wharf St}

\section{STREET USERS}

PEDESTRIANS

PRIVATE VEHICLE USERS

DOING BUSINESS

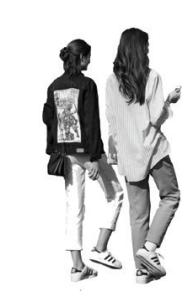

TAKING REGIONAL TRANSIT USERS
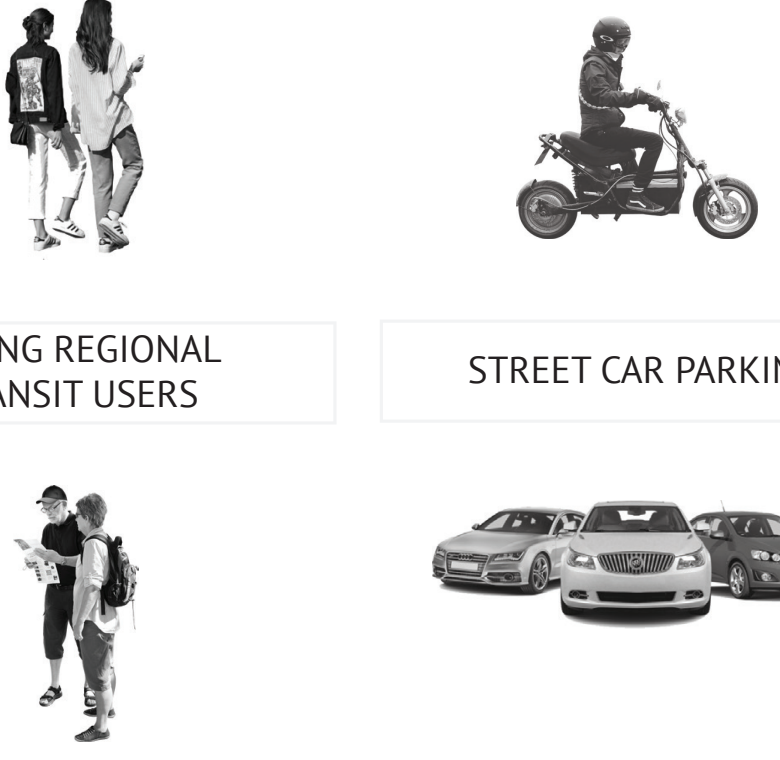

STREET CAR PARKING

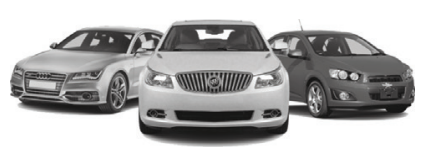

ACTIVITIES

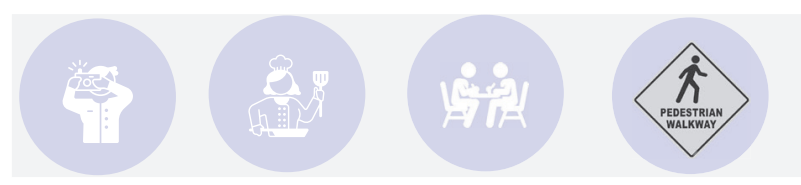

MODE OF TRANSPORT

\section{CIVIC HEART STREET: Wharf St}

\section{STREET USERS}

PEDESTRIANS

PRIVATE VEHICLE USERS

STREET CAR PARKING
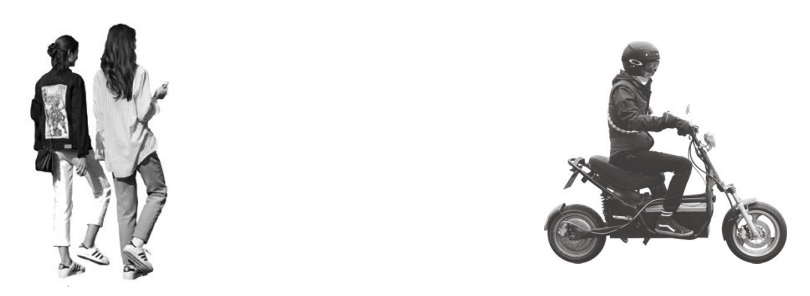

STUDENTS

DOING BUSINESS
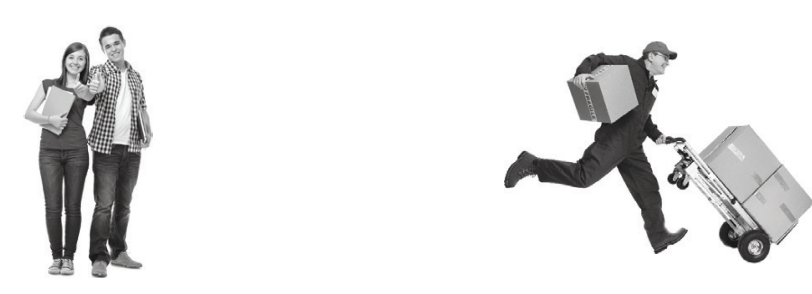

CYCLISTS

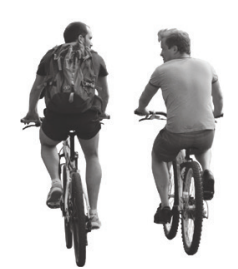

ACTIVITIES

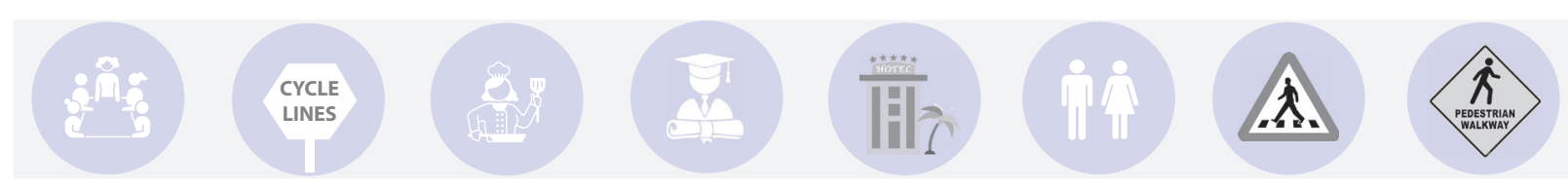

MODE OF TRANSPORT
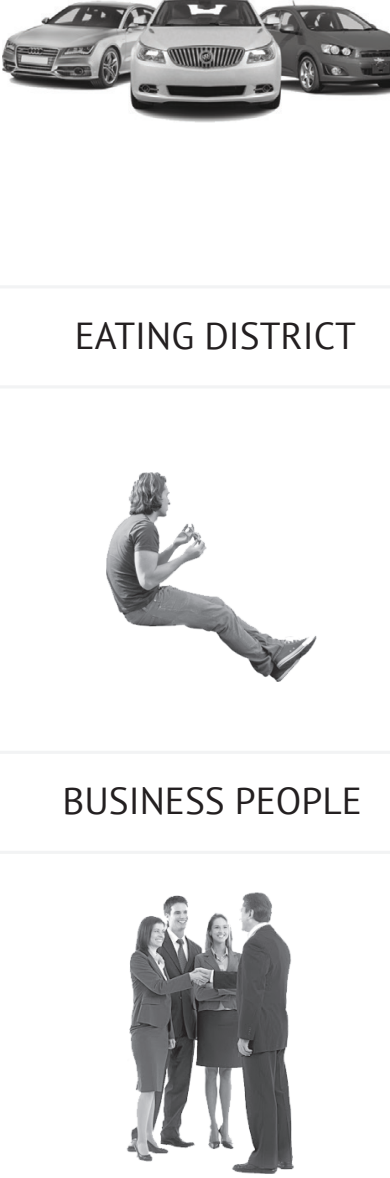

EATING DISTRICT

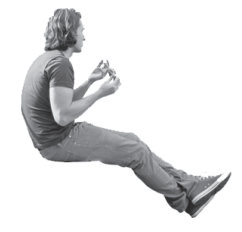

BUSINESS PEOPLE

1. 
Detail Drawing (1:500) in A3

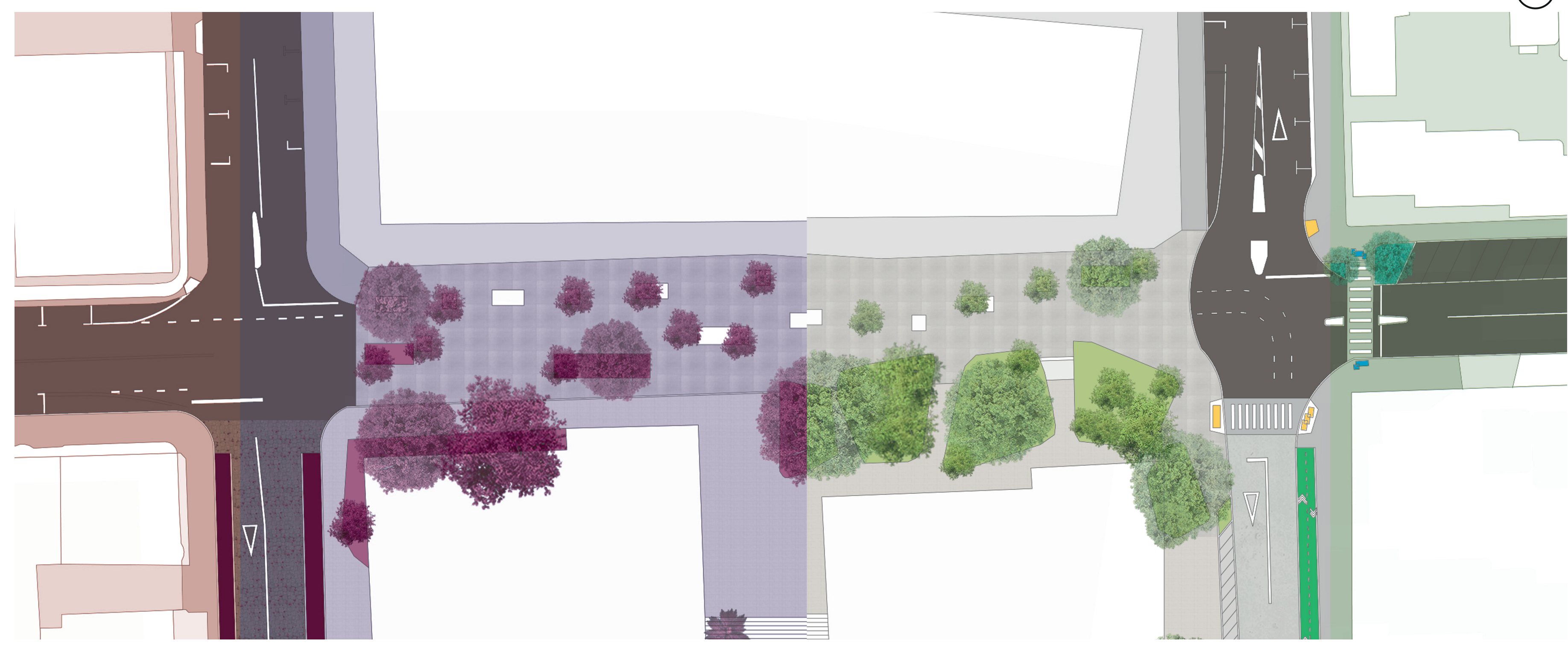

\section{Durham Street}

\section{Civic Heart Street}

Design Objectives:

1. Active Street (Hybrid Street Type 2)

2.Linear Park Street (Hybrid Street Type 3)

Pedestrian Only Linear Park Street

: Creating an accessible street park connecting

proposed Hotel area, Civic Square and

Waterfront.

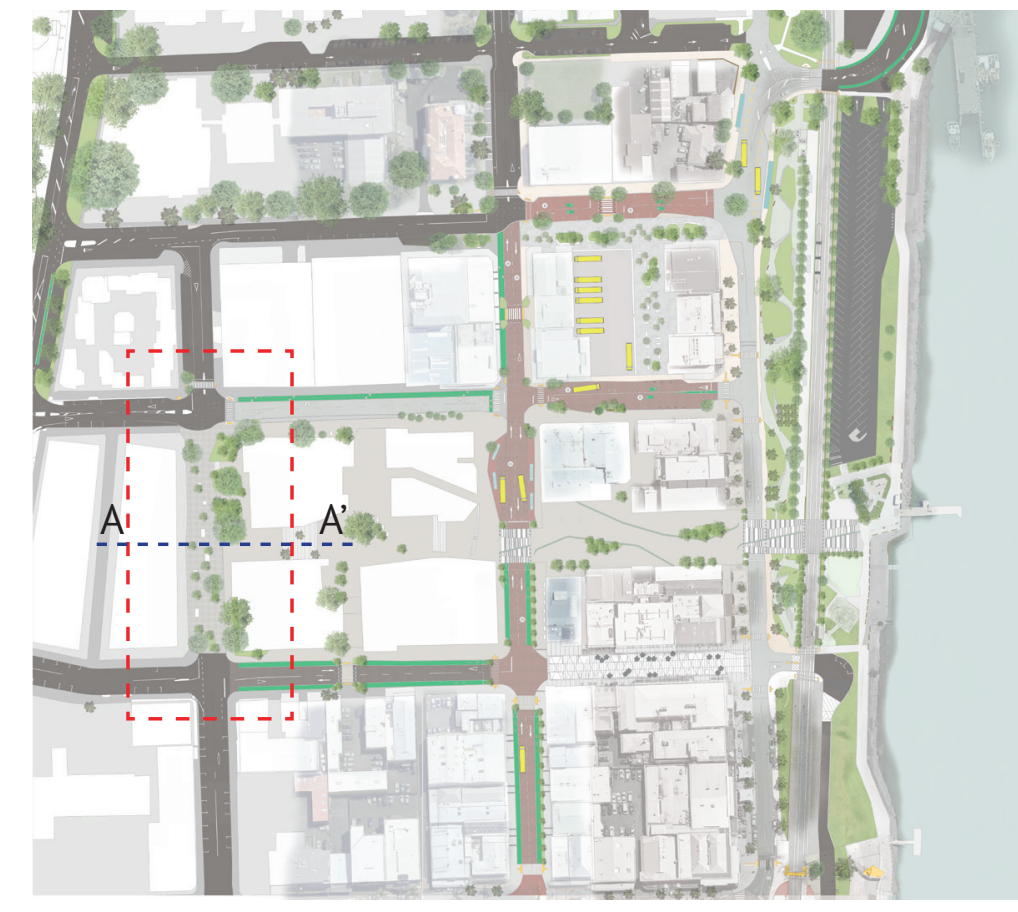




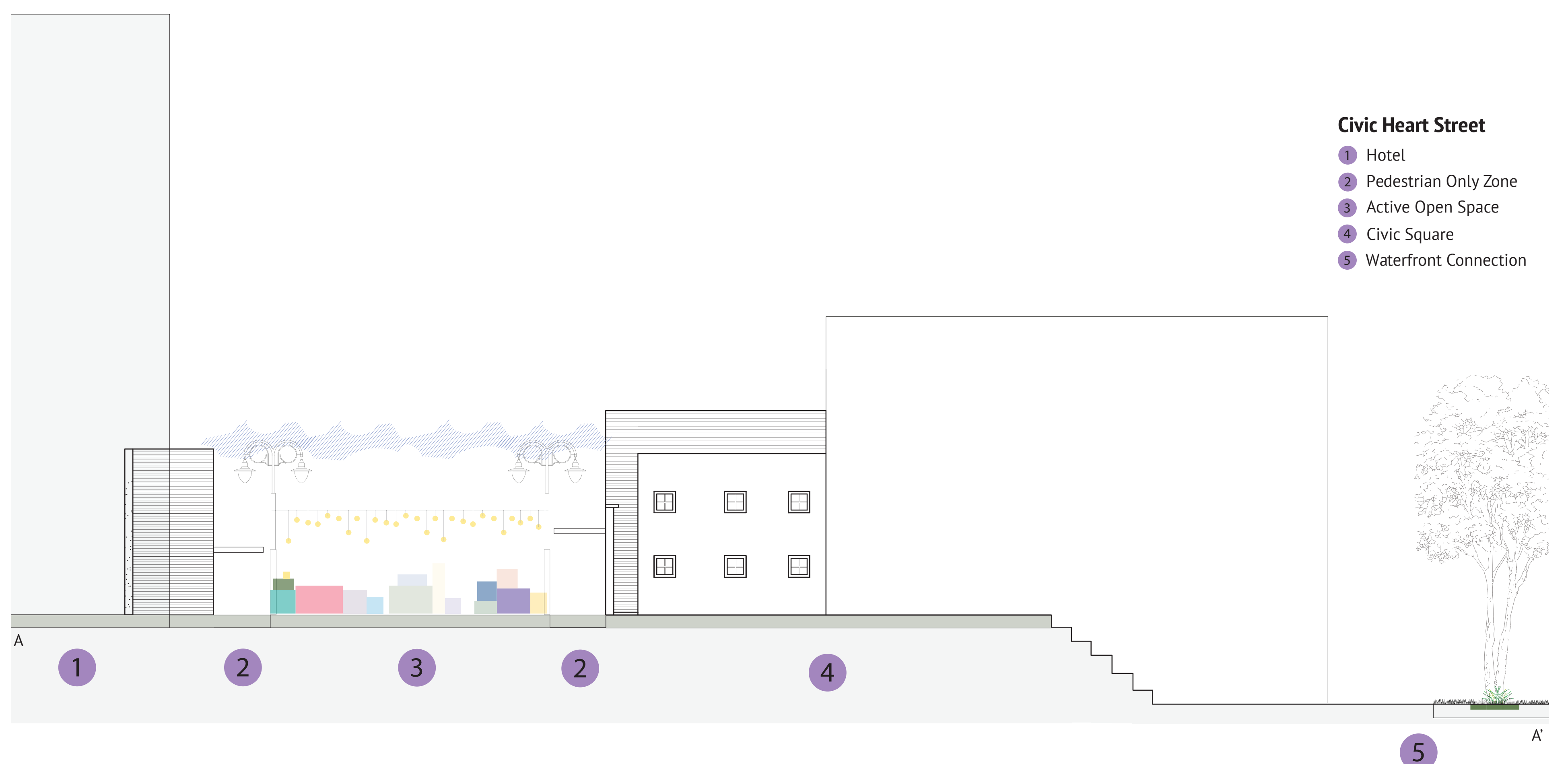




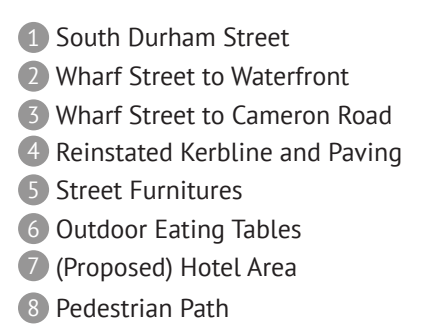

9 Kerbline

Civic Square Western Entrance

(1) Raised Lawn/Garden Mounds

Wall Seatings $P$

4 Hamilton Street to Gameron Road

(15) North Durham Street

(16) Hamilton Street

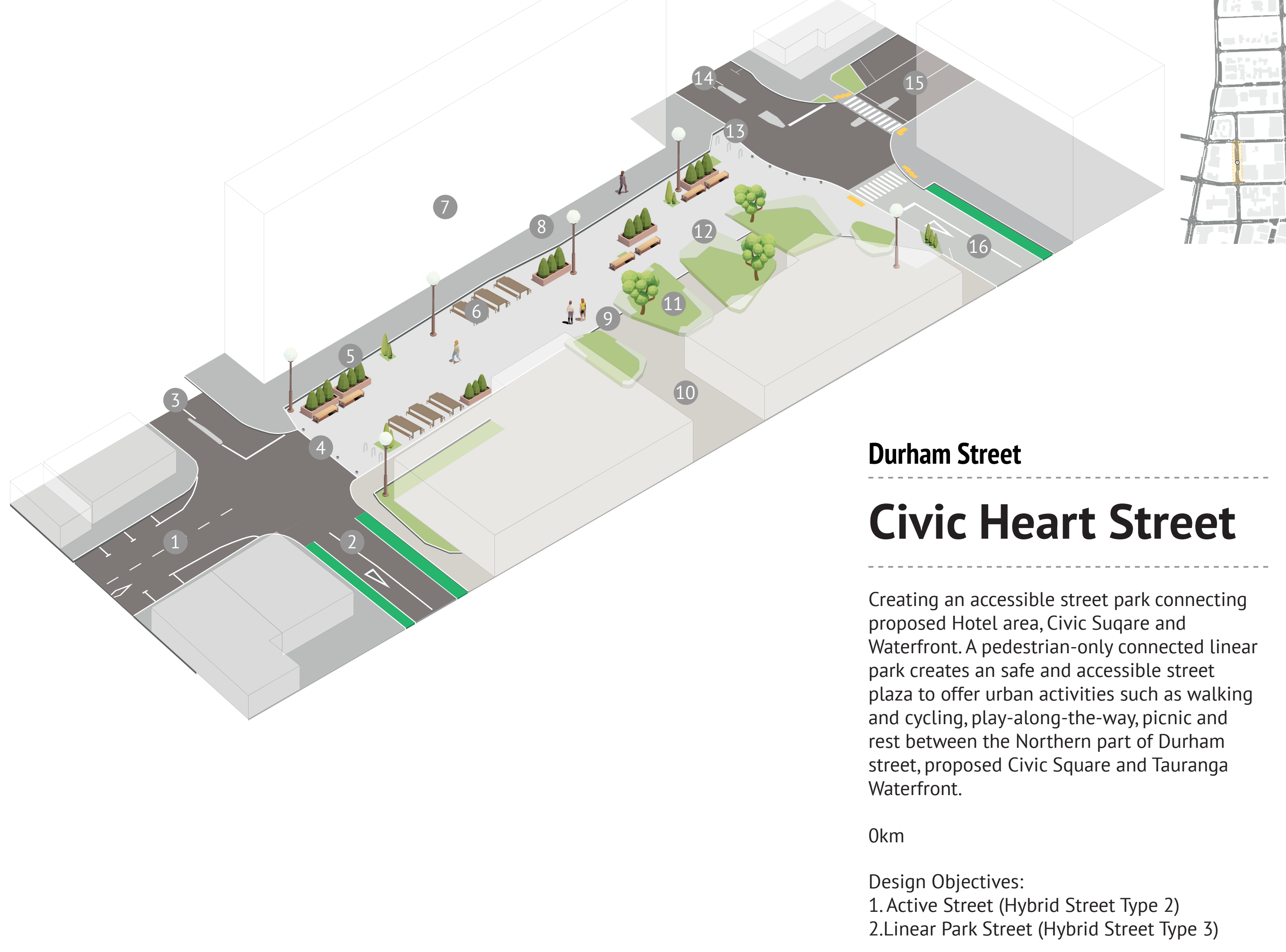


GREEN STREET PARK: Durham Street

\section{STREET USERS}

PEDESTRIANS

PRIVATE VEHICLE USERS

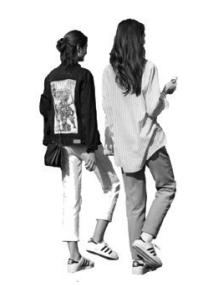

ACTIVITIES

$\underset{\text { BUS }}{\text { BARING }}$ A.

MODE OF TRANSPORT

GREEN STREET PARK: Durham Street

STREET USERS

\begin{tabular}{l|l} 
PEDESTRIANS PEOPLE WITH DISABILITIES & PAL
\end{tabular}

CHILDREN/ PARENT
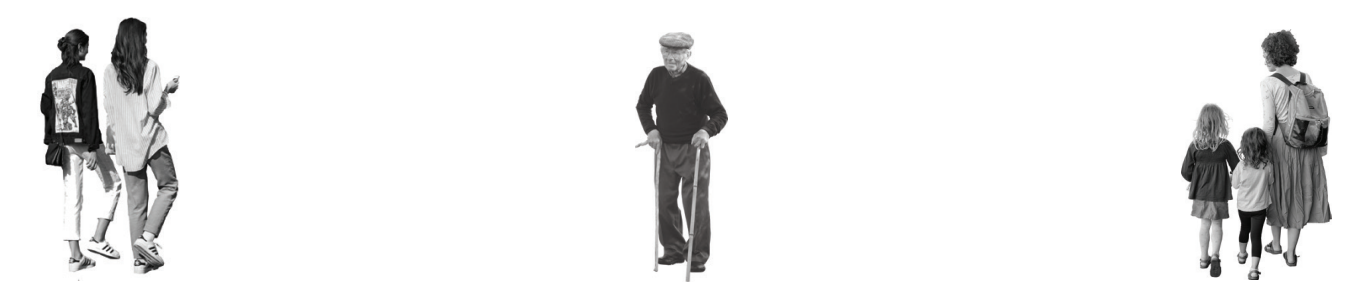

STUDENTS

DOING BUSINESS

EATING DISTRICT

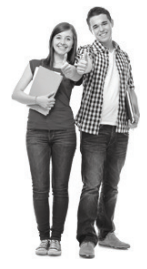

ACCOMMODATION USERS

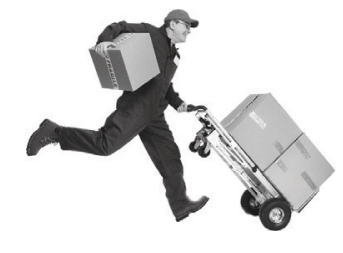

CYCLISTS

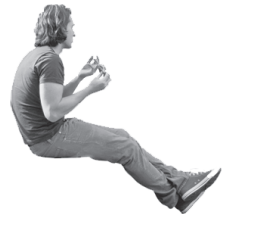

BUSINESS PEOPLE
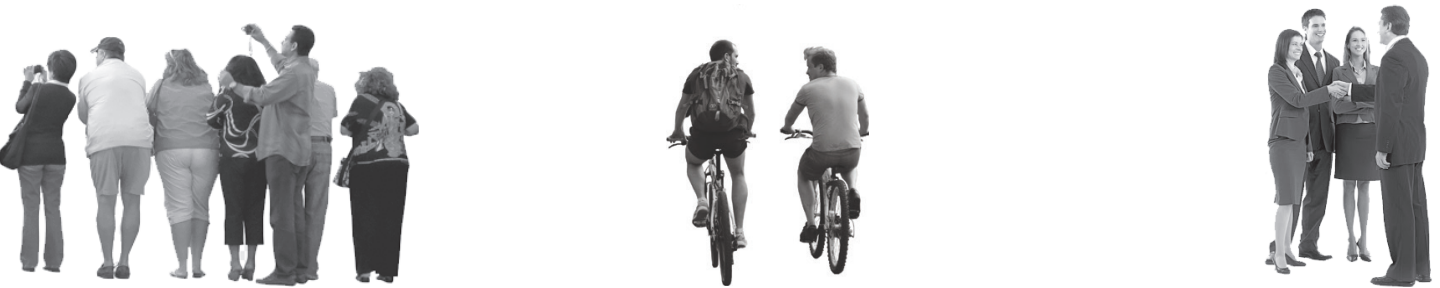

ACTIVITIES

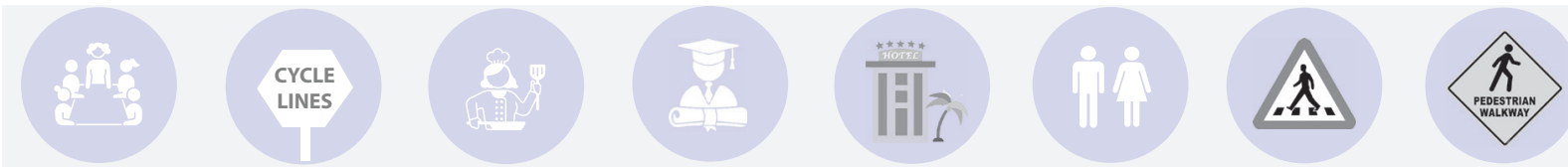

MODE OF TRANSPORT 
Site Plan
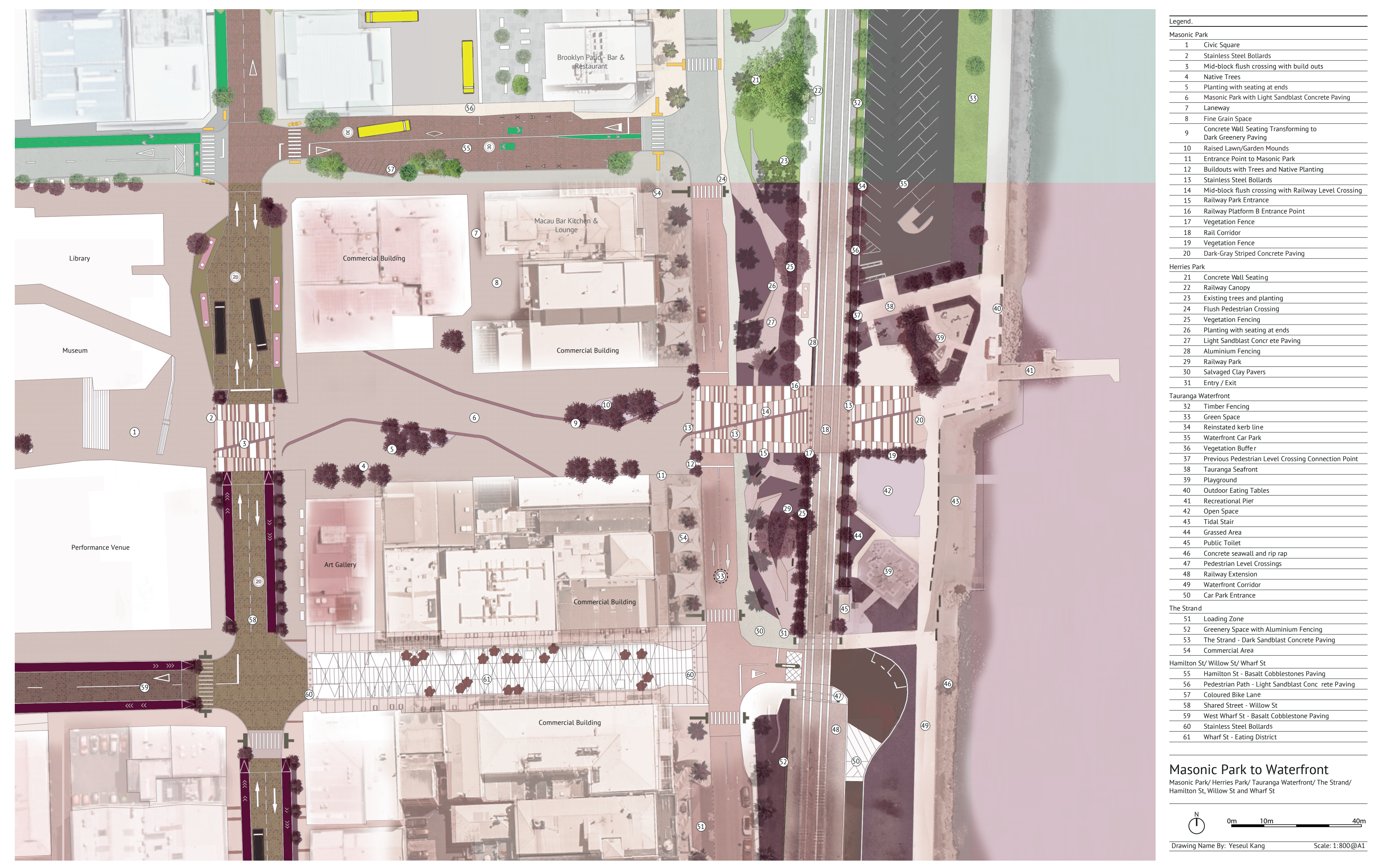


\section{Site Programming}

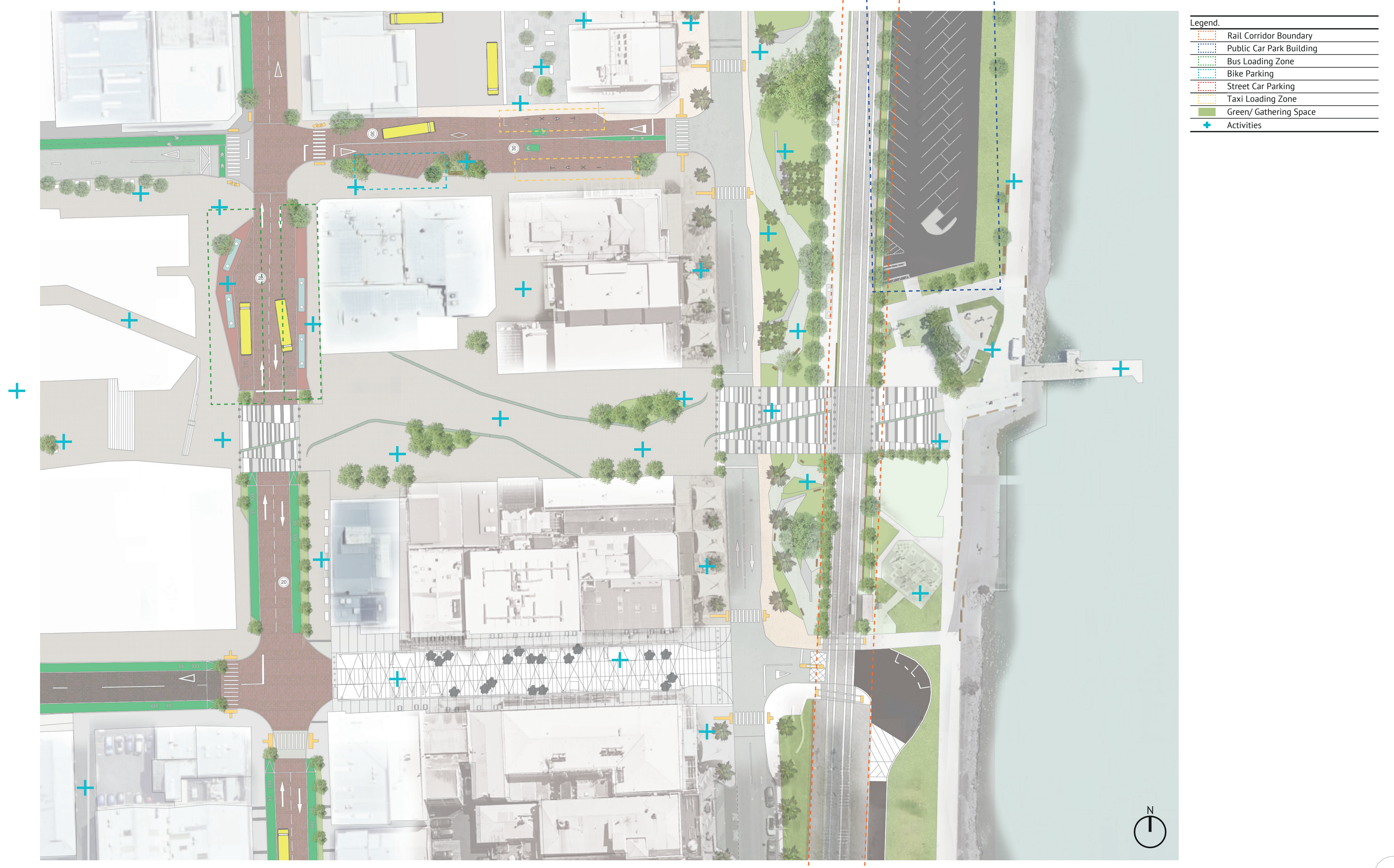




\section{Movement}

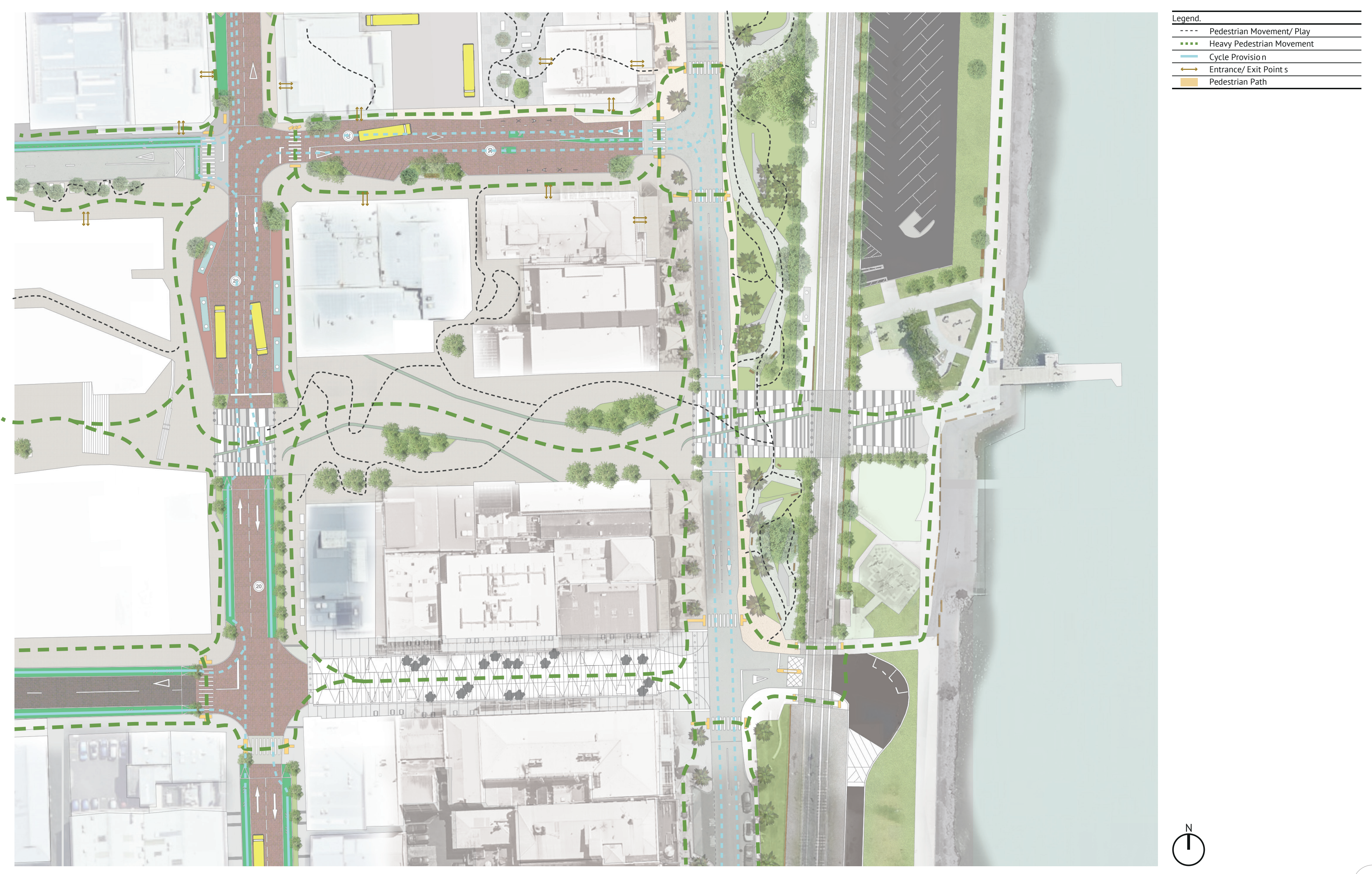




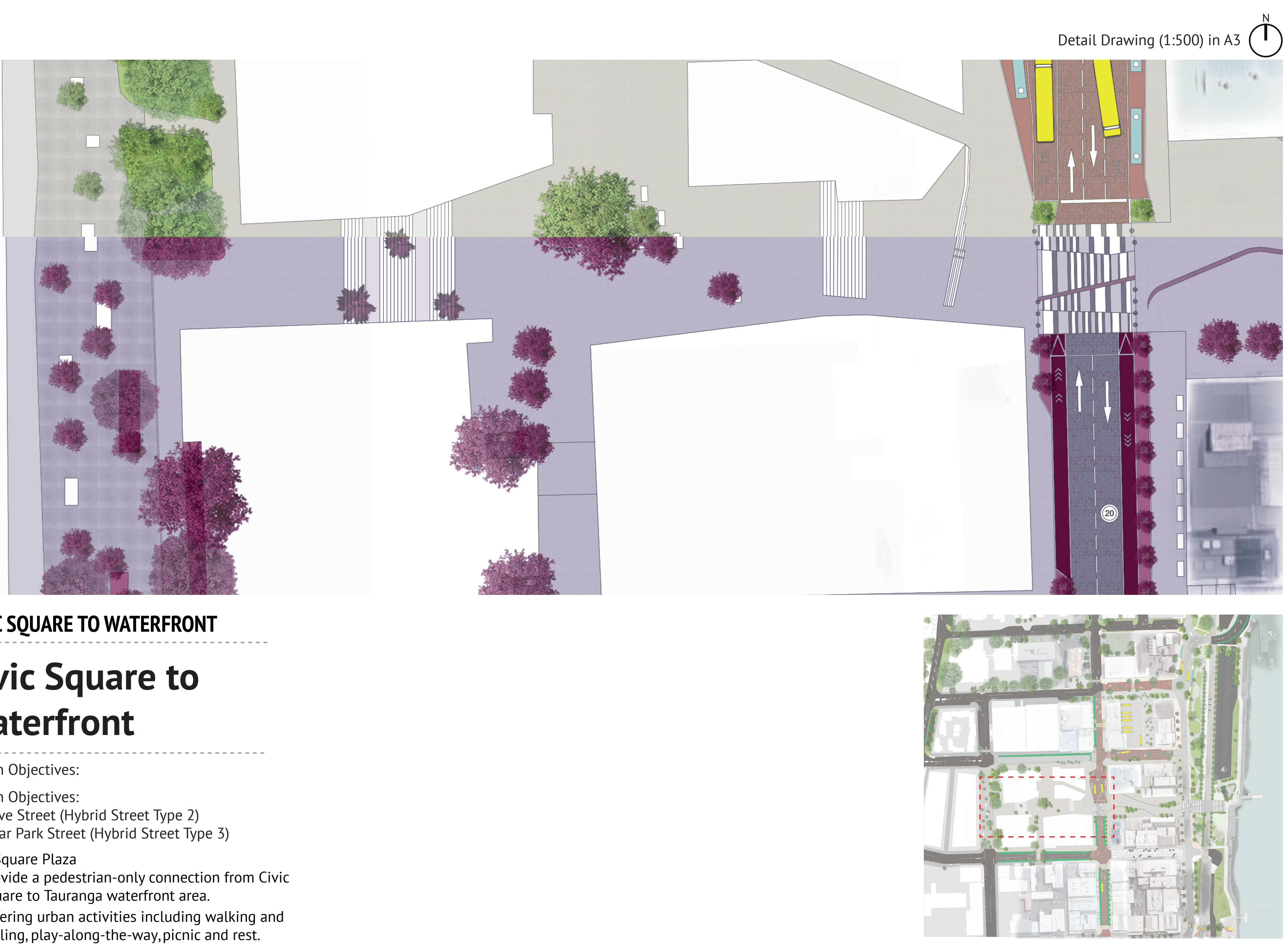


(1) Pedestrian Only Linear Park Street

Civic Square Western Entran

4 Southern Exit to Wharr 5

5) Open/Public Space

Ramp and Wheelchair Access
7 Civic Square Eastern Entrance
8 Flush Pedestrian Crossing with build outs

9 Masonic Park to Waterfront

10. Willow Street

(12) Northern Exit to Hamilton Street

13 Double Side Cycle Lane

(4) Hamilton Street

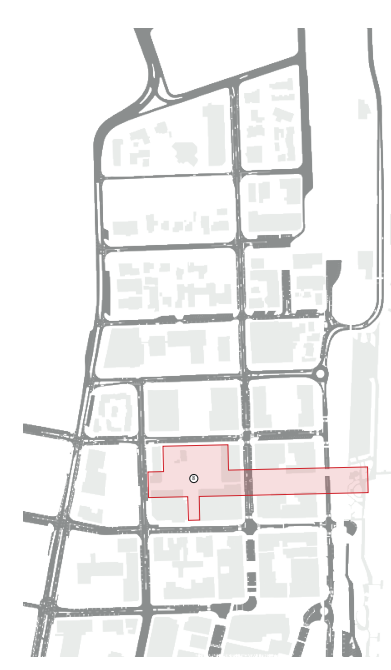

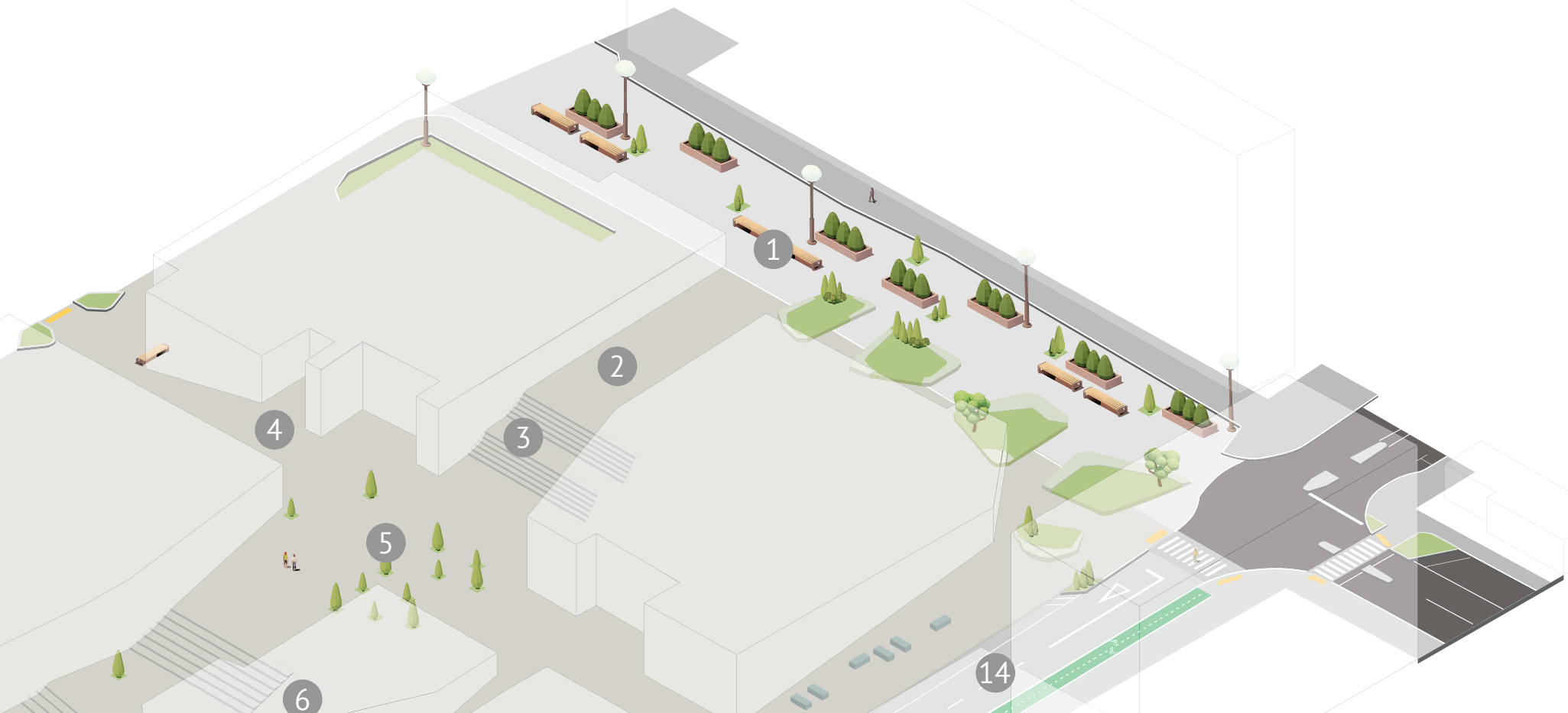

CIVIC SOUARE TO WATERFRONT

\section{Civic Square to} Waterfront

Civic Square/ Centre Plaza establishes a pedestrian-only connection from Civic square to Tauranga waterfront area and it offers a range of activities distinctive from the retail

and commercial city centre.

$0 \mathrm{~km}$

Design Objectives:

Design Objectives:

1. Active Street (Hybrid Street Type 2)

2.Linear Park Street (Hybrid Street Type 3) 


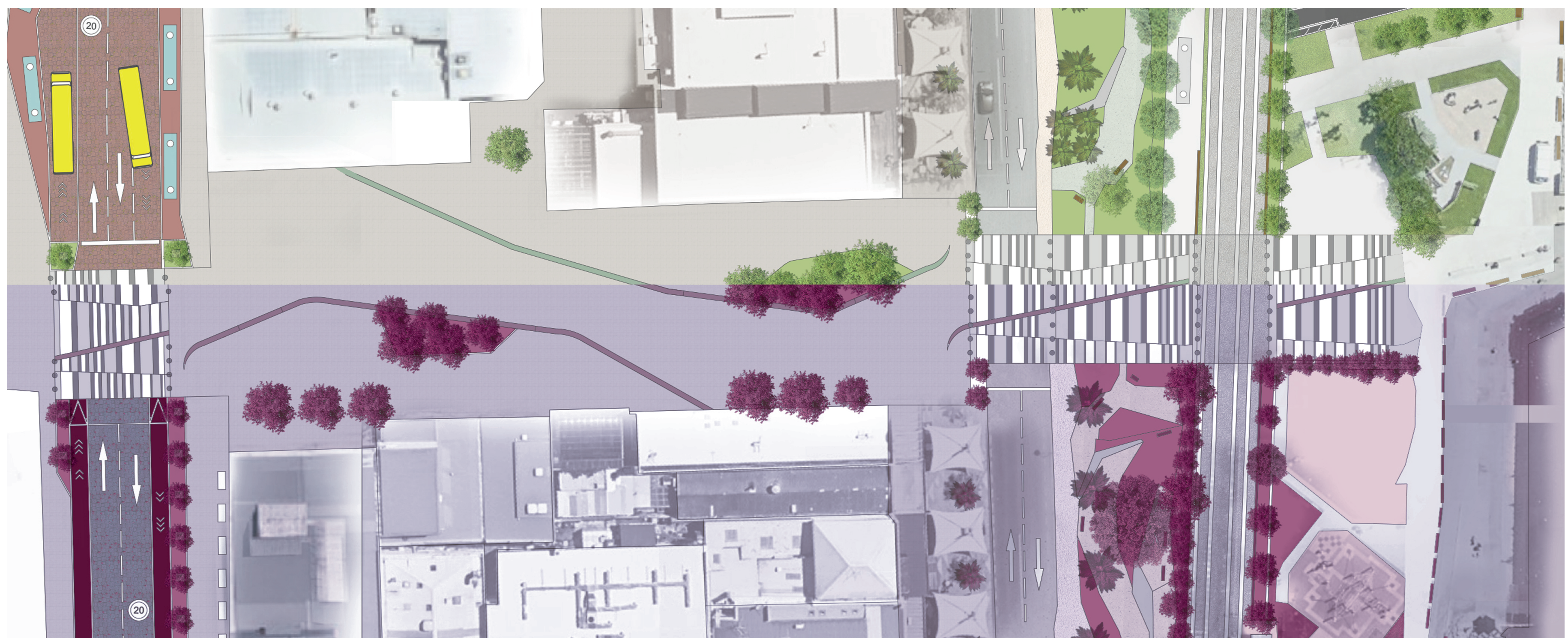

\section{CIVIC SQUARE TO WATERFRONT}

\section{Civic Square to Waterfront}

\section{Design Objectives:}

1. Active Street (Hybrid Street Type 2)

2.Linear Park Street (Hybrid Street Type 3)

Civic Square Plaza

1. Provide a pedestrian-only connection from Civic

square to Tauranga waterfront area.

2. Offering urban activities including walking and

cycling, play-along-the-way, picnic and rest.

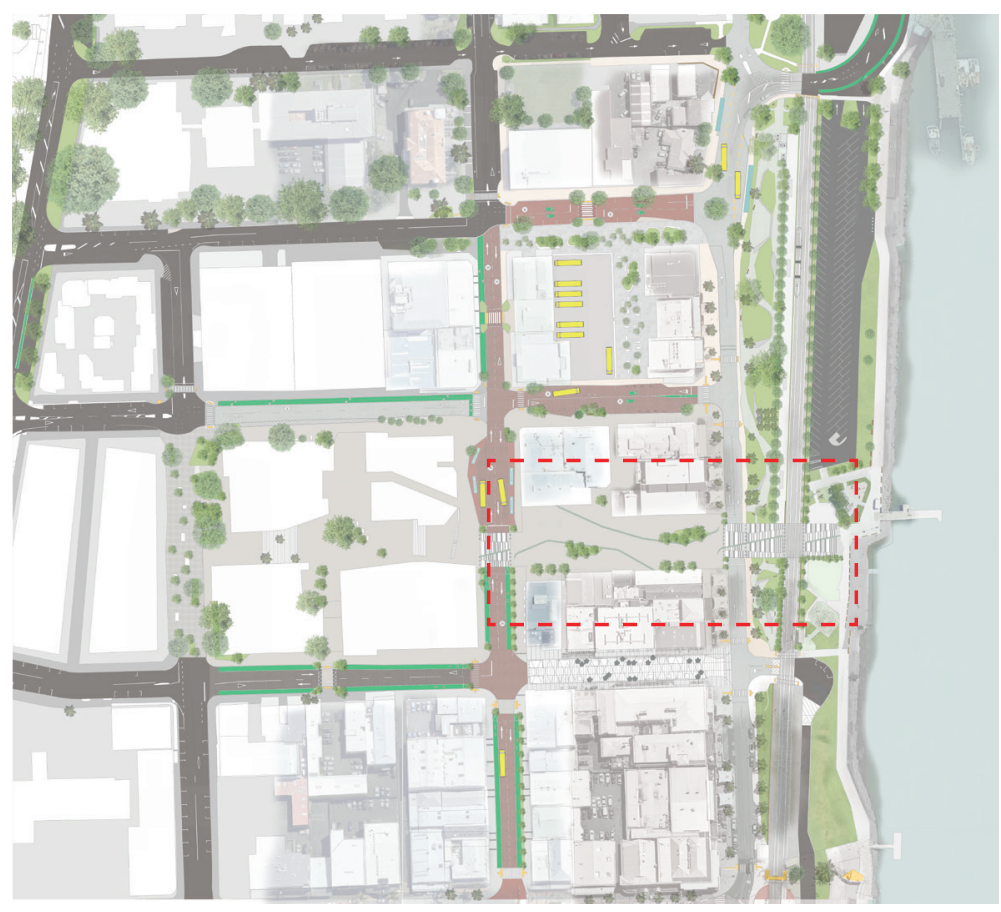




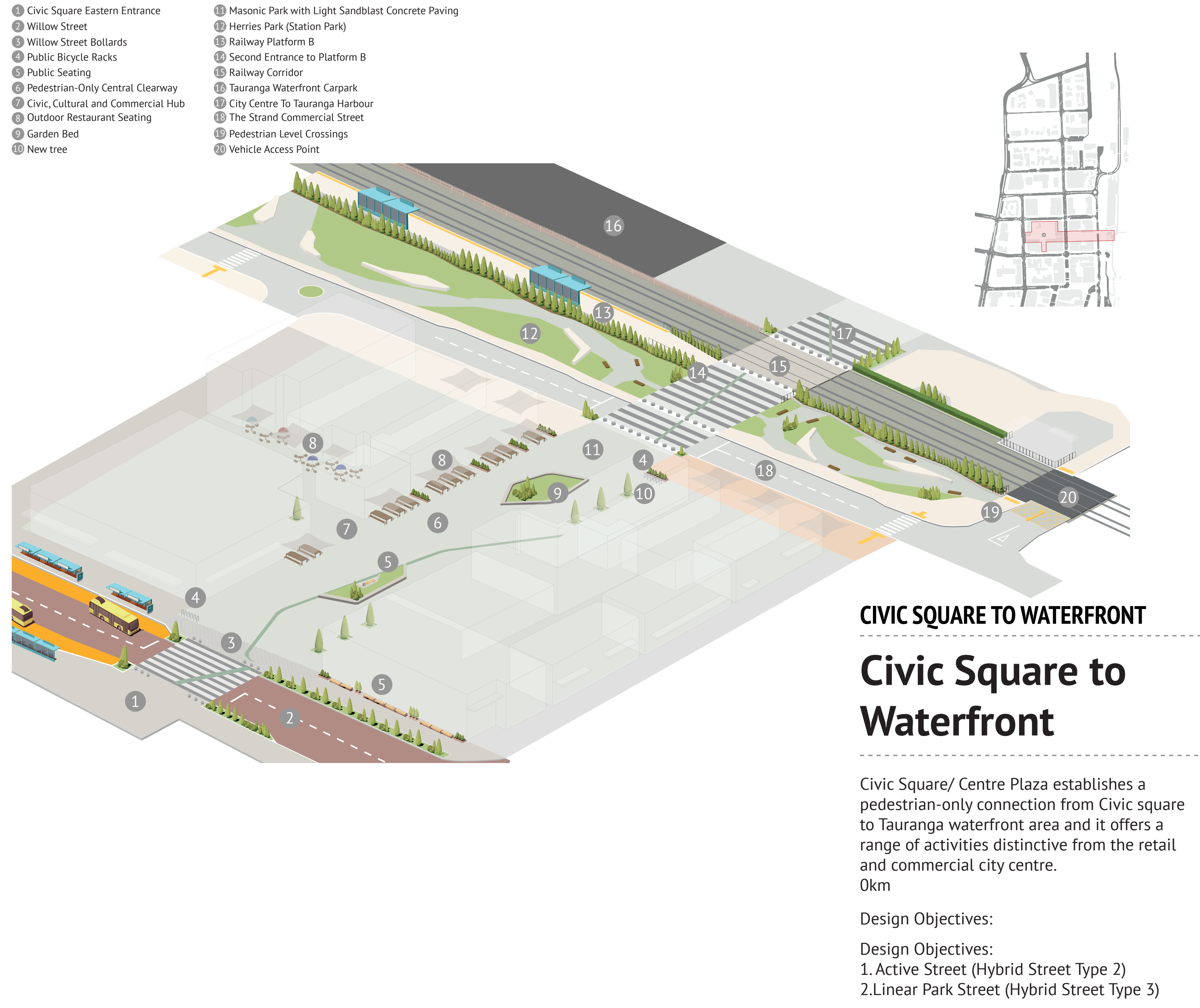




\section{CIVIC SQUARE TO WATERFRONT : Civic Square/ Masonic Park}

\section{STREET USERS}

PEDESTRIANS

CAR PARKING
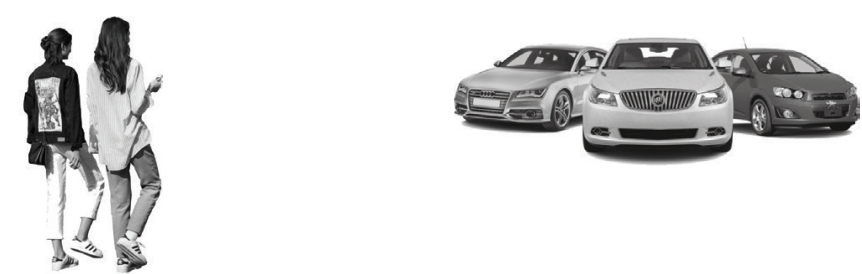

PRIVATE VEHICLE USERS

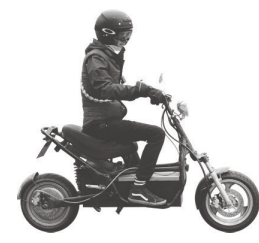

ACTIVITIES

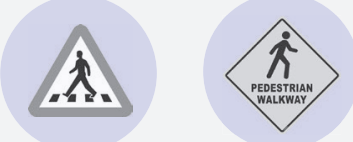

MODE OF TRANSPORT

\section{CIVIC SOUARE TO WATERFRONT : Civic Square/ Masonic Park}

\section{STREET USERS}

DOING BUSINESS

PEDESTRIANS

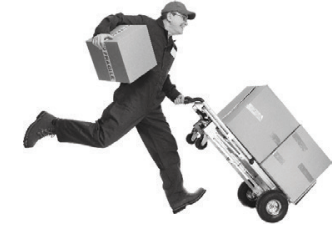

PEOPLE WITH DISABILITIES

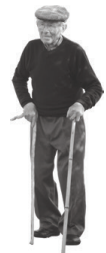

DOING BUSINESS

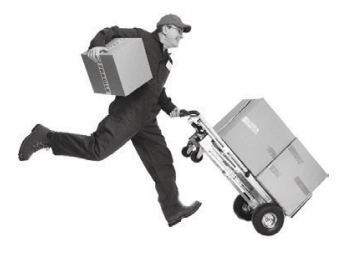

CYCLISTS

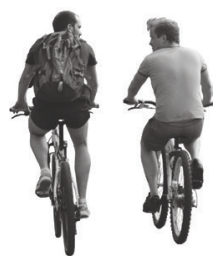

ACTIVITIES

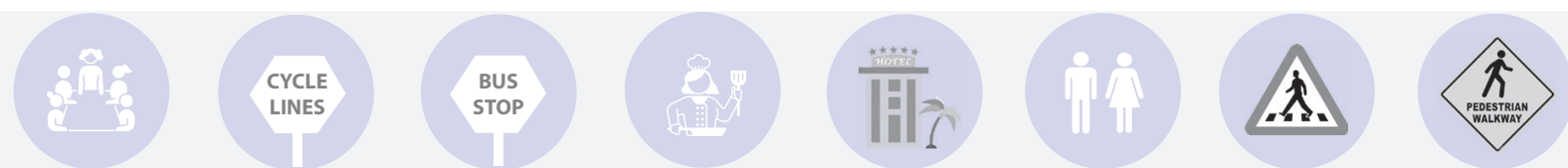

MODE OF TRANSPORT
CHILDREN/ PARENT

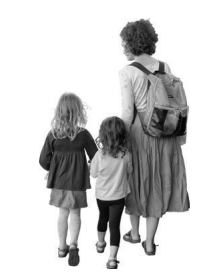

EATING DISTRICT

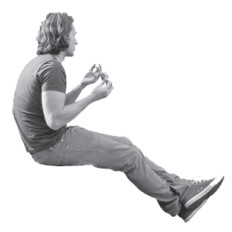

BUSINESS PEOPLE

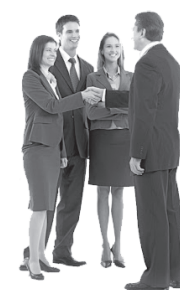

A. A

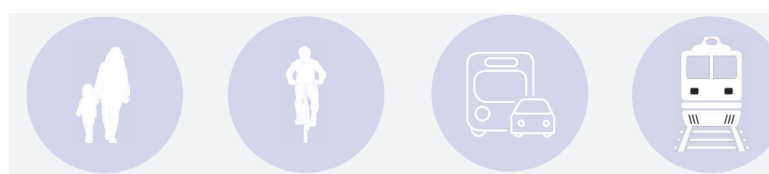




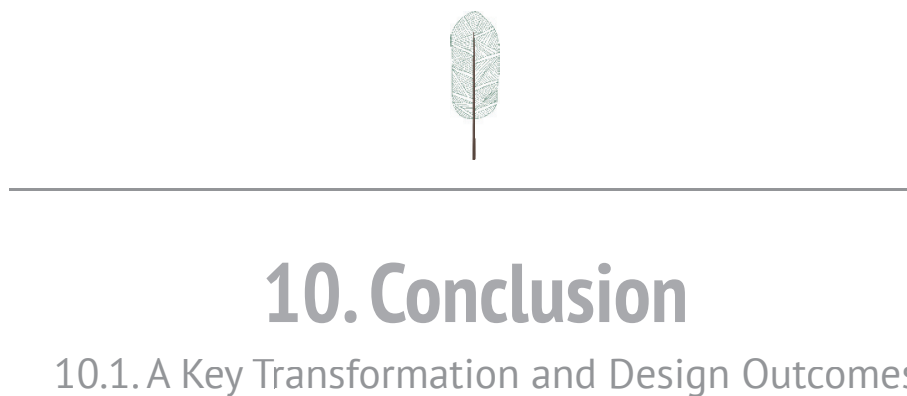

10.1. A Key Transformation and Design Outcomes 10.2. Design Limitations and Further Study

10.3. Conclusion 


\subsection{A Key Transformation}

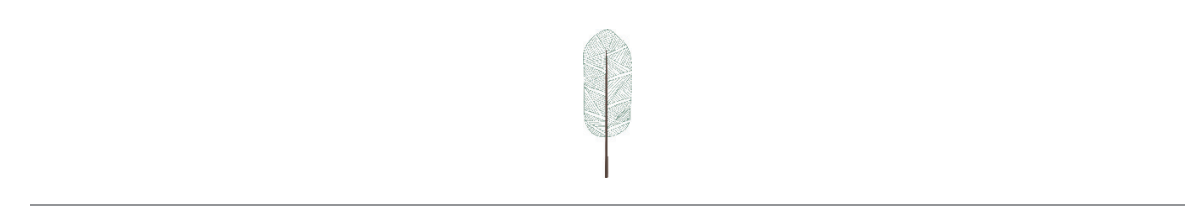

TYPICAL STREET TYPOLOGY

\section{BEFORE}

1. Engineering focused street design.

2. Mono functional support.

3. Location focused design.

4. Low connectivity with other types of vehicle.

5. Limit targeted users.

6. Streets are based on single-use zoning and heavy automobile usage create poor environments for people.

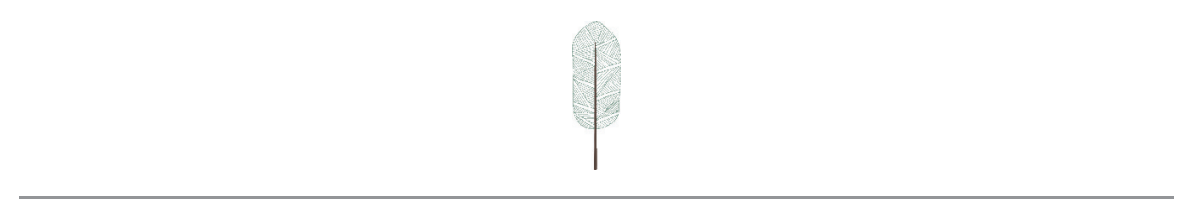

HYBRID STREET TYPOLOGY

\section{AFTER}

1. Landscape architecture focused public space design.

2. Multi functional support.

3. Amenity focused design.

4. Connectivity with other types of vehicle and surrounded facilities.

5. Access for everyone.

6. Hybrid street which provides a wide variety of activities to promote vibrant community. 


\subsection{Reflections}

: Limitations and Further Study

As with the majority of street typology studies, the findings of the research identifies a few limitations. Due to the scope of the site for the final design testing, there were some challenges and limitations throughout the process in the design stage; 1 . Site scale, and 2. Site locations.

The project has been developed the following five design strategies for the vision of 'Hybrid Street': Sustainable Transport Priority Street, Active Street,

Linear Park Street, Commercial Street and Transport Interchange Street on 11 existing sites or streets in Tauranga CBD area. However, those 11 Tauranga city streets did not show significant differences in their street identity, then there were some limitations to test the variety of hybrid street typologies. To better understand th implications of the results, future studies could further address in different regions

on different types of streets. 


\subsection{Conclusion $\$$}

The research, 'Hybrid Street Design' advocates a pe- The site analysis was performed in two different destrian and transit-friendly streetscape connecting study areas. First, to define existing street condithe rail lines to encourage street activities on the tions and second, establishing Tauranga street tyurban and suburban fabric, and also supports other types of sustainable transport modes. A hybrid term

of street typology articulates a vision and strategic Eleven areas (four sites and seven streets) had been approach with design criteria to advance key objec- designed through the developing stage with identives. designed through the developing stage with iden-
tified specific names which were 1 Public transport interchange street, 2 Waterfront precinct shared A range of options/typologies were considered for spaces, 3 East-west railway station access, 4 Eastachieving the objectives of creating the desired hu- west sustainable transport priority street, 5 Northman focused street environment and transport sus- south city connection street, 6 West Wharf: Sustaintainability. able Transport Priority Street \& East Wharf: Food District Street, 7 Civic heart street, 8 Civic square to waterfront street.

To achieve the research question, existing studies and reviews of street typology needed to be dealt

with to understand the basic roles of transit street's The project has been developed the following five characteristics in 'Literature Review'. Through a 'De- design strategies for the vision of 'Hybrid Street'. sign Criteria' stage, an articulate 'Hybrid Street Ty- Eleven designed streets show significant differpology' was defined to use in 'Design Stage'. ences in a single detailed design but their overall spatial identity seems similar then there were some

Having carried out that investigation, the five hy- limitations to test the variety of hybrid street tybrid street typologies have been identified through pologies. To better understand the implications of the research study. The five hybrid street typologies the results, future studies could further address on take into account the scale, density, diversity of des- different region's streets which has significantly diftinations, quality of place as well as the significance ferent landscape architectural environments and of movement by different modes.

$$
\text { scales. }
$$

The investigated hybrid street typology has been Nonetheless a few limitations, I believe 'Hybrid applied and tested into the seven different streets Functioned Street Design Study' suggests a soluand four sites in Tauranga city centre where have tion to improve current issues and indicates a good significantly different spatial characteristics.

strategy for supporting a government's long-term plan and furthermore, the vision of a new street design guideline. 
1. Borrowed City: Motoelastico . Damdi: N.p., 2013. Print.

2. Ceccon, Paolo, and Laura Zampieri. Paths, Tracks, and Trails : Designing for Pedestrian and Cyclists . Mulgrave, Victoria: The Images Publishing Group Pty Ltd, 2016. Print.

3. Morten, Gjerde. Movement and access ("path"). 2010. Print.

4. Jacobs, Allan B. Great Streets . Cambridge, Mass: MIT Press, 1993. Print.

5. Walker, Jarrett. Human Transit : How Clearer Thinking About Public Transit Can Enrich Our Communities and Our Lives. Washington, DC: Island Press/Center for Resource Economics, 2012. Print.

6. Lynch, Kevin. The Image of the City. Cambridge [Mass: Massachusetts Institute of Technology Press, 1960. Print.

7. Bendiks, Stefan, Degros, Aglaée, and Colville-Andersen, Mikael. Fietsinfrastructuur $=\mathrm{Cy}$ cle infrastructure. Rotterdam: nai010 uitgevers/ nai010 publishers, 2013. Print.

8. Auckland Transport. "Chapter 21 Public Transport - Rail." 2013. Print.

9. Walker, Jarrett. Human Transit How Clearer Thinking About Public Transit Can Enrich Our Communities and Our Lives. Washington, D.C: Island Press, 2012. Print.
10. Forman Richard T. T"Human Structures" Urban Ecology: Science of Cities. New York: Cambridge University Press, 2014. 275-313. Print.

11. Ooi, Giok Ling., and Yuen, Belinda K. P. World Cities Achieving Liveability and Vibrancy. Singapore World Scientific, 2010. Print.

12. Slepian, Jenny, and Stephenso n, Janet. “Moving Forward with Transit-Oriented Development in NZ:" Planning quarterly 163 (2006): 24-26. Print.

13. Newman, Peter and Kenworthy, Jeffrey. "Cities and Automobile Dependence - an International Sourcebook." Utilities policy 1 July 1991 52-52. Web.

14. Baker Karl and Nunns Peter."2015 Australasian Transport Research Forum." Access, amenity, and agglomeration: What can we expect from rapid transit projects? (2015): n. pag. Print.

15. ITDP. TOD STANDARD. Institute for Transportation and Development Policy TOD Standard, 3rd ed. New York: ITDP, 2017. Print.

16. Rik, Houthaeve. Light rail provides a design for a healthy and liveable urban public space. Light rail design and public space, 45th ISOCARP Congress 2009. Print.
Figure 1. National Context (2021). Victoria University. Dorothy Kang.

Figure 2. Western Bay of Plenty

Wider National Land Transport Network (2021).

Victoria University. Dorothy Kang.

Figure 3. Smartgrowth (2019). Urban Form and Transport Initiative. Foundation Report.

Figure 4. Statistics New Zealand (2018)

Population estimates by broad age groups.

www.stats.govt.nz/information-releases/ subnational-population-estimates-at-30-june2018-provisional.

Figure 5. Tauranga Transport Programme (2018) Tauranga has the highest single occupancy rate in the country for journey to work in a major city.

Figure 6. Nexus (2019); Draft Tauranga Transport Programme,"Travel demand management in Tauranga survey".

Figure 7. Arataki - Waka Kotahi (2020). REGIONAL SUMMARY BAY OF PLENTY REGION. https://www.nzta.govt.nz/assets/planning-andinvestment/arataki/docs/regional-summarybay-of-plenty-august-2020.pdf

Figure 8. 2013 Census Demographics and Deprivation Data - Bay of Plenty.

Figure 9. The Proportion of Sustainable Modes (2021). Victoria University. Dorothy Kang. 
Figure 10. Public Transport System and deprivation in Western Bay of Plenty Region. (2021). Victoria University. Dorothy Kang.

Figure 11. Land Use Patterns (2021). Victoria University. Dorothy Kang.

Figure 12. Land Use Patterns in the western Bay of Plenty (2021). Victoria University. Dorothy Kang.

Figure 13. Mono-centric Representation (2021). Victoria University. Dorothy Kang.

Figure 14. Network Analysis with Traffic Conflicts (2021). Victoria University. Dorothy Kang.

Figure 15. Aligned growth and transport infrastructure development in Bay of Plenty Region (2021). Victoria University. Dorothy Kang.

Figure 16. Research Opportunities (2021). Victoria University. Dorothy Kang.

Figure 17. Research Purpose Figure (2021). Victoria University. Dorothy Kang.

Figure 18. Research Question (2021). Victoria University. Dorothy Kang.

Figure 19. Research Investigation and Methodology (2021). Victoria University. Dorothy Kang.
Figure 20. Regional Rapid Rail Proposal By Grater Auckland (2021).Victoria University. Dorothy Kang.

Figure 21. Distance and Time Comparison from Omokoroa to Tauranga CBD (2021). Victoria University. Dorothy Kang.

Figure 22. Future Development Strategy By SmartGrowth (2021). Victoria University. Dorothy Kang.

Figure 23. The Urban Form and Transport Initiative (UFTI) By NZ Transport Agency and SmartGrowth (2021). Victoria University. Dorothy Kang.

Figure 24. Literature Review (2021). Victoria University. Dorothy Kang.

Figure 25. STREET USES FOR PLAYING VIDEO GAMES (2021). Victoria University. Dorothy Kang.

Figure 26. Anticipatory orientation: Terrace/ Plateau (2021). Victoria University. Dorothy Kang.

Figure 27. Path and goal (2021). Victoria University. Dorothy Kang.

Figure 28. Path routing: visual links (2021) Victoria University. Dorothy Kang.
Figure 29. Path routing: use of the area (2021). Victoria University. Dorothy Kang.

Figure 30. Path Junctions (2021). Victoria University. Dorothy Kang.

Figure 31. Path Junctions and a Stopping Behaviour (2021). Victoria University. Dorothy Kang.

Figure 32. Path Joints (2021). Victoria University. Dorothy Kang.

Figure 33. Passenger Train Service in Western Bay of Plenty (2021). Victoria University. Dorothy Kang.

Figure 34. Existing Transport Infrastructures (2021).Victoria University. Dorothy Kang.

Figure 35. Spatial Identities (2021). Victoria University. Dorothy Kang.

Figure 36. Characteristics of the street identity (2021). Victoria University. Dorothy Kang.

Figure 37. Tauranga Precinct (2021). Victoria University. Dorothy Kang.

Figure 38. Railway Station Opportunities (2021) Victoria University. Dorothy Kang. 


\section{Appendix 1. RAILWAY CIVIL ENGINEERING}

Figure 1. Railway Platform Configuration/ Edge Plan (2021). Victoria University. Dorothy Kang.

Figure 2. Platform Configurations/ Dimensions. Victoria University. Dorothy Kang.

Figure 3. Vertical Movement- Ramp (2021)

Victoria University. Dorothy Kang.

Figure 4. Integration Of Engineering And Operational Elements - Platforms (2021). Victoria University. Dorothy Kang.

Figure 5. Station Context And Urban Integration (2021). Victoria University. Dorothy Kang.

Figure 6. Rail Corridor Landscape Buffer Example 1 and 2 (2021). Victoria University. Dorothy Kang.

\section{Appendix 2. PRECEDENT STUDIES}

Figure 7-14. Wellington Railway Station

Precedents (2021). Victoria University. Dorothy Kang.

Figure 15-18. Wellington Railway Station Precedents (2021). Victoria University. Dorothy Kang.

Appendix 3. TYPOLOGY STUDIES

Figure 19-25. Typology Studies

Appendix 4. TAURANGA STATION/ STREETS DESIGN SKETCHES

Figure 26. Site Context (2021). Victoria University. Dorothy Kang.
Figure 27. Existing Street Conditions (2021). Victoria University. Dorothy Kang.

Figure 28. Design Strategy (2021). Victoria University. Dorothy Kang.

Figure 29. Tauranga City's Streets (2021) Victoria University. Dorothy Kang.

Figure 30. Old Tauranga Station Layout (2021). Victoria University. Dorothy Kang.

Figure 31. Railway Extension (Possibility) (2021). Victoria University. Dorothy Kang.

Figure 32. Railway Crossing Measures (2021). Victoria University. Dorothy Kang.

Figure 33. Final Decisions For Train Lines (2021). Victoria University. Dorothy Kang.

Figure 34. Railway Crossings (2021). Victoria University. Dorothy Kang.

Figure 35. Design Layouts (2021). Victoria University. Dorothy Kang.

Figure 36. Station Site A (2021). Victoria University. Dorothy Kang.

Figure 37. Station Site B (2021). Victoria University. Dorothy Kang.

Figure 38. Station Site A: Platform Idea (2021). Victoria University. Dorothy Kang.

Figure 39. Station Site B: Platform Idea (2021) Victoria University. Dorothy Kang.

Figure 40. Two Station's Sites (2021). Victoria University. Dorothy Kang.
Figure 41. Platform B and Street Layouts (2021). Victoria University. Dorothy Kang.

Figure 42. Platform B Design Layout (2021).

Victoria University. Dorothy Kang.

Figure 43. Platform B and Street Connections and Access Points (2021). Victoria University. Dorothy Kang

Figure 44. Station Park (Herries Park) (2021). Victoria University. Dorothy Kang.

Figure 45. Station Park Details Design (2021) Victoria University. Dorothy Kang.

Figure 46. Station Park Connections (2021). Victoria University. Dorothy Kang.

Figure 47. Platform Ramp Designs and Calculation (2021). Victoria University. Dorothy Kang.

\section{Appendix 5. WESTERN BAY OF PLENTY} CONTEXT STUDIES

Figure 48. Moving Forward/ BOP Long Term Plan (2021). Victoria University. Dorothy Kang.

Figure 49. Street Typology in Omokoroa and Te Puna (2021). Victoria University. Dorothy Kang.

Figure 50. Omokoroa Existing Street Conditions (2021). Victoria University. Dorothy Kang.

Figure 51. Omokoroa Station Idea Sketch (2021). Victoria University. Dorothy Kang. 
RAILWAY CIVIL ENGINEERING :TDMI ENGINEERING DESIGN CODE BY PUBLIC TRANSPORT - RAIL INFRASTRUCTURE

Figure 5. Station Context And Urban Integration

Figure 1. Railway Platform Configuration/ Edge Plan

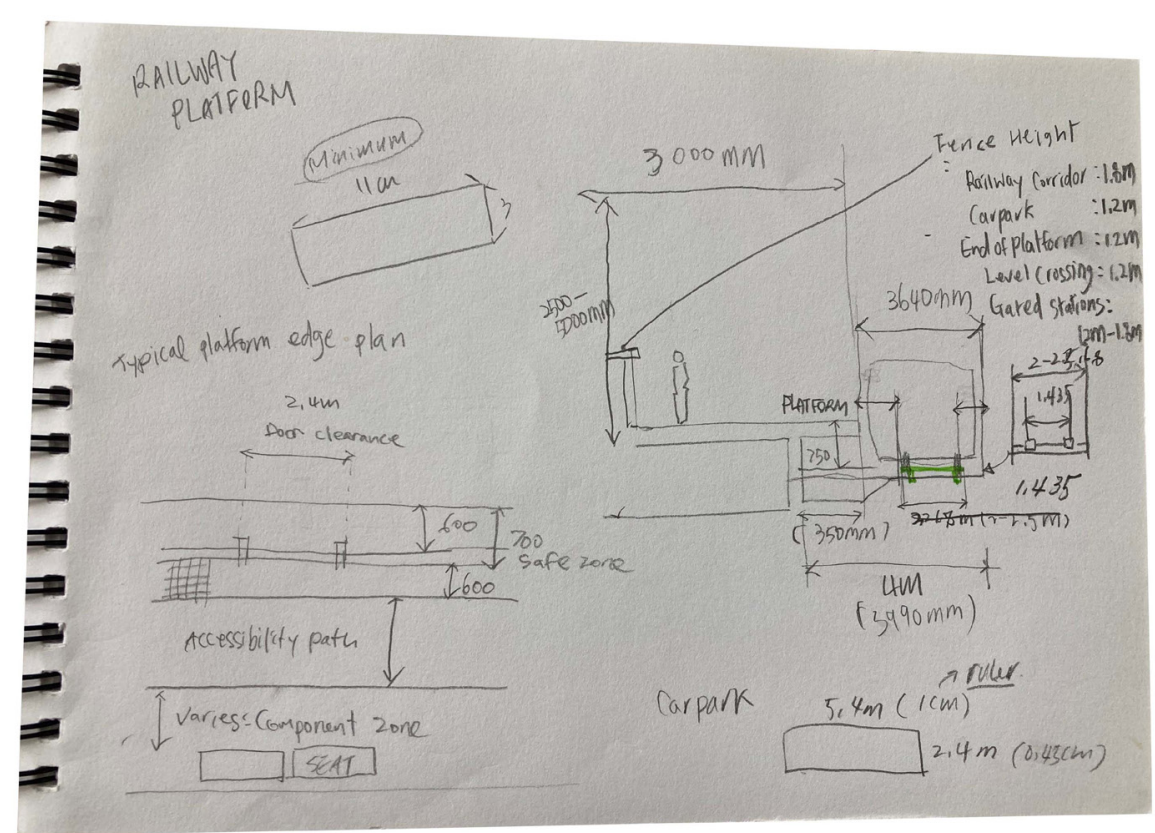

Figure 2. Platform Configurations/ Dimensions

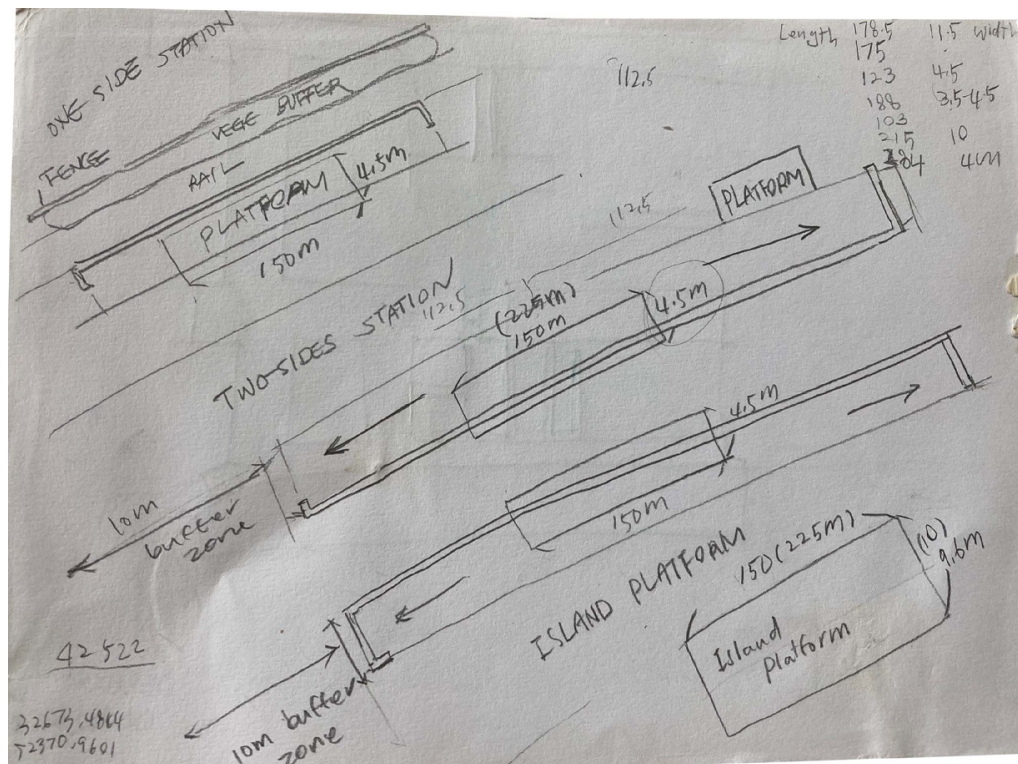

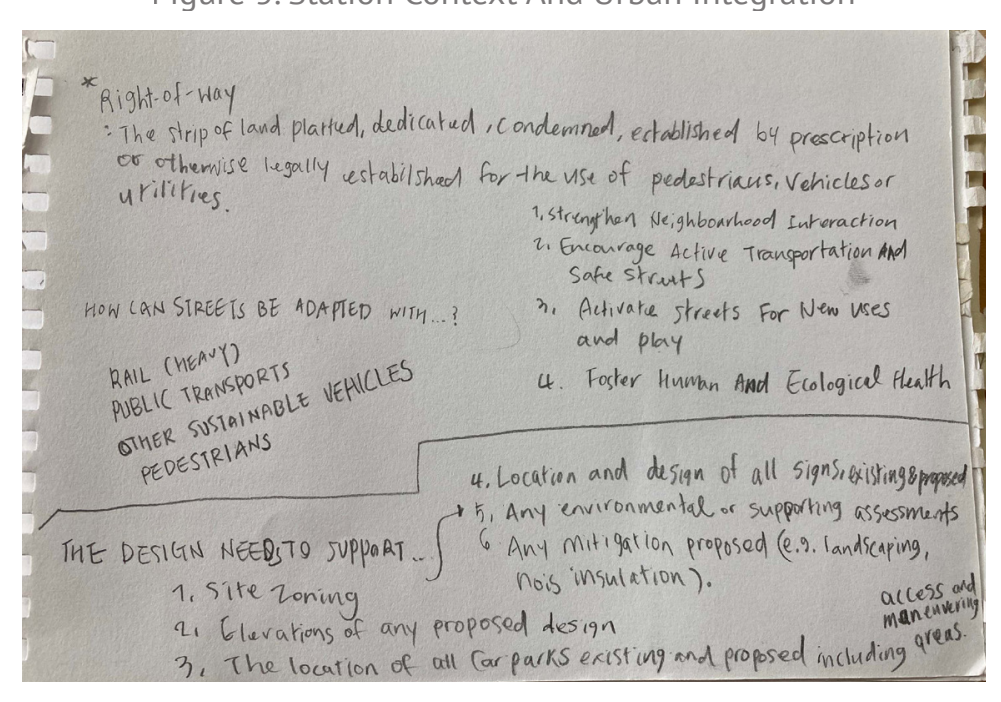

Figure 4. Integration Of Engineering And Operational Elements - Platforms

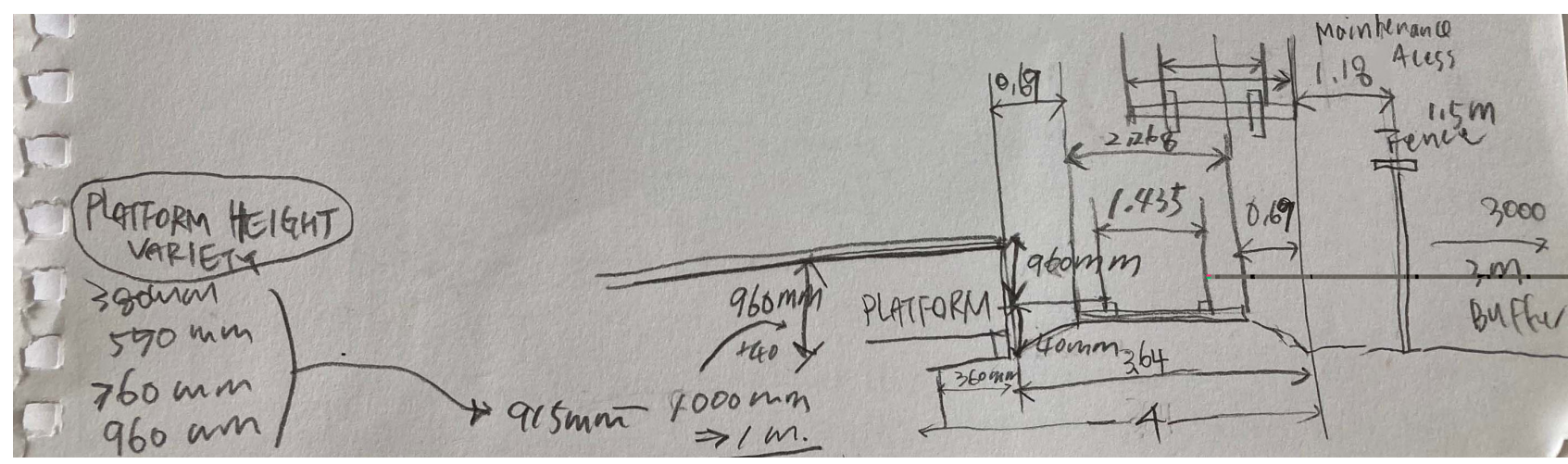

Figure 6. Rail Corridor Landscape Buffer Example 1 and 2.

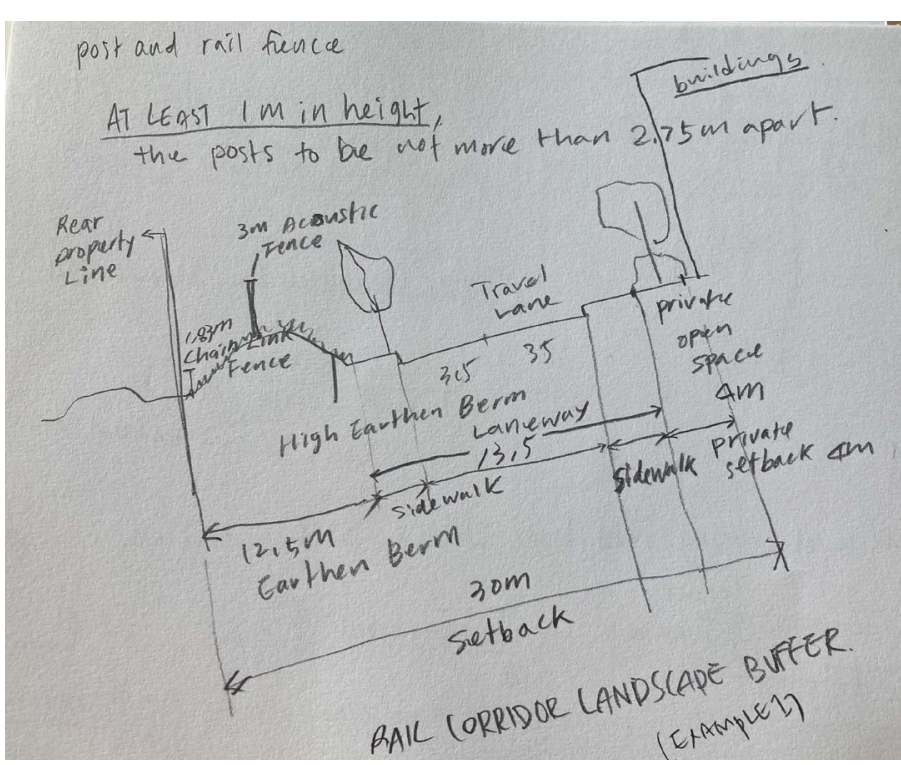

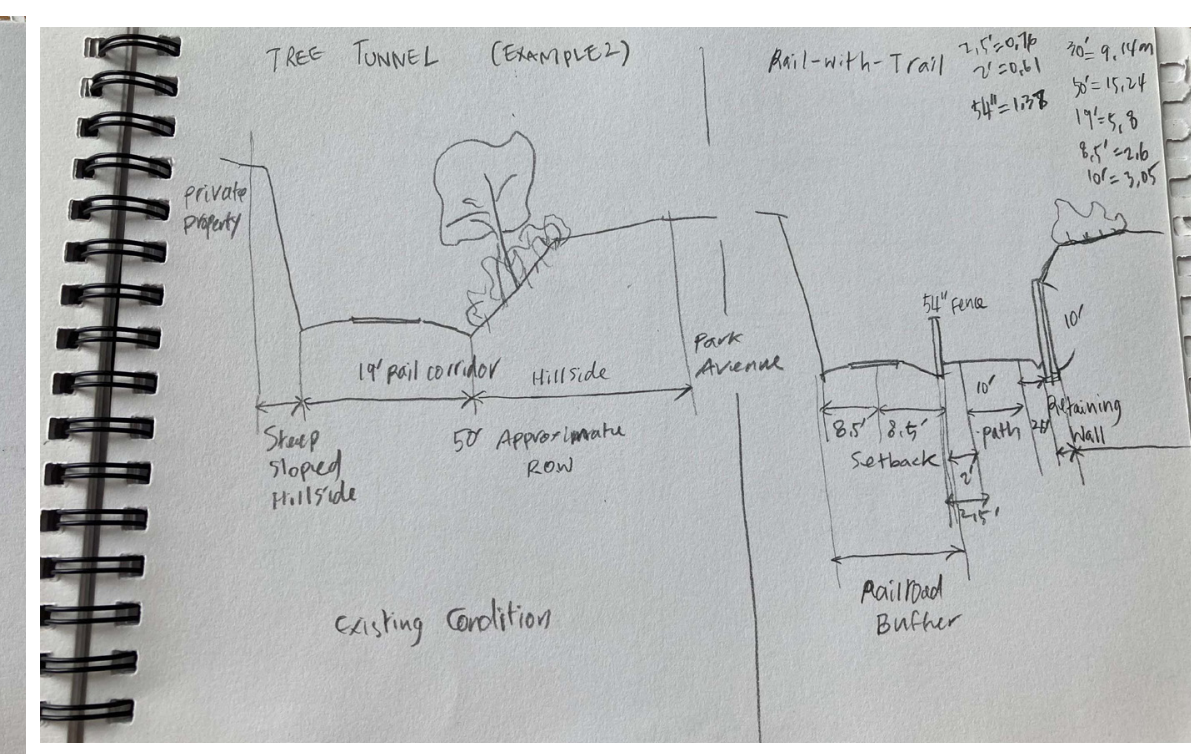


PRECEDENT STUDIES : RAILWAY STATION DESIGNS/ LAYOUTS KPL: KAPITI LINE
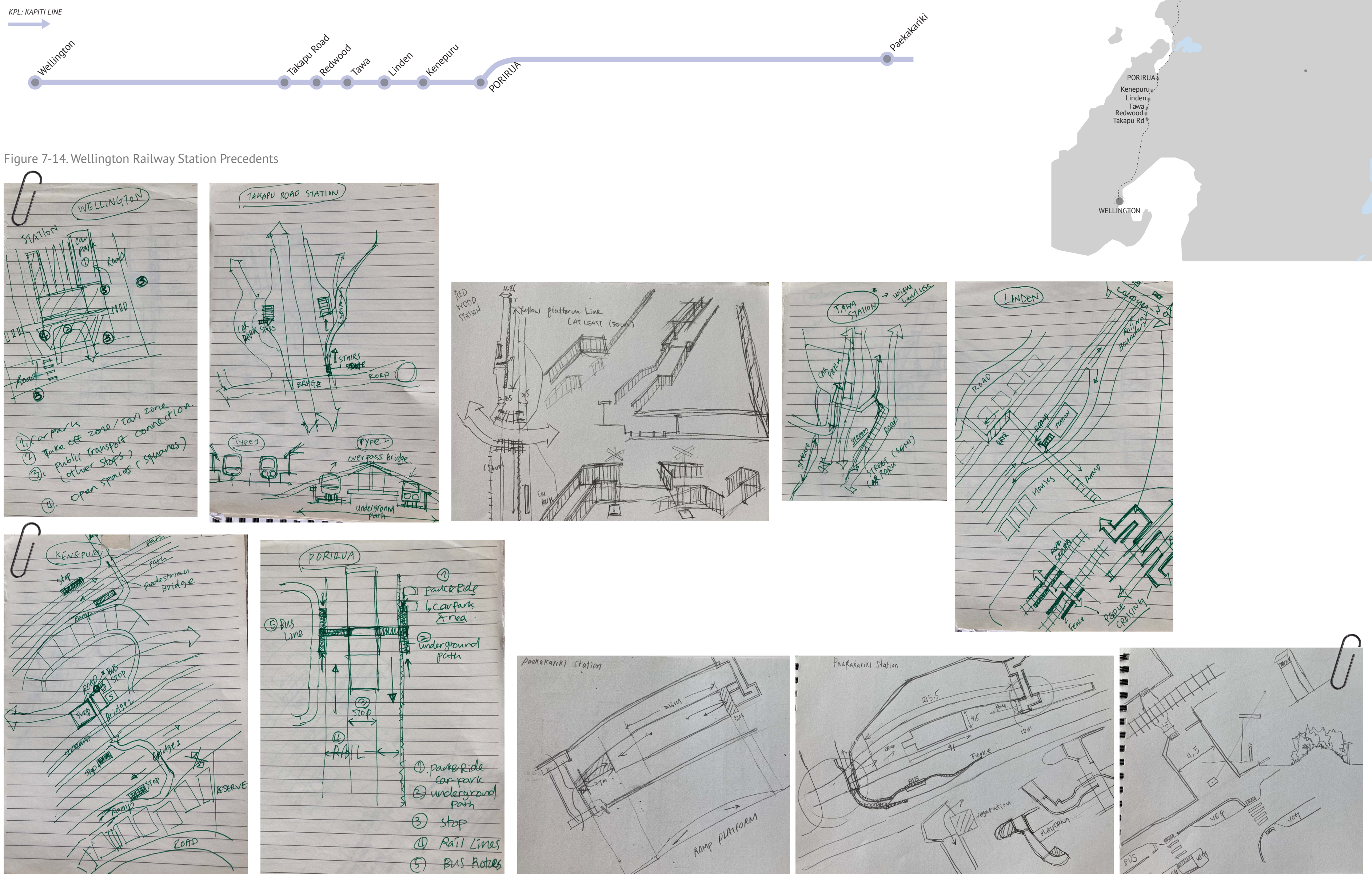
PRECEDENT STUDIES : RAILWAY STATION DESIGNS/ LAYOUTS

HVL: HUTT VALLEY LINE

HV: HUTT VALLEY LINE

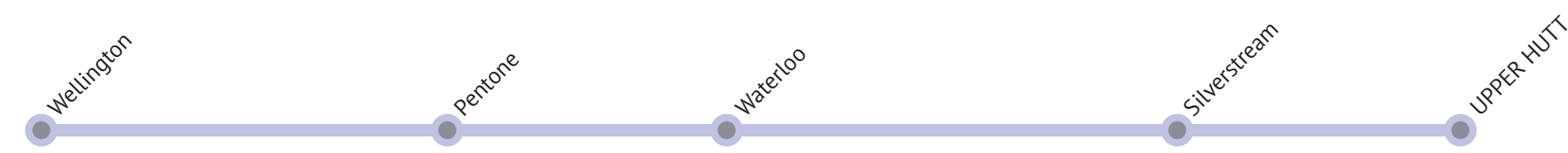

Figure 15-18. Wellington Railway Station Precedents
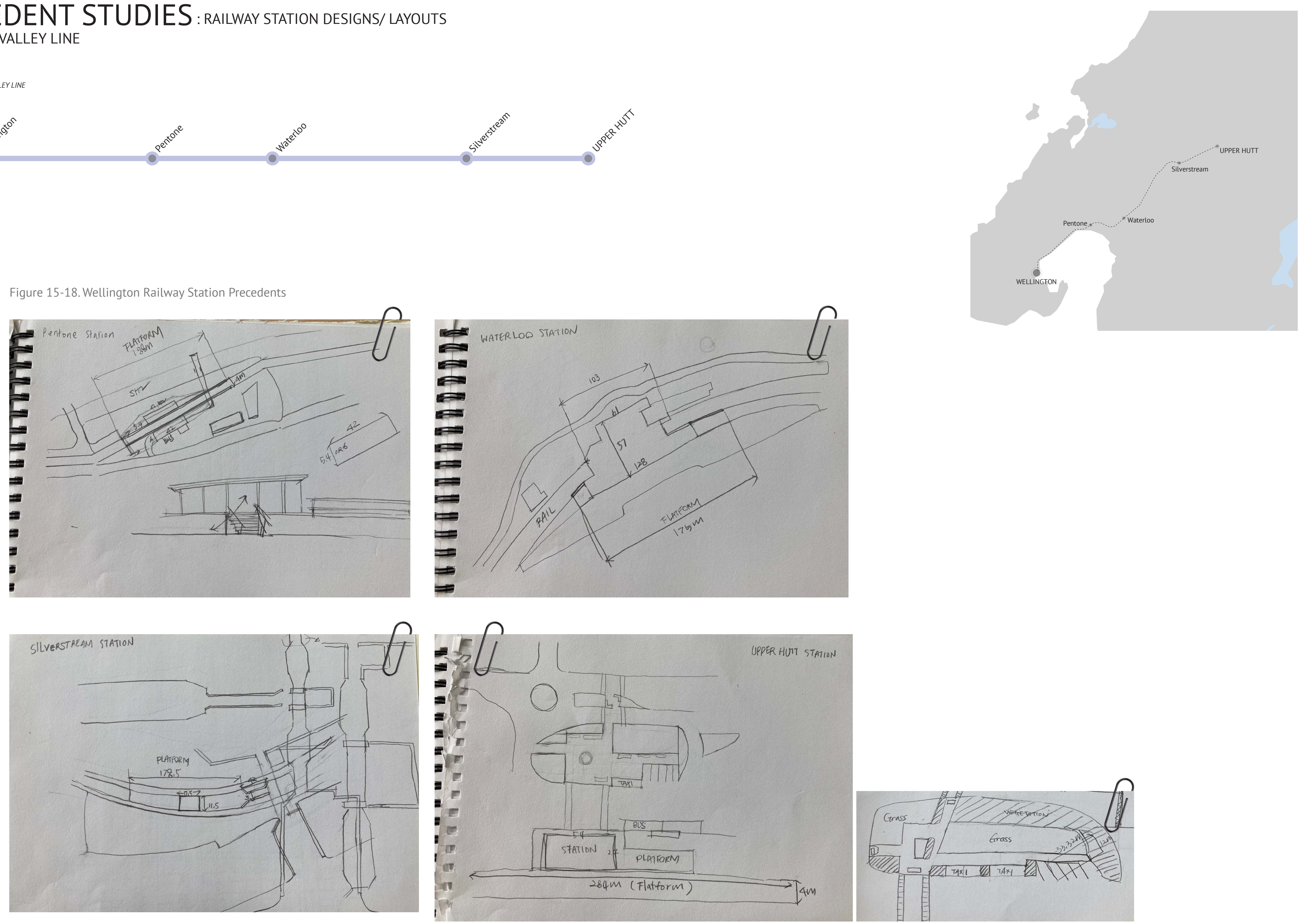

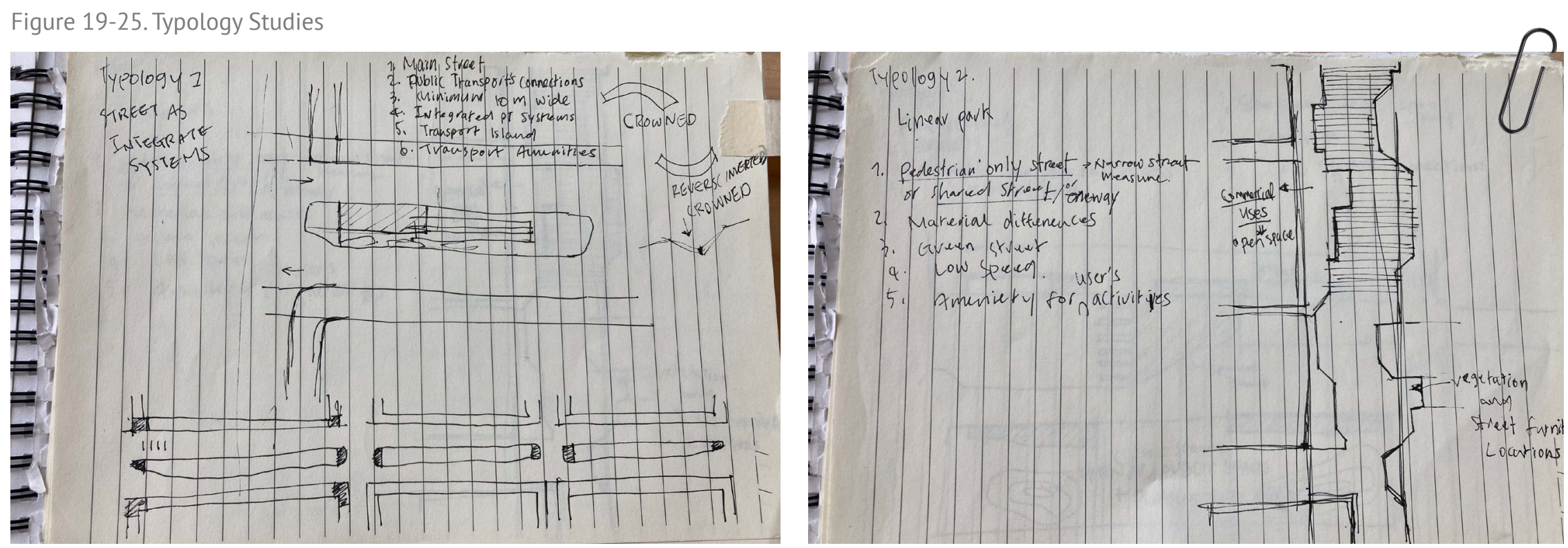

The investigated hybrid street typology will be applied and tested on 11 different streets in Tauranga city business district

areas (CBD) where have significantly

different spatial characteristics to see how it advances key objectives and achieves the research visions.
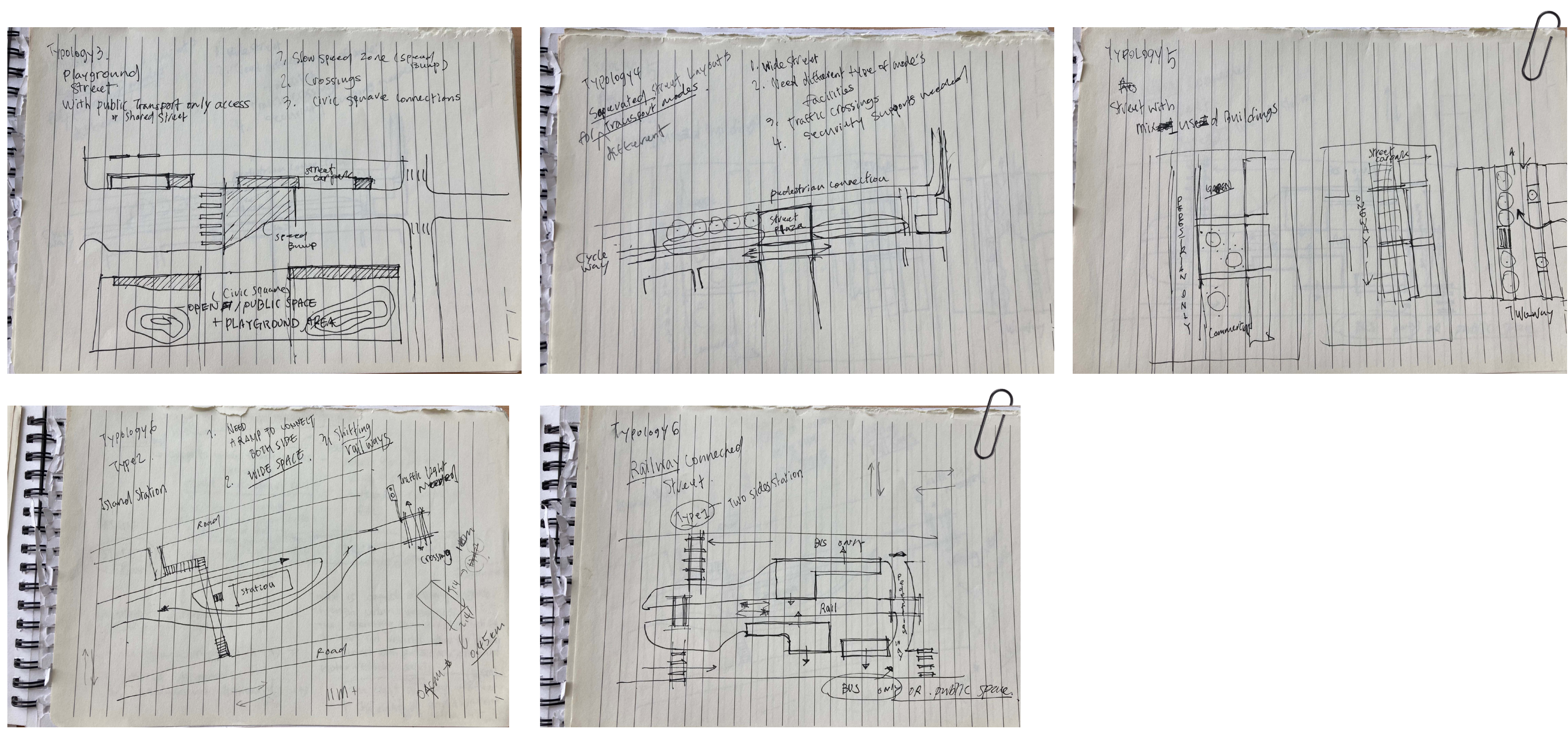
DESIGN SKETCHES : TAURANGA STATION/ STREET DESIGN SKETCHES DESIGN CONTEXT
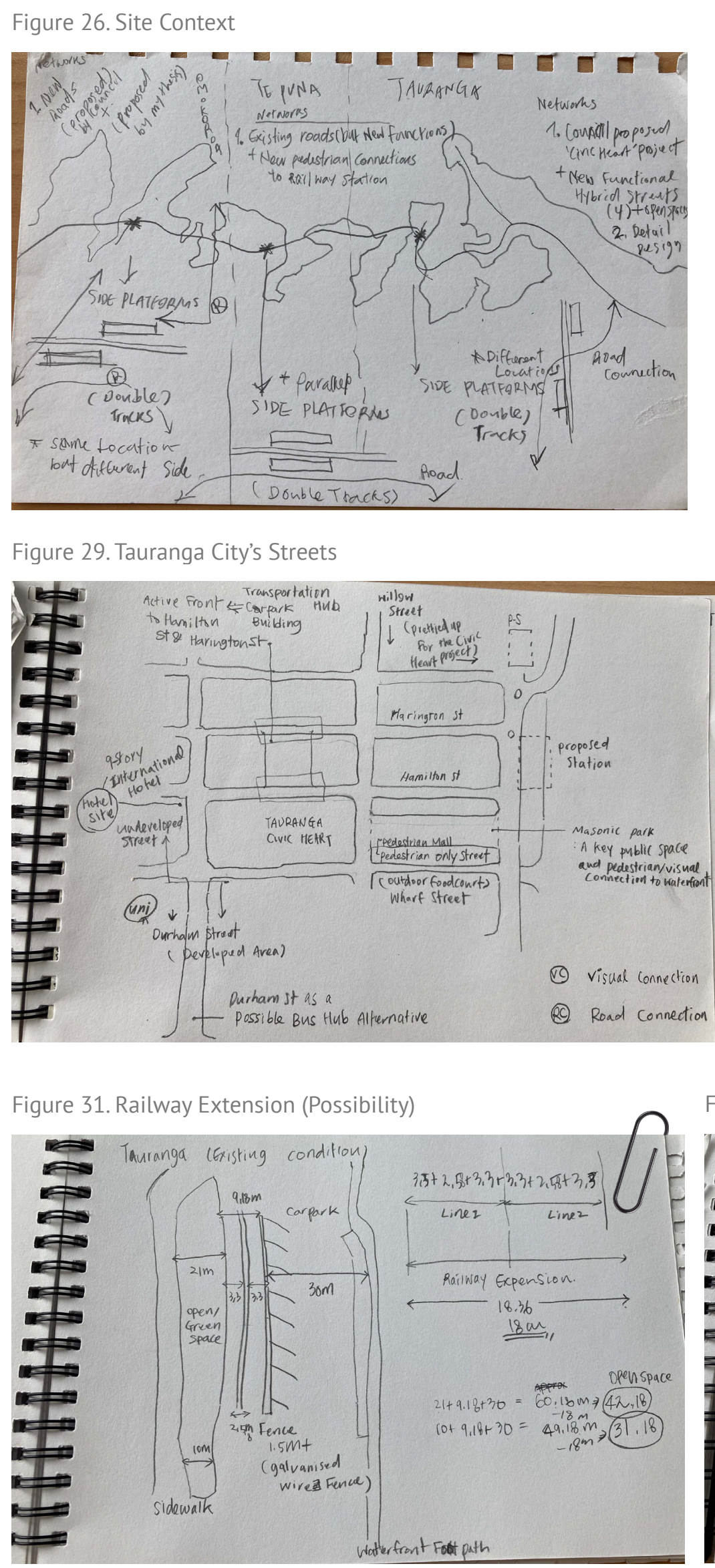

Figure 27. Existing Street Conditions

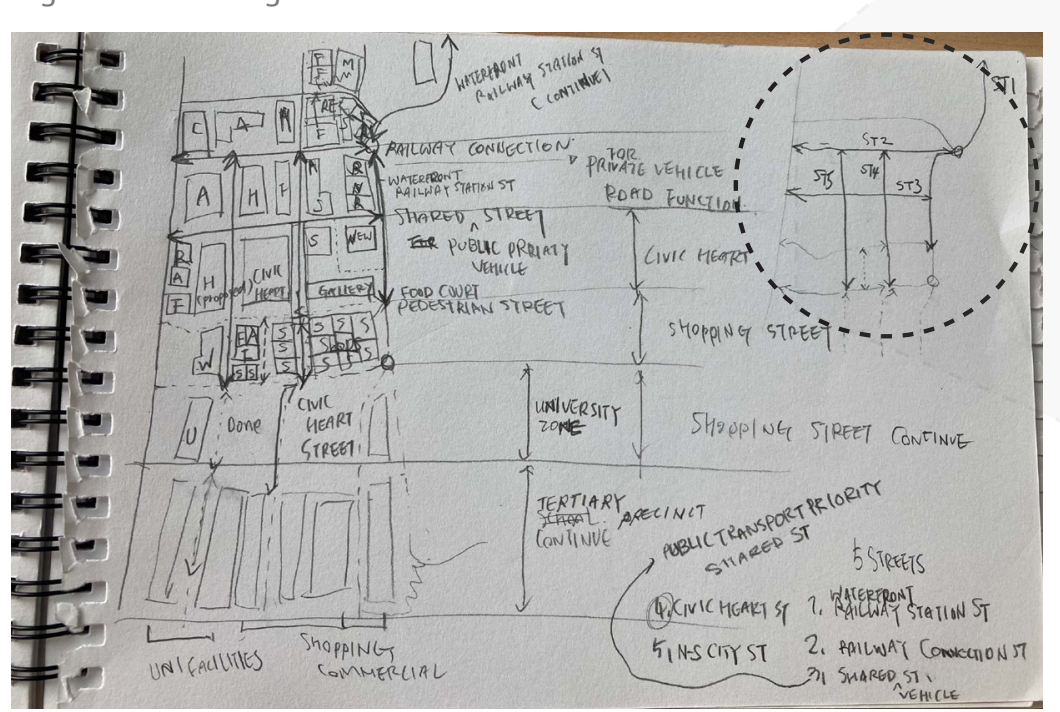

Figure 30. Old Tauranga Station Layout
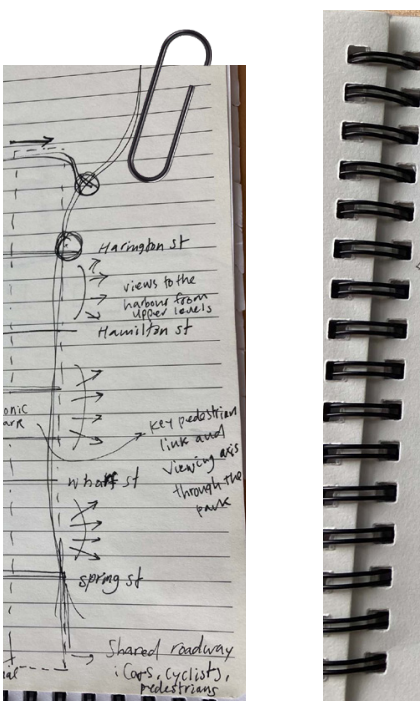

Figure 32. Railway Crossing Measures

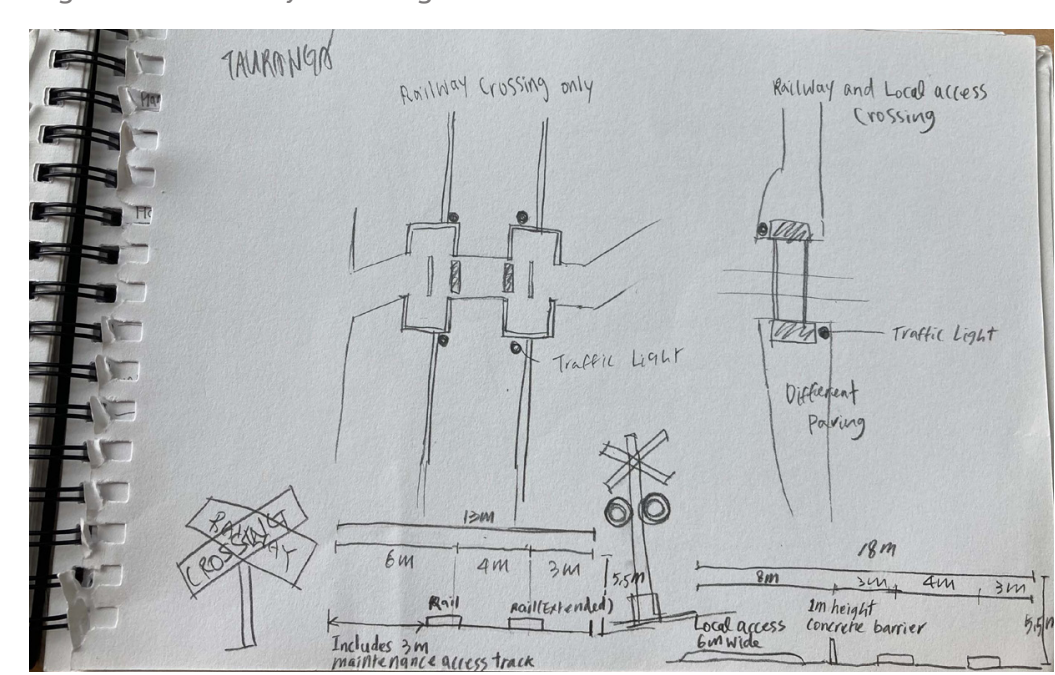

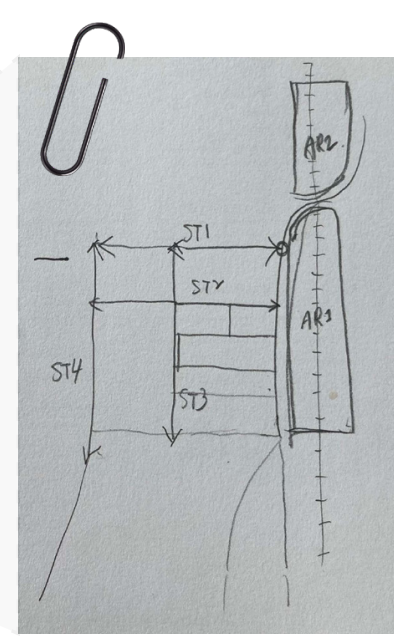

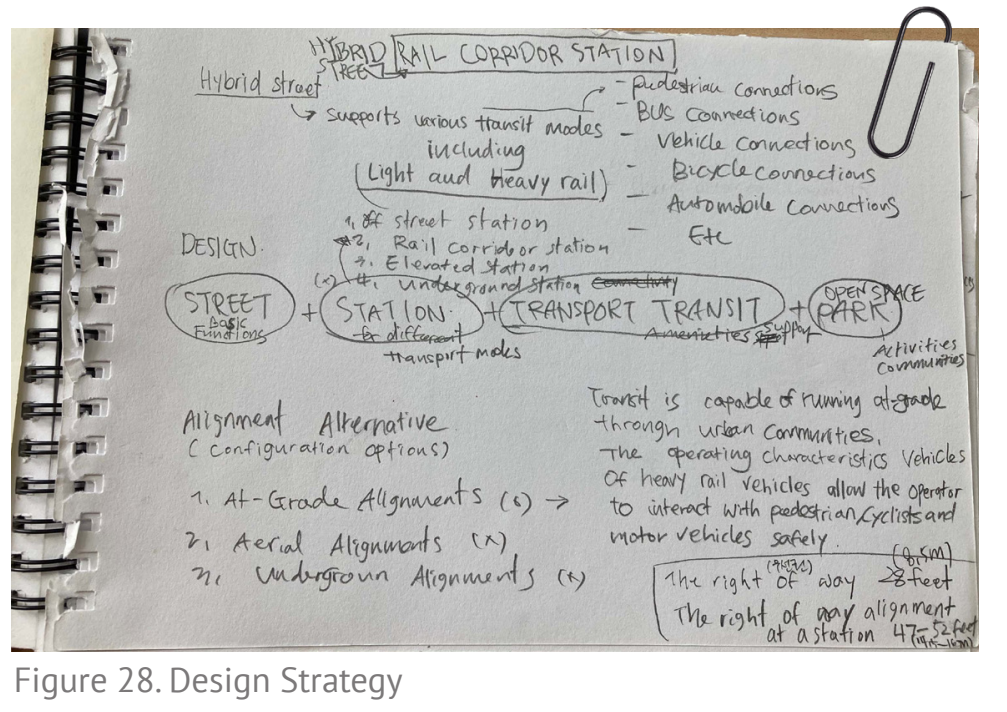

4

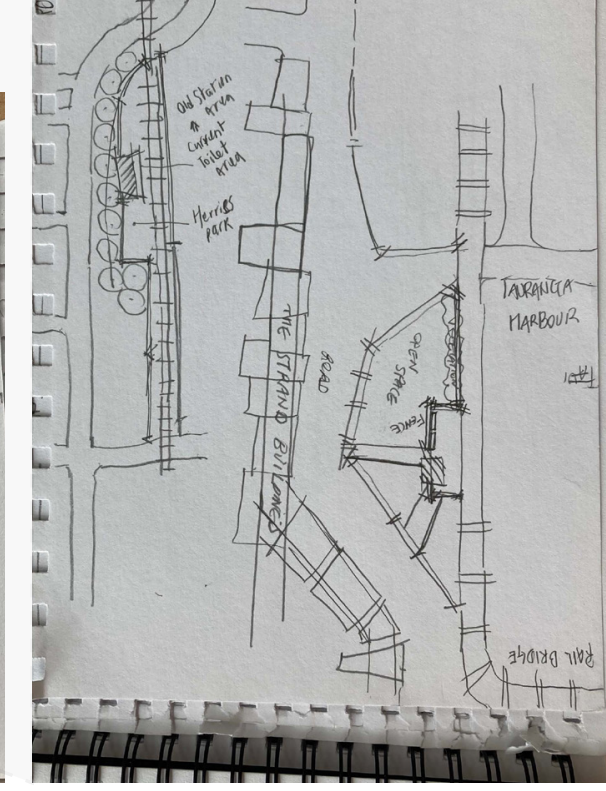

Figure 33. Final Decisions For Train Lines

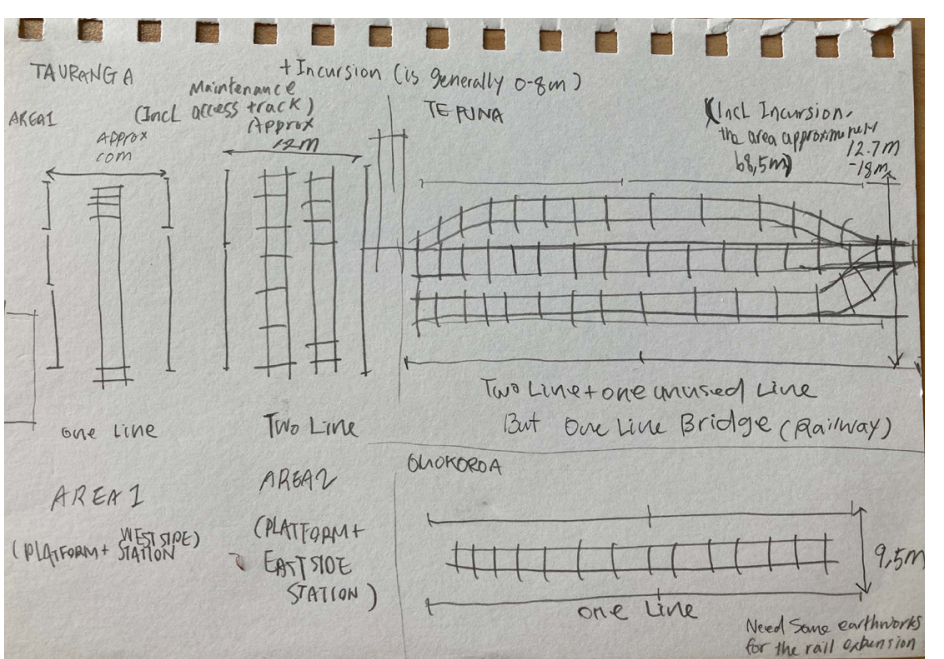

Figure 34. Railway Crossings

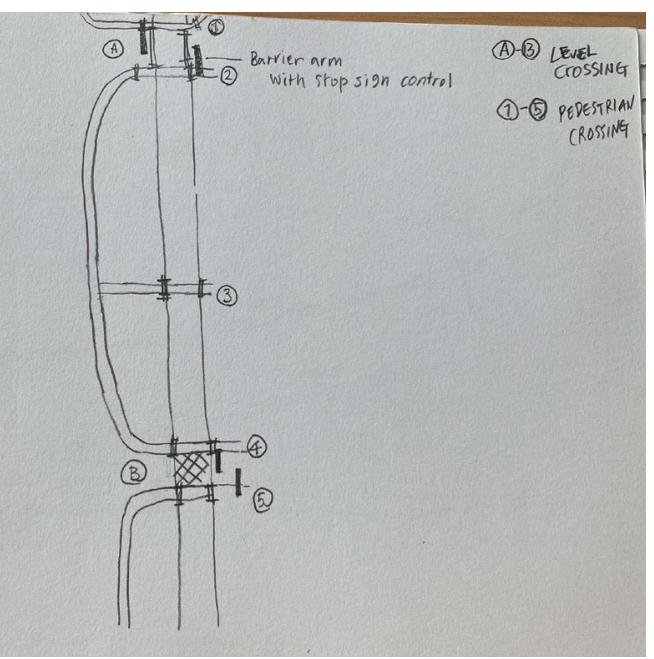


DESIGN SKETCHES : tauRANGA STATION/ STREET DESIGN SKETCHES CONCEPT DESIGN
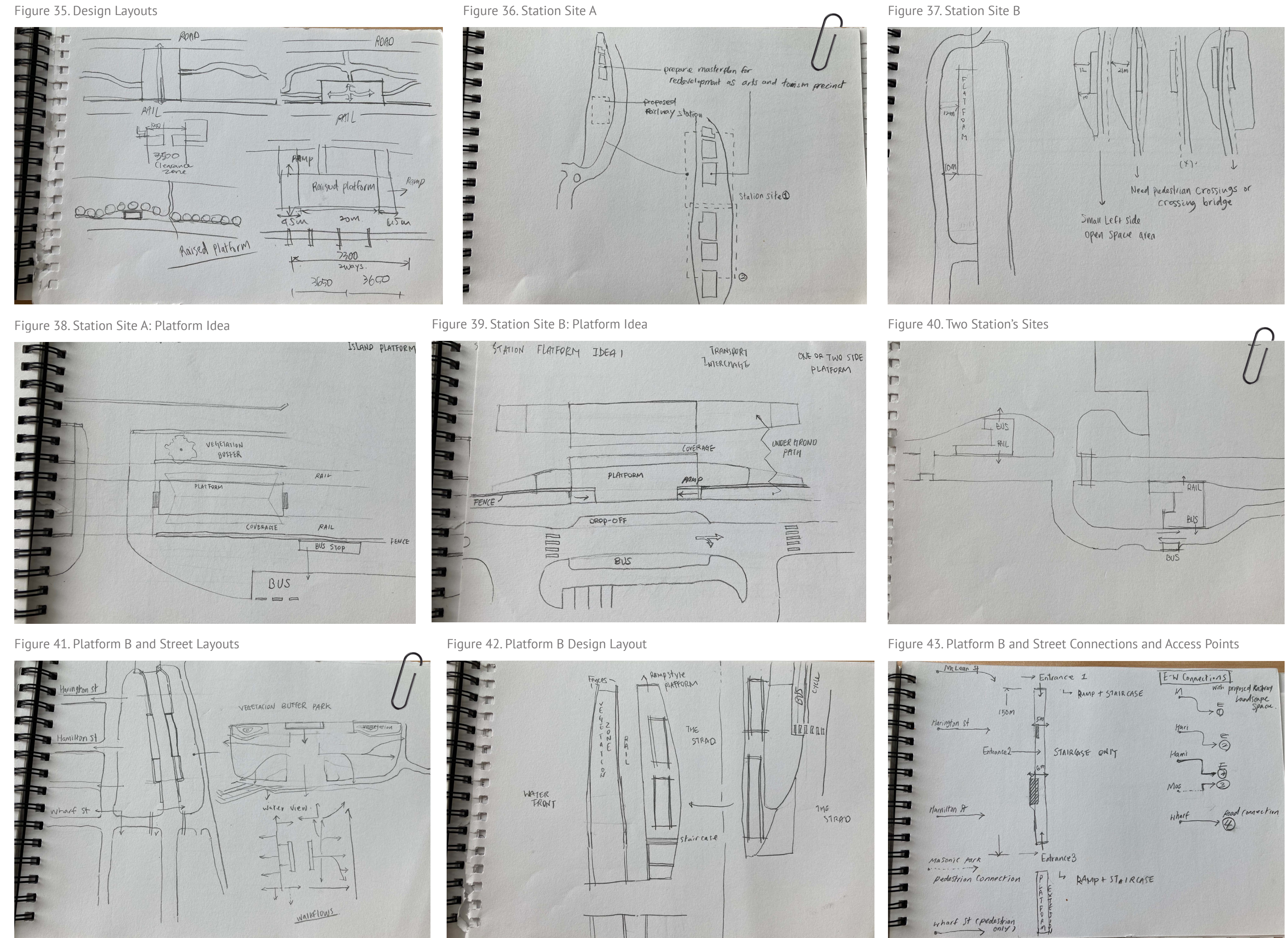
DESIGN SKETCHES : tAURANGA STATION/ STREET DESIGN SKETCHES CONCEPT DESIGN
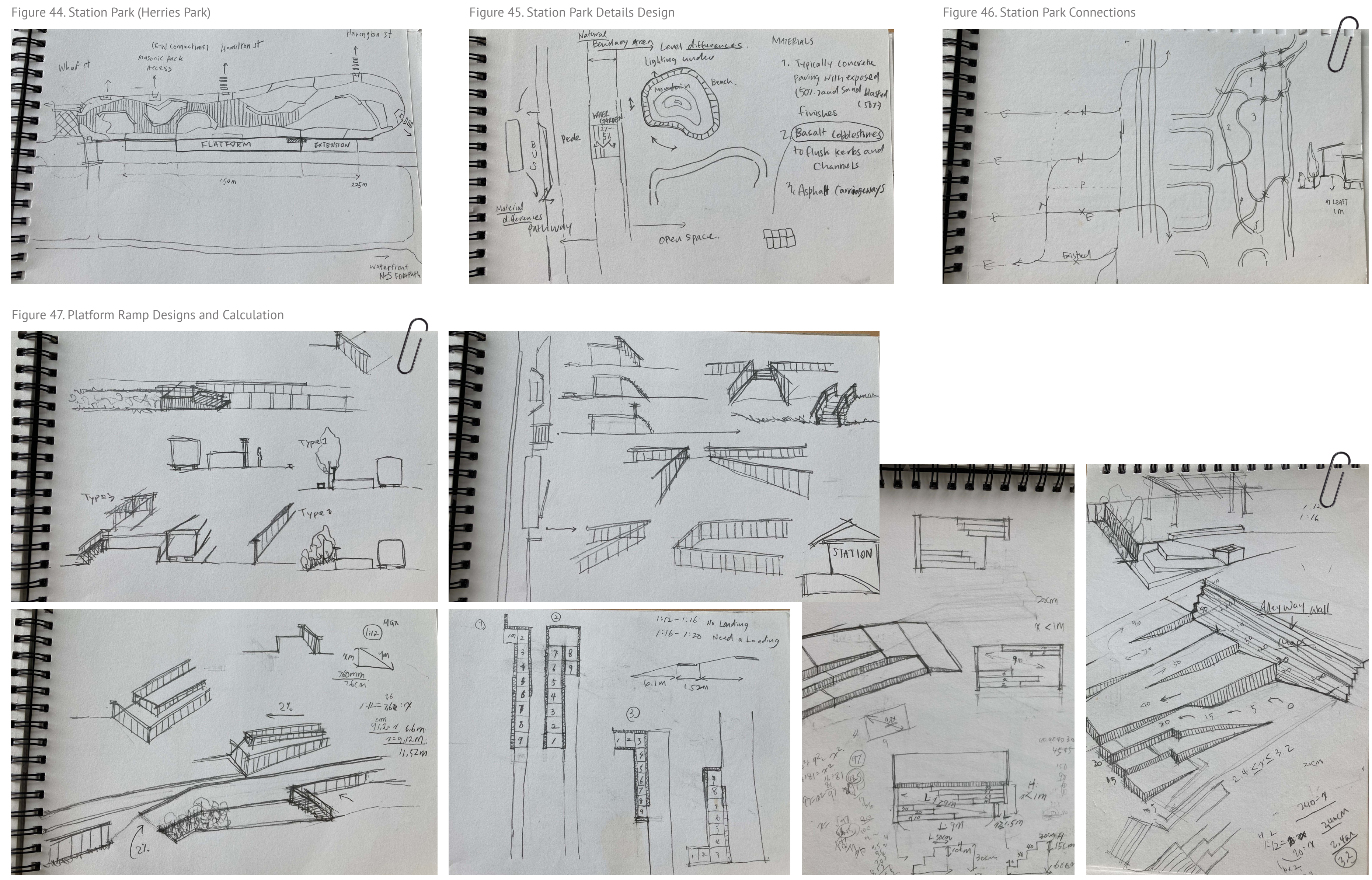
FURTHER STUDY :WESTERN BAY OF PLENTY CONTEXT STUDIES OMOKOROA/TE PUNA

FURTHER STUDY:WESTERN BAY OF PLENTY CONTEXT STUDIES OMOKOROA/TE PUNA

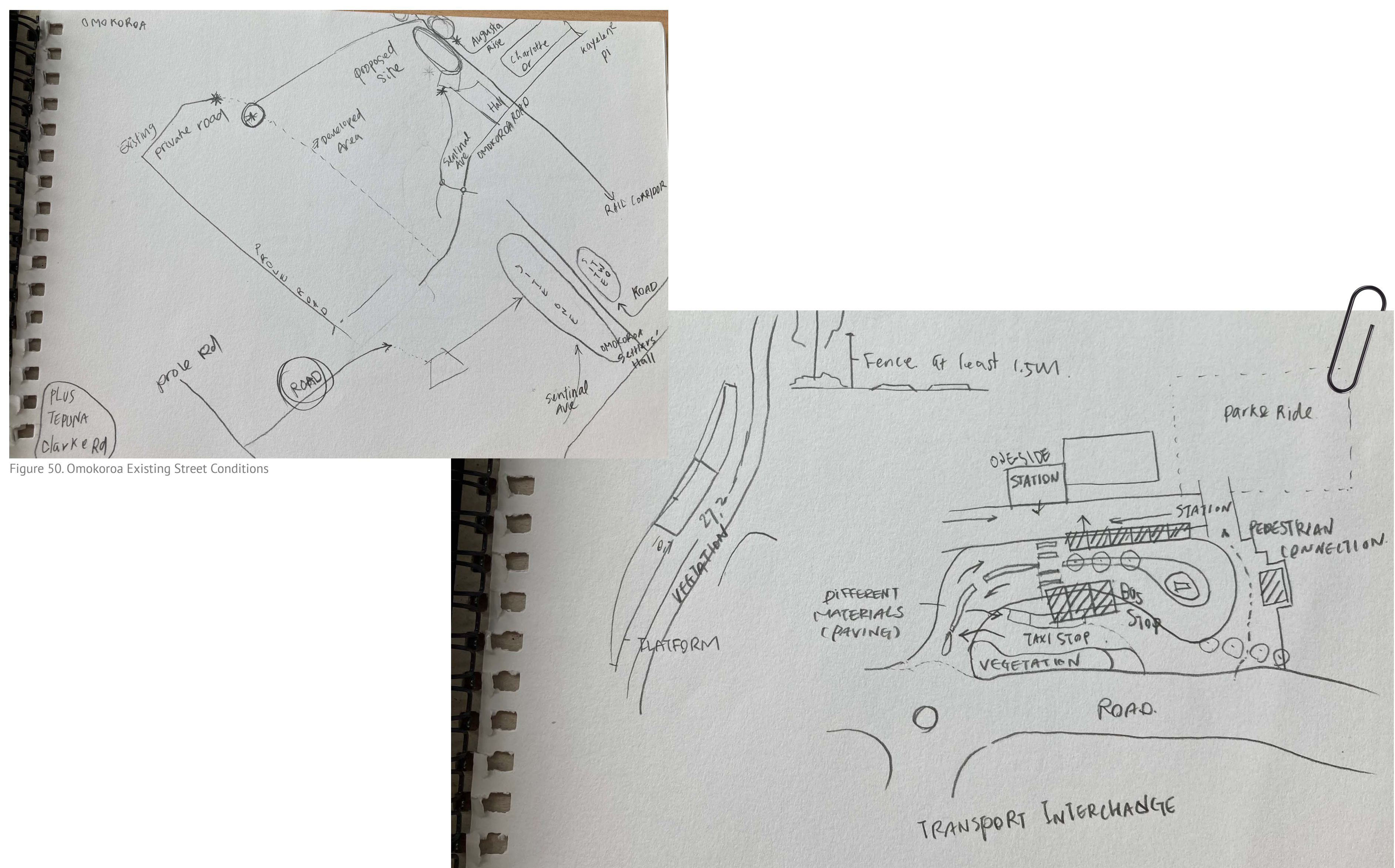




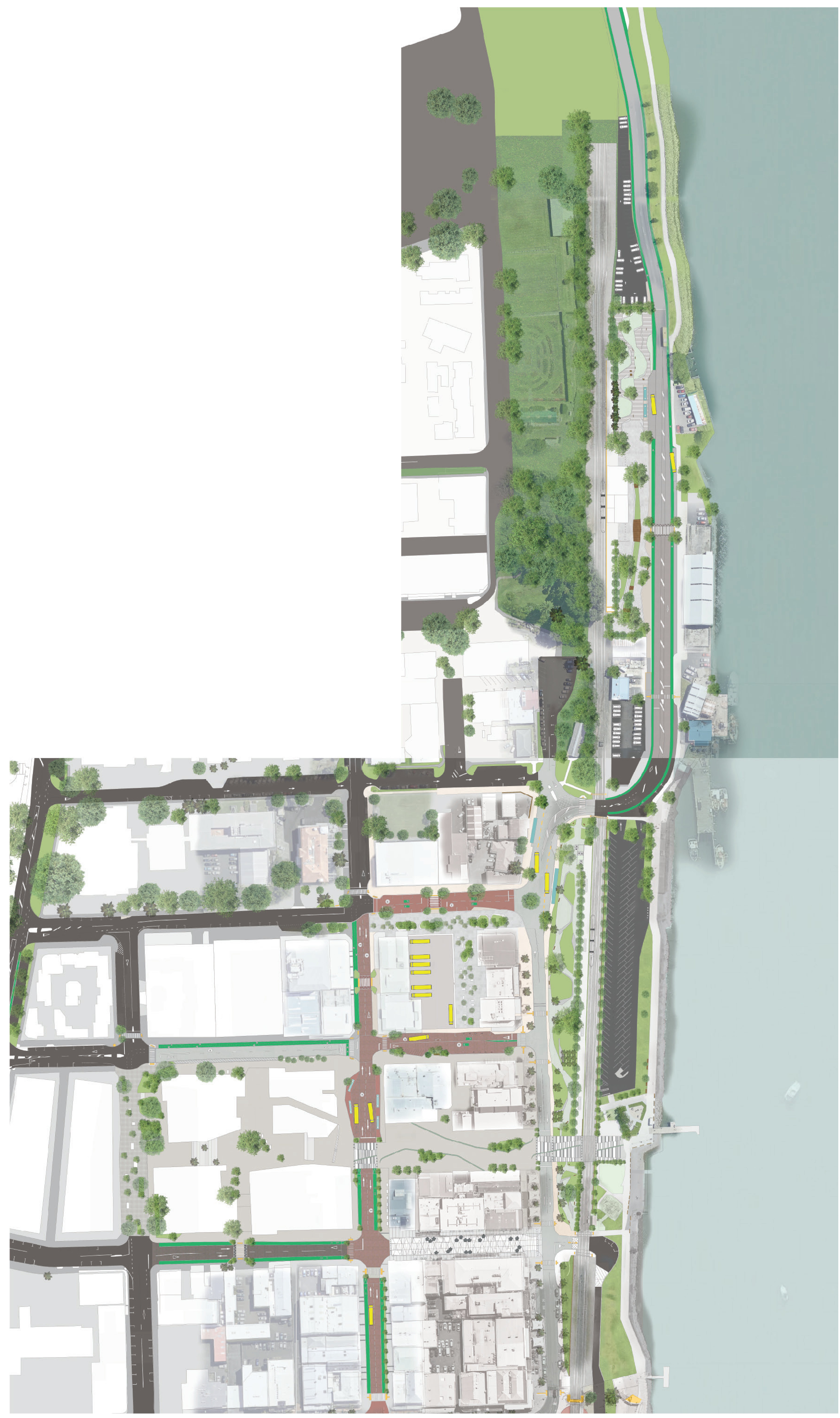

SITE PLAN

Tauranga Waterf hestrand/Masonic Park/ Herries Park/ Willow St What St tand Durham St Ty Interchange/ Civic Square (Propossa)

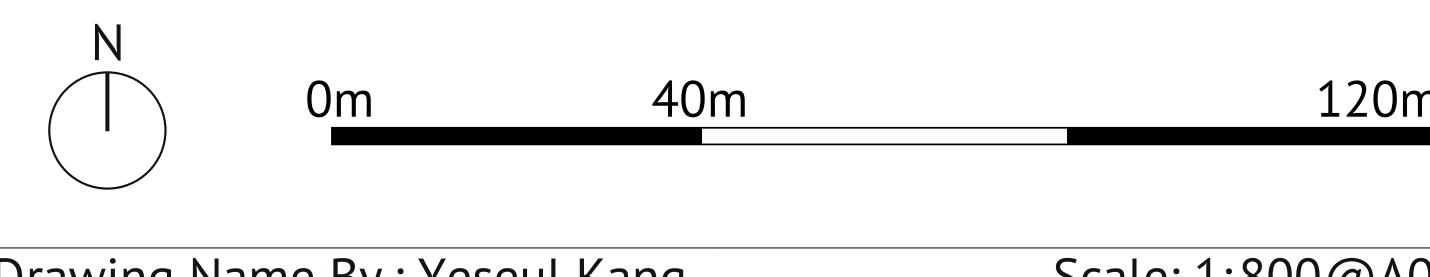

